\title{
Armut - Arbeit - Menschenwürde
}

\author{
Die Euböische Rede des \\ Dion von Prusa
}

Scripta Antiquitatis Posterioris

ad Ethicam REligionemque pertinentia

XIX

\section{Mohr Siebeck}




\title{
SAPERE
}

Scripta Antiquitatis Posterioris

ad Ethicam Religionemque pertinentia

Schriften der späteren Antike

zu ethischen und religiösen Fragen

\author{
Herausgegeben von \\ Rainer Hirsch-Luipold, Reinhard Feldmeier \\ und Heinz-Günther Nesselrath \\ unter der Mitarbeit von \\ Serena Pirrotta und Christian Zgoll
}

\section{Band XIX}

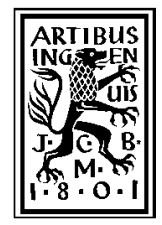





\section{Armut - Arbeit - Menschenwürde}

Die Euböische Rede des Dion von Prusa

eingeleitet, übersetzt und

mit interpretierenden Essays versehen von

Gustav Adolf Lehmann, Dorit Engster, Dorothee Gall, Hans Rupprecht Goette, Elisabeth Herrmann-Otto, Werner Heun und Barbara Zehnpfennig 
SAPERE wird als Vorhaben der Akademie der Wissenschaften zu Göttingen im Rahmen des Akademienprogramms von der Bundesrepublik Deutschland und vom Land Niedersachsen gefördert.

e-ISBN PDF 978-3-16-156436-9

ISBN 978-3-16-151825-6

Die Deutsche Nationalbibliothek verzeichnet diese Publikation in der Deutschen Nationalbibliographie; detaillierte bibliographische Daten sind im Internet über http://dnb.d-nb.de abrufbar.

\section{(C) 2012 Mohr Siebeck Tübingen.}

Das Werk einschließlich aller seiner Teile ist urheberrechtlich geschützt. Jede Verwertung außerhalb der engen Grenzen des Urheberrechtsgesetzes ist ohne Zustimmung des Verlags unzulässig und strafbar. Das gilt insbesondere für Vervielfältigungen, Übersetzungen, Mikroverfilmungen und die Einspeicherung und Verarbeitung in elektronischen Systemen.

Das Buch wurde von Nils Jäger und Serena Pirrotta in der SAPERE-Arbeitsstelle in Göttingen gesetzt, von Laupp \& Göbel in Nehren auf alterungsbeständiges Werkdruckpapier gedruckt und von der Buchbinderei Nädele in Nehren gebunden. 


\section{SAPERE}

Griechische und lateinische Texte der späteren Antike (1.-4. Jh. n. Chr.) haben lange Zeit gegenüber den sogenannten ,klassischen' Epochen im Schatten gestanden. Dabei haben die ersten vier nachchristlichen Jahrhunderte im griechischen wie im lateinischen Bereich eine Fülle von Werken zu philosophischen, ethischen und religiösen Fragen hervorgebracht, die sich ihre Aktualität bis heute bewahrt haben. Die - seit Beginn des Jahres 2009 von der Union der deutschen Akademien der Wissenschaften geförderte - Reihe SAPERE (Scripta Antiquitatis Posterioris ad Ethicam REligionemque pertinentia, ,Schriften der späteren Antike zu ethischen und religiösen Fragen') hat sich zur Aufgabe gemacht, gerade solche Texte über eine neuartige Verbindung von Edition, Übersetzung und interdisziplinärer Kommentierung in Essayform zu erschließen.

Der Name SAPERE knüpft bewusst an die unterschiedlichen Konnotationen des lateinischen Verbs an. Neben der intellektuellen Dimension (die Kant in der Übersetzung von sapere aude, „Habe Mut, dich deines eigenen Verstandes zu bedienen“, zum Wahlspruch der Aufklärung gemacht hat), soll auch an die sinnliche des "Schmeckens" zu ihrem Recht kommen: Einerseits sollen wichtige Quellentexte für den Diskurs in verschiedenen Disziplinen (Theologie und Religionswissenschaft, Philologie, Philosophie, Geschichte, Archäologie ...) aufbereitet, andererseits aber Leserinnen und Leser auch ",auf den Geschmack" der behandelten Texte gebracht werden. Deshalb wird die sorgfältige wissenschaftliche Untersuchung der Texte, die in den Essays aus unterschiedlichen Fachperspektiven beleuchtet werden, verbunden mit einer sprachlichen Präsentation, welche die geistesgeschichtliche Relevanz im Blick behält und die antiken Autoren zugleich als Gesprächspartner in gegenwärtigen Fragestellungen zur Geltung bringt. 



\section{Vorwort zu diesem Band}

Der erste Teil der Euböischen Rede des Dion von Prusa, die anmutige „JägerErzählung“ (§§ 1-80), zählt sicherlich zu den bekanntesten Prosa-Stücken aus der griechischen Literatur der römischen Kaiserzeit und hat wiederholt Aufnahme in einschlägige Anthologien gefunden. Dagegen wurden die anschließenden Darlegungen Dions, dem die Euböische Idylle hier nach eigenem Bekunden lediglich als Ausgangspunkt gedient hat, zumeist vollständig ignoriert oder aber als "moralisierende Betrachtungen“, die man dem Autor "gern schenken" möchte, abqualifiziert (Ed. Meyer, Kleine schriften II, S. 168; s. u.).

Dieses fatale Desinteresse betrifft sogar das von Dion im dritten Hauptteil seines Euboikos Logos (ab § 104) entwickelte sozialethische und ökonomische Reformprogramm, mit dem die Lage der erwerbslosen Stadtarmut in den Zentren der Polis-Gemeinden grundlegend, mit den Mitteln einer fürsorglichen "Stadtpolitik“, verbessert werden sollte. Es geht dabei immerhin um eine Thematik, die auch für unsere Gegenwart kaum an Aktualität und Bedeutung verloren hat - nämlich um das Prinzip der Menschenwürde und die sich daraus ergebenden Bedingungen für ein sinnvolles und segensreiches, aus öffentlichen Mitteln zu förderndes Arbeitsbeschaffungsprogramm. Sorgen um gravierende Verletzungen der Menschenwürde, die zu einer Gefahr für den Zusammenhalt der bürgerlichen Gesellschaft werden können, bestimmen auch Dions Digression (ab § 133) über die destruktiven Wirkungen einer öffentlich tolerierten oder gar geförderten Prostitution und libertinage.

Den Herausgebern der SAPERE-Reihe sei herzlich dafür gedankt, dass sie das Projekt einer umfassenden Übersetzung, Kommentierung und interdisziplinären Bearbeitung der Euböischen Rede in ihr Programm aufgenommen haben; H.-G. Nesselrath und R. Feldmeier haben mich stets mit Rat und Hilfe unterstützt und zugleich ermutigt, nach kompetenten Bearbeitern auch für die über den antiken Kulturbereich hinausführenden rechtshistorischen und rechtstheoretisch-philosophischen Aspekte in Dions Werk Ausschau zu halten.

So konnte auf dem von der SAPERE-Geschäftsstelle vorbereiteten Kolloquium am 14./15.02.2011 ein breiter, fruchtbarer Gedankenaustausch stattfinden. Dass es bei einigen Sachpunkten mehr als nur eine Meinung gab, wird den aufmerksamen, kritischen Leser angesichts der Komplexität des Euboikos Logos weder verwundern noch beunruhigen. Allen Teilneh- 
mern an diesem Kolloquium und allen Mitautoren an diesem Band gilt mein aufrichtiger Dank.

Nicht minder herzlich darf ich mich hier erneut für freundschaftlichen Rat und überaus wertvolle Hilfe bei R. Kassel (Köln) bedanken - ebenso aber auch bei Serena Pirrotta für die kompetente, sorgfältige Arbeit an der Druckvorbereitung und bei Balbina Bäbler für präzises Korrekturlesen.

Göttingen, im Oktober 2011

Gustav Adolf Lehmann 


\section{Inhaltsverzeichnis}

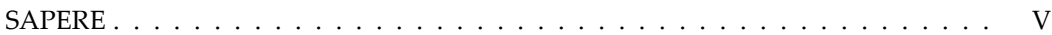

Vorwort zum Band $\ldots \ldots \ldots \ldots \ldots \ldots \ldots$ VII

\section{A. Einführung}

Einführung in die Schrift (Gustav Adolf Lehmann) . . . . . . . . . . . . 3

1. Der Autor . . . . . . . . . . . . . . . . . . . 3

2. Überlegungen zur Datierung und zur Textfassung der Euböischen Rede . . . . 20

3. Hinweise zur Textvorlage $\ldots \ldots \ldots \ldots 22$

\section{B. Text, Übersetzung und Anmerkungen}

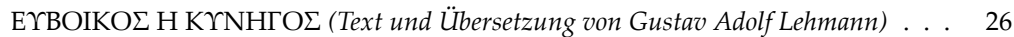

Anmerkungen zur Übersetzung (Gustav Adolf Lehmann) . . . . . . . . . . . . . 86

\section{Essays}

Mythos, Utopie und Sozialprogramm. Struktur und Gattung

des Euboikos logos (Dorothee Gall) . . . . . . . . . . . . . . . . . . . . 123

1. Zur Struktur des Textes . . . . . . . . . . . . . . . . . . . . . 123

2. Die Einheit der Rede und ihre narratologische Struktur . . . . . . . . . . . 132

3. Gattung. . . . . . . . . . . . . . . . 136

Fiktion oder Realität? Dions Euboikos Logos in der althistorischen

Forschungsdiskussion seit Eduard Meyer (Dorit Engster) . . . . . . . . . 143

1. Der Euboikos in der sozialgeschichtlichen Debatte . . . . . . . . . . . . . . . 144

2. Utopische Motive und Realitätsbezug _. . . . . . . . . . . . . . . . 146

3. Der Euboikos als Quelle für die ökonomischen Verhältnisse . . . . . . . . . . . 151

4. Die Rede als Quelle für die politischen Verhältnisse . . . . . . . . . . . . 156

5. Die Rede als Quelle für die sozialen Verhältnisse der Kaiserzeit . . . . . . . . 158

6. Der Euboikos als Quelle für die antike Sklaverei . . . . . . . . . . . . . . . . 161

7. Der Euboikos als Spiegel kaiserzeitlicher Politik . . . . . . . . . . . . . 162

Die Topographie der Karystia in der Euböischen Rede des Dion von Prusa - Autopsie oder Fiktion? (Hans Rupprecht Goette) . . . . . . . . . . 167

1. Die Landschaft der Jäger-Episode . . . . . . . . . . . . . . . . . . . . . . . . . 169

2. Die Stadt der Jäger-Episode ． . . . . . . . . . . . . . . . . . . . . . 174 
Was begründet Menschenwürde? Eine antike Antwort auf eine moderne Frage (Barbara Zehnpfennig) . . . . . . . . . . . . . . . . . . . . . 191

1. Die Problemlage . . . . . . . . . . . . . . . . . . . . . . . . . . 191

2. Menschenwürde in der aktuellen Diskussion . . . . . . . . . . . . . . 193

3. Dions Verständnis von Menschenwürde . . . . . . . . . . . . . . . . . . . . . 198

4. Antike Naivität - moderne Aufgeklärtheit? . . . . . . . . . . . . . . . . 208

Armut, Arbeit, Sklaverei und Prostitution in der römischen Kaiserzeit im (Spannungs-)Verhältnis zur dionischen Menschenwürde

(Elisabeth Herrmann-Otto) . . . . . . . . . . . . . . . . . . . . . . . . . . . . . 213

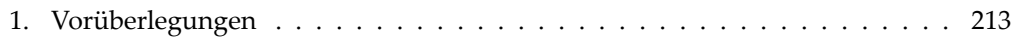

2. Ein Armutsdiskurs bei Dion von Prusa? . . . . . . . . . . . . . . . . . 214

3. Armut und Arbeit in der griechisch-römischen Antike . . . . . . . . . . 217

4. Sklaverei, Prostitution und Menschenwürde . . . . . . . . . . . . . . . . 225

5. Dions einzigartige sozio-ökonomische Erkenntnisse . . . . . . . . . . 231

Einflüsse der Stoa auf die Entwicklung von Menschenwürde und Menschenrechten bis zum Ende des 18. Jahrhunderts (Werner Heun) 235

1. Vorbemerkung . . . . . . . . . . . . . . . . . . . . 235

2. Der Ausgangspunkt: Stoische Lehren . . . . . . . . . . . . . . . . . . . . . . . . 238

3. Menschenwürde . . . . . . . . . . . . . . . . . . . . . . . . . . . . 239

4. Menschenrechte . . . . . . . . . . . . . . . . . . . . . . . . 245

5. Resümee und Ausblick . . . . . . . . . . . . . . . . . . . . . . . . 254

\section{Anhang}

I. Literaturverzeichnis . . . . . . . . . . . . . . . . . . . . . . . . . . 257

1. Abkürzungen . . . . . . . . . . . . . . . . . 257

2. Ausgaben, Kommentare und Übersetzungen . . . . . . . . . . . . . . . 258

3. Sekundärliteratur (und Editionen anderer Autoren) . . . . . . . . . . 258

4. Abbildungsnachweis . . . . . . . . . . . . . . . . 268

II. Indices (Nils Jäger, Serena Pirrotta) $\ldots \ldots \ldots \ldots$. . . . . . . . . . . . . . 268

1. Stellenregister (in Auswahl) _. . . . . . . . . . . . . . . . . . . 268

2. Namensregister . . . . . . . . . . . . . . . . . . 271

III. Die Autoren dieses Bandes . . . . . . . . . . . . . . . . . . . . . 275 
A. Einführung 



\title{
Einführung in die Schrift
}

\author{
Gustav Adolf Lehmann
}

\section{Der Autor ${ }^{1}$}

Dion, Sohn des Pasikrates, aus Prusa ad Olympum in Bithynien (heute Bursa; am Nordwestrand Anatoliens gelegen, ca. $15 \mathrm{~km}$ von der Südküste des Marmara-Meers entfernt) wurde als faszinierender Redner in der Öffentlichkeit von der Nachwelt - vielleicht auch schon von seinen Zeitgenossen - mit dem Ehrennamen Chrysóstomos („Goldmund“) ausgezeichnet. Seine Lebenszeit lässt sich allerdings, ebenso wie die seines Altersgenossen Plutarchos von Chaironeia, nur vage mit den (jeweils wohl etwas zu weit ausgreifenden) Eckdaten 40-120 n. Chr. umreißen. Beide, Plutarch wie Dion, zählen zu den ersten Repräsentanten jener umfassenden „Renaissance" des Griechentums im römischen Kaiserreich, die, in Anlehnung an das Biographien-Werk des Flavius Philostratos, auch als Zweite Sophistik bezeichnet wird. ${ }^{2}$ In Dions Leben und Werk lässt sich beispielhaft der Anfang einer (bald immer weiter ausgreifenden) positiven Integration der sozio-politischen und intellektuellen Eliten des griechischen Ostens in die Führungsschichten und die Herrschaftsordnung des Imperium Romanum erfassen. Daher ist es gewiss auch kein Zufall, dass die Wechselfälle in der römischen Principatsgeschichte der 2. Hälfte des 1. Jhs. n. Chr. auf dem Lebenweg Dions weitaus tiefere Spuren hinterlassen haben als in der vita

\footnotetext{
${ }^{1}$ Die folgenden Darlegungen zu Dions Leben und Werk sollen den instruktiven Überblick von H.-J. KLAUCK in Band 2 der SAPERE-Reihe (KLAUCK 2000, 9-25) lediglich ergänzen; Ähnliches gilt im Hinblick auf die eingehende Würdigung der „,philosophischen Botschaft" Dions in Forschner 2003. Unsere „Einführung“ konzentriert sich daher auf die für ein genaueres Verständnis der Euböischen Rede (or. 7/13 Arnim) wichtigen Fragen und Sachverhalte. Unter diesem Aspekt soll hier auch auf die aktuellen, vor allem in dem von S. SwaIN herausgegebenen Forschungsband (SwaIn 2000) vertretenen Positionen in der modernen Forschungsdiskussion näher eingegangen werden.

${ }^{2}$ Philostr. V.Soph. I 7; Philostrat hat die Bezeichnung „Sophisten“ freilich als einen Ehrentitel aufgefasst, während Dion selbst, der sich persönlich gerne mit der Gestalt eines Sokrates oder Diogenes (abgesehen von dem bekanntlich auf langen Irrfahrten umhergetriebenen Odysseus, s.u.) identifizierte, diese Benennung noch eindeutig als Schimpfwort verstand. Zum Begriff "Zweite Sophistik" s.auch die Studie von G. Anderson, The Second Sophistic. A cultural Phenomenon in the Roman Empire (London / New York 1993) 216-219 (zu Dion) und generell die umfassende Darstellung von S. SwaIn, Hellenism and Empire, Language, Classicism, and Power in the Greek World, AD 50 - 250 (Oxford 1996).
} 
Plutarchs. Und zu diesen Umbrüchen und Zäsuren findet sich dementsprechend in dem im Corpus Dioneum partiell erhaltenen Schrifttum ein vielfältiges Echo - vom Ende der Ära Neros (54-68 n.Chr.) bis zum Höhepunkt der Herrschaft Trajans (98-117 n.Chr.).

Im überlieferten Corpus der Schriften Dions vereinigen sich, nach einem noch erkennbaren (und von den spätantiken Herausgebern weitgehend durchgehaltenen) Gliederungskonzept, Gelegenheitsschriften aus unterschiedlichen Zeitstufen und spielerische Erzeugnisse einer kunstvollen Rhetorik, oft nur in fragmentarischem Zustand erhalten, mit längeren Abhandlungen, die sich in ihrer philosophisch-ethischen Thematik an einem "sokratischen“ Kynismus orientieren, der in sein Weltbild jedoch auch Gedankengut der Stoa zu integrieren suchte. ${ }^{3}$ Von besonderem Interesse (im Hinblick auf Dions Arbeitsweise) sind hier ferner ausgearbeitete Textstücke wie das Libysche Märchen (or. 5), das, als Einzelerzählung konzipiert, offenbar auch für Erläuterungen (ev. als Beilage) im Rahmen eines größeren Dialog-Werkes Verwendung gefunden hat. ${ }^{4}$ Hinzu kommen vorbereitete Argumentationen für Proömien und Reden, aber auch vollständig ausformulierte Stellungnahmen aus der Praxis eines ehrgeizigen und tatkräftigen „Kommunalpolitikers“, der auch über seiner Vortragstätigkeit als populärphilosophischer Mahnredner in Rom und bei gelegentlichen, prestigeträchtigen Auftritten in wichtigen Städten des griechischen Ostens niemals die speziellen Anliegen und Entwicklungen in seiner Heimatpolis Prusa aus den Augen verloren hat. ${ }^{5}$

Eine umfassende Würdigung der (in manchen Details heute mehr denn je umstrittenen) vita Dions, verbunden mit einem allgemeinen Überblick über sein vielgestaltiges œuvre, würde den Rahmen dieser „Einführung“ deutlich überschreiten. ${ }^{6}$ Unsere Darlegungen konzentrieren sich daher auf die Aspekte und Gegebenheiten, die für ein sachliches Verständnis des $E u$ boikos Logos in seiner eigentümlichen Struktur, einschließlich der von Dion in dieser Schrift mit großer Eindringlichkeit vorgetragenen sozialethi-

\footnotetext{
${ }^{3}$ Zur Problematik s. Forschner 2003, bes. 139-145.

${ }^{4}$ Vgl. die (für sich genommen kaum verständliche) Anspielung in or. 4 (,,̈̈ber die Herrschaft") §§ 73f.

${ }^{5}$ Zur thematischen Gliederung der Schriften im Corpus Dioneum s. die Überblicksskizzen von H. J. Klauck (KLaucK 2000, S. 21-24). H. v. Arnim hat in der Einleitung seiner DionAusgabe (ARnim 1893, p. III-XXXX), in der Sache durchaus zu Recht, dafür plädiert, der bei Photios (ca. 810-893) bibl. cod. 209 bezeugten Reihenfolge der Schriften als der älteren Tradition zu folgen. Arnim hat jedoch gleichwohl in seiner Edition die "konventionelle“ Anordnung des Corpus grundsätzlich beibehalten; ihr sind auch alle späteren Textausgaben gefolgt. - Aus dem Corpus lassen sich leider keinerlei Aufschlüsse über Dions persönliche Beziehungen zu so wichtigen Zeitgenossen wie Plutarch, Apollonios von Tyana oder Euphrates von Tyros gewinnen.

${ }^{6}$ S. o. Anm. 1; vgl. die ausführliche „introduction“ von S. SwaIn in SwaIn 2000 sowie MiLAzzo 2007, 11-48. Die Interpretation der Euböischen Rede ist hier freilich auf einige ausgewählte Passagen der Jäger-Erzählung beschränkt.
} 
schen und sozioökonomischen Programmatik, wichtig erscheinen. Aus einer Perspektive, in der auch der „praktizierende Stadtpolitiker" Dion genauer in den Blick genommen wird, lassen sich die im zweiten Teil der Schrift entfaltete Thematik und generell die politisch-sozialen Anliegen des Autors offensichtlich besser erfassen und in den Kontext seiner Zeit einordnen.

Umso drängender stellt sich vor diesem Hintergrund allerdings die Frage, ob die faszinierende Erzählung von den menschlichen Qualitäten und dem harmonischen Zusammenleben der Jäger-Familien im Bergwald des südlichen Euböa, die den überlieferten ersten Teil des Logos ausfüllt, ihrem Inhalt nach lediglich als romantisierende Utopie bzw. als realitätsferne Absage an die städtische Zivilisation aufzufassen ist. ${ }^{7}$ Dass der kunstvoll und mit großem kompositorischen Geschick gestaltete Kurz-Roman der JägerErzählung nicht als simpler Erlebnisbericht gelesen werden kann, lässt sich anhand einer gründlichen literarisch-stilistischen Analyse klar erkennen (s. D. GALL, u. S. 125-129).

In die gleiche Richtung weisen die beträchtlichen Divergenzen in der dionischen Erzählung und den archäologisch-topographischen Befunden im Umkreis der südeuböischen Polis Karystos in dieser Zeit (s. den Beitrag von H. R. Goette in diesem Band). Es stellt sich allerdings die Frage, ob man hinter den wiederholten Authentizitätsbeteuerungen Dions ( $\S \S 1$ und 81) nicht doch einen generellen Anspruch auf Wirklichkeitsrepräsentation anerkennen sollte. Schließlich war es für den Autor geradezu unvermeidlich, diese Erzählung im Ganzen durch Auslassungen und Verfremdungen verallgemeinerungsfähig zu machen (weit über Südeuböa hinaus), wenn sie, als Digression innerhalb einer populärphilosophischen Abhandlung, Dions Hörern / Lesern glaubhaft vor Augen führen sollte, welche Chancen für eine menschenwürdige Existenz in einer ganz mit der Natur verbundenen Lebensform enthalten seien. Hatten sich doch die beiden JägerFamilien - bei äußerer Armut und bar jeden Geldbesitzes - am Rande des städtischen Territoriums und seiner Zivilisation eine Heimstatt im Bergwald geschaffen, in der sie ihr bescheidenes, arbeitsreiches Alltagsleben eigenständig und frei einzurichten vermochten - und dies in sittlich vorbildlicher Haltung gegenüber allen Geboten der Gastfreundschaft, familiärer Solidarität und tätiger Menschenliebe, ohne darüber die Loyalität zur eigenen Polis in irgendeiner Weise in Frage zu stellen. Von diesem, durch ein lebensnahes $\pi \alpha \varrho \alpha ́ \delta \varepsilon \imath \gamma \mu \alpha$ abgesicherten Ausgangspunkt aus konnte dann im 2. Teil der Schrift die ungleich schwierigere Frage nach angemessenen,

\footnotetext{
${ }^{7}$ Vgl. dazu die Auffassung von S. Swain (Swain 2000, 31f.), wonach Dions Anliegen in der Euböischen Rede schlechthin in der Kontrastierung eines utopisch-idyllischen „rural life .. with the evils of urbanism" bestanden hätte; ähnliche Akzentuierungen finden sich u. a. in den Interpretationen von Milazzo 2007, 184 u. 189 und Desideri 2000, 99f. (und andererseits 104f.).
} 
menschenwürdigen Lebens- und Arbeitsmöglichkeiten für die Stadtarmut argumentativ entfaltet und beantwortet werden (s. u. S. 110-115).

Wenn wir auf Dions Aktivitäten und Erfahrungen als prominenter "Stadtpolitiker" (und Bauherr) in seiner bithynischen Heimatpolis schauen, so kann bei ihm schwerlich nur von einem "gesellschaftlichem Spiel, ,Wohltaten gegen Ehrungen'“ die Rede sein. ${ }^{8}$ Persönlicher Ehrgeiz, Lokalpatriotismus und das Gefühl einer tiefen Verpflichtung gegenüber einer stolzen Familientradition haben Dions lebenslanges Engagement in der Gemeinde-Politik von Prusa bestimmt: Beide Großväter und Dions Vater, später seine Brüder (und schließlich wohl auch sein Sohn) haben als

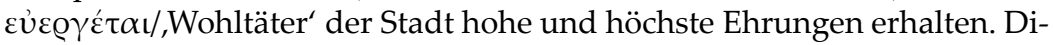
ons Mutter war nach ihrem Tode von der Bürgerschaft - durch Aufstellung einer Ehrenstatue in Verbindung mit einem Altar - sogar (heroen)kultische Verehrung für ihre außerordentlichen Leistungen für die Polis zuerkannt worden. ${ }^{9}$

Von den opulenten Lebensumständen des jungen Dion im Schoße dieser hochangesehenen Honoratioren-Familie gibt die Einleitung zu der literaturkritischen Studie or. 52 (35 Arnim, Über die Bogenwaffen des Philoktetes - zweifellos eine Jugendschrift) eine konkrete Vorstellung: Mit wenigen Worten wird das Ambiente eines weitläufigen, reich ausgestatteten Landgutes im Besitz der Familie, in dem sich sogar eine eigene PferdeRennbahn befand, umrissen. Darüber hinaus erfahren wir aus der (einige Zeit später in Prusa gehaltenen) Rechtfertigungsrede, or. 46 (29 Arnim), dass Dions Ländereien in der $\chi \omega \omega \varrho \alpha$ von Prusa vorrangig auf lukrativen Wein-Anbau und Viehwirtschaft ausgerichtet waren, während Brotgetreide fast nur für den Eigenbedarf produziert wurde. ${ }^{10}$ Prusa war als eine

\footnotetext{
${ }^{8}$ Gegen H.-J. KLAUCK, in: KLAUCK 2000, 11 (im Anschluss an allgemeine Feststellungen in dem bekannten Werk von P. VeYne, Le pain et le cirque [Paris 1976]); Dion selbst hat heftige Kritik an der oft anzutreffenden Oberflächlichkeit und der zumeist sehr geringen Dauer der stadtpolitischen Engagements und der Ziellosigkeit des damit verbundenen „Euergetismus" von zahlreichen Angehörigen der städtischen Oberschicht geübt: bes. or. 34 (2. Tarsos-Rede) $\S \S 29 \mathrm{f}$.

${ }^{9}$ Vgl. die Angaben in den Bithynischen Reden: orr. 41,6. 44,3-5. 46,2-7. 50,7. Der Großvater mütterlicherseits hatte durch aufwendige Spenden und Stiftungen in Prusa und benachbarten Städten u.a. den Status eines römischen Bürgers erlangt. Seine hohen Vermögensverluste konnte er später in Rom durch Lehrtätigkeiten wieder ausgleichen und darüber hinaus sogar in ein persönliches Freundschaftsverhältnis zu Kaiser Claudius (41-54 n. Chr.) eintreten. Sein Engagement als Vertrauensmann und "Wohltäter" seiner Heimatstadt blieb, wie Dion beteuert, auch während des Aufenthaltes in Rom stets lebendig und wirksam; angeblich hatte er dort kurz vor Claudius' Tode bereits in aller Form eine Initiative vorbereitet, um Prusa durch einen förmlichen kaiserlichen Gunsterweis in den Status einer „unabhängigen Polis“ innerhalb der römischen Provinz erheben zu lassen.

${ }^{10}$ Vgl. or. 46,7-9; mit den Gegebenheiten des Weinanbaus und den Bedingungen für Leben und Arbeit von Hirten war Dion somit von Jugend an gut vertraut; s.u. Anm. 93 S. $103 f$. - Dions landwirtschaftlicher Betrieb war offenbar, wie die Güter anderer Großgrundbesitzer in dieser Zeit, vorrangig auf das Exportgeschäft orientiert; vgl. hierzu auch die Infor-
} 
Königsstadt 184 v.Chr. von dem bithynischen Herrscher Prusias II. in einer landwirtschaftlich sehr ertragreichen Region am Fuß des „mysischen Olympos" (heute: Ulu Dagh, 2543 m hoch, mit kostbarem Hochwaldbestand an den Bergflanken) gegründet worden. ${ }^{11}$ Als relativ junge Gründung konnte die Stadt daher für sich nicht den Sonderstatus einer althellenischen Polis (im griechischen Mutterland bzw. hier am Küstensaum des westlichen und nördlichen Kleinasiens) beanspruchen; die institutionelle Ordnung in Dions Heimatpolis basierte somit in ihren verfassungspolitischen Strukturen primär auf der lex Pompeia, dem 63 v. Chr. vom Imperator Pompeius entworfenen „Grundgesetz" für die Doppelprovinz BithyniaPontus: Den jeweils für ein Jahr von der Bürgerschaft gewählten obersten Magistraten (mit einem ő $\chi \omega v$ an der Spitze) stand ein zahlenmäßig relativ kleines Ratsgremium zur Seite, dessen Mitglieder, durch Zuwahl oder Bekleidung einer hohen Magistratur qualifiziert, (wie römische Senatoren) jeweils auf Lebenszeit bestellt wurden. Dieser Stadtrat rekrutierte sich daher zum größten Teil aus Angehörigen der wohlhabendsten Familien der Polis. $^{12}$

Immerhin aber war die ekklesia der Stadt, die allen Vollbürgern offen stand, eine in ihrer inneren Dynamik „,starke“ Institution in allen Bereichen und Streitfragen der Gemeinde-Politik geblieben - wenngleich nunmehr unter der Kontrolle der (einander in raschem Wechsel ablösenden, gelegentlich auch interventionistisch agierenden) römischen Proconsuln. Daher verstand sich die Polis Prusa selbst auch uneingeschränkt als eine hel-

mationen bei Suet. Dom. 7,2 u. 14,2. - Für Getreide, dessen Vorratshaltung in den meisten größeren Stadtzentren von der öffentlichen Hand intensiv kontrolliert und nach Marktlage immer wieder streng reguliert wurde, ließen sich in durchschnittlichen Wirtschaftsjahren an Ort und Stelle vermutlich nur mäßige Preise erzielen. - Darüber hinaus verfügte Dions Familie wohl auch über einen beträchtlichen Kapitalbesitz, der für ehrgeizige Bauprojekte in der Stadt, aber auch zu Darlehensgeschäften, nicht zuletzt aber auch zu Spendenbeiträgen für die Anliegen der Polis eingesetzt werden konnte (§ 5).

${ }^{11}$ Überdies gab es in Prusa starke Thermalquellen, sogar im engeren Stadtgebiet, die beiläufig auch bei Dion Erwähnung finden (or. 46,9). Der Aufstieg Prusas zu einem beliebten Badeort hat dagegen wohl erst später, in hadrianischer Zeit, eingesetzt; vgl. den fragmentarischen Kaiser-Brief: IK 39 II (Bonn 1993) nr. 4, 65-67 (mit weiteren Belegen).

${ }^{12} \mathrm{Vgl}$. die entsprechenden Angaben in der amtlichen Korrespondenz Plinius' d. J. mit Kaiser Trajan: ep. X 79,114 u. 115; daher sind auch die Erklärungen Dions, in seiner politischen Haltung grundsätzlich auf der Seite des Ratsgremiums in Prusa zu stehen (or. 50,1-5; vgl. or. 48,9f. und 13f.) von erheblicher Bedeutung. Diese Einstellung hielt ihn freilich nicht davon $\mathrm{ab}$, sich gegen die zeitweilig von römischen Statthaltern verfügten Entrechtungen des Demos bzw. der Ekklesia in der Stadt auszusprechen (s. u. a. orr. 43,7. 48,1-3. 50,3). Auch in der 2. Tarsos-Rede (or. 34,27f.) distanziert sich Dion von Beschränkungen der politischen Rechte in der Bürgerschaft nach timokratischen (Census-)Kriterien; allgemein zu den inneren Spannungen in den bithynischen Städten vgl. auch Plinius ep. X 34,1 (Antwort Trajans). 
lenische Demokratie. ${ }^{13}$ Vor der ekklesia wie vor dem Rat mussten sich die konkurrierenden Ratgeber und „Wohltäter“ der Stadt gegeneinander behaupten und für ihre unterschiedlichen Ziele und Methoden, vor allem in der „Wohlfahrtspolitik“ der Gemeinde, eintreten. Denn von einem oligarchisch in sich geschlossenen, durchgehend an einer gemeinsamen Interessenlage orientierten „Honoratiorenregime" konnte damals offensichtlich (noch) nicht die Rede sein.

Nach Ausweis der Bithynischen Reden Dions, aber auch den Angaben in manchen epigraphischen Zeitdokumenten zufolge, wurde die innerstädtische Politik vieler Poleis des griechischen Ostens tatsächlich von zwei gegeneinander gerichteten "Grundmustern" bestimmt: Den aktiven Politikern der einen Richtung war es mit ihren Initiativen primär darum zu tun, aus dem Haushalt der Polis sowie von wohlhabenden Sponsoren Mittel für konsumtive Ausgaben freizumachen und bei jeder Gelegenheit, mit starker Unterstützung aus der ekklesia, Geld- und Sachspenden zugunsten der städtischen Bevölkerung, vor allem der erwerbs- und beschäftigungslosen Armen, einzufordern, deren wirtschaftliche Lage sich jedoch durch derartige douceurs kaum nachhaltig verbessern ließ. Die Politiker dieser Richtung kannten freilich nur zu gut die Wünsche und akuten Nöte ihrer Klientel und standen ihr wohl auch der sozialen Herkunft nach ziemlich nahe. ${ }^{14}$

Die andere "stadtpolitische" Strömung, vornehmlich von wohlhabenden Bürgern und ambitionierten „Wohltätern“ repräsentiert, setzte sich demgegenüber gerne für sichtbare Strukturverbesserungen, mit besonderer Vorliebe aber für prestigeträchtige Verschönerungen des Stadtbildes ein, mit denen zugleich das persönliche Ansehen des Sponsors bzw. curator und der Rang der Heimatpolis sowohl innerhalb der miteinander in unablässigem Wettstreit stehenden Griechenstädte als auch in der Wertschätzung der römischen Instanzen angehoben werden konnten. ${ }^{15}$ Für diese hochgesteckten Ziele ließen sich bei entsprechenden Anlässen auch die städtischen Massen in der ekklesia begeistern; im harten Alltagsleben gewannen in der Volksversammlung jedoch (verständlicherweise) die ak-

\footnotetext{
${ }^{13}$ Dion, or. 46 (Rechtfertigungsrede) $§ 2$; Dion selbst äußert sich bekanntlich immer wieder skeptisch hinsichtlich der Verfassungsrealität in einer Demokratie: Vgl. u.a. or. 3,47f.

${ }^{14}$ S. Dion, orr. 40,10 und 45,14f.; vor diesem Hintergrund gewinnt die Gestalt des „Demagogen “ in der Jäger-Erzählung (ab § 26) deutlich an Profil. S. ferner Plinius' Angaben über seine Revision der Staatskasse und -gelder in Prusa: ep. X 17a,3; ferner 23,2 (Umwidmung der für Ölspenden an die Stadtbevölkerung aufgewendeten Haushaltsmittel der Polis für den Bau eines neuen Stadtbades) sowie ep. 70 und 71.

${ }^{15} \mathrm{Zu}$ Dions anspruchsvollem Programm einer Verschönerung des Stadtbildes von Prusa und nachhaltigen Verbesserung der städtischen Infrastruktur vgl. orr. 40,8f.; 45,12 und 47,12-14. - Immerhin spricht auch Plinius nach seinem Besuch der Stadt von einer foedissima facies civitatis in Prusa und der Notwendigkeit, Rang und Würde dieser Polis durch ansehnliche Bauten zu heben: ep. X 70,1.
} 
tuellen Wünsche der Stadtarmut nach materiellen Erleichterungen und handfesten Sachspenden, von heftigen politischen Willenskundgebungen begleitet, leicht wieder die Oberhand über die allzu ehrgeizigen und vorrangig auf den dauerhaften Ruhm der „Wohltäter“ ausgerichteten Projekte. $^{16}$

Zur Position eines Vertrauensmanns des Demos und anerkannten Mehrheitsführers im Rat und in der ekklesia konnte langfristig freilich nur derjenige aufsteigen, der bei wichtigen Anlässen über die Mittel verfügte, sich auch auf der provinzialen Ebene, im Gremium der Abgeordneten für den

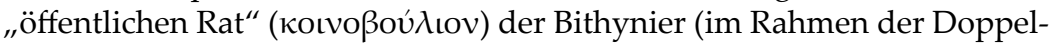
provinz von Bithynia-Pontus), Gehör zu verschaffen. Darüber hinaus aber kam es darauf an, möglichst enge, persönliche Beziehungen zu einflussreichen Senatoren in Rom, vor allem natürlich zu Angehörigen des Kaiserhauses, anzuknüpfen. Nur dann konnte man sich äußerstenfalls - und mit Unterstützung durch die bithynische Ratsversammlung - auch einmal auf einen ernsthaften Disput (und einen anschließenden Rechenschaftsprozess vor dem Senat in Rom) mit einem der amtierenden Proconsuln einlassen, der sich gegenüber der Polis-Bürgerschaft und ihrer Führung abweisend und feindselig verhalten hatte. ${ }^{17}$

Dion hat sich schon früh, bald nachdem er über seinen Anteil aus dem Erbe des Vaters selbständig verfügen konnte, auf diesen „Karriereweg“ eines ehrgeizigen, auf prestigeträchtige Erfolge zum Vorteil für seine Heimatgemeinde bedachten "Stadtpolitikers" begeben. ${ }^{18}$ Auch ein glückli-

\footnotetext{
${ }^{16}$ Zur leicht möglichen Mobilisierung des Volkszorns gegen derartige Projekte und die dafür verantwortlichen „Wohltäter" und curatores bietet ein instruktives Beispiel der Brief des Kaisers Antoninus Pius an die Bürgerschaft von Ephesos: Inschr. v. Ephesos nr. 1491 (IK 15 [Bonn 1980] 34-36); vgl. dazu auch die Dokumente nr. 1492 u. 1493. Mit Nachdruck

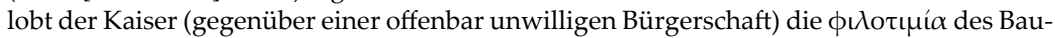
herrn und „Wohltäters“ P. Vedius Antoninus und seine aufwendigen Bemühungen um

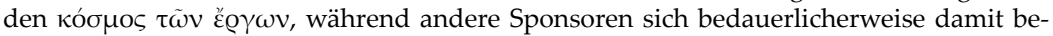
gnügt hätten, durch öffentliche Schauspiele, Geldverteilungen und mit der Ankündigung von Wettkämpfen rasch zu den begehrten Ehrungen zu gelangen, ohne sich um die langfristigen Interessen ihres Gemeinwesens und die Schönheit des Stadtbildes zu bekümmern. Gegen den Widerstand in der Bürgerschaft hatte der „Wohltäter“ P. Vedius Antoninus (um 145 n. Chr.) über den amtierenden Statthalter Ti. Claudius Iulianus den Kaiser persönlich um Unterstützung bitten lassen.

${ }^{17}$ Während sich in Dions Reden nur vage Anspielungen (orr. 43,7f.; 48,1-3) auf die wechselvollen Auseinandersetzungen der Stadt (bzw. des bithynischen кoเvoßoú $\lambda$ ıov) mit Proconsuln wie Iulius Bassus (103/4 n. Chr.) und später Varenus Rufus (106 n. Chr.) finden, ergibt sich hierzu aus Plinius' Briefen ein sehr lebendiges, anschauliches Bild: ep. IV 9,1-22; V 20,1-7; VI 5,1-4. 13,1-5. 29,10-11; VII 6,1-6. 10,1-3; vgl. auch ep. X 56,4 u. 57,2.

${ }^{18}$ Die Rechtfertigungsrede or. 46 lässt hier erkennen, dass sich, anlässlich eines akuten Anstiegs der Preise für Brotgetreide in Prusa, gegen den jungen „Wohltäter“ Dion und ein von ihm betriebenes Bauprojekt (eine ansehnliche Säulenhalle) auch gewalttätiger Volkszorn mobilisieren ließ - wegen angeblicher Preistreiberei oder einer allzu sichtbar gewordenen, aufreizenden Gleichgültigkeit angesichts der von Teilen der Stadtbevölkerung empfundenen Notlage. Immerhin hatte Dion zuvor allein für das Bauland zur Er-
} 
ches Familienleben - mit einer Frau, der Dion über den Tod hinaus die Treue hielt, und einem kleinen Sohn - konnte den aufstrebenden Rhetoriklehrer und (lokalpatriotisch engagierten) Literaten nicht von Versuchen abhalten, nach dem Ende der Bürgerkriegswirren von 69/70 n. Chr. in Rom, am „Ort der Macht" , Fuß zu fassen. ${ }^{19}$ So ist Dion im Rom der 70er Jahre während (vermutlich) mehrerer längerer Aufenthalte - offensichtlich sehr darum bemüht gewesen, an die patriotischen Aktivitäten und die ertragreiche Lehrtätigkeit seines einst mit dem Princeps Claudius befreundeten Großvaters anzuknüpfen.

$\mathrm{Zu}$ den prägenden Persönlichkeiten, die Dion damals in Rom kennenlernte, zählte der angesehene und unerschrockene (immer wieder von Verbannung und Maßregelungen betroffene) stoische Philosoph C. Musonius Rufus, der Lehrer Epiktets. Musonius' philosophische Ethik hat Dion offenbar innerlich tief beeindruckt, auch wenn er zeitweilig - vielleicht aus politischem Opportunismus - an Person und Lehre des römischen Philosophen explizite Kritik geübt hat. ${ }^{20}$ Im Euboikos Logos ist jedenfalls der Einfluss von Musonius' Ethik nicht zu übersehen (s. u. Anm. 158 S. 115).

Wichtiger waren für Dion in dieser Phase jedoch seine Kontakte zu politisch einflussreichen Persönlichkeiten der neuen senatorischen Führungs-

richtung dieser innerstädtischen Stoa nicht weniger als 50000 Drachmen aus Privatmitteln eingesetzt.

${ }^{19}$ Von Dions Ehefrau und dem kleinen Sohn, die wir beide dem Namen nach nicht kennen, ist erstmals in or. 46 die Rede (die Bemerkung or. 41,6 weist auf weitere Kinder Dions, wahrscheinlich Töchter, hin). Der erwachsene Sohn wird später in den Bithynischen Reden mehrfach erwähnt (vor allem or. 50,5 u. 10). Dion hat bekanntlich beide überlebt und ihnen im Rahmen des von ihm (für die Polis) geleiteten großen Bibliotheksbaus 111/2 n. Chr., den Plinius d. J. (ep. X 81,7f.) erwähnt, eine monumentale Grabstätte (im Stadtbereich) errichten lassen. - Die Erzählung in Philostrats vita Apollonii V 31-37, wonach Dion als anerkannter Philosoph bereits im Sommer 69 n. Chr., zusammen mit Apollonios und dem (feindlich gesinnten) Philosophen Euphrates von Tyros in Alexandria von Vespasian, in der entscheidenden Phase unmittelbar vor der Kaiser-Proklamation am 1.7.69 n. Chr., zu einer politisch-philosophischen "Gipfelkonferenz" eingeladen worden sei, stellt zweifelsfrei eine Fiktion dar, die primär das Ansehen und den Rang des großen „Wundermannes" Apollonios erhöhen sollte. Vermutlich ging es Philostrat hier um ein Gegenstück zu der fiktiven aber historisch-literarisch gelungenen Dialogeinlage des ebenfalls am Severer-Hof tätigen Cassius Dio über die Gestaltung des augusteischen Prinzipats (LII 1-48: vertrauliche Unterredung des Octavian/Augustus mit Agrippa und Maecenas). - Zu den spektakulären Ereignissen während Vespasians Besuch in Alexandrien und der Kaiser-Proklamation (durch die römische Besatzungsarmee in Ägypten) am 1. Juli 69 n. Chr. s. die wichtige Studie von A. Henrichs, „Vespasian's visit to Alexandria“, ZPE 3 (1968) 51-80.

${ }^{20} \mathrm{Zu}$ dem persönlich mutigen Verhalten des Musonius Rufus in der Bürgerkriegskrise 70 n. Chr. s. Tac. Hist. III 81 u. IV 10; von Vespasian erneut aus Rom vertrieben, wurde Musonius später unter Titus rehabilitiert und zurückgerufen. Auf Musonius dürfte sich der anonyme Verweis (in der Rhodier-Rede, or. 31,122) auf einen römischen Philosophen beziehen, „der als einziger in strikter Übereinstimmung mit seinen Grundsätzen lebt". Das Verhältnis zu Musonius blieb in dieser Phase jedoch nicht störungsfrei, wie die Angaben bei Synesios (Dion 1,9) bezeugen. 
schicht; er erhielt das römische Bürgerrecht und konnte offenbar auch $\mathrm{Zu}$ tritt zum kaiserlichen Hof erlangen. ${ }^{21}$ Zeitweilig dürfte er zur engeren Entourage des Kaisersohnes Titus, des mächtigen Mitregenten und Nachfolgers Vespasians, gehört haben. ${ }^{22}$ Dass Dion, wie verschiedentlich in der neueren Forschung behauptet, in dieser Zeit bereits mit dem Anspruch und in der Gewandung eines kynischen Philosophen und Mahnredners aufgetreten sein soll, lässt sich durch kein verlässliches Quellenzeugnis belegen. ${ }^{23}$ In seinem Bemühen um eine möglichst enge Verbindung mit der römischen Reichsführung unterscheidet sich Dion im übrigen markant von seinem boiotischen Altersgenossen Plutarch, der sich im Rahmen philosophischer Vortragstätigkeiten in Rom vollauf mit der Rolle eines (nur zeitweilig aktiven und engagierten) „Sachwalters“ für die Belange seiner Heimatstadt Chaironeia sowie die Anliegen der Region Boiotien (oder allenfalls noch der Provinz Achaia) begnügt hat. ${ }^{24}$

Dion war seinerseits offenbar gerne bereit, sich im Interesse der kaiserlichen Regierung auch in anderen Bereichen des griechischen Ostens zu engagieren und die ehrenvolle Aufgabe eines erkennbar autorisierten "Sonderbotschafters" gegenüber angesehenen Polis-Gemeinden zu übernehmen. Es ging dabei um heikle Fragen im öffentlichen, stadtpolitischen Leben dieser Gemeinden, in denen die römische Führung nur ungern mit ihrem Herrschaftsapparat und seiner verbindlichen, die Autonomie (und das stets empfindliche Selbstbewusstsein) hellenischer Poleis verletzenden Befehlsgewalt eingreifen mochte. Als ein Zeugnis aus dieser Ära wird man die umfangreiche Rhodier-Rede (or. 31; wahrscheinlich zu Beginn der Alleinregierung des Titus) ansehen dürfen, in der, mit Hilfe einer langen

\footnotetext{
${ }^{21}$ Auf diese Zeit in Rom wirft Dions Sendschreiben mit Empfehlungen für eine angemessene, aber nicht allzu aufwendige Elementarbildung im Bereich der griechischen Rhetorik (or. 18/68 ARNim: an einen hochrangigen, in politisch-administrativer Verantwortung stehenden Politiker in Rom gerichtet) ein bezeichnendes Licht; in der Ära Vespasians waren bekanntlich zahlreiche Offiziere der siegreichen Bürgerkriegsarmeen in die (unter Nero stark dezimierten) Senatsränge aufgenommen worden. - Unabhängig von der Frage, ob Dion (Cocceianus) sein persönliches römisches Bürgerrecht durch Vermittlung (und Bürgschaft) des späteren Kaisers M. Cocceius Nerva erlangte oder über den (unter Domitian hingerichteten) L. Salvius Otho Cocceianus (s. Suet. Dom. 10,3 und Tac. Hist. II 48), hat eine enge freundschaftliche Beziehung zu Nerva schon lange vor der Verbannung Dions bestanden (vgl. u. a. or. 45,2f.).

${ }^{22}$ Dafür spricht u. a. Dions Dialog-Gedenkschrift für den von Titus sehr bewunderten, in jungem Alter verstorbenen Boxer Melankomas (or. 29); vgl. v. ArNim 1898, 142-148. Die Rolle, die Philostrat im 5. Buch der Apollonios-vita Dion zuschreibt, ist reine Fiktion.

${ }^{23}$ S. zu diesem Problembereich die Studie von H. Siревоттом, „, The date of Dio of Prusa's Rhodian and Alexandrian orations", Historia 41 (1992) 407-419; Sіревоттом schließt (sehr zu Recht) aus historisch eindeutigen Befunden eine Datierung der Alexandria-Rede in die flavische Ära aus. Er rückt jedoch (m. E. zu Unrecht) gleichzeitig die Rhodier-Rede chronologisch-historisch nahe an die Alexandria-Rede heran und datiert beide in die Regierungszeit Trajans.

${ }^{24}$ Vgl. dazu die Selbstzeugnisse Plutarchs in Dem. 2,2 und De curios. 15, 522 D-E.
} 
Reihe historischer exempla und allgemeiner, politisch-rechtlicher Erwägungen, auf einen Missbrauch in dieser Polis eingegangen wird, ältere Ehrenstatuen durch einen (kostengünstigen) Austausch der Sockelinschriften auf neue Machthaber und Wohltäter der Stadt „umzuwidmen“ und zu aktualisieren. ${ }^{25}$ Dion betont zwar, dass seine Stellungnahme ohne ein spezielles Mandat erfolge, dennoch greift hier eine Interpretation, die die Kritik des Autors lediglich auf die gängigen Vorstellungen und das etablierte „soziale Wertesystem" eines Vertreters der „Honoratioren-Schicht" reduzieren will, entschieden zu kurz. ${ }^{26}$

Der politische Hintergrund wird vielmehr in verschiedenen Bemerkungen Dions deutlich sichtbar: Rhodos hatte von der Reichsführung soeben - nach harten Umbrüchen unter Claudius und Vespasian - die „Freiheit" und seinen ansehnlichen Insel- und Festlandbesitz zurückerhalten. Um diesen neuen, aber prekären Status ihrer Polis abzusichern, hatten es die Rhodier danach zu einer regelrechten Inflation der Statuenehrungen für römische Würdenträger und einflussreiche Persönlichkeiten kommen lassen und sich aus dem reichen Fundus der Stadt an älteren Ehrenmonumenten mit dem von Dion scharf kritisierten Verfahren „,bedient“. Dion lässt es hier seinerseits auch nicht an Mahnungen fehlen, dass diese Unsitte nicht nur den Ruf von Rhodos in Hellas, sondern am Ende auch die Beziehungen der Polis zu ihren Freunden und römischen Wohltätern beschädigen werde. ${ }^{27}$ Von der an die Rhodier adressierten Denkschrift / Rede heben sich die Alexandria-Rede (or. 32) und ebenso die 2. Tarsos-Rede (or. 34), die beide eindeutig in die Ära Trajans zu datieren sind, in Sprache und Gedankenführung deutlich ab: Einerseits gibt Dion hier die Nähe seiner politischen (und auch „sozialpädagogischen“) Anliegen und Forderungen zu den Wünschen der Reichsführung deutlich zu erkennen, andererseits hebt er seine persönliche Unabhängigkeit in der Rolle eines populär-philosophischen Mahnredners hervor. ${ }^{28}$ Über die tiefe Zäsur der Verbannungszeit hinweg

\footnotetext{
${ }^{25}$ Der Text wendet sich offenkundig an das Ratsgremium der rhodischen Polis, das täglich zu einer regulären Sitzung zusammentritt (§ 4), ist aber wohl eher als Leserede bzw. Sendschreiben aufzufassen (vgl. v. Arnim 1898, 210f.).

${ }^{26}$ Gegen KLAUCK 2000, 11-12 u. 207-8; ebenso wenig sollte man diese Rede als bloß virtuose, politisch irrelevante „Prunk“- bzw. „Konzertrede“ missverstehen.

${ }^{27}$ Besonders aufschlussreich ist in dieser Hinsicht der Abschnitt §§ 105-112. Auch sonst wird immer wieder auf das entscheidend wichtige Verhältnis zu Rom angespielt: vgl. u. a. $\S \S 66-68,155$. Daneben steht die Mahnung an die rhodischen Bürger, sich nicht den Unsitten im zeitgenössischen Athen und in Sparta anzupassen (§§ 121-123): Rhodos sei inzwischen als die letzte große und würdige Polis in Hellas übrig geblieben (§§ 158-161)!

${ }^{28}$ Vgl. or. 31,20-22. Im Falle einer inneren Beruhigung und eines dezenteren Umgangs miteinander kann er den Alexandrinern sogar Aussichten auf einen Kaiserbesuch in ihrer Stadt eröffnen: $\S \S 29$ u. 95f.; zur modernen Forschungsdiskussion s. G. SALMERI, „Dio, Rome and the civic Life of Asia Minor", in: Swain 2000, 82f., und Anm. 142. - Zu dem politischen Hintergrund und den weitreichenden Vorschlägen der 2. Tarsos-Rede (or. 34) s. die eingehende Untersuchung von D. Kienast / H. CAstritius, „Ein vernachlässigtes Zeug-
} 
hat Dion offensichtlich keine Mühe gescheut, um vor verschiedenen PolisBürgerschaften als autorisierter "Mediator" aufzutreten, nunmehr jedoch stets im ärmlichen Gewand und mit dem Prestige eines auf seine innere und äußere Unabhängigkeit stolzen Philosophen und Wanderpredigers.

Umstritten sind in der modernen Forschungsdiskussion allerdings auch die näheren Umstände, die zu Dions Verbannung in der Ära Domitians (81-96 n.Chr.) geführt haben, sowie die zeitliche Dauer dieses Exils: Bekanntlich hat Philostrat, der in seinem biographischen Roman freilich ganz allein dem überragenden Helden Apollonios von Tyana den Rang eines echten, moralischen „Widerstandskämpfers“ gegen den tyrannischen Kaiser zuerkennen will, die $\phi v \gamma \eta ́$ Dions als bloße Überreaktion und Flucht eines angsterfüllten „Drückebergers“ in kritischer Zeit dargestellt - eine Auffassung, die inzwischen auch von einer Reihe moderner Forscher mit Nachdruck vertreten wird. ${ }^{29}$ Selbst wenn man dem expliziten autobiographischen Selbstzeugnis Dions in der (in Athen gehaltenen) or. 13 (12 Arnim) nicht in allen Details folgen will, so wird man doch die klaren Angaben, namentlich in den Reden orr. 1 und 3, die sich direkt an den (seit 98 n.Chr. allein regierenden) Princeps Trajan wendeten und ihm persönlich gewidmet waren, schwerlich einfach beiseite schieben können.

Die Tatsache, dass Domitian gegen den aufstrebenden, selbst in Rom mit großem Erfolg tätigen Rhetor und ehrgeizigen "Stadtpolitiker" die Coercitionsmaßnahme einer relegatio perpetua sowohl aus Rom und ganz Italien als auch aus der Heimatprovinz Bithynia-Pontus verfügt hat, lässt sich daher aus Dions vita schwerlich eliminieren. ${ }^{30}$ Er selbst nennt (in der etwas ausführlicheren Notiz in or. 13) als Grund für diese Bestrafung seine persönliche, freundschaftliche Beziehung zu einem hochgestellten römischen Politiker und Angehörigen der Kaiserfamilie, den der argwöhnische Tyrann hatte beseitigen lassen. Zu dem Namen und der Identität dieses Tyrannenopfers macht Dion freilich weder hier noch an anderer Stelle in seinem Werk konkrete Angaben; in der neueren Forschungsdiskussion hat

nis für die Reichspolitik Trajans: die zweite tarsische Rede des Dion von Prusa", Historia 20 (1971) 62-80; immerhin konnte Dion es hier in seiner Rede wagen, nicht nur allgemein für Verbesserungen und Bemühungen um „Eintracht“ in den Beziehungen von Tarsos zu den Nachbar-Poleis zu werben, sondern gegenüber den Tarsiern sogar konkret die Forderung nach der Aufnahme einer bislang deklassierten Bevölkerungsgruppe in der Stadt, der "Leineweber", in den Vollbürgerverband zu erheben.

${ }^{29}$ S. Moles 1978 (u. a. auf der Basis einer sehr bedenklichen Interpretation von Dions or. 13); vgl. dazu Desideri 2000, 101 mit Anm. 10, und Swain 2000, 45f.

${ }^{30}$ Ein besonders eindrucksvolle Zeugnis stellt die Notiz (or. 19,1f.) über ein Treffen Dions mit seiner Familie und Freunden aus Prusa in Kyzikos, einer „freien“ Griechenstadt im Bereich der Provinz Asia (nicht allzu weit entfernt von der Heimatpolis Prusa) dar - aber der Relegierte blieb bei dieser Gelegenheit bemüht, den Grenzbereich von Bithynia-Pontus nicht zu berühren und wagte sich hier in die städtische Öffentlichkeit nur anlässlich einer Gesangsdarbietung, zu der mehr als 3000 Zuhörer vor dem Ratsgebäude zusammenströmten; vgl. dazu auch or. 1,50f. 
man daher neben dem von Domitian zum Tode verurteilten T. Flavius Sabinus, einem Vetter des Kaisers, auch L. Salvius Otho Cocceianus in Erwägung gezogen. ${ }^{31}$ In der Rechtfertigungsrede or. 40, die Dion vor der Öffentlichkeit in Prusa 100 n. Chr., nach seiner Rückkehr von einer (insgesamt sehr erfolgreichen) Huldigungsgesandtschaft zu dem neuen Princeps Trajan, gehalten hat, ist unmissverständlich von einer sehr langen Dauer der Verbannung (,während so vieler Jahre meiner Verfemung und Flucht“!) die Rede, in der er beinahe schon die Hoffnung auf eine Rehabilitation und Heimkehr aufgegeben hatte (\$§ 2 u. 12).

Der Status eines Relegierten, dem kein fester Aufenthaltsort (als Zwangsdomizil) zugewiesen war, nötigte Dion zu einem unsteten Wanderleben, vielfach in Not und Gefahr; Jedenfalls sah er sich als weitgehend schutzloser Verfemter zur Vorsicht genötigt, um nicht in den Gesichtskreis römischer Behörden und feindseliger Widersacher in Prusa bzw. in seiner Heimatprovinz zu geraten. Gelegentliche, kurzfristige Treffen mit seiner Familie und befreundeten Bürgern aus Prusa mussten vorsichtig und mit großer Sorgfalt vorbereitet werden; vor allem durfte niemals Aufsehen erregt werden. ${ }^{32}$ Selbst in der Peloponnes, auf dem Weg nach Olympia, hielt es Dion damals für geraten, die großen Straßen und die Öffentlichkeit in den Stadtzentren zu meiden (or. 1,51). Dafür erfuhr er auf seinen Wanderfahrten immer wieder die spontane Hilfsbereitschaft und Solidarität der armen Landbevölkerung - von „ehrbaren Leuten wie Hirten und Jägern“ gegenüber Verfolgten und Unglücklichen. ${ }^{33}$ Die in Rom von höchster Stelle angeordnete Verbannung war zwar nicht mit einer generellen Konfiskation von Hab und Gut des Gemaßregelten verbunden; sie stellte jedoch neben den auf Dauer natürlich unvermeidlichen Vermögensverlusten und Benachteiligungen - einen vernichtenden Schlag gegen die bisher erlang-

\footnotetext{
${ }^{31}$ Dion hatte zum Kreis der Freunde und Ratgeber dieses hochrangigen Senators bzw. Angehörigen des Kaiserhauses gehört; Dion vergleicht seine Bestrafung nach dem Sturz und Tod seines hochgestellten Freundes mit den bei der Bestattung skythischer Könige einst üblichen Menschenopfern am Grabhügel aus der Schar der Diener und Nebenfrauen des Fürsten (vgl. Hdt. IV 71-73). - Dions Angaben passen am besten zu T. Flavius Sabinus, der 82 n. Chr. unmittelbar nach seiner Wahl zum Consul hingerichtet wurde: Suet. Dom. 10,4, vgl. auch Philostr. V. Apol. VII 7, p. 132. - Zu L. Salvius Otho Cocceianus (einem Neffen des 69 n.Chr. nur kurze Zeit regierenden Usurpators und Kaisers Otho) s. Suet. Dom. 10,3 u. Tacitus Hist. II 48; s. auch o. Anm. 21. Salvius Cocceianus war seinerseits auch mit Nerva eng verwandt. Seine Ermordung fällt ebenfalls vor $88 \mathrm{n}$. Chr.; s. generell H. Sidebоттом, „Dio of Prusa and the Flavian dynasty“, CQ 46 (1996) 47-56.

${ }^{32}$ Vgl. die klaren Angaben in der Bithynischen Rede (or. 45) §§ 1f. und die Schilderung seiner Zusammenkunft mit Angehörigen und Freunden bei einem Aufenthalt in der Hafenstadt Kyzikos (im Bereich der Provinz Asia) im Fragment or. 19,1-3 (vgl. o. Anm. 30).

${ }^{33}$ Bei Philostrat (V. Apol. I 7) finden sich einige Angaben, wonach Dion auf seinen Fluchten den Lebensunterhalt zeitweilig mit harter körperlicher Arbeit, u. a. als Gärtner, verdienen musste.
} 
te Position Dions in seiner Heimatpolis dar. ${ }^{34}$ Seine engsten Angehörigen haben danach offenbar für eine gewisse Zeit ihren Wohnsitz von Prusa in die benachbarte Hafenstadt Apameia verlegt, wo sie, im Schutze eines ererbten Ehrenbürgerrechtes, offensichtlich freier und unbeobachteter leben konnten. ${ }^{35}$ Denn in Prusa dominierten von nun an Dions Rivalen und Widersacher für lange Zeit (wahrscheinlich mehr als ein Jahrzehnt) auf der Bühne der Gemeinde-Politik und im öffentlichen Leben der Polis. In dieser Phase konnten sie ausreichend Anhänger um sich versammeln, so dass sie sich später auch von der unter Kaiser Nerva (96/7 n.Chr.) verfügten Rehabilitation Dions und seiner triumphalen Rückkehr nach Prusa nicht entmutigen ließen, wie eine lange Reihe bitterer Äußerungen in den Bithynischen Reden über gehässige Anfeindungen und sachlich unbegründete Opposition gegen die von Dion erneut ergriffenen Initiativen für öffentliche Baumaßnahmen in Prusa nahelegen und schließlich Plinius' Angaben in seinem amtlichen Briefwechsel mit dem Kaiser 111/2 n.Chr. dokumentarisch belegen. ${ }^{36}$

Eine prominente Gestalt unter den Gegenspielern in Prusa dürfte der in den Plinius-Briefen näher charakterisierte „Philosoph“ Flavius Archippos gewesen sein: Er stieg, ungeachtet einer dunklen Vergangeheit, in der Ära Domitians - angeblich nachdem er mit Erfolg eine schmeichlerische Denkschrift an den Kaiser übersandt hatte - zum anerkannten Vertrauensmann des Herrschers in der Stadt auf und erhielt in Prusa hohe und höchste Auszeichnungen der Polis zuerkannt. ${ }^{37}$ So war es geradezu unvermeidlich, dass Dion sich hier schon bald nach seiner Heimkehr wieder führend in der "Stadtpolitik" engagierte - und zwar sowohl mit Rücksicht auf die manifesten Interessen seiner Familie nach einer langen Leidenszeit, als

\footnotetext{
${ }^{34}$ Die Tatsache, dass Dions Besitz in Prusa auch nach dem Verbannungsbefehl grundsätzlich unangetastet blieb, spricht deutlich gegen eine Datierung dieser Coercitionsmaßnahme in die späteren Jahre der Regierung Domitians; in der Spätphase wurde nämlich das Interesse des Kaiser an Konfiskationen immer größer: Suet. Dom. 12,1-2, vgl. c. 9,1-2. - Zu den Vermögensverlusten, die Dions Familie und er persönlich gleichwohl im Laufe der langen Verbannungszeit zu beklagen hatten, s. or. 45,10f.

${ }^{35}$ Vgl. or. 41 (in Apameia an den Rat der Polis und weitere Zuhörer gerichtet) $\S \S 1$ und $6 f$.

${ }^{36}$ So weist Dion mit Bitterkeit auf hämische Kritik an dem von ihm auf- oder ausgebauten Familiendomizil in der Stadt hin, das als „Goldenes Haus“ (und damit als imitatio des bauwütigen Tyrannen Nero) von Dions Gegnern bezeichnet wurde (or. 47,14f.). Ohnehin wurden die von Dion initiierten Bauvorhaben und Eingriffe in das Stadtbild von Prusa (Abriss eines offenbar an der Hauptstraße gelegenen alten Schmiede-Gebäudes und ev. sogar die Verlegung von Staatsgräbern aus dem Stadtzentrum) als Maßnahmen eines Tyrannen verunglimpft (orr. 40,8f. u. 47,16f.).

${ }^{37}$ Vgl. dazu Plinius' ausführliche Mitteilungen (mit Dokumenten) in ep. X 58-60 und dem Briefbericht X 81 über das 112 n. Chr. von Archippos (und seinem „Anwalt" Eumolpos) gegen Dion angestrengte Verfahren vor dem Statthalter. Auf Flavius Archippos - als notorisch "dunklen Ehrenmann“ - lassen sich wohl auch Dions Klagen in or. 45,4f. beziehen.
} 
auch angesichts der großen Hoffnungen, die man in Prusa nun allgemein auf seine engen persönlichen Beziehungen zu dem neuen Princeps Nerva setzte. ${ }^{38}$ Mit seinem hohen Ansehen auch in anderen Städten Bithyniens konnte Dion alsbald, mit Rückendeckung aus Rom, erfolgreiche Verhandlungen über den Abschluss von ó $\mu$ óvot $\alpha$-Verträgen führen, die sowohl im ökonomischen Bereich als auch hinsichtlich der Angleichungen im städtischen Bürgerrecht erhebliche Bedeutung gehabt haben. ${ }^{39}$

Einen Maßstab dafür, welche Bedeutung Dion ganz persönlich einer prominenten Stellung in der "Stadtpolitik" von Prusa beimaß, lässt sich freilich schon aus der Tatsache gewinnen, dass er sich unmittelbar nach seiner Rückkehr vor der politischen Öffentlichkeit der Polis mit einem ebenso ehrgeizigen wie aufwendigen Programm zur baupolitischen Verschönerung und Erneuerung der Stadt zu Worte gemeldet hat. Aus explizit genannten Projekten sollten der Bürgerschaft erhebliche Strukturverbesserungen und neue Einkünfte erwachsen. Im Rückblick muss sich Dion in diesem Zusammenhang freilich eingestehen, dass er sich damals mit einem so unbändigen patriotischen Eifer für das Wohl von Prusa und eine fällige Rangerhöhung seiner Heimatpolis weit von den anerkannten Prinzipien einer philosophischen Lebensführung entfernt habe. ${ }^{40}$

Allerdings gab es in der Stadt zu dieser Zeit und auch noch später, wie aus Plinius' Notizen deutlich hervorgeht, baupolitisch viel zu tun, zumindest wenn man sich im Stadtbild des Zentralorts dem Standard einer wirklich erstrangigen Gemeinde annähern wollte. Dabei zeigte der Haushalt dieser Polis, wie Plinius als Statthalter und erfahrener, strenger Revisor alsbald vermelden konnte, durchaus keine Merkmale einer gefährlichen Überschuldung. ${ }^{41}$ Jedenfalls bleibt - gerade im Hinblick auf eine

\footnotetext{
${ }^{38}$ Eine ernste längerfristige Erkrankung hinderte Dion dann freilich an der fälligen Reise nach Rom; erst im Zuge der Huldigungsgesandtschaft an Trajan (99 n. Chr.) konnte Dion, an der Spitze einer (keineswegs einmütig auftretenden) Delegation aus Prusa, eine Statusverbesserung für seine Heimatpolis erreichen (u. a. Erweiterung des Ratsgremiums auf 100 Mitglieder): vgl. orr. 44,12 und 45,2f. 6-10; zu Flavius Archippos s. die einschlägigen Angaben in Plin. ep. X 58-60.

${ }^{39} \mathrm{Vgl}$. u. a. or. $40,17 \mathrm{f}$. u. 33 sowie orr. 38 u. 41. Zum materiellen Inhalt von ó $\mu$ óvot $\alpha-$ Verträgen, der über die "Städtepartnerschaften“ unserer Gegenwart hinaus gegangen ist s. D. KIENAST, „Die Homonoia-Veträge der römischen Kaiserzeit“, JNG 14 (1964) 51-84 bes. 63f. und dens., "Zu den Homonoia-Vereinbarungen der Römischen Kaiserzeit", ZPE 109 (1995) 267-282. Zum Interesse der römischen Reichsführung an Vereinbarungen dieser Art zwischen den Städten des griechischen Ostens s. auch Plinius d. J., Panegyr. 80,3.

${ }^{40}$ Vgl. dazu u. a. Dions Expectorationen orr. 40,1f. u. 44,1f. u. 6f.; s. andererseits die unverhüllte Drohung mit einem definitiven Bruch und Ausstieg aus der "Stadtpolitik“ in Prusa: or. 47,10f.

${ }^{41}$ Vgl. Plinius' Angaben zur Situation des städtischen Haushaltes in Prusa (ep. X 17a. b) und seine Zweifel hinsichtlich einiger für öffentliche Bauten erstellten Kostenvoranschläge. Immerhin weist Plinius hier auch auf ein hässliches, längst veraltetes Badehaus der Stadt hin (ep. X 23 u. 24), das er in der von ihm insgesamt als eher unansehnlich eingeschätzten Stadt dringend durch einen Neubau ersetzt sehen wollte. - In finanzieller Hinsicht waren,
} 
angemessene Interpretation der Euböischen Rede - die Tatsache von Bedeutung, dass der weitgereiste Dion sich nach der Rehabilitation, auch in seiner liebgewonnenen kynisch-stoischen Philosophentracht, ohne Zögern und mit ganzem Herzen wieder dem Aufgabenbereich eines engagierten „Wohltäters" und aktiven Bauherrn in seiner Heimatpolis zugewandt hat - allen Verdrießlichkeiten und persönlich-politischen Widerständen innerhalb der Bürgerschaft zum Trotz. ${ }^{42}$

Selbst in seiner letzten Lebensphase (111/112 n.Chr.) begegnet uns Dion

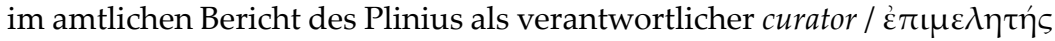
eines großen Bauprojektes, das nach seiner Fertigstellung in die Nutzung und das Eigentum der Stadt übergeben werden sollte: Es handelte sich um einen Bibliotheksbau, in dessen zentralem Saal eine Statue Trajans Aufstellung gefunden hatte; damit sollte diese Anlage, über den öffentlichen Loyalitätsgestus hinaus, offenbar unter den Schutz von Kaiser-Kult und -Macht gestellt werden. Das Bibliotheksgebäude war jedoch architektonisch (zumindest äußerlich) mit einem von Arkaden umgebenen Hof (area) verbunden, in dessen Zentrum sich ein für Dions Frau und Sohn errichtetes Grabmonument befand. ${ }^{43}$ Auf diese (angeblich oder tatsächlich) unerlaubte Kombination einer Stätte des Kaiserkultes mit Grabanlagen zielte der maiestas-Klagevorwurf von Dions Widersachern, der aber von Kaiser Trajan in seinem Rescript mit großer Entschiedenheit zurückgewiesen worden ist. ${ }^{44}$ Unbestreitbar ist jedoch die Tatsache, dass diese architektonisch anspruchsvolle Anlage den persönlichen Ruhm Dions als „Wohltäter" und erfolgreicher, um die Pflege von Bildung und Wissen in Prusa in besonderem Maße verdienter "Stadtpolitiker" auf besonders

nach Plinius' Urteil, in Prusa vor allem einige konsumtive Ausgaben der Polis im Sozialbereich problematisch.

${ }^{42}$ Ein schönes Zeugnis für Dions Begeisterung über architektonisch gelungene, hochgeschossige Großbauten (Säulenhallen / Arkaden): or. 47,15.

${ }^{43}$ S. Plin. ep. X 81,7; die Klage der beiden Widersacher Dions stützte sich zunächst auf den Vorwurf, das vollendete und zur Übernahme durch die Stadt beim Rat angemeldete Gebäude entspreche nicht dem ursprünglich genehmigten Bauplan (81,2). - Die an Plinius gerichtete Bitte der beiden Kläger, über ihre causa nicht in Prusa, sondern in Nikaia verhandeln zu lassen, lässt jedoch erkennen, dass sie inzwischen in ihrer Heimatpolis nicht mehr mit Wohlwollen und breiter Unterstützung rechnen konnten. - Zweifellos sollte an der von Plinius inspizierten, prominenten Stätte später auch Dions eigenes Grab angelegt werden. Falls sich der Arkadenhof mit den Gräbern von Dions Frau und Sohn, wie anzunehmen, im engeren Stadtareal befand, so wäre dies ein Beleg für einen von der Polis zuvor bereits bewilligten Heroen-Kult für die beiden Verstorbenen. Die Kombination der Grabstätte mit dem Bibliotheksbau war aber gleichwohl nur möglich geworden, weil Dion, als großzügiger Sponsor und verantwortlicher curator, dafür aus seinen privaten Mitteln ein passendes, direkt anschließendes Baugrundstück zur Verfügung gestellt hatte.

${ }^{44}$ Plinius / Trajan, ep. X 81,6 u. 8 sowie 82,1-2; allerdings verlangt und erwartet der Kaiser, dass Dion in dem nun einmal eröffneten Verfahren seine (schon vorbereitete) Abrechnung über die Kosten und über die gesamte Bauplanung und -ausführung dem Statthalter Plinius zur Genehmigung vorlegt (im Sinne der utilitas civitatis). 
eindrucksvolle Weise verewigen sollte. Bezeichnenderweise begegnet eine vergleichbare funktionale Verbindung eines monumentalen "Wohltäter"und Stifter-Grabes mit einem gemeinnützigen Bibliotheksbau auch in der nur wenige Jahre später in der Metropole Ephesos vollendeten, grandiosen Celsus-Bibliothek. ${ }^{45}$

So eröffnen uns die Informationen aus Plinius' Amtsschreiben einen Blick auf eine Seite im Leben und Werk des Dion von Prusa, die weit von den Prinzipien der stoischen Ethik und den Maximen popular-philosophischer Mahnreden eines kynisch-sokratischen Weisen entfernt erscheint. In der Sache lässt sich hier allerdings eine solide Brücke zu den Selbstzeugnissen Dions in seinen Bithynischen Reden (aus den Jahren zwischen ca. 100 und 105 n. Chr.) schlagen, wobei der Bibliotheksbau von 112 n. Chr. (mitsamt seinen sepulkralen „Annexen“) gewiss noch nicht zu jenen Projekten gehört hat, die in den überlieferten Reden vor der Polis-Öffentlichkeit in Prusa empfohlen und verteidigt worden sind. Daher können wir aus diesem unermüdlichen, über mehr als ein Jahrzehnt hin fortgesetzten Engagement Dions als Bauherr, curator und "Stadtpolitiker" bei ihm mit einiger Sicherheit auf die sozioökonomischen Vorstellungen zurückschließen, die hinter dem im Euboikos Logos nur knapp (und primär von der negativen Seite her) umrissenen „Beschäftigungsprogramm“ für die Stadtarmut gestanden haben: Es ging Dion offensichtlich um ansehnliche, gemeinnützige Bauprojekte, an deren Ausführung alle „,anständigen“ (nicht mit unnötigen Luxusbedürfnissen befassten) Zweige von Handwerk und Gewerbe (s.u. Anm. 141 S. 111f.) in der jeweiligen Stadt beteiligt sein sollten - finanziell getragen von einer im griechischen Osten wie auch sonst in der Mittelmeer-Ökumene schon lange üblich gewordenen Kombination von Haushaltsmitteln der Gemeinde mit großzügigen Spenden und Hilfeleistungen reicher Sponsoren aus der soziopolitischen Führungsschicht des jeweiligen Bürgerverbandes. ${ }^{46}$

\footnotetext{
${ }^{45}$ Die Celsus-Bibliothek in Ephesos wurde von dem ursprünglich aus Sardes stammenden Ti. Iulius Celsus Polemaeanus (cos. 92 n. Chr.; ca. 105/6 n. Chr. Proconsul in Asia) gestiftet, aber erst von seinem Sohn Ti. Iulius Aquila Polemaeanus (cos. suff. 110 n. Chr.) in hadrianischer Zeit fertiggestellt. S. H. Engelmann, "Celsusbibliothek und Auditorium in Ephesos", ÖJh 62 (1993) 105-111. - Die Idee, einen Bibliotheksbau architektonisch mit einem Grabmonument zu verbinden, dürfte durch die damals in Rom kurz vor der baulichen Vollendung stehende Konzeption für den Exedra-Hof der Trajanssäule (hinter der Basilica Ulpia) an Ansehen und Gewicht gewonnen haben; dieser Platz wurde an den beiden Schmalseiten von zwei gleichgestaltigen Bibliotheksbauten (für die lateinische und die griechische Literatur) eingefasst, während der Sockel der Säule als Grablege für den Princeps Trajan vorgesehen war; s. R. Meneghini, „Die ,Bibliotheca Ulpia'. Neueste Ausgrabungen in der Bibliothek im Trajansforum in Rom", in: W. Hoepfner (Hrsg.), Antike Bibliotheken (Mainz 2002) 117-122.

${ }^{46}$ Dabei konnte es nicht ausbleiben, dass manche Baumaßnahme arg verzögert wurde, weil die zugesagten privaten Finanzmittel und Leistungen nicht rechtzeitig (bzw. in der richtigen Reihenfolge) bereitgestellt und erbracht werden konnten; die zuvor bereits aus
} 
Im Hinblick auf seine Heimatstadt Prusa gingen Dions Pläne sogar weit über Programme zur urbanistischen Erneuerung und Verschönerung des Stadtbildes hinaus: Seine Konzeption zielte mit Hafenanlagen und Schiffsbau, im engen Verbund mit der Nachbarpolis Apameia an der Küste, auf nachhaltig verbesserte Wirtschaftsstrukturen und attraktive Erwerbsmöglichkeiten für alle qualifizierten Beschäftigten; deren Zahl wollte Dion, über die Mobilisierung des in der gesamten Bevölkerung von Prusa vorhandenen Potentials hinaus, sogar durch Anwerbung von Arbeitskräften aus dem weiteren Umland noch erheblich erweitern. ${ }^{47}$

Die Intensität, mit der Dion in diesem Tätigkeitsbereich bis in seine letzten Lebensjahre hinein aktiv geblieben ist, zwingt jedenfalls zu dem Schluss, dass für ihn das im zweiten Hauptteil der Euböischen Rede vorgetragene Programm zur Verbesserung der Lebensbedingungen für die arbeitswilligen Angehörigen der Stadtarmut in der griechischen Poliswelt kein müßiges, nur theoretisierendes oder auf eine romantische Utopie ausgerichtetes Gedankenspiel gewesen ist. Vielmehr ging es um das Herzensanliegen eines mit dem sozialen Leben in Stadt und Land im Osten des Römischen Reiches bestens vertrauten „Wanderpredigers", der zugleich über reiche Erfahrungen als praxiserprobter "Stadtpolitiker" und Sponsor in seiner Heimatpolis verfügte. In seiner sozialethischen Orientierung war

der Stadtkasse entnommenen Geldsummen verblieben daher ungebührlich lange in der Hand der für das jeweilige Projekt zuständigen curatores / غ̇ं $\mu \mu \varepsilon \lambda \eta \tau \alpha$ ó oder wurden gar missbräuchlich zunächst für andere Zwecke eingesetzt. Diese von Plinius in seiner amtlichen Korrespondenz immer wieder erwähnten Missstände bilden im Rahmen der Euböischen Rede offenbar den stadtpolitischen Hintergrund in der Erzählung des Jägers vom stürmischen Verlauf der ekklesia-Versammlung (§§ 25f. u. 29; s. u. Anm. 35 S. 93 und Anm. 39. 40 S. 94).

${ }^{47}$ In der Forschungsdiskussion wird oft übersehen, dass die finanzielle Lage nicht allein des Stadthaushaltes von Prusa, sondern auch in zahlreichen anderen Gemeinden Bithyniens von dem auf diesem Gebiet sehr erfahrenen Statthalters Plinius so rasch und effizient verbessert werden konnte, dass schon bald nach festen und ergiebigen Anlagemöglichkeiten für die in beträchtlichem Umfang angesammelten Bargeld-Reserven gesucht werden musste: vgl. Plinius / Trajan ep. X 54 u. 55 - Dions Hinweise (in der „Stadtrede“ or. 45,12-16) lassen erkennen, dass sein urbanistischer Plan für einen auf Prusa zentrierten ovvoıkı $\sigma \mu o ́ \varsigma$ (auch unter Einbeziehung von Bevölkerungsgruppen, die noch über kein Vollbürgerrecht verfügten?) weit über ehrgeizige Einzelbauwerke und bloße Verschönerungen des Stadtbildes hinausgriff; zugleich wird hier beteuert, dass Dion auch für die Zukunft an diesem (von der Volksversammlung zuvor grundsätzlich und mit großer Mehrheit gebilligten) Konzept festhalten will; um so weniger wird man daher im Hinblick auf die Euböische Rede von einer romantisierenden Absage des Autors an das Stadtleben (und einer Empfehlung zum Rückzug auf das Land) ausgehen dürfen; vgl. auch u. S. 108 Anm. 123 zur Übersetzung. Bemerkenswert ist in diesem Zusammenhang auch der Verweis (or. 40,30f.) auf die bestehenden ökonomischen und soziopolitischen Verbindungen zwischen dem (holzreichen) Prusa mit seiner weiten, fruchtbaren Landmark und dem benachbarten Hafenplatz Apameia an der Propontis-Küste. - Die von Dion unterstützte (und mit persönlichem Ein-

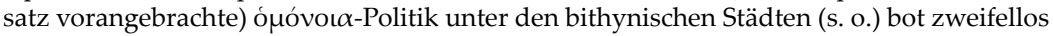
eine gute Basis für Projekte dieser Größenordnung. 
und blieb Dion allerdings - über alle politisch-ökonomische Pragmatik in seinem Konzept hinaus und ungeachtet der gewissermaßen „angeborenen“ Überzeugungen und Vorurteile eines Angehörigen der städtischen Honoratiorenschicht - immer dem Menschenbild der Stoa und hier vor allem den Prinzipien einer universalen Menschenwürde verpflichtet.

\section{2. Überlegungen zur Zeitstellung und zur Textfassung der Euböischen Rede ${ }^{48}$}

In ihrem überlieferten kompositorischen Gefüge ist diese Schrift im Ganzen sicherlich der letzten Lebensphase Dions zuzuordnen: Gleich zu Beginn des erhaltenen Textes weist der Autor (vermutlich noch im Rahmen

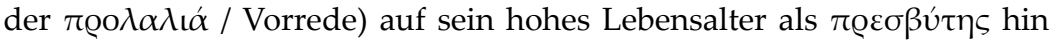
und verbindet mit feiner Selbstironie den greisenhaften Hang zur Weitschweifigkeit (das $\pi \lambda \alpha v \tilde{\alpha} \sigma \theta \alpha \iota$ c่v $\lambda o ́ \gamma o \iota \varsigma)$ mit dem unsteten Vagabundenleben, das er in den langen Jahren seiner Verbannung zu führen hatte. ${ }^{49}$ Seit der Aufhebung der Relegationsstrafe, nach dem Tode Domitians im September 96 n. Chr. und der Rückkehr Dions in die Tätigkeitsbereiche eines führenden Stadtpolitikers seiner Heimatpolis war jedenfalls schon geraume Zeit vergangen; im Hinblick auf die Olympische Rede wird man daher für den Euboikos Logos mit einem Datum deutlich nach 105 n. Chr. (aber kaum später als die Plinius-,,Episode“ von 112 n. Chr.) zu rechnen haben.

Dieser eindeutige Befund gilt jedoch nicht notwendig auch für die in der Euböischen Rede eher äußerlich miteinander verbundenen Text-Blöcke, insbesondere nicht für die kunstvoll ausgestaltete Jäger-Erzählung und den anschließenden ironisch-kritischen Homer-Kommentar zu Aspekten der Heimkehr des Odysseus nach Ithaka und zu dem Schicksal des Menelaos von Sparta (\$§ 83-96). Anders dürfte es dagegen um die Darlegungen in Dions politisch-sozialen Programm zu Gunsten der Stadtarmut stehen - und erst recht um die (vermutlich als Improvisation auf ein bestimmtes Auditorium hin ausgerichtete) Digression über die fatalen Auswirkungen von Prostitution und libertinage auf die bürgerliche Gesellschaft in Hellas und vor allem auch in Rom (bes. § 140-151).

Freilich hat sich der Autor sehr darum bemüht, diese in ihrem Charakter sich deutlich voneinander abhebenden Textteile durch Verweise und

\footnotetext{
${ }^{48} \mathrm{Zu}$ den inhaltlichen und literarisch-stilistischen Eigentümlichkeiten dieser Schrift s. den Beitrag von D. GALL in diesem Band.

${ }^{49}$ Or. 7 (13 ArNim) § 1; in der Olympischen Rede, die sich zuverlässig auf die Zeit um 105 n. Chr. datieren lässt, hatte Dion dagegen noch von seinem „reifen“ bzw. „vorgerückten Lebensalter" gesprochen (or. 12/11 ARNIM, §§ 15 u. 20).
} 
Argumentationen fest miteinander zu verklammern. ${ }^{50}$ Nur umso klarer treten demgegenüber im sprachlichen Duktus die Unterschiede hervor; vor allem im letzten Werkabschnitt ist im Satzbau die Annäherung an einen freien, mündlichen Vortragstil unübersehbar. Bekanntlich hat Philostrat in seiner knappen Werkübersicht (V. Soph. VII 1) Dions Euböische Rede (unter dem bezeichnenden Titel ó Eủßozús / "der Mann von Euböa“, s. u. Anm. 1 S. 86) als eine Schrift ohne ernsthaften philosophischen Gehalt bewertet und sie als sehr gelungene Spielerei in sophistischer Manier mit Dions (nicht erhaltenem Traktat) „Lob des Papageis“ und Ähnlichem gleichgesetzt. Gegen dieses Urteil hat jedoch schon Synesios (Dion 2,38c) heftig protestiert; immerhin liegt die Vermutung nahe, dass Philostrat von der Euböischen Rede allein eine Textfassung kannte, die im Wesentlichen nur die Jäger-Erzählung enthielt - ohne die nachfolgenden Kommentare und v. a. das politisch-soziale und moralphilosophische Programm des dritten Hauptteils.

Wiederholt hat Dion selbst darauf hingewiesen, dass seine rege Vortragstätigkeit, in Rom wie im griechischen Osten, rasch in eine weitgespannte schriftliche Verbreitung eingemündet ist - und das keineswegs immer mit Willen und Wissen des Autors. Tatsächlich genoss er eben unter seinen Zeitgenossen den Ruf eines vorzüglichen, packenden „Stegreifredners" und war darüber hinaus als erprobter, charakterstarker Moralphilosoph überall in den gebildeten Kreisen gut bekannt. ${ }^{51}$ „Meine Reden“, so klagt Dion gelegentlich, „, sind sozusagen bei allen bekannt und werden überallhin verbreitet - wie einfache Straßenlieder, die von Knaben in den Städten zur Abendzeit gesungen werden. “52 Und diese Verbreitung habe sich leider auch noch in unterschiedlichen Versionen oder gar Fragmenten vollzogen, wobei man den Redetexten vielfach - mit und ohne bestimmte Absichten - auch noch Korrekturen und „Verbesserungen" habe angedeihen lassen: Dions Weisheit muss man daher nicht käuflich erwerben, „man braucht sich nur zu bücken und sie vom Boden aufzuheben!“

Es liegt auf der Hand, dass Dion hier konkret an tachygraphische Mitschriften denkt, die offenbar in beträchtlicher Zahl (und weitgehend ohne seine Kontrolle) von Lehrvorträgen und Reden angefertigt wurden und auf privater Basis rasche Verbreitung gefunden haben. Bekanntlich hatte gerade im Rom der Flavier-Zeit die Tachygraphie-Technik einen neuen, großen Aufschwung genommen, vor allem nachdem Titus auf diesem Gebiet öffentlich sein persönliches Interesse und Können eindrucksvoll unter

\footnotetext{
${ }^{50}$ Als Rahmenthema diente Dion eine inhaltliche Auseinandersetzung mit einer Passage aus Euripides' Elektra v. 424-431; s. u. Anm. 99 S. 104f. und Anm. 117 S. 107.

${ }^{51}$ Vgl. u. a. Dion or. 45,1 (Verweis auf Reden und Schriften des Autors); s. ferner das wichtige Zeugnis bei Philostrat, V. Apol. V 37.

${ }^{52}$ Im Entwurf eines Redeproömiums: or. 42,4f.
} 
Beweis gestellt hatte. ${ }^{53}$ Auch in der Folgezeit fand in Rom, besonders in der senatorischen Führungsschicht, der Einsatz von Tachygraphen - zu amtlichen Zwecken wie auch in Privatangelegenheiten - weite Verbreitung. ${ }^{54}$ Schließlich ist $\mathrm{zu}$ bedenken, dass unsere gesamte Überlieferung von den Lehrvorträgen des Musonius und seines Schülers Epiktet auf tachygraphischen Aufzeichnungen basiert. Daher wird man gerade bei der in ihrem Umfang vollauf zu einer $\mu$ ovó $\beta \iota \beta \lambda$ os-Schrift geeigneten Euböischen Rede, die erst sekundär in das dionische Corpus eingegliedert worden ist, durchaus an eine ursprüngliche Schriftfassung zu denken haben, die sich über tachygraphische Aufzeichnungen direkt von der Vortragstätigkeit Dions (bei einem seiner zahlreichen Aufenthalte in Rom) hergeleitet haben mag. Lässt man sich näher auf diese (gewiss nicht zeitfremde) Perspektive ein, so kann man offensichtlich manche Eigentümlichkeiten in diesem komplexen Werkzusammenhang - nicht zuletzt die auffälligen Ungleichgewichte zwischen den großen Textblöcken im Gefüge der Rede - besser verstehen und auf diesem Wege möglicherweise zu einer gerechteren Interpretation gelangen: Denn unter dieser Voraussetzung gewinnt Dions didaktisches Bemühen erheblich an Profil, zunächst mit faszinierenden Versatzstücken aus seinem Repertoire unter den Hörern einen festen Ausgangspunkt für sein eigentliches Anliegen, das im 2. Hauptteil vorgestellte Reformprogramm für die "Stadtarmut" und die Invektiven gegen Prostitution und libertinage, zu gewinnen. Was die überlieferte Textfassung damit ihrer Genese nach - in der Konsequenz einer solchen Hypothese - an Geschlossenheit und Verbindlichkeit hinsichtlich ihrer äußeren Form und Durcharbeitung verlieren könnte, würden Dions Meisterschaft im freien Vortrag, vor allem aber die Ernsthaftigkeit seines Engagements als Reformer und Erzieher leicht hinzugewinnen.

\section{Hinweise zur Textvorlage}

Basis des Arbeitstextes und unserer Übersetzung ist die kommentierte Edition der Euböischen Rede von D. Russell (1992). Nur an wenigen Stellen bestand Veranlassung, von Russells Text abzuweichen:

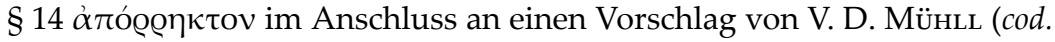

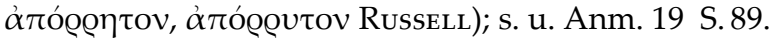

\footnotetext{
${ }^{53}$ Nach Suet. Tit. 3,2 konnte Titus eine solche Fertigkeit in der Tachygraphie erreichen, dass er sich bei Gelegenheit sogar auf einen Wettstreit mit professionellen amanuenses und notarii einlassen konnte.

${ }^{54}$ Vgl. die Hinweise bei Plinius ep. III 5,11 und 15 sowie IX 20,2 und 36,2; s. auch H. C. Teitler, Notarii and excerptores (Amsterdam 1985) bes. 27-29 und 31-34.
} 


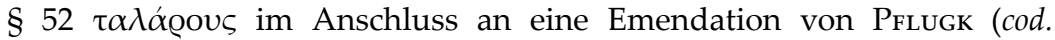

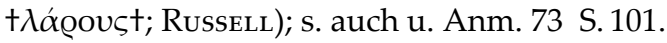

$\S 60$ Der Beginn der zweiten Rede des „,anständigen“ Politikers wird (mit v. Arnim) als Fragesatz aufgefasst.

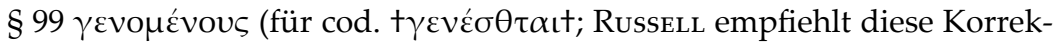
tur, ohne sie in den Text zu setzen).

$\S 102$ In Übernahme der von Russell vorgeschlagenen (aber nicht in den

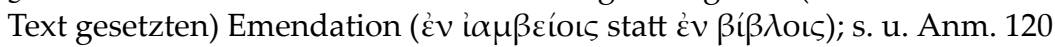
S. 108.

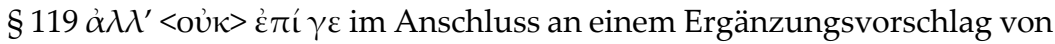
Reiske (von v. Arnim übernommen).

$\S 129$ Im Anschluss an die Emendation von v. Arnim (p. 214, 8 App. crit.):

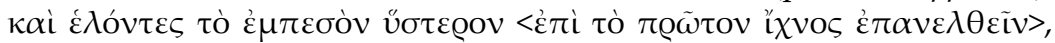
Russell folgt hier (mit Bedenken: S. 149) der handschriftlichen Tradition

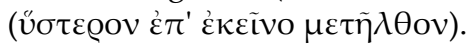

$\S 143 \tau \ddot{\alpha} \lambda \lambda \alpha \gamma \varepsilon$ (für $+\dot{\alpha} \lambda \lambda \dot{\alpha} t$, von v. Arnim getilgt); diese Emendation wird von Russell (im App.) vorgeschlagen, aber nicht in seinen Text aufgenommen.

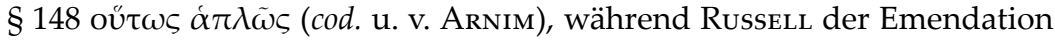

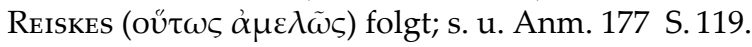



B. Text, Übersetzung und Anmerkungen 


\section{$\triangle \mathrm{I} \Omega \mathrm{N}$

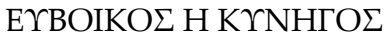

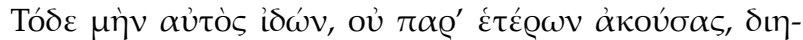

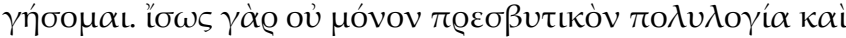

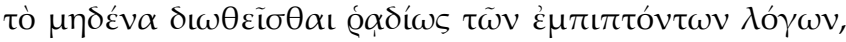

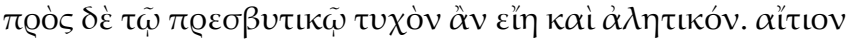

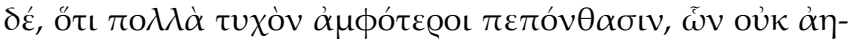

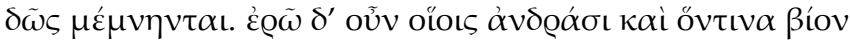

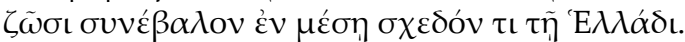

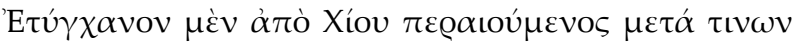

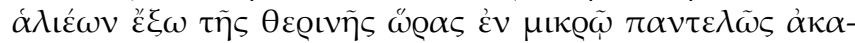

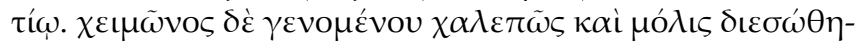

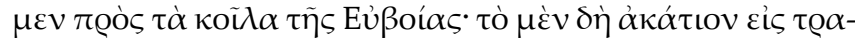

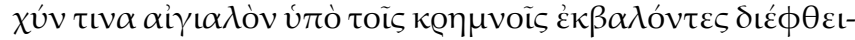

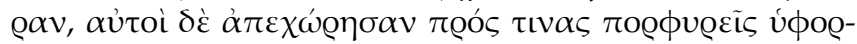

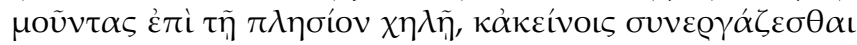

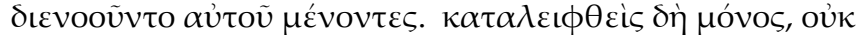

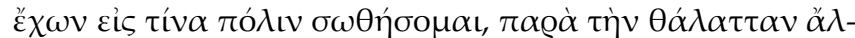

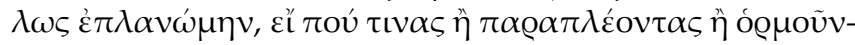

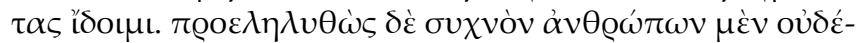

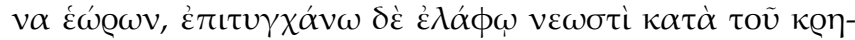

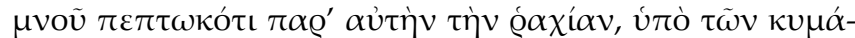

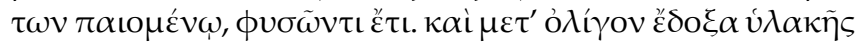

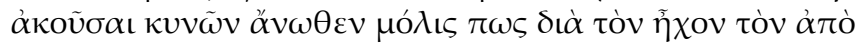

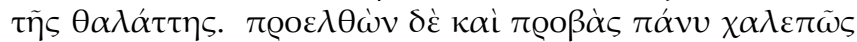

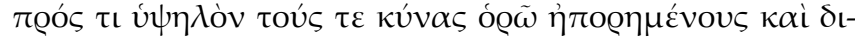

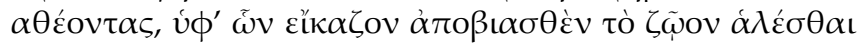

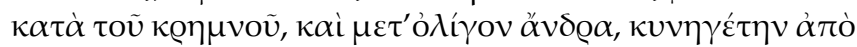

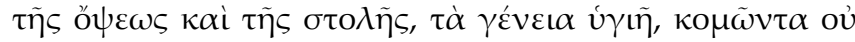

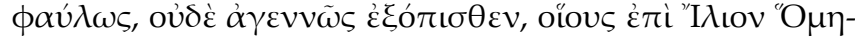

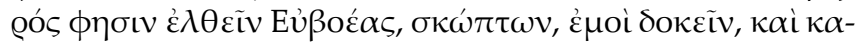




\section{$\mathrm{DION}$}

Die Euböische Rede oder Der Jäger (or. 7; 13 Arnim) ${ }^{1}$

Ende des Prö̈miums der Rede: Eine Episode aus der Exilzeit des Autors (§ 1)

[1] Das Folgende kann ich dagegen als Augenzeuge berichten, ohne mich auf Erzählungen anderer verlassen zu müssen. ${ }^{2}$ Vielleicht sind ja Redelust und die Abneigung, auf einen Gesprächsgegenstand, der einem gerade eingefallen ist, zu verzichten, nicht nur ein Kennzeichen des Alters. Über das typische Verhalten eines alten Menschen hinaus könnte es sich wohl auch um die Eigenart eines Mannes handeln, der lange auf Irrfahrten unterwegs gewesen ist. Der Grund liegt eben darin, dass beide schon viel durchgemacht haben und sich daran recht gerne erinnern wollen. ${ }^{3}$ Ich werde nun erzählen, mit Menschen welcher Art ich zusammengetroffen bin, nahezu in der Mitte von Hellas, und wie sie ihr Leben eingerichtet haben. ${ }^{4}$

Erster Teil des Reiseberichts: Die Landung bei den "Höhlen von Euböa“ (§§ 2-4) [2] Ich befand mich damals, - der Sommer war längst vergangen - gerade auf der Überfahrt, von Chios her, zusammen mit einigen Seeleuten in einem ganz kleinen Boot. ${ }^{5}$ Da brach ein heftiger Wintersturm los, und nur mit Mühe retteten wir uns in den Bereich der „Höhlen von Euböa“. ${ }^{6}$ Das Boot freilich ließen meine Begleiter an einem steinigen Strand unterhalb der Steilküste auflaufen und dabei zu Bruch gehen. Sie selbst aber begaben sich fort zu einer Gruppe von Purpurfischern, ${ }^{7}$ die an einem Felsvorsprung in der Nähe vor Anker lagen. Sie beabsichtigten, sich diesen anzuschließen und mit ihnen zusammenzuarbeiten; sie wollten daher dort bleiben. [3] Alleingelassen wusste ich nun nicht, nach welcher Stadt hin ich mich in Sicherheit bringen sollte, und irrte aufs Geratewohl am Meer entlang, ob ich vielleicht ein vorbeifahrendes oder vor Anker liegendes Schiff sehen könnte. Als ich nun eine längere Strecke gegangen war und dabei keinen Menschen zu Gesicht bekam, da stoße ich auf einen Hirsch, der erst kurz zuvor von der Anhöhe herabgestürzt war und direkt in der Brandung lag. Die Wellen schlugen auf ihn ein, er schnaubte aber noch. Und wenig später glaubte ich, von oben her das Gebell von Hunden zu vernehmen, allerdings nur ganz schwach wegen des tosenden Meeres. [4] Ich machte mich auf und bestieg mit großer Mühe einen höher gelegenen Platz, und da sehe ich , wie die Hunde ziellos durcheinander liefen. ${ }^{8}$ Ich vermutete daher, dass sie das Tier gehetzt und zum Sprung von der Anhöhe gezwungen hatten. Und wenig später erblicke ich einen Mann - nach Aussehen und 


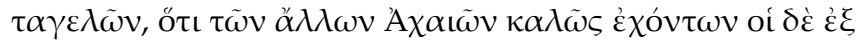

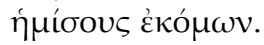

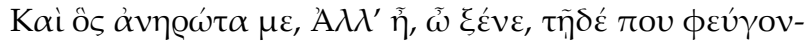

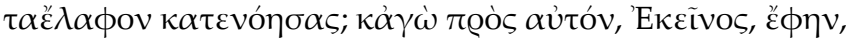

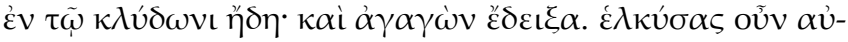

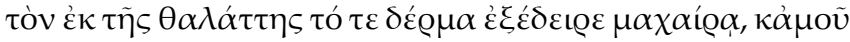

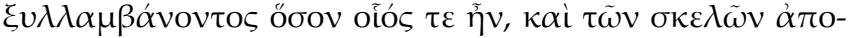

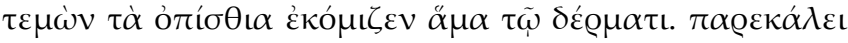

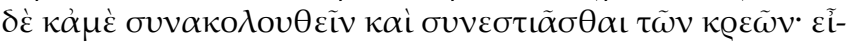

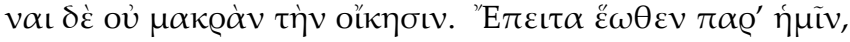

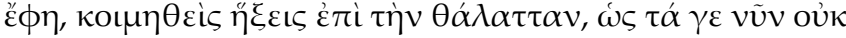

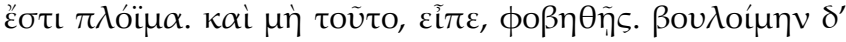

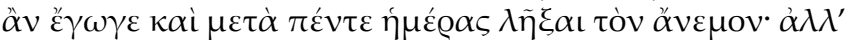

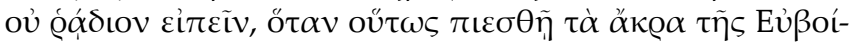

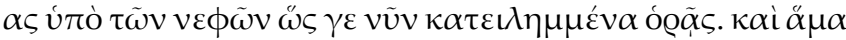

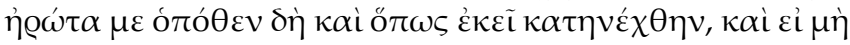

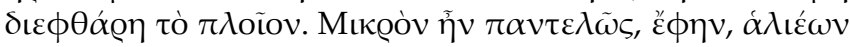

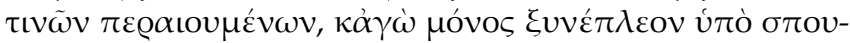

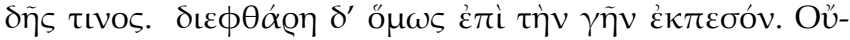

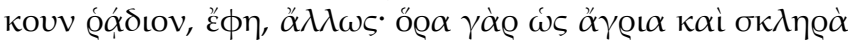

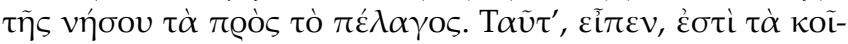

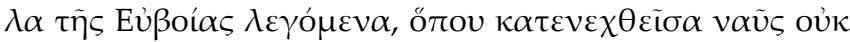

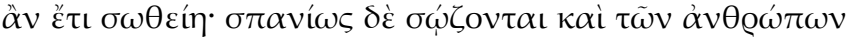

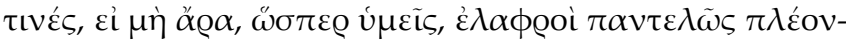

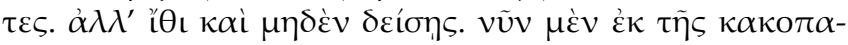

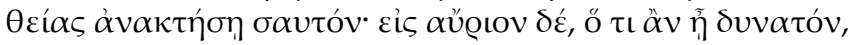

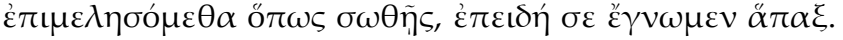

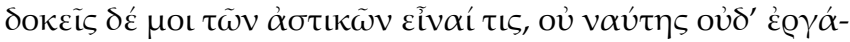

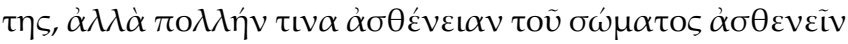

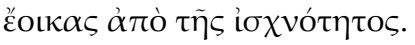

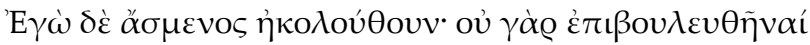

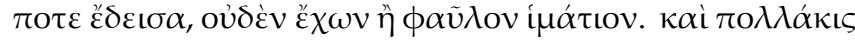


Ausrüstung ein Jäger - mit kräftigem Bart und langem Haupthaar, aber nicht in der hässlichen und unedlen Tracht mit Haaren nur am Hinterkopf, wie Homer die Euböer nach Ilion kommen lässt. ${ }^{9}$ Mir scheint, dass er (Homer) sich dabei über sie lustig macht, weil sie, während die übrigen Achäer von gutem Aussehen waren, nur auf der Hälfte des Kopfes langes Haar trugen.

Die Begegnung mit dem Jäger (§§ 5-10)

[5] Und dieser fragte mich: „Hallo, fremder Mann, hast du hier irgendwo einen flüchtigen Hirsch gesehen?“ Ich antwortete ihm: „Das Tier liegt bereits da in der Brandung", und ich führte ihn hin und zeigte es ihm. Er holte den Hirsch aus dem Meer und zog ihm mit einem Messer das Fell ab, wobei auch ich, so gut ich konnte, mit Hand anlegte. Er schnitt die beiden Hinterkeulen des Hirsches ab und machte sich daran, sie, zusammen mit dem Fell, fortzutragen. Dabei forderte er mich auf, ihm zu folgen und mich an dem Bratenschmaus von diesem Fleisch mit zu beteiligen. Seine Behausung sei gar nicht weit von hier. [6] „Wenn du dich dann bei uns ausgeschlafen hast", fuhr er fort, ,"kannst du morgen ans Meer zurückkehren, das aber zum jetzigen Zeitpunkt nicht befahrbar ist. Lass dich aber davon", so sagte er, „nicht beunruhigen. Ich jedenfalls wäre schon zufrieden, wenn der Sturm nach fünf Tagen nachlassen würde. Aber das wird sich nicht leicht sagen lassen, wenn die Bergspitzen von Euböa, wie du jetzt siehst, derart fest von den Wolken umdrängt und eingehüllt werden ". ${ }^{10}$ Und zugleich fragte er mich, woher ich komme und wie ich dorthin verschlagen wurde und ob mein Schiff nicht gescheitert sei. ${ }^{11}$ „Es war nur ein winziges Boot", sagte ich, "und gehörte einigen Seeleuten, die herüberfahren wollten; ich fuhr ganz allein mit ihnen mit, denn ich war in eiliger Sache unterwegs. [7] Gleichwohl zerbrach das Boot, als es auf das Land auffuhr". „Das war wohl kaum zu vermeiden", sagte er. "Sieh nur, wie wild und felsig der Strand der Insel zum Meer hin abfällt". „Dies“, sagte er, „sind die sogenannten Höhlen von Euböa; wenn ein Schiff hierher getrieben wird, ist eine Rettung nicht mehr möglich. Nur selten können dabei einige von den Menschen ihr Leben retten - es sei denn, sie sind, wie ihr, auf einem leichten Fahrzeug unterwegs gewesen. Aber komm mit und sei ganz unbesorgt. Jetzt solltest du dich von der Überanstrengung und der Mühsal erholen! Morgen aber werden wir uns, so gut es nur geht, um dein weiteres Wohl bekümmern, nachdem wir nun einmal mit dir Bekanntschaft geschlossen haben. [8] Du scheinst mir eher ein Stadtmensch zu sein, weder ein Seemann noch ein Landarbeiter. Offenbar leidest du an ziemlicher Körperschwäche, der Schmächtigkeit nach zu schließen".

Ich folgte ihm bereitwillig. Denn ich habe nie eine böse Absicht befürchtet, bestand doch mein einziger Besitz nur aus einem schäbigen Mantel. [9] 


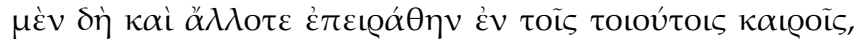

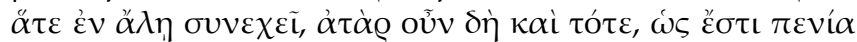

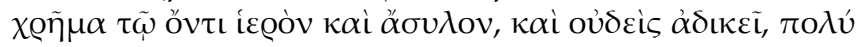
$\gamma \varepsilon \tilde{\eta} \tau \tau$ ๆ

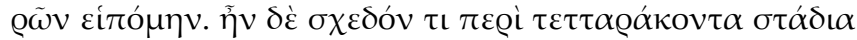

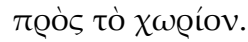

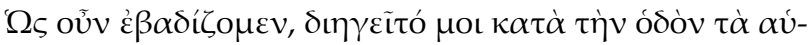

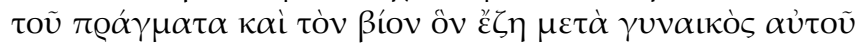

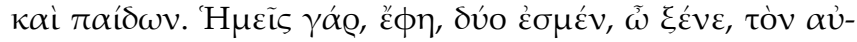

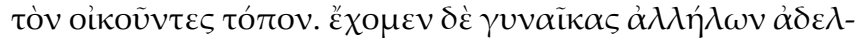

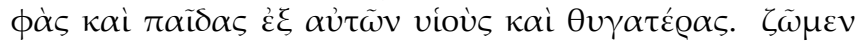

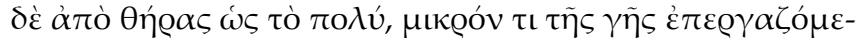

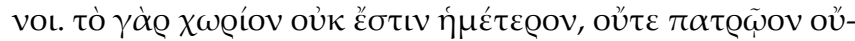

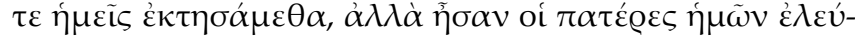

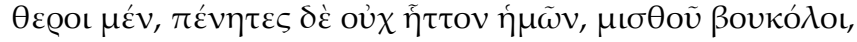

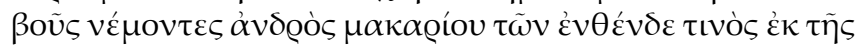

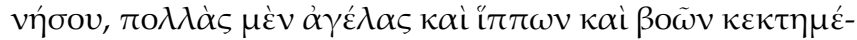

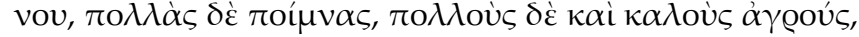

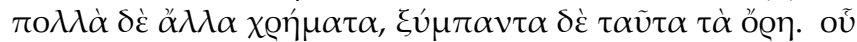

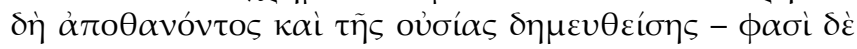

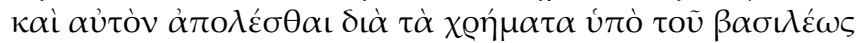

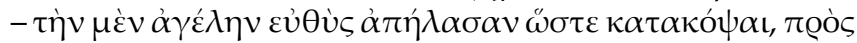

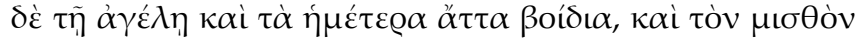

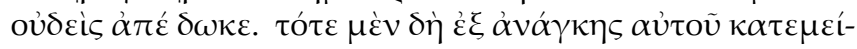

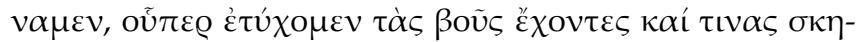

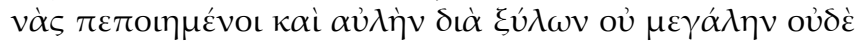

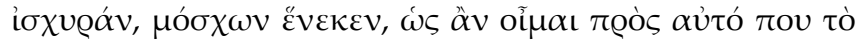

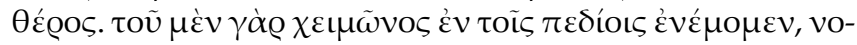

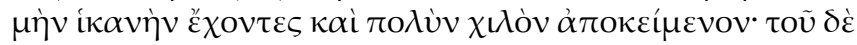

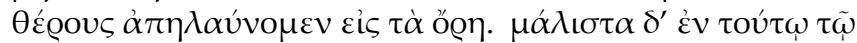

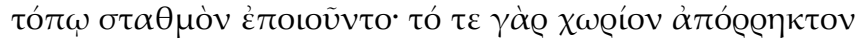

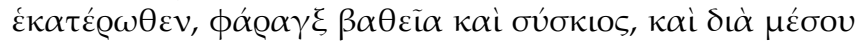

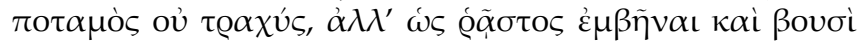

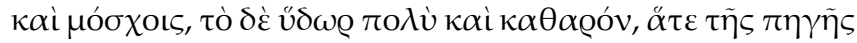

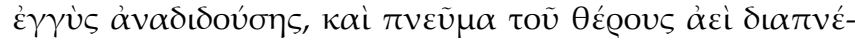

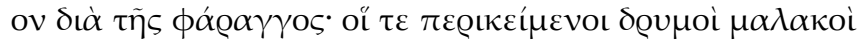

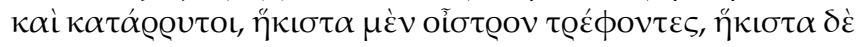

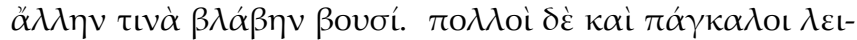

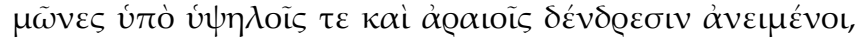


Denn hatte ich hatte schon oft, auch bei anderen Gelegenheiten - denn ich befand mich fortwährend auf unsteter Wanderschaft ${ }^{12}$ - die Erfahrung gemacht und machte sie gerade auch diesmal, dass Armut in Wahrheit etwas Heiliges ist und Schutz gewährt. Niemand fügt einem ein Unrecht zu - seltener noch als jenen, die den Heroldsstab bei sich führen. ${ }^{13}$ [10] So folgte ich ihm damals guten Mutes. Der Weg zu seinem Wohnplatz betrug annähernd 40 Stadien. ${ }^{14}$

\section{Die Erzählung des Jägers (§§ 10-63)}

Während wir voranschritten, erzählte er mir unterwegs von seinen Verhältnissen und dem Leben, das er zusammen mit seiner Frau und seinen Kindern führte. „Wir sind nämlich, mein Gastfreund, zwei Familienväter und wohnen an demselben Ort. Jeder von uns ist verheiratet mit der Schwester des anderen; und sie haben uns Söhne und Töchter geschenkt. [11] Wir leben aber größtenteils von der Jagd, doch bebauen wir auch ein kleines Stück Land. Das Grundstück ist nämlich nicht unser Eigentum, weder haben wir es von unseren Vätern ererbt noch käuflich erworben. ${ }^{15}$ Vielmehr waren unsere Väter zwar freie Leute, aber arm wie wir, und arbeiteten für Lohn als Rinderhirten. ${ }^{16}$ Sie hüteten die Herde eines reichen Eigentümers, eines Mannes von hier, von der Insel. Dieser besaß viele Herden von Pferden und Rindern, auch von Schafen, und viel gutes Ackerland und sonstiges Besitztum und das ganze Bergland hier. [12] Wie dieser nun den Tod gefunden hatte und sein Besitz eingezogen wurde - man sagt aber, der Herrscher habe auch ihn umbringen lassen wegen seines Vermögens - da trieb man sogleich die Herde fort, um sie abzuschlachten - mit dieser Herde aber auch einige Rinderlein, die uns gehörten. Und niemand zahlte den Lohn aus. ${ }^{17}$ [13] Damals blieben wir notgedrungen dort, wo wir die Rinder gehütet und uns Hütten gebaut hatten, auch einen hölzernen Pferch, weder groß noch besonders fest, der Kälber wegen - und, wie ich glaube, nur für den Aufenthalt im Sommer bestimmt. Denn im Winter hüteten wir die Herde in den Ebenen, wo wir ausreichend Weideland zur Verfügung hatten und wo sich viel Heu im Vorrat befand. Im Sommer aber trieben wir die Tiere wieder zurück in die Berge. ${ }^{18}$ [14] Am liebsten aber nahmen unsere Väter an diesem Ort ihr Quartier. Denn der Platz wird auf beiden Seiten durch steile Abhänge begrenzt und bildet einen tiefen, schattigen Einschnitt im Gelände. ${ }^{19}$ Mitten hindurch fließt ein Bach, nicht reißend, sondern bequem zu durchschreiten für Rinder und Kälber. Sein Wasser fließt reichlich und ist klar, da die Quelle ganz in der Nähe entspringt. Und im Sommer weht ständig ein Lufthauch durch den Talgrund. Die umliegenden Eichenwälder haben weiche und feuchte Böden, sind aber keineswegs eine Brutstätte für Bremsen und sonstige Rinderplagen. [15] Viele, wunderschöne Wiesen breiten sich aus unter hohen, weit auseinan- 


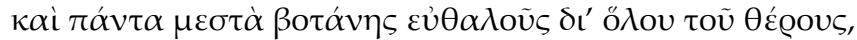
$\omega$

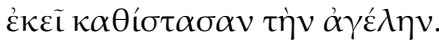

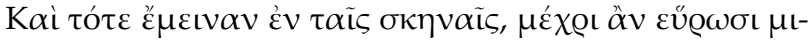

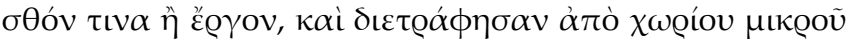

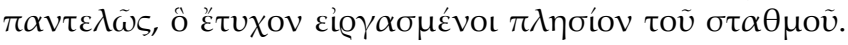

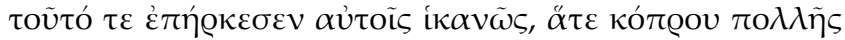

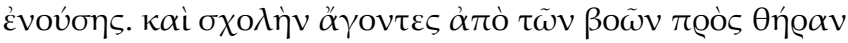

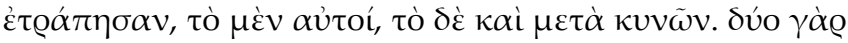

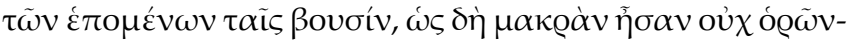

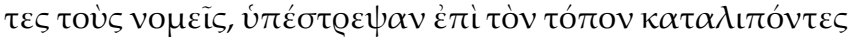

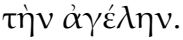

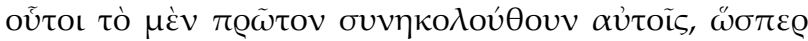

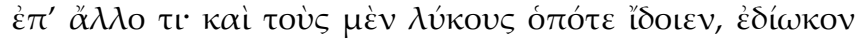

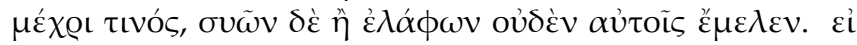

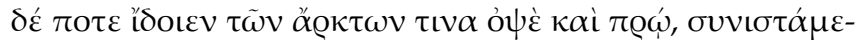

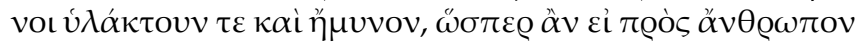

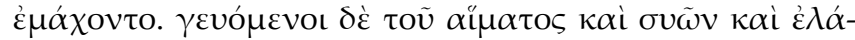

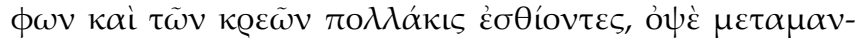

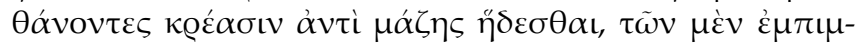

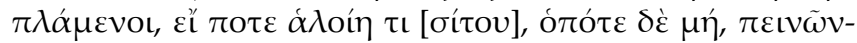
$\tau \varepsilon \varsigma, \mu \tilde{\alpha} \lambda$ hov

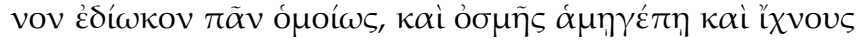

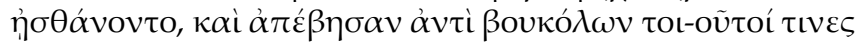

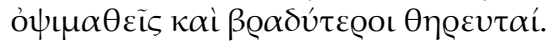

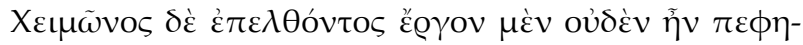

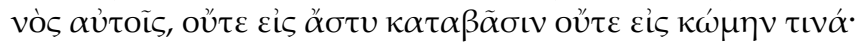

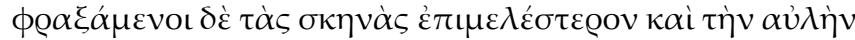

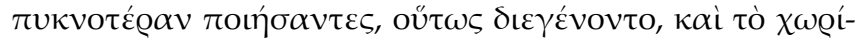

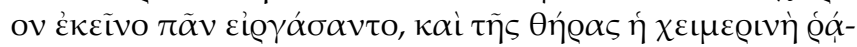

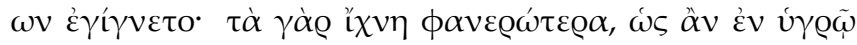

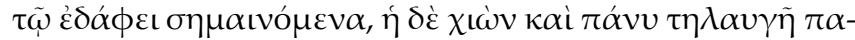

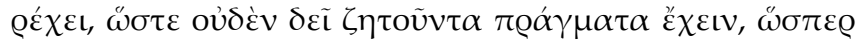

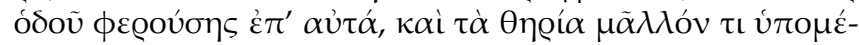

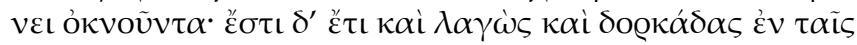

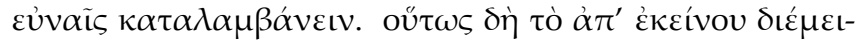

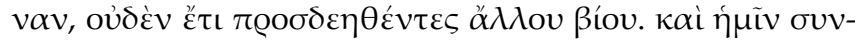


der stehenden Bäumen. Und alles ist voll von üppig gedeihendem Futter den ganzen Sommer hindurch, so dass man keine Weidewechsel über ein größeres Gebiet hin vornehmen musste. ${ }^{20}$ Aus diesen Gründen trieben sie für gewöhnlich ihre Herde dorthin.

Und damals blieben sie also dort in ihren Hütten, bis sie Lohndienste und andere Arbeit gefunden hätten. Und sie lebten vom Ertrag eines ganz kleinen Grundstücks, das sie bestellt hatten, in der Nähe der Viehhürde. [16] Und dieses reichte für sie vollständig aus, da im Boden reichlich Dünger steckte. Und da sie mit den Rindern nun nichts mehr zu tun hatten, wandten sie sich der Jagd zu - mal für sich allein, mal mit Hunden. ${ }^{21}$ Denn zwei von den Hunden, die den Rindern folgten, hatten sich, als sie weit voraus gelaufen waren und die Hirten nicht mehr sehen konnten, von der Herde getrennt und waren hierher zurückgekehrt. ${ }^{22}$

\section{Aus Hirtenhunden werden leidlich brauchbare Jagdhunde}

Diese beiden Hunde folgten nun unseren Vätern - zunächst ohne sich um die Jagd zu kümmern. Sobald sie Wölfe erblickten, verfolgten sie diese zwar über eine gewisse Strecke, Wildschweine und Hirsche jedoch beachteten sie überhaupt nicht. [17] Wenn sie aber einmal einen Bären erblickten, ${ }^{23}$ spät am Abend und auch in der Frühe, dann drängten sie sich aneinander, bellten ihn an und suchten ihn fernzuhalten, wie wenn sie es mit einem Menschen als Gegner zu tun hätten. Wie sie aber nun oftmals von dem Blut und Fleisch von Wildschweinen und Hirschen kosteten, da lernten sie spät noch hinzu, Fleisch lieber zu mögen als Gerstenbrei. Sie stopften sich damit voll, wenn Jagdbeute gemacht worden war, und wenn nicht, dann hungerten sie. Deshalb passten sie nun schon eher auf und verfolgten jedes auftauchende Wild mit gleichem Eifer. Auch lernten sie es irgendwie, auf Geruch und Spur der Wildtiere zu achten. Und so wurden sie schließlich, wenn auch erst spät, aus Hirtenhunden noch leidlich entwickelte, ziemlich langsame Jagdhunde. ${ }^{24}$

[18] Als es aber Winter geworden war, da war für unsere Väter keinerlei Beschäftigungsmöglichkeit zu sehen, weder nachdem sie in die Stadt hinabgestiegen waren, noch in irgendeinem Dorfe. ${ }^{25}$ Sie dichteten daher die Hüttenwände sorgfältig ab, machten die Umzäunung des Pferchs fester und fristeten so ihren Lebensunterhalt. Sie nahmen jetzt das ganze Areal in Nutzung, und was die Jagd anging, so erwies sich diese im Winter als bequemer. [19] Denn die Spuren sind deutlicher, da sie sich im feuchten Boden abzeichnen; der Schnee aber macht sie weithin sichtbar, so dass man sich auf der Suche gar keine Mühe geben muss, wie wenn ein Weg direkt zu den Tieren führt, die ihrerseits langsamer und zögerlicher sind. Man kann Hasen und Rehwild dann sogar an ihren Lagerplätzen überraschen. ${ }^{26}$ [20] In dieser Weise hielten sie sich seitdem hier auf und hatten 


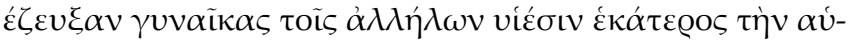

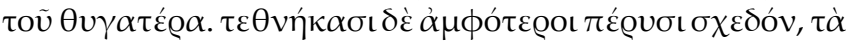

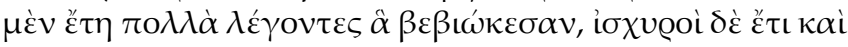

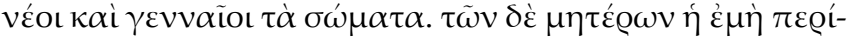
$\varepsilon \sigma \tau \mathrm{\tau}$.

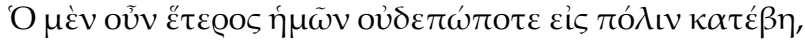

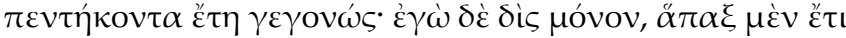

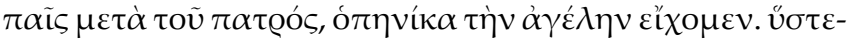

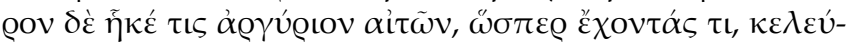

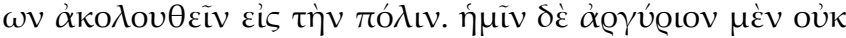

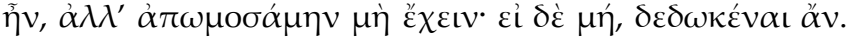

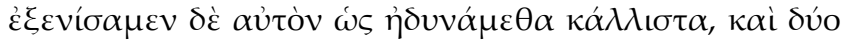

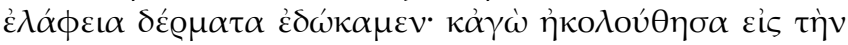

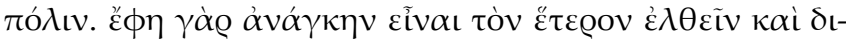

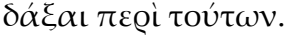

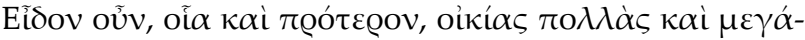

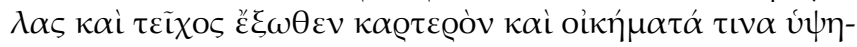

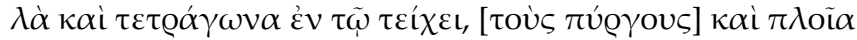

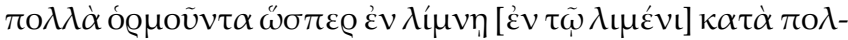

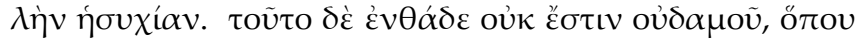

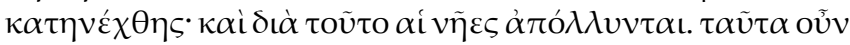

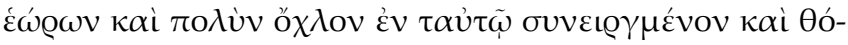

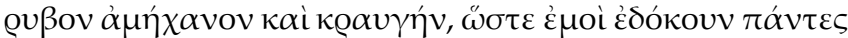

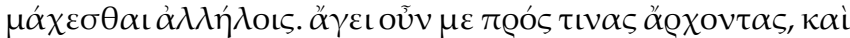

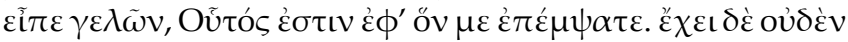

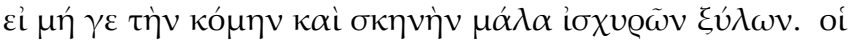

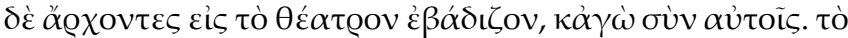

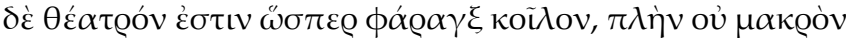

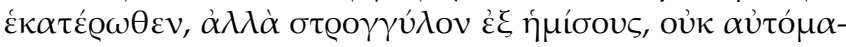

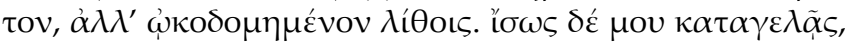

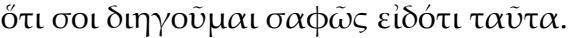

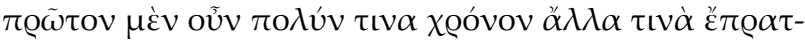

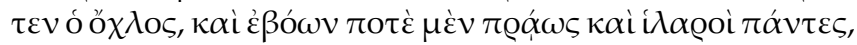

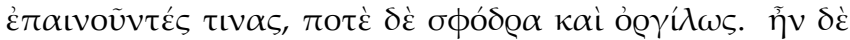

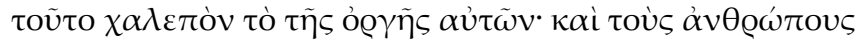

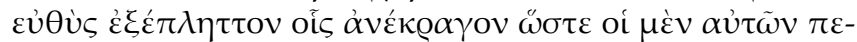


kein Verlangen mehr nach einer anderen Lebensweise. Und ein jeder von ihnen gab wechselseitig uns, den Söhnen, seine Tochter zur Frau. Beide sind vor etwa einem Jahr gestorben, viele Lebensjahre zählend und doch noch rüstig und jugendstark in ihrer Körperkraft. Von den Müttern aber ist die meine noch am Leben.

\section{Einbestellung und Aufenthalt des Jägers in der Stadt}

[21] Der eine von uns beiden hat sich noch nie in die Stadt hinab begeben und ist immerhin 50 Jahre alt. Ich selbst war nur zweimal dort: Einmal, noch als Kind zusammen mit meinem Vater, zu der Zeit, als wir (noch) die Herde hatten. ${ }^{27}$ Später dann kam einer zu uns und forderte Silbergeld als wenn wir davon welches hätten - und befahl uns, ihm in die Stadt zu folgen. Wir hatten aber einfach kein Geld; ich schwor einen Eid darauf und dass wir es ihm anderenfalls gegeben hätten. [22] Wir haben ihn jedenfalls, so gut wir nur konnten, bewirtet und gaben ihm auch zwei Hirschfelle als Geschenk. ${ }^{28}$ Und ich folgte ihm in die Stadt, denn er sagte, einer von uns beiden müsse mitkommen und über die Angelegenheit Auskunft geben. ${ }^{29}$

Da bekam ich nun, wie auch schon früher, viele große Häuser zu sehen und außen herum eine mächtige Mauer mit einigen hochgebauten, rechteckigen Häuschen oben darauf, und auch viele Schiffe, die dort vor Anker lagen, ganz in Ruhe wie auf einem Teich. ${ }^{30}$ [23] So etwas gibt es nirgendwo hier bei uns, wo du an Land geraten bist. Und deshalb gehen hier die Schiffe zugrunde. Dies alles schaute ich mir an, dazu auch die große Menschenmenge, die auf ein und derselben Stelle zusammengedrängt war, und einen unerträglichen Lärm und Geschrei machte, so dass es mir schien, als ob sie alle gegeneinander kämpften. ${ }^{31}$ Er (der Amtsbote) führt mich nun zu einigen Amtsträgern hin, und dann sagte er zu ihnen lachend: „Dieser hier ist es, zu dem ihr mich geschickt habt. Sein Besitz aber besteht allein aus seinem langen Haarschopf und einer Hütte aus ziemlich dicken Balken“. [24] Die Amtsträger aber waren auf dem Weg zum Theater, und ich ging mit ihnen. ${ }^{32}$ Das Theater aber sieht aus wie eine hohle Schlucht, aber nicht von beiden Seiten her in die Länge gestreckt, sondern zu einem Halbkreis gerundet - nicht natürlich entstanden, sondern mit Steinen aufgebaut. ${ }^{33}$ Vielleicht aber lachst du mich aus, weil ich dir etwas erzähle, das du längst genau kennst.

\section{Verhandlungen und Anschuldigungen vor der Volksversammlung}

Zunächst behandelte die Menge über lange Zeit andere Gegenstände; und bald erhoben sie freundlich und heiter ihre Stimmen, wenn sie Beifall spendeten, bald aber auch laut und zornig. ${ }^{34}$ [25] Diese Zornausbrüche waren aber ganz schrecklich. Und den Menschen, gegen die sie anbrüllten, jagten sie sogleich großen Schrecken ein, so dass die einen mit flehentlichem Bit- 


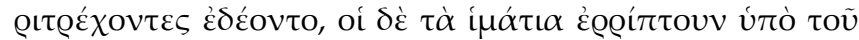

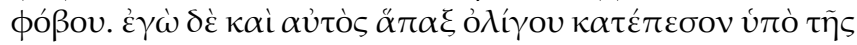

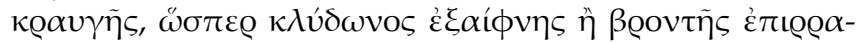

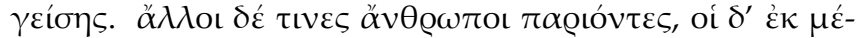

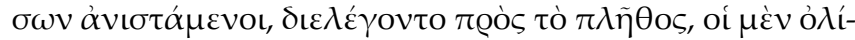

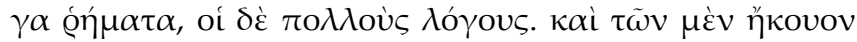

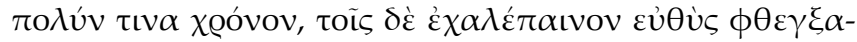

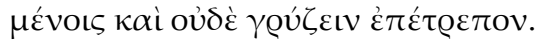

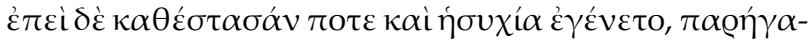

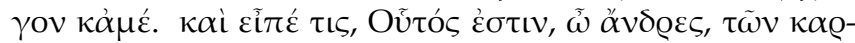

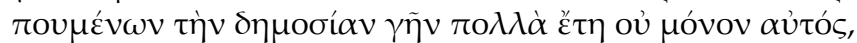

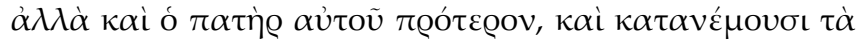

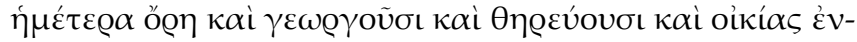

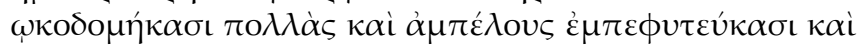

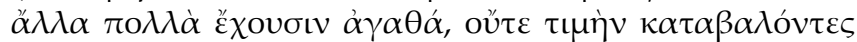

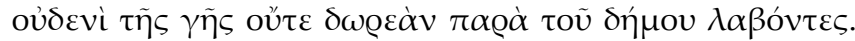

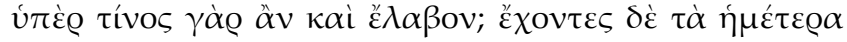

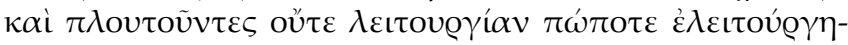

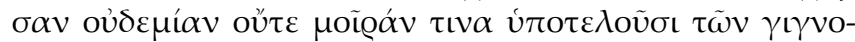

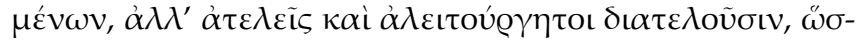

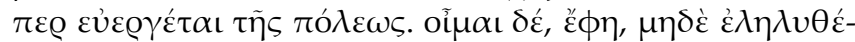

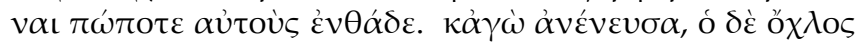

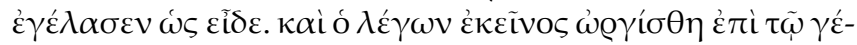

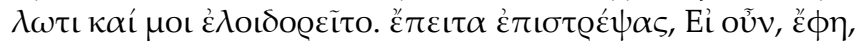

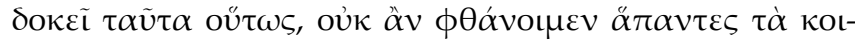

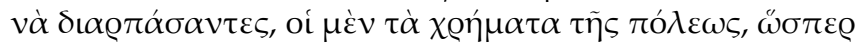

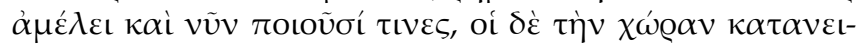

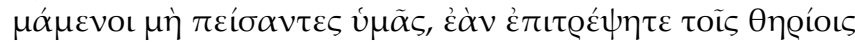

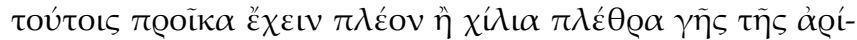

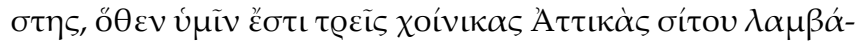

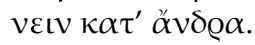

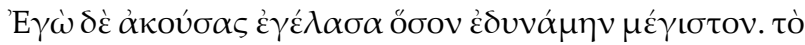

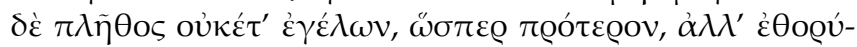

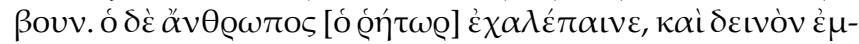

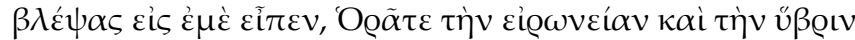

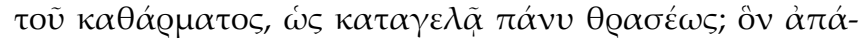

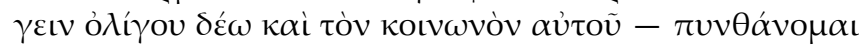

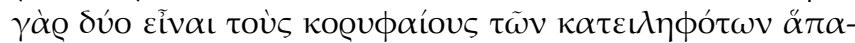

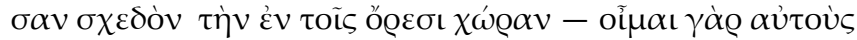


ten (vor der Versammlung) hin- und herliefen und die anderen aus Furcht ihre Mäntel zu Boden warfen. ${ }^{35}$ Und ich selbst wäre auch einmal beinahe umgefallen wegen ihres Geschreis, als wenn eine Woge oder ein Donnerschlag über einen plötzlich hereinbricht. ${ }^{36}$ [26] Einige Männer kamen nach vorn (in die Orchestra), andere erhoben sich mitten aus der Versammlung und sprachen zur Volksmenge - manchmal nur wenige Worte, manchmal auch lange Reden. Und den einen hörte man lange Zeit zu, die anderen aber beschimpfte man, kaum dass sie mit der Rede begonnen hatten, und gestattete ihnen nicht einmal einen Muckser. ${ }^{37}$

Nachdem sie sich aber schließlich beruhigt hatten und Stille eingekehrt war, da führte man auch mich vor. Und ein Mann begann mit einer Rede: [27] „Dieser hier ist einer von den Leuten, die seit vielen Jahren das Gemeindeland ausbeuten - nicht allein er selbst, sondern zuvor schon sein Vater. Und sie nutzen unser Bergland als Weide und bebauen unser Ackerland; sie gehen dort zur Jagd und haben viele Häuser hineingebaut. ${ }^{38}$ Sie haben auch Weinstöcke gepflanzt und erzielen noch andere große Gewinne daraus, ohne an jemanden Pacht für das Land bezahlt zu haben oder vom Volk mit dem Land beschenkt worden zu sein. [28] Wofür hätten sie es denn auch als Geschenk erhalten sollen? Sie haben sich unseren Besitz angeeignet und sind reiche Leute und haben doch niemals irgendeine Liturgie übernommen oder Ernteabgaben erbracht. ${ }^{39}$ Sie leben hier, von Steuerabgaben befreit und ohne Liturgieverpflichtungen, als wären sie anerkannte Wohltäter der Stadt. Ich glaube sogar", fuhr er fort, "sie sind noch niemals hierher, in die Stadt, gekommen". [29] Und wie ich meinen Kopf (verneinend) zurückwarf, brach die Menge bei dem Anblick in Gelächter aus. Jener aber ärgerte sich über das Gelächter und warf mir Schimpfworte zu. Dann wandte er sich wieder der Volksmenge zu und sagte: „Wenn das so gebilligt wird, dann können wir alle gar nicht schnell genug mit der Plünderung des Gemeindebesitzes beginnen, die einen bei den Geldern der Stadt, wie es einige ganz gewiss schon jetzt betreiben. Die anderen werden die Landflur unter sich aufteilen, ohne euch dabei zu fragen, wenn ihr diesen Raubtieren hier gestattet, umsonst mehr als 1000 Plethren besten Landes zu besetzen, von dem ihr drei Maß (choinix) Kornspende pro Mann bekommen könntet. ${ }^{40}$

[30] Wie ich das hörte, lachte ich los, so laut ich nur konnte. Die Menge aber lachte gar nicht mehr wie vorher, sondern wurde unruhig. Der Mann aber war entrüstet, blickte mich finster an und rief: „Seht ihr die Scheinheiligkeit und Unverschämtheit dieses Schuftes, wie dreist er uns auslacht? Es fehlt nicht viel, dass ich ihn und auch seinen Komplizen abführen lasse ${ }^{41}$ - denn ich höre, dass es zwei Anführer bei dieser Bande gibt, die nahezu das ganze Land in den Bergen an sich gerissen hat. [31] Ich glaube nämlich, dass sie sich auch an dem Strandgut aus den Schiffskatastrophen vergrei- 


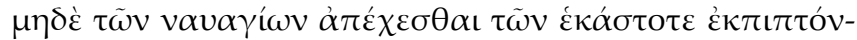

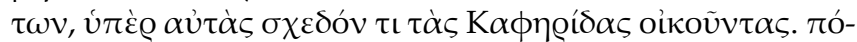

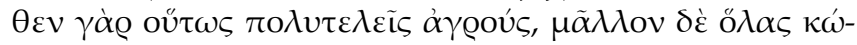

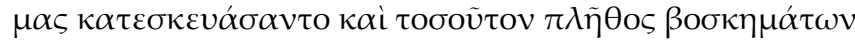

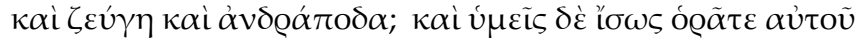

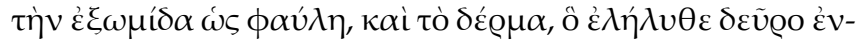

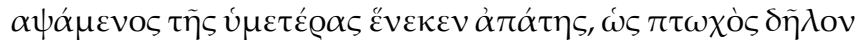

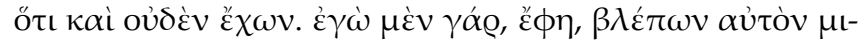

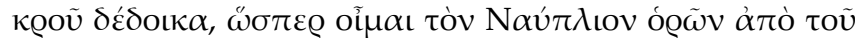

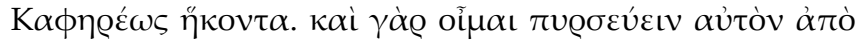

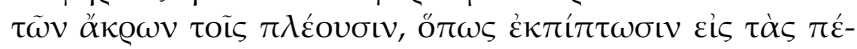

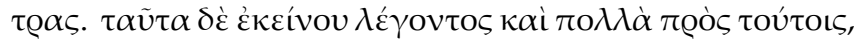

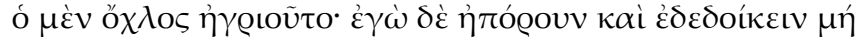

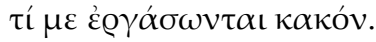

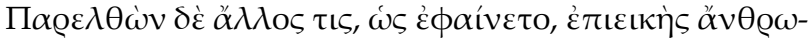

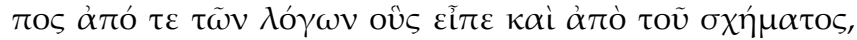

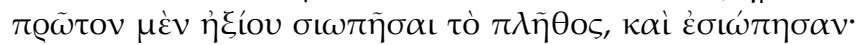

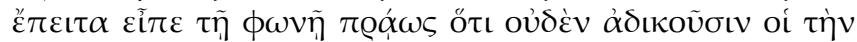

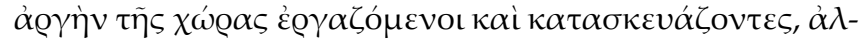

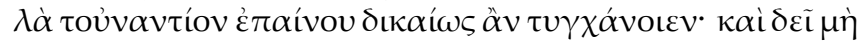

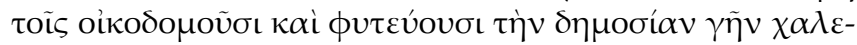

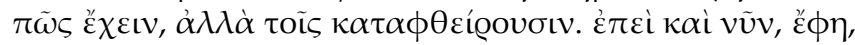

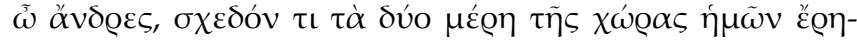

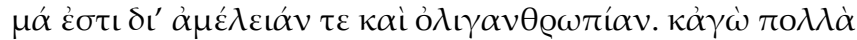

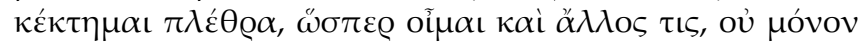

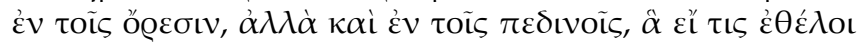

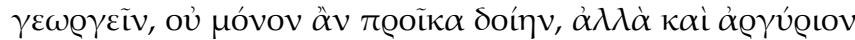

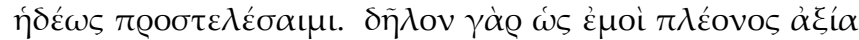

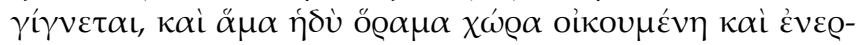

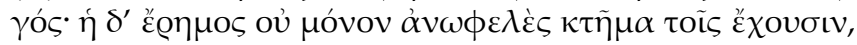

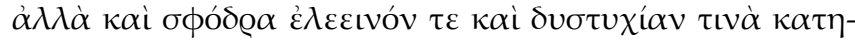

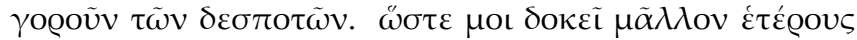

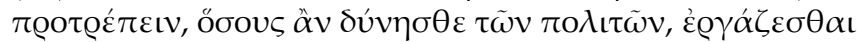

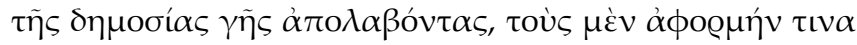

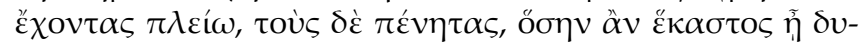

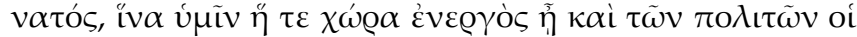

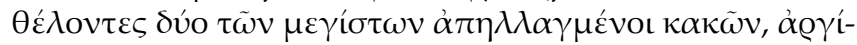

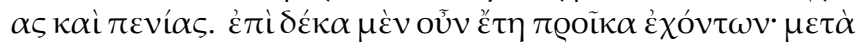

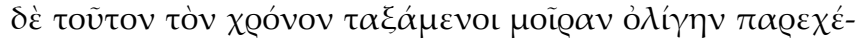

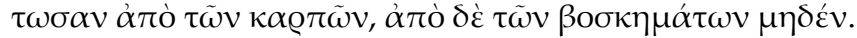


fen, sooft dort etwas angetrieben wird; sie wohnen ja nahezu oberhalb der Klippen des Kaps Kaphereus. ${ }^{42}$ Woher denn haben sie sich so kostbares Ackerland und sogar ganze Dörfer verschafft und dazu eine solche Fülle an Vieh, Zugtieren und Sklaven? [32] Ihr schaut vielleicht auf seinen Arbeitskittel, und wie schäbig er ist, sowie auf das Lederwams, in dem er hergekommen ist, um euch zu betrügen, als sei er natürlich ein Bettler und Habenichts. Ich nämlich“, so fuhr er fort, „,ich empfand beinahe Angst, als ich ihn erblickte, und es schien mir, als ob ich den Unhold Nauplios leibhaftig vom Kap Kaphereus her kommen sähe. ${ }^{43}$ Ich glaube nämlich, dass er dort den Seefahrern von der Höhe aus Feuersignale gibt, damit sie auf den Felsen auflaufen". [33] Als er dieses und noch mehr dazu sagte, wurde die Menge immer wilder. Ich aber war völlig ratlos und fürchtete, sie würden mir Gewalt antun.

\section{Auftritt und Rede des anständigen Politikers}

Da aber kam ein anderer nach vorn, ein anständiger, maßvoller Mann, wie aus seinen Worten, die er sprach, und aus seinem Auftreten deutlich wurde. Zunächst verlangte er, die Menge möge schweigen, und sie schwiegen. ${ }^{44}$ Danach erklärte er mit ruhiger Stimme, dass diejenigen, die brachliegendes Land bebauten und in Ordnung hielten, keineswegs Unrecht täten, sondern ganz im Gegenteil einen Anspruch auf eine Belobigung besäßen. [34] „Man soll nicht denen, die auf dem Gemeindeland Häuser bauen und es bepflanzen, Vorwürfe machen, sondern denen, die es verkommen lassen. Denn gegenwärtig, liebe Mitbürger", so sagte er, „liegen nahezu zwei Drittel unseres Landes brach, aus Nachlässigkeit und wegen des Mangels an Menschen. ${ }^{45}$ Auch ich besitze viele Plethren Land, wie wohl auch andere hier, nicht nur im Bergland, sondern auch in der Ebene, ${ }^{46}$ die ich dem, der sie landwirtschaftlich nutzen will, nicht nur ohne Pacht überlassen wollte, sondern ihm gern auch noch Geld dazu geben würde. [35] Denn es ist doch klar, dass mein Besitz an Wert gewinnen und zugleich als bewohntes und bestelltes Land einen schönen Anblick bieten würde. Wüstes Land ist dagegen für die Besitzer nicht nur nutzlos, sondern auch ein mitleiderregender und vom Missgeschick der Eigentümer zeugender Anblick. [36] Daher erscheint es mir richtiger, von den übrigen Bürgern so viele, wie ihr nur könnt, dazu anzuspornen, das Gemeindeland in Nutzung zu nehmen. Dabei sollen diejenigen, die über Mittel verfügen, einen größeren Anteil erhalten, die Armen hingegen soviel Land, wie ein jeder bewirtschaften kann, damit eure Landflur bestellt wird und die Willigen unter den Bürgern von zwei der größten Übel befreit sind - von der Untätigkeit und der Armut. ${ }^{47}$ [37] Auf zehn Jahre sollen sie das Land abgabenfrei erhalten; nach diesem Zeitraum sollen sie, nach Vereinbarung, einen 


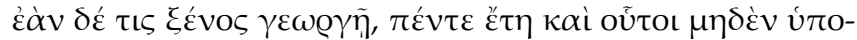

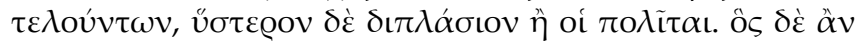

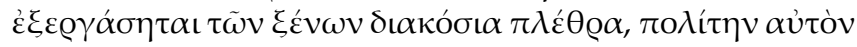

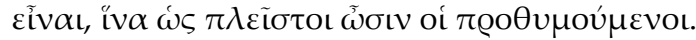

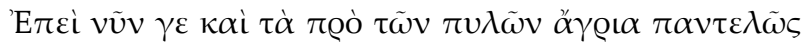

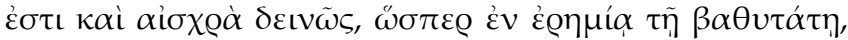

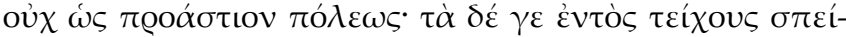

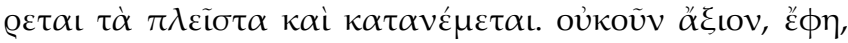

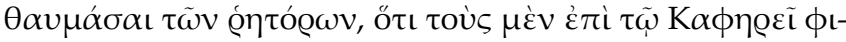

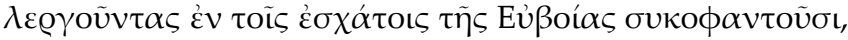

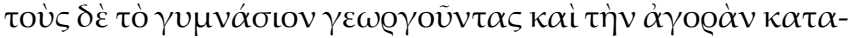

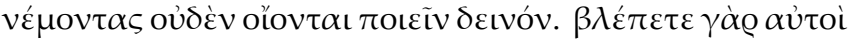

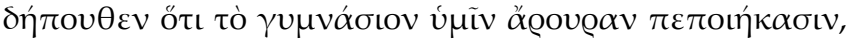

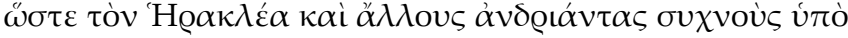

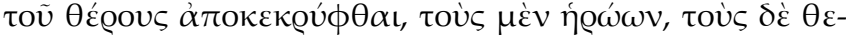

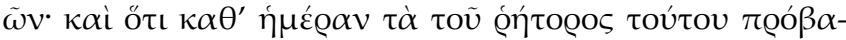

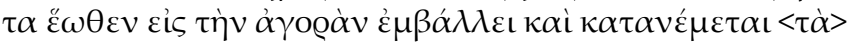

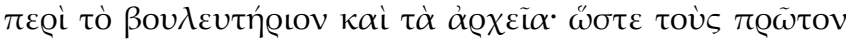

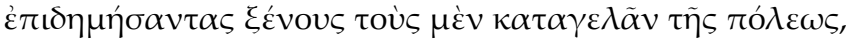

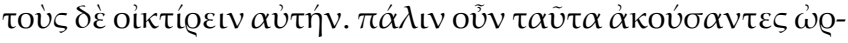

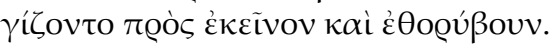

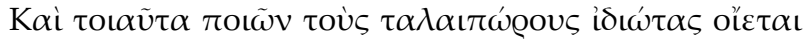

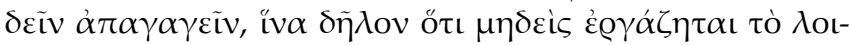

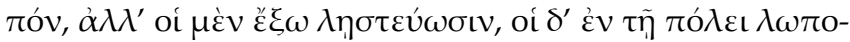

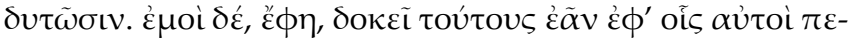

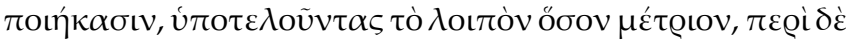

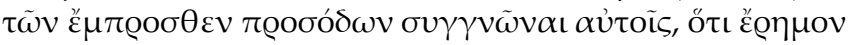

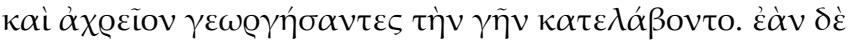

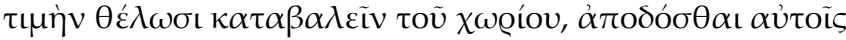

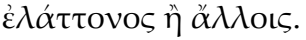

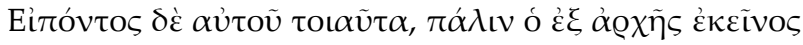

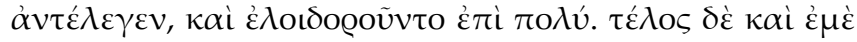

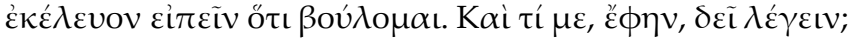

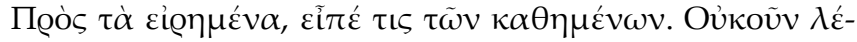


kleinen Teil vom Ernteertrag abliefern, von dem Vieh auf der Weide dagegen gar nichts. ${ }^{48}$ Wenn aber ein Nicht-Bürger Landwirtschaft betreibt, soll auch für ihn Abgabenfreiheit gelten - auf fünf Jahre, danach aber soll er einen doppelt so hohen Betrag entrichten wie die Bürger. Derjenige aber, der von den Nicht-Bürgern 200 Plethren unter den Pflug nimmt, soll Bürger unserer Polis sein, damit möglichst viele sich dieses zum Ziel setzen. ${ }^{49}$

[38] Jetzt ist aber selbst die Landflur vor unseren Toren völlig verwildert und ein schrecklicher Anblick wie in tiefster Ödnis, als handele es sich nicht um den Vorstadtbereich einer Polis. ${ }^{50}$ Dagegen wird das Areal innerhalb der Mauern zum größten Teil als Ackerland und Viehweide genutzt. Sollte man sich daher nicht", so sagte er, „über die Redner hier wundern, ${ }^{51}$ dass sie gegen Leute, die beim Kap Kaphereus, im hintersten Winkel Euböas, fleißig bei der Arbeit sind, Klage erheben, während sie andererseits meinen, dass diejenigen, die das Gymnasion als Acker nutzen und ihr Vieh auf dem Marktplatz (agorá) weiden lassen, gar nichts Schlimmes tun ${ }^{52}$ [39] Ihr seht doch wahrlich selbst, dass man euer Gymnasion zur Feldflur gemacht hat, so dass zur Erntezeit im Sommer die HeraklesStatue und viele andere Standbilder von Heroen und von Göttern gar nicht mehr zu sehen sind. ${ }^{53}$ Auch habt ihr vor Augen, wie tagtäglich vom frühen Morgen an die Schafe meines Vorredners hier in den Marktplatz einfallen und das Terrain um das Ratsgebäude und die Amtslokale herum abgrasen. Dies hat bewirkt, dass von den Fremden, die zum ersten Mal unsere Stadt besuchen, die einen über unsere Polis spotten und die anderen sie bemitleiden" ${ }^{54}$ Wie die Menge nun wiederum diese Worte hörte, da wandte sie sich zornig und laut gegen jenen Vorredner.

[40] „Trotz solchen Verhaltens ist er der Meinung, dass man diese armen, einfachen Leute abführen und in Haft nehmen müsse, offenbar damit in Zukunft niemand mehr Lust hat zu arbeiten, sondern die Leute außerhalb der Stadt als Räuber ihr Unwesen treiben, und die in der Stadt als Kriminelle und Diebe. ${ }^{55}$ Ich bin daher der Meinung, diese Leute auf dem Besitz zu belassen, den sie sich erarbeitet haben, wobei sie in Zukunft eine maßvolle Abgabe zahlen sollen. Für die Einkünfte in der Vergangenheit soll ihnen diese erlassen werden, weil sie durch ihre Arbeit nutzloses Ödland urbar gemacht und in Besitz genommen haben. Wenn sie aber einen Kaufpreis für das Grundstück zahlen wollen, soll man ihnen dieses zu einem niedrigeren als den üblichen Preis verkaufen“. ${ }^{26}$

\section{Die Stellungnahme des Jägers}

[41] Nachdem er mit diesen Worten geendet hatte, da legte wieder jener Vorredner Einspruch ein, und sie beschimpften einander über längere Zeit. ${ }^{57}$ Zuletzt aber forderte man auch mich auf, meine Ansicht darzulegen. „Und was soll ich denn sagen?", fragte ich. „Was du über die vorge- 


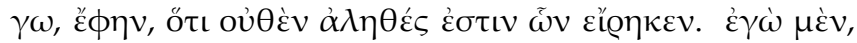

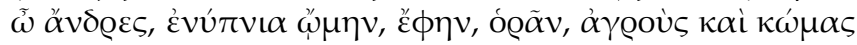

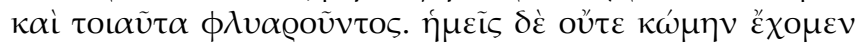

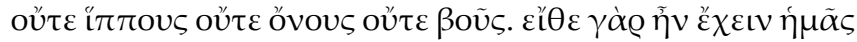

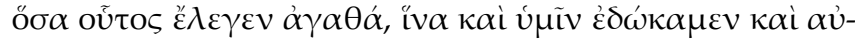

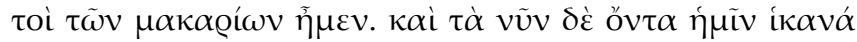

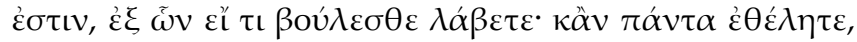

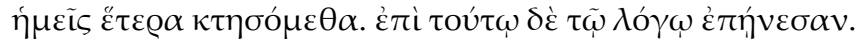

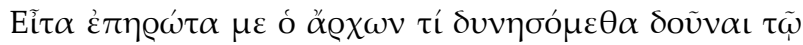

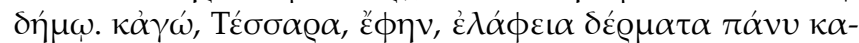

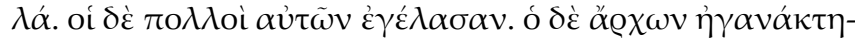

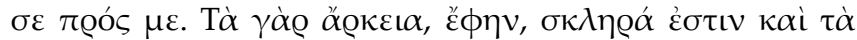

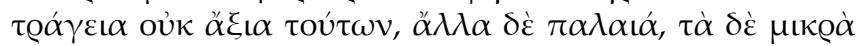

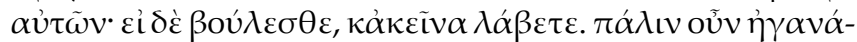

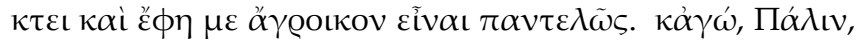

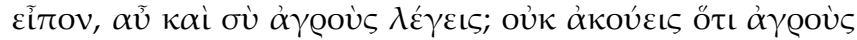

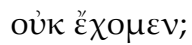

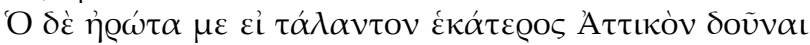

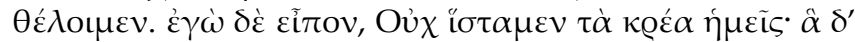

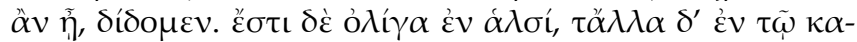

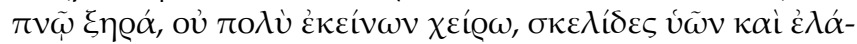

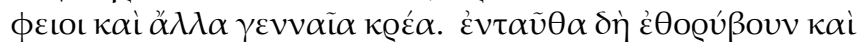

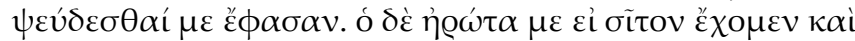

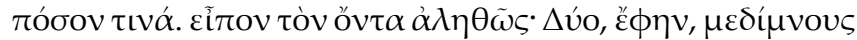

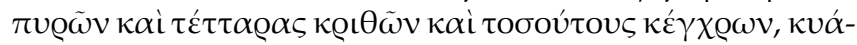

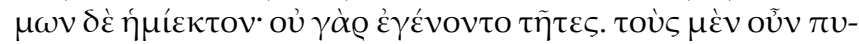

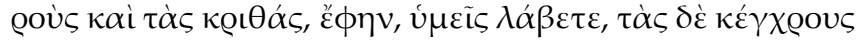

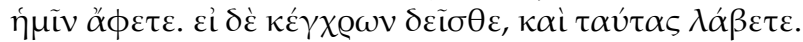

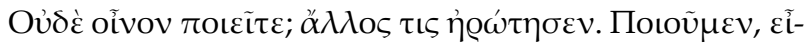

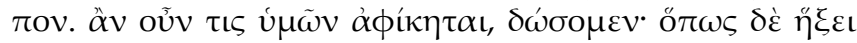

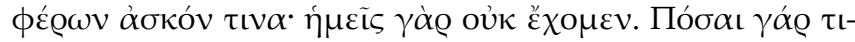

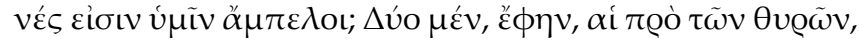

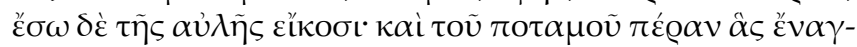

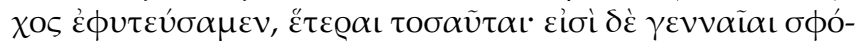

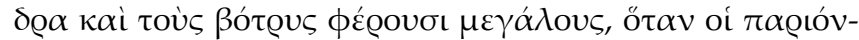

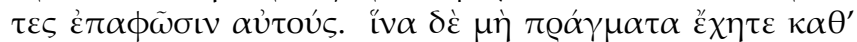

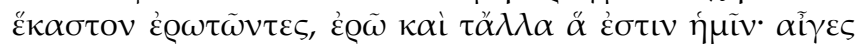

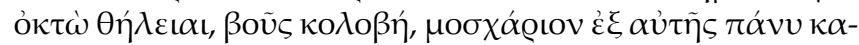


tragenen Reden denkst", sagte einer von den vor mir sitzenden Zuhörern. "Also sage ich, dass nichts Wahres an dem ist, was der eine gesagt hat. [42] Ich, liebe Mitbürger, glaubte zu träumen, als er von Äckern und Dörfern und dergleichen schwätzte. Wir haben nämlich weder ein Dorf noch Pferde, Esel oder Rinder. Ach, hätten wir doch all diese guten Dinge, von denen jener sprach, damit wir euch davon etwas abgäben und unsererseits $\mathrm{zu}$ den reichen Leuten gehörten! ${ }^{58}$ Was wir nun wirklich haben, reicht für uns aus - nehmt euch etwas davon, wenn ihr wollt! Und wenn ihr alles wollt, dann werden wir uns etwas Neues erwerben!" Zu diesen Worten spendeten sie mir Beifall. ${ }^{59}$

[43] Sodann befragte mich der Amtsträger, wie viel wir dem Volk geben könnten. ${ }^{60}$ Ich sagte: „Vier Hirschfelle, und zwar sehr schöne!“ Da lachten die meisten von ihnen. Der Amtsträger aber machte mir gegenüber ein ärgerliches Gesicht. „Die Bärenfelle“, fügte ich hinzu, „sind nämlich rauh und die Bocksfelle nicht so wertvoll - die einen schon alt, die anderen klein. ${ }^{61}$ Wenn ihr aber wollt, so nehmt auch diese!" Jetzt wurde er wieder ärgerlich und sagte, ich sei ein richtiger Tölpel, wie er gerade vom Acker komme. [44] Und ich dagegen: „Erneut redest auch du von Äckern, hast du nicht gehört, dass wir gar keinen Acker haben?"62

Er aber fragte mich, ob wir bereit seien, jeder ein athenisches Talent zu geben. ${ }^{63}$ Ich antwortete: „Wir wiegen unsere Fleischportionen nicht ab, was aber davon vorhanden ist, geben wir euch. Eine kleine Menge liegt im Salz, der Rest ist geräuchert und trocken, im Wert aber nicht viel schlechter: Wildschweinschinken sowie Hirschkeulen und anderes gutes Fleisch“. [45] Da wurde die Menge jedoch unruhig, und man bezeichnete mich als Lügner. ${ }^{64}$ Der Amtsträger aber fragte, ob wir Getreide besäßen und wie viel davon. Ich sagte ihm genau die Wahrheit: „Zwei Scheffel (médimnos) Weizen und vier Scheffel Gerste, ebensoviel Hirse und nur ein Zwölftel Maß Bohnen; in diesem Jahr sind sie nämlich nicht gediehen. ${ }^{65} \mathrm{Nehmt}$ euch nur den Weizen und die Gerste und lasst uns die Hirse übrig. Wenn ihr aber Bedarf an Hirse habt, dann nehmt auch diese!“

[46] „Macht ihr denn keinen Wein?", fragte ein anderer. „Machen wir", sagte ich, „und sollte jetzt einer zu uns kommen, so werden wir ihm davon abgeben. Er müsste aber, wenn er kommt, einen Lederschlauch mitbringen. Wir haben nämlich keinen." „Wie viele Weinstöcke habt ihr denn?" "Zwei“, sagte ich, „vor den Eingangstüren und zwanzig innerhalb des Hofs; und eben so viele jenseits des Flusslaufs, die wir erst kürzlich gepflanzt haben. Sie sind aber von sehr guter Art und tragen große Trauben, wenn diejenigen, die daran vorbeigehen, sie in Ruhe lassen. [47] Damit ihr jedoch nicht mühsam nach allen Einzelheiten fragen müsst, werde ich euch unseren sonstigen Besitz aufzählen: acht Ziegen, eine Kuh mit abge- 


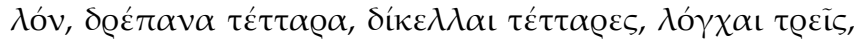

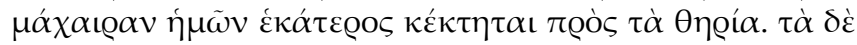

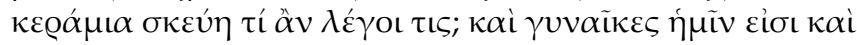

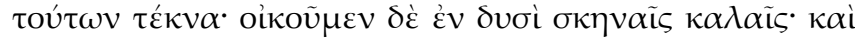

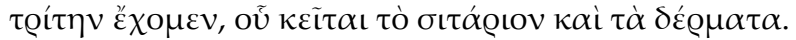

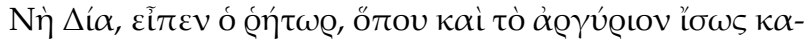

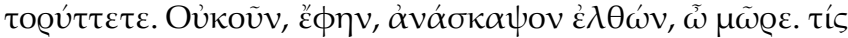

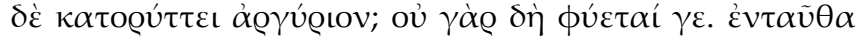

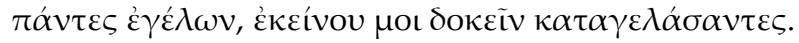

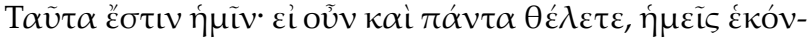

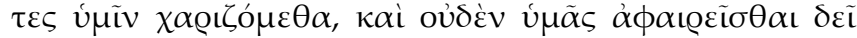

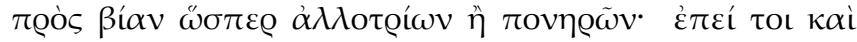

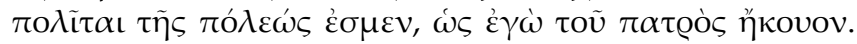

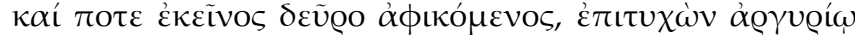

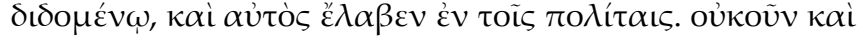

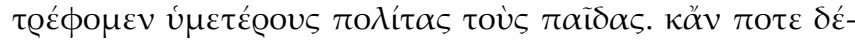

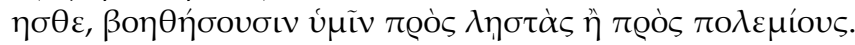

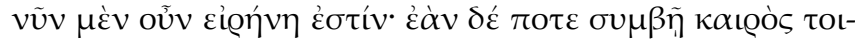

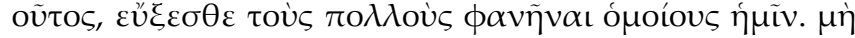

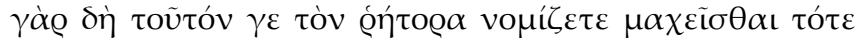

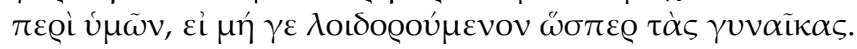

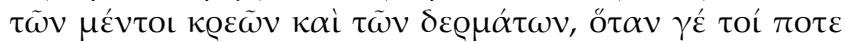

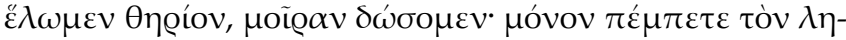

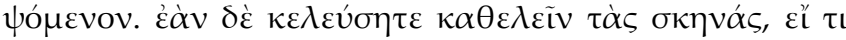

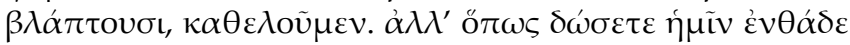

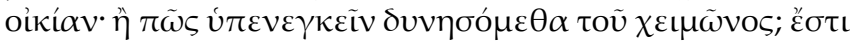

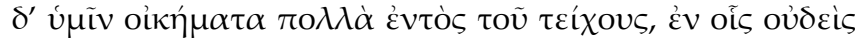

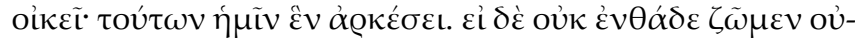

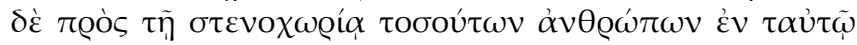

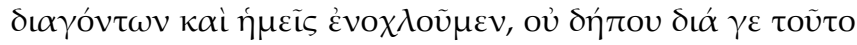

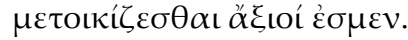

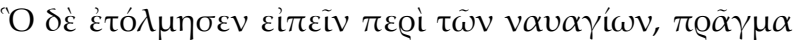

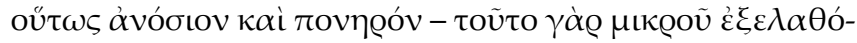

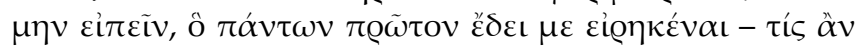

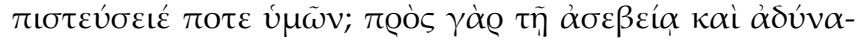

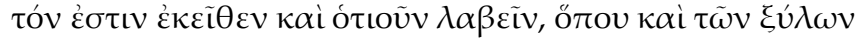


stoßenen Hörnern und von ihr ein ganz süßes Kälbchen; ${ }^{66}$ dazu vier Sichelmesser und vier Hacken sowie drei Lanzen. Jeder von uns beiden hat ein Messer für die Jagd. Was soll man noch weiter über das Tongeschirr reden? Außerdem haben wir Frauen und von ihnen Kinder; wir wohnen in zwei schönen, ansehnlichen Hütten, dazu haben wir noch eine dritte als Lagerraum für unser Getreideschätzchen und für die Tierfelle. ${ }^{\prime 67}$

[48] „Beim Zeus“, rief der Politiker, „und da vergrabt ihr wohl euer Silbergeld.“ „Warum kommst du dann nicht her", antwortete ich, „und gräbst es aus, du Dummkopf! Wer vergräbt denn Silbergeld? Es kann doch gar nicht sprießen und wachsen. " Da erhob sich Gelächter, und mir schien es, als lachten sie ihn aus. ${ }^{68}$

„Das ist unser ganzer Besitz. Wenn ihr nun davon alles haben wollt, dann überlassen wir es euch freiwillig und gerne. Ihr braucht es nicht mit Gewalt an euch bringen, als hättet ihr es mit landfremden Kriminellen zu tun. [49] Denn wir sind wirklich Bürger dieser Polis, wie ich von meinem Vater gehört habe. Und einmal ist er hierher, in die Stadt, gekommen, als gerade eine Geldspende ausgezahlt wurde, und er hat damals seinen Teil in der Gemeinschaft der Bürger erhalten. ${ }^{69}$ Daher ziehen wir unsere Kinder zu eueren Mitbürgern heran. Und solltet ihr ihrer einmal bedürfen, so werden sie euch im Kampf gegen Räuberbanden und Feinde Hilfe leisten. Jetzt herrscht zwar tiefer Friede. ${ }^{70}$ Wenn aber ein solcher Notfall eintreffen sollte, werdet ihr froh sein, wenn sich die große Menge als so wehrhaft erweist, wie wir es sind. Glaubt doch nicht, dass jener Politiker da für euch in den Kampf ziehen wird - es sei denn mit Schimpfereien nach Weiberart! [50] Von dem Fleisch und den Fellen werden wir, wenn wir Wild erlegt haben, einen Anteil abgeben; ihr solltet aber uns jemanden zum Abholen schicken. Wenn ihr uns jedoch befehlt, die Hütten niederzureißen, weil sie irgendwie stören, werden wir das tun. Ihr müsstet uns dann aber hier ein Haus zur Verfügung stellen - wie könnten wir sonst den Winter überstehen? Es gibt bei euch ja viele Häuser innerhalb der Stadtmauer, in denen niemand wohnt. Von diesen wird eines für uns ausreichen. Wenn wir aber nun nicht hier leben und wir euch - bei der Enge in der Stadt, wo schon so viele Menschen auf ein und derselben Stelle ihr Leben verbringen ${ }^{71}$ nicht auch noch zur Last fallen, dann sollte deswegen doch kein Grund bestehen, uns aus unserem Wohnsitz auszusiedeln.

\section{Hilfe und Fürsorge für Schiffbrüchige am Kap Kaphereus}

[51] Was er aber frech behauptet hat hinsichtlich des Strandgutes - eine so gemeine und schändliche Sache! - das hätte ich jetzt beinahe vergessen und dabei hätte ich doch gleich an erster Stelle darauf antworten müssen! ${ }^{72}$ Wer von euch kann ihm da Glauben schenken? Denn ganz abgesehen von der Ruchlosigkeit ist es auch völlig unmöglich, von dort irgendetwas zu 


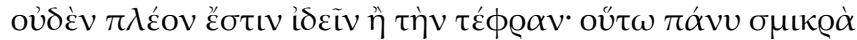

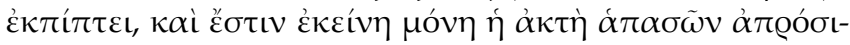

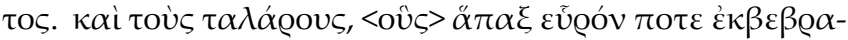

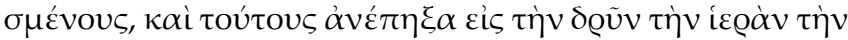

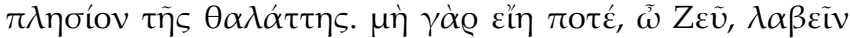

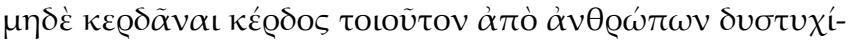

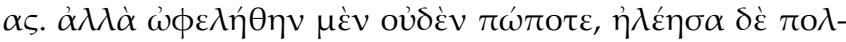

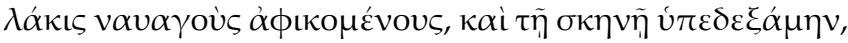

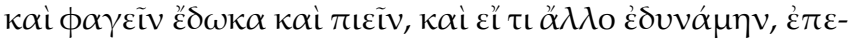

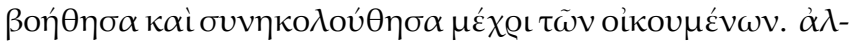

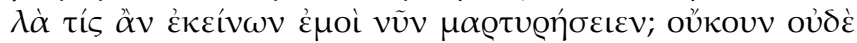

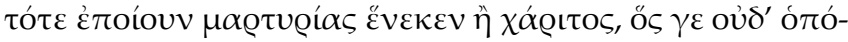

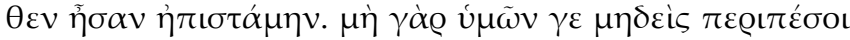

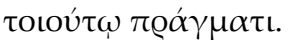

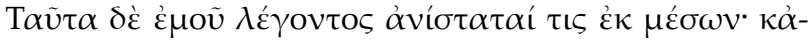

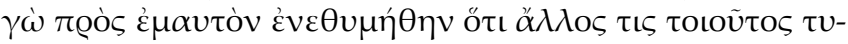

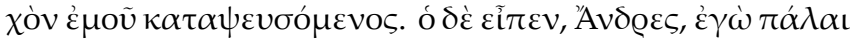

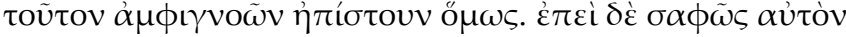

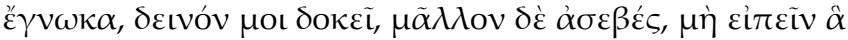

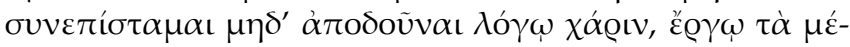

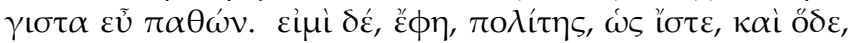

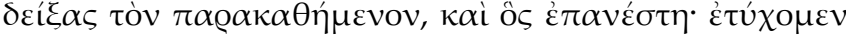

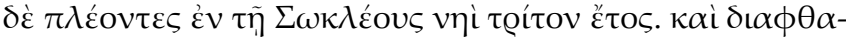

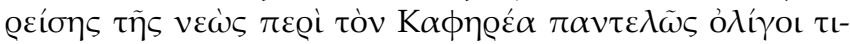

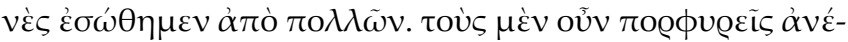

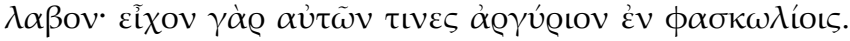

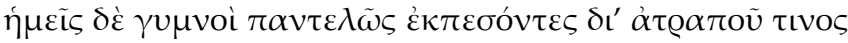

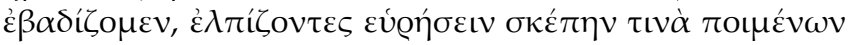

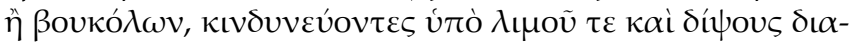

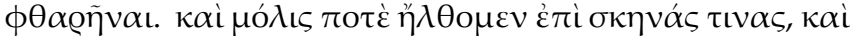

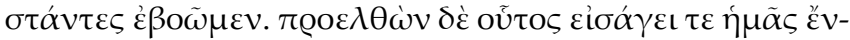

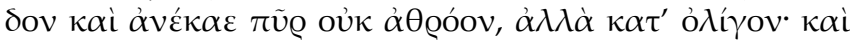

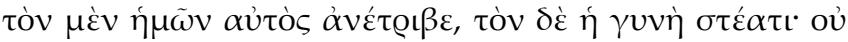

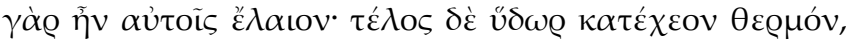

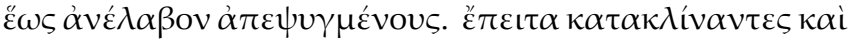

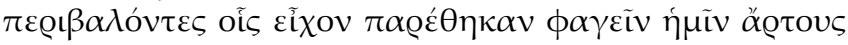

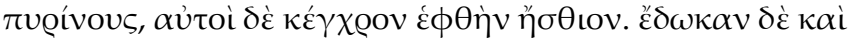

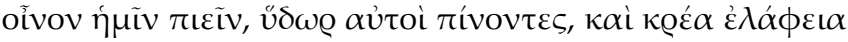

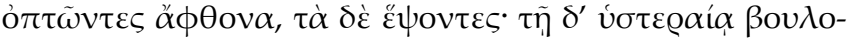


holen, wo man selbst von den Hölzern nicht mehr zu sehen bekommt als Staubkörner; so winzig klein sind die angeschwemmten Stücke! Auch ist das Vorgebirge dort allein im Vergleich zu allen anderen (Küstenabschnitten) völlig unzugänglich. [52] Und die Körbchen, die ich einmal am Strand angespült fand, die habe ich an der heiligen Eiche befestigt, die nahe am Meer steht. Nie und nimmer, beim Zeus, soll man so etwas an sich nehmen und einen Gewinn aus dem Unglück anderer Menschen ziehen! ${ }^{73}$ Niemals habe ich mich da an irgendetwas bereichert, sondern habe mich oft mitleidig um die dort angelangten Schiffbrüchigen gekümmert und sie in meiner Hütte aufgenommen. Ich habe ihnen zu essen und zu trinken gegeben. Ich habe ihnen geholfen, wo immer ich konnte, und sie dann bis ins bewohnte Gebiet geleitet. [53] Aber wer von ihnen könnte mir das jetzt als Zeuge bestätigen? Ich tat dies ja auch nicht in der Erwartung eines Zeugnisses und späteren Dankes. Ich habe ja nicht einmal mitbekommen, woher sie stammten. Es möge doch niemand von euch in eine solche Lage geraten!“

\section{Der Bericht des Schiffbrüchigen}

Und wie ich dies sage, da steht mitten in der Versammlung einer auf, ${ }^{74}$ und ich dachte schon bei mir: ,Das ist wohl noch so einer, der gegen mich Lügen vorbringen wird'. [54] Er sagte jedoch: ,Liebe Mitbürger, ich war mir hinsichtlich dieses Mannes schon seit einiger Zeit unsicher und konnte es einfach nicht glauben. Da ich ihn jetzt aber genau wiedererkannt habe, erscheint es mir schrecklich - um nicht zu sagen gottlos - wenn ich nicht mitteilte, was ich über ihn weiß, und nicht wenigstens mit Worten Dank abstattete, wo mir mit Taten sehr viel Gutes erwiesen wurde. [55] Ich bin, wie ihr wisst, Bürger dieser Stadt, wie dieser hier', und damit zeigte er auf den Mann, der neben ihm saß, und auch dieser erhob sich. ,Wir fuhren vor zwei Jahren zur See auf dem Schiff des Sokles. Und als unser Schiff am Kap Kaphereus gescheitert war, konnten sich nur ganz wenige aus unserer großen Zahl retten. Einige fanden Aufnahme bei Purpurfischern, denn sie hatten Silbergeld im Beutel. ${ }^{75}$ Wir aber wurden nackt und bloß ans Land gespült und gingen einen Pfad entlang in der Hoffnung, ein Obdach bei Schäfern oder Rinderhirten zu finden, da wir sonst an Hunger und Durst hätten zugrunde gehen müssen. [56] Nur mit großer Mühe gelangten wir zu einigen Hütten, blieben dort stehen und riefen um Hilfe. Da trat dieser Mann heraus - und führt uns in seine Wohnung hinein! Er machte ein Feuer an, nicht gleich zu voller Glut, sondern mit allmählicher Steigerung der Wärme. Den einen von uns rieb er selbst, den anderen seine Frau mit Talg ein, denn Olivenöl besaßen sie nicht. Schließlich gossen sie warmes Wasser über uns, bis sie uns aus der Kältestarre herausgeholt hatten. [57] Danach bereiteten sie uns ein Lager und deckten uns mit dem, was sie hatten, zu. Als Speise stellten sie uns Weizenbrote hin, sie selbst aber aßen gekochte 


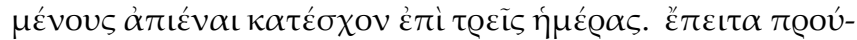

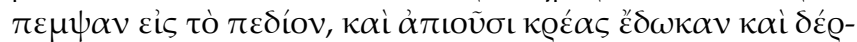

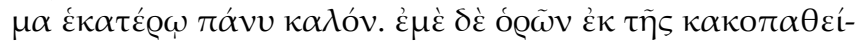

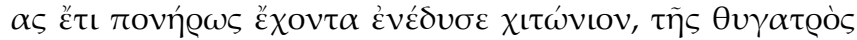

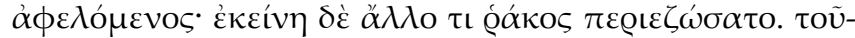

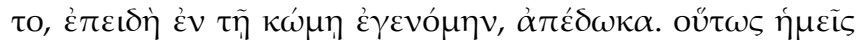

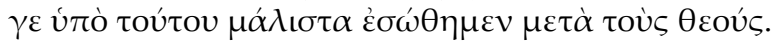

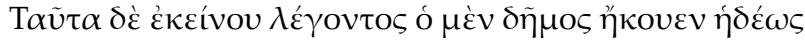

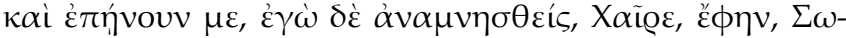

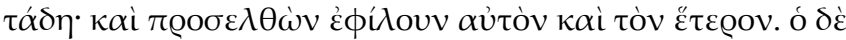

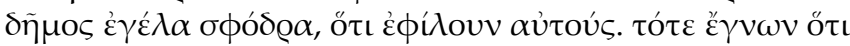

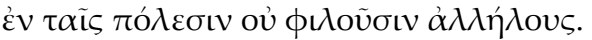

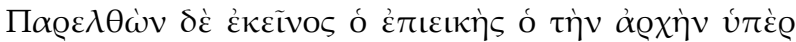

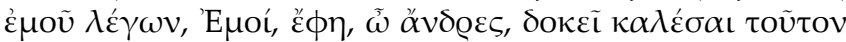

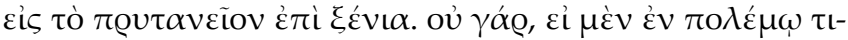

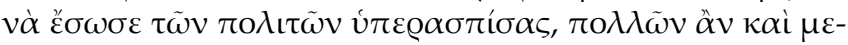

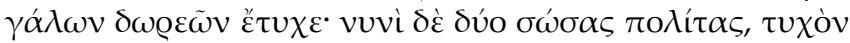

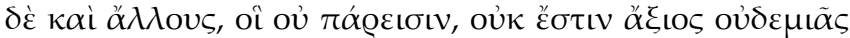

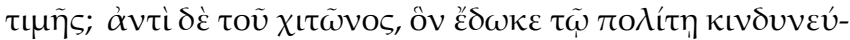

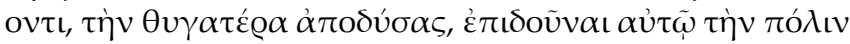

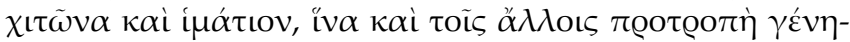

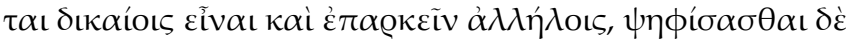

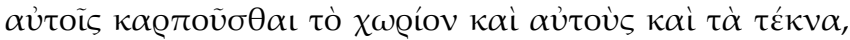

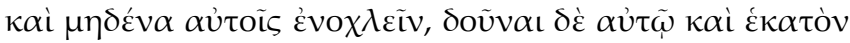

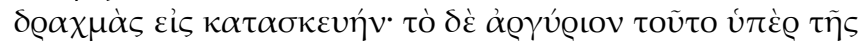

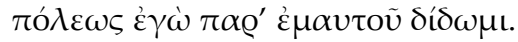

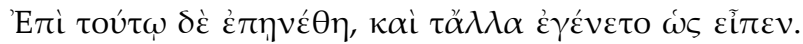

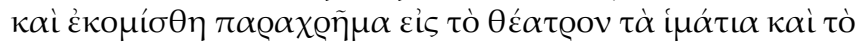

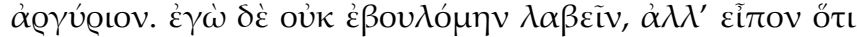

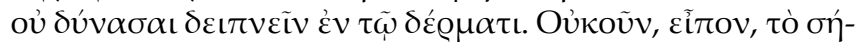

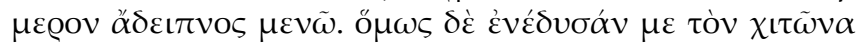

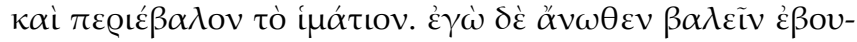

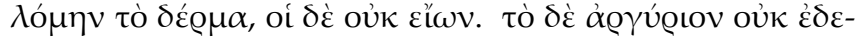


Hirse; auch gaben sie uns Wein zu trinken, selber aber tranken sie Wasser. ${ }^{76}$ Und große Portionen Hirschfleisch brieten und kochten sie für uns. Als wir am folgenden Tag fortgehen wollten, behielten sie uns noch drei Tage bei sich. [58] Dann haben sie uns in die Ebene hinabgeleitet und gaben uns zum Abschied noch Fleisch mit und für jeden von uns ein sehr schönes Fell. Wie er aber sah, dass es mir von der Überanstrengung her noch ziemlich schlecht ging, da nahm er seiner Tochter den Rock ab und steckte mich hinein; sie aber band sich etwas anderes, einen Tuchfetzen, um. Das Kleidungsstück gab ich dann zurück, nachdem ich in unserem Dorf angelangt war. So verdanken wir diesem Mann hier, gleich nach den Göttern, unsere Rettung.'

[59] Die Rede des Mannes hörte sich das Volk mit Vergnügen an und spendete mir Beifall. Ich erkannte ihn nun auch und rief: ,Sei mir gegrüßt, lieber Sotades!' Und ich eilte zu ihm hin und küßte ihn und seinen Gefährten. Das Volk aber lachte gewaltig darüber, dass ich die beiden küsste. Damals wurde mir klar, dass die Leute in den Städten einander keine Küsse geben. ${ }^{77}$

\section{Beschlüsse der Volksversammlung}

[60] Da kam jener anständige Politiker, der sich anfangs schon für mich eingesetzt hatte, nach vorn und sprach: ,Liebe Mitbürger, ich möchte den Antrag stellen, diesen Mann in das Prytaneion zum festlichen Gastmahl einzuladen. ${ }^{78}$ Wären ihm nämlich nicht, wenn er im Kriege einen unserer Bürger mit dem Schilde geschützt und ihm das Leben gerettet hätte, zahlreiche große Ehrengeschenke zuteil geworden? Nachdem er jetzt aber zwei Bürger gerettet hat und möglicherweise noch andere, die hier nicht anwesend sind, hat er da vielleicht keine Ehrung verdient? [61] Für das Gewandstück, das er der Tochter wegnahm und es dem Mitbürger gab, der sich in Not befand, soll ihm die Polis ein Gewand und einen Mantel schenken, damit es auch für alle übrigen einen Ansporn gibt, anständig zu sein und einander Hilfe zu leisten. Ferner soll ihnen und ihren Kindern durch einen Volksbeschluss die Nutzung des Anwesens zuerkannt werden; auch soll niemand sie behelligen dürfen. Des weiteren soll man dem Manne hier 100 Drachmen geben für die Ausrüstung; ${ }^{79}$ diesen Geldbetrag will ich für die Polis entrichten.'

[62] Für dieses Angebot erhielt er Beifall, ${ }^{80}$ und auch alles andere erfolgte so, wie er es beantragt hatte: Auf der Stelle wurden die Gewänder und das Geld in das Theater gebracht. Ich aber wollte nichts annehmen; man sagte jedoch zu mir: ,Du kannst unmöglich im Lederwams am abendlichen Bankett teilnehmen!' Ich sagte: Dann bleibe ich eben für heute ohne Mahlzeit!' Gleichwohl steckten sie mich in das Untergewand und legten mir den Mantel um. Ich wollte mir noch oben darüber mein Lederwams anziehen, 


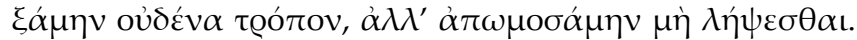

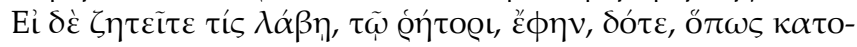

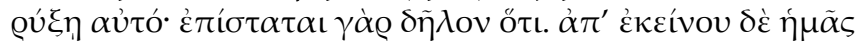

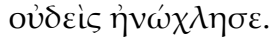

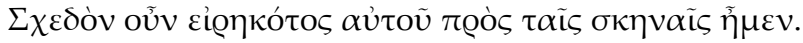

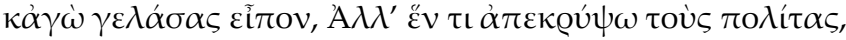

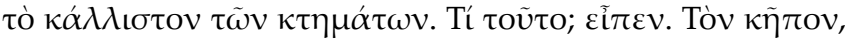

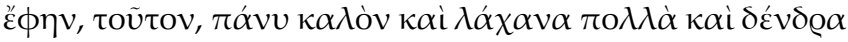

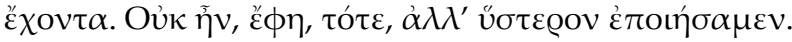

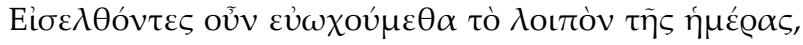

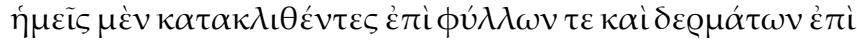

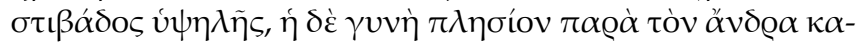

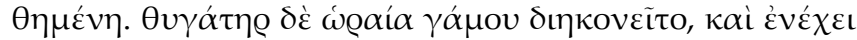

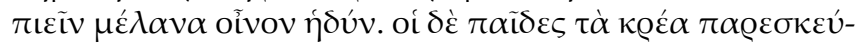

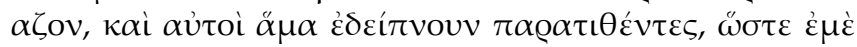

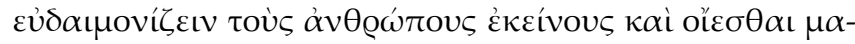

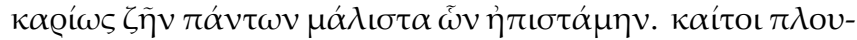

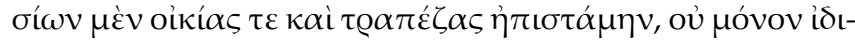

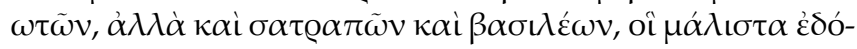

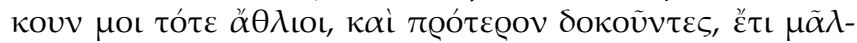

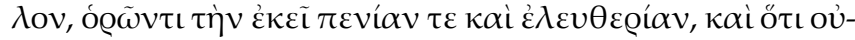

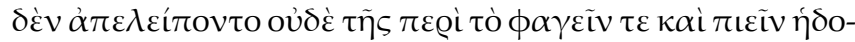

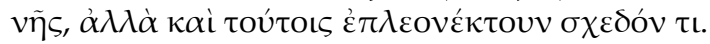

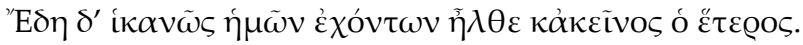

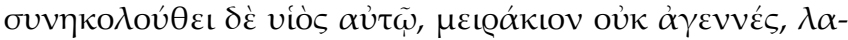

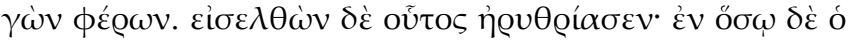

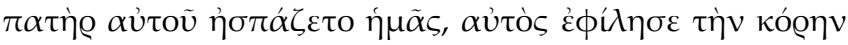

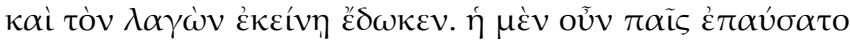

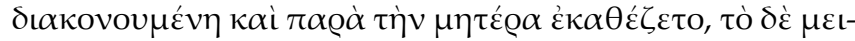

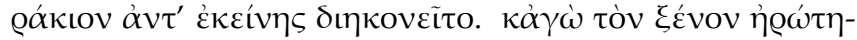

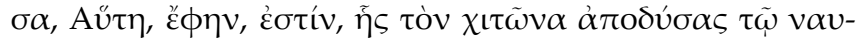

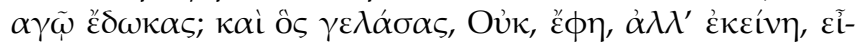

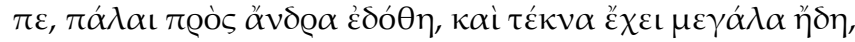

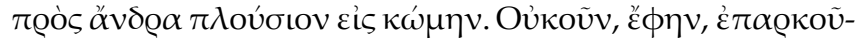


aber das ließen sie nicht zu. [63] Das Geld aber habe ich rundheraus nicht angenommen und sogar geschworen, es nicht anrühren zu wollen: ,Wenn ihr jemanden sucht, der es nehmen mag, dann gebt es doch dem Politiker da, damit er es eingräbt; er versteht sich ja offenbar darauf.' Seit jener Zeit hat uns niemand mehr behelligt."

\section{Fortsetzung des Reiseberichts ( $\$ \S 64-80$ )}

[64] Er hatte seine Erzählung beinahe beendet, als wir bei den Hütten ankamen. Und ich sagte lachend zu ihm: „Eine Sache hast du deinen Mitbürgern verheimlicht - und zwar das schönste Stück von eurem Besitz!“ "Was soll das sein?“, fragte er. „Den wunderschönen Garten dort, in dem sich reichlich Gemüse und Obstbäume befinden." „Den gab es damals noch nicht", entgegnete er, „den haben wir erst später angelegt."

[65] Wir gingen hinein und verbrachten den Rest des Tages mit einem herrlichen Schmaus: Wir Männer streckten uns beide auf einem hohen Lager aus Laub und Fellen aus, während die Frau sich in der Nähe ihres Mannes hinsetzte. ${ }^{81}$ Eine Tochter, in heiratsfähigem Alter, übernahm die Bedienung und schenkte uns zum Trinken wohlschmeckenden Rotwein ein. Die jungen Burschen aber bereiteten das Fleisch, setzten es uns vor und aßen selber mit. So musste ich diese Menschen glücklich preisen und zu der Überzeugung kommen, dass sie ein glückliches Leben führten - und das am meisten von allen, die ich kennengelernt habe. [66] Immerhin bin ich in den Häusern und an den Gästetafeln nicht nur bei reichen Leuten gewesen, sondern tatsächlich sogar bei Statthaltern und Herrschern („Königen“). ${ }^{82}$ Diese erschienen mir damals als besonders unglückliche Menschen - und dies schon früher, noch mehr jedoch, als ich die Armut und die Freiheit dort, in der Hütte, erlebte und sah, dass sie nicht einmal im Genuss von Speise und Trank schlechter gestellt waren, sondern den reichen Leuten selbst hierin fast noch etwas voraushatten. ${ }^{83}$

\section{Das junge Paar}

[67] Als wir schon hinreichend gesättigt waren, kam auch der Schwager, der andere der beiden Jäger zu uns, in Begleitung seines Sohnes, eines ansehnlichen jungen Mannes, der einen Hasen mitbrachte. Beim Eintreten wurde er rot und gab, während sein Vater uns freundlich begrüßte, der jungen Frau einen Kuss; ihr überreichte er den Hasen. ${ }^{84}$ Das Mädchen hörte nun auf, uns zu bedienen, und setzte sich zu ihrer Mutter. An seiner Stelle übernahm der junge Mann die Bedienung. ${ }^{85}$ [68] Und ich fragte meinen Gastgeber: „Ist sie es, der du das Gewand weggenommen hast, um es dem Schiffbrüchigen zu geben?“ Er entgegnete lachend: „Aber nein! Jene Tochter wurde schon vor langer Zeit mit einem Mann verheiratet und hat schon große Kinder - mit einem reichen Mann in einem Dorf." Ich bemerk- 


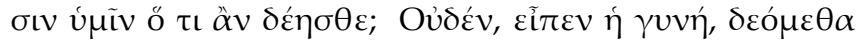

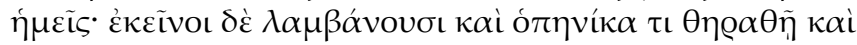

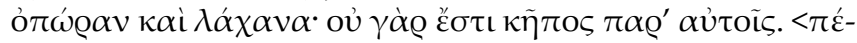

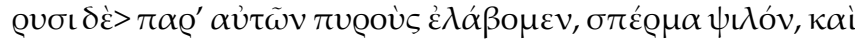

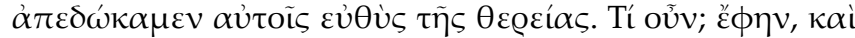

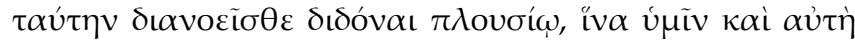

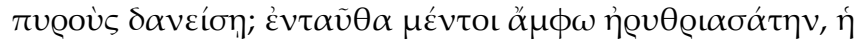

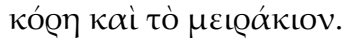

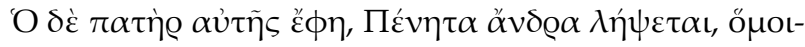

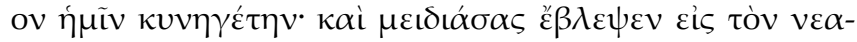

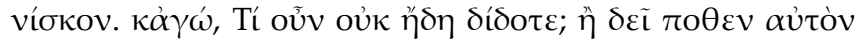

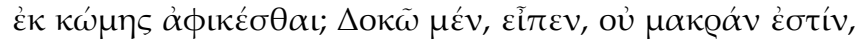

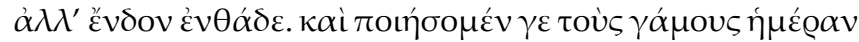

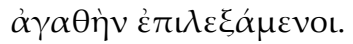

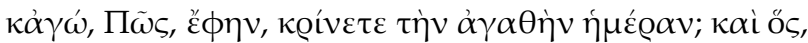

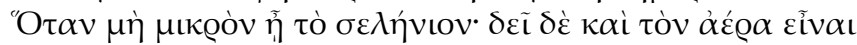

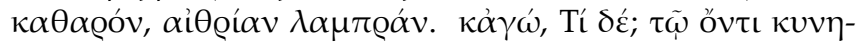

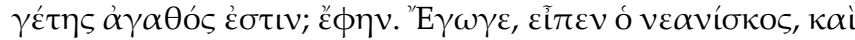

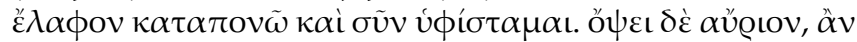

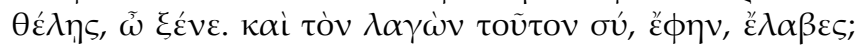

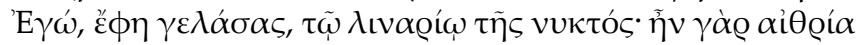

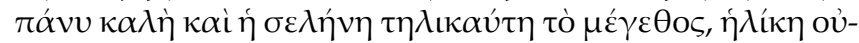

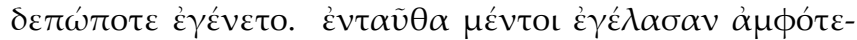

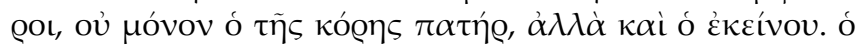

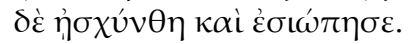

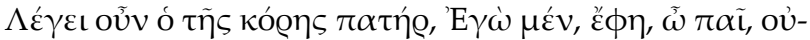

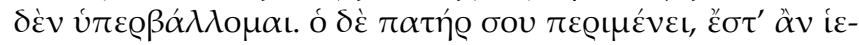

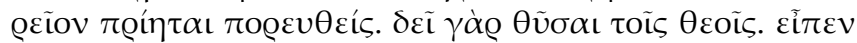

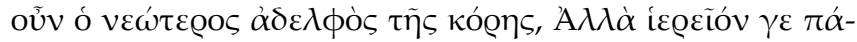

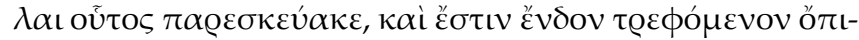

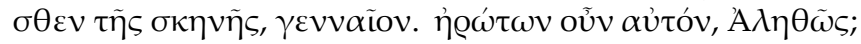

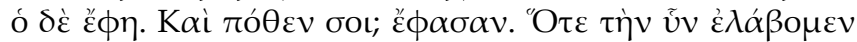

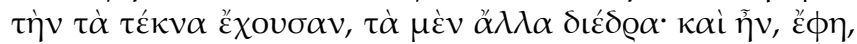

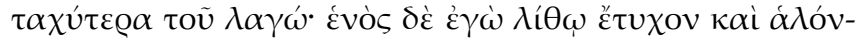

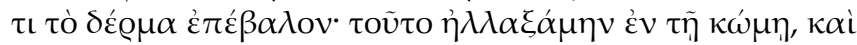

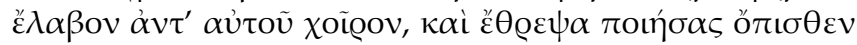

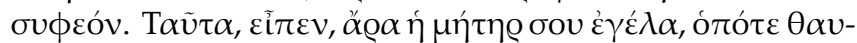

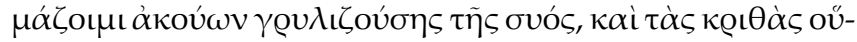


te dazu: „Diese helfen euch also mit allem aus, was immer ihr braucht?" [69] „Keineswegs“, antwortete mir die Frau, „,wir bitten sie unsererseits um nichts! Sie bekommen vielmehr von uns einen Anteil an der Jagdbeute sowie Obst und Gemüse, denn sie haben keinen Hausgarten zur Verfügung. Im vergangenen Jahr aber haben wir von ihnen Weizen erhalten, nur zur Aussaat, und ihnen das Saatgut sofort nach der Ernte zurückgegeben. ${ }^{\text {"86 }}$ Ich fragte sodann: „Was nun? Wollt ihr auch diese Tochter einem reichen Mann zur Frau geben, damit sie euch ebenfalls Weizen ausborgt?“ Da erröteten sie beide zugleich, das Mädchen und der junge Mann. ${ }^{87}$

[70] Ihr Vater aber sagte: „Sie wird einen armen Mann heiraten, einen Jäger wie wir.“ Und mit einem Lächeln schaute er nach dem Jüngling. „Warum gebt ihr sie dann nicht schon in die Ehe?", fragte ich. „Oder muss er erst aus irgendeinem Dorf hier eintreffen?" „Ich denke“, sagte der Vater, „er ist gar nicht weit weg, sondern hier im Raum. Und wir werden die Hochzeit auch feiern, wenn wir einen guten Tag dafür ausgewählt haben."

\section{Der Hochzeitstermin}

Dazu fragte ich: „Wonach bestimmt ihr denn diesen guten Tag?“ Er antwortete: „Wenn das Möndchen nicht mehr klein ist. Auch muss die Luft klar und der Himmel heiter sein. "88 [71] Ich fragte weiter: „Und wie steht es? Ist er wirklich ein guter Jäger?“ "Ich kann jedenfalls", antwortete mir der Jüngling, „den Hirsch in der Verfolgung erschöpfen und das Wildschwein im Kampf abfangen. Das kannst du dir morgen anschauen, wenn du willst, lieber Gastfreund.“ Ich fragte ihn: „Diesen Hasen da, hast du den selbst gefangen?" "Jawohl“, sagte er und lachte, "mit dem Netzchen während der Nacht! Denn der Himmel war ganz klar, und der Mond so mächtig groß, wie er noch nie zuvor gewesen ist." [72] Da lachten sie aber beide, nicht nur der Vater des Mädchens, sondern auch der des Jünglings. Dieser jedoch schämte sich und verstummte. ${ }^{89}$

Nun aber ergreift der Vater des Mädchens das Wort: „Ich bin es nicht, mein Junge“", so sagte er, „, der die Hochzeit hinauszögert. ${ }^{90}$ Dein Vater wartet noch ab, bis er sich aufmacht, um ein Opfertier zu erwerben. Denn man muss doch den Göttern ein Opfer darbringen." Da sagte der jüngere Bruder des Mädchens: „Aber der da hat doch längst für ein Opfertier gesorgt. Es befindet sich in einem Verschlag hinten an der Hütte - ein Prachtexemplar!“ [73] Ich fragte den jungen Mann: „Stimmt das?“ Er bejahte. „Und woher hast du das Tier?", fragten die beiden Väter. „Als wir die Wildsau mit den Frischlingen zu fassen bekamen, da rannten die übrigen weg - sie waren eben schneller als der Hase! Einen aber traf ich mit einem Stein und warf ihm, als ich ihn gefangen hatte, mein Lederzeug über. Dieses Tier tauschte ich im Dorf gegen ein Ferkel ein. ${ }^{91}$ Das habe ich hier gefüttert, nachdem ich zuvor von hinten her einen Schweinekoben angelegt hatte." 


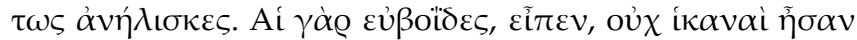

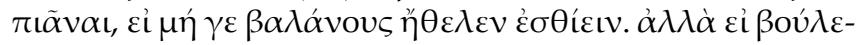

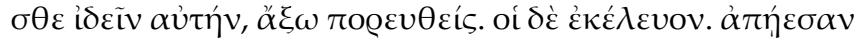

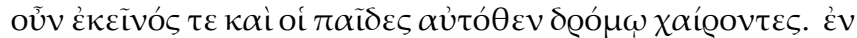

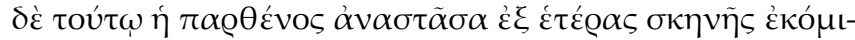

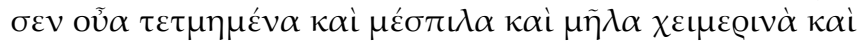

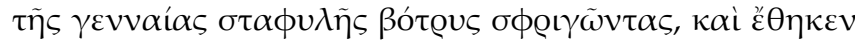

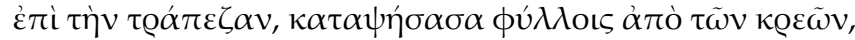

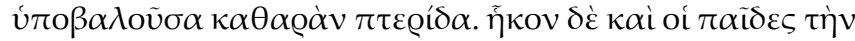

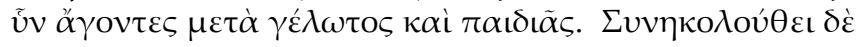

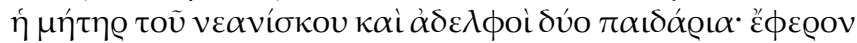

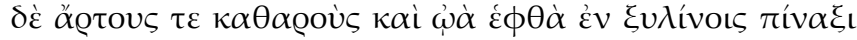

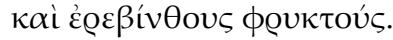

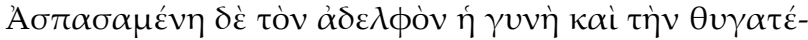

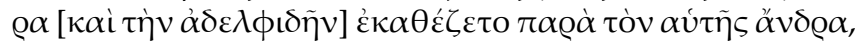

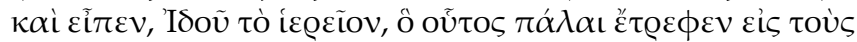

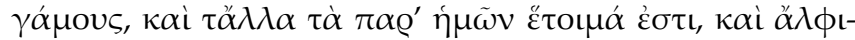

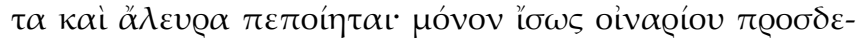

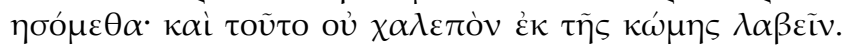

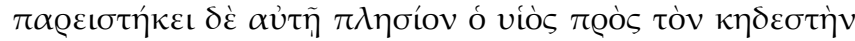

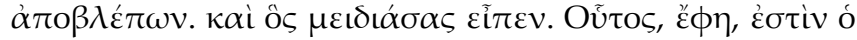

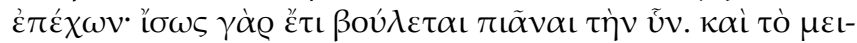

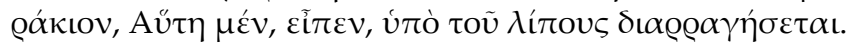

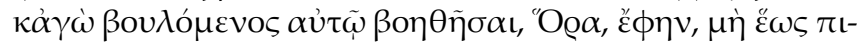

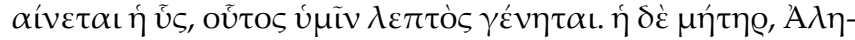

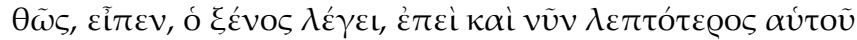

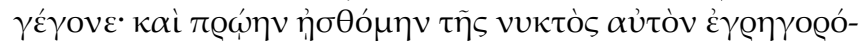

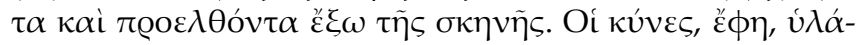

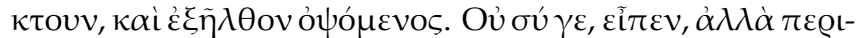

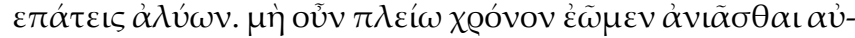

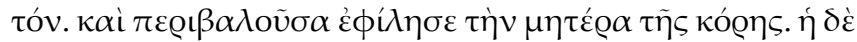

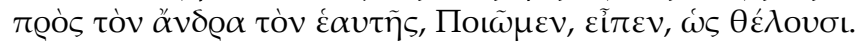

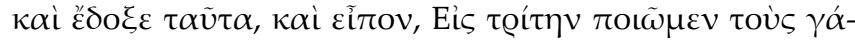

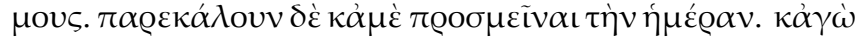

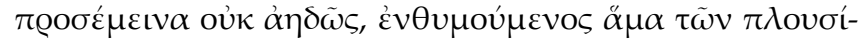

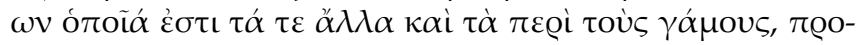

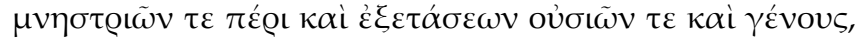

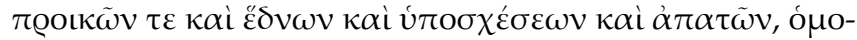


[74] „Darüber also lachte deine Mutter immerfort", bemerkte der Vater, „wenn ich mich darüber wunderte, ein Schwein grunzen zu hören! Und auf diese Weise hast du unsere Gerste aufgebraucht. " 92 Der Jüngling aber erklärte: „Die Esskastanien reichten eben nicht aus, um die Sau zu mästen, da sie doch keine Eicheln fressen mochte. Aber wenn ihr die Sau sehen wollt, gehe ich und hole sie herein!“ Man gestattete es ihm, worauf er und die Kinder mit fröhlichem Lärm im Laufschritt davon eilten. [75] Währendessen hatte sich die Jungfrau aufgemacht und aus der anderen Hütte aufgeschnittene Früchte des Speierlingbaumes, Mispeln, Winteräpfel und pralle Trauben von der guten Weinsorte herbeigebracht. ${ }^{93}$ Sie legte dies alles auf den Tisch, den sie zuvor mit Blättern von den Resten der Fleischmahlzeit gereinigt und mit sauberem Farn gedeckt hatte. Da kamen auch schon die Kinder zurück und trieben die Sau mit viel Spaß und Gelächter vor sich her. [76] Mit ihnen kam die Mutter des jungen Mannes herein und dazu zwei seiner Brüder, die noch im Kindesalter waren; sie brachten helles, sauberes Brot, gekochte Eier in hölzernen Schüsseln und geröstete Erbsen mit.

Die Frau begrüßte ihren Bruder und dessen Tochter und setzte sich dann neben ihren Mann und sprach: „Sieh mal an - da ist ja das Opfertier, das er schon lange gemästet hat für die Hochzeitsfeier. Und auch alles andere ist bei uns vorhanden: Opfergerste und Weizenmehl sind vorbereitet. ${ }^{94}$ Vielleicht wird es uns noch ein wenig am Weinchen fehlen, aber das lässt sich leicht aus dem Dorfe beschaffen. "95 [77] Ihr Sohn war neben sie getreten und schaute seinen (künftigen) Schwiegervater an. Dieser lächelte und sagte: „Der ist es doch, der die Sache aufhält. Denn er will wohl das Schwein noch fetter machen!“ Der junge Bursche entgegnete: „Aber es platzt doch schon bald vor Fett und Speck auseinander!“ [78] Ich wollte ihm zu Hilfe kommen und sagte: „Passt nur auf, dass euch, während die Sau immer fetter wird, dieser Jüngling hier ganz abmagert!“ Und seine Mutter meinte: „Unser Gastfreund hat völlig recht, denn er ist schon jetzt magerer geworden als er sein sollte. Kürzlich merkte ich, daß er in der Nacht aufgewacht war und sich aus der Hütte hinausschlich." „Die Hunde bellten“, versuchte er zu erklären, „und ich ging nur hinaus, um nach ihnen zu sehen." [79] „Das stimmt nicht", sagte sie, „du liefst vielmehr ganz unruhig draußen herum. Wir sollten ihn jetzt nicht noch länger quälen!“ Und sie umarmte und küsste die Mutter des Mädchens; diese aber wandte sich an ihren Mann: „,Dann wollen wir so handeln, wie sie es wünschen!“96 Dies fand Zustimmung, und man legte fest: „Am übernächsten Tag wird Hochzeit gefeiert!“ Mich aber bat man, bis dahin bei ihnen zu bleiben. [80] Ich nahm dies gerne an und bedachte, wie es bei den reichen Leuten und gerade bei Hochzeiten zugeht - mit Heiratsvermittlerinnen und mit Nachforschungen über Vermögen und Abstammung, mit Brautgeschenken und 


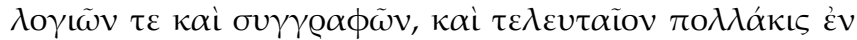

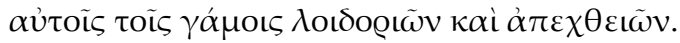

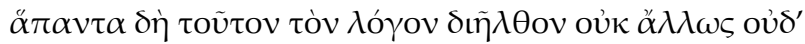

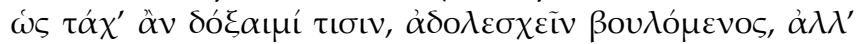

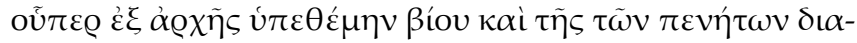

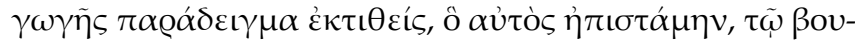

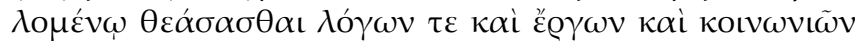

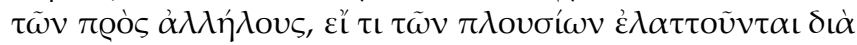

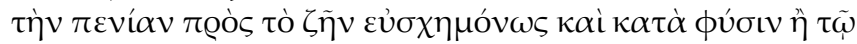

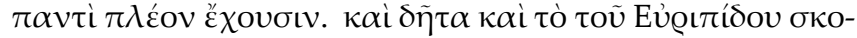

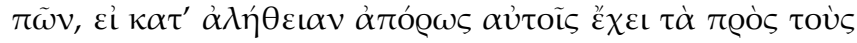

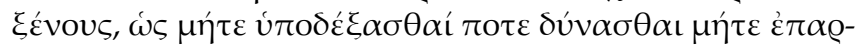

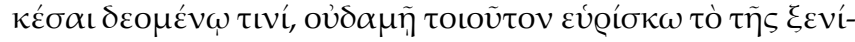

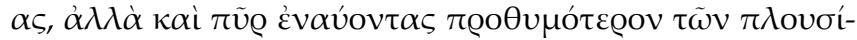

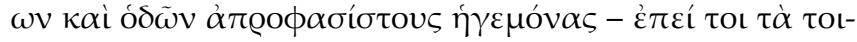

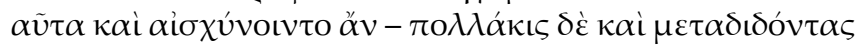

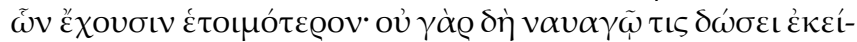

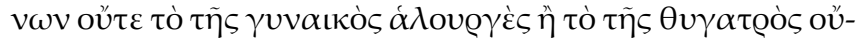

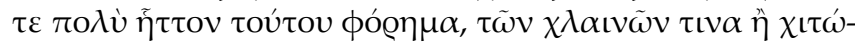

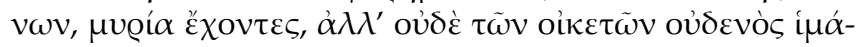
tıov.

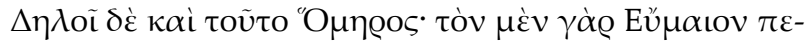

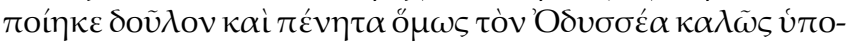

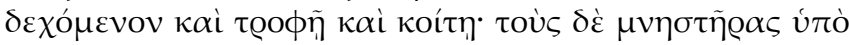

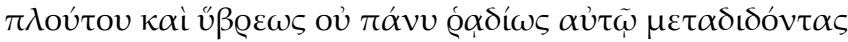

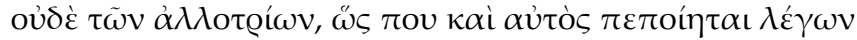

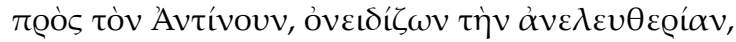

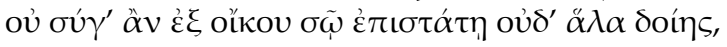

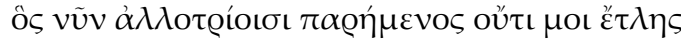

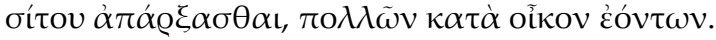

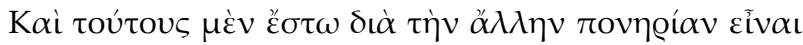

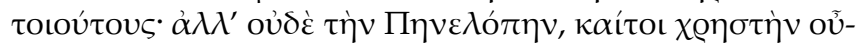

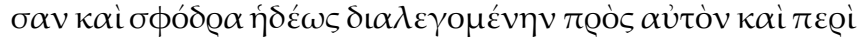


Mitgiftbeträgen, mit Versprechungen und Täuschungen, mit Vereinbarungen und Schriftsätzen und am Ende, oftmals noch während der Hochzeitsfeier, mit Beschimpfungen und offenem Zank und Streit. ${ }^{97}$

\section{Dions Kommentar zur Jäger-Episode (\$§ 81-102)}

[81] Diese ganze Geschichte habe ich bis zum Ende erzählt, nicht um zu plaudern, wie es einigen vielleicht erscheinen könnte, sondern aus keinem anderen Grunde, als um, entsprechend dem am Anfang festgelegten Thema, ${ }^{98}$ ein Beispiel für die Lebensführung und die Verhaltensweisen unter den Armen vor Augen zu führen, das ich persönlich erlebt habe. Wer will, kann sich hier anhand von ihren Worten und Taten sowie dem Umgang miteinander ein Bild davon machen, ob sie wegen ihrer Armut gegenüber den Reichen irgendwo benachteiligt sind - im Hinblick auf ein würdiges und der Natur gemäßes Leben - oder ob sie, aufs Ganze gesehen, sogar besser abschneiden. [82] Wenn ich kritisch Euripides' Wort überdenke, ob den Armen denn wirklich keine Möglichkeit gegenüber Fremden gegeben ist, sie gastlich aufzunehmen oder einem Bittenden ausreichende Hilfe zu leisten, so kann ich dafür keine Bestätigung finden. ${ }^{99}$ Vielmehr sind Arme weitaus eher als reiche Leute bereit, Feuer vom Herd abzugeben, und sie machen auch keine Ausflüchte, um sich als Wegbegleiter zur Verfügung zu stellen, da sie sich für ein solches Fehlverhalten gewiss schämen würden. ${ }^{100}$ Oft geben sie auch bereitwilliger als reiche Leute von ihrer Habe etwas $a b$ - denn von diesen gibt sicherlich niemand einem Schiffbrüchigen das Purpurgewand seiner Gattin oder Tochter ab und gewiss auch kein Gewandstück von weitaus geringerem Wert, eines der zahllosen Ober- und Untergewänder in seinem Besitz, nicht einmal den Mantel eines seiner Haussklaven.

\section{Homer und die Heimkehr des Odysseus}

[83] Auch dies macht Homer deutlich, lässt er doch Eumaios, obwohl er als Unfreier in Armut lebt, den Odysseus auf anständige Weise, mit Nahrung und Unterkunft, aufnehmen, ${ }^{101}$ während die Freier diesem in ihrem Reichtum und Übermut nur zögerlich etwas abgeben - und das von fremden Hab und Gut! So erhebt bei Homer Odysseus auch persönlich gegen Antinoos den Vorwurf schäbiger Knauserei:,,Du würdest ja dem, der als Bittsteller an Dich herantritt, aus Deinem Hausbesitz nicht einmal ein Salzkorn geben, / Du, der Du hier, an fremder Tafel sitzend, es nicht über das Herz bringst, / mir von den Speisen etwas abzugeben, wo doch so viel davon im Hause ist. “102

[84] Soll es nun mit den Freiern - angesichts ihrer auch sonst gezeigten Schlechtigkeit - so bestellt gewesen sein! Aber nicht einmal Penelope, die doch einen anständigen Charakter besitzt, sich überaus freundlich an 


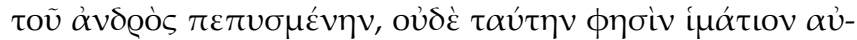

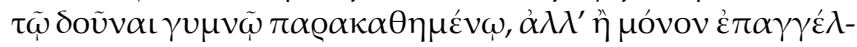

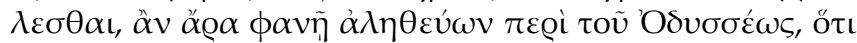

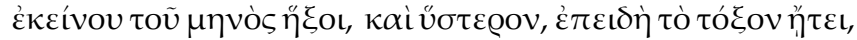

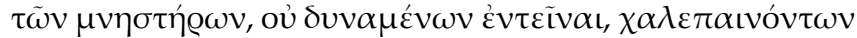

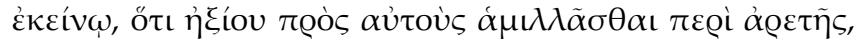

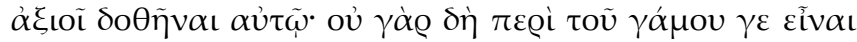

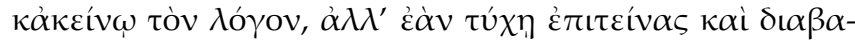

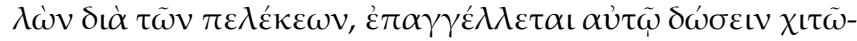

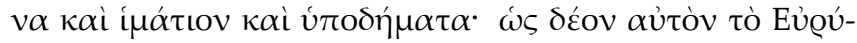

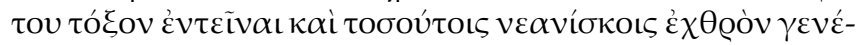

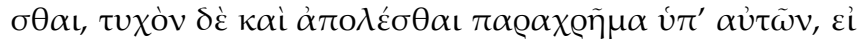

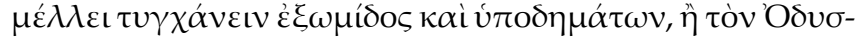

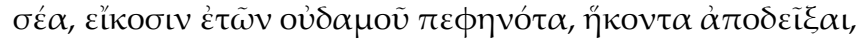

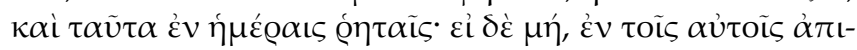

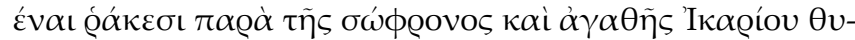

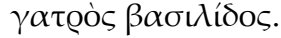

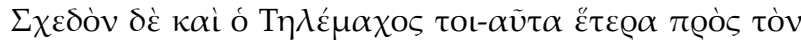

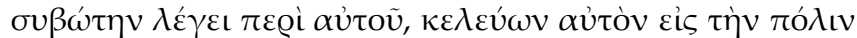

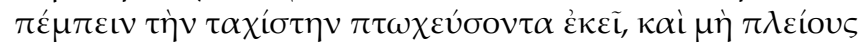

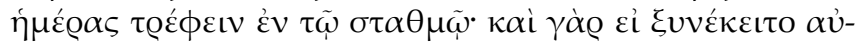

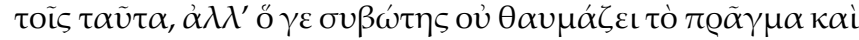

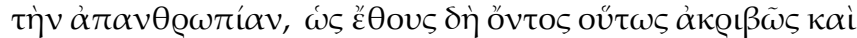

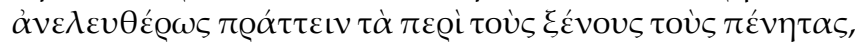

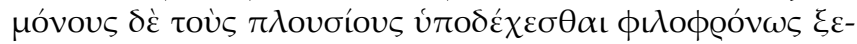

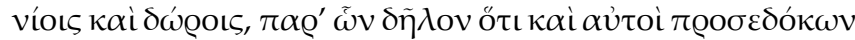

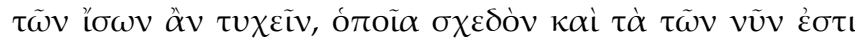

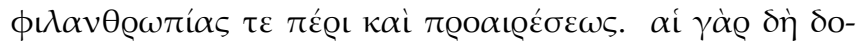

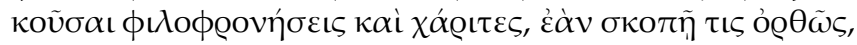

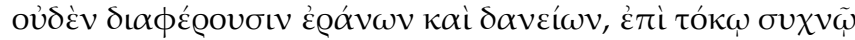

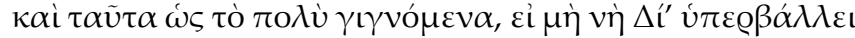

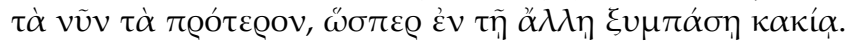

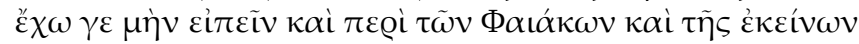

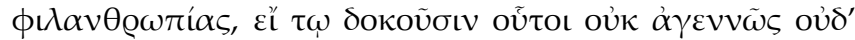

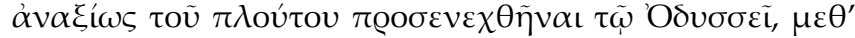

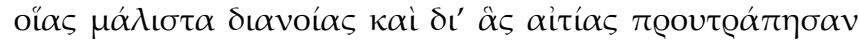

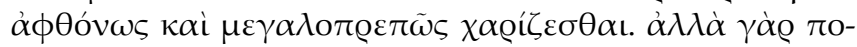

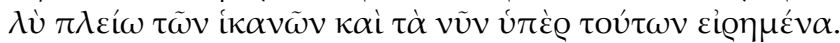


Odysseus wendet und ihn nach ihrem Gatten befragt, lässt der Dichter einen Mantel an den Mann herausgeben, der, dürftig bekleidet, in Lumpen neben ihr sitzt. Vielmehr stellt sie ihm bei Homer ein solches Geschenk lediglich in Aussicht, falls sich seine Nachricht bewahrheiten sollte, dass Odysseus noch im gleichen Monat heimkehren werde. ${ }^{103}$ [85] Und später, als Odysseus um den Bogen bat, den die Freier nicht zu spannen vermochten, und diese über ihn entrüstet waren, weil er mit ihnen in einen Wettstreit um den Preis der Tüchtigkeit eintreten wollte, da verlangt sie, dass man ihm den Bogen übergebe: Denn das Heiratsversprechen gelte natürlich nicht für jenen Mann da! Falls es ihm aber gelingen sollte, den Bogen zu spannen und mit ihm durch die Beile hindurch zu schießen, verspricht sie ihm als Belohnung ein Untergewand, einen Mantel sowie Schuhe. ${ }^{104}$ [86] Da musste er also zuerst den Bogen des Eurytos spannen und sich so viele junge Männer zu Feinden machen, vielleicht sogar von ihrer Hand umgehend den Tod erleiden - nur um der Aussicht auf einen neuen Kittel und Schuhwerk willen! Oder er hatte die Heimkehr des Odysseus, den man seit 20 Jahren nirgends hatte sehen können, in der fraglichen Frist eindeutig nachzuweisen - andernfalls hätte er sich in genau den selben Lumpen aus dem Haus der so klugen und anständigen, königlichen Tochter des Ikarios wieder davonmachen müssen. ${ }^{105}$

[87] In ähnlicher Weise äußert sich auch Telemachos über ihn - im Gespräch mit dem Sauhirten, als er diesem befiehlt, den Odysseus so schnell wie möglich in die Stadt fortzuschicken, damit er dort betteln gehe, und ihn nicht über mehrere Tage hin auf dem Viehhof zu beköstigen. Denn selbst wenn dies zwischen Odysseus und Telemachos verabredet worden war, so zeigt sich der Sauhirt doch gar nicht überrascht von dieser Anweisung und ihrer Unmenschlichkeit. ${ }^{106}$ [88] (Er hört zu), als ob es üblich gewesen sei, dermaßen knauserig und schäbig mit armen Leuten aus der Fremde umzugehen und allein die Reichen großzügig und mit Gastgeschenken aufzunehmen, von denen man natürlich eine gleichwertige Gegenleistung erwarten konnte, was genau mit unserer heutigen Einstellung gegenüber Menschenliebe und einer entsprechenden Gesinnung übereinstimmt! [89] Denn auch das, was als Freundschaftsdienst und Gefälligkeit ausgegeben wird, unterscheidet sich, wenn man genau hinsieht, in keiner Weise von Darlehens- und Versicherungsgeschäften (auf Gegenseitigkeit) - und das in der Regel auch noch zu hohen Zinsen! ${ }^{107}$ Es sei denn, beim Zeus, dass die Gegenwart hier, wie bei allen sonstigen Übeln, die Vergangenheit noch übertrifft! [90] Auch könnte ich noch etwas über die Phäaken und ihre angebliche Menschenliebe sagen - falls jemand der Meinung sein sollte, ihr Verhalten gegenüber Odysseus sei höchst anständig und ihrem Wohlstand angemessen gewesen - und zwar darüber, mit welcher Gesinnung und aus welchen Motiven sie sich dazu bewegen ließen, ihn 


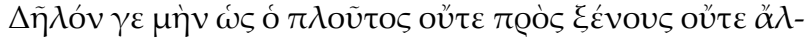

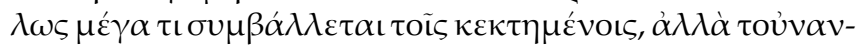

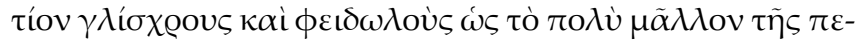

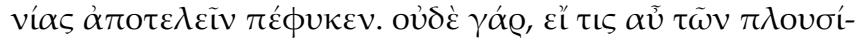

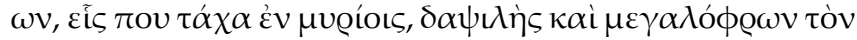

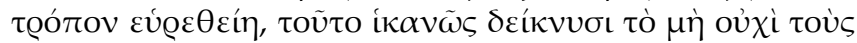

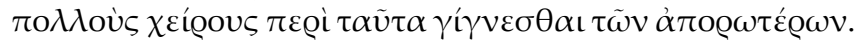

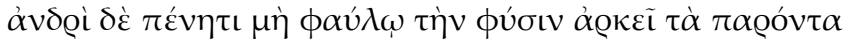

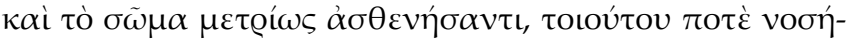

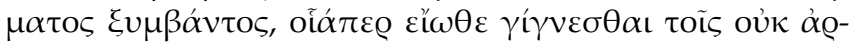

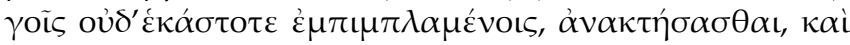

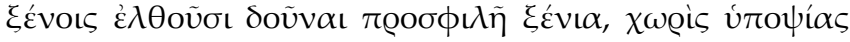

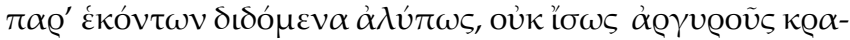

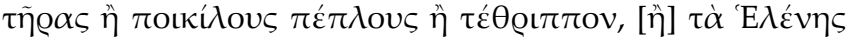

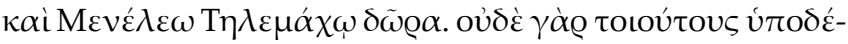

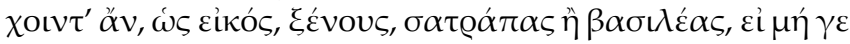

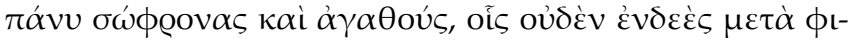

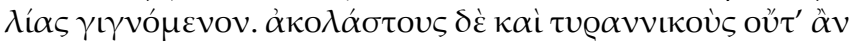

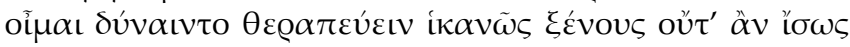

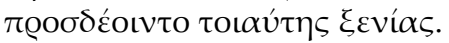

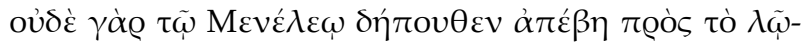

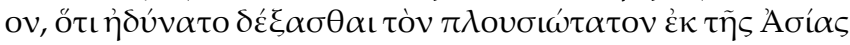

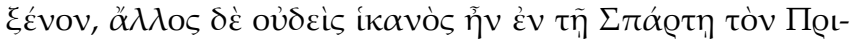

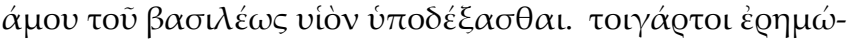

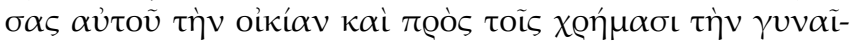

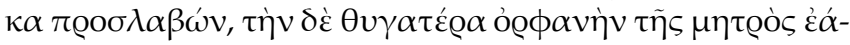

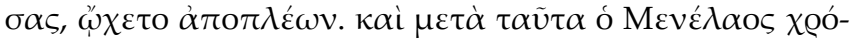

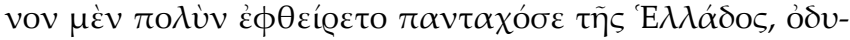

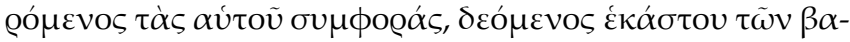

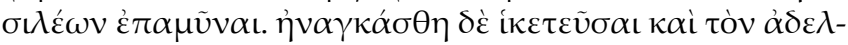

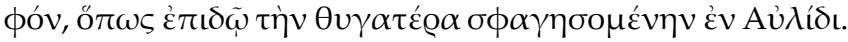

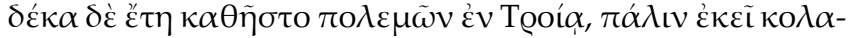

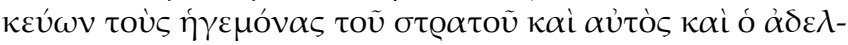


mit großem Aufwand zu unterstützen. ${ }^{108}$ Aber was ich zu diesem Thema gesagt habe, ist schon längst mehr als ausreichend.

\section{Gastfreundschaft und Menschenwürde bei Arm und Reich}

[91] Deutlich ist jedenfalls, dass der Reichtum seinen Besitzern weder im Hinblick auf Gastfreundschaft gegenüber Fremden, noch in anderen Dingen zum Vorteil gereicht, sondern im Gegenteil sie, weitaus eher als die Armut, zu kleinlichen und knauserigen Menschen macht. ${ }^{109}$ Denn selbst wenn man irgendwo einen Reichen, einen einzigen unter zehntausend, als großzügig und hochherzig in seinem Charakter finden sollte, so zeigt dies hinreichend, dass die große Mehrheit in dieser Hinsicht sich als schlechter erweist als die ärmere Bevölkerung. [92] Einem armen Mann, sofern er nicht von schwacher Konstitution ist, reichen seine bescheidenen Mittel aus, um sich auch von einer leichteren Krankheit - wie sie Leuten zustößt, die nicht untätig sind und sich nicht bei jeder Mahlzeit den Bauch vollschlagen - wieder zu erholen und dabei doch Freunden, die von auswärts gekommen sind, liebe Gastgeschenke zu machen, ohne Verdacht zu erregen, ganz aus freien Stücken und mit guter Laune im Gefolge. ${ }^{110}$ [93] Allerdings handelt es sich hier wohl nicht gerade um silberne Mischkrüge, buntgewirkte Prachtgewänder oder gar ein Viergespann, womit Helena und Menelaos den Telemachos beschenkten! ${ }^{111}$ Die armen Leute dürften auch kaum Besuch von so hochrangigen Gästen erhalten - nämlich von Statthaltern oder Herrschern - wenn es sich bei diesen nicht um außerordentlich weise und gutherzige Menschen handelt, denen nichts dürftig erscheint, wenn es mit Liebe bereitet wird. Zügellose und tyrannisch gesinnte Besucher ${ }^{112}$ könnten sie allerdings, so meine ich, nicht zufriedenstellen; sie hätten wohl auch kein Bedürfnis nach solchen gastfreundschaftlichen Beziehungen.

\section{Menelaos von Sparta und Dions Kritik an den Tragödiendichtern}

[94] Denn auch dem Menelaos ist es wahrlich nicht zum Vorteil ausgeschlagen, dass er den reichsten Gast aus Asien zu empfangen vermochte und kein anderer in Sparta imstande war, den Sohn des Königs Priamos bei sich aufzunehmen. [95] Denn dieser Gast räumte ihm sein Haus aus, und nahm außer den Schätzen auch noch die Gattin mit und fuhr davon, während die Tochter, ohne Mutter, als Waise zurückblieb. ${ }^{113}$ Danach war Menelaos über lange Zeit auf Reisen unterwegs, um überall in Hellas sein Unglück zu beklagen und jeden König einzeln um Hilfe zu bitten. Er musste sogar notgedrungen seinen Bruder anflehen, die Opferung der eigenen Tochter in Aulis zu akzeptieren und mit anzusehen. ${ }^{114}$ [96] Zehn Jahre lang saß er dann im Krieg vor Troia fest und hatte dort erneut die Anführer des Heeres zu umschmeicheln, er selbst und sein Bruder. Geschah dies nicht, wurden sie zornig und drohten jedesmal mit der Abfahrt. ${ }^{115}$ Viele Mühen 


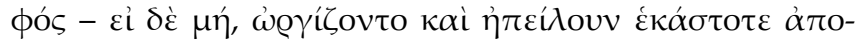

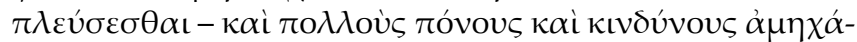

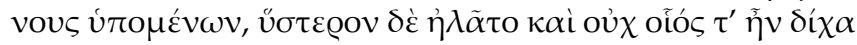

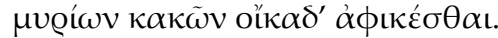

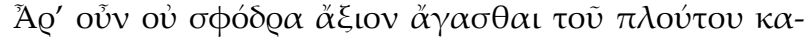

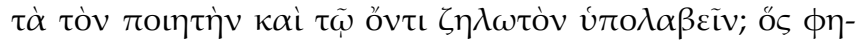

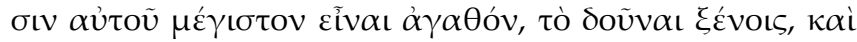

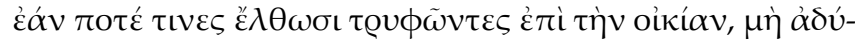

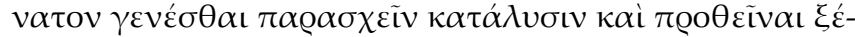

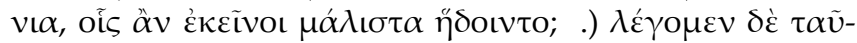

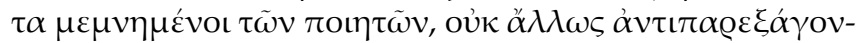

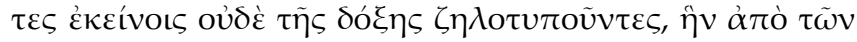

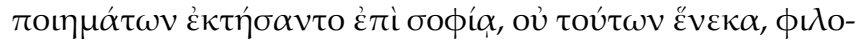

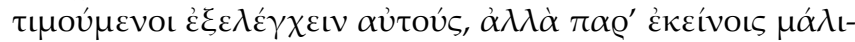

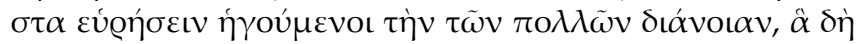

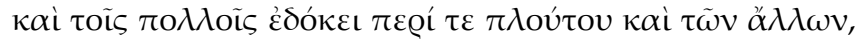

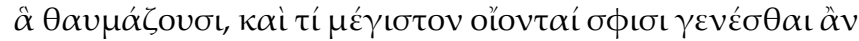

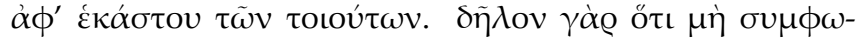

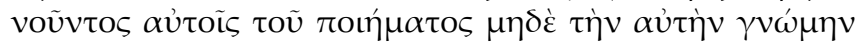

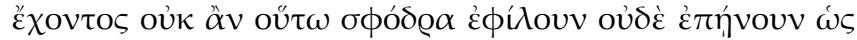

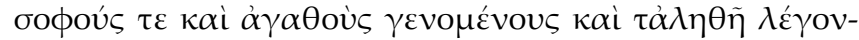

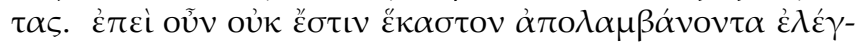

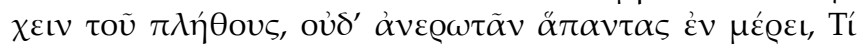

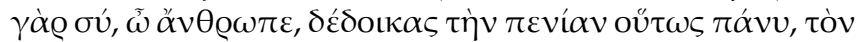

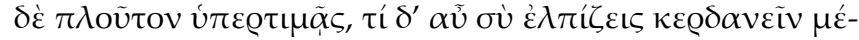

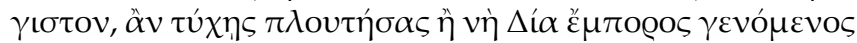

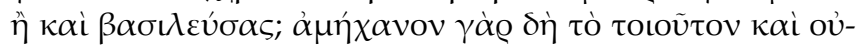

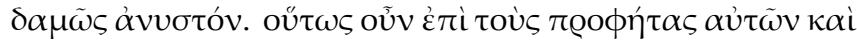

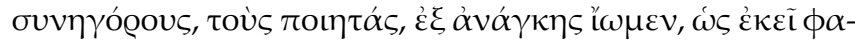

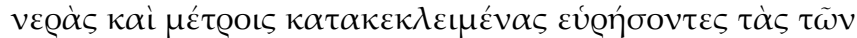

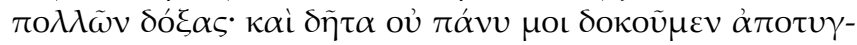

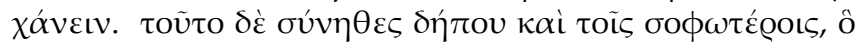

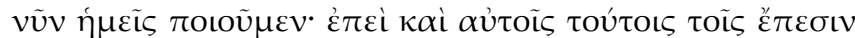

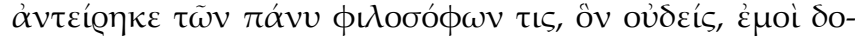

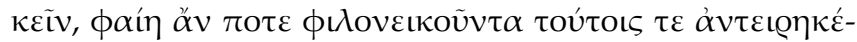

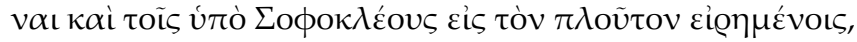

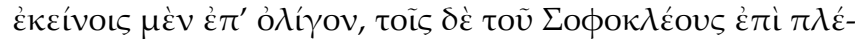
ov, oủ $\mu \eta \dot{v} v$,

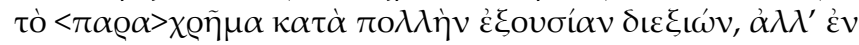
i $\alpha \mu \beta \varepsilon$ ćoıs $\gamma \varrho \alpha ́ \phi \omega v$. 
und große Gefahren hatte er zu bestehen und geriet danach noch auf Irrfahrten; erst nach unzähligen Rückschlägen gelang es ihm, in die Heimat zurückzukehren. ${ }^{116}$

[97] Ist es also angemessen, dem Dichter zu folgen und den Reichtum über die Maßen zu bewundern? Sollte man wirklich danach streben, ihn zu gewinnen? Behauptet der Dichter doch, der größte Vorteil des Reichtums bestehe darin, Gastfreunde zu bedenken und auch äußerst wohlhabenden Besuchern, wenn sie ins Haus kommen, Unterkunft geben zu können, ferner ihnen Gastgeschenke darzureichen, an denen sie wirklich größte Freude haben. ${ }^{117}$ [98] Ich äußere diese Kritik an den Dichtern freilich nicht aufs Geratewohl, um gegen sie zu Felde zu ziehen - etwa aus Eifersucht wegen ihres Ansehens, das sie sich mit ihren Werken, aufgrund ihrer Kunst, erworben haben. Nicht deshalb, nicht aus dem ehrgeizigen Bestreben, sie zu widerlegen, tue ich dies, sondern weil ich der Meinung bin, dass man bei ihnen am ehesten die Denkweise der großen Mehrheit antreffen kann - das, was die breite Masse über den Reichtum und andere Gegenstände der Bewunderung denkt und was man für sich selbst als größten Gewinn von jedem dieser Glücksgüter erwartet. [99] Denn es ist ja klar, dass man die Dichter, wenn ihr Werk sich nicht in Übereinstimmung mit der Volksmasse befände und nicht die gleichen Auffassungen verträte, keineswegs so leidenschaftlich liebte und ihnen Beifall spendete als Männern, die zu Weisheit und Güte gelangt seien und die schlechthin die Wahrheit sagten. ${ }^{118}$ [100] Nun ist es freilich nicht möglich, jeden Einzelnen aus der Menge beiseite zu nehmen und ihm seinen Irrtum nachzuweisen oder an einen jeden der Reihe nach die Frage zu stellen: „Warum, lieber Mann, fürchtest Du so sehr die Armut, und warum schätzt Du den Reichtum so übermäßig? Welchen großen Gewinn erhoffst Du Dir davon, zu Reichtum zu gelangen, indem Du es, beim Zeus, zu einem Kaufmann oder gar zu einem König gebracht hast?“ Ein solches Vorgehen ist nämlich höchst schwierig und praktisch undurchführbar. [101] Daher wollen wir also, notgedrungen, an die Propheten und Anwälte der Volksmenge herantreten, nämlich die Dichter. Denn bei ihnen können wir ganz deutlich und in das Versmaß eingeschlossen die Überzeugungen der großen Mehrheit finden. Jedenfalls gehen wir dabei, wie ich glaube, nicht sehr in die Irre. [102] Dieser Weg, den wir jetzt einschlagen, ist nämlich schon von größeren Gelehrten regelmäßig beschritten worden. Denn den eben genannten Versen hat ein ganz bedeutender Philosoph widersprochen, dem niemand, so meine ich, jemals unterstellen wird, dass er aus Streitsucht gegen sie Widerspruch erhoben habe, so wie er sich auch gegen die Worte des Sophokles bezüglich des Reichtums wendet - und zwar gegen die Stelle bei Euripides nur kurz, 


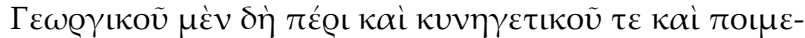

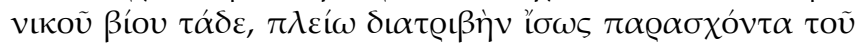

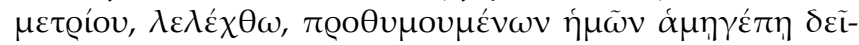

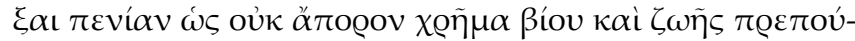

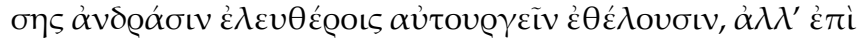

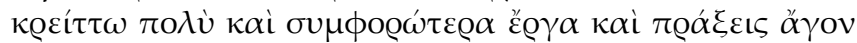

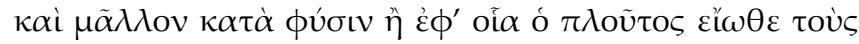

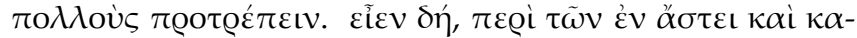

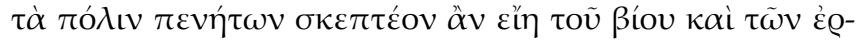

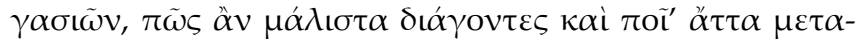

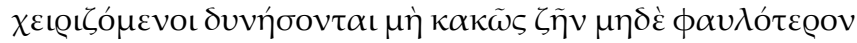

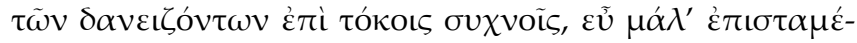

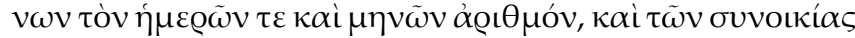

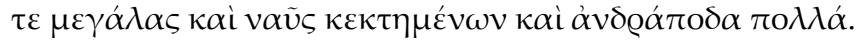

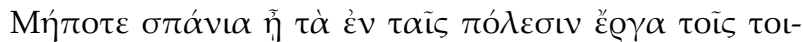

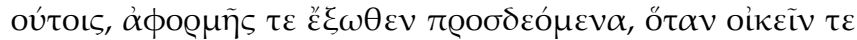

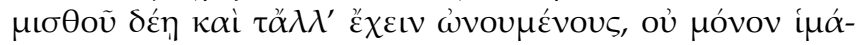

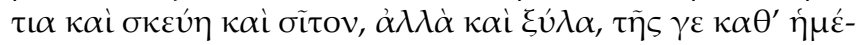

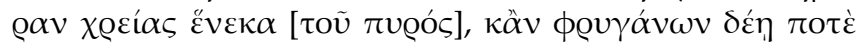

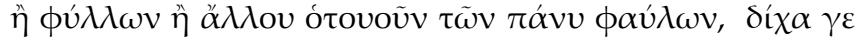

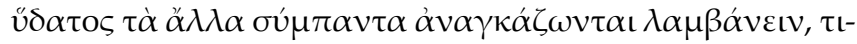

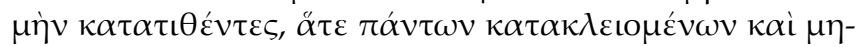

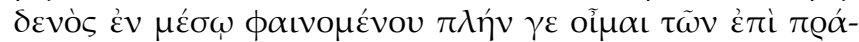

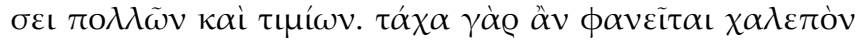

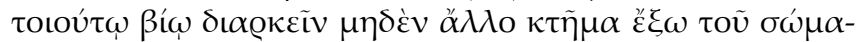

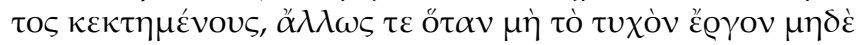

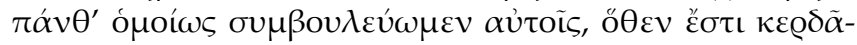

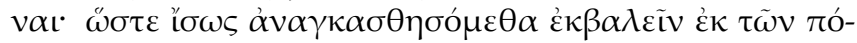

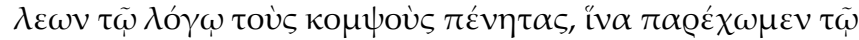

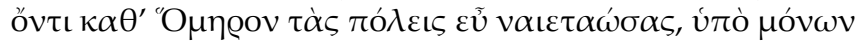

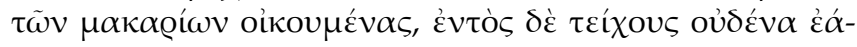

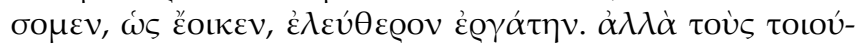

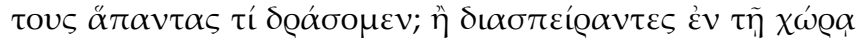

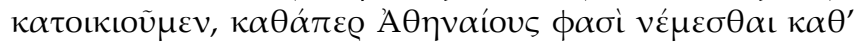


gegen Sophokles' Verse etwas eingehender, ${ }^{119}$ wobei er sich aber nicht ausführlich, wie wir jetzt, geäußert hat, da er seine Kritik nicht in einer Rede aus dem Stegreif und mit großem Freiraum vorträgt, sondern in Bindung an das iambische Versmaß (?) niederschreibt. ${ }^{120}$

Überleitung zum thematischen Schwerpunkt: Armut und Arbeit in der Stadt [103] Über die Lebensweise eines Bauern, eines Jägers und Hirten soll dies genügen, wobei vielleicht schon viel zu viel Zeit auf dieses Thema verwendet wurde: Ich wollte irgendwie deutlich machen, dass Armut keineswegs ein unüberwindliches Hindernis für freie und arbeitswillige Männer ist, ein würdiges Leben zu führen, sondern sie zu weitaus wichtigeren, nützlicheren und naturgemäßeren Beschäftigungen hinführt als es der Reichtum bei den meisten Menschen bewirkt. [104] Damit aber soll es genug sein! ${ }^{121}$ Nun gilt es hinsichtlich der Lebensweise und der Arbeitsmöglichkeiten der Armen innerhalb des Stadtbereiches ihrer Polis zu schauen, ${ }^{122}$ auf welche Weise sie in ihrer Lebensführung und mit welchen Beschäftigungen am ehesten imstande sein werden, würdig zu leben - und zwar nicht schlechter als diejenigen, die Geld zu hohen Zinsen ausleihen und sich trefflich auf die Berechnung von (Zins-) Tagen und Monaten verstehen ${ }^{123}$ und als diejenigen, die große Mietshäuser sowie Schiffe und viele Sklaven ihr eigen nennen.

[105] Es könnte freilich sein, dass etwa für solche Armen Arbeitsmöglichkeiten in Städten nur spärlich vorhanden sind und der Unterstützung von außen her bedürfen ${ }^{124}$ - da sie (die Armen) zur Miete wohnen und auch alle sonstigen Dinge kaufen müssen, nicht allein Kleidung, Hausgeräte und Nahrung, sondern auch Holz für den täglichen Bedarf; wenn einmal Bedarf an Reisig und Laubstreu oder andere banale Kleinigkeiten besteht, [106] dann sie gezwungen, für sämtliche Güter - allein mit Ausnahme von Wasser ${ }^{125}$ - einen Kaufpreis zu zahlen, da ihnen alles verschlossen und nichts frei zugänglich ist - außer, wie ich glaube, den vielen, für teures Geld auf dem Markt angebotenen Waren. Und so zeigt sich auch, dass es schwer ist, unter solchen Lebensbedingungen durchzukommen, wenn man nichts anderes als seine Körperkraft besitzt - und zumal, wenn wir ihnen nicht jede beliebige Arbeit, die Erwerbsmöglichkeiten bietet, anraten und auch nicht jede Beschäftigung in gleicher Weise bewerten. ${ }^{126}$ [107] Werden wir also am Ende in unserer Argumentation sogar genötigt sein, die „lieben und guten Armen“ aus ihren Städten auszuweisen, damit wir wirklich, wie Homer es ausdrückt, zu „gut bewohnten Städten“ gelangen, in denen sich nur noch wohlhabende Leute aufhalten und in deren Mauerring wir, so scheint es, keinen freien Lohnarbeiter mehr dulden wollen? ${ }^{127}$ Aber was sollen wir dann mit all diesen Leuten anfangen? Sollen wir sie 


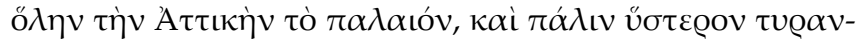

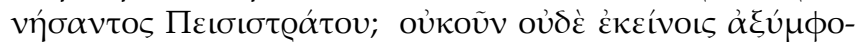

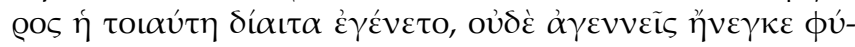

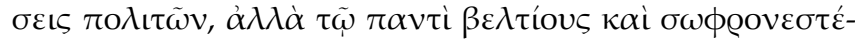

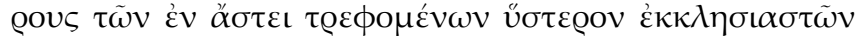

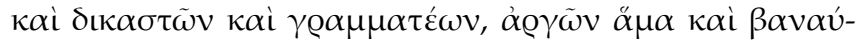

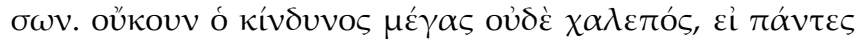

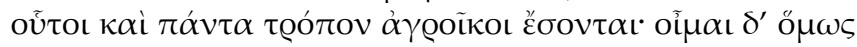

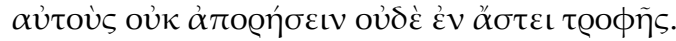

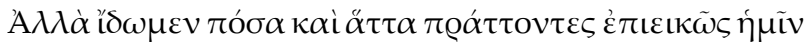

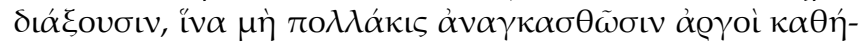

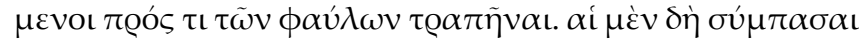

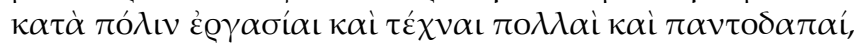

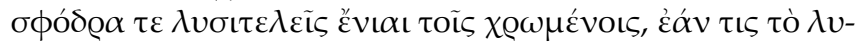

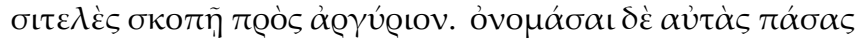

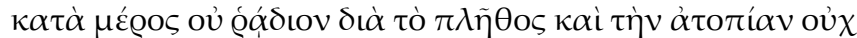

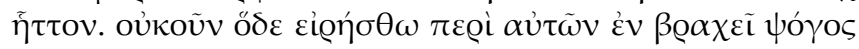

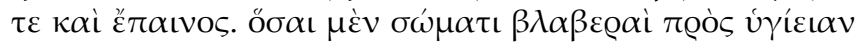

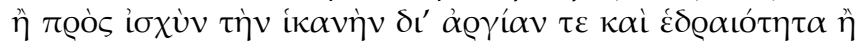

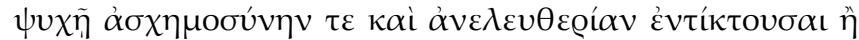

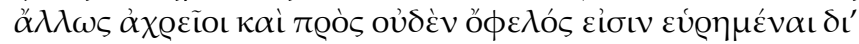

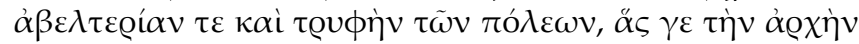

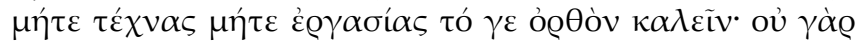

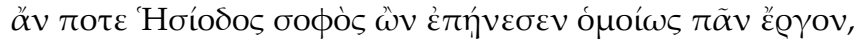

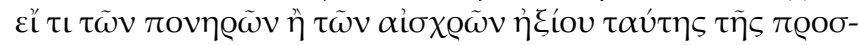

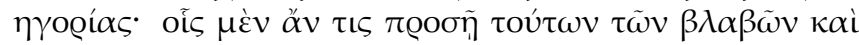

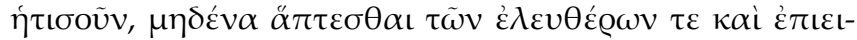

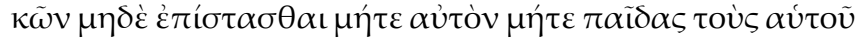

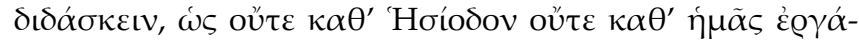

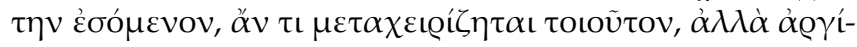

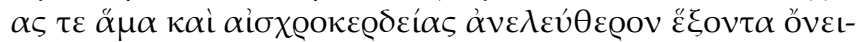

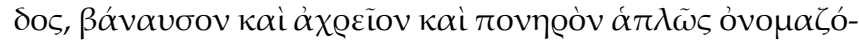

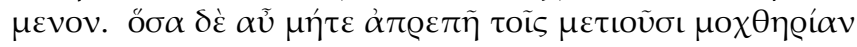

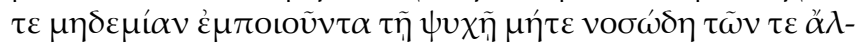

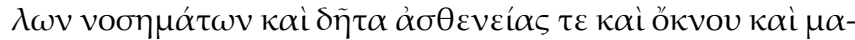

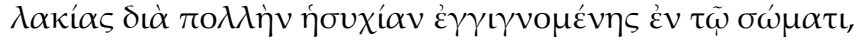


auf dem Lande, über das Territorium verstreut, ansiedeln, so wie die Athener in alter Zeit, wie man sagt, in ganz Attika auf dem Lande gelebt haben und später wieder unter der Tyrannis des Peisistratos? ${ }^{128}$ [108] Diese Lebensweise war für sie sicherlich vorteilhaft und hat der Natur und Mentalität der Bürger nicht geschadet, sondern sie in jeder Hinsicht zu besseren und bescheideneren Menschen gemacht als die, die sich später in der Stadt durchfüttern ließen, als Mitglieder der Volksversammlung, der Gerichte und als Schreiber im öffentlichen Dienst - ebenso arbeitsscheu wie ungebildet! ${ }^{129}$ Es wäre also gewiss weder besonders riskant noch schwierig durchzuführen, wenn diese Leute allesamt und in jeder Weise zu einer richtigen Landbevölkerung werden sollten. Ich bin jedoch der Meinung, dass es ihnen gleichwohl auch in der Stadt nicht an Nahrung und Unterhalt mangeln wird. ${ }^{130}$

\section{Menschenwürde und angemessene Beschäftigungsmöglichkeiten}

[109] Wir wollen aber sehen, wieviele und welche Tätigkeiten sie ausüben können und dabei, nach unserer Meinung, ein anständiges Leben führen werden, damit sie nicht oftmals genötigt sind, beschäftigungslos herumzusitzen und sich üblen Dingen zuzuwenden. ${ }^{131}$ Die Beschäftigungen und Handwerksbereiche sind insgesamt in der Stadt ebenso zahlreich wie vielgestaltig; einige sind auch für die, die sie ausüben, äußerst gewinnbringend, wenn man "gewinnbringend" nach dem Geldwert beurteilt. [110] Sie alle im einzelnen aufzuzählen ist angesichts der großen Zahl gar nicht leicht - nicht weniger auch deswegen, weil dies hier ganz unangemessen wäre. Dies aber soll über sie in aller Kürze als Kritik wie als Empfehlung gesagt sein: Mit allen Beschäftigungen, soweit sie für den Leib gesundheitsschädigend sind und seine (für den Alltag) hinlänglich große Körperkraft durch Bewegungsmangel und zu langes Sitzen beeinträchtigen oder die im Bereich der Seele die Würde und Freiheit des Menschen beschädigen oder in anderer Hinsicht ganz nutzlos sind, da sie nur dem törichten Luxusleben in den Städten entsprungen sind und die man folglich von vornherein weder als richtiges „Handwerk" noch als „Arbeit" bezeichnen sollte $^{132}$ - denn niemals hätte ein weiser Mann wie Hesiodos jede Arbeit unterschiedslos gelobt, wenn er etwas Schlechtes und Abstoßendes mit der Würde dieses Namens für vereinbar gehalten hätte. ${ }^{133}$ - [111] Mit Beschäftigungen also, die irgendeines dieser Defizite aufweisen, sollte sich kein freier und anständiger Mensch abgeben. Weder sollte er sich hier um Fertigkeiten bemühen, noch diese seinen Kindern beibringen, weil er weder nach Hesiodos noch nach unserer Meinung ein wirklicher "Arbeiter" sein wird, wenn er solche Dinge betreibt. ${ }^{134}$ Vielmehr wird er sich den Vorwurf gefallen lassen müssen, eine würdelose und unproduktive Faulenzerei um schnöden Gewinnes willen zu betreiben, und im Ruf eines ungebildeten, 


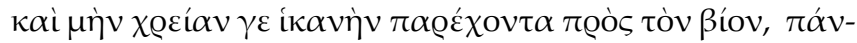

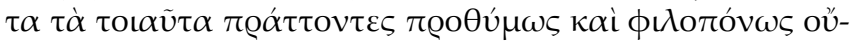

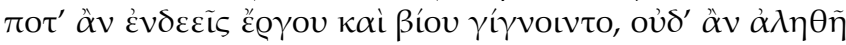

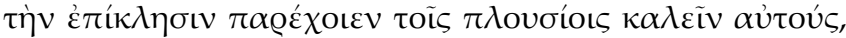

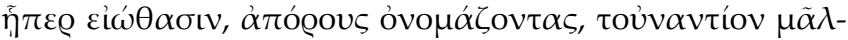

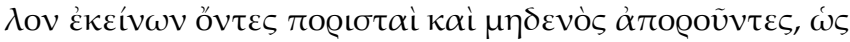

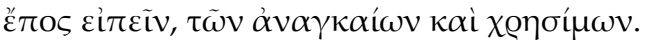

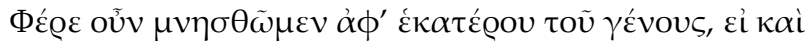

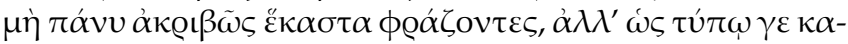

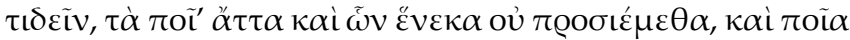

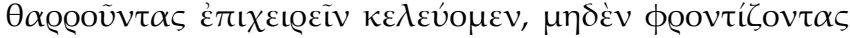

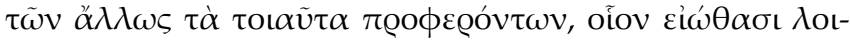

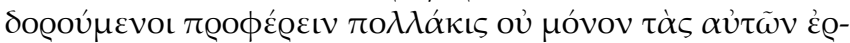

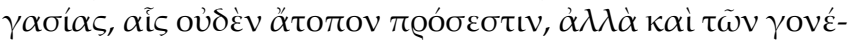

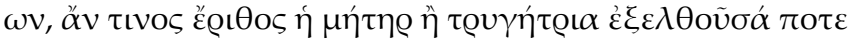

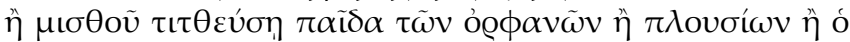

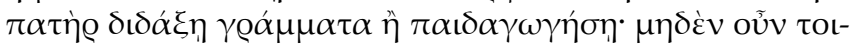

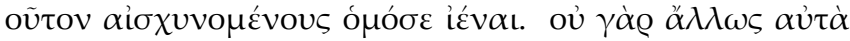

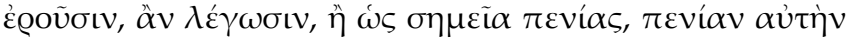

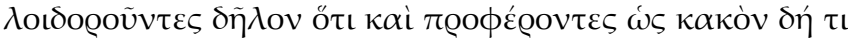

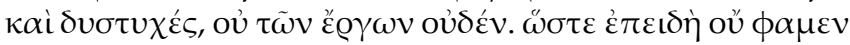

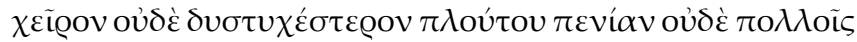

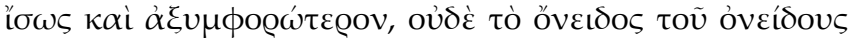

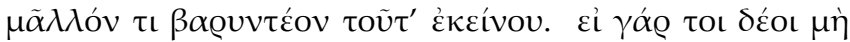

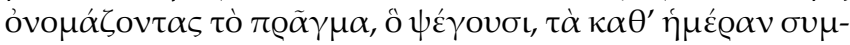

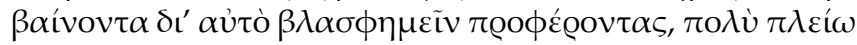

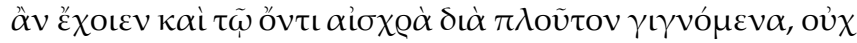

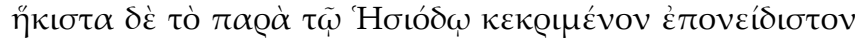

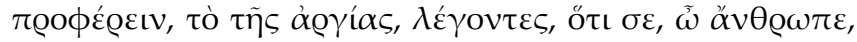

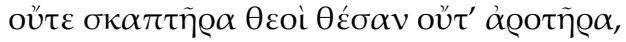

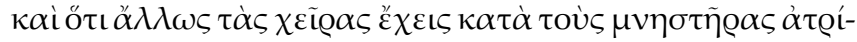

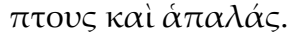


unbrauchbaren und verkommenen Menschen stehen. [112] Was aber die Beschäftigungen betrifft, die weder die Würde der arbeitenden Menschen beeinträchtigen, noch der Seele Schaden zufügen noch im Bereich des Körpers Krankheit und Leid bewirken, weder generell noch dadurch, dass sie durch Stillsitzen (den Menschen) schlaff und weichlich werden lassen, und die dazu noch ein zum Leben ausreichendes Einkommen einbringen - [113] wenn Leute solchen Arbeiten bereitwillig und fleißig nachgehen, wird es bei ihnen keinen Mangel an Beschäftigung und Lebensunterhalt geben, und sie würden auch die Bezeichnung, mit der die Reichen sie häufig und gern benennen - „die Schicht der Erwerbs- und Hilflosen“ - als falsch erweisen. Denn sie sind ganz im Gegenteil - und in höherem Maße als die Reichen ${ }^{135}$ - produktiv tätig und entbehren so gut wie nichts von den wirklich notwendigen und nützlichen Gütern.

[114] Nun wollen wir uns von beiden Arten von Beschäftigungen ausgehend ins Gedächtnis rufen - nicht in allen Detailfragen, wohl aber dem Umriss nach - welche wir aus welchen Gründen ablehnen und welche die Leute getrost, nach unserer dringenden Empfehlung, ergreifen können. ${ }^{136}$ Dabei sollen sie sich nicht um diejenigen kümmern, die sich aufs Geratewohl mit Hohn und Spott über Beschäftigungen, an denen nichts Unziemliches zu finden ist, zu äußern belieben und dazu auch noch die Berufstätigkeit der Eltern verunglimpfen, wenn beispielweise die Mutter von jemandem außer Haus tätig war als Dienstmagd oder bei der Weinlese mitarbeitete oder gegen Bezahlung Amme bei einem Waisenkind oder einem Kind aus reichem Hause gewesen ist oder wenn der Vater sich als Schullehrer oder Erzieher betätigt hatte. ${ }^{137}$ Von solcher Kritik sollen sie sich keinesfalls beirren lassen, sondern ihre Arbeit in Angriff nehmen. [115] Denn mit solchen Äußerungen zielen die Spötter doch nur auf sichtbare Anzeichen von Armut, die sie natürlich selbst als ein schlimmes Übel und Unglück schmähen wollen, nicht aber auf den Charakter dieser Beschäftigungen. Da wir aber nun behaupten, dass die Armut überhaupt kein größeres Übel oder Unglück sei als der Reichtum und überdies für viele vielleicht sogar vorteilhafter, so soll man sich über die Schmähungen gegen die eine Seite keinesfalls mehr ärgern als über die gegen die andere. [116] Denn wenn es darum geht, dass die Leute, ohne den Sachverhalt selbst, den sie schmähen, wirklich zu bezeichnen, lediglich die alltäglichen Folgen daraus mit Spott überziehen, dann hätten sie weitaus mehr und wirklich Schändliches, das um des Reichtums willen geschieht, vorzubringen - nicht zuletzt den Tadel, den Hesiodos gegen Arbeitsscheu und Untätigkeit erhoben hat; auch müssten sie sagen: „Mensch, Dir haben die Götter weder zum Graben noch zum Pflügen Geschick gegeben“. ${ }^{138}$ Und man sollte hinzufügen: „Unbrauchbare Hände hast Du, ganz nach Art der Freier: weichlich und zart!“139 


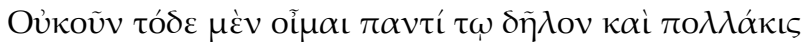

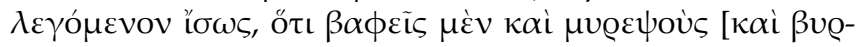

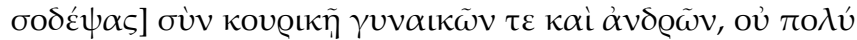

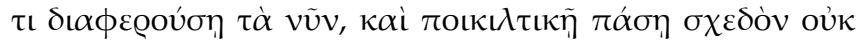

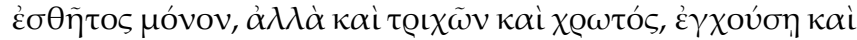

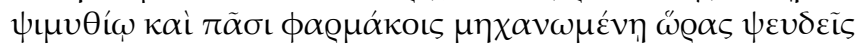

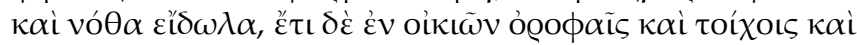

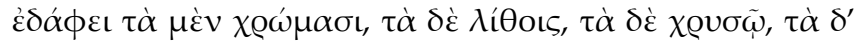

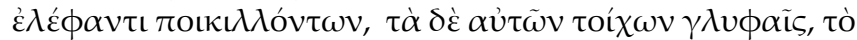

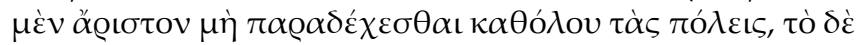

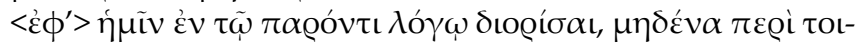

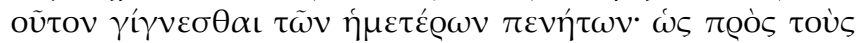

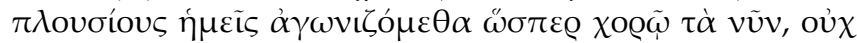

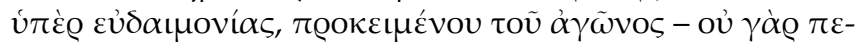

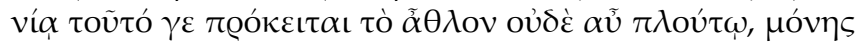

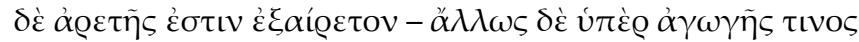

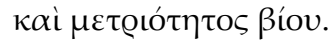

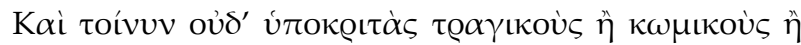

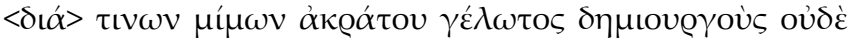

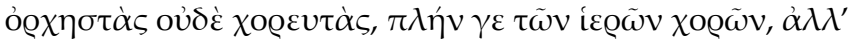

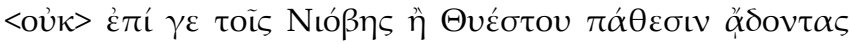

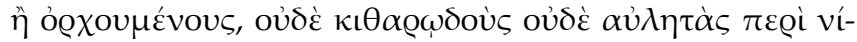

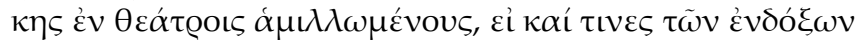

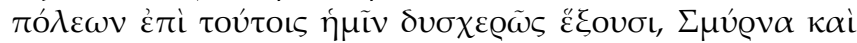

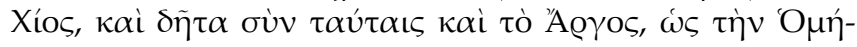

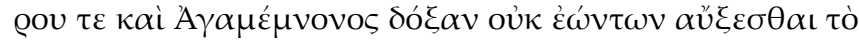

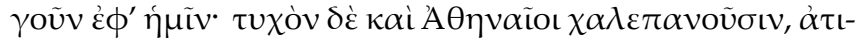

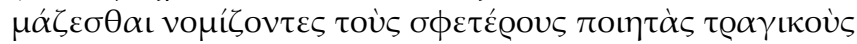

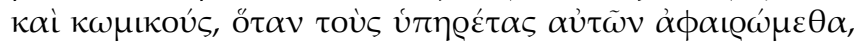

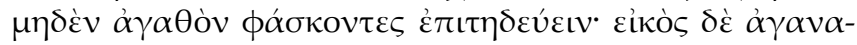

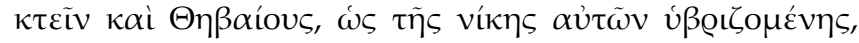

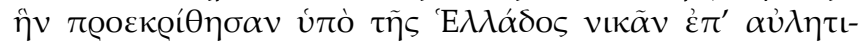

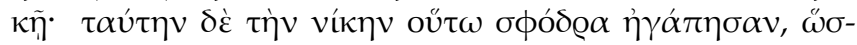

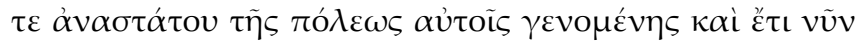

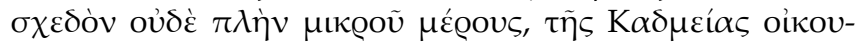

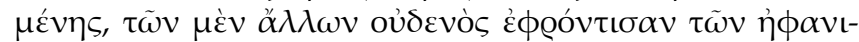

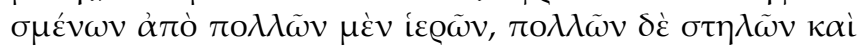

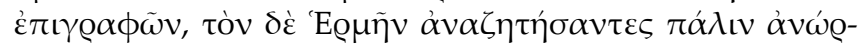




\section{Unproduktive und schädliche Tätigkeiten}

[117] Das Folgende ist nun, so meine ich, jedem klar und wird wohl auch oft gesagt: Färber und Salbenköche suchen mit Kosmetik für Frauen und Männer - da gibt es heute keinen großen Unterschied mehr - und ihrer ganzen Kunst des Umfärbens, nicht nur der Kleidung, sondern auch des Haares und der Haut, unter Einsatz von Rouge und Bleiweiß und allen sonstigen Mitteln, ein verlogenes und gefälschtes Bild von jugendlicher Schönheit zu erzeugen. ${ }^{140}$ Ebenso steht es mit den Tätigkeiten der Leute, die auf den Dächern, Wänden und dem Fußboden der Häuser Zierat aus Farben, Steinen, Gold und Elfenbein anbringen und mit Stuck die Wände schmücken ${ }^{141}$ - [118] dies alles sollten die Städte am besten überhaupt nicht zulassen! Unsere Aufgabe aber besteht darin, in der gegenwärtigen Untersuchung festzulegen, dass keiner unserer Armen eine solche Beschäftigung annehmen darf. Denn wir befinden uns gegenwärtig im Wettstreit mit den Reichen, wie bei einer Choraufführung, ${ }^{142}$ wobei es in diesem Kampf nicht um das Lebensglück schlechthin geht - dieser Siegespreis ist weder für Reichtum noch für Armut ausgesetzt, sondern ausschließlich für Tugendhaftigkeit und Selbst-Vollendung (areté) reserviert. Anders gesagt: es geht um eine bestimmte Erziehung und maßvolle Lebensweise.

[119] Auch die Betätigungen von Schauspielern in Tragödien oder Komödien oder der Produzenten von Spaß und zügellosem Gelächter in Mimos-Possen, ${ }^{143}$ auch nicht die von Tänzern und Chorsängern kommen (als Berufe für die Stadtarmut) in Betracht - mit Ausnahme der Mitwirkung in den heiligen Chören (bei Festfeiern). Aber sie sollen nicht die Leiden der Niobe oder des Thyestes in Gesang und Tanz zur Darstellung bringen $^{144}$ und sich auch nicht in Theatern am Wettstreit um den Siegespreis im Kithara-Gesang oder im Spiel des aulos-Instruments beteiligen. Dies soll gelten, auch wenn uns einige berühmte Städte deswegen grollen werden - Smyrna und Chios und mit diesen sicherlich auch Argos, als wollten wir es, so weit es an uns liegt, nicht zulassen, dass sich der Ruhm Homers und Agamemnons noch weiter ausbreite. ${ }^{145}$ [120] Vielleicht werden auch Leute aus Athen entrüstet sein, in der Meinung, wir verachteten ihre Tragödienund Komödiendichter, wenn wir ihnen das Dienstpersonal wegnehmen, indem wir behaupten, diese Leute betrieben nichts Gutes. Wahrscheinlich grollt man uns auch in Theben, als ob ihr Siegespreis geschändet werde, der ihnen einst den ersten Rang in Hellas einbrachte - im aulos-Spiel! ${ }^{146}$ [121] Diesen Siegespreis haben sie so hoch geschätzt, dass sie, nachdem ihre Stadt zerstört worden war - und auch jetzt ist ja nur ein kleiner Teil davon, die Kadmeia-Burg, bewohnt - sich um die vielen anderen verschwundenen Heiligtümer, Stelen und Inschriften nicht bekümmert haben, aber 


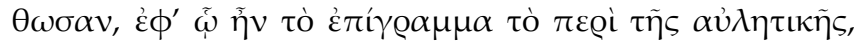

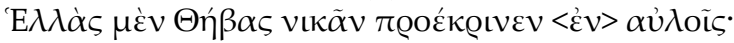

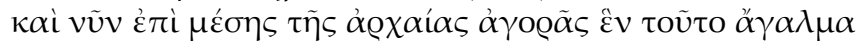

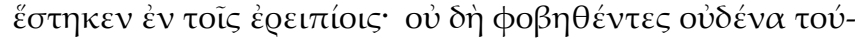

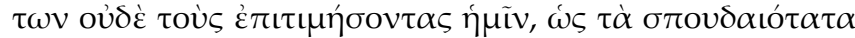

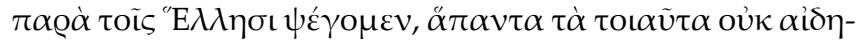

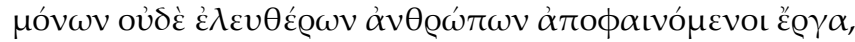

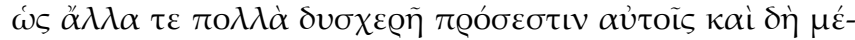

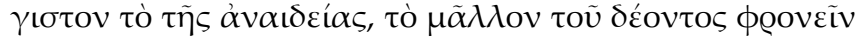

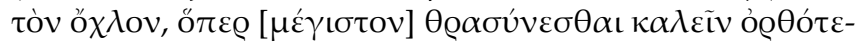
@ov.

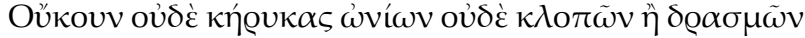

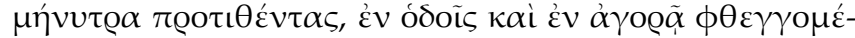

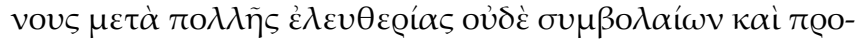

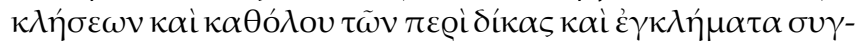

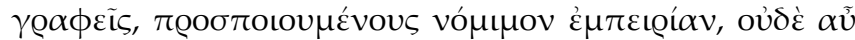

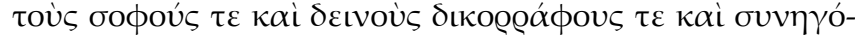

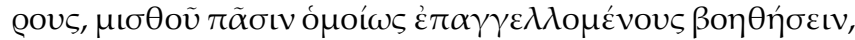

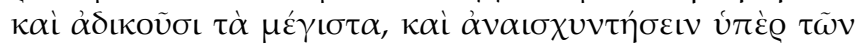

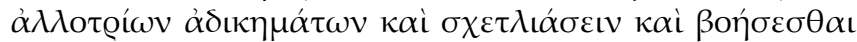

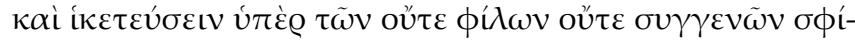

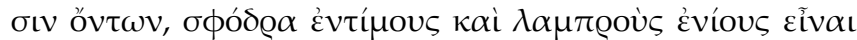

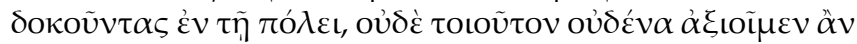

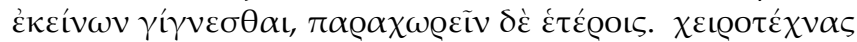

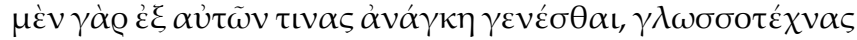

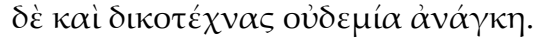

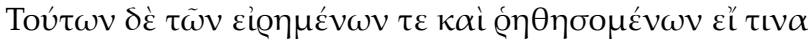

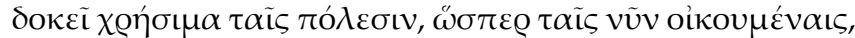

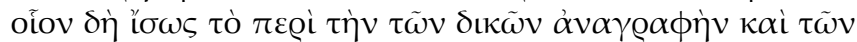

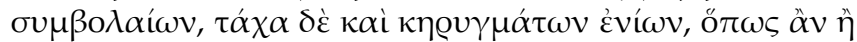

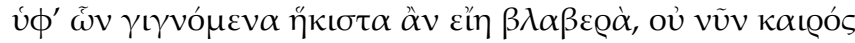

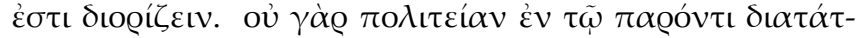

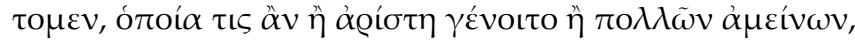

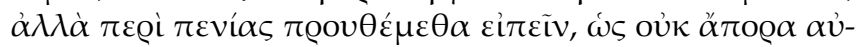

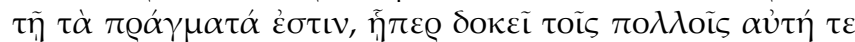

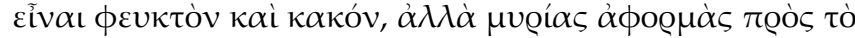

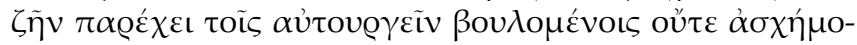

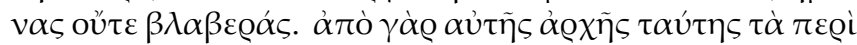

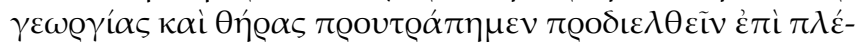


jene Hermes-Statue wieder hervorgeholt und aufgestellt haben, auf dem der Ehrentitel in der Kunst des aulos-Spiels steht: Hellas gab Theben den Siegespreis im aulos-Spiel. Auch jetzt steht dieses Denkmal allein auf dem Alten Marktplatz (agora), inmitten der Trümmer ringsum. ${ }^{147}$ [122] Wir aber fürchten keinen von diesen Kritikern und auch nicht diejenigen, die gegen uns den Vorwurf erheben, wir wollten die wichtigsten Errungenschaften der Hellenen herabwürdigen; indem wir aufzeigen, dass derartige Betätigungen nicht zu Menschen mit Respektgefühl und freiheitlicher Gesinnung passen, weil damit viele Übel verbunden sind - als schlimmstes von allen die Neigung zur Schamlosigkeit, kurzum: der Übermut der breiten Masse oder, richtiger gesagt, ihre Frechheit. ${ }^{148}$

[123] Und ebenso wenig sollen sich unsere Armen als Herolde und Ausrufer (von angebotenen Waren) oder von Belohnungen in Fällen von Diebstahl oder des Entlaufens von Sklaven betätigen und mit ungehemmtem Geschrei auf den Straßen und dem Marktplatz herumtreiben. Auch an der Niederschrift von Verträgen und Gerichtsvorladungen sowie allen sonstigen Prozess- und Klage-Unterlagen sollen sie nicht beteiligt sein und so tun, als wenn sie kundige Rechtsgelehrte seien. Und keinesfalls sollen sie schlaue und rücksichtslose Prozess-Anzettler und Anwälte sein, die um Bezahlung willen allen ohne Unterschied, selbst den größten Übeltätern, ihre Hilfe anbieten, die frech die Verbrechen anderer Leute bemänteln und sich laut jammernd und bettelnd für Menschen einsetzen wollen, mit denen sie weder verwandt noch befreundet sind. Einige von diesen "Advokaten" genießen in ihrer Polis sogar Ehre und Ansehen - nach unserer Meinung aber darf niemand aus der Stadtarmut einen solchen „Beruf" erlernen; vielmehr soll er diesen anderen überlassen. ${ }^{149}$ [124] Denn als geschickte Handwerker werden wohl manche von ihnen benötigt, an Zungendreschern und Rechtsverdrehern aber besteht überhaupt kein Bedarf.

Wenn aber einige der besprochenen und der noch zu behandelnden Tätigkeiten für die Polis-Gemeinden, so wie sie gegenwärtig bestehen, eben doch nützlich erscheinen - wie etwa die Protokollierung von ProzessVerfahren oder von Verträgen und dazu auch amtliche Bekanntmachungen durch Herolde - so ist jetzt nicht der richtige Zeitpunkt, um näher zu bestimmen, wie und durch wen diese Geschäfte mit möglichst geringen Nachteilen betrieben werden sollten. ${ }^{150}$ [125] Denn im Augenblick entwerfen wir ja keine Verfassungsordnung, welche als die beste oder doch besser als viele andere gelten könne; vielmehr haben wir uns vorgenommen, hinsichtlich der Armut aufzuzeigen, dass mit ihr keineswegs eine hoffnungslose Lage verbunden ist, so wie sie von der Masse als ein Übel eingeschätzt wird, dem man unbedingt entgehen müsse. ${ }^{151}$ Tatsächlich bietet sie vielmehr für die, die mit ihren eigenen Händen arbeiten wollen, 


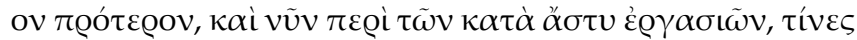

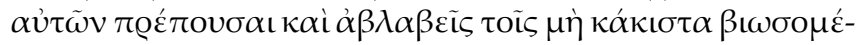

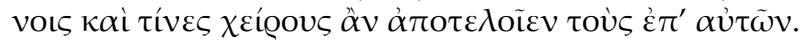

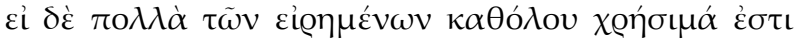

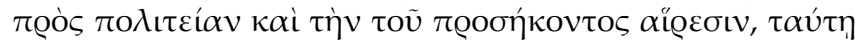

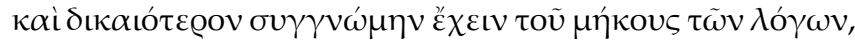

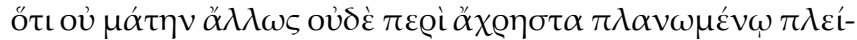

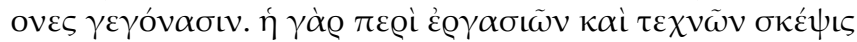

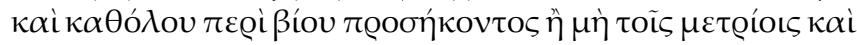

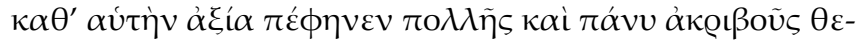

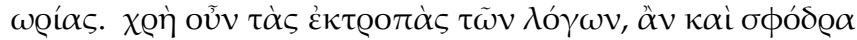

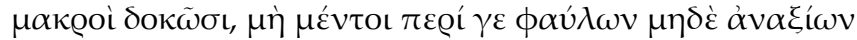

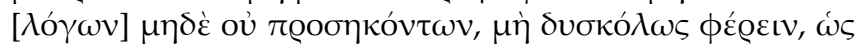

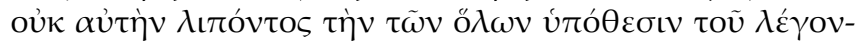

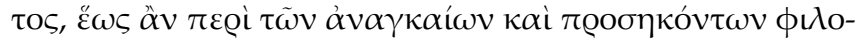

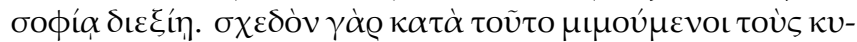

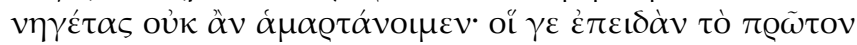

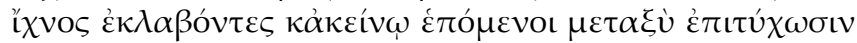

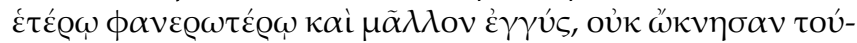

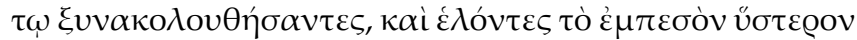

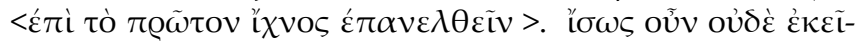

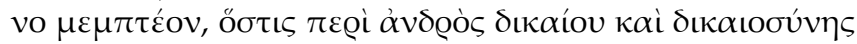

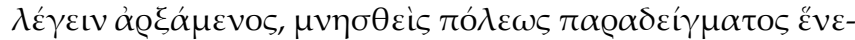

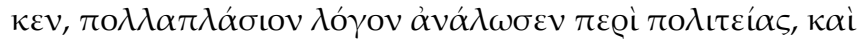

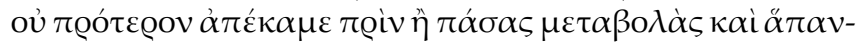

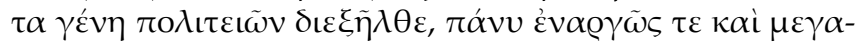

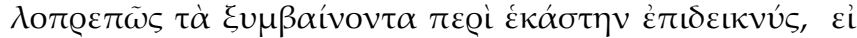

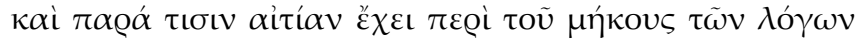

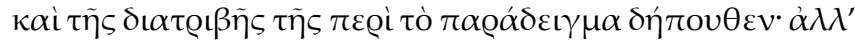

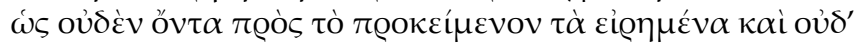

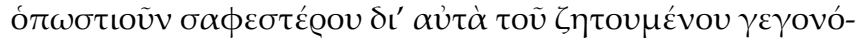

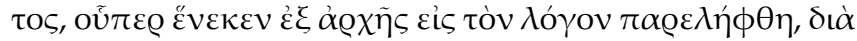

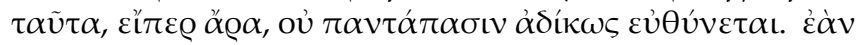

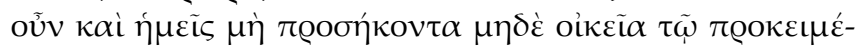

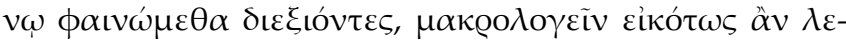

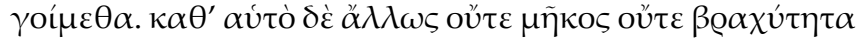


zahllose Chancen zur Lebensführung - und zwar recht ordentliche und unschädliche. [126] Denn von diesem Ausgangspunkt aus sahen wir uns zuvor veranlasst, ausführlich über Landwirtschaft und Jagd zu berichten, so wie jetzt über die Arbeitsmöglichkeiten und Gewerbe im Stadtbereich: welche von ihnen angemessen und unschädlich sind für die, die kein elendes Leben führen wollen, und welche für diejenigen, die sich mit ihnen befassen, verderblich sind. ${ }^{152}$

\section{Rechtfertigung ausführlicher Exkurse und Argumentationen}

[127] Wenn aber vieles von dem, was gesagt wurde, sich im allgemeinen als nützlich im Hinblick auf die bürgerliche Grundordnung und eine Orientierung auf das politisch Richtige erweist, so sollte man unter diesem Aspekt Verständnis auch für die Länge unserer Darlegungen aufbringen, weil sie nicht ohne Ertrag und in zielloser Beschäftigung mit Unnützem an Umfang zugenommen haben. Denn die Untersuchung von Arbeitsmöglichkeiten und handwerklichen Berufen und generell über richtige und falsche Lebensführung für Leute mit bescheidenen Mitteln ist an sich schon ein Gegenstand, der eine umfassende und sehr genaue Untersuchung verdient. ${ }^{153}$ [128] Man sollte also über die Exkurse in meinen Darlegungen, auch wenn sie allzu langatmig erscheinen mögen, sich dabei jedoch nicht mit geringfügigen oder zu unwürdigen und wertlosen Gegenständen beschäftigen, nicht ungehalten sein: Denn der Redner hat das Generalthema nicht aus dem Auge verloren, so lange er notwendige und zur Philosophie passende Fragen erörtert. ${ }^{154}$ [129] Denn wenn wir uns in dieser Hinsicht gewissermaßen an das Vorbild der Jäger halten, werden wir schwerlich in die Irre gehen: Haben diese nämlich eine erste Spur aufgenommen und stoßen, dieser folgend, dabei auf eine andere, deutlichere und frischere Spur, so halten sie sich, ohne zu zögern, zunächst an diese und kehren dann, nachdem sie ihren Fang gemacht haben, zu jener ersten Spur zurück. ${ }^{155}$ [130] Darum ist wohl auch jenes Vorgehen nicht zu tadeln, mit dem jemand, nachdem er mit Darlegungen zur Frage nach dem gerechten Menschen und der Gerechtigkeit begonnen hat, sich dann aber der Polis als Modell zuwandte und nach einer vielfach längeren Erörterung über ihre Verfassungsordnung nicht eher endet, als bis er alle Verfassungsumbrüche und alle Arten von Grundordnungen abgehandelt hat. ${ }^{156}$ Dabei ist seine Darstellung überaus klar und vorzüglich in der Herausarbeitung der Merkmale einer jeden Staatsform. [131] Freilich ist er auch von einigen Kritikern wegen des Umfangs seiner Darlegungen und natürlich auch wegen des langen Verweilens bei seinem Staatsmodell getadelt worden. ${ }^{157}$ Falls jedoch das Gesagte nicht mit dem gestellten Thema zusammenhängt und wenn dadurch in den anstehenden Fragen überhaupt nichts deutlicher geworden ist - um deretwillen es von Anfang an in die Erörterung einbe- 


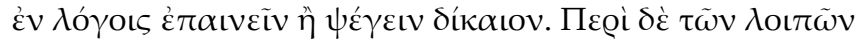

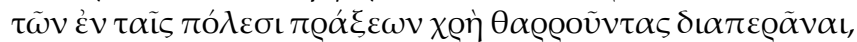

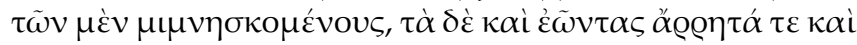

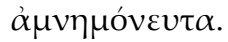

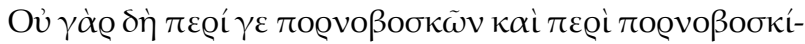

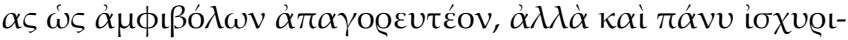

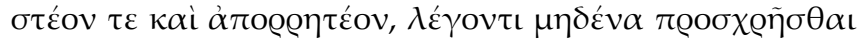

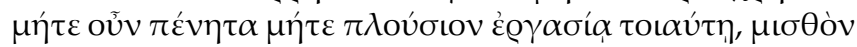

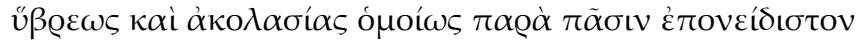

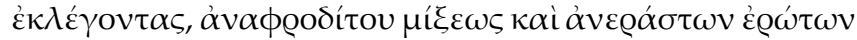

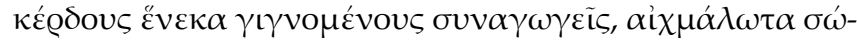

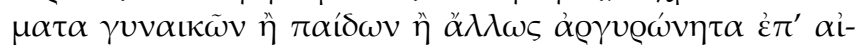

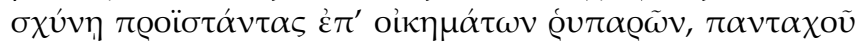

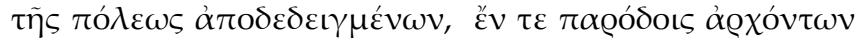

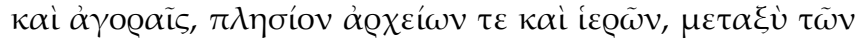

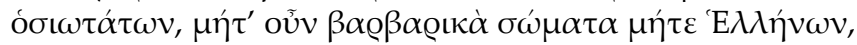

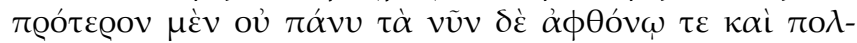

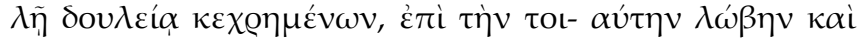

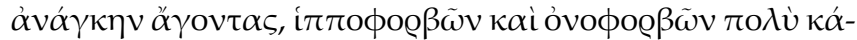

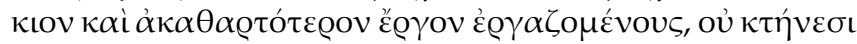

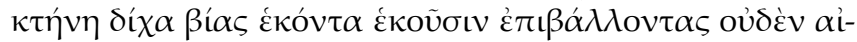

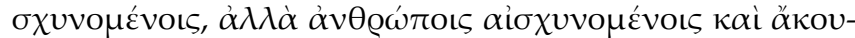

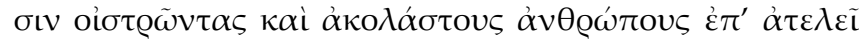

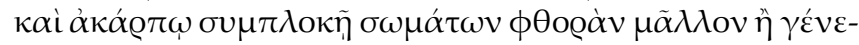

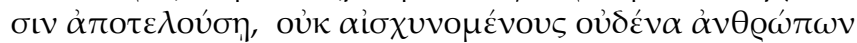

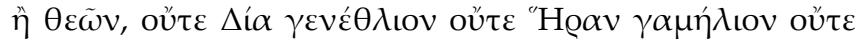

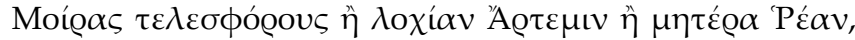

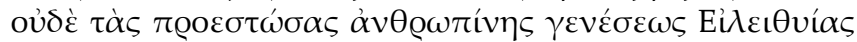

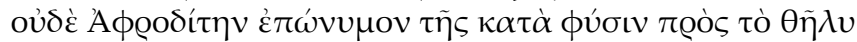

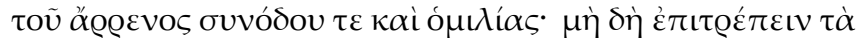

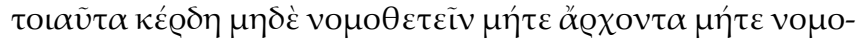

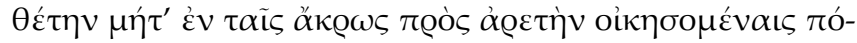

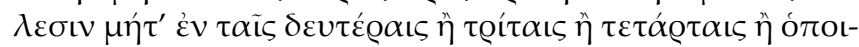

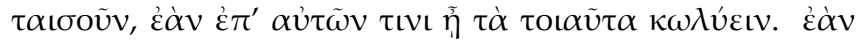

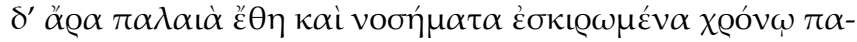


zogen wurde - dann ist, wenn überhaupt, ein kritisches Urteil nicht ganz unberechtigt. [132] Wenn sich also zeigen sollte, dass auch wir unpassende und nicht zum Thema gehörige Dinge behandeln, dann verdienen wir den Vorwurf der Weitschweifigkeit. Im übrigen sollte für sich genommen weder die Länge noch die Kürze einer Rede ein Grund für Lob oder Tadel sein. Wir wollen also getrost unsere Darlegungen zu den Tätigkeiten in den Städten zu Ende bringen, indem wir auf einiges deutlich hinweisen, über anderes jedoch stillschweigend hinweggehen. ${ }^{158}$

\section{Die Prostitution als Gefahr für die Menschenwürde und die bürgerliche Gesellschaft (§§ 133-140)}

[133] Dagegen dürfen wir uns allerdings hinsichtlich des Treibens der Bordellbesitzer und ihres „Berufs" nicht auf eine matte Unentschiedenheit zurückziehen, sondern müssen mit Entschlossenheit ein Verbot aussprechen, dass niemand, weder ein Reicher noch ein Armer, ein solches "Gewerbe" ausüben darf - dass nämlich jemand aus Missbrauch und zügelloser Gier einen Lohn bezieht, der bei allen Menschen in gleicher Weise verachtet wird! Sie bringen, als Zuhälter, Menschen zu lieblosem Geschlechtsverkehr ohne Zuneigung und Zärtlichkeit zusammen, um bloßen Gewinns willen. Sie bieten die Körper von Frauen und Kindern, die durch Kriegsgefangenschaft oder auf andere Weise zu Kaufsklaven wurden, zur Schändung in schmutzigen Behausungen dar, die überall in der Stadt wahrgenommen werden - nämlich an den Zugängen zum Sitz der Magistrate und an den offenen Marktplätzen, in der Nähe von Amtshäusern und Heiligtümern, mitten unter den ehrwürdigsten Gebäuden. ${ }^{159}$ [134] Weder barbarische noch hellenische Menschen, die zuvor in Freiheit lebten, sich jetzt aber in härtester Knechtschaft befinden, sollen sie in eine solche Schande und Unfreiheit treiben dürfen, indem sie ein viel übleres und weitaus schmutzigeres Gewerbe als Pferde- oder Eselzüchter ausüben; denn sie bringen nicht, wie diese, ohne Gewaltanwendung Vieh mit Vieh zu einer geschlechtlichen Vereinigung zusammen, ohne dass es dabei Widerwillen und Scham gibt. Sie lassen vielmehr auf Menschen, die Scham empfinden und widerstreben, geile Wüstlinge los - zu einer sinnlosen und unfruchtbaren Vereinigung der Leiber, die eher Vernichtung als neues Leben hervorbringt. ${ }^{160}$ [135] Sie schämen sich weder vor Menschen noch Göttern, nicht vor Zeus Genethlios, nicht vor Hera, der Hüterin der Ehe, nicht vor den allgewaltigen Moiren oder vor Artemis, der Schützerin der Gebärenden, nicht vor der Muttergottheit Rhea oder den geburtshelfenden Gottheiten (Eileithyien) ${ }^{161}$ und auch nicht vor Aphrodite, der Patronin der natürlichen geschlechtlichen Vereinigung und Gemeinschaft von Mann und Frau. [136] Diese schmutzigen Geschäfte darf weder ein Magistrat erlauben noch ein Gesetzgeber zulassen - und zwar weder in den hochrangig 


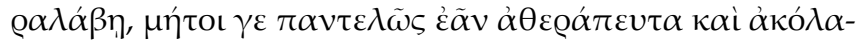

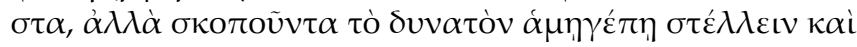

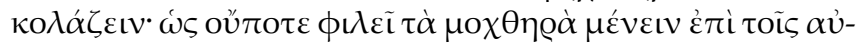

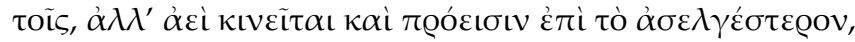

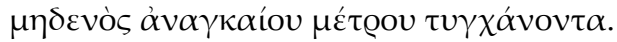

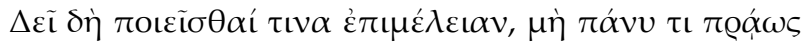
138

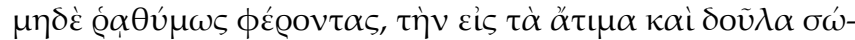

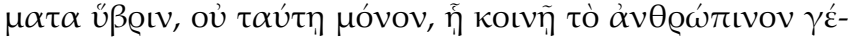

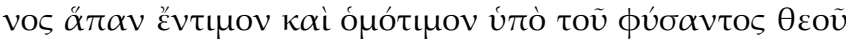

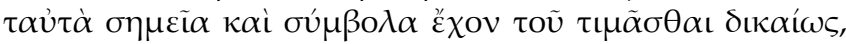

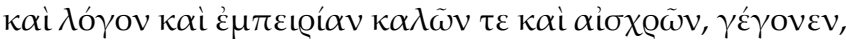

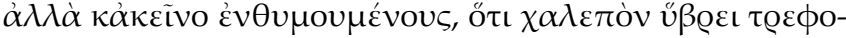

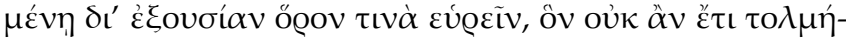

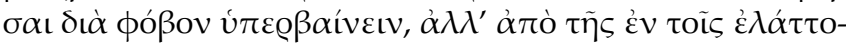

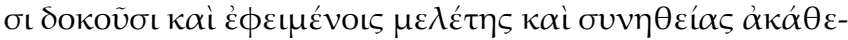

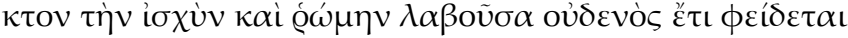
$\tau \tilde{\omega} v \lambda \operatorname{lot} \pi \tilde{\omega} v$.

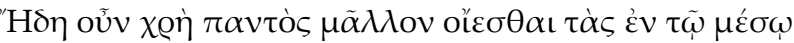

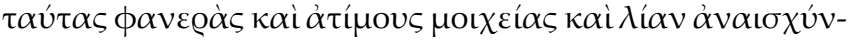

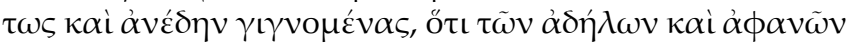

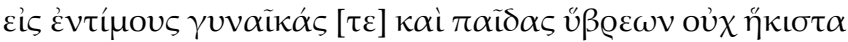

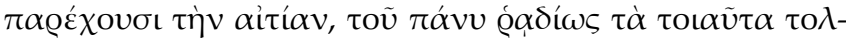

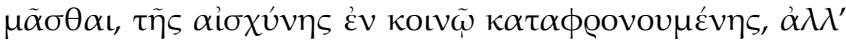

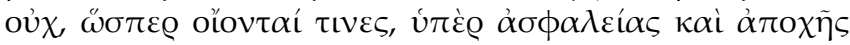

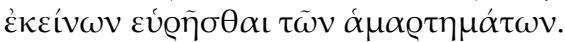

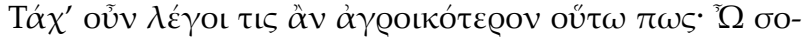

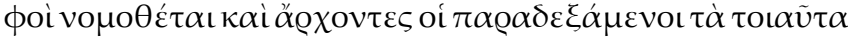

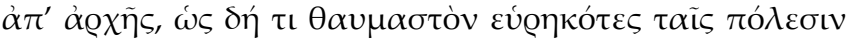

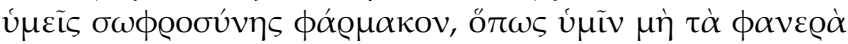

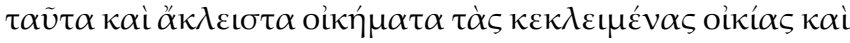

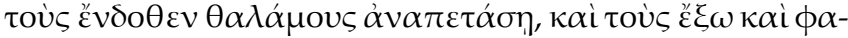

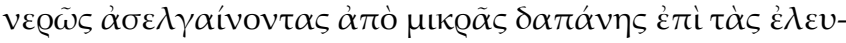

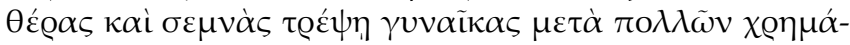

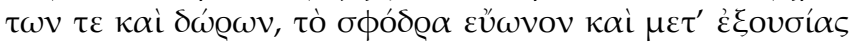


auf Trefflichkeit und Güte einzurichtenden Städten, noch in den zweit-, dritt- und viertrangigen oder sonst wie gestellten Gemeinden ${ }^{162}$ - wenn es noch in der Macht eines von ihnen liegen sollte, dies zu verhindern. [137] Trifft er (der Gesetzgeber) aber auf alte Gewohnheiten und Krankheiten, die sich mit der Zeit eingenistet haben, so soll er diese jedenfalls nicht ganz ohne Behandlung und Zügelung lassen, sondern muss ihnen im Rahmen des Möglichen, auf irgendeine Weise Einhalt gebieten und sie mäßigen. Denn Laster pflegen nicht auf der Stelle zu treten, sondern sind ständig in Bewegung und auf dem Vormarsch zu noch größeren Ausschweifungen, wenn sie nicht auf die notwendigen Schranken stoßen. ${ }^{163}$

[138] Man muss hier also mit Sorgfalt vorgehen und darf den Missbrauch von entehrten und versklavten Menschen nicht nachsichtig und leichtfertig hinnehmen, und zwar nicht allein aus dem Grund, weil das ganze Menschengeschlecht gemeinsam über Ehre und gleichen Rang verfügt, da es ja von seinem Schöpfergott mit denselben charakteristischen Merkmalen ausgestattet worden ist, um gerechtermaßen Ehre zu empfangen: nämlich mit Vernunft und dem Wissen um Gut und Böse. ${ }^{164}$ Man muss hier vielmehr auch bedenken, dass es schwierig ist, für Freveltat und Laster, wenn sie nach Belieben zunehmen dürfen, noch irgendwelche Grenzen zu finden, die sie aus Furcht nicht mehr zu überschreiten wagen. Tatsächlich gewinnt die Lasterhaftigkeit durch Praxis und Eingewöhnung bei scheinbar geringfügigen und zugelassenen Betätigungen eine nicht mehr einzudämmende Kraft und schreckt am Ende vor nichts mehr zurück.

[139] So sollte man jedenfalls zu der Einsicht gelangen, dass die ganz unverhüllt und schamlos in der Öffentlichkeit praktizierte Unzucht nicht zum wenigsten verantwortlich ist für die heimlichen, vor der Gesellschaft verborgenen Übergriffe gegen ehrbare Frauen und Kinder, und zwar weil man dies ganz bedenkenlos riskiert, wenn Schamhaftigkeit in der Öffentlichkeit nichts mehr gilt. Diese Praxis (der Bordelle) wurde also nicht, wie einige meinen, im wirklichen Interesse der Sicherheit und der Prävention von derartigen Vergehen erfunden. ${ }^{165}$

[140] Dazu könnte nun einer, rasch und etwas ungehobelt, Folgendes sagen: ,Ach ihr weisen Gesetzgeber und Amtsträger, die ihr von Anfang an solche Sitten akzeptiert habt, in der Meinung, ihr hättet ein wunderbares Heilmittel für eure Städte gegen Ausschweifungen und Lasterhaftigkeit gefunden! Passt nur auf, dass euch diese öffentlichen und unverschlossenen Häuser nicht die verschlossenen Privathäuser öffnen und die Türen zum Intimbereich der Schlafzimmer aufstoßen! Und seht zu, dass diejenigen, die jetzt draußen auf der Straße und in der Öffentlichkeit, mit geringem Aufwand, ihren Lastern frönen, sich nicht an freie und angese- 


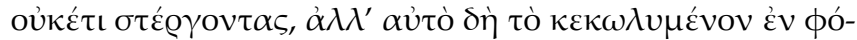

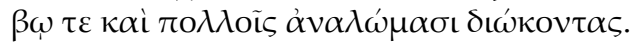

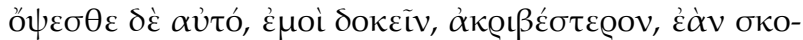

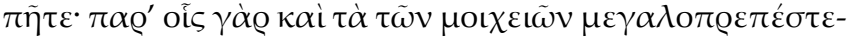

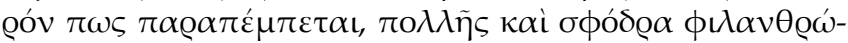

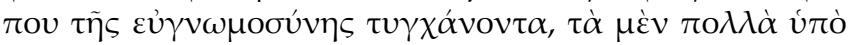

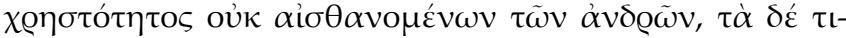

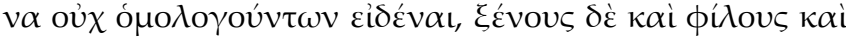

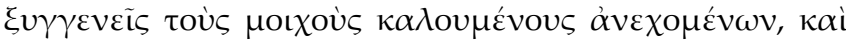

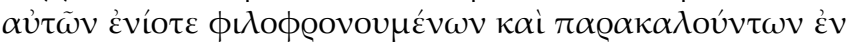

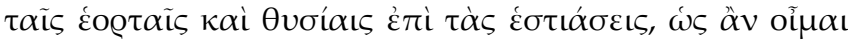

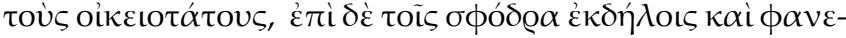

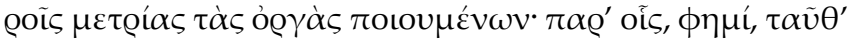

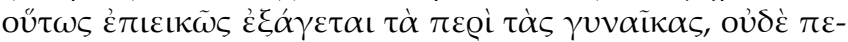

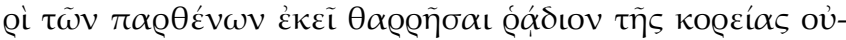

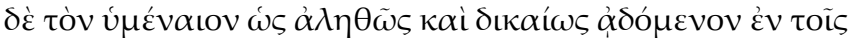

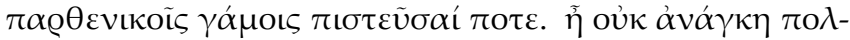

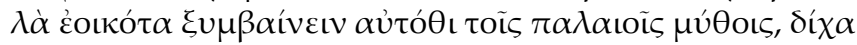

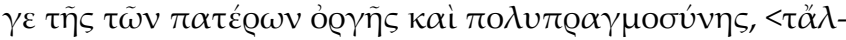

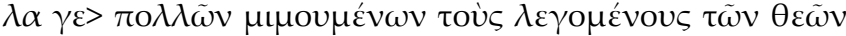

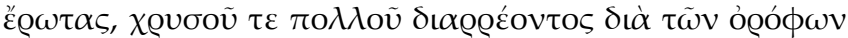

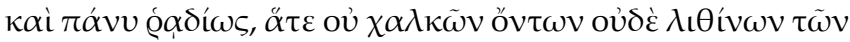

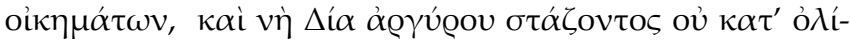

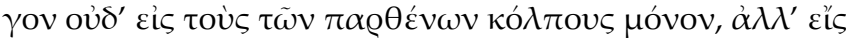

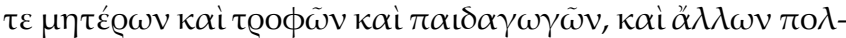

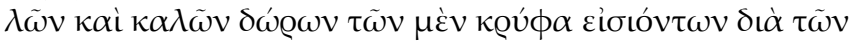

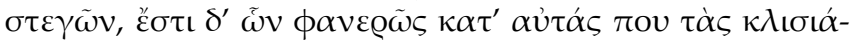

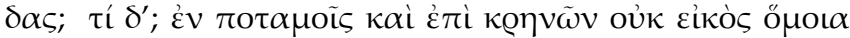

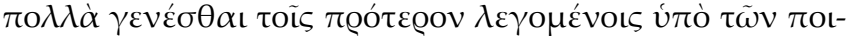

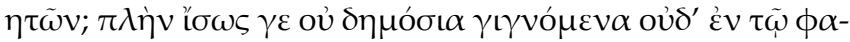

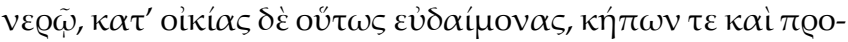

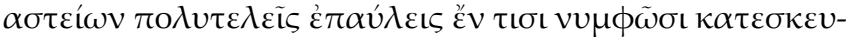

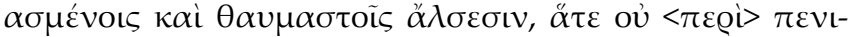

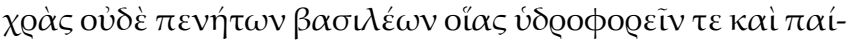

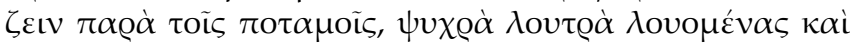

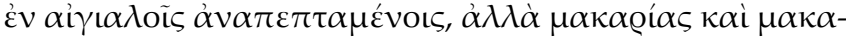

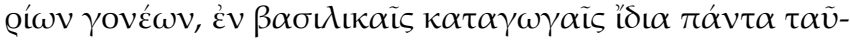


hene Frauen mit Geschenken für viel Geld heranmachen, weil sie mit dem allzu billigen und nach Belieben zur Verfügung stehenden Genuss nicht mehr zufrieden sind - auf der Jagd nach hindernisreichen und gefahrvollen Abenteuern mit hohem Kostenaufwand! ${ }^{166}$

Kritik an der ,libertinage' in der großstädtischen (römischen) Oberschicht [141] Ihr werdet den Sachverhalt, meiner Meinung nach, jedoch besser erkennen, wenn ihr euch Folgendes überlegt: In einem Gemeinwesen, wo man über Ehebruch recht großzügig hinwegsieht und diese Affäre mit bereitwilligem und allzu freundlichem Verständnis ihren Lauf nehmen lässt, wobei die Ehemänner das meiste aus Gutmütigkeit einfach nicht wahrnehmen, gewisse Dinge auch gar nicht wissen wollen und damit einverstanden sind, dass die Ehebrecher in ihrem Haus als Gastfreunde, Vertraute und Verwandte bezeichnet werden, wobei diese manchmal zu Gastmählern bei Festen und Opferfeiern freundlich eingeladen werden, als wären sie, so mein Eindruck, die engsten Vertrauten und Freunde, [142] während man sich höchstens über ganz eklatante, öffentliche Skandale in Grenzen zornig zeigt ${ }^{167}$ - dort also, so meine ich, wo in den Beziehungen zu den Ehefrauen so großzügig Gastfreundschaft praktiziert wird, da wird man kaum noch den Mut aufbringen, an die Unberührtheit der Mädchen zu glauben und darauf zu vertrauen, dass das Brautlied bei ihrer jungfräulichen Verheiratung wirklich mit Fug und Recht gesungen wird. ${ }^{168}$ [143] Muss da nicht viel von dem passieren, was den alten Sagenstoffen gleicht - freilich ohne den Zorn und das Widerstreben der Väter? Denn in den übrigen Dingen ahmen viele die angeblichen Liebesabenteuer der Götter nach - mit viel Gold, das durch die Dächer hindurch fließt ${ }^{169}$ - und dies ganz ohne Schwierigkeiten, da die Räumlichkeiten eben nicht aus Bronze oder festem Stein bestehen. [144] Auch tröpfelt hier, beim Zeus, nicht gerade wenig Silber herab - nicht nur in Busen und Gewandbausch der Mädchen, sondern auch der Mütter, der Ammen und Erzieherinnen; dazu kommen dann auch noch viele schöne Geschenke, von denen einige heimlich durch das Dach hineingelangen, andere aber auch ihren Weg ganz offen durch die Türen finden. ${ }^{170}$ [145] Ist es da vielleicht verwunderlich, dass sich an Flüssen und Brunnen viel von dem ereignet, was den älteren Sagen-Erzählungen der Dichter gleichkommt? ${ }^{171}$ Freilich nicht gerade in der Öffentlichkeit, wohl aber in Häusern, so reich ausgestattet (wie hier zu sehen), in prunkvollen Villen mit Gartenanlagen im Vorstadtbereich, auf geschmückten Brautlagern und in zauberhaft schönen Hainen - denn es geht nicht um arme Mädchen oder solchen aus ärmlichen Königshäusern, die Wasser holen müssen, am Flussufer spielen und sogar am offenen Strand ein Bad in kaltem Wasser nehmen. ${ }^{172}$ Es handelt sich vielmehr um 


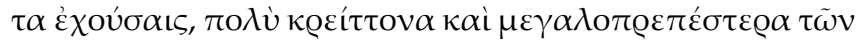

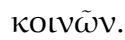

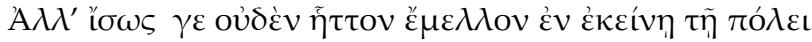

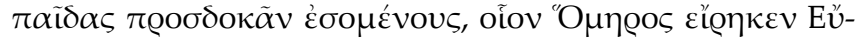

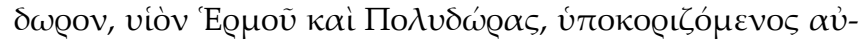

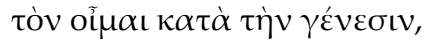

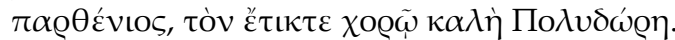

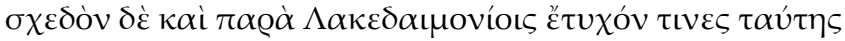

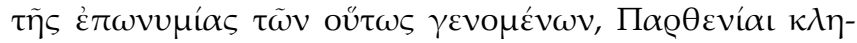

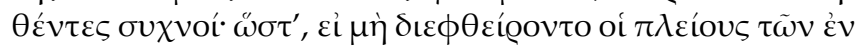

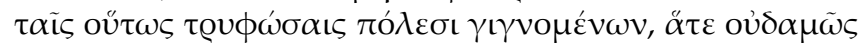

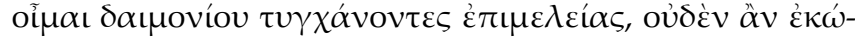

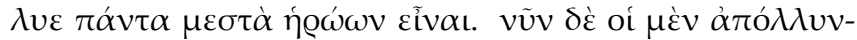

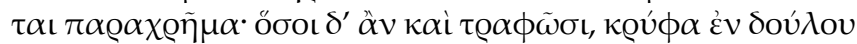

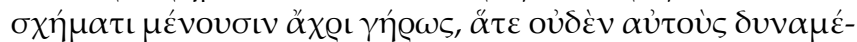

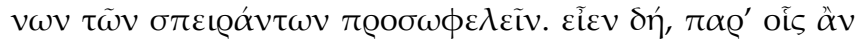

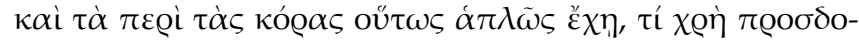

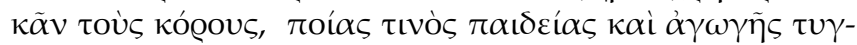

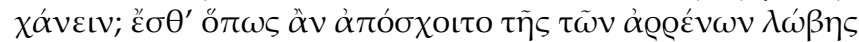

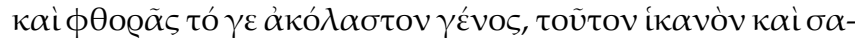

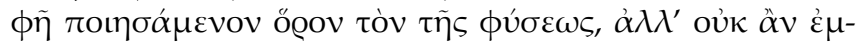

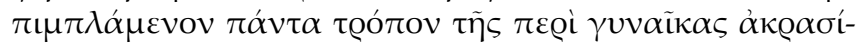

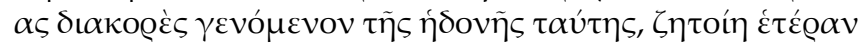

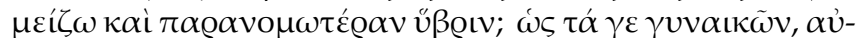

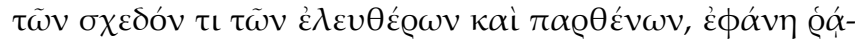

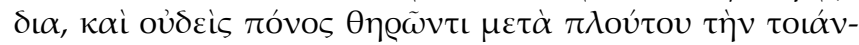

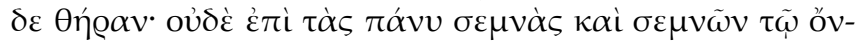

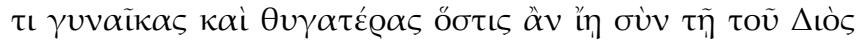

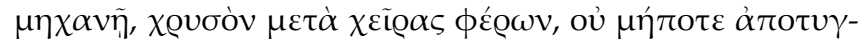

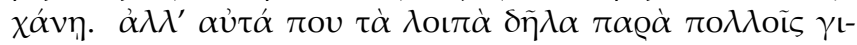

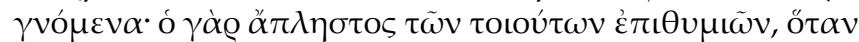

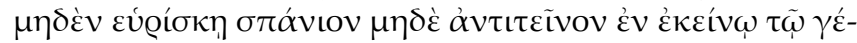

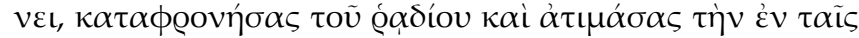

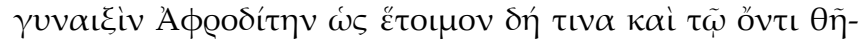

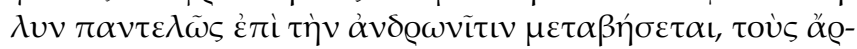

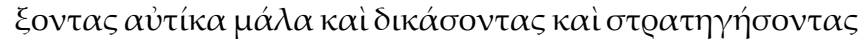

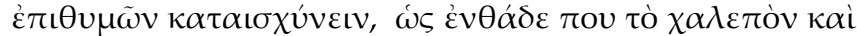

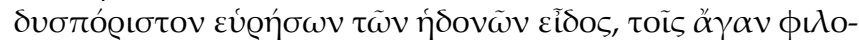

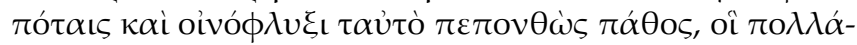

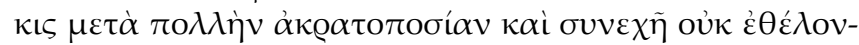


reiche Mädchen von reichen Eltern, die in hochherrschaftlichen Villen alles das besitzen - und zwar weitaus besser und großartiger als die Anlagen für die Öffentlichkeit. ${ }^{173}$

[146] Aber nichts desto weniger sollten in jener Stadt (von der die Rede ist) Kinder zu erwarten sein, wie Homer den Sohn des Hermes und der Polydora, den Eudoros, seine Zeugung euphemistisch verschleiernd, charakterisiert: der ein Jungfrauensohn war, den die im Reigentanz liebliche Polydore gebar. ${ }^{174}$ [147] Und auch bei den Lakedaimoniern gab es Leute mit diesem Beinamen, da sie eben so ins Leben gekommen waren - und zwar ziemlich viele, die Partheniai hießen. ${ }^{175}$ Daher stünde wohl nichts im Wege - wenn die Mehrzahl von ihnen, die in Städten, die derart vom Wohlstand verdorben sind, geboren werden, nicht umkäme, weil sich, meiner Meinung nach, keine Gottheit irgendwie um sie kümmert - dass die Welt ganz voll von solchen ,Heroen' wäre. [148] Heutzutage aber gehen die einen gleich nach der Geburt zugrunde und diejenigen, die aufgezogen wurden, verbleiben unerkannt, bis ins Greisenalter, im Status von Sklaven, da ihnen ihre Erzeuger keine Hilfe leisten können. ${ }^{176}$ Damit sei's wirklich genug! Was aber hat man wohl dort, wo es einfach so um die Mädchen steht, von den Jünglingen zu erwarten? ${ }^{177}$ [149] Welche Art von Bildung und Erziehung wird ihnen zuteil werden? Ist es überhaupt möglich, dass sich diese zügellose Generation von der verderblichen Unzucht mit Männern fernhält und die klaren Grenzen respektiert, die die Natur hier setzt? ${ }^{178}$ Werden sie sich nicht im Gegenteil, da sie ihre Begierde mit Frauen in jeder Weise befriedigt haben und dieser Lust schon überdrüssig geworden sind, auf die Suche nach einer anderen, noch wüsteren und widergesetzlicheren Unzucht machen? [150] Denn die Verführung von Frauen, gerade auch der freien und unverheirateten, hat sich ihnen als zu leicht erwiesen; mühelos ist die Jagd für den, der mit reichen Mitteln diese Art von Beute einfangen will. Selbst bei sehr hochgestellten Frauen und Töchtern aus wirklich angesehenen Familien wird einer, der das Hilfsmittel des Zeus einsetzt ${ }^{179}$ und Gold in seinen Händen mitbringt, das Ziel niemals verfehlen. [151] Was daraus folgt, ist wohl klar und ereignet sich bei vielen: Wer jedenfalls bei dieser Art von Wollust unbefriedigt bleibt, da ihm hier alles überreichlich und ohne Widerstreben angeboten wird, und wer so den leicht zu erlangenden Liebesgenuss mit Frauen verachtet, als etwas schlechthin Verfügbares und in Wahrheit durchaus Unmännlich-Weibliches - der wird hinüberwechseln in den Männersaal und seine Begierde darauf ausrichten, die jungen Männer zu schänden, die im Begriff stehen, schon bald hohe Ämter zu bekleiden und sich als Richter und Strategen (Praetoren) zu betätigen. ${ }^{180}$ [152] Hier jedenfalls, so glaubt er, wird er eine Art von Wollust finden, $\mathrm{zu}$ deren Befriedigung ernsthafte und schwer zu meisternde Hindernisse 


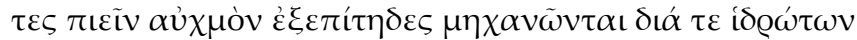

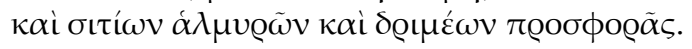


überwunden werden müssen. Er leidet so an der gleichen Sucht wie die allzu sehr dem Wein ergebenen Trinker, die oftmals nach starkem, fortgesetzten Genuss von ungemischtem Wein ${ }^{181}$ keine Lust mehr am Trinken verspüren und sich nun künstlich Durst verschaffen - durch schweißtreibende Anstrengungen und den Verzehr von salzigen und scharf gewürzten Speisen. ${ }^{182}$ 


\section{Anmerkungen zur Übersetzung}

1 Zur inhaltlichen Problematik des Titels der Rede s. Einführung S. 21. - Bei Philostrat (V. Soph. I 7) und bei Synesios (Dion 2) steht die Schrift unter der Bezeichnung ó Eủßocús (,,der Mann aus Euböa“), wobei Synesios freilich danach, in seiner inhaltlichen Würdigung, deutlich macht, dass er die gesamte Schrift (zumindest in dem uns überlieferten Textbestand) genau gekannt hat. In der Werkübersicht bei Photios (Bibl.

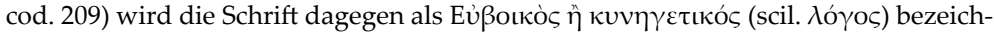
net.

2 Der abrupte Textbeginn, der sich hier schwerlich als rhetorischer Kunstgriff auffassen lässt, gibt noch zu erkennen, dass zuvor von Berichten über gesellschaftlich „,alternative“, d.h. solidarische, ohne soziale Spannungen, in Harmonie und relativer Armut verwirklichte Lebensformen - möglicherweise in fernen Ländern - die Rede gewe-

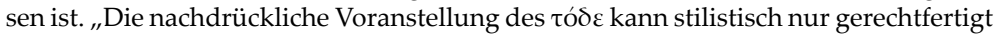
werden, durch des Schriftstellers Absicht ein Neues, zu dem er übergehen will, von dem Früheren abzuheben." (v. ArNim, 1891, 397). Auch in den $§ \S 36.40 .81 f$. und 125 finden sich Hinweise auf eine zuvor, im (verlorenen) Prooemium der Schrift erörterte Definition des Generalthemas der Abhandlung, zu dem die Erzählung §§ 2-80 nur als ein anschauliches (und für einen Teil-Aspekt lehrreiches) Modell beitragen sollte. Weitere Rückverweise machen darüber hinaus deutlich, dass in diesem ProoemiumAbschnitt vorrangig über die angeblich große und positive Macht des Reichtums sowie eine entsprechende Passage in Euripides' Elektra (v. 424-431) - wahrscheinlich zugleich auch über eine Sentenz in Sophokles' Aleadai-Drama - gesprochen worden ist, s.u. Anm. 99 u. 117; zu Dions persönlichem Interesse an der euripideischen Elektra-Tragödie vgl. auch die Zitate in or. $13 \S 5$. - Aus der Tatsache, dass am Schluss der Schrift die Darlegungen ebenso abrupt abbrechen (§ 151), hat v. ARNiм 1981, 404-406 zu Recht auf eine mechanische (vermutlich schon früh in der Überlieferung der Schrift eingetretene) Verstümmelung der ursprünglichen Textfassung von or. 7 (13 Arnim) geschlossen (s. u. Anm. 182, vgl. o. Einführung S. 22).

3 Diese vorgreifende Entschuldigung für den behaglich-ausschweifenden Erzähl- und Argumentationsstil des Autors (vgl. dazu auch $\S \S 102 \mathrm{u}$. 126) stellt nicht nur eine captatio benevolentiae dar, sondern ist auch ein Indiz dafür, dass die Exilzeit Dions mit ihren Abenteuern, Irrfahrten und Entbehrungen bereits längere Zeit zurücklag; s. dazu v. Arnim 1898, 455-457. Zum Vergleich bietet sich in dieser Hinsicht die Olympische Rede (or. 12) an, die mit großer Wahrscheinlichkeit auf $105 \mathrm{n}$. Chr. datiert werden kann (s. u. Anm. 13).

4 Mit dem Hinweis auf „die Mitte von Hellas“ wird ausdrücklich unterstrichen, dass es jedenfalls um konkrete Ereignisse und Zustände aus der Lebenszeit des Erzählers (und nicht um einen kühnen Utopie-Entwurf oder einen phantasievollen Reiseroman bzw. (wie in or. 36 Borysthenes-Rede) um die Begegnung mit einer Ansiedlung ganz am Rande der griechischen Kulturwelt (d.h. an der Nordost-Grenze des Imperium Romanum) gehen soll. - Demgegenüber dürfte Dions Schilderung der Essener-Gemeinde am Toten Meer als einer Gemeinschaft, die sich zu absolut friedlichem und harmonischen Zusammenleben gefunden hatte, wohl eher utopische (bzw. eu-topische) Elemente enthalten haben; vgl. dazu das Zeugnis bei Synesios, Dion 3 p. 240,10 TerzaghI. - Ein Beispiel für die Ausgestaltung eines Utopie / „Eutopie“ - Entwurfs findet sich in 
Dions Indien - Exkurs in der Kelainai-Rede (or. $35 \S \S 18-24$ ) - hier freilich nur in einer ironischen Brechung.

5 Dions Verbannungsstrafe (relegatio) hinderte ihn nicht an Reisen und Aufenthalten außerhalb Italiens und seiner Heimatprovinz Bithynien-Pontos (s. o. S. 13f.); allerdings musste er sich in seiner prekären Situation schon vor dem bloßen Anschein eines Regelverstoßes hüten. Das von dem Erzähler und den Seeleuten ursprünglich angestrebte Reiseziel (nach Athen, durch den „Kanal“ zwischen Euböa und der Insel Andros? Oder zu einem Hafenplatz in Süd-Thessalien?) bleibt hier absichtlich im Unklaren; zwischen Mitte November und Mitte März ruhte normalerweise die Schif-

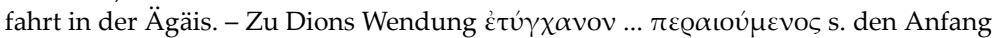

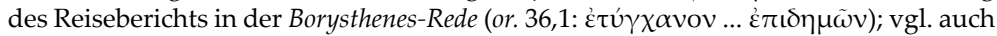
NesSelrath 2003, 66 Anm. 2 mit weiteren Belegen.

$6 \mathrm{Zu}$ den „Höhlen von Euböa“ und ihrer geographischen Position vgl. §§ 7 und 31, s. ferner Hdt. VIII 13f. Aus Dions Angaben geht klar hervor, dass es sich um den hafenlosen, notorisch gefährlichen Küstenabschnitt an dem (bei antiken Autoren oft erwähnten) Kap Kaphereus im Südosten Euböas handeln muss (s. den Essay von H. R. GoEtTe u. S. 169-172); Strabons Angaben zu den „Höhlen von Euböa“ (X 1,2 p. 445,6f.: zwischen Aulis, nahe Chalkis, und Geraistos an der Südküste der Insel) sind dagegen problematisch (vgl. dazu den Stellenkommentar von St. RADT): Strabon folgt an dieser Stelle einer geographischen Tradition, die auch bei Val. Max. I 8,10 bezeugt ist: Der Begriff der koulá wird hier, mit einer gewissen Plausibilität, auf die Meerenge zwischen Rhamnus (in den Bergen Nordost-Attikas) und dem gebirgigen Südwestrand Euböas bezogen; vgl. dagegen jedoch die geographischen Angaben bei Eur. Tr. 84 und Livius (P.) XXXI 47, ferner Tzetzes zu Lykophron, Alexandra 386 (p. 145,24 ScheER).

7 Purpurfischerei wurde im kaiserzeitlichen Griechenland an vielen Plätzen betrieben (u. a. an der lakonischen und thessalischen Küste sowie bei der Insel Gyaros; im Hinblick auf Euböa weisen die archäologischen Zeugnisse (s. u. H. R. GoeTte S. 172) und die geographisch-biologischen Gegebenheiten freilich eher auf die seichteren Gewässer vor Chalkis und Eretria hin. In Dions Darstellung wird jedoch auch in $\S 55$ der Aufenthalts- und Arbeitsbereich dieser (auf Geld und Profit bedachten) Purpurfischer an die Steilküste Euböas, nahe dem Kap Kaphereus, verlegt. Im Hinblick auf Dions später vorgetragene Urteile über unproduktive und schädliche Gewerbe und Tätigkeiten (bes. § 117) wird man daher die rastlose, körperlich sehr anstrengende MurexFischerei als wertlose Dienstleistung für pure Luxusbedürfnisse einzustufen haben; s. generell H. Blum, Purpur als Statussymbol (Bonn 1978) u. die Überlegungen (zur Verwendung der Purpurfarbe für die römischen „Staatsgewänder“) von H. R. GoEtTE, Studien zu römischen Togadarstellungen (Mainz 1989) 4-6. - In der Reise-Erzählung bleibt unklar, ob die Seeleute, mit denen Dion von Chios aufgebrochen sein will, von vornherein daran gedacht, zu den an der Küste Euböas arbeitenden Purpurfischern zu fahren. Ebenso konnten sie natürlich auch aus langjähriger Erfahrung mit den Aufenthalts- und Arbeitsplätzen dieser Fischer (vgl. § 55) vertraut sein; s. o. Anm. 5.

8 Der abrupte Tempuswechsel vom Praeteritum in das Präsens (in den $\S \S 3$ f. sowie später in den $\$ \S 23.53$ und 56) soll offenbar in Verbindung mit einem lockeren Umgangston die Anschaulichkeit (und Authentizität) des jeweiligen Erzählberichtes steigern und zugleich inhaltlich bedeutsame Wendungen innerhalb der narratio akzentuieren.

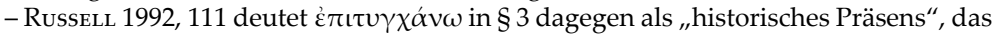
die vorangehende Beschreibung ( $\varepsilon \omega \varrho \omega \nu$ ) gezielt unterbricht.

9 Dion spielt auf die Charakterisierung einer spezifisch euböischen Haartracht in der Ilias II 12 und 542 an; vgl. dazu auch den Hinweis in Dions Dialogschrift or. 2 (Über königliche Herrschaft) §12. Zu Dions Auffassung von einer "natürlichen“ und wahrhaft hellenischen Haar- und Barttracht s. or. 36 (Borysthenes-Rede) $§ 17$ und die Selbstzeugnisse or. 47,25 und Olympische Rede (or. 12) $§ 15$; langes Haar und Vollbart als äußeres 
Zeichen eines Philosophen: or. 72 (Über die äußere Erscheinung) §§ 1-2; vgl. aber auch or. 35 (Kelainai-Rede) §§ 2f. u. 11f.

10 Zum Problem einer Umstellung im überlieferten Text von $\S 6$ s. gegen die Vorschläge von v. Arnim (1893/6, Bd. I S. 190 u. II S. 338f.) zu Recht die Bedenken von RusselL (1992, 112). Die Übersetzung folgt hier auch der von Russell erwogenen Änderung

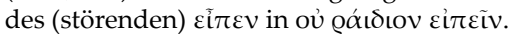

11 Der feine Sinn des Jägers für die Regeln der Gastfreundschaft zeigt sich auch darin, dass er dem Schiffbrüchigen sogleich seine Hilfe anbietet, noch bevor er sich nach dessen Herkunft und seinem Schicksal auf dem Reiseweg erkundigt hat.

12 Ein deutlicher Hinweis auf die Zeit der Verbannungszeit des Autors; zu der ärmlichen Kleidung Dions und den entbehrungsreichen Lebensverhältnissen, in denen er sich damals befand s. u.a. die Ausführungen in or. 13 (in Athen vorgetragen) § 10f.

13 Vgl. dazu die ganz ähnliche Formulierung der Diogenes-Rede (or. 6) §§ 60-62 und die stolze Feststellung Dions (Olympische Rede [or.12] § 20) über seinen Auftritt als furchtloser Wanderer-Philosoph mitten im römischen Heerlager an der unteren Donau (kurz vor dem Beginn des 2. Daker-Feldzuges des Kaisers Trajan 105 n. Chr., der die endgültige Unterwerfung des feindlichen Königreiches bringen sollte). An dieser Stelle klingt erneut innerhalb der Erzählung das Hauptthema des Traktats an: der Rang und die Würde von (äußerlich gesehen) armen, aber arbeitsamen und werktätigen Menschen in der realen Alltagswelt. Vgl. zu diesem zentralen Aspekt der Schrift auch $\S \S 36.40 .81$ f. und 103.

1440 Stadien entsprechen einer Strecke von rund 7,5 km. - Die Behausungen der beiden "Jäger"-Familien befanden sich somit, Dion zufolge, im Bereich der bewaldeten Osthänge des mächtigen (bis zu 1398 m aufsteigenden) Oche-Gebirges im Süden/Südosten Euböas (vgl. auch den Hinweis § 31).

15 Zur Ehrlichkeit und Wahrheitsliebe des Jägers vgl. auch § 65. Der in § 61 erwähnte, das Verfahren vor der ekklesia der Polis beendende Volksbeschluss enthielt tatsächlich nur die Erlaubnis einer ungehinderten (und abgabenfreien) Nutzung des in Gemeindebesitz verbleibenden Grundstücks.

16 Die Väter der beiden Jägerfamilien waren also freie Lohnarbeiter gewesen; aus § 49 geht hervor, dass sie auch das Bürgerrecht in der für dieses Gebiet zuständigen Polis besaßen. - Neben ihrer Entlohnung hatten die Hirten (offenbar gewohnheitsmäßig) ein Anrecht, innerhalb der ihnen anvertrauten Herde ein privates „Sondervermögen“ zu bilden (gewissermaßen als peculium).

17 Die Katastrophe des euböischen Großgrundbesitzers dürfte sich wahrscheinlich in der Ära des Kaisers Nero (54-68 n.Chr.) ereignet haben, vermutlich zu Beginn oder gegen Mitte der 60er Jahre. Jedenfalls sollte dieser Vorgang, im Rahmen der Erzählung, um ca. 25 bis 30 Jahre der Begegnung des Autors mit dem Jäger und seiner Familie (in der Verbannungszeit Dions) vorausgegangen sein (s. o. Einführung); vgl. dazu auch die konkrete Altersangabe für den Schwager des Jägers (§ 21). - Die direkt vom Kaiser (im griechischen Osten regulär als $\beta \alpha \sigma \iota \lambda \varepsilon u ́ \varsigma$ / „König“ / "Herrscher" bezeichnet, vgl. dazu u. a. die ausführlichen Erörterungen in der Römischen Geschichte von Cassius Dio: LIII 17,1-4 und 18,2) verfügte Konfiskation des gesamten Besitzes war offenbar auf einen möglichst schnellen Gewinn aus der raschen Aneignung der mobilen Habe des Verurteilten gerichtet gewesen, während der Grundbesitz auf Euböa - auch um die tätige Mithilfe der lokalen Behörden an der Exekution sicherzustellen - zum größten Teil in das Eigentum der Polis überführt wurde (vor allem die weitgehend nur als Viehweide nutzbaren Liegenschaften im Bergland). Dieser Zugewinn hat freilich die finanzielle Situation dieser Polis in der Folgezeit nicht wesentlich verbessern können (s. u.). - Zu dem mörderischen Tyrannenregime, den Perversitäten und dem würdelosen Auftreten Neros s. Dions Bemerkungen in orr. 4,134. 21,6 u. 8f. 31 (An die Rhodier) § 148. In dem (für die ,auktoriale Zeit“ als aktuell verstandenen) Hinweis auf die noch lange nach Neros Ende, bis in die Gegenwart hinein, auftretenden Pseudo- 
Nerones (im Kurz-Dialog or. 21,10) spricht sich allerdings Dions Verbitterung über das Regiment des (in seinen Augen noch schlimmeren) Tyrannen Domitian aus; vgl. auch or. 1,50.

18 Zur Viehwirtschaft im antiken Griechenland in einer Form der Transhumanz, die insbesondere die ertragreichen Grünlandflächen in den Ebenen vor Überweidung schützen sollte, s. ST. Georgoudi, „La transhumance dans la Grèce ancienne“, REG 87 (1974), 155-185; vgl. auch Varro, De re rustica II 29-12. - Während der Großgrundbesitzer (und Arbeitgeber) auf Euböa durch seinen Reichtum ins Verderben gestürzt wurde, konnten seine armen Rinderhirten - trotz der schmerzlichen Einbußen, die auch sie im Zuge der Konfiskation erleiden mussten - ihr Überleben durch eigene Anstrengungen und Arbeit sichern. Auf die Belastungen und existenziellen Risiken, die mit großem Reichtum verbunden sein können, geht Dion später (\$§ 93-96) noch ausführlicher ein.

19 Zur Textproblematik vgl. Russell 1992, 115, der zwar die Konjektur P. V. D. MüHLL's

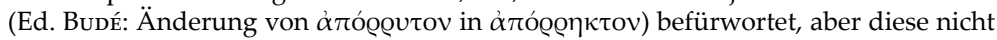

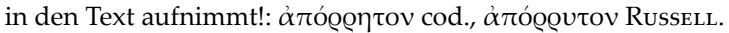

20 In die anschauliche Schilderung der Schönheit des Wohnsitzes und der Annehmlichkeiten seiner Umgebung werden vom Autor, mit feinem literarischen Gespür, nüchterne Hinweise des Jägers auf den landwirtschaftlichen Ertrag und die Nutzung des Anwesens eingefügt; zu Dions berühmter (leider verlorener) Schilderung der landschaftlichen Schönheit des Tempe-Tals am Unterlauf des Peneios (Thessalien) s. Synesios, Dion 3 und Aelian, VH III 1. Eine knappe, aber eindrucksvolle Landschaftsschilderung findet sich ferner in Dions Erzählung von seiner Begegnung mit einer wahrsagenden Priesterin in einem ländlichen Herakles-Heiligtum im Alpheiostal: or. $1,52 \mathrm{f}$.

21 Die Jagd mit Spürhunden setzte - gerade bei einem Jäger ohne Reittier - ein hohes Maß an Körperkraft und Gewandtheit voraus, da dieser mit dem aufgescheuchten Wild und den verfolgenden Hunden in ausdauerndem Lauf mithalten musste und gegebenenfalls auch das schließlich gestellte, angriffsbereite Tier mit dem Jagdspieß abzufangen hatte, s. dazu auch $\S \S 71$ f. und Dions Lobpreis dieser Form der Jagd zu Fuß oder zu Pferde (or. 3,135f.; mit deutlichem Bezug auf die Jagdleidenschaft Kaiser Trajans), als einer guten „Vorübung für das Kriegshandwerk“ und als einer Betätigung, aus der Körperkraft und Lebensfreude erwachsen. Die Jagd aus Wildgehegen heraus, bei der die Jäger an dem durch vorbereitete Netzsperren und Stoffwände stark eingeengten Ausgang auf das herangetriebene Wild lediglich zu warten hatten, wird von Dion dagegen als bequemliche "persische Unsitte“ abgewertet. In der Kynegetikos-Schrift Xenophons (in ihrer Echtheit umstritten) wie auch im Jagdbuch Arrians betonen die Autoren nachdrücklich, wie sehr die anstrengende "Jagd mit dem Hunde $^{\prime \prime}$ als hervorragendes Erziehungsmittel für Leib und Geist gelten könne; s. ferner W. RoEsner, Die Geschichte der Jagd (Zürich 2004).

22 Zum Verhalten der Hirtenhunde, die nach einiger Zeit zu ihren alten Herren zurückkehrten, vgl. Varro, De re rustica II 9,6 sowie 9,10 (Ernährung von Hirtenhunden allein mit Brei!), s. dazu auch Arrian, Cyneg. 8,1.

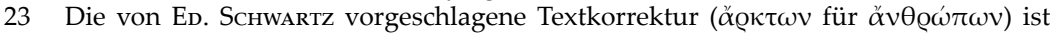
zweifellos sinnvoll; zumal der Jäger in seiner „Besitzstandserklärung“ vor der ekklesia ausdrücklich auch die (allzu rauhen) Bärenfelle erwähnt: §43. - Zur Bärenjagd in Griechenland und im Ägäisraum vgl. u.a. die bekannte, stolze Epigramm-Weihinschrift von Kaiser Hadrian aus dem Eros-Heiligtum bei Thespiai: IG VII 1818 (G. KaIBEL, Epigrammata Graeca ex Lapidibus collecta [Berlin 1878] Nr. 811); Hadrian erhoffte sich als Gegengabe und Dank für sein ganz persönliches Weihgeschenk, das Fell eines (mit eigener Hand, vom Pferde herab, getöteten) Bären, einen von Eros übermittelten Hauch von der Aphrodite Urania (deren Wesen, nach Platon, Symp. 181 c, nicht von weiblicher, sondern „,von männlicher“ Natur bestimmt wird!). S. ferner E. SCHE- 
RING, „Hadrian als Jäger. Jagd als Mittel kaiserlicher Selbstdarstellung“, in: W. MARTINI (Hrsg.), Die Jagd der Eliten in den Erinnerungskulturen von der Antike bis in die Frühe Neuzeit (Göttingen 2000) 129-155.

24 Der hier in aller Breite geschilderte Prozess einer allmählichen, natürlichen „Umerziehung“ der tumben Hirtenhunde zu "spät entwickelten“ (und daher nicht mehr besonders lern- und leistungsfähigen) Jagdhunden dürfte nicht zuletzt auch mit Dions soziopolitischer Konzeption in Zusammenhang stehen: Durch Gewöhnung an das Landleben und seine Freuden könnte wohl auch bei manchen Angehörigen der beschäftigungslosen Stadtarmut eine leidlich positive Umorientierung eintreten; vgl. auch $\S \S 107 f$. - Als zuverlässige Hirten- und Haushunde schätzte man im antiken Hellas vor allem die großen Molosserhunde; als Jagdhunde par excellence galten dagegen die kleineren Lakoner-/Spartaner-Hunde sowie die Hunde aus Kreta: Xenophon, Cyneg. 10; Arrian, Cyneg. 2,29; vgl. F. ORTH, „Hund“, RE VIII (1913) [2540-2582] 2548-2551 u. 2560-2566, s. zu Einsatz und Ausbildung von Hirten- und Jagdhunden u. a. D. J. Brewer, Dogs in Antiquity (Warminster 2001).

25 In der Übersetzung von ElLIGER 1967 ist diese (inhaltlich wichtige) Stelle irreführend übersetzt worden: „War aber der Winter gekommen, hatten unsere Väter nichts mehr zu tun, da sie weder in die Stadt hinabstiegen noch in ein Dorf“ (S. 115; ähnlich H. Номмец, Dion von Prusa. Euboische Idylle. Übersetzung mit Einführung [Zürich / Stuttgart 1959] 8, richtig dagegen Russell ad. loc.). Dion lässt an dieser Stelle vielmehr deutlich erkennen, dass die beiden Familienväter sich keineswegs aus einer grundsätzlichen Abneigung gegen das Leben in der Stadt heraus (oder gar in romantischer Verklärung des „einfachen“ Landlebens), sondern allein aus Not, wegen anhaltender Erwerbslosigkeit, aus dem engeren Bereich der Polis in die Einsamkeit der Berge und Wälder zurückgezogen haben. Dabei haben sie im übrigen in der Folgezeit mindestens zu einer der Dorfsiedlungen in der Nähe enge (auch familiäre) Verbindungen angeknüpft (s. u.).

26 Tatsächlich sind Wildtiere wie Hase und Reh daran gewöhnt (und darauf angewiesen), in der kalten Jahreszeit möglichst sparsam mit ihren Energiereserven umzugehen.

27 S. dazu die Angabe in $\S 49$, wonach der Vater des Jägers als armer, aber freier Lohnarbeiter mit Bürgerrecht die Gelegenheit nicht versäumt hatte, sich in die Stadt zu begeben, um bei der Auszahlung einer pauschal (und nach Präsenz) an die gesamte Bürgerschaft verteilten Geldspende seinen Anteil in Empfang zu nehmen. Die im Waldgebirge von vornherein als Jäger (und Gärtner) aufgewachsenen Söhne der ehemaligen Rinderhirten haben jedoch ihrerseits das Interesse an diesen nur im Stadtbereich erhältlichen Zuwendungen gänzlich verloren.

28 Die Jäger-Familien bedenken jeden Ankömmling in ihrer Waldeinsamkeit nach Kräften mit einem Gastgeschenk - und dies nicht in Erwartung einer Gegenleistung, sondern aus einem natürlichen, alter hellenischer Sitte entsprechenden Anstandsgefühl heraus. - Hirschfelle, statt Geld, stellten für den Jäger auch sonst einen konkreten, verlässlichen Wertmaßstab dar; vgl. dazu die Angaben in seiner „Besitzstandserklärung" vor der Volksversammlung §§ 43. - Der Amtsbote hatte offenbar Vollmacht erhalten, die von der Polis angeforderte Steuer-Nachzahlung in Silbergeld von den Jägern gleich an Ort und Stelle zu kassieren, im Weigerungsfalle aber einen Vertreter der angeblichen Steuersünder pünktlich zur Verhandlung in der anberaumten Volksversammlung vorzuführen.

29 Der überbrachten amtlichen Ladung an die Jäger war offensichtlich eine Vorberatung in der Polis vorausgegangen, die zu einer entsprechenden Handlungsanweisung an die Magistrate bzw. Prytanen und zur Plazierung dieser Angelegenheit auf die Tagesordnung einer regulären (und verbindlich terminierten) ekklesia-Versammlung geführt hatte. In diesem vom Jäger natürlich nicht erwähnten (sicherlich auch nicht durchschauten) Vorverfahren, das vermutlich vor dem Rat (bulé) der Polis durch- 
zuführen war, hatten sich, wie in der Erzählung implizit vorausgesetzt wird, auch schon "politische Fronten“ herausgebildet, wie die zu diesem Tagesordnungspunkt bereits detailliert vorbereiteten Reden der beiden Hauptkontrahenten vor der Volksversammlung erkennen lassen (s.u.). Dabei bleibt in Dions Erzählung unklar, ob die ekklesia hier-im Verfahren gegen die Jäger-Familien und zuvor gegen die in der Volksversammlung angeschuldigten Bürger - bereits als aktive Gerichtsinstanz in Betracht zu ziehen ist oder allenfalls Vorbeschlüsse zur Konstituierung entsprechender Gerichtsgremien zu fassen hatte.

30 Der naive Erzähler verkennt die fortifikatorische Bedeutung der Turmaufsätze auf der hohen Stadtmauer; auch die Anlage und ökonomische Bedeutung des in den Stadtbereich direkt einbezogenen Hafenplatzes sind ihm nicht vertraut. Als identifizierbare Polis bietet sich für diese Erzählung - anhand der vom Autor dargebotenen Details - am ehesten Karystos (im äußersten Süden Euböas) an: Das mehrfach mit großem Nachdruck erwähnte Kap Kaphereus im Hinterland der Stadt (in der Zeit der venezianischen Besetzung Euböas zu Cabo d'Oro verballhornt), in dessen Nähe der Wohnsitz der Jägerfamilien lag, gehörte wahrscheinlich zum Territorium der Polis Karystos. Dagegen lassen sich die Angaben in der Erzählung über ein zum engeren Stadtbereich und seinem Mauerring gehörendes, geschütztes Hafenbecken schwerlich mit den Gegebenheiten in der weit nach Süden geöffneten (von Fallwinden vom Oche-Gebirge herab und von Melthemi-Stürmen aus dem Süden bedrohten) Bay von Karystos in Übereinstimmung bringen (s. u. GoEtTE, S. 174-177). Ob man aus diesen Befunden (s. auch o. Anm. 7) bereits den Schluss ziehen kann, dass der Autor Süd-Euböa niemals kennen gelernt habe, steht jedoch dahin: Dions Anliegen gemäß zielen die Angaben in der Jäger-Erzählung in erster Linie auf ein allgemeines Bild von den Verhältnissen in den Polis-Gemeinden des zeitgenössischen Griechenlands. Spezifische Züge, die über die vom Autor vorgenommene Einordnung der (ungenannt bleibenden) Polis in Raum und Zeit hinausgingen, konnten da nur stören. - Denkbare kritische Anmerkungen des Autors zu dem in kaiserlicher Regie betriebenen Abbau von CipollinoMarmor aus der Karystia (Goette s. u. S. 188f.) waren ohnehin mit der von Dion geschätzten Rolle eines Vertrauten der römischen Führung (s. o. Einführung S. 10f.) unvereinbar. Jedenfalls aber war Dion der Abbau von farbigem Marmor im Gebiet von Karystos, wie das Zeugnis im Traktat or. 79,2 explizit belegt, keineswegs unbekannt; überdies wird an dieser Stelle, freilich ohne weitere Details zu nennen, ausdrücklich konstatiert, dass die polis der Karystier in der Gegenwart zu den „unbedeutenden

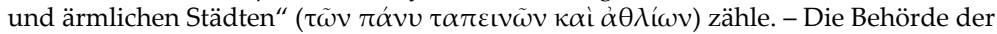

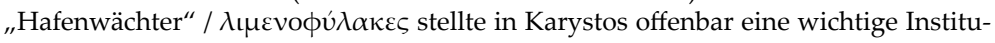
tion dar; vgl. die Katalog-Fragmente IG XII 9, nr. 8 u. 9. GoetTe (s. u. S. 183f.) will als eigentlichen Hafenplatz von Karystos die weiter östlich gelegene, geschützte Bucht von Geraistos in Anspruch nehmen; für diese Annahme spricht jedenfalls die Tatsache, dass die Kontrolle über den Hafen der Polis einer eigenen Behörde anvertraut worden war, und nicht zum unmittelbaren Aufgabenbereich der (üblichen) städtischen Ober-Magistrate von Karystos gehört hat. - Die wiederholten Verweise auf die „Höhlen von Euböa“, das Kap Kaphereus und schließlich die Untaten des Nauplios (s. u.) gaben freilich einem mutterländisch-griechischen, mit der epischen Sagentradition (und ihrer Ausgestaltung durch die Tragiker) vertrauten Leser-Publikum, Indizien an die Hand, um die im Mittelpunkt der Jäger-Erzählung stehende Polis zu identifizieren. Dion aber hatte als Autor durchaus kein Interesse daran, diese eine Polis, mit ihren inneren Gebrechen (u.a. einer gierig nach Spenden verlangenden ekklesia und einer z.T. mit bedenklichen demagogischen Mitteln agierenden Führung), auch namentlich vorzuführen und sie damit regelrecht ,an den Pranger zu stellen“. Insofern entsprachen nicht nur das diskrete Verschweigen des Polis-Namens, sondern wohl auch bewusste Verfremdungen bzw. Ausblendungen in den topographischen 
Angaben den Intentionen des Autors. Zu Dions genereller Zurückhaltung hinsichtlich direkter Namensnennungen vgl. orr. 15,3. 21,6f. und 11.

31 Zum Topos der schockartigen Konfrontation eines naiven, unerfahrenen Landmannes mit dem turbulenten Treiben im Zentrum einer Stadt, in der eine Atmosphäre allgemeiner, lärmiger Geschäftigkeit und Aggressivität herrscht, s. u. a. Verg. Ecl. 1,19; vgl. auch Dions Schilderung in or. 20,9f.

32 Im Erzählbericht des Jägers, der von seinem Lebensweg her keinerlei Kenntnisse über die Präliminarien und den regulären Instanzenzug innerhalb der Entscheidungsfindung der Polis haben konnte, bleibt verständlicherweise unklar, ob es sich bei diesen

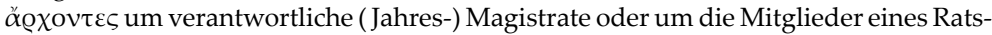
präsidiums der bulé handelte, die (wie im klassischen Athen die Prytanen bzw. später die prohedroi) auch in der ekklesia-Versammlung den Vorsitz zu übernehmen hatten. Möglicherweise hat sich von der Polis Karystos eine Liste der Mitglieder des Stadtrats (aus hadrianischer Zeit) erhalten, die, noch immer nach demokratischer Sitte, jeweils für ein Amtsjahr durch Losung aus der Bürgerschaft bestellt wurden: IG XII, 9, 11. Dieses Gremium bestand aus 72 Ratsherren in 12 Abteilungen, die sich offenbar allmonatlich in der Wahrnehmung ihrer präsidialen Aufgaben abwechselten; an

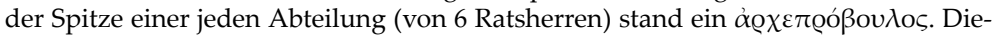
se Terminologie lässt darauf schließen, dass zu den Aufgaben der jeweils amtieren-

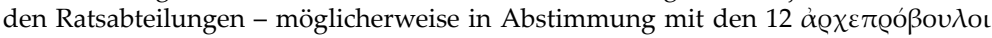
insgesamt - neben der Vorbereitung der Tagesordnung für die ekklesia auch die For-

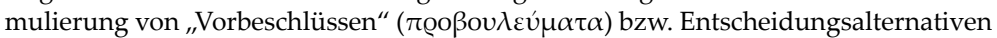
gezählt hat (s. u. Anm. 34). - Nach F. CaIrNs, „IG XII.9 11: An Inscription of Karystos", ZPE 134 (2001) 121-136 soll dieser Inschriftenblock jedoch nicht von Karystos, dem Fundort auf Euböa, stammen, sondern über See, aus dem südlichen Kleinasien, dorthin verbracht worden sein.

33 In der umständlichen Beschreibung des regelmäßig für die Volksversammlung genutzten Theaterbaus knüpft der Jäger an die Schilderung seines eigenen Wohnsitzes (s. o.) in der Bergwald-Region an. - Bereits in der (um $355 \mathrm{v}$. Chr. verfassten) militärund politikwissenschaftlichen Abhandlung des Aeneas Tacticus zählt das Theater im Stadtareal ebenso wie die Agora zu den politisch zentralen Plätzen einer Polis, die im akuten Krisenfall einen besonderen Schutz von der bedrohten Bürgerschaft verlangten: vgl. III 5f. - Für das 1. Jh. n. Chr. bietet der Bericht über eine spontane Versammlung und Protestkundgebung gegen die Mission des Apostels Paulus in Ephesos (Lukas, Apg. 19, 29-32) einen illustrativen Beleg, wobei der amtierende grammateus (des demos oder der bulé?) die aufgeregte Menge hier eindringlich auf die Instanz einer regulären ekklesia-Versammlung verweist; vgl. jetzt Vujčrć 2009, 160. Auch in Dions Heimat-Polis ist das Theater der reguläre Versammlungsplatz für die Volksversammlung: or. 40,6f.

34 Der Ablauf dieser ekklesia-Tagung basierte offensichtlich auf einer umfangreichen (und entsprechend vorbereiteten und bekanntgemachten) Tagesordnung; vgl. VUJčıć 2009, 165-167. Die Entscheidungskompetenz liegt ganz in der Hand der souveränen Bürgerschaft; jedenfalls kann von einer straffen, autoritativen Steuerung der Volksversammlung durch die präsidierenden archontes-Amtsträger hier keine Rede sein (vgl. § 43): Die gut besuchte ekklesia äußert sich, im Fortgang der zu behandelnden Sachverhalte und Fragen, höchst unterschiedlich und stets impulsiv; spontane Wortmeldungen und Beschlussanträge werden, im Rahmen der Tagesordnung, ohne formale Bedenken aufgegriffen und in der Beschlussfassung berücksichtigt (s. u. Anm. 37). - Ehrenbeschlüsse für Spenden oder in Aussicht gestellte private Leistungen zugunsten der Polis, aber auch Klagen über Vernachlässigung bzw. missbräuchliche Nutzung von Gemeindebesitz und -grundstücken oder Rückstände in der Erfüllung übernommener Liturgie-Verpflichtungen haben erkennbar einen großen Teil 
der Agenda ausgemacht; in diese Richtung weist auch die mit drohenden Untertönen versehene Bemerkung in der Anklagerede des „Demagogen“ (§ 29).

35 Die bildhaft-plastische Schilderung des Jägers zielt auf die Fassungslosigkeit und emotionalisierte Verzweiflung der in der Versammlung attackierten Bürger, nicht auf einen spezifischen Demutsgestus; eher wäre wohl an einen Impuls zu schnellen flehentlichen Bewegungen innerhalb der Orchestra vor der ekklesia zu denken; vgl. hierzu auch die genaue Entsprechung (in Dions Schilderung der wilden Leidenschaftlichkeit und Gestik unter dem Rennbahn-Publikum in Alexandrien): or. 32 (15 Arnim) § 89. - Die Polis ist in ihrer eigenen Rechtsphäre autonom, und die ekklesia kann offenbar schwerwiegende Sanktionen verhängen; bezeichnend ist in diesem Zusammenhang auch die spontane Bemerkung in Plutarchs Amatorius-Dialog 11,755B zur Situation im zeitgenössischen Thespiai (Boiotien). Von einem solidarisch handelnden und die Volksmasse beliebig, nach den eigenen Interessen, lenkendem „Honoratiorenregime“ kann hier, in der "Mitte von Hellas“, gewiss nicht die Rede sein. Dafür bestehen auch viel zu scharfe Rivalitäten und persönlich-sachliche Gegensätze unter den aktiven Politikern dieser Stadt - ein Umstand, den der hier nur allzu sachverständige Zeitgenosse Plutarch von Chaironeia in seiner (über den persönlichen Adressaten hinaus an die politischen Führungsschichten der kaiserzeitlichen Polisstaaten gerichteten) Denkschrift Praecepta gerendae reipublicae (798A-825F) bekanntlich sehr beklagt. Aufschlussreich sind in dieser Hinsicht auch die Bemerkungen Dions in seiner Rechtfertigungsrede vor dem Demos in Prusa or. 45,8.

36 Zu der angsteinflößenden Kulisse und schwer beherrschbaren Dynamik einer großen, gut besuchten Volksversammlung s. auch die Bemerkungen Plutarchs, der die Volksmassen in den zeitgenössischen ekklesia-Versammlungen u.a. mit einem „argwöhni-

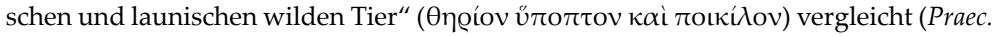
ger. rei. 800C, vgl. 801E) und ihre Beifalls- und Unmutsäußerungen mit aufgewühlter Meeresbrandung (819F); vgl. auch Dions Bemerkung (2. Tarsos-Rede § 33), wonach der führende Gemeinde-Politiker sich immer wieder gegen die emotionalisierte Volksmenge zu stemmen habe - „,wie ein Vorgebirge“" das der Brandung des Meeres standhält und dahinter einen sicheren Naturhafen bildet; zum häufigen Vergleich einer erregten Volksmenge mit dem Meer s. auch Dion, or. 3,49 u. or. 32,22f. (mit ZitatVerweis auf Il. II 144-146); vgl. auch Liv. XXXVIII 10,5 u. Polyb. XXI 31,9-11 B.-W., ferner Cicero, Pro Cluentio 138. - Die Zähmung und, wenn es denn sein muss, auch die Manipulation der allzu impulsiven, aber noch immer über weitreichende Kompetenzen verfügenden Volksversammlung ist daher, nach Plutarchs Auffassung (Praec. ger. rei. 818 C), eine der wesentlichen Aufgaben des klugen, verantwortungsbewussten Stadtpolitikers, der seine Polis vor inneren Unruhen und einer dann drohenden Intervention der römischen Herrschaftsträger bewahren will; hierauf weisen nicht zuletzt die Mahnungen des grammateus auf der spontan im Theater stattfindenden Protestkundgebung in Ephesos hin (s.o. Anm. 33).

37 Offenbar stand grundsätzlich jedem Bürger dieser Polis volles Rederecht ( $\pi \alpha \varrho \varrho \eta \sigma i ́ \alpha)$ in der Volksversammlung zu; diese konnte freilich auch ihrerseits nach Belieben Beifall und Missfallen äußern. Generell wurde hier, anders als in der klassischen Demokratie Athens, das Reglement für Reden, persönliche Stellungnahmen oder auch nur einfache Wortmeldungen vor der Öffentlichkeit sehr liberal gehandhabt, so dass viel Raum für Emotionsäußerungen und sogar tumultartige Unmutsbekundungen gegeben war. Dagegen haben zu Dions Zeit in der kilikischen Metropole Tarsos (und zeitweilig wohl auch in Prusa; s. o. S.7) erhebliche timokratische Einschränkungen des Rede- und Antragsrechtes in der ekklesia bestanden. - Mit großem Geschick hat der Autor die umständliche, aber aus kritischer Distanz beobachtende Schilderung des politisch ganz unerfahrenen Jägers vom Verlauf einer stürmisch bewegten Volksversammlung zu einer satirischen Überzeichnung genutzt, in der zweifellos Dions eigene Erfahrungen, namentlich mit der ekklesia von Prusa, ihren Niederschlag ge- 
funden haben; vgl. dazu u.a. die in scharfem Ton vorgetragenen Verteidigungsreden in Prusa orr. 46 und 47. - Allerdings wird man in diesem Rahmen auch die Unterschiede zwischen der politischen Praxis in einer ",alt-hellenischen“ Polis (mit traditioneller Demokratie; vgl. für diese Zeit auch Plutarch, Praec. ger. reip. 817A-B) und der verfassungspolitischen Situation in Städten wie Tarsos oder Prusa berücksichtigen müssen, zu deren wichtigsten Institutionen - unter römischer Einflussnahme - mächtige Ratsgremien mit Zensus-Qualifikation (und lebenslänglicher Mitgliedschaft der einmal gewählten Ratsherren) zählten; zu den anhaltenden Spannungen zwischen Rat und Ekklesia in den beiden genannten Polis-Gemeinden s. Dion, or. 34,16 und or. 50 passim.

38 Der „Demagoge“ projiziert mit diesem Anklagepunkt ein charakteristisches „Feindbild“ auf den mittellosen, am Rande der $\chi \omega \omega \varrho \alpha$ lebenden Jäger: Die vorbereitete Attacke richtet sich gegen reiche Mitbürger, die ihren enormen Grundbesitz angeblich durch Okkupation von Gemeindeland noch zu erweitern bestrebt sind, sich den Freuden der Jagd hingeben, daher auch permanent auf dem Lande wohnen und sich vom Leben im urbanen Zentrum der Polis zurückziehen wollen. Sie denken auch gar nicht mehr daran, dort ihren finanziellen und politisch-sozialen Verpflichtungen gegenüber der Stadtbevölkerung und der Polis-Bürgerschaft insgesamt nachzukommen.

39 Das Gebiet an den „Höhlen von Euböa“ gehörte offensichtlich zum Territorium der (ungenannt bleibenden, aber zumindest grosso modo lokalisierbaren) Polis. - Wenig später ist in der Anklagerede des „Demagogen“ sogar von ganzen Dörfern die Rede, die sich die Jägerfamilien dort angeblich angeeignet haben sollen. Grundsätzlich bestand für das gesamte Territorium der Stadt eine Steuerpflicht, die nur für aner-

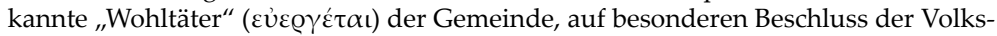
versammlung, aufgehoben werden konnte. Darüber hinaus waren für die Nutzung des Gemeindelandes alljährlich Abgaben zu entrichten. In dieser Hinsicht konnte den Jäger-Familien tatsächlich eine Verfehlung zum Vorwurf gemacht werden. - Als Liturgie (Grundbedeutung: ,Dienst für das Volk') wurden Leistungen bezeichnet, die in unregelmäßigen Abständen aus den Privatmitteln wohlhabender Bürger - entsprechend ihrer Finanzkraft und auf mehr oder weniger freiwilliger Basis - für die Allgemeinheit erbracht wurden; im Vordergrund standen die würdige Ausgestaltung der alljährlich gefeierten Feste der Polis, aber auch die Übernahme von Gesandtschaften (auf eigene Kosten) und die Leitung und Finanzierung wichtiger Bauvorhaben der Stadt.

40 Das $\pi \lambda \varepsilon \dot{\theta} \operatorname{\varrho ov}$ (=10000 Quadratfuß) umfasste ca. 9,5 ar; 1000 Plethren waren also eine Fläche von nicht weniger als 95 ha. - Das attische Hohlmaß choinix fasste ca. 0,9 Liter; das Maß- und Gewichtesystem der euböischen Polis entsprach also vollständig dem der Athener, vgl. auch § 44. In den Behauptungen des "Demagogen“ bleibt (gewiss absichtlich) unklar, ob die angeblich erreichbare „Sachspende" für die Bürgerschaft aus den fälligen Abgaben oder insgesamt aus der Getreide-Ernte des großen „Landgutes" in den Bergen bestritten werden sollte; alle Angaben basieren (als Karikatur!) auf maßlosen und in demagogischer Manier präsentierten Übertreibungen. Es ist daher auch nicht möglich, aus diesen „Daten“ auf die Gesamtzahl der erwachsenen und empfangsberechtigten Polis-Bürger zu schließen. In der sofortigen Reaktion innerhalb der Volksversammlung zeigt sich im Hinblick auf Liturgien-Leistungen und „Wohltaten" der Reichen die besondere Vorliebe des Demos für direkte, pauschale Austeilungen von Geld- und Sachspenden an die Stadtbürger (statt gemeinnütziger und auch auf längere Sicht nutzbringender bzw. urbanistisch sinnvoller Investitionen).

41 Der Redner droht mit einem Verfahren, das aus dem Strafrecht der athenischen Demokratie des 5./4. Jh. v. Chr. gut bekannt ist ( $\alpha \pi \alpha \gamma \omega \gamma \eta$ ) und demnach auch in der Rechtspraxis der euböischen Städte Aufnahme gefunden hat: Kriminelle konnten bei offenkundigem Tatbestand bzw. auf frischer Tat ertappt - von engagierten Bürgern festgenommen und umgehend der für Verhaftungen und Strafvollzug zuständigen Behörde übergeben werden. Dieses Verfahren fand in Athen auch bei politischen 
Straftaten (und bei Gefahr im Verzuge!), mit Zustimmung der Volksversammlung, Anwendung. Die härtesten Konsequenzen einer solchen Inhaftierung konnten allerdings durch die Stellung von Bürgen zumindest vorläufig abgewendet werden; s. J. H. Lipsius, Das attische Recht und Rechtsverfahren (Leipzig 1905) 317.

42 Das Felsenkap Kaphereus bildet die Spitze des nördlichen, weit nach Osten gerichteten Ausläufers des Oche-Gebirges im Südosten Euböas. In der griechischen Sagentradition war vornehmlich dieses Kap der Ort des fatalen Schiffsbruchs der von Troia siegreich heimkehrenden Achäer-Flotte. Die Gefährlichkeit des Seeweges um das Kap Kaphereus herum war in der Antike sprichwörtlich: Hdt. VIII 7,1; Strabon VIII 6, 2 p. 368,33 RadT; Pausanias II 23,1 u 36,6 u. Philodem, Rhet. 1 p. 260,20 Sudhaus u.a.m. - Zur Verpflichtung der Statthalter, gegen heimtückische Feuersignale von Fischern und generell gegen Strandräuberei vorzugehen, s. Ulpian, Dig. 47,9,10.

43 Nauplios, der Vater des Palamedes, hatte durch irreführende Feuersignale die Flotte der Achäer in die Klippen am Kap Kaphereus gelenkt, um mit dieser Katastrophe Rache für die Hinrichtung seines Sohnes während der Belagerung von Troia zu nehmen (Apollodoros, epit. VI 7,11; Schol. Eur. Or. 432; Schol. Lycophr. Al. 386 u. 1093; Hyg. Fab. 116; s. o. Anm. 42 zu Strabon und Pausanias). Der kluge und erfindungsreiche Palamedes war dort von seinen persönlichen Feinden, Odysseus und den Atriden, fälschlich des Verrats beschuldigt und im Heerlager zum Tode durch Steinigung verurteilt worden; s. zu diesem Mythos auch Dion, or. 13,21 u. Sophokles, Nauplios, TrGrF III p. 353f.

44 In seinem Auftreten unterscheidet sich dieser Politiker markant vom Habitus seines demagogisch-anklägerischen Vorredners; schon eine einfache Bitte des offenbar sehr angesehenen Mannes reicht aus, um die aufgebrachte Menge im Theater wieder zur Ruhe zu bringen. Mit festem Selbstbewusstsein weist er ohne Umschweife auch ( $\S$ 34) auf seinen großen (partiell freilich brachliegenden) Landbesitz auf dem Territorium der Polis hin und distanziert sich schon damit von seinem offenbar wesentlich ärmeren, als „Demagoge“ agierenden Rivalen, der sich, hier wie auch sonst, um die wirklichen, längerfristigen Interessen und das Erscheinungsbild seiner Heimatstadt nicht angemessen gekümmert habe (s.u.). - Mit Lokalpolitikern dieses Schlages und ihrer hartnäckigen Opposition gegen große Bauprojekte ambitionierter „Wohltäter“ (die freilich neben Nutzen und Ansehen ihrer Heimatstadt auch ihr ganz persönliches Prestige mit hohen öffentlichen Ehrungen steigern wollten) hat sich Dion in Prusa des öfteren auseinandersetzen müssen (vgl. u.a. orr. 40. 45.46 und 47). Diese „Demagogen" beriefen sich ihrerseits gerne auf die manifesten Tagesbedürfnisse und Versorgungsansprüche der ärmeren, städtischen Volksschichten.

45 Aus dem Zusammenhang wird deutlich, dass $\dot{\alpha} \varrho \gamma$ í $\alpha$ hier nicht einfach als „Arbeitslosigkeit", sondern negativ als „Untätigkeit" bzw. „Nachlässigkeit“ aufzufassen ist. Die durch einen starken Geburtenrückgang in Griechenland ausgelöste, bereits kurz nach der Mitte des 2. Jh. v. Chr. spürbar gewordene „demographische Krise“ ist schon in Polybios' Historien-Werk thematisiert und nach ihren (angeblich mentalitätsbedingten) Ursachen und fatalen Wirkungen hin analysiert worden (XXXVI 17,5-10 B.W.). Zur modernen Forschungsdiskussion über die allgemeine Lage im kaiserzeitlichen Hellas s. KL. Freitag, „Das Problem der schrumpfenden Stadt in der griechischen Antike“, in: A. Lampen / A. Owzar (Hrsgg.), Schrumpfende Städte. Ein Phänomen zwischen Antike und Moderne (Köln u.a. 2008) 1-15.

46 Auch hier wird deutlich, dass die $\chi \omega$ ○ $\alpha$ dieser Polis sich, anders als die Landmark von Eretria, nicht über mehrere Landschaften und Klein-Regionen (mit Unterzentren) erstreckte, sondern - wie in der Karystia - einerseits aus einer fruchtbaren Ebene im engeren Umkreis des Stadtgebietes und andererseits aus dem sich bis zum Kap Kaphereus hin erstreckenden Wald- und Berggelände des Oche-Gebirges bestanden hat (s. o. Anm. 30). 
47 An dieser Stelle klingt offenbar erneut das am (verlorenen) Anfang der Schrift definierte Generalthema der Abhandlung an; vgl. $\S \S 9,40$ und besonders 81 .

48 Mit dem hier nur knapp umrissenen „Agrar- und Sozialprogramm“ befand sich der „anständige Politiker“ in bester Übereinstimmung mit den, seit der Ära Nervas auch von der Reichsführung, insbesondere in Italien, ergriffenen Initiativen zur Restrukturierung der Landwirtschaft und gleichzeitigen Förderung verarmter, landloser Bevölkerungsschichten; vgl. die in dem Dokument CIL VIII, nr. 10570 noch greifbare lex Hadriani zu einer mit öffentlichen Mitteln geförderten Vergabe von Wirtschaftsparzellen in Erbpacht auf kaiserlichem Domänenland an arme bzw. landlose Arbeitswillige. Eine gute Parallele zu den Vorschlägen des ,, anständigen Politikers“ stellt die (allerdings durch ein Edikt des Statthalters M. Ulpius sowie ein Sendschreiben des Proconsuls Geminius Modestus abgesicherte) Vergabe von Landparzellen aus Gemeinde- und Tempelbesitz durch die obersten Stadtmagistrate an jeden nutzungswilligen Bürger in der kleinen boiotischen Polis Thisbe dar; für diese in ihrer Größe begrenzten und auf Erbpacht übergebenen Anbauflächen und Grundstücke soll in den ersten fünf Jahren ihrer Bewirtschaftung völlige Abgabenfreiheit bestehen: Syll. ${ }^{3} 884=$ IG VII p. 748 (Ende des 2. Jh. n. Chr.; vgl. auch PIR ${ }^{2}$, IV nr. 150). Ein ähnliches, angeblich jedoch auf das gesamte Reichsgebiet bezogenes Ansiedlungs- und Bewirtschaftungsprojekt wird im Geschichtswerk Herodians (II 4,6) dem Kaiser Pertinax, der freilich nur kurze Zeit (193 n. Chr.) regiert hat, zugeschrieben. Immerhin hatte schon Kaiser Claudius (in einem leider nur fragmentarisch erhaltenen Brief an den Proconsul von Achaia L. Junius Gallio) gegen die Verödung des Gemeindelandes von Delphi die Initiative zu einem großzügigen Siedlungsprogramm ergriffen: J. H. Oliver, Greek Constitutions of Early Roman Emperors (Philadelphia 1989) nr. 31.- Auffällig bleibt in unserem Zusammenhang, dass in der Rede des ",anständigen Politikers“, in dessen Projektplan immerhin ein großer Teil des Gemeindevermögens einzubeziehen war, kein Wort darüber verloren wird, ob es notwendig oder zumindest vorteilhaft sein könne, zuvor jedenfalls die Zustimmung des römischen Statthalters oder sogar der Regierung in Rom einzuholen. - Den ",anständigen Politiker" wird man mitsamt seinem auf soziale Stabilisierung ausgerichteten Agrarprogramm ohne Bedenken als Identifikationsfigur für Dion in seiner Eigenschaft als „,Stadtpolitiker“ in der Polis Prusa in Anspruch nehmen dürfen.

49200 Plethren entsprechen rund 19 ha, stellen also die ökonomische Basis für einen sehr ansehnlichen Bauernhof dar (erst recht im Hinblick auf antike Verhältnisse; dazu die Befunde, die H. LohmanN in topographischen survey-Studien in Süd-Attika ermitteln konnte: Atene I [Köln u.a. 1993]). - Noch immer besaß das lokale Polis-Bürgerrecht einen hohen Stellenwert, war es doch vielerorts mit beträchtlichen sozialen Vergünstigungen ausgestattet; im kilikischen Tarsos konnte man zu dieser Zeit das individuelle Polis-Bürgerrecht mit einer ansehnlichen Liturgie-Spende von 500 Drachmen erwerben. Die Vergabe des Bürgerrechts blieb daher auch fest in der Kompetenz der Polis-Gemeinden, die sich freilich ihrerseits von der Anwerbung und dauerhaften Gewinnung wirtschaftlich tüchtiger und qualifizierter Zuwanderer große Vorteile versprechen konnten, vgl. dazu auch das in or. 45,13 knapp umrissene Projekt Dions, in seiner Heimatstadt einen großen бvvoıkı $\sigma$ uós, unter Einbeziehung der (offenbar noch nicht zur Voll-Bürgerschaft zählenden) Landbevölkerung, aber auch mit starker Beteiligung von Zuwanderern aus anderen Städten, in Gang zu setzen. In die gleiche Richtung zielen Dions Empfehlungen zur Bürgerrechtspolitik in Tarsos, dem Provinzzentrum Kilikiens: 2. Tarsos-Rede or. 34,21-23. - In der Rede des „,anständigen Politikers“ klingt bereits an dieser Stelle (vgl. u. § 60) der Wortlaut der bekannten „hortativen Formel" aus der Standardfassung hellenischer Volksversammlungsbeschlüsse an (und markiert so die Nähe zur stadtpolitischen Praxis).

50 Die Entvölkerung und der sozio-ökonomische Niedergang in den Städten und Landgebieten des zeitgenössischen Griechenlands wird von Dion des öfteren beklagt; vgl. 
hier $\S 121$, ferner or. 12 (Olympische Rede) § 85 sowie or. 31 (Rhodier-Rede) § 158f. und or. 33 (1. Tarsos-Rede) § 24, speziell zu Thessalien und Arkadien; vgl. auch die Klage in Plutarchs Dialogschrift De defectu oraculorum 8,413F-414D über die bedrückende

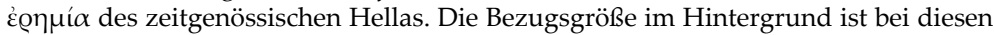
gegenwartskritischen Bemerkungen freilich stets die Blütezeit des klassischen Hellas im 5./4. Jh. v. Chr. Angesichts der in konkreten topographisch-historischen Sachverhalten vielfach übereinstimmenden Angaben bei Pausanias wird man diese Aussagen jedoch nicht leichthin relativieren oder gar als literarischen Topos auffassen dürfen. In den besonders drastischen Angaben in Strabons Geographica VIII 4,11 p. 362, 28-32 RADT (Lakonien), VIII 8,1 p. 388, 17-23 (Arkadien); IX 2,5 p. 403, 1-7 (Theben-Boiotien) spiegeln sich allerdings noch die großen Substanzverluste und Zerstörungen gerade in Griechenland während der römischen Bürgerkriege des 1. Jh. v. Chr. wider (s. o. Anm. 48). Die Kontroversen in der aktuellen archäologischen und althistorischen Forschungsdiskussion halten in diesen Grundsatzfragen noch immer an (s. u. den Beitrag von ENGSTER in diesem Band). - Immerhin ist es während eines nur kurzen Durchganges durch die Stadt dem scharfen Auge des Jägers nicht entgangen, dass nicht wenige Häuser im Stadtareal, das insgesamt doch von einer so großen, lärmenden Menschenmasse bevölkert wurde, leer standen: $§ 50$.

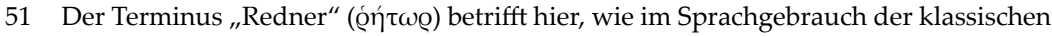
Demokratie Athens des 5./4. Jh. v. Chr., den (persönlich verantwortlichen) Antragsteller im Ratsgremium oder in der Volksversammlung: Es geht also um die aktiven, miteinander heftig rivalisierenden Politiker der Stadt, nicht etwa um „Rhetoriklehrer" oder „Festredner“; s. dazu auch Dions Ausführungen in dem Fragment or. 22,1. 5f.

52 Ein Gymnasion (mit Übungsplätzen für allgemeine Jugendbildung, Wehrsport und agonistische Festlichkeiten) und eine Agora, an der sich die wichtigsten Amtsgebäude befanden, waren die für das politisch-gesellschaftliche Leben in der Stadt zentralen Plätze; s. generell R. HAENsch, „Amtslokal und Staatlichkeit in den griechischen Poleis“, Hermes 131 (2003) 172-195. Seit der Epoche des Hellenismus gehörte eine Gymnasion-Anlage (möglichst innerhalb des Mauerrings der Stadt) zu den in politischer wie urbanistischer Hinsicht nahezu unentbehrlichen Einrichtungen einer Polis. Der Höhepunkt der institutionellen und architektonischen Ausgestaltung der Gymnasien wurde in der Welt der hellenischen Polisstaaten offenbar erst im 2. Jh. v. Chr. erreicht, s. dazu die einschlägigen Beiträge in dem Sammelband: KAH / Scholz 2004. Der Erhaltungszustand der Anlagen im Gymnasion war in der Kaiserzeit freilich davon abhängig, ob die Institution der Ephebie bzw. der Neoi-Gemeinschaft (eines inzwischen nur noch auf freiwilliger Basis geleisteten Milizdienstes, in Verbindung mit sportlich-athletischen und paramilitärischen Übungen) in der jeweiligen Polis noch aufrechterhalten wurde; vgl. dazu Dions kritische Bemerkungen zu dem Betrieb und den typischen Besuchern der zeitgenössischen Gymnasion- und Palästra-Anlagen: or. 3 (Über das Herrschertum) \& 126: Dion wertet die dort betriebenen Leibesübungen als unproduktive und ziellose Beschäftigung für wohlhabende Müßiggänger. Zu den spezifischen Funktionen und der (vielfach vorgenommenen) Umgestaltung der Gymnasions-Stätte durch Bäderanlagen in der hohen Römischen Kaiserzeit s. u.a. die Studie von W. PLeKet, "The Infrastructure of Sport in the Cities of the Greek World“, Scienze dell' Antichità 10 (2000) 627-644; vgl. dazu auch Dio, or. 47,17.

53 Statuen und regelmäßig ausgerichtete Kultfeiern für die in besonderer Weise mit der Jugend verbundenen Gottheiten Eros, Hermes und Herakles gehörten zu der normalen Skulpturausstattung eines Gymnasions, s. dazu R. von DEN HofF, „Ornamenta $\gamma v \mu v \alpha \sigma \iota \omega \delta \eta \eta "$, in: КAH / Scholz 2004, 373-405. und das kritische Korreferat von W. MARTINI, „Bemerkungen zur Statuenausstattung der hellenistischen Gymnasien“, ebendort S. 407.

54 Mit dem Verweis auf diese ohne Rücksicht auf die Belange und das Erscheinungsbild der Stadt betriebene Kleinviehhaltung - mit täglichem Austrieb aus dem Wohnhaus 
heraus (zu dem üblicherweise ein Hof mit einem kleinen Hausgarten gehörte) - wird der „demagogische“ Ankläger von seinem Gegenspieler, dem wohlhabenden, „anständigen Politiker", als ärmlicher, an der Würde und dem guten Aussehen seiner Heimatstadt (im Rang-Wettstreit mit den Nachbar-Poleis und auch bei ihrer Werbung um hochrangige Besucher aus dem „Ausland") desinteressierter Banause abqualifiziert. - In or. 40,8 erinnert Dion seine Mitbürger in Prusa eindringlich daran, wie sehr sich ihre Polis bei Antrittsbesuchen von Proconsuln schon durch den Anblick, den damals ein hässliches, verfallenes Gebäude mitten im Zentrum der Stadt bot, regelrecht blamiert habe.

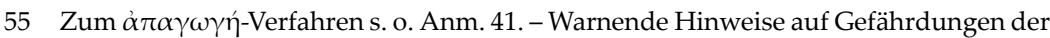
Sicherheit der Polis durch Kriminalität im Innern der Stadt und durch Räuberbanden in der verödeten $\chi \omega \hat{\varrho} \alpha$ begegnen mehrfach in der Schrift, ohne dass der Autor diesem Problem jedoch große Aufmerksamkeit schenken wollte, vgl. §§ 48f. (aus der Rede des Jägers) und 109. Zur Gefährdung der Einwohner auf dem Lande in dieser Zeit durch Räuberbanden s. u.a. Apuleius, Metam. IV 23,4 (Ausspruch eines Räubers:,,Armut zwingt uns in diesen Beruf“), vgl. auch Metam. II 18 (Thessalien): Die Truppen des Statthalters waren zu weit entfernt, um an Ort und Stelle Sicherheit gewährleisten zu können. S. ferner die Dokumentation bei Th. Grünewald, Räuber, Rebellen, Rivalen, Rächer. Studien zu latrones im Römischen Reich (Stuttgart 1999), passim. - Zum späteren erfolgreichen Einsatz städtischer Alarmeinheiten während des Einfalls der Kostoboken (170/1 n. Chr.) in Hellas s. dagegen Paus. X 34,5.

56 Auf diese Klausel in dem Beschlussantrag, den der „anständige Politiker“ am Ende seiner Rede skizzenhaft vorgetragen hat, beziehen sich die anschließenden Fragen des ă $\chi \omega v-{ }_{-}$, Amtsträgers “ an den Jäger: $\S \S 43 f$.

57 Auf den Rest der immer leidenschaftlicher geführten Debatte zwischen dem „Demagogen", der sich, ungeachtet der Unmutsäußerungen in der ekklesia, offensichtlich noch nicht in die Enge gedrängt fühlen musste, und seinem in soziopolitischer Hinsicht weit überlegenen Rivalen wird nicht weiter eingegangen. Beide sind hinreichend als erbitterte, auch persönlich verfeindete Gegenspieler auf der Ebene der StadtPolitik vorgestellt worden.

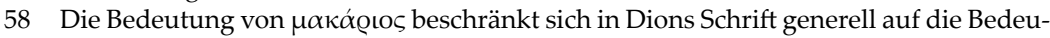
tung ,reich' / , wohlhabend': vgl. auch $\S \S 107$ und 145. - Auf den vom „Demagogen“ behaupteten (nach damaligen Kaufpreisen jedoch unerschwinglich teuren) Erwerb und Besitz von Sklaven geht der Jäger in seiner Erwiderung überhaupt nicht ein; vgl. dazu generell Dion, or. 10 (Diogenes-Dialog).

59 Zeugen diese Worte des Jägers von selbstbewusster Großzügigkeit und einer kraftvollen, inneren Freiheit gegenüber allen materiellen Gütern (eine wahrhaft philosophische Haltung, die er offensichtlich auch bei seinen Familienangehörigen voraussetzen konnte), so reagiert die Volksversammlung geradezu reflexhaft auf jedes Anzeichen für eine in Aussicht stehende Geld- oder Sachspende mit erwartungsvollem Beifall, ohne sich über die jeweiligen Gegebenheiten ernsthaft Gedanken zu machen; s. dazu auch $\S \S 44$ und 62, vgl. ferner Dions energische Abmahnung in der Alexandria-Rede or. 32 (15 ARnim) §31. Den Hintergrund für dieses Verhalten stellt sicherlich eine zumindest für Teile der städtischen Bevölkerung akute und bedrückende Notsituation, in einem vollständig von der Geldwirtschaft bestimmten Alltagsleben, dar - eine Problematik, mit der sich Dion später ( $\S \S 105 f$.) eingehend auseinandersetzt; zur Erwartungshaltung der Stadtarmut und ihrer Hoffnung auf Geldspenden aus den Kreisen der Wohlhabenden s. auch Plinius, ep. X 116,1f. u. 117,1.

60 Diese Anfrage des offenbar mit dem Präsidium in der ekklesia beauftragten Amtsträgers zielte, dem Zusammenhang nach, nicht auf eine angeblich abstrakte und „ideologische" Spendenbereitschaft, die es gegenüber dem demos durch ein prinzipielles Bekenntnis zu bekräftigen galt (gegen MA 2000, 114). Vielmehr ging es darum, unverzüglich und in aller Öffentlichkeit eine handfeste Kaufpreis-Summe für den auf 
Gemeindeland errichteten Wohnsitz und das Anwesen der Jäger auszuhandeln. Die im Anschluss daran geschilderte Verärgerung des präsidierenden ǒ $\chi \omega \omega v$ erklärt sich aus der naiven Verständnislosigkeit des Jägers, der persönlich weder Geld besaß noch jemals Erfahrungen mit Geldanlagen und -zahlungen gemacht hatte; vgl. dazu auch $\S 48$.

61 Zur Kleinvieh-Haltung der Jäger-Familien an ihrem Wohnsitz vgl. auch § 47; auffällig ist allein, dass weder Schafe noch Federvieh Erwähnung finden; zu letzterem s. jedoch $\S 76$. Angesichts der intensiven Jagd auf Wildschweine konnte - jedenfalls für den Alltagsbedarf - auf die Aufzucht und Mast von Hausschweinen leicht verzichtet werden (s.u. $\S \S 72$ ).

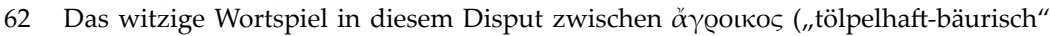

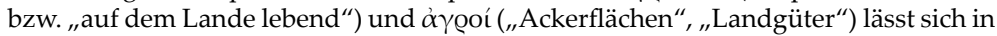
der Übersetzung nur unvollkommen wiedergeben.

63 Das attische Talent konnte sowohl als gängiges Marktgewicht (von ca. $27 \mathrm{~kg}$ ) wie auch als Münzfuß-Standard im Währungssystem (mit ca. 26,2 kg =100 Minen = 6000 Drachmen) verstanden werden; s. Aristoteles, Ath. pol. 10,1-2 (zur modernen Forschungsdiskussion über diese Angaben s. P. J. Rhodes, A commentary on the Aristotelian Ath.

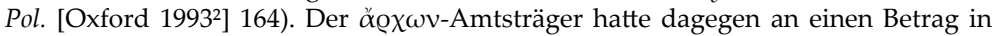
Silbergeld gedacht, wobei seine phantastisch hohen Kaufpreis-Vorstellungen für das Anwesen der Jäger-Familien sich offenbar noch immer an den Behauptungen in der Rede des "Demagogen“ orientierten. Die in Aussicht genommenen zwei Talente (= 12000 Drachmen / Denare) sollten offenbar von der Stadtkasse, mit Zustimmung der ekklesia, umgehend an den Demos ausgeteilt werden. Der Jäger, dem jeder Gedanke an Silbergeld fern lag, bezog die Fragen des Amtsträgers dagegen auf die künftig an die Polis zu entrichtenden Ernte- und Pacht-Abgaben (vgl. auch § 46), und so wird lustig aneinander vorbeigeredet!

64 Die erneut wachsende Unruhe und feindselige Stimmung in der Versammlung zeigen an, dass mehr und mehr Zuhörer aus den Worten des Jägers den Eindruck gewannen, dass sich die Aussichten auf eine nennenswerte Geld- oder Sachspende in Luft auflösten. Die detaillierten, mit naivem Eifer präsentierten Angaben des Jägers über die Qualitäten der verschiedenen Fellsorten so wie auch der an seinem Wohnsitz vorhandenen Fleischvorräte boten da sicherlich keinen Trost.

65 Der attische medimnos / "Scheffel“ entsprach als Hohlmaß für (trockenes) Erntegut ca. 421 (= 48 choinikes, s. o. Anm. 40): Die vorhandene Menge an Bohnen füllte somit nur vier choinikes und kam allenfalls als Saatgut für die nächste Ernteperiode in Betracht. Weizen (זv@ós / triticum) wurde grundsätzlich nur auf besonders gutem Boden angebaut, Gerste und Hirse gediehen auch auf weniger ertragreichen Flächen. Für den alltäglichen Verzehr kam im Haushalt der Jäger-Familien offenbar vorrangig Hirse in Betracht (s. § 57), Weizenbrot blieb für besondere Gelegenheiten reserviert (s. auch $\S 76$ ). Die angegebenen (für zwei Familien mit heranwachsenden Kindern recht geringen) Vorratsmengen, von denen ein Teil noch als Saatgut zurückzubehalten war, machen deutlich, dass die Jäger in ihrem Anwesen jeweils nur wenige Plethren Land intensiv als Anbauflächen nutzten: Zu Recht ist in der „Besitzstandserklärung“ (§ 47) nur von einem ,Getreideschätzchen' / oıtá@ıov die Rede. Wie der Überblick über die verfügbaren Haus- und Handwerksgeräte ausweist (§47), kamen für die Kultivierung des Bodens und die Vorbereitung der Aussaat in erster Linie die vier vorhandenen zweizinkigen Hacken ( $\delta \dot{\kappa} \kappa \varepsilon \lambda \lambda \alpha \iota)$ in Betracht; eine eiserne Pflugschar und zum Pflügen einer größeren Fläche geeignetes Zugvieh besaßen die Jäger dagegen nicht. Die erzielten Erntemengen reichten dementsprechend - in erkennbarem Kontrast zu ihrem Vorrat an sorgsam konserviertem Fleisch - kaum über die bloße Subsistenz hinaus (zum Vergleich: Ein Spartiat hatte für seine Person allmonatlich einen Mindestbeitrag an Getreide von $1 \frac{1}{2}$ attischen medimnoi innerhalb seiner Syssitien-Gemeinschaft beizusteuern); vgl. zum durchschnittlichen Weizen- / Getreide-Bedarf antiker Haushalte 
die von PRell 1997, 189) auch auf der Basis dokumentarischer Zeugnisse erarbeitete Tabelle. Durch adäquaten Austausch, vor allem mit kostbarem Wildbret, daneben später wohl auch mit Obst und Gemüse, war es den Jägern jedoch offensichtlich gelungen, sich ganz aus eigener Kraft in ihrer (unter großen Anstrengungen errungenen) Autarkie zu behaupten; vgl. dazu die in $\S 69$ gegebenen Auskünfte.

66 Aus dem Hinweis auf Kuh und Kälbchen (mit der Möglichkeit, Milch, Rahm und Käse für den eigenen Verbrauch zu gewinnen) ergibt sich, dass man sich die Jäger, die keinen eigenen Stier (und offenbar auch keinen Ziegenbock) besitzen, keineswegs als „Einsiedler" vorstellen soll, vielmehr stehen sie, an der Grenze des besiedelten Kulturlandes, mit mindestens einem Landwirt und Herdenbesitzer in der Nähe in engerem Kontakt. Denn um den „,wohlhabenden“ Schwiegersohn (s. § 68) kann es sich damals, zum Zeitpunkt des Auftritts des Jägers vor der ekklesia, noch nicht gehandelt haben. - Von einem benachbarten Dorf aus kann man im übrigen auch, der Erzählung des Schiffbrüchigen zufolge ( $\$ 58)$, den Rock der Tochter des Jägers sicher an seine Besitzerin zurückgehen lassen; und die Jäger sind imstande, dort (nach § 76) jederzeit etwas Wein (oder auch ein Ferkel zur Mast als Opfertier!) einzutauschen.

67 Mit literarischem Feingefühl hat es der Autor verstanden, in die knappe Aufzählung dieses äußerst kargen Bestands an Hausrat, Jagd- und Arbeitsgerät und des sonstigen mobilen Besitzes der Jäger-Familien das anrührende Gefühl einer tiefen Zufriedenheit des Berichterstatters mit seinem Wohnsitz und seinen bescheidenen Lebensverhältnissen zu legen.

68 In seiner naiven Unbefangenheit verkennt der Jäger eine in den wohlhabenden Schichten der Städte bereits seit langer Zeit übliche Praxis, vorhandenes, hoch begehrtes Bargeld durch Vergraben nicht nur vor Dieben, sondern auch vor gierigen Mitbürgern zu schützen, die regelmäßig Liturgien, Geldspenden und Sonderabgaben von den Vermögenden bzw. „Besserverdienenden“ in ihrer Polis einforderten; vgl. schon Aristophanes, Plutos 237-241. - Am Ende greift der Jäger jedoch das Thema „Geldvergraben“ noch einmal auf und versetzt dem „Demagogen" einen weiteren, gezielten Seitenhieb (\$ 63).

69 Über offizielle Bürgerausweise $(\sigma u ́ \mu \beta o \lambda \alpha)$, wie sie in manchen Polis-Gemeinden schon seit dem 5./4. Jh. v.Chr. üblich geworden waren, oder über andere urkundliche Belege verfügen die Jäger also nicht; abgesehen von der mündlichen, familiären Tradition reicht aber offenbar der Verweis auf die Teilnahme des Vaters an einer pauschalen Geldverteilung (s. o.) aus, um im Zweifelsfall einen Nachweis aus den offiziell geführten Bürgerverzeichnissen führen zu können. - Von der Reichsmetropole Rom bis zu den Landstädten in den Provinzen gehörten pauschale Geld- und Sachspenden an die Gesamtheit der Bürgerschaft - auch ohne Verbindung mit den großen Festen der jeweiligen Polis - schon seit der Klassik des 5./4. Jh. zum Alltag in den urbanen Zentren. Zu den Geld- und Sachmittelspenden im kaiserzeitlichen Rom vgl. u. a. Suet. Claud. 21, 1-4; Dom. 5,5. Zu den im griechischen Osten üblichen ठı $\alpha v o \mu \alpha i ́$ s. QuAß 1993, 303-317.; vgl. auch die große Getreidespende, mit der Atticus seinen „Einstand“ gegenüber der Bürgerschaft von Athen festlich abgeleistet hat: Cornelius Nepos, $v$. Att. 2,6.

70 Deutlicher Hinweis auf die allgemeine pax Romana, in der freilich Gefährdungen der inneren Sicherheit, wie sie von Piraten und Räuberbanden ausgehen konnten, nicht auszuschließen waren (Anm. 55); zur Jagd als einer guten Vorübung für Kriegshandwerk und Kampfeinsatz s.o. Anm. 21.

71 Vgl. § 23 zu der (zumindest nach dem subjektiven Empfinden des Jägers) schlimmen Überfüllung und der generellen „Unwirtlichkeit" im dicht bevölkerten InnenstadtRaum. - Wilamowitz (Hinweis bei v. Arnim im App.) bevorzugt hier die von einer

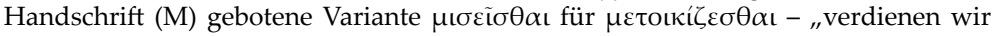
also deswegen [weil wir nicht in der Stadt leben wollen] wirklich eueren Hass?". Die vorangehende Argumentation und der Hinweis auf die leerstehenden Häuser im 
Stadtareal, von denen eines den Jäger-Familien wohl schon genügen könnte, ihnen aber doch erst einmal von der Polis zugewiesen werden müsste, verliert dann jedoch ihren Sinn, vgl. dazu auch Russell, 1992, 124.

72 Die Unterstellung des „Demagogen“, er agiere wie ein zweiter Nauplios am Kap Kaphereus und schlage aus dem Unglück der Schiffbrüchigen Gewinn, hat den Jäger in heftige Erregung versetzt; zuvor hatte er die übrigen Anschuldigungen und Beschimpfungen vor der ekklesia äußerlich ruhig, mit schlichten, entwaffnenden Erläuterungen oder mit trockenem Witz zurückgewiesen. Unter rhetorisch-technischem Aspekt war es im übrigen recht wirkungsvoll, die Entgegnung auf den gravierendsten Vorwurf ganz an das Ende der Stellungnahme zu rücken - mit der Beteuerung, diesen Punkt „,beinahe vergessen zu haben“!

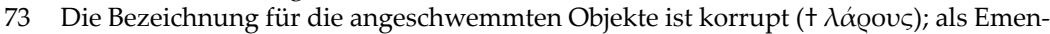

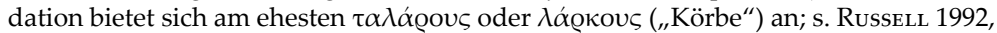
124f. - Die Eiche, dem Zeus zugehörig, findet als heiliger Baum bereits in der Ilias (V 693) Erwähnung; zur kultischen Verehrung von exponiert stehenden, ansehnlichen Bäumen und Baumgruppen vgl. auch Dions eindrucksvolle Beschreibung des ländlichen Hains in Elis (dem Herakles geweiht) mit den dort versammelten, bescheidenen Weihegaben: or. 1,52; vgl. dazu auch Dions Darlegungen in or. 12,61 (Baumkulte als Ausdruck einer urtümlichen Religiosität).

74 Mit dem Tempuswechsel werden hier (und wenig später in § 56) neue, überraschende Wendungen im Erzählbericht sprachlich hervorgehoben (s. o. Anm. 8); vgl. auch \$72.

75 Erneut wird auf die menschliche Teilnahmslosigkeit und unverhüllte Geldgier der (angeblich nahe dem Kap Kaphereus arbeitenden) Purpurfischer hingewiesen (s. o. Anm. 7).

76 Den erschöpften und unterkühlten Schiffbrüchigen wird die kostbarste und nur in begrenzter Menge vorhandene Verpflegung zuteil; ihre gastfreundlichen Betreuer begnügen sich dagegen mit Hirsebrei und schlichtem Trinkwasser.

77 Der Satz ist mit Absicht doppeldeutig formuliert und kann, da ,Kuss' / фí $\uparrow \mu \alpha$ sich von $\phi \iota \lambda \varepsilon \tilde{i} v$ herleitet, auch meinen: „(damals wurde mir klar) dass die Leute in den Städten einander nicht lieben". - Im homerischen Epos, besonders in der Odyssee, ist des öfteren von Begrüßungsküssen aus Wiedersehensfreude die Rede, und Dion mag darin wohl eine althellenische, fern von städtischer Mode lebendig gebliebene Sitte gesehen haben. Ansonsten sprechen die literarischen Zeugnisse eher gegen eine weite Verbreitung dieser Begrüßungsweise - ganz im Gegensatz zu den Gepflogenheiten in der römischen Oberschicht schon in der Zeit der mittleren und späten Republik (Pol. 6,11 a, 6); vgl. die Zeugnisse bei W. KRoLL, „,Kuß“, RE Suppl. V (1931) 511-520. - Nach Wilamowitz (Griechisches Lesebuch I 2,13 [Berlin 1902]) soll das Gelächter im Theaterrund jedoch eher von dem Kontrastbild einer innigen Umarmung zwischen dem zottigen Jäger im schäbigen Lederwams und den von ihm auf das herzlichste begrüßten „,begüterten Städtern“ ausgelöst worden sein; s. dagegen jedoch RusseLL 1992,126.

78 Die Einladung zu einem festlichen Bankett im Prytaneion (an der Agora, s. o.) zusammen mit dem amtierenden Ratsausschuss, den obersten Magistraten sowie anderen verdienten Bürgern der Polis stellt hier, wie in Athen, eine hohe Ehrung dar; sie war in Athen und andernorts ursprünglich nur für Bürger der Polis reserviert, wurde jedoch inzwischen auch ,ausländischen“ Gesandtschaften und prominenten Besuchern der Stadt auf Beschluss der ekklesia zuerkannt; zu den Belegen in Athen s.

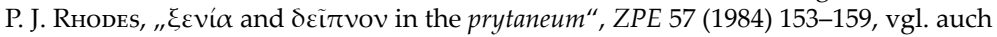
R. KASSEL, "Gesandtschaft in Ithaka“, ZPE 144 (2003) 7. - Bezeichnenderweise sind es in der Erzählung nicht die aus ihrer Notlage nach dem Schiffbruch geretteten Bürger, von denen die Initiative zu einem Ehrendekret für den Jäger ausgeht; vielmehr ergreift der prominente „, anständige Politiker“, als erfahrener ó $\tau^{\prime} \omega \omega^{-}$, Antragsteller“, sogleich die Gelegenheit, um mit einer passenden, patriotisch anrührenden Begrün- 
dung einen formvollendeten neuen ekklesia-Beschluss auf den Weg zu bringen (und damit seinen Tageserfolg über den „Demagogen“ zu vollenden).

79 Erneut klingt hier die aus zahlreichen Ehrendekreten bekannte ",hortative Klausel“ an (s. o. Anm. 49). - Mit seiner Bereitschaft, die Ehrengabe der Polis, 100 Drachmen, aus dem eigenen Vermögen zu bezahlen, kann der ", anständige Politiker“ weiteren Beifall in der Versammlung für sich verbuchen.

80 Das (von der ekklesia zu beschließende) Geldgeschenk soll somit zur besseren „Ausrüstung" der Landwirtschaft (d. h. zur Beschaffung von weiteren Geräten sowie eines Zugtieres) dienen. Der Jäger wehrt sich jedoch leidenschaftlich gegen diese Art von Honorierung seiner Hilfeleistungen, die in seinen Augen nichts anderes sein konnten als die Befolgung eines verbindlichen Gastrechtsgebots bzw. einer schlechthin mitmenschlichen Verpflichtung. Hier kam es Dion wohl sehr darauf an zu zeigen, dass der Jäger in seiner selbstbewussten Armut und Autarkie instinktiv ein Gespür dafür entwickelt hat, dass ein solcher „Kapitaleinsatz“ (immerhin ein Drittel des BruttoJahresgehalts eines römischen Legionärs) leicht die genügsame und selbstbestimmte - und damit ungeachtet eines hohen Arbeitsaufwandes durchaus freie - Lebensweise der Jäger-Familien verändern konnte.

81 Russell 1992, 127 weist überzeugend auf die große Nähe von Dions Schilderung und Wortwahl zu Platons Beschreibung der einfachen Gastlichkeiten und behaglichen Genüsse in der im Dialog skizzierten „,ersten Polis“ hin (die Sokrates' Gesprächspartner Glaukon freilich spöttisch als „Polis der Schweine“ charakterisiert: Rep. 372b) vgl. dazu auch §§ 129-131 mit ausdrücklichem Hinweis auf Platons Politeia.

82 Mit der archaisierenden Bezeichnung „Satrapen“ für die Provinzgouverneure konnte Dion; dem literarischen Geschmack der Zeit entsprechend, hier und auch sonst den terminus technicus der korrekten Titulatur des römischen Statthalters vermeiden. Mit den ,Königen' / ,Herrschern' ( $\beta \alpha \sigma \iota \lambda \varepsilon \tilde{\varsigma}$ ), an deren Tafel er einst sitzen durfte, können wohl auch Klientelkönige des Imperium Romanum im griechischen Osten gemeint sein, der Gedankenführung nach ist es jedoch wahrscheinlicher, hier an die Lebensphase Dions in Rom vor der Verbannung und seinen (zeitweiligen) Zugang sogar zum Kaiserhof in der Ära der flavischen Dynastie zu denken (vgl. auch Anm. 31 S. 14). Zur grammatischen Struktur dieses Satzes s. die Untersuchungen von A. Wistrand, EIKOTA. „Emendationen und Untersuchungen zu griechischen Prosaikern der Kaiserzeit" ", Bull. de la Societé Royale des Lettres de Lund (1930/31) 6f. (134f.) und II (1932/3) 26 (Hinweis R. KasSEL).

83 Die enge, ursächliche Verbindung von maßvoller $\pi \varepsilon v i ́ \alpha$ und غ̇ $\lambda \varepsilon v \theta \varepsilon \rho i ́ \alpha$ bildet bekanntlich einen Leitgedanken in der Geschichtsdarstellung Herodots: vgl. Hdt. I 32, 5-6 (Rede Solons), VII 102, 1 (Demaratos-Rede) u. IX 122, 3-4 (Ratschlag und Warnung des Kyros).

84 Ungeachtet seiner Verlegenheit nutzt der junge Mann rasch den Augenblick, in dem sein Vater den fremden Gast begrüßt, um dem geliebten Mädchen einen Kuss zu geben. - Hasen, lebendig gefangen (vgl. § 71), waren als Streichel- und Schoßtiere seit alters ein Geschenk, das auf erotische Zuneigung und Liebe hinweisen sollte; s. dazu G. Косн-Harnack, Knabenliebe und Tiergeschenke (Berlin 1983), zu Tiergeschenken s. jetzt auch J. M. Barringer, The hunt in Ancient Greece (Baltimore/London 2001) bes. 70-124 (Hinweis v. H. R. GoetTE). Mit dem gefangenen Häschen im Arm konnte die junge Frau den Gast und die Eltern nicht mehr aufmerksam bedienen; der junge Mann löste sie daher in dieser Tätigkeit sogleich ab.

85 Die Zubereitung der Fleischspeisen und die aufmerksame Bedienung des Gastes und der Eltern übernehmen, ohne dass es dazu einer Aufforderung bedarf, die heranwachsenden Kinder der Jäger-Familien; vgl. dazu auch Dions erzieherische Mahnungen or. 10 (9 АRnim) § 13 u. generell Seneca, ep. 47.

86 Die schnelle Entgegnung der Frau zeigt, wie viel den Eltern der verheirateten Tochter daran liegt, dass der (angeblich „,reiche“) Schwiegersohn im Dorf seiner Frau keines- 
falls ihre Herkunft aus einer armen Familie zum Vorwurf machen kann. Auch wird deutlich, dass der Ertrag der Getreide-Ernte sich seither keineswegs wesentlich verbessert hat (s. o. Anm. 65). - Bemerkenswert sind ferner der Freimut und die natürliche Unbefangenheit, mit der die Frauen und Kinder der Jäger-Familien sich gegenüber dem fremden Gast verhalten und mit ihm Gespräche führen. - Das unverheiratete Mädchen nimmt freilich, als Braut, mit keinem Wort an dem Gespräch teil.

87 Der Erzähler hat die tiefe gegenseitige Zuneigung und Liebe des jungen Paares rasch erkannt und will den beiden mit seinen gezielten Nachfragen "weiterhelfen“. - In ihrer schamhaften Befangenheit gleichen die beiden durchaus den keuschen Liebespaaren in den zeitgenössischen Roman-Erzählungen.

88 Die Vollmondphase als günstige Zeit für eine Hochzeit wird auch bei Euripides, Iph. Aul. 716f. und Pindar, Isth. 8, 43 (Hochzeit der Thetis) hervorgehoben, während von Hesiod (Erga 800) jeweils der vierte Tag eines Monats empfohlen wird; aber auch die Neumondphase konnte als besonders glückbringend gelten (Plutarch, fr. 105 SANDвасн, nach Russell 1992, 129) - Die häufige Verwendung von Deminutiven (im Mun-

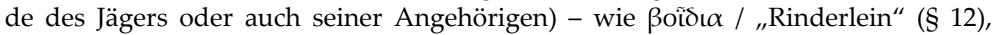

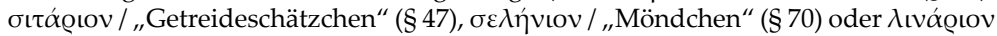
/ „Netzchen“ (§ 71, sowie § 76 oivóóov / „Weinchen“) - ist wohl (nach Wilamowitz 1902) als bewusste Annäherung an die Umgangssprache des einfachen Volkes zu verstehen.

89 Somit waren die vom Brautvater zuvor genannten Bedingungen für die Wahl eines günstigen, Glück verheißenden Hochzeitstermins - Vollmondphase und klares, heiteres Wetter (§ 70) - vollauf erfüllt (mit einem gewissen Widerspruch zu den Wetterangaben und -prognosen in $\S \S 2$ u. 6!). Zugleich wird aus den Worten des jungen Jägers sein ungeduldig - inniger Wunsch nach der raschen Festlegung eines möglichst kurzfristigen Hochzeitstermins deutlich. Der junge Mann ist jedoch viel zu schamhaft und respektvoll, um seinem Onkel und künftigem Schwiegervater offen zu widersprechen.

90 Der an dieser Stelle besonders auffällige Tempuswechsel unterstreicht den lockeren Gesprächston des Autors; zugleich aber wird mit diesem Stilmittel wieder ein Wendepunkt im Erzählbericht eingeleitet.

91 In der Regel wurden Haustiere und nur ausnahmsweise (vor allem für Artemis) Jagdbeute als Opfertiere ausgewählt. Auch sollten Opfertiere in bestem Zustand und gut genährt sein. - Mit der Opferung eines Schweins wurde vorrangig Demeter, die mütterliche Göttin der Erde und der Fruchtbarkeit, geehrt; dabei kamen für Demeter und ähnliche Gottheiten sowohl Opfertiere weiblichen als auch männlichen Geschlechts in Betracht, vgl. die Hinweise bei L. ZieHEN, „'Opfer“, RE XXXV (1939) [579-627] 595,13f.

92 Die Mutter des jungen Mannes (und Frau des Jägers) war also längst informiert und unterstützt ihren Sohn hier auch im Gespräch (vgl. §§ 76 u. 78) mit diplomatischem Geschick und Feingefühl.

93 Zu den Früchten, die aus der Vorratshütte der Jäger-Familienaufgetischt werden: Das Mispel-Steinobst wird erst zu Beginn des Winters geerntet. Die birnenförmigkugeligen Früchte des Speierling-Baumes (regional auch Sperberbaum genannt) müssen nach der Ernte im Herbst noch einige Zeit lagern, um ausreichende Fruchtsüße zu erlangen. Für den Verzehr wird die harte Schale der Früchte aufgeschnitten, um das musartige, säuerlich-süße Fruchtfleisch heraussaugen zu können. Zu den Früchten des Speierlingbaumes, sorbus domestica, (Verbreitung, Erntezeit, Aufbewahrung, Konservierung, Zubereitung und Genuss) s. die umfassende, maßgebliche Darstellung von W. Kausch-Blecken v. Schmeling, Der Speierling: Sorbus domestica (Bovenden 2000) (Selbstverlag). Jahreszeitlich passen zu diesen Früchten (und zu den Angaben des Erzählers in $\S \S 2$ und 6) jedoch nicht die zuvor bereits in $\S 46$ erwähnten "prallen Weintrauben“; man wird an dieser Stelle wohl an ein schlichtes Versehen Dions zu denken haben. Allerdings besteht kein Problem, wenn hier ursprünglich 
an getrocknete Trauben gedacht war. Im übrigen waren auch die Früchte des Speierlingbaumes in getrocknetem Zustand ein bewährtes Mittel gegen Magen- und Durchfallbeschwerden (wie sie bei einem zeitweilig von Unterkühlung betroffenen Schiffbrüchigen leicht auftreten konnten). - Russell 1992, 130, verweist (im Hinblick auf $\S 46)$ überzeugend auf die große Nähe des dionischen Textes zu den Bestimmungen Platons in Leg. 844d-e.

94 Das Gerstenschrot wurde, mit Salz durchmischt, zur Opferstätte in einem Korb getragen, auf dessen Boden das Opfermesser lag. Während eines feierlichen Gebets (i. d. R. mit aulos-Begleitung) wurde die Gerste aus dem Korb auf Altar, Opferstätte und das herangeführte Tier geworfen, bis das Messer im Korb aufgedeckt war und der Vollzug der blutigen Opferhandlung erfolgen konnte. - Mit dem erwähnten Weizenmehl sollte dagegen feines Weißbrot für das Festmahl gebacken werden.

$95 \mathrm{Zu}$ den festen Beziehungen der Jäger-Familien zu einem Dorf in der Nähe s. o. Anm. 65.

96 Die beiden Frauen stehen in der Terminfrage fest auf der Seite des jungen Paares; gleichwohl bleibt die Autorität der Familienväter, vor allem des noch zögernden Brautvaters, gewahrt.

97 Heiratsvermittlerinnen spielten schon im Athen des 5./4. Jh. v. Chr. eine wichtige, oft freilich auch problematische Rolle bei der Anbahnung arrangierter Ehebündnisse unter zumeist wohlhabenden Familien; vgl. Ar. Nub. 41 und Xen. Mem. II 6,36. - Zu Dions Vorstellungen von einem erfüllten und glücklichen Ehe- und Familienleben (in weitgehender Übereinstimmung mit Plutarch) s. jetzt Hawlex 2000.

98 Die „Jäger Episode“ findet damit ihren Abschluss: Dion betont noch einmal (vgl. § 1) die Authentizität seiner Erzählung als eines persönlichen Erlebnis- und Erfahrungsberichts aus der Zeit seiner Verbannung. Gleichzeitig wird jedoch auch betont, dass die "Jäger-Idylle" - zumindest im Rahmen dieser Abhandlung - nicht als eine in sich eigenständige Erzählung zu gelten hat, sondern lediglich als anschauliches Paradigma für einen (Teil-) Aspekt des zuvor, im (offensichtlich verlorenen) Prooemium der Schrift vorgestellten Generalthemas dienen sollte (s. o. Anm. 2; vgl. dazu auch die überleitenden Bemerkungen in § 103). Mit dieser Erzählung sollte auch nicht einfach ein ,idyllisch“-positives Kontrastbild zu dem naturfernen Leben und Treiben in der unruhevollen, von mannigfachen Nöten und Krisen geplagten Stadt entworfen werden, wie Dions weitere Darlegungen zeigen. Die Frage, wann und vor allem zu welchem Zweck die literarisch-künstlerische Ausformung dieser Erzählung ursprünglich erfolgt ist, bleibt von diesen allgemeinen Feststellungen unberührt.

99 Aus den Hinweisen in §§ 81f. lässt sich erschließen, dass es grundsätzlich um die Frage geht, inwiefern gerade die ärmeren Bevölkerungsschichten, auf dem Land wie in der Stadt (s. u. §§ 104f.), über die Fähigkeit verfügen, ein anständiges, menschenwür-

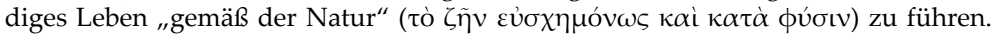
Als populäre Gegenposition aber hat sich Dion die @́ñ den Bauern (v. 424-431) in Euripides' Elektra-Tragödie (aufgeführt wahrscheinlich im Frühjahr 413 v. Chr.) ausgewählt, der - nach freundlichen Einladungsworten an die überraschend erschienenen, hochgestellten Besucher (Orestes und Pylades mit Gefolge) sowie einer dringlichen Mahnung an Elektra, alle Vorräte im Haus für ein ausrei-

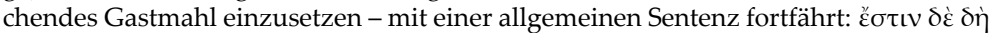

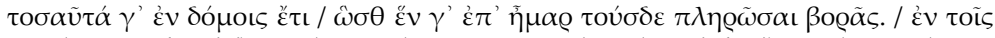

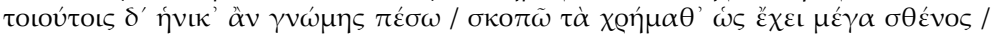

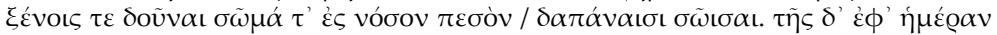

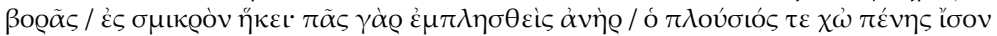

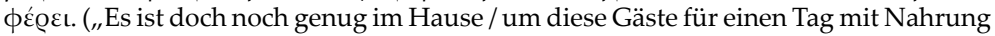
zu versorgen! / Sobald ich in solcher Lage nachdenke, / sehe ich, wie Geldbesitz über große Macht verfügt, / Gastfreunden Geschenke zu machen und den eigenen Leib, wenn ihn Krankheiten heimsuchen, / durch entsprechende Aufwendungen zu retten. 
Die Sorge um die tägliche Nahrung ist da / nur eine Kleinigkeit. Ist Sättigung erreicht, so hat ein jeder, / der reiche wie der arme Mann, das Gleiche erhalten.") Dions Interesse gilt hier allein der Sentenz; weder das ท̃ $\theta$ os des edelgesinnten Bauern, der aus freien Stücken mit der verstoßenen Königstochter nur in einer Scheinehe zusammenlebt, noch die in diesem Drama von Euripides besonders eindrucksvoll formulierten Absagen an überkommene soziale Vorurteile (vgl. u. a. v. 367-397) werden angemessen gewürdigt. - Zu dieser bekannten Stellungnahme s. auch Plut. De aud. poet. 12 p.

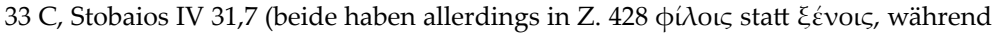
Dion mit der MS.-Tradition des Euripides übereinstimmt). Dion geht auf diese Worte des armen Landwirtes hier in einer Weise ein, die voraussetzt, dass der Textabschnitt schon einmal zuvor, in der Einleitung der Abhandlung, im Wortlaut zitiert (und in diesem Zusammenhang auch bereits kritisch erörtert) worden ist.

100 Dion verweist hier auf einen in der griechischen Welt allgemein bekannten Kanon ethischer „Minimalgebote“ zur Hilfeleistung für gänzlich Fremde ebenso wie für Nachbarn, nämlich: Feuer vom eigenen Herd abzugeben, Durstigen Wasser zu reichen bzw. sie zu einer Quelle oder einem Brunnen zu bringen, ferner Ortsfremde auf den richtigen Weg zu führen; vgl. Hdt. VII 231 u. Xen. Mem. II 2,12; s. ferner Schol. Soph. Ant. 255; Diphilos frg. 62 K.-A.; Cic. De off. II 54; Varro, De re rust. II 5,4; Clem. Al. Strom. II 139, 1; s. die grundlegende Untersuchung von J. Bernays, „Philons Hypothetika und die Verwünschungen des Buzygen in Athen“, in: H. Usener (Hrsg.), Gesammelte Abhandlungen Bd.1, 272-274); R. Pfeiffer, Callimachos I (Oxford 1949), zu fr. 193 Anm. 25 (S. 175) u. W. Schulze, „Beiträge zur Wort- und Sittengeschichte“, in : Kleine Schriften (Göttingen 1934) 191. Zu diesem (ungeschriebenen) Kanon von Verpflichtungen zur Mitmenschlichkeit zählten ferner die Gebote, auch einen fremden Toten niemals unbestattet zu lassen sowie einem Ratsuchenden immer eine ehrliche Auskunft zu erteilen. Gegen alle, die diese einfachen Gebote der Humanität verletzen sollten, richteten sich in Athen - im Rahmen eines besonderen Demeter-Festes, an dem der Ackerbau als Grundlage aller menschlichen Zivilisation gefeiert wurde - alljährlich die öffentlichen Verwünschungen eines Repräsentanten des Priester-Geschlechts der Buzygen.

101 Zur großzügigen Aufnahme des Odysseus bei dem unfreien Schweinehirten Eumaios s. Od. XIV 55-81. - Im Folgenden dient Homer, speziell die Odyssee, als allgemein bekannter Grundtext für die Erörterung und Verdeutlichung ethischer Fragen (vgl. dazu auch die Dialogtexte orr. 55 und 56). Überdies bot die Gestalt des Irrfahrten und Schiffbrüche meisternden „Spätheimkehrers“ Odysseus und die Erzählung von seiner höchst unterschiedlichen Aufnahme in der Heimat (als „Bettler-König“) für Dion besonders reizvolle Möglichkeiten zur Selbst-Identifikation (vgl. hierzu bes. or. 13,10 und or. 45,11, ferner or. 1,50 und or. 2,20 sowie or. 9,9; or. 14, 22 und or. 49,12).

102 Od. XVII 455-457; der letzte Vers stellt bei Dion eine beachtenswerte Variante zur Ms.-

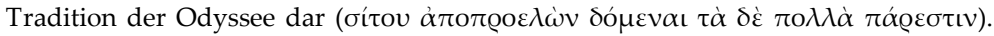
Antinoos tritt unter den Freiern im Hause des Odysseus als besonders wortmächtiger und rücksichtsloser Anführer auf.

103 Zu Recht betont Russel 1992, 133, dass Dions scharfe Kritik an Penelope den Inhalt ihrer Worte und Versprechungen Od. XIX 306-328 einseitig, aber rhetorisch wirksam uminterpretiert (wohl auch mit Bezug auf Od. XVII 549f.). - Vgl. bereits Polybios abfällige Bemerkungen (XII 26b,5 B.-W.) über das rein rhetorische, substanzlose Spiel mit

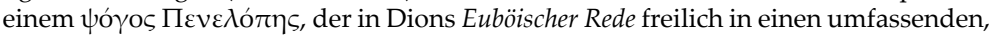
ernsthaften Gedankengang eingeordnet ist.

104 Diese Kritik bezieht sich konkret auf Penelopes Äußerungen Od. XXI 311-319 und 330-342; mit dem Wechsel in das Präsens will Dion offenbar die Intensität seiner wachsenden moralischen Entrüstung unterstreichen. Die von Penelope, im Falle eines Schießerfolges, angekündigten Geschenke (v. 339-342) - „eine schöne Gewandung mit Mantel und Chiton, einen spitzen Speer und ein zweischneidiges Schwert, ferner 
Sandalen und eine Reiseausstattung, wohin es den landfremden Mann auch ziehen möge." - werden von Dion weder vollständig benannt noch angemessen gewürdigt.

105 Bei den Phäaken hatte sich Odysseus gerühmt, als junger Mann den Bogen des Eurytos (jene „Wunderwaffe", mit der wenig später der Freiermord auf Ithaka ausgeführt wird) von Iphitos, dem Sohn und Erben des "großen Eurytos von Oichalia“ (der sich als Meister des Bogenschießens mit Herakles messen konnte) als Geschenk erhalten zu haben (Od. VIII 224-228; vgl. XXI 11-40); sein Leben aber hatte Eurytos durch seine respektlose Herausforderung des Gottes Apollon zum Wettstreit im Bogenschießen verloren. Andere (jüngere) Sagenversionen verbinden den Untergang des Eurytos und seiner Polis Oichalia dagegen mit den Zügen des Herakles, wobei die Lokalisierung von Oichalia in der antiken Tradition (zwischen Arkadien, Messenien und Thessalien) umstritten blieb. - Umstritten war auch die Heimat und Genealogie der Penelope, Tochter des Ikarios, die beide mit Sparta in Verbindung gebracht worden sind. Nach Od. XV 16 u. XIX 158 aber hatten Ikarios und seine Söhne, die Brüder der Penelope, jedoch Wohnsitze auf Ithaka (zu den unterschiedlichen Zuordnungen des Ikarios und seiner Nachkommen s. E. Wüst, „Penelope“, RE XXXVII [1937] [460-493] 461f.). - Dions Kritik am Verhalten der Penelope zielt nicht - wie andere antike Traditionen (vgl. Hdt. II 145, 4; Paus. VIII 12,6; vgl. Sen. ep. 88,8) - auf die eheliche Treue und Keuschheit der Gemahlin des Odysseus, sondern auf einen (in seinen Augen aber höchst bedenklichen) Mangel an Weitblick, Großzügigkeit und Herzensbildung.

106 Dions kritische Bemerkungen zielen auf Od. XVII 10-15. - Im Anschluss an Penelope wird nun anhand der Darstellung in der Odyssee dem Königssohn Telemachos - im Vergleich mit dem armen, unfreien Schweinehirten Eumaios - ein gravierender Mangel an Großherzigkeit und schlechthin an Mitmenschlichkeit ( $\alpha \pi \alpha \nu \theta \varrho \omega \pi i ́ \alpha)$ nachgewiesen.

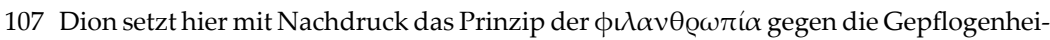
ten und Erwartungshaltungen des adligen "Gabentauschs" im homerischen Epos. Bei $\delta \alpha v \varepsilon \tilde{i} \alpha$ handelt es sich um Darlehen, die - in der Regel kurzfristig und unter Bürgschaftsleistung - vom Schuldner zusammen mit den vereinbarten Zinsen zurückzuzahlen sind. Dagegen stellen die ع́o $\alpha$ vo (abgesehen von der Grundbedeutung, gemeinsam bestrittene Festmähler' / ,bottle-parties') in der griechischen Welt SpenderGemeinschaften vornehmlich auf privater Basis dar, die für einen bestimmten Zweck Geldsummen zusammenbringen und vereinbarungsgemäß einsetzen. Die einmalig oder regelmäßig zu leistenden Beiträge können einem oder mehreren Mitgliedern der

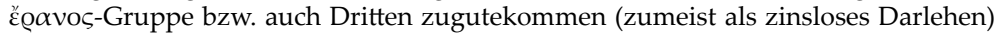
oder für ein gemeinsames Anliegen zum Nutzen aller verwendet werden; s. dazu bes. Demosthenes, Gegen Meidias (or. 21) §§ 184f. - Schon im Hellenismus begegnen aber auch eranos-Kassen als öffentlich kontrollierte, zweckgebundene Einrichtungen (zu Lasten der Wohlhabenden) für die Unterstützung und Förderung der ärmeren Bevölkerungsschichten (vgl. Polyb. XXXVIII 11, 10); dementsprechend existierte in Bithynien-Pontos noch in der Ära Trajans (auf der Basis der lex Pompeia, s. o. S. 7) in der autonomen Polis Amisos ein eranos-Fonds als städtische Armen-Kasse (s. Plinius, ep. X 92 und 93).

108 Es bleibt unklar, auf welche Angaben und Details in der Darstellug der Odyssee sich diese grundsätzliche Abwertung der Phäaken und der Motive für ihre aufwendige Hilfeleistung zugunsten des schiffbrüchigen Odysseus stützen könnte; vgl. RusselL 1992, 135. Jedenfalls konnte Dion - zumindest vor einem Auditorium, das zuvor seine minutiöse Penelope-Kritik angehört hatte - mit dieser kühnen praeteritio seine kritische Argumentation rhetorisch höchst wirkungsvoll abrunden.

109 Erneut wird in Dions Darlegungen auf die schon in $\S 82$ kritisch kommentierte Sentenz aus Euripides' Elektra-Tragödie angespielt.

110 Der Hinweis auf das geringe Krankheitsrisiko für arbeitsame und bescheiden lebende Menschen zielt ebenfalls auf die Klagerede des Bauern in der euripideischen Elektra 
(v. 428f.); zu Dions Vorstellung, dass eine bescheidene Lebensführung, möglichst an der frischen Luft, die Gesundheit stärke und am besten vor ernsten Erkrankungen und Leiden schütze, s. auch or. 3,83. - Gastgeschenke, wie sie von armen Leuten dargereicht werden können, stehen nicht im Verdacht, dass man ihretwegen von dem Beschenkten eine kostspielige Gegenleistung erwartet oder mit ihnen gar einen Bestechungsversuch unternimmt.

$111 \mathrm{Zu}$ den üppigen Gastgeschenken, die Telemachos auf seiner Erkundungsreise von Menelaos und Helena in Lakedaimon empfing, s. Od. IV 589-592. 615-619 und XV 101-107.

$112 \mathrm{Zu}$ Dions (archaisierender) Verwendung der Begriffe $\sigma \alpha \tau \varrho \alpha ́ \pi \alpha \iota$ und $\beta \alpha \sigma \iota \lambda \varepsilon \tilde{\iota} \varsigma$ s.o. Anm. 82 (zu § 66). - Im Zuge seiner Homer-Exegese leitet Dion hier von der Gestalt des Menelaos über zu dem fatalen Besuch, den der ,zügellose und tyrannisch gesinnte" Prinz Paris aus Troia dem Königshof in Sparta abstattete; der spektakuläre Bruch des Gastrechtes durch Paris wird im Folgenden mit allen Konsequenzen für den betrogenen Gastgeber Menelaos erörtert und ausgemalt (§§ 94-96).

113 Dion legt hier den Akzent auf die räuberische Aneignung der Schätze des Menelaos durch Paris. - Hermione, Helenas und Menelaos' Tochter, wurde (nach Apoll. epit. 3,3) im Alter von nur neun Jahren von ihrer, mit Paris nach Troia abreisenden Mutter in Sparta zurückgelassen. Nach Od. IV 4-7 wurde sie von Menelaos noch während der Belagerung von Troia dem Sohn des Achilleus, Neoptolemos, als Frau zugesprochen: Die später in Sparta geschlossene Ehe blieb jedoch kinderlos. Nach Neoptolemos' gewaltsamem Tode wurde Hermione schließlich Gattin des Orestes; s. zu diesen Sagenversionen die Analysen von S. FunKe, Aiakidenmythos und epeirotisches Königtum. Der Weg einer hellenischen Monarchie (Stuttgart 2000) bes. S. 29-32, 59f. und 76-79.

114 Menelaos' aktive Beteiligung an den Verhandlungen über die (primär von dem Seher Kalchas und von Odysseus betriebene) Opferung Iphigeneias, der Tochter Agamemnons, in Aulis (Euböa), wird von Dion absichtlich, im Sinne seiner Interpretation, übertrieben.

115 Die dramatischste Krise im Achaierheer vor Troia war bekanntlich der „Zorn des Achilleus" (über die von Agamemnon verfügte Beschlagnahmung der kriegsgefangenen Briseis) und sein Ausscheiden aus den Kämpfen gegen die Troer - das zentrale Thema der homerischen Ilias.

116 Für Dion, der sich hier in erster Linie auf die Odyssee stützt, bestand keine Notwen-

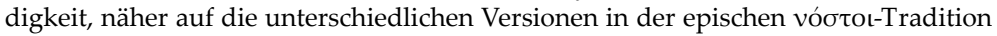
einzugehen.

117 Es geht noch immer um die Sentenz aus Euripides' Elektra (s. o. Anm. 99), wobei Dions Paraphrase freilich über den Wortlaut bei Euripides hinausgeht.

118 Die Vorstellung, dass gerade die Tragödiendichter als Repräsentanten - und zugleich als Erzieher oder Verführer - ihres Volkes zu gelten haben, dient bekanntlich schon als Basis für Aristophanes' Komödie Die Frösche (Aufführung Frühjahr 405 v. Chr.); dabei wird, wie hier bei Dion, die gesamte Gnomik in den Dramen ohne Rücksicht auf die jeweilige Personenbindung und Sympathielenkung dem Dichter persönlich zugeordnet. - Die einfühlsame Studie, in der Dion sowohl nach literarisch-ästhetischen als auch nach ethischen Kriterien die Philoktetes-Tragödien der Klassiker Aischylos, Sophokles und Euripides würdigt und miteinander vergleicht (or. 52), gehört offensichtlich ebenso zu den Jugendwerken im dionischen Corpus wie der Achilleus-Dialog (or. 58) und die Prosa-Paraphrase zu dem Prolog und der ersten Szene des euripideischen Philoktetes-Dramas (or. 59); vgl. v. Arnim 1898, 163f. - Russell 1992, 49 App. u. 137, empfiehlt im Hinblick auf die Textkorruptel $+\gamma \varepsilon v \varepsilon ́ \sigma \theta \alpha$ เ (von Reiske u. v. Arnim getilgt) als einfachste Lösung die Korrektur $\gamma \varepsilon v o \mu \varepsilon ́$ vous (freilich ohne diese in den Text zu setzen).

119 S. Sophokles frg. 88 RAdt (aus dem Drama Aleadai, mit thematischem Bezug auf die Telephos-Sage). Die von Dion hier nur knapp erwähnte Sentenz aus der sophoklei- 
schen Tragödie war offenbar (neben der rhesis aus der euripideischen Elektra) sehr bekannt und wird sowohl bei Plut. De aud. poet. 4,21 B (v. 6-10) als auch bei Stobaios (IV 31,27 und 103; zur euripideischen Sentenz in IV 31,7 vgl. o. Anm. 99) zitiert. Plutarch bezeugt darüber hinaus (in 12,33 C), dass es sich bei dem von Dion hier ohne Namensnennung charakterisierten "ganz bedeutenden Philosophen", der scharfe Kritik an den entsprechenden Sentenzen in den Dramen des Sophokles und Euripides übte, um Kleanthes von Assos gehandelt hat (der trotz bitterer Armut und harter körperlicher Arbeitsbelastung in Athen zum Philosophie-Studium gelangt war und 262/1 v. Chr. zum Nachfolger Zenons als Schulhaupt der Stoa gewählt wurde): SVF I 562 Arnim (eine witzige Parodie auf die Verse aus der euripideischen „Elektra“). Der ent-

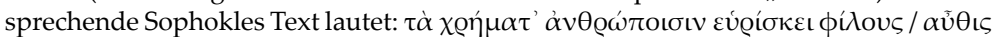

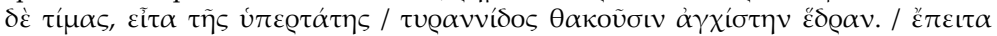

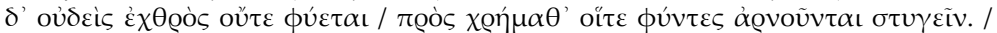

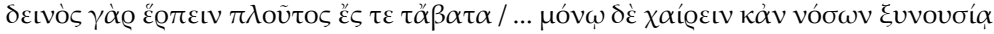

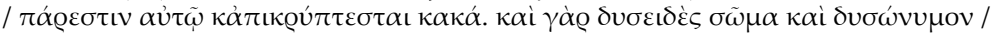

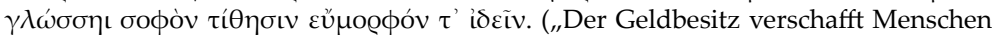
Freunde / und Ehrungen zugleich, dann nehmen sie Platz / ganz nah am Thronsitz der allerhöchsten Herrschaft. / Und ferner ist auf der einen Seite niemand feindlichgegenüber dem Geld eingestellt, und auf der anderen Seite leugnen diejenigen, die es (doch) sind, es zu hassen. / Denn Reichtum besitzt gewaltige Macht, sich auch in das Intimste einzuschleichen / ... Nur mit Reichtum kann es noch Wohlbefinden geben, wenn sich Krankheiten einstellen; nur er kann Übelstände verheimlichen: Und [Reichtum] bewirkt denn auch, dass man mit hässlichem Leib und von üblem Rufe als weise und als schön erscheint “); zu Kleanthes als „Mode-Autor" in stadtrömischen Philosophenkreisen s. Iuvenal, Sat. 2,7.

120 Die Textüberlieferung èv $\beta \iota \beta \lambda$ íoıৎ ist wohl zu Recht von EMPERIUs angezweifelt worden; die von Russell 1992, 138 vorgeschlagene Emendation ćv ì $\alpha \mu \beta \varepsilon$ ćoı (,,in Bindung an das iambische Versmaß“) passt vorzüglich zu dem Sachverhalt und dem Gedankengang im Text. In jedem Falle gibt Dion hier auch einen wichtigen Hinweis auf seine eigene Arbeitsweise und die konkreten Rahmenbedingungen für den überlie-

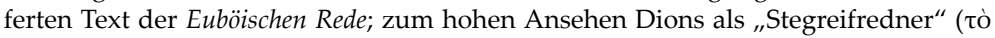

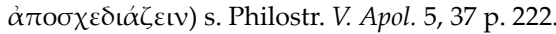

121 In diesem Resümee wird die „Jäger-Erzählung“ selbst nur kurz berührt, und die Darlegungen in den §§ 82-102 finden überhaupt keine Erwähnung. Umso deutlicher wird das Hauptthema - die Verbindung von Armut und Arbeitswillen mit der Fähigkeit, zu einem menschenwürdigen Leben zu finden - von Dion herausgestellt. Man wird diese knappe Zusammenfassung mitsamt der Überleitung zu einem neuen thematischen Schwerpunkt (vgl. auch u. § 126) am ehesten als improvisierten Neu-Einsatz im Rahmen einer längeren (sich möglicherweise sogar über zwei Tage erstreckenden) Vortragsveranstaltung aufzufassen haben.

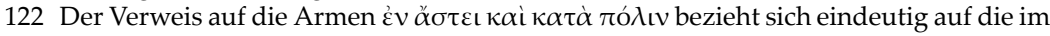

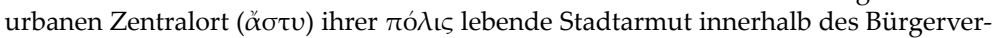

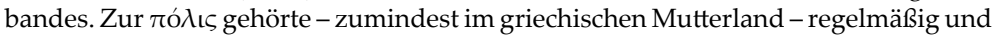
ohne jede politisch-rechtliche Abstufung das ländliche Territorium, die $\chi \omega \omega \varrho \alpha$ mit ihren Dörfern und Gehöften, einschließlich des unbewohnten Wald- und Ödlandes im jeweiligen Grenzbereich.

123 Zur (mitunter rabiaten) Praxis in der Festlegung von Rückzahlungsterminen und der keine Festtage berücksichtigende Berechnung von Zinstagen, s. Plut. De vitando 2, p. 828a, vgl. aber schon die Eröffnungsszene in Aristophanes' Nubes. - Zu den bereits in den Kreisen der Nobilität der klassischen Republik in Rom verbreiteten, Geschäftsusancen vgl. die aufschlussreichen Hinweise bei Polybios, XXXI 27, 6-11 B.-W. Das auf eher kurze Fristen und raschen Profit ausgerichtete Darlehensgeschäft hatte sich auch im griechischen Osten vielfach an das rigide römische Muster angepasst. 
124 Diese für Dions sozialpolitische Konzeption wichtige Stelle weist sprachlich einige Schwierigkeiten auf; unsere Übersetzung dieser "difficult and confused sentence" folgt der von Russell 1992, 139f.) vorgeschlagenen Deutung. - Der Sache nach lässt sich erkennen, dass ein „Arbeitsmarkt" innerhalb der Städte, der ausreichende und auskömmliche Beschäftigungsmöglichkeiten für die Schicht der Stadtarmut bereitstellen soll, einer Unterstützung "von außen her" bedarf - d. h. durch öffentliche Bauvorhaben und Investitionen, die sich aber nur durch Mobilisierung ehrgeiziger „Sponsoren“ innerhalb und außerhalb der Polis erreichen lassen. Dions Vorstellungen auf diesem Gebiet, die an dieser Stelle nur vage und allgemein angedeutet werden, lassen sich vor allem in seinen politischen Rechtfertigungsreden in seiner Heimatpolis Prusa konkret erfassen (s. o. Einführung S. 16-18): Dort bekennt er sich, selbst bereits in hohem Alter stehend, als ambitionierter (und zugleich umstrittener) Bauherr und Stadtpolitiker mit Nachdruck zu einem urbanistischen Programm, das auf eine gründliche städtebauliche Erneuerung in Prusa abzielte und zu wesentlichen Verbesserungen der Infrastruktur und damit der wirtschaftlichen Situation seiner Heimatstadt führen sollte: Bezeichnend ist hier der programmatische Hinweis in or. 45,12 auf seine persönlichen Initiativen nicht nur zur Errichtung von ansehnlichen Säulenhallen und Aquaedukten, sondern auch zum Ausbau der Stadtmauern sowie von Hafenund Werftanlagen sogar außerhalb des Stadtbereichs von Prusa (offenbar immer eingebunden in einen Finanzierungsrahmen aus anvertrautem öffentlichen Kapital und privat aufgebrachten oder eingeworbenen Sponsorengeldern). Von Bedeutung ist in diesem Zusammenhang. aber auch Dions Hinweis in or. 40,10 auf eine hartnäckige innerstädtische Opposition in Prusa gegen seine Person und seine ehrgeizige, an langfristigen Vorteilen und Status-Verbesserungen für die Polis orientierte Stadt- und Baupolitik; diese Opposition suchte nach Dions Einschätzung dauerhaften Rückhalt

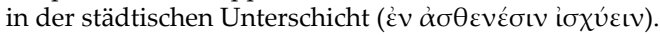

125 Kostenlose Wasserversorgung - in der Regel durch Aquaedukte und Laufbrunnenanlagen in der Stadt - gehörte offensichtlich zum Standard städtischen Lebens in dieser Zeit; vgl. dazu die spöttischen Bemerkungen in Horaz' iter Brundisinum (Sat. I 5,88) über die Versorgungslage in einer kleinen apulischen Stadt, in der er zum käuflichen Erwerb von Wasser (venit vilissima rerum / hic aqua!) genötigt war; vgl. auch Strabon XII 6,1 p. 568,8 RADT (zu einer ähnlichen Notlage in Lykaonien). - Im griechischen Osten der hohen Kaiserzeit lässt sich der (von der Principatsführung in Rom grundsätzlich geförderte, aber weder in finanzieller noch in urbanistischer bzw. "baupolitischer" Hinsicht maßgeblich gelenkte) Ausbau der Wasserversorgung durch Initiativen lokaler Sponsoren und Stadtpolitiker besonders gut in Ephesos in epigraphischen Zeugnissen dokumentieren: s. die Untersuchungen in: G. WiPLINGER (Hrsg.), Cura aquarum in Ephesus (Leuven 2006); vgl. auch G. Garbrecht (u.a.), Die Wasserversorgung von Pergamon (Berlin 2001).

126 Vgl. Dions Definitionen und Vorstellungen von angemessenen Arbeitsbereichen und gewerblichen Berufen ab §§ 109f.

127 ,Gut bewohnt' - eine Standardbezeichnung für städtische Zentralorte in den homerischen Epen (z. B. Il. II 648; Od. XIII 285). Zur positiven Konnotation des Begriffs

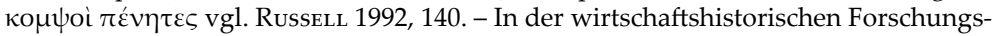
diskussion gegen Ende des 19. Jh. hat dieser Beleg in der Euböischen Rede für die Existenz einer (auch und gerade in der Polis-Bürgerschaft verbreiteten und sozialpolitisch geförderten) freien Lohnarbeit als eines sozioökonomisch relevanten Sektors in den Städten der römischen Kaiserzeit eine gewisse Rolle gespielt - vorgestellt von ED. MEYER in einer Beilage zu seiner Studie: „Die wirtschaftliche Entwicklung des Altertums" in: Kleine Schriften I (1924) 164-168, vgl. u. den Beitrag von D. EnGSTER, S. 144f.

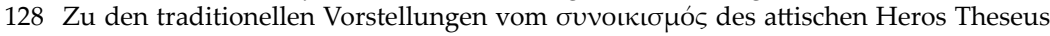
und zu den sozial- und strukturpolitischen Maßnahmen des Peisistratos s. Thuc. II 15; Arist. Ath. pol. 16,2-3 sowie Plut. Thes. 24,1-4. Auch andernorts hat es in der Epo- 
che der Älteren Tyrannis angeblich ähnliche ordnungspolitische Maßnahmen gegeben, mit denen die Landflucht und der Zustrom in die Stadtzentren der Polisstaaten unterbunden werden sollten - insbes. unter Kypselos und Periandros in Korinth (u.a. Verordnungen gegen Müßiggang und zur Eindämmung des Sklavenerwerbs). - Seine historischen Beispiele nimmt Dion ganz überwiegend aus den Epochen des archaischen und klassischen Hellas, vor allem aus der Geschichte und den Institutionen Athens, aber auch Spartas (vgl. die Bemerkungen des Autors in or. 50,2). Bezeichnend ist hierfür auch die von Dion getroffene und zu gründlicher Lektüre empfohlene Auswahl von Geschichtswerken in seiner Denkschrift über die Schulung in politischer Rhetorik (or. 18,10); als historische Informationsquellen kamen für Dion natürlich auch Ephoros und Aristoteles' Verfassungen-Sammlung in Betracht. - Insgesamt hebt sich jedoch Dions Verhältnis zur großen griechischen Vergangenheit (vgl. allerdings das Schlusswort des Zeus in Dions Olympischer Rede or. 12,85 zum traurigen Zustand des zeitgenössischen Hellas) erkennbar ab von der romantischen Liebe und Sehnsucht Plutarchs nach der großen klassischen Blütezeit seiner böotischen Heimatregion - vgl. dazu die Erzählungen und Rückblicke in De genio Socratis (s. dazu die neue kommentierte Ausgabe der Schrift De Socratis daemonio von H.-G. Nesselrath [ed.], On the daimonion of Socrates SAPERE XVI [Tübingen 2010])

129 Diese Kritik an der Masse des athenischen Demos begegnet bereits in der antidemokratischen Agitation des späten 5. Jh. v. Chr. (vgl. dazu u.a. Platon, Gorgias 515e); zum allgemeinen Misstrauen gegenüber professionellen Schreibern und Angestellten im öffentlichen Dienst der demokratischen Polis vgl. Demosthenes' persönliche Invektive gegen Aischines (Kranzrede, or. 18,127 und 261). Auch der stark belastete

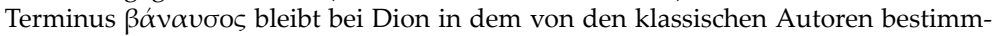
ten Bedeutungsbereich: „vulgäre und bildungsferne, nur zu mechanischen Tätigkeiten in geschlossenen Produktionsstätten befähigte Arbeiter". - In der politischen Öffentlichkeit der attischen Demokratie, zumindest des 4. Jh. v. Chr., wurden hingegen persönliche Wortmeldungen und Initiativen von authentischen "Arbeiter-Politikern“

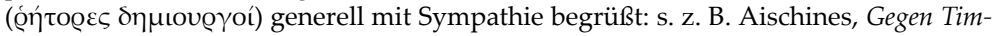
archos (or. 1) § $27 \mathrm{u}$. Demosthenes, 2. Olynth. Rede (or. 2) § 30; vgl. ferner die Hinweise bei G.A. Lehmann, Oligarchische Herrschaft im klassischen Athen (Opladen 1997) 95f.

130 In diesem Abschnitt wird deutlich, dass Dions Anliegen in seiner „Euböischen Idylle" nicht auf die Perspektive eines "philosophisch begründeten Antikapitalismus und Antiurbanismus" reduziert werden darf (J. PALM, Rom, Römertum und Imperium in der griechischen Literatur der Kaiserzeit [Lund 1959] 20). Dion, der bis an sein Lebensende aktiver Stadtpolitiker und ambitionierter Bauherr in Prusa blieb, wird man gewiss nicht auf Neigungen zur Weltflucht oder eine grundsätzliche Absage an die städtische Zivilisation und das ihr entsprechende Finanz- und Wirtschaftsleben festlegen dürfen; dies zeigen unmissverständlich die anschließenden Darlegungen zu Dions "Reform- und Beschäftigungsprogramm“; vgl. §§ 125f.

131 Auch der (durch Arbeitslosigkeit erzwungene) Müßiggang ist eben „aller Laster Anfang“" und eine gefährliche Quelle innerstädtischer Kriminalität; vgl. o. § 40 mit Anm. 55.

132 In feierlicher Sprache stellt Dion seine Definition von menschenwürdiger und in positivem Sinne produktiver Arbeit im Rahmen seines Beschäftigungsprogramms für die Stadtarmut vor; Russell 1992, 141 verweist hier hinsichtlich des Sprachstils auf Platon, Leges VI 774c. Inhaltlich stehen im Vordergrund handwerkliche Beschäftigungen mit körperlicher, überwiegend im Freien geleisteter Arbeit, „,sitzende Tätigkeiten“ werden von Dion als ungesund abgelehnt (s. auch § 112) und ebenso alle Betätigungen, die die Seele und Würde des Menschen beschädigen. - Zur Textproblematik s. RusSELL 1992, 141, der sich für Reiskes Ergänzung (

133 Konsequent beruft sich Dion auf Hesiods Erga, in denen harte, aber planvoll und eigenständig geleistete körperliche Arbeit als unerlässliche Voraussetzung für die Voll- 


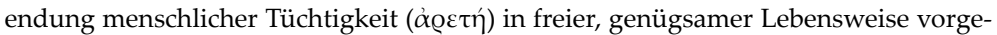
stellt wird; vgl. bes. Erga 298-316.

134 Handwerkliche Fertigkeiten und Gewerbe wurden offensichtlich primär innerhalb der Familie vermittelt und weitergeführt.

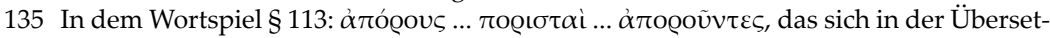
zung nicht wiedergeben lässt, sieht Russell 1992, 142 eine bewusste Anspielung auf Plat. Symp. 202d.

136 Im folgenden werden freilich die von Dion abgelehnten Erwerbsmöglichkeiten und Berufe klar benannt und kritisiert, während er sich in seinen positiven Empfehlungen mit Andeutungen begnügt; hier geht es ihm vornehmlich um die Betonung der in $\S 110$ definierten Bedingungen für menschenwürdige und sinnvolle, produktive Beschäftigungen (vgl. §§ 125-126).

137 Russell 1992, 142f. führt diese Liste ehrbarer und zu Unrecht geringgeschätzter Beschäftigungen und Dienstleistungen auf „Lesefrüchte“ Dions aus Passagen in der Rede für Euxitheos gegen Eubulides (Corp. Demosthen. Nr. 57 § 45) und aus Demosthenes' Attacke auf Aischines' Vater in der Kranzrede (or. 18,258) zurück. Tatsächlich sind die Übereinstimmungen hier so groß, dass mit einer bewussten literarischen Anspielung gerechnet werden muss. Gleichwohl wird man Russell nicht folgen können, wenn er dem sozial-ethischen Appell Dions deshalb keine Bedeutung ", as a statement of contemporary social facts" beimessen will. Immerhin spricht sich Dion auch in der (politisch zweifellos relevanten) 2. Tarsos-Rede (or. 34,21 und 23) ausdrücklich gegen eine Missachtung ehrbarer (wenngleich schlecht bezahlter) handwerklicher Arbeit aus. Zum Komödienspott über die angebliche Beschäftigung von Euripides' Mutter als Gemüsehändlerin s. Ar. Thesm. 387 (vgl. C. Austin / S. D. Olson, Aristophanes. Thesmophoriazusae. Ed. with Introduction and Commentary [Oxford / New York 2004] 177); vgl. andererseits den selbstbewussten Hinweis des Sokrates auf die Tätigkeit seiner Mutter Phainarete als Hebamme (Platon, Theaet. 149a-150d).

138 Erneut verweist Dion auf Hesiod Erga 311 (s. o. Anm. 133). Des weiteren verweist Dion auf eine Stelle in der humorvollen (damals traditionell Homer zugeschriebenen) Margites-Verserzählung, die vollständiger bei Aristoteles, Eth. Nicom. VI 7,1141 a 12, zitiert wird: „Ihm (Margites) hatten die Götter weder zum Graben noch zum Pflügen Geschick gegeben; / er war auch sonst nicht gescheit und in jedem Handwerk ein Versager" (,Homerus', frg. 2; M. WEst, Iambi et Elegi Graeci II. Ed. altera [Oxford 1992] 73); zum sprichwörtlichen Tölpel Margites vgl. Dion or. 67 (50 ARNIM) § 4.

139 Vgl. hier Od. XXI 150f.; diese Wendung wurde offenbar gern zur Charakterisierung unmännlicher Verzärtelung (und würdeloser Arbeitsscheu) zitiert und abgewandelt, s. Dion or. 16,7 .

140 Dions Abneigung gegen das Färber-Handwerk (s. dagegen die ganz andere Einschätzung in or. 34,23) hängt hier möglicherweise mit seiner ungünstigen Darstellung des Verhaltens der geldgierigen (nach den Angaben im Text offensichtlich an der Ostküste Euböas tätigen; s. o. Anm. 7 und 75) Purpurfischer zusammen; diese waren schließlich die Lieferanten für ein wertloses Gewerbe im naturfernen Luxusbetrieb; vgl. dazu auch Plut. Per. 1, 4. - Die É $\gamma \chi 0 u \sigma \alpha / \not ̈ \gamma \chi o v \sigma \alpha-P f l a n z e ~(A l k a n n a$ tinctoria) fand üblicherweise als Rouge Verwendung, mit Bleiweiß ( $\psi \mu u v \theta \iota \nu v)$ wurde demgegenüber der Teint aufgehellt (vgl. u. a. Lys. or. 1,17 und Ar. Eccl. 878 und 929).

141 Dion positioniert sich hier deutlich u.a. gegen die zu Beginn des 2. Jh. n. Chr. einsetzende Blüte und Ausbreitung der aufwendigen, polychromen Mosaik-Technik: S. u. a. D. Von Boeselager, Antike Mosaiken in Sizilien, 1983 u. O. Bingöl, Malerei und Mosaiken der Antike in der Türkei 1997 sowie M. D. Dunbabin, Mosaics of the Greek and Roman World, 1999. Zu der immer beliebter werdenden Verwendung des farbigen CipollinoMarmors s. u. H. R. Goette, S.188f. Vgl. dazu auch die Kritik an der überladenen, mit der Verwendung kostbarer Materialien sinnlos protzenden Prunksucht in Rom, 
gegen die Dion für eine gründliche urbanistische Reform plädiert (or. 13 / 12 ARNim $\S \S 32-36)$.

142 Die Metapher von zwei miteinander im Wettstreit stehenden Chören (der Armen gegen die Reichen) entstammt den besonders im Athen der Klassik beliebten Dithyrambos-Agonen, an denen jahraus, jahrein die gesamte (männliche) Bürgerschaft intensiv beteiligt war. Tatsächlich greift Dion hier direkt auf Platons Darlegungen (Rep. IX 580b) zurück. Im Unterschied zu Platon soll es nach Dion dabei jedoch nicht um

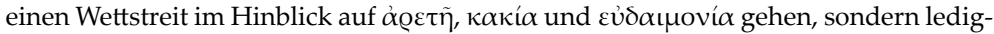
lich um eine maßvolle, menschenwürdige Lebensform. Nach Dions (in diesem Punkt

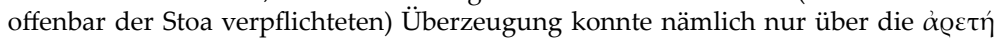

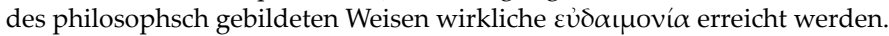

143 Unmissverständlich bezieht sich Dion auch hier auf Platons bekannte Forderung (Rep. II 380a-c) nach einer Ausweisung der Tragödien- und Komödien-Dichter aus dem „idealen“ Staatswesen. Dagegen zielt die anschließende scharfe Polemik gegen Mimos-Possen und revue-artige Darstellungen tragischer Themen im PantomimenTanz oder in Gesangeinlagen offensichtlich auf zeitgenössische Aufführungsformen; vgl. Dions Kritik an dem im zeitgenössischen Alexandria üblich gewordenen Theaterbetrieb (or. 32,4f. und 62), das mit Tanz, Akrobatik und potpourri-artigen Arrangements auf bloße Unterhaltungseffekte abzielte. Russell 1992, 145 verweist hier zu Recht auf Lukian, De saltatione 41 u. 43; vgl. dazu aber auch die eingehende Beschreibung einer privat arrangierten Pantomimen-Darstellung (mit dem Thema der Heimholung Ariadnes durch Dionysos) bereits in Xenophons Symposion (2,1-3 u. 9,2-4.). - In seiner Polemik gegen Pantomimen-Aufführungen und aufreizende Darbietungen von Tänzerinnen befand sich Dion übrigens in bester Übereinstimmung mit den von Kaiser Trajan gleich nach dessen Einzug in Rom getroffenen Maßnahmen (s. Plin. Paneg. 46,1-5, vgl. auch die detaillierten Darlegungen in Dions or. 2,56). - Wichtige Bemerkungen Dions zu den zeitgenössischen Aufführungsformen klassischer attischer Tragödien finden sich in dem Traktat-Fragment or. 19,5: Lediglich die iambischen Sprechverse werden noch zu Gehör gebracht, während man auf die metrisch und musikalisch offenbar zu anspruchsvollen Chorlieder generell verzichtet.

144 Auch der Verweis auf die sowohl in ethischer als auch in religiöser Hinsicht höchst anstößigen Sagengestalten Niobe und Thyestes (in denen menschliche Hybris von den Göttern gnadenlos-grausam geahndet wird) nimmt direkt auf Platons Darlegungen Bezug. Darüber darf jedoch nicht vergessen werden, dass es in diesem Abschnitt des Euboikos Logos - im Unterschied zu Platons nomothetischen Verdikten - nicht um generelle, kategorische „Berufsverbote“, sondern um die inhaltlichen Aspekte und Schwerpunkte eines aktuellen (öffentlich zu fördernden) Beschäftigungsprogramms zugunsten der Stadtarmut in den Polis-Gemeinden des griechischen Ostens gehen soll.

145 Chios, Smyrna und Argos gehörten traditionell zu dem Kreis von Polis-Gemeinden, die Anspruch erhoben, die Heimat Homers gewesen zu sein. - Das Aulos-/AuloiInstrument, das auf zwei miteinander (locker) verbundenen Rohren (mit jeweils 5 Griff-Löchern) gespielt wurde, kann am ehesten als eine Doppel-Oboe verstanden werden. Es handelt sich um das wichtigste Blasinstrument im Musikleben des antiken Hellas, das sowohl im Opferkult, als auch in der Begleitung von Einzel- und Chorsängern und als Einzelinstrument im virtuosen Spiel eingesetzt wurde.

$146 \mathrm{Zu}$ diesem agonalen Siegesdenkmal, einem Hermen-Monument, und dem zugehörigen Epigramm (in § 121 nur teilweise zitiert) s. Menandr. Rhet. 360,22 u. Anth. Pal. XVI 28; vgl. Paus. IX 12,5. - In Plutarchs Amatorius-Dialog (1,749B-C) findet sich ein zeitgenössisches Zeugnis dafür, mit welcher Anteilnahme die bürgerliche Öffentlichkeit in der kleinen boiotischen Polis Thespiai den Verlauf eines musikalischen Wettbewerbs verfolgte, so dass sogar heftige Krawalle befürchtet werden mussten: GöRGEMANNs 2011, 48 und 140; vgl. dazu aber auch Amat. 10,755A-B. - Zur hohen Wertschätzung 
des aulos(Doppel-Oboe) - Spiels in Theben s. ferner die Angaben zur musikalischen Erziehung, die dem großen Strategen und Politiker Epameinondas in seiner Jugend zuteil wurde: Aistoxenos bei Ath. IV $184 \mathrm{~d}$ - e und Nep. Epam. 2,1.

$147 \mathrm{Zu}$ der Zerstörung Thebens im Herbst 335 v. Chr. (unter dem Druck Alexanders d. Gr. vom Synhedrion des hellenischen cị̀̂́vๆ-Bundes verfügt; s. u.a. Hypereides, Epitaphios (6) §§ 4f. sowie die ausführlichen Darstellungen bei Arr. Al. Anab. I 7-9 und (dramatisch ausgeschmückt) bei Diod. Hist. Bibl. XVII 8-17 (nach Kleitarchos von Alexandrien); ferner Plut. Alex. 11. - Zu dem systematischen Wiederaufbau der Stadt unter dem Diadochen Kassandros 315 v. Chr. s. u. a. Diod. Hist. Bibl. XIX 53,2; 54,2 u. 63,4 (mit Hieronymos von Kardia als Basis) und Syll $l^{3}$ Nr. 337, ferner Plut. Demetr. 40,6. S. im Hinblick auf die späteren Zerstörungen und Einbußen der Stadt in der Zeit des Mithradates-Krieges (87 v. Chr. Kapitulation Thebens und harte Bestrafung durch Cornelius Sulla) und zu dem aktuellen Befund im 2. Jh. n. Chr. zu Dions Aussagen in der Euböischen Rede sowohl Strabon IX 2,25 p. 410, 14f. RadT als auch Paus. VIII 33,2 sowie IX 7,4-6, ferner App. Mithr. 30 u. 57; Plut. Sull. 19,11f.

148 Ungeachtet seiner zuvor so nachdrücklich bekundeten Sympathie für die Schicht der Armen (und seinem präzisen Verständnis für die finanziell schwierige Lage der Stadtarmut in ihrem Alltagsleben) zeigt Dion hier tiefe Vorbehalte gegenüber den ungebärdigen Massenversammlungen in einer ekklesia (s. dazu o. §§ 24-26) oder bei Theaterund Sportveranstaltungen; vgl. auch den konkreten Hinweis in einer Volksrede in Prusa (or. 40,29) auf mögliche spontane Auseinandersetzungen zwischen „Stadtparteien" aus Prusa und der Nachbarstadt Apameia bei Veranstaltungen im Stadion wie im Theater; s. ferner seine Vorwürfe und Klagen in der Alexandrien-Rede (or. 32,28 und 55-59). - Von der Ausbreitung der (aus Rom übernommenen) blutrünstigen Gladiatorenspiele auch im griechischen Osten (sogar in Athen!), die Dion in der (wahrscheinlich schon aus der flavischen Zeit stammenden) Rhodier-Rede (or. 31,121f.) bitter beklagt, ist dagegen in der Euböischen Rede mit keinem Wort die Rede. Freilich schloss die von Dion all seinen reformerischen Überlegungen vorangestellte Definition echter, förderungswürdiger Arbeit, die grundsätzlich mit körperlicher und seelischer Unversehrtheit einhergehen müsse, diesen Bereich eines geradezu entmenschlichten öffentlichen „Unterhaltungsbetriebs" a limine aus.

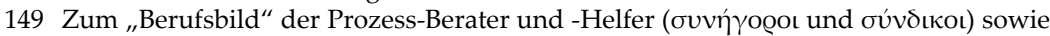
der Prozessreden-Schreiber im Athen des 5. und 4. Jh. v. Chr. s. bereits Ar. Nub. 483 und frg. 205,9 K.-A. - Ob ein Zusammenhang zwischen diesen Darlegungen und der Gestalt des (offenbar aus eher ärmlichen Verhältnissen stammenden) „Demagogen“ in der Jägererzählung angedeutet werden sollte, bleibt unklar. Gegenbild zu den von Dion abgelehnten „Prozess-Anzettlern“ ist jedenfalls die Gestalt des Jägers, der lieber auf seinen mühselig erworbenen Besitz in den Bergen (s. o. § 42f.) verzichten, als den Rechtsfrieden mit den Bürgern seiner Polis stören will; s. dazu auch u. D. GALL, S. 127.

150 Deutlich unterstreicht Dion die Ausrichtung seines „Programms“ auf die zeitgenössischen Verhältnisse in den Polis-Gemeinden des griechischen Ostens. Wenn zuvor, § 123, wie Russell 1992, 147 feststellt, einschlägige Termini des attischen Prozessrechts der Klassik des 5./4. Jh. v. Chr. begegnen, so bedeutet dies keineswegs, dass wir es hier bloß mit einem literarischen Spiel, ohne Bezug zur aktuellen Gegenwart des Autors, zu tun haben. Vielmehr ist davon auszugehen, dass gerade das Prozessrecht der athenischen Polis-Demokratie - ebenso wie das attische Privatrecht - längst vielfach auf die Institutionen innerhalb der griechischen Staatenwelt prägend eingewirkt hatte. - Die für die Stadtarmut benötigten (zusätzlichen) Arbeitsplätze sollten jedenfalls nicht im Umkreis des Gerichtswesens und des "öffentlichen Dienstes", sondern im produktiven, handwerklichen Bereich geschaffen werden; bekanntlich rühmt Dion in der Kaiser Trajan gewidmeten Rede (or. 3,124f.) an den körperlich besonders anstrengenden Berufen von Schmieden, Schiffbauern und Zimmerleuten, dass gerade sie den 
Menschen - ebenso wie die Landarbeit - ein Dasein in Gesundheit und Lebensfreude eröffneten.

151 Noch einmal wird das übergreifende Thema der Abhandlung (,Armut - Arbeit Menschenwürde") umrissen und klar von jedem philosophischen Entwurf einer idealen Staats- und Gesellschaftsordnung abgegrenzt; vgl. o. § 102 mit Anm. 119. - Mit seiner schroffen Absage an pure "Schreibtisch-Tätigkeiten" und Formen juristischrhetorischer „Fortbildung“ macht Dion deutlich, dass sein fürsorglicher Paternalismus auf die moralisch-sittliche Ebene ausgerichtet bleibt und keineswegs auf eine umfassende politisch-soziale „Emanzipation“ der städtischen Unterschichten abzielt; vgl. in diesem Zusammenhang auch Dions sarkastische Bemerkungen in or. 35 (Kelainai-Rede) § 15 über die vermeintlichen "Segnungen“, die sich alsbald aus der allgemein so heiß begehrten Gerichtshoheit für eine Polis wie Kelainai (in Phrygien) ergeben würden - mit exzellenten Beschäftigungs- und Verdienstmöglichkeiten vornehmlich für Prozessberater, Richter, Beamte, Dienstboten, Maultiertreiber, Kuppler und Huren!

152 Mit diesem knappen Resümee und der nachfolgenden Bitte des Autors um Verständnis für Umfang und Ausführlichkeit seiner Darlegungen hätte die Abhandlung an sich beendet werden können (als Beispiel für eine überraschend kurze peroratio zum Abschluss einer weitläufigen, exkursreichen Rede vgl. Dions' Olympische Rede [or. 12] $\S \S 84 f$.$) . - In der erhaltenen Fassung der Euböischen Rede leitet jedoch der ausführlich$ begründete Exkurs §§ 127-132 über zu einem heftigen Protest Dions gegen alle Formen einer staatlich geduldeten (oder sogar ausdrücklich anerkannten und fiskalisch ausgenutzten) Prostitution ( $\S \S 133-140$ ), vor deren Begleiterscheinungen und langfristig fatalen Folgen nicht allein die Stadtarmut, sondern auch alle unfreien Personen in der Stadt und die ganze bürgerliche Gesellschaft unbedingt geschützt werden müssten.

153 Die Übersetzung folgt hier der Deutung von Russell (1992, 148), der $\mu$ ćtoเoเ als (gängigen) Euphemismus für ,arme' (= , bescheiden-maßvolle') Leute auffasst.

154 Vgl. o. §§ 1 und 102 mit Anm. 3; während Dion zuvor (und ebenso in der Olympischen Rede [or. 12] § 16) eher entschuldigend und mit Selbstironie auf seine Neigung

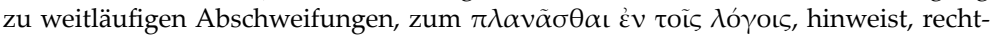
fertigt er dieses Verfahren hier ausdrücklich als sinnvoll für seine Untersuchung und gewinnbringend für die Hörer des Lehrvortrages; als Argumentationshilfe und Vorbild nimmt er im Folgenden Platons Politeia in Anspruch.

155 Mit der Metapher von den auf verschiedenen Spuren nach Beute suchenden Jägern wird offenbar auch an die Erzählung des Jägers aus Euböa (o. §§ 19f.) angeknüpft; zu Recht verweist Russell seinerseits $(1992,149)$ auf Parallelen in Platons Dialogen: Rep. 432 d; Leg. 654 b; Parmen. 128 c und Lysis 218 c. - Der Text ist am Ende von § 129 gestört, lässt sich aber sinngemäß ergänzen; vgl. Russell 1992, 56 App. und 149. Unsere Textvorlage und Übersetzung folgen der von H. v. ARNIm empfohlenen Emendation (p.

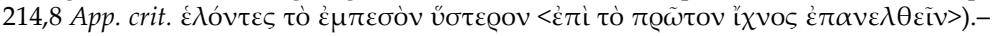
Die sorgfältig entwickelte Metapher lässt für die folgenden Darlegungen einen ausführlichen, weit über das eigentliche Thema der Euböischen Rede hinausführenden Exkurs erwarten.

156 Dion skizziert klar den Gedankengang in Platons Politeia, die im ersten Buch mit der Frage nach einer Definition der Gerechtigkeit beginnt und sich dann dem Aufbau eines idealen Staatswesen als besser erkennbares Modell $(\pi \alpha \varrho \alpha ́ \delta \varepsilon \iota \gamma \mu \alpha)$ zuwendet. Die Schilderung der Verfassungsumbrüche $\left(\mu \varepsilon \tau \alpha \beta \beta_{0} \lambda \alpha i\right.$ ) und die äußerst lebendige Charakterisierung der verschiedenen, einander ablösenden Grundordnungen bilden den Inhalt der Bücher 8 und 9.

157 Während Dion hier in Platons Verfassungslehre nur ein Modell für das Hauptthema,

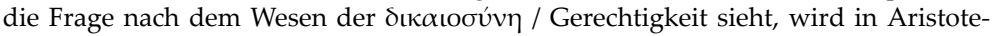
les' einschlägiger Kritik an Platon (Politika II 1,2-3, 11 p. 1261a6-1266a30) die in der 
Politeia entwickelte Ordnung schlechthin als Grundlage der platonischen Staatslehre verstanden, an der sich auch der Verfassungsentwurf der späteren Nomoi weitgehend orientiert habe.

158 Noch einmal betont Dion das in $\S 125$ (s. o. Anm. 151) formulierte Thema der Abhandlung; in den folgenden Darlegungen geht es jedoch kaum noch um die Scheidung von empfehlenswerten oder grundsätzlich abzulehnenden Beschäftigungsmöglichkeiten für die Stadtarmut, sondern primär um eine uneingeschränkte Verurteilung der Prostitution (bei Reichen wie Armen) sowie aller Formen sexueller libertinage. Dions Ansichten stimmen hier weitgehend mit den Positionen seines römischen Lehrers C. Musonius Rufus überein (Diatribe 12-13 B, p. 63-70 Hense); zur philosophischen Persönlichkeit des Musonius s. o. Einführung S. 10, vgl. auch Dion or. 31,122. Aus der Gewöhnung an die menschenverachtende ro@veí $\alpha$ erwächst, Dion zufolge, die destruktive Neigung zur riskanten (Ehe und Familie zerstörenden), sexuell aber auch reizvolleren $\mu$ oı $\chi \varepsilon$ í $\alpha$. Der (finanziell oftmals ruinöse) Umgang mit anspruchsvollen und teuren Hetären spielt in Dions Darlegungen dagegen keine Rolle. Vielmehr schließt sich hier (ab § 141) die Schilderung einer weiteren, noch bedenklicheren Phase sexueller Zügellosigkeit an, die ihren Ursprung in einem Klima der Duldung und Gleichgültigkeit (oder gar offener Connivenz) der Gesellschaft gegenüber Ehebruch und libertinage findet: die Verführung junger Mädchen aus wohlhabenden Familien der (römischen) Oberschicht und schließlich die aus Überdruss und Hybris erwachsenden paedo- bzw. ephebophilen Versuchungen und Verführungen im Umgang skrupelloser roués mit der heranwachsenden männlichen Jugend namentlich des ordo senatorius (§ 151).

159 Tatsächlich finden sich Bordelle, nicht erst in den Städten der Kaiserzeit, vielfach in der Nähe von Heiligtümern und zentralen Plätzen (z. B. in Athen in unmittelbarer Nähe des sakralen Pompeion-Gebäudes nahe dem Dipylon-Tor oder in Rom an der via sacra in unmittelbarer Nachbarschaft zum Vesta-Heiligtum); zum sog. Bau Z am Dipylon und seiner Deutung als Bordell s. H. Lind, „Ein Hetärenhaus am heiligen Tor? Der Athenabau Z und die bei Isaios (6,20f.) erwähnte Synoikia Euktemons “, MH 45 (1988) 158-169. S. ferner die Hinweise und Belege im Beitrag von E. Hermann-Otтo (unten S. 225-233); weitere Literatur: Stumpr 1998; FARAone / McClure 2006.

160 Dion deutet inhaltlich nur vage auf die in den antiken Bordellen auf unterschiedliche Weise praktizierten Empfängnisverhütungen und Abtreibungen hin. - RussELL 1992, 151 hat diese ebenso ernsthaft wie kunstvoll (mit Reimanklängen und Chiasmen) ausformulierte Periode treffend analysiert; in der Übersetzung lässt sich dieser, vom Autor absichtsvoll eingesetzte hohe Ton nur unvollkommen wiedergeben.

161 Artemis Lochia, die jungfräuliche Schutzgottheit während der Geburt, konnte die Schmerzen der Niederkunft lindern, aber auch den Tod einer Gebärenden bewirken. Die Kulte der Muttergottheit Rhea, der Gemahlin des Kronos und Mutter von Zeus und Hera (ferner von Poseidon und Hades, Hesiod zufolge auch noch von Hestia und Demeter) sowie der Eileithyien (Il. XIX 119), der Geburtshelferinnen, reichen im Ägäisraum bis in die vorgriechische Zeit des 3./2. Jahrtausends v. Chr. hinauf; s. jetzt die Studie von M. Xagorari-Gleißner, Meter Theon. Die Göttermutter bei den Griechen, Peleus Bd. 40 (Ruhpolding 2010). In der Kaiserzeit wurde die Verehrung der meter theōn vom Kybele-Kult überformt, der seit 206 v. Chr. eine feste Position in der römischen Staatsreligion einnahm; s. auch D. Engster, Konkurrenz oder Nebeneinander. Mysterienkulte in der hohen römischen Kaiserzeit (München 2002) S. 13-20. u. bes. S. 152f. - Musonius beruft sich bekanntlich in der in den Philosophenschulen diskutierten Streitfrage, ob ein Philosoph sich auf Ehe und Familie einlassen solle (Diatr. 14, 70-76 Hense), auf die fundamentale göttliche Macht von Hera, Eros und Aphrodite, der sich auch ein Philosoph, auf Frömmigkeit bedacht, nicht entziehen dürfe. In der ehelichen Liebe werden, Musonius zufolge, Mann und Frau zu einem einzigen lebenstiftenden Leib: Diatr. 13a, 67,8f. und 68,1 Hense; vgl. Diatr. 14, 74 Hense. 
162 Bezeichnend für Dions Vorstellungen von einer in sich nach Rangstufen gegliederten Polis-Staatenwelt (unter römischer Provinzialherrschaft) ist u.a. sein Appell an die Mitbürger in Prusa, sich in ihrer Stadt- und Baupolitik grundsätzlich nur an den wirklich großen Vorbildern $(\pi \alpha \varrho \alpha \delta \varepsilon i ́ \gamma \mu \alpha \tau \alpha)$ von Smyrna, Ephesos, Tarsos und Antiochien (am Orontes) zu orientieren: or. 40,11, vgl. §6. Diese Polis-Gemeinden zählten für Dion (und ebenso für sein Auditorium) gewissermaßen zur "ersten Liga“ unter den Städten des griechischen Ostens, vgl. dazu auch die Mahnungen und Vorschläge in or. 34 (2. Tarsos-Rede) §§ 7f. 13f. 43f. Rangstreitigkeiten unter den wirklich großen Städten über leere Titel und reine Prestigefragen wertet Dion dagegen als den (sprichwörtlichen) „Streit um den Schatten des Esels“, denn Macht und Herrschaft hielten ja längst andere in ihren Händen: $\S 48$.

$163 \mathrm{Zu}$ der Auffassung, dass sich Mißstände und Laster in ständiger, expansiver Bewegung befinden und sich dementsprechend nur schwer eindämmen lassen, vgl. auch Dions Position in or. 31 (Rhodier-Rede) §§ 141-145 (vgl. dazu Sen. ep. 47,21.)

164 In diesem knappen Referat zur klassischen Lehre der Stoa von der universalen Verwandtschaft und prinzipiellen Gleichheit / Gleichwertigkeit aller Menschen, besonders in ihrer Beziehung zum universalen Schöpfergott (vgl. Sen. ep. 120, 1-4), wird deutlich, dass diese Leitgedanken die Basis für ein System der Ethik und Selbsterziehung bilden sollten und keineswegs auf eine äußere Durchsetzung (mit politischen Mitteln) abzielten. Darüber hinaus besaß Dion auch genügend politische Erfahrung um zu wissen, wie wenig sich von diesen philosophischen Grundsätzen, unter den festgefügten Rahmenbedingungen der kaiserzeitlichen Gesellschaft, in der soziopolitischen Praxis verwirklichen ließ. Seine Argumentation legt daher pragmatisch den Hauptakzent auf die "soziale Hygiene“ und somit auf das Ausbreitungsrisiko, das die mit der (vornehmlich von Unfreien ausgeübten) Prostitution notwendig verbundenen Übel und Laster in sich bergen; vgl. dazu auch den Gedankengang in §§ 150f. - Jedenfalls unterscheidet sich Dions bescheidener „Pragmatismus“ an dieser Stelle eher positiv von der opportunistischen Doppelbödigkeit, mit der viele Jahrhunderte später, in der Redaktion der berühmten ",bill of rights“ von Virginia (vom Juni 1776) und in der amerikanischen Unabhängigkeitserklärung (vom 4. 7. 1776), von der Gleichheit der Menschen und ihren unveräußerlichen Rechten die Rede gewesen ist, der Skandal der Sklaverei und des Sklavenhandels jedoch bewusst übergangen wurde; John Locke (1632-1704), der bekanntlich mit seinem Privatvermögen im lukrativen interkontinentalen Sklavenhandel (von Westafrika aus nach Amerika) stark engagiert war, hatte demgegenüber in seiner bekannten Second Treatise of Government zwar die von Natur aus gegebene Gleichheit aller Menschen konstatiert, den Sklaven jedoch explizit die bürgerliche Rechtsfähigkeit abgesprochen, indem er für sie den Status von Kriegsgefangenen postulierte; s. ferner den Essay von W. Heun unten S.251f. Dion beharrt seinerseits dagegen auf der Position einer prinzipiellen, natürlichen und unveräußerlichen Menschenwürde, die gerade auch den unfreien und versklavten Menschen zustehe.

165 In Solons Gesetzeswerk sind die Prostitution und der Betrieb von Bordellen offenkundig vorausgesetzt worden (vgl. Plut. Sol. 23,1-3); erst in späterer Tradition wird Solon dann persönlich die Einrichtung von staatlich besteuerten Bordellen und darüber hinaus die Gründung eines Heiligtums der Aphrodite Pandemos in Stadt-Athen zugeschrieben - mit dem Ziel, bürgerliche Ehen und Familien vor dem Eindringen sexuell begehrlicher junger Männer zu schützen und die gesellschaftliche Ordnung insgesamt zu entlasten: Philemon, Adelphoi Fr. 3 (wahrscheinlich aus der Rede eines Zuhälters. PCG VII 230f.) und Nikandros, Kolophoniaká (FGrHist 271/2 F 9) aus Ath. XIII 569e-d. Zu der Auffassung, wonach die Prostitution als zuverlässiges und bequemes "Ventil“ unbedingt den Vorzug vor dem gefährlichen adulterium verdiene, s. Hor. Sat. I 2 - Zu der im Kynismos vertretenen Auffassung, wonach Bordellbesuche eine zumindest empfehlenswerte (und überdies preisgünstige) Alternative zu ehe- 
brecherischen Abenteuern seien, s. die Belege bei H. HerTer, „Dirne“ (A2/B), RAC III (1957) [1154-1213] 1181. Eine strengere Position nahm in dieser Frage Musonius ein, der in einem - auch ohne Verletzung ehelicher Bindungen - mit Prostituierten vollzogenen Geschlechtsverkehr eine Entehrung und Versündigung des ,Freiers' an sich selbst sah: Diatribe 12, p. 63,17 und 64,4 HENSE; ähnlich urteilte offensichtlich auch Apollonios von Tyana: Philostr., V. Apol. I 13 und VI 11. Demgegenüber ist es für Dion bezeichnend, dass er den Akzent hier auf die (gewissermaßen objektive) Verletzung der Menschenwürde legt, die durch die Prostitution an der (i. d. R. unfreien) Frau begangen wird; unter diesem Aspekt ist es im übrigen bemerkenswert, dass zu dieser Zeit beim Verkauf einer Sklavin grundsätzlich eine Nebenabrede als verbindlich angesehen worden ist, wonach die betroffene Frau von den neuen Besitzern nicht zur Prostitution gezwungen werden durfte, wenn sie nicht zuvor schon als Prostituierte tätig gewesen war: Ulpian, Dig. 37, 14, 7 .

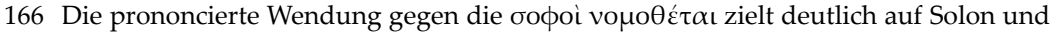
seine (angebliche) „Förderung“ der Prostitution als probates Präventionsmittel gegen Verführung, Ehebruch und gesellschaftlich-familiäre Konflikte innerhalb der Bürgerschaft. - Die Warnung vor den verderblichen Langzeit-Wirkungen sexueller Zügellosigkeit und gesellschaftlich akzeptierter libertinage wird in den folgenden Abschnitten weiter entfaltet. Hat Dion hier - zunächst wohl auf den mündlichen Vortrag beschränkt - über einen älteren Abschluss seines logos hinaus (vermutlich verbunden mit einer inzwischen fälligen Rückkehr zum Hauptthema „Armut - Arbeit - Menschenwürde") zu einer großen Erweiterung angesetzt, die sich auf die Lebenswelt und entsprechende popularphilosophische Erwartungen eines hochrangigen römischen Publikums einließ? - In der in Athen gehaltenen or. 13 (12 ARNIM) §§ 31-37 geht Dion, mit deutlich ironischem Unterton, auf seine rege Vortragstätigkeit in Rom (vor großem Publikum) näher ein und benennt einige der dort von ihm behandelten sozialethischen Fragen (die sich durchaus auch auf praktische Konsequenzen für die Urbanistik dieser übergroßen Weltstadt erstreckt hätten!); deutliche Rom-Kritik (mit Verweis auf die aus Griechenland verschleppte Beute-Kunst) äußert Dion auch im Traktat or. 79 (Über den Reichtum) §§ 1-5.

167 Vgl. in diesem Zusammenhang die bitteren Feststellungen in Juvenals „Frauensatire“ 6, 136-141 (daneben aber auch die auf die Homosexuellen-Szene in Rom ausgerichtete "Gegenrede" der Ehebrecherin Laronia: Sat. 2,37-148); s. ferner Tacitus, Germ. 19,3-5 und die durch Dokumente (Tabula von Larinum) bestätigten Angaben über Senatsdekrete gegen frivole Praktiken, mit denen die gesellschaftlich weithin tolerierte, polygame libertinage in der römischen Oberschicht rechtlich abgesichert werden sollte: Sueton. v. Tib. 35 und Tacitus, Ann. II 85, s. dazu auch Ovid, Ars III, 611f.; vgl. u. a. D. Engster, „,Römisches Frauenlob und Polyandrie - die Grabinschrift der Allia Potestas", in: Archiv für Kulturgeschichte (AKG) 85 (2003) 143-170. - Dions Klagen und Vorhaltungen passen hier schwerlich zu den Verhältnissen im zeitgenössischen Hellas, wohl aber gut zum stadtrömischen Ambiente nicht allein der senatorischen bzw. ritterständischen Oberschichten; vgl. dazu auch v. ARNim 1898, 457f.

168 Zur traditionellen Gestalt der Hymenäen-/Epithalamien-Lieder (mit hohem Lob auf die Jungfräulichkeit der Braut und die von beiden Seiten zu erwartende eheliche Treue) vgl. die von Catull mit hoher literarischer Kunst ausgeformten Hochzeitslieder nr. 61 und vor allem nr. 62, 97f. u. 217f.

169 Der in der Argolis beheimatete Danae-Mythos ist mehrfach von den athenischen Tragikern ausgestaltet worden: Verstört durch einen delphischen Orakelspruch, der ihm den Tod durch die Hand des Sohns seiner einzigen Tochter Danae ankündigte, traf der König Akrisios von Argos aufwendige Vorkehrungen, um die heranwachsende Danae, die am Ende die Stammmutter des frühgriechisch-peloponnesischen DanaoiVolkes werden sollte, in einem unterirdischen Spezial-Gefängnis (mit Bronzewänden) von der Außenwelt abzusperren. Nach ihrer von Zeus im Goldregen bewirkten 
Schwangerschaft und der Geburt des Sohns Perseus wurde Danae mit ihrem Kind in eine hölzerne Lade eingeschlossen und im Meer ausgesetzt. - Die Übersetzung folgt hier der von Russell vorgeschlagenen Korrektur von tả $\lambda \lambda \dot{\alpha} \dagger$ (in v. ArNIm's Edition getilgt) in $\tau \alpha ̋ ́ \lambda \lambda \alpha$.

170 Die Übersetzung folgt hier der überzeugenden emendatio von GAZDA: $\kappa \lambda \iota \sigma \iota \alpha ́ \delta \alpha \varsigma$ statt

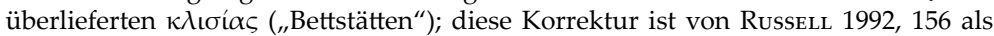
„surely right" anerkannt worden.

171 Hier wird auf die in der Od. XI 235-257 eindrucksvoll gewürdigte Heroine Tyro angespielt, die von Poseidon in Gestalt des schönen Flussgottes Enipeus verführt und geschwängert wurde; ähnlich steht es mit der Verbindung zwischen Polydora und dem Flussgott Spercheios in Il. XVI 175 (s. u. Anm. 174).

172 Dions Verweis auf prächtige suburbane Villen ( eingebettet in aufwendig ausgestaltete Gärten und weitläufige Haine ( $\alpha \varkappa \lambda \sigma \varepsilon \sigma \iota)$, bezieht sich mit großer Wahrscheinlichkeit auf die Umgebung von Rom; auch dürfte die

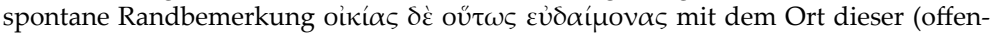
bar vor einem vornehmen römischen Publikum absolvierten) Vortragsveranstaltung in direktem Zusammenhang stehen. - Als eine der (im Vergleich mit zeitgenössischer römischer Üppigkeit) „armen“ Königstöchter der griechischen Mythentradition ist hier offensichtlich auch die berühmte Nausikaa, die Tochter des Phäakenkönigs Alkinoos, eingestuft worden: Od. VI. und VII. Gesang.

173 Die Anspielung auf die (architektonisch überaus imposanten) „öffentlichen BäderAnlagen" könnte sich auf die berühmten (damals wohl gerade erst fertiggestellten) Thermen Trajans am Rande des Esquilins beziehen. Zu der Bäder-Kultur und der Ausgestaltung öffentlicher Thermen im 2. Jh. n. Chr. s. generell K. YegüL, Bathing in the Roman World (New York / Cambridge 2010).

174 Zitat aus Il. XVI 179f.; die menschliche Geliebte des Hermes war freilich Polymele, Tochter des Phylas; Dion hat diesen Vers, in spontanem, freien Zitat, offensichtlich mit Il. VI 175 verwechselt (s. o. Anm. 171). - Die homerische Formulierung $\pi \alpha \varrho \theta \varepsilon ́ v ı s$ / "Jungfrauensohn“ stellte in Dions Augen lediglich einen Euphemismus für vóӨos („Bastard“) dar.

175 Bei den Partheniai handelte es sich wohl um eine (wahrscheinlich einem hochrangigen Adelsgeschlecht zugeordnete) Bevölkerungsgruppe in Sparta, die sich dem festen, egalitären Zusammenschluss der Kriegergenossenschaft der spartiatischen ő $\mu$ oเo (dem Kosmos „der Gleichen“) widersetzte und schließlich zur Auswanderung genötigt wurde (Gründung von Tarent unter dem Oikisten Phalanthos); vgl. dazu Aristoteles, Polit. VI, 1306 b 27-1307 a 3. An den auffälligen Namen dieser Gruppe haben sich unterschiedliche (aitiologische) Legenden angeschlossen: Zum einen sollen mit diesem (offenbar als Diskriminierung aufgefassten) Namen Söhne von Spartiaten nachträglich bezeichnet worden sein, die sich an dem langwierigen 1. Messenischen Krieg nicht beteiligt hätten. Der anderen Version zufolge soll es sich um Kinder gehandelt haben, die in Sparta während der langen (durch einen feierlichen Eid bekräftigten) Abwesenheit des vor Messene stehenden Kriegeraufgebots unehelich (aber in staatlichem Auftrage!) gezeugt worden seien: Antiochos von Syrakus FGrHist 533 F 13 und Ephoros von Kyme FGrHist 70 F 216 aus Strabon VI 3,3 p. 278 RAdT, ferner Theopomp FGrHist 115 F 71; s. u. a. M. MeIER, Aristokraten und Damoden. Untersuchungen zur inneren Entwicklung Spartas im 7. Jh. v.Chr. u. zur politischen Funktion der Dichtung des Tyrtaios (Stuttgart 1999) bes. 121-142.

176 S. u. den Beitrag von E. Hermann-Otto, u. S. 217f.; vgl. auch H. S. Nielsen, „Alumnus a term of relation denoting Qasi-Adoption", in: Classica et Mediaevalia (C\&M) 38 (1987) 141-188 zum prekären, oftmals unfreien Status der von bekannten „Ablage“-Stellen jeweils ins Haus geholten und großgezogenen $\theta \varrho \varepsilon \pi \tau o$ / alumni; vgl. dazu u.a. Plinius, ep. X 65 und 66, aber auch Juvenal, Sat. 6, 602f. S. J. Martin / A. NitschKe (Hrsgg.), Zur Sozialgeschichte der Kindheit (Freiburg i.Br. 1986). 
177 Die lockere Wortwahl lässt an dieser Stelle recht deutlich den mündlichen Vortragsstil durchschimmern; dies gilt besonders für die temperamentvolle Interjektion $\varepsilon \tilde{I} \varepsilon v$ $\delta \eta ́$ (vgl. auch schon § 104) und im Anschluss daran für die Wendung oư $\tau \omega \varsigma \alpha \tilde{\alpha} \lambda \tilde{\omega} \varsigma$ („einfach so“). Russell (1992, 157, vgl. 60 in der Text-Edition) hat allerdings hier, gegen die Überlieferung, der (ein wenig banalen) Konjektur Reiskes $\dot{\alpha} \mu \varepsilon \lambda \tilde{\omega} \varsigma$ (,im Zustand der Vernachlässigung befindlich“ o. ä.) den Vorzug gegeben.

178 Dions Äußerungen und Urteile über die Homosexualität sind weniger eindeutig, als es dieser Verweis auf die "Grenzen ... die die Natur hier setzt", nahelegt: Dagegen wird in der an Trajan gerichteten (zumindest aber dem Kaiser gewidmeten) or. 3 ( $\S \S$ 98f.) - sicherlich in bewusster Anpassung an entsprechende Neigungen des Kaisers - der Pädophilie geradezu der gleiche Rang wie der Liebe zu Frauen zuerkannt (die Angabe in der Historia Augusta [v. Hadr. 2,7; vgl. 3,3] über die ausgeprägte Paedophilie Trajans gehen allerdings wohl auf die - gerade in diesem Punkte sicherlich tendenziöse Autobiographie Hadrians - zurück). - Beachtung verdienen in diesem Zusammenhang Dions differenzierende Bemerkungen in or. 36 (19 ARnim, Borysthenes-Rede) $\S 8$, die eine sublimierte („hellenische“) Form der Homoerotik - im Sinne des platonischen Symposion (178b-180c) - von einem „,barbarisch“-kruden Verkehr zwischen Männern und Jünglingen deutlich abzuheben suchen. Allerdings war in der Kodifikation der platonischen Nomoi eine regelrechte Ächtung der (als widernatürlich gewerteten) Homosexualität vorgesehen: Leg. 636c-e und 835d-842a. Und schon im Gorgias (494e) wurde der homosexuelle Akt selbst als unsäglich und abnorm bewertet (vgl. dazu auch Aristoteles, Eth. Nicom. VII, 1148b 29-31). - Bei der in Dions Euboikos Logos vorgetragenen Stellungnahme geht es vor allem um eine entschiedene Warnung vor einer primär bisexuell orientierten und auf paedo- bzw. ephebophile Hypervirilität ausgerichteten Veranlagung mutmaßlicher Verführer. Zu den im Altertum wahrgenommenen und sehr unterschiedlich bewerteten Formen der Homosexualität s. K. J. Dover, Greek Homosexuality (London 1978) bes. S. 105f. und 168-170. Ein wichtiges Zeugnis stellt in diesem Zusammenhang die selbstbewusste Rede des „beken-

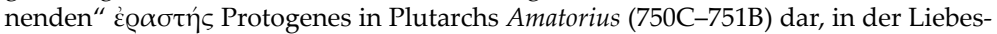
beziehungen zu Frauen rundheraus als triebhaft und minderen Ranges charakterisiert werden, weil sie zu weibisch-unmännlichem Verhalten verleiteten: Diese (gleichsam naturhaft-dumpfe) Geschlechtsbeziehung verdiene daher nicht den Ehrennamen „Eros“; s. jetzt die kommentierte Edition von H. GöRGEMANNS u.a. (GörgEMANNs 2011) bes. S. 33f. und 246-248. Plutarchs eigenes, entschiedenes Urteil findet sich dazu im Amatorius 23,768E, vgl. auch 5 p. 751 DE (mit Komm.). - Habitus und Verhaltensweisen des eher effeminierten $\pi \alpha \dot{\theta} \bullet \kappa \circ \varsigma$ stießen dagegen, wie schon die $\delta \iota \alpha \beta о \lambda \eta ́$ gegen Politiker im Athen des 5./4. Jh. v. Chr. zeigt, generell auf Spott und einhellige Verachtung (u. a. Platon, Symp. 192a, ferner Aischines' Rede Gegen Timarchos 19f. und Ar. Eq. 878f.).

179 An dieser Stelle wird erneut an den Danae-Mythos und das von Zeus eingesetzte Verführungsmittel des über das Dach des Verlieses eindringenden Goldregens erinnert.

180 Dion gibt hier einen deutlichen Hinweis darauf, dass er ernsthaft an römische Jugendliche, vornehmlich aus dem ordo senatorius, denkt, die kurz vor dem Eintritt in den senatorischen cursus honorum stehen und schon bald hochrangige Magistraturen und Amtsstellungen einnehmen sollen. - Dass Dion mit seinen drastischen Warnungen vor der Verführungsmacht des mos Graeciae tatsächlich einen empfindlichen Nerv in den Kreisen der römischen Oberschicht getroffen hat, illustriert $u$. a. als zeitgenössisches Zeugnis das (stilisierte) Briefschreiben des jüngeren Plinius an Corellia, eine hochangesehene Witwe aus senatorischer Familie (ep. III 4,3f.): Hier wird, verbunden mit Empfehlungen für einen tüchtigen und charakterlich soliden Rhetorik-Lehrer, ernsthaft auf mögliche Gefährdungen ihres jugendschönen Sohnes in der Phase seines Studiums durch ephebophile, homosexuell veranlagte Verführer eingegangen. In bezeichnendem Unterschied zur griechischen Welt fehlte es in der römischen Ge- 
sellschaft an einer Tradition, nach der sich homosexuelle Päderastie als eine vorgeblich von pädagogischem oder gar heroischem Eros beseelte Freundschaft zwischen reifen Männern und Knaben / Jünglingen (zwischen 12-18 Jahren) auffassen (bzw. beschönigen) ließ, (vgl. die Aussagen in der berühmten Grabinschrift IG I ${ }^{3}, 2$ nr. 1399 [aus der Zeit um 500 v. Chr.], ferner die Differenzierungen bei Platon, Symp. 482 b-d.), s. auch die Studie von W. Lengauer, "Eros among citizens", in: Palamedes. A Journal of Ancient History 1 (2006) 67-84. Im kaiserzeitlichen Rom war jedenfalls die lex Scantinia de Venere nefanda (aus republikanischer Zeit stammend) unter Domitian neu belebt und in einschlägigen Gerichtsverfahren zur Geltung gebracht worden, s. Suet. Dom. 8,3, vgl. Caelius bei Cicero, Fam. VIII 12,3 und 14,4, und dazu Juvenal, Sat. 2,44. Im übrigen galt in römischer Perspektive der Vollzug des homosexuellen Aktes schlechthin

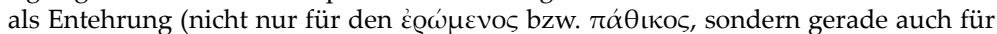
den „aktiven Partner“): vgl. u. a. Martial. Epigr. IX 47; IX 57; sowie XII 42 (zu den in Kreisen der römischen Oberschicht intern gefeierten ",Schwulen-Hochzeiten“); ferner Iuvenal, Sat. 9,27-54.

$181 \mathrm{Zu}$ den von hemmungslosen Trinkern angewendeten Praktiken, die neues heftiges Verlangen nach einer Fortsetzung des Gelages wecken sollten, vgl. Juvenal, Sat. 6, 425f. u. Plinius, NH XIV 137f. - In der griechischen Welt galt der Genuss ungemischten Weines grundsätzlich als barbarische Unsitte; das im Symposion allgemein übliche Maß bestand in einer Mischung von einem Teil Wein auf zwei bis drei Teilen Wasser (vgl. Ath. X 426b-f). - Das älteste Beispiel für einen nach Barbarenart unkontrollierten Weinkonsum (mit entsprechenden Folgen) stellte der Kyklop Polyphemos (Od. IX 353-374) dar; doch standen späterhin auch die athenischen Bürgerfrauen generell in Verdacht, heimlich einer ungehemmten Trunksucht mit ungemischtem Wein zu frönen (vgl. u.a. Ar.. Thesm. 393. 431-435. 686-761).

$182 \mathrm{Zu}$ dem abrupten Abbruch des überlieferten Textes, noch bevor der zuletzt mit großer Ausführlichkeit entwickelte Gedankengang sinnvoll abgeschlossen werden konnte, s. o. Anm. 2 (zu der analogen Situation am Anfang der Abhandlung - ein Befund, der auf eine mechanische Beschädigung einer ursprünglich, d.h. vor der Aufnahme in das Corpus Dioneum, wohl als monóbiblos - Monographie verbreiteten Schrift hindeutet, von der am Ende aber nur noch ein (aus einsichtigen Kostengründen) beidseitig beschriftetes Exemplar als Vorlage für die Aufnahme in den Pergamentcodex zur Verfügung stand; s. o. S. 22 und vor allem die eindringende Untersuchung von v. ArNiM 1891, 397f.; vgl. dazu auch den Hinweis bel Polybios XI 1a,3 B.-W. auf das Beschädi-

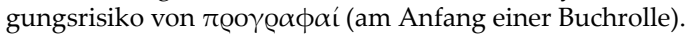


C. Essays 



\title{
Mythos, Utopie und Sozialprogramm. Struktur und Gattung des Euboikos logos
}

\author{
Dorothee Gall
}

Unter den an lebendig geschilderten Szenen und Motiven reichen Texten Dions von Prusa sticht der Euboikos logos nicht nur durch seinen Umfang, sondern auch durch die Vereinigung von Themenblöcken sehr unterschiedlicher Natur heraus. Damit wirft der Text verschiedene Fragen auf: Welche Thematik und Intention prägen die einzelnen Teile? Welchen literarischen Motiven und Textsorten sind sie verpflichtet? In welchem Verhältnis stehen sie zueinander, und inwieweit fügen sie sich einem einheitlichen Konzept?

Antworten auf diese Fragen sollen aus einer eingehenden Textanalyse gewonnen werden, die in drei Schritten vorgeht: Zunächst werden die Struktur des Gesamttextes und die für seine Teile zentralen Motive, Subtexte und Intentionen entfaltet; dem Zusammenhalt dieser Einzelteile, d.h. den Überleitungen, Verweisen und Parallelen, ist ein zweiter Untersuchungsgang gewidmet. Abschließend wird das in der Forschung häufig diskutierte Problem einer Gattungsbestimmung des Euboikos logos neu aufgeworfen.

\section{Zur Struktur des Textes}

Die Rede umfasst in ihrer erhaltenen Form zwei Großteile, deren zweiter Teil in sich wiederum unterteilt ist: ${ }^{1}$ Am Anfang steht eine Art ,Reisebericht' des Ich-Erzählers über ein Erlebnis auf Euböa (Teil I: §§ 2-80); ihm folgt eine Erörterung über die Vorteile der Armut gegenüber dem Reichtum und über Mittel zur Bekämpfung der Armut in der Stadt. Dieser zweite Passus beginnt mit einer Mythenexegese (Teil II: $\S \S 81-102$ ), an die sich Erwägungen über ein Beschäftigungsprogramm in der Stadt (Teil III: §§ 104-Textende) anschließen. Die Invektive gegen den städtischen Sittenverfall (§§ 141-151) $)^{2}$ ist in einer Art Präambel (§ 128-132) als digressio gekenn-

\footnotetext{
${ }^{1}$ Vgl. zum Folgenden auch die Einteilungen und Überschriften in der Übersetzung von G. A. Lehmann.

${ }^{2}$ V. ARnim 1898, 457 vermutet, dass Dion sehr konkret Rom meint: „Obgleich nämlich der Redner keinen Ort nennt und seine Betrachtungen ganz allgemein hält, ist doch klar, dass er von $\S 141$ an römische Verhältnisse im Auge hat."
} 
zeichnet. Vermutlich kehrte Dion also gegen Schluss seiner Rede zum Thema der Arbeit für die städtische Bevölkerung zurück; dieser Schluss ist aber nicht überliefert.

$\mathrm{Ob}$ auch ein Einleitungspassus verloren ging, wie zuerst von Arnim nachzuweisen suchte, ${ }^{3}$ ist in der Forschung umstritten. ${ }^{4}$ In der vorliegenden Form setzt Dion mit einigen die folgende Erzählung rechtfertigenden Erörterungen ein, deren Schwergewicht auf der Behauptung der Authentizität des Erlebten liegt. ${ }^{5}$ Der Hinweis auf Erfahrung und Alter, ebenso wie das Zugeständnis einer gewissen altersbedingten Nachgiebigkeit gegenüber der eigenen Fabulier-Freude, vertragen sich durchaus mit der Funktion einer Redeeröffnung. Zudem ist die Einleitung syntaktisch unverstümmelt und völlig verständlich. Dass Dion nicht damit beginnt, seine eigentliche Rede-Intention zu bestimmen, ist keineswegs ungewöhnlich; auch sonst nimmt seine Rede öfter ihren Ausgang von einer kleinen Erzählung - oder sogar einem Märchen - , aus dem sich dann das Thema allmählich herauskristallisiert. ${ }^{6}$

Der umfänglichste der genannten drei Großteile ist der erste - ein detaillierter Bericht über eine ungewöhnliche Begegnung des nach einem Schiffbruch an der Küste Euböas gestrandeten Ich-Erzählers mit einem dort auf dem Lande ansässigen Mann (er soll im Folgenden gemäß der Forschungstradition als Jäger bezeichnet werden, obwohl er ebenso gut ein Bauer ist). Dion hat diesen umfänglichen Passus besonders sorgfältig strukturiert und eine Binnenerzählung, innerhalb der Binnenerzählung drei Re-

\footnotetext{
${ }^{3}$ V. Arnim 1891, 397f.

${ }^{4}$ Moles 1995, 179 schließt aus den „,echoes" zwischen den Paragraphen 1 und 81, ,that the work's beginning is not lost”; anders Russell 1992, 12 („Moreover, von Arnim's conclusion [1891] is surely right in essence: it is actually incomplete, both beginning and end being lost.").

${ }^{5}$ Der Frage nach der biographischen Echtheit des Reiseberichts geht Reuter 1932, 8-12 mit etwas erschöpfender Ausführlichkeit nach; die Frage (REUTER beantwortet sie negativ) hat keine wirkliche Bedeutung (vgl. Russell 1992, 9: „What kernel of real experience there was does not much matter [...]). “ In jedem Fall lässt sich aus den die Rede einleitenden Beteuerungen der Autopsie kein Schluss ziehen; vgl. Anderson 1976, 95: Die Authentizitätsbeteuerung des Anfangs sei „the normal formula for beginning a fictitious tale: it is common enough to be parodied by Lucian several times [...]."

${ }^{6}$ Allein schon die Königsreden arbeiten in dieser Hinsicht mit ganz unterschiedlichen Techniken: Die erste setzt episodisch ein und reflektiert dann über die Möglichkeiten der Rede, zum Guten zu beeinflussen, ehe das Thema, der gute König, überhaupt erst definiert wird; die zweite kommt gleich zum Thema, indem sie Alexander und Philipp im Gespräch über Homer zeigt und damit die alles Weitere bestimmende Homer-Exegese eröffnet; die dritte beginnt mit einem scheinbar episodischen Motiv (ein Ausspruch des Sokrates), das sich aber dann als fundamental für die folgende Untersuchung über Schmeichelei und die gerechte Herrschaft erweist; die vierte Rede setzt wiederum unmittelbar in der über den ganzen Redeverlauf durchgehaltenen Situation ein. Sehr unvermittelt beginnt im übrigen auch der Borysthenitikos Logos.
} 
den und im Anschluss daran eine lebhaft geschilderte ländliche Szenerie, ein Gastmahl, in ihn integriert. ${ }^{7}$

Die Erzählung ist ihrerseits in drei Teile gegliedert: Der erste Teil umfasst den Bericht vom Schiffbruch und der Begegnung des Erzählers mit dem Jäger, der ihn zu sich einlädt. Gemeinsam mit dem dritten Teil, der ein Gastmahl im Haus des Jägers schildert, bildet dieser Einsatz einen Rahmen um den Mittelteil, die Erzählung des Jägers auf dem gemeinsamen Weg zu seiner Hütte. In diesen Rahmenpassagen lässt sich als literarischer Subtext die Odyssee, speziell die Erlebnisse des Odysseus auf seinen Irrfahrten, ausmachen: Schiffbruch, ${ }^{8}$ Verlust der Gefährten, Begegnung mit einem Hirsch am Strand (in der Odyssee erlegt Odysseus auf der Insel der Kirke einen Hirsch und bereitet ihn zu), ${ }^{9}$ dann mit einem hilfreichen Einheimischen (bei Homer: Nausikaa), gastliche Aufnahme (Eumaios bzw. die Phäaken). Dion rückt sich damit selbst zeitweise in die Rolle des ,homerischen Dulders'; auf dieser Folie, die ja auch Odysseus' leidvolle Erfahrungen mit einfließen lässt, erscheinen der Jäger, seine Familie und Behausung zugleich wie die beglückte Insel der Phäaken: eine Zuflucht, aus der Rettung, Trost und Hilfe erwachsen. ${ }^{10}$ Die Einladung des Jägers korrespondiert dem gemäß Nausikaas Erläuterungen, wenn sie Odysseus auffordert, ihr zum Palast ihres Vaters zu folgen (Od. VI 255-315).

In der Binnenerzählung ( $\$ \S 10-63)^{11}$ berichtet der Jäger von seiner Familie, seinen Lebensumständen und seinem Aufenthalt in der Stadt, wo er zu einer gerichtlichen Verhandlung geladen war, in der über seine Steuerpflicht und die seines Nachbarn entschieden werden sollte; beide Familien siedelten ja auf Staatsland. Der ,Selbstbericht' stellt wiederum eine Parallele zur Odyssee, speziell zu den Apologen des Odysseus, dar. Er ist auch in seiner Funktion durchaus vergleichbar: Wie Odysseus' Apologe inner-

\footnotetext{
${ }^{7}$ V. Arnim 1898, 473, der den Euboikos logos für eine Stegreifrede hält („,Dio sagt es uns hier ausdrücklich, dass er nicht schreibt, sondern redet, und nicht geschriebenes redet, sondern was ihm der Augenblick eingiebt"), wofür er sich auf Dions selbstreferentielle Bezich-

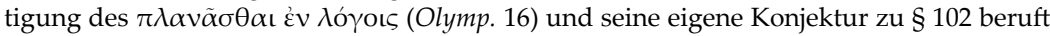

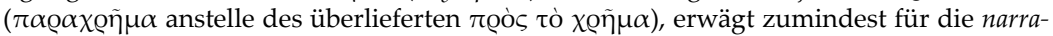
tio eine schriftliche Ausarbeitung (474). Dions eigenes Bekenntnis zu spontan entfalteter und ungeordneter Themenfülle und auch der gelegentlich beiläufig-improvisiert wirkende Charakter der Rede dürften aber wohl eher - gemäß aristotelischer Theorie der Glaubwürdigkeit - rhetorischer Strategie verpflichtet sein.

${ }^{8}$ Vgl. Reuter 1932, 13-16 (unter Verweis auf Philostrats Heroikos).

${ }^{9}$ Vgl. Russell 1992, 8 und DaneK 2009, 420.

${ }^{10}$ Odysseus ist als exemplum im Kontext moralphilosophischer Erörterungen recht geläufig. Bei Dion hat die Selbstidentifikation mit Odysseus aber zudem den autobiographischen Hintergrund der Exilerfahrung; das tritt v.a. im 13. Logos hervor, wo Dion seine Verbannung im Rekurs auf Motive der Odyssee kommentiert. Vgl. Jones 1978, 46-51 und Russell 1992, 8 („,Odysseus was certainly one of Dio's rôles [...], and both his wisdom and his mendicancy were used as models by the Cynics. “).

${ }^{11}$ Verschiedene Motive der Binnenerzählung sind bei späteren Autoren des 2. Jahrhunderts n. Chr. (Lukian; Philostrat) analog gestaltet; ausführlicher dazu Anderson 1976, 97f.
} 
halb der phäakischen Gesellschaft den heroischen Status des gestrandeten Fremden klären, so wird auch aus den Reden des Jägers sein gesellschaftlicher wie moralischer Status erkenntlich. Zu den aus dem Rahmenteil abzuleitenden Tugenden der Gastfreundschaft treten hier Qualitäten wie Fleiß, Ehrlichkeit, Schlichtheit und Friedfertigkeit hinzu.

Zugleich wirft der Bericht des armen Landbewohners, der (abgesehen von einem Aufenthalt als Kind in Begleitung seines Vaters) zum ersten Mal die Stadt besucht und sie gemäß den auf dem Land erworbenen Kriterien beschreibt und beurteilt, ein teils humoriges, teils kritisches ${ }^{12}$ Licht auf die polis, ihre Einrichtungen und ihre Bürger. ${ }^{13}$ Dabei ist die Perspektive auf den Hafen (\$22f.) und das Theater (\$24) noch unkritisch, der große Nutzen des Hafenbeckens wird sogar hervorgehoben. Der Jäger erscheint als etwas naiv, aber keineswegs töricht: Für beide Lokalitäten findet er anschauliche Worte aus der eigenen Lebenswelt, ${ }^{14}$ und die Naivität liegt eben nur darin, dass er solche Veranschaulichungen der Begriffe überhaupt für notwendig hält (wobei er diese Notwendigkeit selbst hinterfragt, § 24). Auch die allgemeine Schilderung des Betriebs in der ekklesia ist noch relativ wertungsfrei; zwar verweist der Berichterstatter auf den maßlosen Lärm, auch das theatralische Agieren der Redner wird hervorgehoben, und die Volksmenge erscheint als undiszipliniert (§§ 24-26). Aber erst der Auftritt des ersten Redners, dessen Worte in direkter Rede wiedergegeben werden (§ 27-29), führt zur kräftigen Distanzierung des Jägers vom Geschehen: Er lacht den Redner aus, als dieser seinen Besitz in einer völlig überzogenen Weise bestimmt und der Volksversammlung suggeriert, hier seien Abgaben an die einzelnen Bürger einzuholen (§ 30). Der ,Demagoge' sucht dieses Lachen gegen den Jäger zu wenden; v.a. folgert er aus der zuvor vorgebrachten und durch nichts belegten Behauptung, der Jäger und seine Familie hätten sich unrechtmäßig am Besitz der polis bereichert, auf weitere kriminelle Tätigkeiten, nämlich auf Piraterie mittels falsch gesetzter Leuchtfeuer ( $\S$ 30-32).

Dion setzt hier einen kräftigen Akzent der Stadt-Kritik: Gegen den die Tatsachen verfälschenden, unwahre Behauptungen aufstellenden und die Bürger mit ihren Eigeninteressen ködernden Demagogen steht dem schlichten Landmann nur das Lachen zur Verfügung; die argumentative Selbstverteidigung, wie sie der Zuhörer wohl erwarten dürfte, bleibt aus, dazu ist der Beschuldigte nach eigener Aussage viel zu verängstigt (§ 33). In dieser Wehrlosigkeit des Beschuldigten liegt eine deutliche Anklage

\footnotetext{
${ }^{12}$ Die Kulturkritik ist hier nicht, wie in den wohl etwas älteren sog. Anacharsis-Briefen (Die Briefe des Anacharsis, griech-dt. v. F.H. Reuters [Berlin 1963]; einen Passus zitiert Cic. Tusc. 5,90) aus barbarischer Perspektive geäußert: Der Jäger ist Grieche. Dennoch trägt er auch Züge des ,edlen Wilden', eines in ethnographischer Literatur beliebten Motivs.

${ }^{13} \mathrm{Vgl}$. Jones 1978, 57.

${ }^{14}$ Vgl. Urban 2004, 174, Anm. 26.
} 
gegen die Stadt und ihr Gerichtswesen, in dem der Arme und Unerfahrene, selbst wenn die Lügenhaftigkeit der Anklage offen zu Tage liegt, nur schwer Recht erfährt.

In diesem Fall allerdings geht die Sache gut aus: Ein zweiter Redner tritt auf und spricht zugunsten des Verleumdeten (\$§ 33-40). In seinen Mund legt Dion Aspekte seiner eigenen Kultur- und Zeitkritik: Der ,gute' Redner beklagt die mangelnde Sorgfalt der Bürger für ihre Stadt ${ }^{15}$ und die Verwilderung des Stadtumlands; er erhebt den Jäger zum Paradigma für ein Programm, das Abhilfe schaffen könnte. ${ }^{16}$

In einer dritten Rede, mehrfach unterbrochen durch Fragen des Beamten, der dem Verfahren vorsitzt, kommt der Jäger selbst zu Wort und ist nun auch imstande, sich gegen die Vorwürfe des Demagogen zur Wehr zu setzen (§§ 41-53); seine grundsätzliche Bereitschaft, all seinen Besitz der polis zu überlassen, trägt ihm zeitweise die Sympathie der Bürger ein, die auf eine Abgabe hoffen, die nähere Bestimmung dieses Besitzes, Felle und geringe Mengen von Getreide und Wein, zerstört aber diese Illusion, ohne freilich die Glaubwürdigkeit des Landmanns zu beeinträchtigen. Als Zeuge seiner Philanthropie treten dann auch noch - wie dei ex machina zwei Stadtbürger auf, die nach einem Schiffbruch von dem Jäger freundlich aufgenommen und vor dem Tod bewahrt wurden (\$§ 53-58). Als Gipfel seiner Gastfreundschaft wird dabei die Gabe eines Kleides der Tochter referiert, des einzigen, das diese besaß $(\S 58) .{ }^{17}$ Die solcherart beglaubigte Philanthropie des Jägers, die ja sogar zwei Stadtbürgern das Leben rettete, soll - so beantragt nunmehr der ,gute' Redner - durch Geschenke und die Speisung im Prytaneum belohnt werden (\$§ 60f.). Die ihm zuerkannte Kleiderspende muss der Jäger notgedrungen akzeptieren; die Geldzuwendung weist er aber zurück (\$§ 62f.).

Während die Rahmenhandlung das Modell der Odyssee beschwört, ${ }^{18}$ trägt die Binnenerzählung Züge der platonischen Apologie: Schon die Absurdität der Anklage verweist auf den Subtext: Wie der platonische Sokrates zu Beginn seiner Verteidigung zwar die Redegewalt seiner Ankläger

\footnotetext{
${ }^{15}$ Dies mit parodistisch-übersteigerter Tendenz: Dass das hohe Gras im Gymnasion den Blick auf die Götterstatuen verwehrt oder auf der Agora das Vieh herdenweise weidet, scheint doch überzogen. Vgl. aber Prop. Eleg. II 6,36 (im Kontext der Sittenkritik): ... velavit aranea fanum / et male desertos occupat herba deos.

${ }^{16}$ Freilich wird Dion selbst dieses Programm, nämlich die Ansiedlung der Armen auf dem Land, später als nicht in großem Umfang durchführbar bewerten (§§ 107f.).

${ }^{17}$ Das Motiv der Kleidspende wird in der Mythenexegese des zweiten Hauptteils aufgegriffen, wenn Dion Penelope vorwirft, dem (noch unerkannten) Odysseus nicht einmal bedingungsfrei einen Mantel zu schenken (§ 84).

${ }^{18}$ Diese ist in der Binnenerzählung aber nicht ganz ausgeblendet; DANEK 2009, 419f. weist auf, wie im Vorwurf des ,schlechten' Redners, der Jäger führe durch falsch gesetzte Leuchtfeuer Schiffe in den Schiffbruch, ein Motiv aus einer Vorgängerversion der Odyssee aufgegriffen ist, wo Nauplios die von Troia zurückkehrende Flotte auf diese Weise vor Euböa stranden lässt; vgl. Apollod. Epit. 6, 7-11; Hyg. Fab. 116.
} 
anerkennt, aber jeglichen Wahrheitsgehalt ihrer Vorwürfe zurückweist, ${ }^{19}$ so konstatiert auch Dions Jäger, zur Stellungnahme aufgefordert: „Also sage ich, dass nichts Wahres an dem ist, was der eine gesagt hat.“ (§ 41). Auch in der apologetischen Technik des Angeklagten, gegen demagogisch verzerrte Vorwürfe die im Gestus der Naivität dargelegte schlichte Wahrheit zu setzen, berühren sich beide Texte. Und nicht zuletzt das Motiv der Speisung im Prytaneum setzt ein weiteres Signal der Anspielung: Im Fall des Sokrates wird diese Auszeichnung als einzig gerechtes Urteil eingefordert, ${ }^{20}$ im Fall des Jägers tatsächlich als Ergebnis des Prozesses vollzogen. Freilich ist dem Euboikos logos die Rede eines Anklägers und eines Verteidigers beigefügt und der Angeklagte selbst kommt erst spät zu Wort. ${ }^{21}$

Im dritten Teil der Erzählung, der zurückführt in die Situation des IchErzählers nach dem Schiffbruch und damit den Rahmen vollendet, geht es vor allem um die natürliche Gastlichkeit der Landleute. Kurz kommt ihr fruchtbarer Garten zur Sprache, Zeichen ihres Fleißes und wachsenden Wohlstandes (§ 64); dann sehen wir den Ich-Erzähler bei einem schlichten Gastmahl mit den beiden Familien (65f.). Hier gewinnt eine geplante Hochzeit zwischen der Tochter des Jägers und dem Sohn seines Nachbarn zunehmend an Gewicht (§§ 70-79); sie dient dem Ich-Erzähler auch dazu, den unangemessenen Aufwand der Eheverhandlungen reicher Leute mit den schlichten und wohlmeinenden Planungen der Landleute zu vergleichen $(\S 80)$. Wie schon in der Gerichtsverhandlung erweisen sich auch hier die armen Landbewohner als tugendhaft, großzügig mit dem Wenigen, das sie besitzen, freundlich und bescheiden.

Mit dem kurzen Geplänkel um die Ehe der beiden jungen Leute tritt ein Liebespaar, dessen Vereinigung durch äußere Umstände verzögert wird, in den Blick des Lesers, ein Motiv, das dazu anregt, den Reisebericht auch auf seine Verwandtschaft zum hellenistischen Roman hin zu überprüfen. ${ }^{22}$

\footnotetext{
${ }^{19}$ Plat. Apol. 17a.

${ }^{20}$ Plat. Apol. 36d.

${ }^{21}$ Mit Sokrates und Odysseus sind dann auch die beiden Gestalten präsent, an denen Dion seinen eigenen Lebensentwurf vorzugsweise misst; s.o. Anm. 10 und S. ForNARo, „Inhalt und Themen der Reden“, übers. v. H.-G. Nesselrath, in: Nesselrath 2009, 6: „Sokrates ist in den Reden Dions ständig präsent; er ist der am meisten von ihm zitierte Philosoph, mehr als Platon, Aristoteles und Diogenes."

${ }^{22}$ P. Morgan, Greek Fiction. The Greek Novel in Context (London 1994) 3 fasst diese Stereotypen folgendermaßen zusammen: "Canonically, they tell of a beautiful and aristocratic young couple who fall in love at first sight, are separated, travel the world in search of one another, until they are reunited and live happily ever after. Their adventures are stereotyped: shipwreck and encounters with pirates and brigands, embroilment in military enterprises, attempts on their fidelity by unwelcome third parties, and various close brushes with death, including the apparent death of one of the partners. [...] The love of the protagonists is equal, reciprocal and passionate, and provides a basis for marriage; this is quite different from classical pederastic or matrimonial models of inequality in sexual relations. High value is set on fidelity and chastity, but varies in its emphasis." Natürlich wird
} 
Zwar sind Parallelen wie Schiffbruch und existenzielle Bedrohung bereits dadurch begründet, dass die Romane, ebenso wie Dions Erzählung, die homerische Odyssee ausbeuteten. Dion scheint aber doch in einer diesen gemeinsamen Urgrund des Abenteuerberichts übersteigenden Weise auf Stereotypen des Romans zurückgegriffen zu haben - die er allerdings teils auf verschiedene Agenten verteilt, teils verharmlost: Aus dem vornehmen jungen Liebespaar wird ein Paar mit geringem sozialem Status, und dieser Status wird auch - anders als in Longos' Daphnis und Chloe, wo die Liebenden ja ebenfalls eine Hirtenexistenz führen - nicht durch eine Anagnorisis korrigiert. Den Schiffbruch erleiden bei Dion nicht die Liebenden, sondern der Erzähler. Die existenzielle Bedrohung trifft ihn und den Vater der Braut, dem auch fälschlich Piraterie vorgeworfen wird. Die jungen Liebenden haben keine Feinde oder Konkurrenten, der Widerstand der Väter gegen die Ehe beschränkt sich auf eine kurze Verzögerung und ist bald überwunden.

Die Überleitung zum zweiten Großteil enthält eine der Präambel zu Teil I entsprechende Rechtfertigung, in der Dion recht elegant die Funktion der vorangegangenen Erzählung bestimmt („,ein Beispiel für die Lebensführung und die Verhaltensweisen unter den Armen vor Augen zu führen, das ich persönlich erlebt habe“, § 81) und dann zu einer Auseinandersetzung mit dem Satz des Euripides überleitet, die Armen seien nicht imstande, Gastlichkeit oder Mildtätigkeit zu leisten; damit ist der Bereich der Literaturexegese eröffnet. ${ }^{23}$ In diesem ersten Teil des zweiten Hauptteils nun gefällt sich Dion in einer Homer-Auslegung, die zunehmend antipodisch zur homerischen Werte-Welt angelegt ist: Der einleitende Vergleich zwischen dem armen Eumaios, der Odysseus gastlich aufnimmt, und den Freiern, die ihn nicht einmal am fremden Gut teilhaben lassen $(\S$ 83), geht noch konform mit der gängigen Interpretation der homerischen Charaktere; dem gemäß kann er auch mit einem Homer-Zitat belegt werden: „Du würdest ja dem, der als Bittsteller an Dich herantritt, aus Deinem Hausbesitz nicht einmal ein Salzkorn geben, / Du, der Du hier, an fremder Tafel sitzend, es nicht über das Herz bringst, / mir von den Speisen etwas abzugeben, wo doch so viel davon im Hause ist. “24 In der Folge kritisiert der Dichtungsexeget Penelope, die dem unerkannten Odysseus nicht ohne Vorbedingungen einen Mantel geben wollte (§ 84-86), Telemachos, der von Eumaios verlangte, den alten Bettler (Odysseus) möglichst bald wieder fortzuschicken (87f.), und die Phäaken und ihre nur vorgetäuschte Philanthropie (§90). Eine solche Interpretation widerspricht ganz eindeu-

das Schema immer wieder variiert; in Longos' Daphnis und Chloe verlässt das Liebespaar die Insel Lesbos ebenso wenig wie es die beiden Liebenden des Euboikos Logos tun.

${ }^{23}$ V. ARNim 1891 vermutet, Dion setze hier einen nicht erhaltenen dichtungsexegetischen Anfangsteil fort.

${ }^{24}$ Hom. Od. XVII 455-7; vgl. dazu Anm. 102 zur Übersetzung. 
tig homerischen Intentionen, was besonders deutlich in der völlig unbelegten Anspielung auf die angeblich schäbigen Motive der Phäaken für ihre Gastfreundschaft zutage tritt. Dions Argumentation ist aber doch, so überraschend sie sich auch dem homerkundigen Publikum präsentiert haben dürfte, geschickt argumentativ entwickelt ${ }^{25}$ und, vor allem in der Kritik an Penelope, aus zeitgenössischer Warte durchaus nachvollziehbar. Nachdem Dion noch aufgewiesen hat, in welchem Ausmaß Menelaos durch seine Gastfreundschaft gegenüber Paris Schaden erlitt (\$§ 94-96), rechtfertigt er seine Methode, aus den Werken der Dichter auf die Meinung der Masse zu schließen (§§ 98-102): Die Dichter seien ja das Sprachrohr allgemein gehegter Meinungen und Urteile. ${ }^{26}$ Dion kehrt dann zu dem im Einsatz des zweiten Hauptteils untersuchten Euripides-Satz zurück, den Armen sei Gastfreundschaft unmöglich. (§ 102). Seine Distanzierung von dieser Wertung verstärkt er hier noch durch den Hinweis auf einen ähnlich lautenden Passus bei Sophokles, den ein bei Dion nicht namentlich genannter Philosoph kritisiert habe. ${ }^{27}$

Die folgende Überleitung zum dritten Hauptteil (§ 103) scheint auf überraschende Weise den Passus der Mythenexegese zu ignorieren und nur das Erzählziel des ersten Hauptteils zu definieren: „Ich wollte irgendwie deutlich machen, dass Armut keineswegs ein unüberwindliches Hindernis für freie und arbeitswillige Männer ist, ein würdiges Leben zu führen, sondern sie zu weitaus wichtigeren, nützlicheren und naturgemäßeren Beschäftigungen hinführt als es der Reichtum bei den meisten Menschen bewirkt." Im letzten Teil dieser Aussage ist aber die Mythenkritik doch auch mit eingeschlossen, die ja nachweisen sollte, dass der Reichtum sich auf die Menschen auch negativ auswirkt und nicht notwendig ein Vorteil ist. Letztlich sind der Reisebericht und die Mythenexegese damit als in verschiedener Weise und aus verschiedener Perspektive anschauliche Belege für den eigentlich programmatischen Teil der Rede, der sich jetzt anschließt, definiert: hier die (angebliche) Empirie, die aufweist, dass Armut und Menschenwürde miteinander vereinbar sind; dort die aus der Literatur gewonnene Erfahrung, dass Reichtum dem Menschen nicht unbedingt von Nutzen ist.

Im letzten (erhaltenen) Großteil wendet Dion eine gewissermaßen chiastische Methodik an. Sehr präzise legt er die Kriterien dar, nach denen er Tätigkeiten befürworten wird: Sie dürfen „,weder die Würde der arbeitenden Menschen beeinträchtigen noch der Seele Schaden zufügen noch

\footnotetext{
${ }^{25}$ Vergleichbar ist der (gelinde gesagt) eigenwillige Umgang mit dem Troia-Stoff im 11. Logos, wo Dion nachweist, dass Troia nie erobert wurde; so wie dort die Interpretation des Mythos an das Publikum (die Bevölkerung Troias) angepasst ist, so ist sie hier den Interessen einer Lehre dienstbar gemacht, die auf Kritik der Reichen abzielt.

${ }^{26}$ Gemeint sind damit falsche Meinungen und Fehlurteile; vgl. Gangloff 2006, 78f.

${ }^{27} \mathrm{Vgl}$. Anm. 119 zu G. A. Lehmanns Übersetzung.
} 
sonst eine Krankheit bewirken oder den Körper durch Stillsitzen schlaff und weichlich werden lassen“ und sollen außerdem „ein zum Leben ausreichendes Einkommen einbringen“ (§ 112). Von den Berufen, die diese Kriterien erfüllen, nennt er dagegen nur einige und diese eher beiläufig und unter dem Aspekt, dass sie zu Unrecht als schimpflich gelten (§ 114) - Dienstmagd, Erntehelfer bei der Weinlese, Amme, Schullehrer und Erzieher, eine Liste, die offensichtlich literarischen Invektiven gegen solche Tätigkeiten entlehnt ist. ${ }^{28}$ Umgekehrt geht Dion bei der Aufzählung abzulehnender Tätigkeiten sehr detailliert vor und zählt ganz präzise eine Reihe von unzulässigen Berufen auf (§§ 117-124): Färber oder Salbenköche ebenso wie Handwerker, die Häuser mit Farbe und Schmuck ausstatten, Schauspieler und Tänzer, Ausrufer bei Ersteigerungen, Verkäufen und ausgesetzten Belohnungen, Gerichtsschreiber, Anwälte, insoweit sie Prozesse anzetteln und das Recht verdrehen. Aus der Reihe lässt sich ein Anhaltspunkt dafür gewinnen, wodurch Dion die zuvor genannten NegativKriterien (Beeinträchtigung der Menschenwürde, der Seele, des Körpers) erfüllt sieht: Sein Verdikt richtet sich nicht nur dagegen, das Stadtproletariat zu Handlangern der luxuria der Reichen zu machen; er lehnt auch jede Beschäftigung ab, die mit Täuschung, Verstellung, Illusion und mit der Verfälschung des Rechts zu tun hat.

Erneut rechtfertigt er dann die Themenvielfalt seines Textes, die sich „als nützlich im Hinblick auf die bürgerliche Grundordnung und eine Orientierung auf das politisch Richtige“" (§ 172) erweisen solle, und zieht dazu zwei eigentlich inkongruente Beispiele bei: Hunde, die auf der Jagd auch fremde Spuren verfolgen, wenn sie ihnen begegnen (§ 129), und die platonische Politeia, deren Autor „mit Darlegungen zur Frage nach dem gerechten Menschen und der Gerechtigkeit begonnen hat, sich dann aber der polis als Modell zuwandte und nach einer vielfach längeren Erörterung über ihre Verfassungsordnung nicht eher endet, als bis er alle Verfassungsumbrüche und alle Arten von Grundordnungen abgehandelt hat" (§ 130). Diese Skizze rückt die Politeia in eine Nähe zum Euboikos Logos, die sich nicht unmittelbar erschließt: Schließlich verfasst Dion kein politisch grundlegendes Staatsmodell, sondern ein Reformprogramm in begrenztem Rahmen. Andererseits beschäftigt auch er sich zunächst mit dem „gerechten Menschen“ (dem Jäger), um sich dann "der Polis zuzuwenden“. Es folgt das Verdikt gegen die Bordellbetreiber und alle, die der Prostitution Vorschub leisten, aus dem sich eine auf Rom gemünzte invektivenhafte Schilderung der verkommenen sittlichen Zustände, vor allem in den Ehen, entwickelt. Mit dem Motiv der Schändung vornehmer und dem Staatsdienst verpflichteter junger Männer bricht der Text ab.

\footnotetext{
${ }^{28}$ Vgl. Russell 1992 ad loc.
} 


\section{Die Einheit der Rede und ihre narratologische Struktur}

Die Übersicht über den Ablauf der Rede hat bereits einige Hinweise auf den inneren Zusammenhalt der einzelnen Themenblöcke gegeben; sie sind einem gedanklichen Programm verpflichtet, das sich gegen die Verachtung der Armut richtet und in der armen Bevölkerung das Potenzial zu besonderer Tugend und Philanthropie sieht. ${ }^{29}$ Sie unterscheiden sich aber in ihrer Methode und Perspektive: Die Möglichkeit ehrenvoller ländlicher Armut wird durch ein exemplum (Teil I: der Jäger und seine Familie) verdeutlicht; die Verteidigung der Armut gegen den Reichtum erfolgt mittels Dichtungsexegese (Teil II). Das Thema ehrenvoller Arbeit in der Stadt wird in einer unmittelbar handlungsorientierten Rede entfaltet (Teil III).

Als zusätzliche verbindende Elemente wirken zunächst die eingefügten Übergänge, gewissermaßen Meta-Diskurse zur Rede, die Abschweifungen rechtfertigen und sie dem zentralen Thema unterwerfen. Ein verbindendes Element sind aber auch Literatur und Mythos: Neben Euripides ist es vor allem die Odyssee, aus der Dion seine Motive für den Mittelteil auswählt; die Odyssee schimmerte auch in den Rahmenteilen der Reiseerzählung als Subtext durch. Der dritte Teil ist sparsamer in seinen mythisch-literarischen Reminiszenzen; immerhin verweist Dion aber auch hier auf Homer ( $\$ 116$; § 146) und Hesiod ( $\$ 110$; $§ 116)$, wohl auch, wenngleich ohne Namensnennung, auf Demosthenes ${ }^{30}$ und Platon (\$§ 119f.); ein mythisches Kolorit trägt die Textpassage §§ 143-145 (zu verführten Mädchen, Bastarden und ausgesetzten Kindern); in $\S \S 143$ f. spielt Dion auf den Danae-Mythos an. ${ }^{31}$

Teil I lässt in der Prozessschilderung die platonische Apologie des Sokrates durchschimmern; diese indirekte Berufung auf Sokrates ist aber auch dem zweiten Teil nicht ganz fremd, schließlich schreibt Platon seinem Sokrates ebenfalls die Methodik der Dichterauslegung in moralisierender

\footnotetext{
${ }^{29} \mathrm{Vgl}$. auch Scannapiecos Bestimmung des Textes als ,"un' analisi delle condizioni socioeconomiche delle $\pi$ ó $\lambda \varepsilon\llcorner\varsigma$ greche d'età imperiale, minate, agli occhi del ,filosofo', da gravi malattie come la corruzione morale e l' eccessiva opulenza. Per la risoluzione di questi problemi viene proposta, in linea con la politica traianea, una rivalutazione delle attività agricole, che avevano visto nel I sec. un lento ma costante declino provocando gravi squilibri sociali; allo spopolamento delle campagne, infatti, si era accompagnato il sovrappopolamento delle città dovuto all' inurbamento dei poveri." (R. SCANNAPIECO, „Polemiche antiepicuree nell' Amatorius di Plutarco e nell' Euboico di Dione di Prusa", in: Aspetti del mondo classico (Salerno 2006) [81-123] 104.

${ }^{30}$ Vgl. G. A. Lehmann, Anm. 137 zur Übersetzung.

${ }^{31}$ In diesen Passagen erweist sich Dion durchaus als gelehrter Kenner der Literatur, er argumentiert aber keineswegs nur für ein elitäres Publikum. Vgl. dazu Gangloff 2006, 194: In der Anspielung auf die populäre Auslegung des Danae-Mythos (Gewinn des Mädchens durch Geschenke) sei die Absicht am Werke, das schlichtere Volk durch allgemein bekannte Mythen zu erfreuen und zugleich den anspruchsvolleren Zuhörer nicht durch die Abwesenheit von Motiven, die einer komplexeren Deutung offen stehen, zu verärgern.
} 
Absicht zu (Protagoras 339a-347d.); ${ }^{32}$ in Teil III beruft sich Dion ausdrücklich auf die platonische Politeia, und eine thematische Parallele lässt sich auch zu Xenophon, Memorabilia II 7 aufweisen: Wenn Sokrates dort dem Aristarchos rät, seine armen Verwandten, die bei ihm Zuflucht gefunden haben, mit Arbeit zu versorgen, um sie weiter ernähren zu können, und ihn davon überzeugt, nicht nur er als ,Arbeitgeber', sondern auch die ,beschäftigten' Verwandten könnten von diesem Verfahren profitieren, dann ist gleichfalls der Anspruch erhoben, Armut und Menschenwürde seien miteinander vereinbar.

Gemeinsam ist allen drei Teilen auch die Zurückweisung einer Haltung, die in der Armut Anlass zu Spott oder Verachtung sieht; die narratio lässt den dem armen Jäger feindlich gesonnenen Demagogen scheitern, die Volksmenge, die den Jäger zuerst auslacht, später die höchste Ehrung für ihn beschließen; sie demonstriert zugleich die Gastfreundschaft der Armen. Die literarische Exegese argumentiert für die sittliche Überlegenheit der Armen über die Reichen und widerlegt den euripideischen Satz, die Armen seien untauglich zur Gastfreundschaft. Der dritte Teil weist die Schmähung der Armen expressis verbis zurück (114-116). Von der menschlichen Würde derer, die in die Prostitution gezwungen werden, nimmt auch die den Text abschließende Sittenkritik ihren Ausgang.

Einheit stiftet darüber hinaus der jeweils mindestens zwei Großteile verbindende Wertekanon: Die Reiseerzählung und die literarische Exegese legen das Schwergewicht auf Gastfreundschaft und Philanthropie bzw. Philoxenie; in den Erlebnissen des Jägers in der Stadt, ebenso wie beim Gastmahl seiner Familie mit dem Ich-Erzähler, manifestiert sich aber auch die Schlichtheit und Bescheidenheit der Landleute, die Unfähigkeit des Jägers, sich zu verstellen, sein Bemühen, im Prozess seinen Frieden mit den Bürgern zu erreichen; eben diese Tugenden der Schlichtheit, Unverstelltheit und des Einsatzes für den Rechtsfrieden ${ }^{33}$ sind auch verbindendes Element der von Dion abgelehnten Berufe.

Die Reiseerzählung weist die Relevanz der genannten sittlichen Qualitäten im Bezug auf drei Referenzbereiche nach: innerhalb der Familie (hier sind v.a. die Hochzeitsvorbereitungen, aber auch das freundschaftliche Miteinander der beiden Familien und die Fürsorge der Jäger-Familie für die verheiratete Tochter zu nennen); gegenüber dem notleidenden Fremden (der Ich-Erzähler ebenso wie die beiden Bürger, die sich in der ekklesia zur Rettung durch den Jäger bekennen); innerhalb der polis (vgl. v.a. die Rede des zweiten Redners, der den Vorteil einer Bewirtschaftung des sonst brachliegenden Landes vertritt). Zwei dieser Referenzbereiche werden im dichtungsexegetischen Teil wieder angesprochen: die Philoxenie

\footnotetext{
${ }^{32}$ Vgl. Russell 1992, 10.

${ }^{33}$ Zur Bedeutung der innerstädtischen ó ${ }^{\prime}$ vot $\alpha$ in Dions Werk vgl. J. HAHN, , Auftreten und Wirken von Philosophen im gesellschaftlichen Leben“, in: Nesselrath 2009, 249.
} 
besonders ausführlich am Beispiel des Odysseus, Familie bzw. Ehe kurz am Beispiel des Menelaos, dessen Reichtum ihn letztendlich die Ehefrau kostete. Ganz dem Bereich der polis ist dann der dritte Teil gewidmet, wobei Dion strikt darauf achtet, den Vorteil für das Staatswesen aus dem Nutzen für den Bürger bzw. das Individuum abzuleiten: Um die moralische Integrität, Autarkie und Menschenwürde des einzelnen geht es hier primär; aber gerade aus dem Mangel an diesen Werten entsteht Übles auch für den Staat (vgl. Dions Sorge vor der schädlichen Auswirkung des Müßiggangs: Kriminalität und vielleicht auch Aufrührertum, § 109; den Hinweis auf den Bedarf - scil. der polis - an gewissen Berufen, § 125; in der letzten digressio die Ablehnung von Prostitution und Zuhälterei nicht zuletzt unter Hinweis auf deren üble Folgen für die Gemeinschaft). Unter diesem Aspekt wird dabei auch das Thema Ehe wieder aufgegriffen: Die Integrität der Ehe kann, so Dion, keinen Bestand haben in einer Gesellschaft, die Prostitution zulässt ( $\S \S 141 \mathrm{f}$.).

Den hier konstatierten Verbindungen und Analogien zwischen den einzelnen Teilen stehen allerdings Elemente gegenüber, die die Einheit des Textes untergraben. An erster Stelle ist das Ungleichgewicht der Teile anzuführen, unter denen, ungeachtet der Tatsache, dass der Schluss und vielleicht auch der Anfang nicht präzise zu bestimmen sind, der Reisebericht einen unverhältnismäßig umfänglichen Teil einnimmt. Ein weiterer Grund dürfte in den sehr stark differenzierten Sprechhaltungen - bzw. der hohen narratologischen Differenzierung - sowie in der Ausrichtung der einzelnen Teile an unterschiedlichen Textsorten (bzw. Gattungen) liegen. ${ }^{34}$

Das „Ich“ begegnet im Text in vielfältigen Facetten: Als auktorialer Autor des Textes (bzw. extradiegetischer Erzähler), der alle Teile zusammenhält und in den Überleitungen auch Meta-Diskurse über seinen Text eröffnet; als personaler (bzw. intradiegetischer) Erzähler innerhalb des Reiseberichts. ${ }^{35}$ In diesem Reisebericht tritt ihm als weiterer personaler (metadiegetischer) Erzähler der Jäger zur Seite, dessen Erzählung wiederum weitere (metametadiegetische) Erzähler zu Wort kommen lässt (die beiden Redner; den vom Jäger geretteten Bürger). Diese narratologische Strukturierung auf mehreren Ebenen macht den Reisebericht zu einem höchst komplexen Gebilde, das sich von der Funktion, die Dion ihm zuweist nämlich den Nachweis zu führen, dass ehrbare Arbeit für Mittellose auf

\footnotetext{
${ }^{34}$ Gerade ein Vergleich mit dem Borysthenitikos (36. Logos), der in seinem Thema, der idealen polis, dem Euboikos Logos verwandt und ebenfalls - u.a. durch Reden - in sich unterteilt ist, macht deutlich, dass die Teile des Euboikos Logos eher aneinander gehängt, als organisch miteinander verbunden sind. Vgl. Forschner 2003, 132f.

${ }^{35}$ Die im Text behauptete Identität des Autor-Ichs mit dem Erzähler-Ich des Reiseberichts ist keineswegs zwingend: Dion hätte den Reisebericht auch als ein fremdes Erlebnis einführen können, wie er das in seinen Reden häufig praktiziert, indem er etwa auf Episoden aus dem Leben Alexanders (1. Königsrede) oder des Diogenes von Sinope zurückgreift.
} 
dem Land möglich ist - wenn nicht thematisch, so doch strukturell weit emanzipiert.

Facettenreich ist aber auch das die Rede zusammenhaltende auktoriale Ich selbst (der Redner; der extradiegetische Erzähler): Es präsentiert sich als Geschichtenerzähler, also (modern gesprochen) als Autor eines fiktionalen Textes; ${ }^{36}$ diesem fiktionalen Text haften aber Elemente des Autobiographischen an, die jeder Zuhörer oder Leser unschwer identifizieren kann, nämlich die Exilsituation, die Dion zwang, sich außerhalb seiner Heimat aufzuhalten und eher die Gesellschaft der einfachen Leute als die der Vornehmen zu suchen. ${ }^{37}$ Weitere Facetten des Ichs sind die des gelehrten Auslegers und Kritikers der Literatur, des Politikers und Gesellschaftskritikers, des (Popular-)Philosophen in ethischen Fragen.

All diese Aspekte sind jeweils an ihrer Stelle deutlich prononciert, stehen aber im Gesamtkomplex des Textes in einer gewissen Spannung zueinander: sie wecken Erwartungen, die nicht eingehalten werden, und scheinen teilweise auch nicht völlig miteinander vereinbar. So ist das autobiographische Element zu Beginn des Reiseberichts scharf konturiert, wird dann aber verdrängt durch den Bericht des Jägers, dessen ,Apologe' eine eigene ,Autobiographie' präsentieren. Der Zuhörer, der im ersten Rahmenteil am Geschick des Erzählers Anteil nahm und seine Erlebnisse nach dem Schiffbruch mit einer gewissen Spannung verfolgte, muss bald erkennen, dass ihn der Erzähler nur auf eine Fährte gelockt hat, die zu einem ganz anderen Ziel führt.

Auch dem Mittelteil mit seiner weitgehend unorthodoxen Mythenauslegung kommt eine Art von Fliehkraft zu: Der ironische Literaturkritiker passt nicht ganz zu dem gesellschaftspolitisch engagierten Programmatiker des letzten Textteils; die etwas zynische Behandlung des Mythos steht in Spannung zu dem ernsthaft empörten Ton der Sittenkritik im letzten Exkurs.

Angesichts dieses Befundes geraten die Überleitungen mit ihren die thematische Vielfalt rechtfertigenden Meta-Diskursen unter den Verdacht, den Kitt für ursprünglich separat konzipierte Texte zu bieten: So hält Desideri den Reisebericht einerseits und Dichtungsexegese und Reformprogramm andererseits für zwei zu unterschiedlichen Zeiten konzipierte Einzelwerke; ${ }^{38}$ Russell vermutet, die erste Ausgabe des Textes habe eine Synthese verschiedener überlieferter Rede-Versionen erstellt, ${ }^{39}$ und Mo-

\footnotetext{
${ }^{36}$ Vgl. Desideri 1978, 224.

${ }^{37}$ In der ersten Königsrede (or. 1,51) verweist Dion auf die interessanten Beobachtungen, die er während seiner Exilzeit bei den Hirten und Bauern auf der Peloponnes machen konnte; vgl. DANEK 2009, 417f.

${ }^{38}$ Desideri 1978, 223: "Questo scritto si compone di due parti nettamente distinte, accostate ma non integrate, certamente frutto di riflessioni maturate in tempi diversi; $[. .$.$] "$

${ }^{39}$ Russell 1992, 12.
} 
les sieht in der erhaltenen Fassung des Euboikos logos ein patchwork aus Teilen verschiedener Reden, die Dion bei verschiedenen Anlässen in verschiedener Ausformung bzw. Kombination von Themen gehalten habe. ${ }^{40}$ Alle drei genannten Autoren rücken damit ab von der Analyse von Arnims, der gerade in der digressiven Technik Dions rhetorisch-didaktische Strategie einer über das zentrale Thema hinausreichenden Wirkungs- und Erziehungsmöglichkeit verwirklicht sah, ${ }^{41}$ eine Rechtfertigung, die dem Typos der Diatribe Rechnung trägt, die sich - soweit sie denn überhaupt gattungsmäßig einigermaßen exakt zu bestimmen ist - gerne der moralischen Didaxe, des Wechsels zwischen direkter Ansprache und vortragenden Erörterungen und des gesamten Arsenals rhetorischer Techniken bedient. ${ }^{42}$ Es bleibt aber doch festzuhalten, dass die genannten Merkmale der Diatribe zwar viele Reden Dions prägen, der Euboikos logos aber eine vergleichsweise ungewöhnliche innere Brüchigkeit aufweist.

\section{Gattung}

Auf die Frage nach der Gattung des Euboikos logos gibt es eine relativ einfache Antwort: Es handelt sich um eine Rede, die einer konkreten Intention verpflichtet ist, also innerhalb der Rhetorik dem $\gamma \varepsilon$ ćvo $\sigma u \mu \beta o v \lambda \varepsilon v \tau \iota \kappa o ́ v$ bzw. genus deliberativum zuzuordnen ist. Diese Rede ist gemäß den Regeln antiker Rhetorik mit Anschaulichkeit und Überzeugung stiftenden Elementen angereichert: mit mythischen Beispielen ebenso wie mit als Erfahrungsbericht eingeführten lebendig geschilderten Szenen aus der eigenen Zeit.

Diese schlichte und zutreffende Zuordnung zur Gattung der oratio kann aber nicht wirklich zufrieden stellen. Umfang und narrative Attraktivität des Reiseberichts verleihen ihm mehr Gewicht als nur den eines exemplarischen Belegs innerhalb einer politischen Rede; zudem verlocken die sehr unterschiedlichen Erzählhaltungen der einzelnen Teile sowie die zahlreichen Subtexte v.a. dichterischer und philosophischer Natur dazu, die Affinität der einzelnen Teile zu anderen Gattungen zu überprüfen.

Die Frage nach der Gattung kann separat an den Reisebericht gestellt werden, der in mancher Hinsicht untereinander verwandte Subtexte wie die Odyssee und den hellenistischen Roman, aber auch eine ganz andersartige Form wie die platonische Apologie anklingen lässt. Der Subtext Odyssee definiert das Geschehen als mythisch, die Romanmotive weisen der Erzählung den Charakter des Fiktionalen zu. Die mythischen und romanhaftfiktionalen Motive sind aber mit realistischen Elementen durchsetzt oder

\footnotetext{
${ }^{40}$ Moles 1995, 177.

${ }^{41}$ Von Arnim 1898, 440.

${ }^{42}$ Vgl. S. K. Stowers, „Diatribe”, übers. v. L. Gondos, HWRh 2 [627-633] 628f.
} 
sogar durch sie konterkariert. ${ }^{43}$ Umgekehrt rekurriert die auf die platonische Apologie anspielende Gerichtsverhandlung auf eine historische Erfahrung, die durch das happy end ins Unerwartete und nicht mehr Realistische umgebogen wird.

Die Forschung hat hier die Begriffe Idyll (eidyllion), novella, Mythos und Utopie erwogen. Davon scheint mir insbesondere die von Reuter ${ }^{44}$ erwogene Anbindung an die Gattung des Eidyllions wenig hilfreich. Der etwas vage Gebrauch des Begriffs in neuerer Zeit (als geschöntes Stimmungsbild ländlich-bukolischer Freude) mag in Details zutreffen; der Lebensbereich des Jägers und seiner Leute trägt Züge des Bukolischen, und damit auch einer Idealisierung der Natur und des Landlebens. ${ }^{45}$ Literaturgeschichtlich korrekt ist aber zu fragen, ob Dion sich in der Stilisierung des Hirtenlebens an Theokrit und seine Nachfolger anschließt. Hier überwiegt über wenige Parallelen das Trennende: Zwar ist auch bei Theokrit das Landleben als positiver Gegenbereich zur Stadt in mit ironischen Zügen versehener Verklärung dargestellt; andererseits fehlen Elemente, die für Theokrit und auch für Vergil prägend sind, so vor allem die musische Kunst als Teil des Landbzw. Hirtenlebens: Dem schlichten Gastmahl der Landleute fehlt jedes musische Element. Auch der für Theokrit und Vergil prägende vertraute Umgang der Hirten mit mythischen Gestalten wie Faunen und Nymphen hat keinen Gegenpart bei Dion, ebenso wenig wie die vitale Ausgelassenheit, die die Hirten zum Wettstreit gegeneinander antreibt oder ihre erotischen Spiele und Werbungen anheizt: Dions Landleute sind - ungeachtet ihres stadtfernen Lebens - von bürgerlicher Bravheit und Arbeitsfreude.

In diesem Verzicht auf eine bukolisch-musische Stilisierung des Jägers und seiner Familie liegt ein Element realistischen Erzählens, ohne dass damit die Orientierung am Typologischen negiert wäre. Es ist aber ein anderer Typos, auf den Dion abzielt: nicht der des den ländlichen Göttern und der Kunst nahen Hirten, sondern der des genügsamen Landmanns, der durch Fleiß und Geschick seinen bescheidenen Lebensunterhalt erwirbt. ${ }^{46}$

${ }^{43}$ DANEK 2009, 421 verweist auf die ausdrückliche Abgrenzung der Haartracht des Jägers (4; vgl. dort Anm. 9) von der homerischen Beschreibung der Haartracht auf Euböa (Il. II 542).

${ }^{44}$ Reuter 1932, 20-23 arbeitet, in Abgrenzung von der hexametrischen Bukolik, mit dem Begriff des Prosa-Idylls.

${ }^{45}$ Desideri 1978, 407 spricht von einem ,,ideale aristocratico di una povertà contadina e pastorale".

${ }^{46}$ Russell 1992, 9 sieht das differenzierende Element vorwiegend in der didaktischen Tendenz: , $[\ldots]$ but the essential point is the professed lesson: that poverty is no bar to hospitality, nor, in general, to a good and happy life." 
Die von Anderson ${ }^{47}$ erwogenen (und zugleich relativierten ${ }^{48}$ ) Begriffe „novella“, „lalia“ und „very short novel“49 legen den Akzent auf die Gestalt der kurzen - und stegreifartig im Plauderton stilisierten (lalia) - Erzählung fiktionalen Charakters. Damit wäre eine formal zutreffende Definition des Reiseberichts gewonnen, die diesen allerdings als völlig isolierten Text auffasst. Selbst wenn die narratio aber erst nachträglich dem theoretischen Teil zugeordnet wurde, ist sie in ihrer überlieferten Form einem moralisierenden Zweck unterworfen, der seine genaue Bestimmung erst durch die nachfolgenden Textteile erhält: Für sich genommen exemplifiziert sie den Sieg von Anstand und Moral über Habgier und Verleumdung; der Kontext macht sie zum Paradigma anständiger ländlicher Arbeit für Besitzlose.

Einen Weg zur Verankerung der narratio im Kontext weist ihre Definition als Mythos, die Desideri vorgenommen ${ }^{50}$ und Danek in jüngster Zeit im Vergleich mit platonischen Mythen neu fundiert hat: In der Einheit von Erfindung und Authentizitätsanspruch sieht er eine Traditionslinie wirksam, die von Platon in die Zweite Sophistik reicht. ${ }^{51}$ Von dieser Warte aus bestimmt Danek plausibel die Funktion des Reiseberichts als „Fiktion, die wie jeder ,Mythos' den Anspruch auf eine ,höhere' Wahrheit erhebt und damit den philosophischen Anspruch der gesamten Rede unterstreicht". ${ }^{52}$ Der Begriff ,Mythos' schließt den der ,Utopie' nicht aus, zumal Platons Mythos von Atlantis zu den frühesten Ausprägungen des Utopischen $^{53} \mathrm{zu}$ rechnen ist. Von Arnim hat gegen diese Gattungszuordnung den Einspruch erhoben, die Konkretheit geographischer und zeitlicher Zuordnung sowie der Verzicht auf Phantastisches oder Märchenhaftes bedeute ein Abweichen von gängigen literarischen Utopien; ${ }^{54}$ die Jäger-Erzählung, die zwar in ihrer Verklärung persönlicher und gesell-

\footnotetext{
${ }^{47}$ Anderson 1976, 97.

${ }^{48}$ Anderson 1976, 97f.: „Or does its [the Euboicus'] very existence make these labels look artificial, since it shows that rhetorical and romantic stories can be improvised by a sophistic writer at any length to suit the purpose of the moment?"

${ }^{49}$ Vgl. auch Perry 1967, 70, der die Erzählung als Werk eines Roman-Autors ohne Erfahrung beurteilt.

${ }^{50}$ Desideri 1978, 225: Die Begegnung mit dem Jäger sei eine Art Gegenmythos zu den von Homer und Euripides erzählten Mythen, in denen die Armut verächtlich und der Reichtum bedeutsam erscheint („La mia convinzione è dunque che L'Euboico costituisca una specie di ,mito' a scopo educativo, sollo stesso piano di molti altri racconti di devozione laica che troviamo qua e là negli scritti dionei [...]."

51 Ähnlich Urbán 2004, 167 Anm. 1.

${ }^{52}$ DANeK 2009, 423.

${ }^{53}$ Als eigene Textgattung hat erst Thomas Morus die Utopie begründet; vgl. KytzLER 2002 und SCHWENDTNER 1994, dessen Untersuchung bei Morus einsetzt.

${ }^{54}$ V. ARnim 1898, 493; vgl. auch 492: „Denn was nicht unglaublich scheint, wenn es als Thatsache berichtet wird, glaubt auch der wollende Mensch in die Welt der Thatsachen einführen zu können“; vgl. auch Reuter 1932, $15 f$.
} 
schaftlicher Verhältnisse, nicht aber in ihrer Ferne zum Jetzt und Hier die Gattungsregeln des Utopischen erfülle, definiert er daher etwas offener als „utopische Tendenzdichtung“, insofern „die beiden Jägerfamilien als ideale Typen zur Veranschaulichung eines sittlichen Ideals gedichtet“ seien.

Derartigen Kautelen ließe sich entgegenhalten, dass sich das Verständnis des Utopischen in jüngerer Zeit in eine Richtung entwickelt hat, die - im Sinne der Realutopie - jeden Gegensatz zu den real existierenden Verhältnissen und damit auch Reformkonzepte und ,Zukunftsentwürfe' mit einschließt. ${ }^{55}$ Gemäß diesem modernen Verständnis entspricht nicht so sehr Dions Reisebericht, wie die ganze Rede den Kriterien des Utopischen. Ungeachtet der neuzeitlichen Gattungsgeschichte seit Thomas Morus bleibt aber zu fragen, ob Dion sich bewusst an ihm bekannte Texte utopischer Prägung anlehnte. Das scheint mir ganz klar der Fall zu sein. Schon die explizite Berufung auf Platons Politeia definiert den Text als utopisch im Sinne eines politischen Ideals. ${ }^{56} \mathrm{Im}$ Reisebericht finden sich zahlreiche weitere Anklänge an antike Utopien: In den Anspielungen auf Odysseus' Aufenthalt im Land der Phäaken wird eines der in der Antike berühmtesten „utopischen“ Gegenbilder zur Realität lebendig. Die ja keineswegs zwingende Ansiedlung des Geschehens auf einer Insel klingt nicht nur an das Motiv

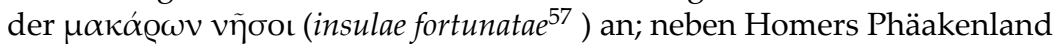

\footnotetext{
${ }^{55}$ R. SChWENDTNER, 1994, 20: „Utopien, die mit planerisch-strategischem Handeln vermittelt werden sollen, gelten oft als ,Entwürfe' - und zwar so oft, dass ,Utopie' und ,Zukunftsentwurf' nicht selten synonym verwendet werden. “ Strenger definiert KYTZLER 2002, 1070, und setzt als Determinanten der Utopie sowohl die „experimentelle Gedankenfigur, welche in phantasiereicher Vorwegnahme durch glückliche Gegenbilder verschiedene schmerzlich empfundene Beeinträchtigungen aufhebt, seien diese natürlicher Herkunft (wie Krankheit, Tod, Hunger, Durst, Hitze, Kälte, Entfernung usw.) oder gesellschaftlichen Ursprungs (wie Ausbeutung, Unterdrückung, Ausgrenzung, Ungerechtigkeiten gegenüber Individuen, Klassen, Rassen und dergleichen" an wie auch die räumliche und bzw. oder zeitliche Distanz (Wunschraum oder Wunschzeit). Zur Bedeutung des Utopischen in der Antike vgl. J. Ferguson, Utopias of the Classical World (London 1975). Eine eingehende Aufarbeitung des Forschungsstandes zum Begriff Utopie sowie eine Analyse einschlägiger hellenistischer Texte leistet WiniarczyK 2011 (zu Theopomp v. Chios, Hekataios v. Abdera, Onesikritos v. Astypalaia, Euhemeros v. Messene, Iambulos und der Uranopolis des Alexarchos). Weder Ferguson noch Winiarczyк gehen auf den Euboikos logos ein.

${ }^{56}$ In größerer Nähe zur Politeia steht allerdings Dions Borysthenitikos Logos mit seinem aus platonischer und stoischer Philosophie entwickelten kosmischen Staatsmodell, einem Ideal, dessen vollkommene Abbildung in der irdischen Wirklichkeit nie gelingen kann (vgl. Nesselrath, in: Nesselrath 2003, 25; Forschner, in: Nesselrath 2003, 145f.). - Jones 1978, 64 bezieht gerade unter dem Aspekt des Utopischen die beiden Reden aufeinander: In der Stadt des Euboikos Logos seien Dions negative Erfahrungen in Prusa verarbeitet; sie sei also ",a portrait of the contemporary Greek city“, und zwar ein Porträt, das in dem Idealort des Borysthenitikos in Umkehrung wieder begegne. Insofern kommt Jones zu dem Schluss: „Dio's two surviving pictures of remote settlements appear to be drawn from his own experience, but tinted with utopian ideals."

${ }^{57}$ Auf einer Insel liegen auch Thomas Morus' Utopia (1516), Campanellas Civitas Solis (1602) und Bacons Nova Atlantis (1627). Zur Insel als Ort antiker Utopien vgl. den Überblick bei WINIARCZYK 2011, 261-3.
} 
Scheria sind auch Platons Atlantis und der Idealstaat des Iamboulos Inselreiche. ${ }^{58}$ Dass Dions Insel einen Namen trägt, der auf der Landkarte $\mathrm{zu}$ verifizieren ist, hindert nicht den $\mathrm{u}$-topischen Charakter der angeblich auf ihr gelegenen ländlichen Siedlung und Stadt: Schon die Art, wie der Erzähler dort landet, entspricht den Topoi des Utopischen: Er sucht Euböa nicht absichtlich auf, sondern wird dorthin verschlagen. Aber auch die konkrete Ortsbestimmung des Anfangs verliert sich zunehmend im Nebulösen: Wenn der Erzähler an der Seite des Jägers die leicht zu identifizierende Küste Euböas und den historisch nachweisbaren Tätigkeitsbereich der Purpurfischer verlässt und seinem Gastgeber ins Landesinnere folgt, scheint er auch den Bereich der konkreten Geographie hinter sich zu lassen. Die kleine Ansiedlung des Jägers ist ebenso unspezifisch im „Irgendwo" angesiedelt wie die Stadt, von der der Jäger erzählen wird. ${ }^{59} \mathrm{Sehr}$ absichtsvoll ist diese Stadt - mag sie auch nach einem konkreten Vorbild gezeichnet sein - nicht mit Namen genannt und auch insgesamt in einer Weise geschildert, die sich nicht in Übereinstimmung mit einem historisch fasslichen Ort bringen lässt. ${ }^{60}$ Stadt und Land haben symbolische Bedeutung - als Räume unterschiedlicher Lebensentwürfe, deren Versöhnung eher Ideal als Wirklichkeit ist. Nicht nur die Familie des Jägers und seines Schwagers repräsentieren in ihrer Friedfertigkeit und völligen Autarkie einen utopischen Lebensentwurf; in quasi utopischem Kontrast zur Realität steht auch die Stadt, in der ein Angeklagter eben nicht - wie dies historisch verbürgt mit Sokrates geschah - trotz seiner Unschuld verurteilt wird, sondern - Höhepunkt der Utopie - sogar noch eine Ehrengabe und die Speisung im Prytaneum erwirkt.

${ }^{58}$ Vgl. dazu Plat. Criti. 120e-121a: ,_[...] sie besaßen nämlich ein Denken, das der Wahrheit verpflichtet und in jeder Weise auf Großes gerichtet war, und mit einer milden und mit Klugheit gepaarten Gelassenheit reagierten sie auf die jeweils sich ergebenden Wechselfälle des Geschicks und verfuhren so auch im Umgang miteinander. Aufgrund dieser Haltung ließen sie außer der Tugend nichts gelten und erachteten alles ihnen zur Verfügung Stehende als gering. Leicht trugen sie die Masse ihres Goldes und ihrer anderen Besitztümer; nicht aber begingen sie Fehltritte, weil sie betrunken vom Luxus aufgrund ihres Reichtums ihrer selbst nicht Herr gewesen wären, sondern nüchtern und scharfsichtig erkannten sie, daß auch dies alles aus einem Wohlwollen, das alle umfaßt, gepaart mit Tugend immer noch zunimmt, daß dagegen, wenn man diese Güter (ohne Maß) erstrebt und ehrt, sowohl sie selbst dahinschwinden als auch die genannte Tugend zusammen mit ihnen zugrunde geht. Da sie also in solcher Weise dachten und solange ihre göttliche Natur ihnen erhalten blieb, vermehrte sich ihnen alles, was ich zuvor dargestellt habe." (Platon. Werke. Übersetzung und Kommentar, VIII 4. Kritias, übers. u. komm. v. H.-G. Nesselrath [Göttingen 2006] 27).

${ }^{59}$ Die gelegentlich erwogene Bestimmung der Stadt als Karysthos (u.a. JonEs 1978, 58) ist nicht haltbar; vgl. DANEK 2009, 418 und insbesondere H.-R. Goette S. 174-189.

${ }^{60}$ Die Unverbindlichkeit der Ortsbestimmung wird besonders deutlich im Vergleich zu der sehr konkreten Ortsbestimmung Borysthenes (= Olbia; vgl. B̈̈вLER 2003) im 36. Logos. 
Meine Untersuchung zu Dions Euboikos logos hat sich auf drei Aspekte konzentriert: die Struktur des Textes, seine Einheit, seine Gattungszugehörigkeit. In keinem dieser drei Analysefelder lässt sich eine ganz einheitliche Antwort finden. Die Struktur erwies sich im Reisebericht als höchst elaboriert, mit raffinierten Verschachtelungen und Korrespondenzen. Die einzelnen Teile sind durch Überleitungen sorgfältig aneinandergebunden. Dennoch hält sich der Eindruck eines Konglomerats aus verschiedenen Themenblöcken unterschiedlichen Umfangs, in denen wechselnde Sprechhaltungen wirksam sind und die in Affinität zu unterschiedlichen literarischen Gattungen stehen.

Vermutlich ist der Euboikos logos nicht von Anfang an als Einheit konzipiert worden; die verschiedenen Teile fügen sich aber allesamt dem Programm, das der theoretische Teil ganz deutlich definiert. Es handelt sich demnach um Texte, die letztlich von ein- und demselben gesellschaftspolitischen Anliegen des Verfassers geprägt sind. Ob Dion die Rede je in der überlieferten Form gehalten hat oder ob er Teile daraus für sich oder in anderer Kombination vorgetragen hat, lässt sich nicht klären. Als der Autor die verschiedenen Teile zu einem Ganzen zusammenschloss und mit überleitenden Zwischenstücken ausstattete, sah er offensichtlich in deren Diversität keinen Nachteil, sondern hielt die neu entstandene Mischform für nützlich gemäß seinen sozialpolitischen Absichten. Und tatsächlich vermag ja der autobiographische Anteil die Glaubwürdigkeit des Berichts zu steigern, dem die Nähe zum platonischen Mythos eine generelle (paradigmatische) Relevanz zuweist; die realistische Schilderung des Arbeitslebens auf dem Land dient der Autorität des politischen Programms, das sich als aus profunder Kenntnis erwachsend zu erkennen gibt; die Idealisierung, v. a. in der ethischen Stilisierung der Landleute, bietet ein Mittel konstruktiver Sitten- und Gesellschaftskritik, das dem Reformprogramm gut ansteht. Das Element des Utopischen ist dabei zugleich eine Provokation der Gesellschaft, über die Grenzen des bisher Gedachten und Erprobten hinaus zu schreiten.

Insofern wäre es völlig verfehlt, in dem utopischen Element der Schilderung eine Desavouierung des sozialpolitischen Programms des dritten Teils zu sehen: Dion ist es ernst mit seinen Gedanken über die Vereinbarkeit von Arbeit und Menschenwürde für die Armen, und die umfängliche Hinführung zu diesem Thema zeigt allenfalls, wie weit man tatsächlich noch von der rechten Würdigung der Armen und ihrer Arbeitskraft entfernt ist. Die Umstände dieser Realität scheinen dann in der Invektive gegen Rom auf, und die affektgeladene Rede lenkt den Blick zurück auf die Utopie - als auf einen Zustand, der Wirklichkeit werden kann und soll. 



\title{
Fiktion oder Realität? \\ Dions Euboikos Logos in der althistorischen Forschungsdiskussion seit Eduard Meyer
}

\author{
Dorit Engster
}

In der modernen Forschungsdiskussion geht es primär um den literarische Rang oder den philosophischen Gehalt des Euboikos Logos. Dabei spielen Fragen der Gattungszuordnung eine Rolle oder des Vergleichs dieser Schrift mit anderen Reden Dions und den Werken zeitgenössischer Autoren. Es hat aber auch Versuche von althistorischer Seite gegeben, die Rede als Quellentext zu nutzen, d.h. auf konkrete Zustände und Verhältnisse zu beziehen. Im Folgenden soll ein Überblick über die wichtigsten Ansätze bzw. Positionen verschiedener Forscher gegeben werden. ${ }^{1}$ Ansatzpunkt für die unterschiedlichen Deutungen sind die detaillierten Schilderungen, die sich in der Rede finden. Die Erzählung über den "Jäger" ist eingebettet in eine ausführliche Beschreibung der Gegebenheiten im Süden der Insel Euboia. ${ }^{2}$ Die Geschichte über die in einfachsten Verhältnissen lebenden zwei Familien ist häufig als rein literarische Idylle oder Utopie charakterisiert worden, als Idealentwurf einer Gegenwelt ohne unmittelbaren Realitätsbezug. Entsprechend werden die vom Autor ebenfalls eingehend geschilderten Zustände in der benachbarten Stadt als bewusst konzipiertes Gegenbild aufgefasst. Andererseits sind diese Angaben zu Stadt und Land auch ernst genommen und als Basis für Überlegungen zur wirtschaftlichen Entwicklung der hohen römischen Kaiserzeit genutzt worden.

Zunächst seien die wichtigsten im Euboikos Logos zu findenden Angaben noch einmal kurz angeführt: Die dort beschriebene Stadt ist weit von ihrer ehemaligen Blüte entfernt und verarmt. Der bedenkliche Zustand der Polisgemeinde wird dadurch charakterisiert, dass selbst zentrale Einrichtungen wie die Agora und das Gymnasium nun verlassen sind bzw. als Weide dienen. Die Stadtmauer umschließt, da die Bevölkerungszahl gesunken ist, nun auch unbewohntes Land und außerhalb der Befestigung

\footnotetext{
${ }^{1}$ Für einen Überblick über die neueren Veröffentlichungen s. DeL CoRno 1980, 191-193; Reardon 1983, 286-292; Harris 1991, 3854-3881. Zu den Themen des Euboikos Logos s. auch Milazzo 2007, 163-226.

${ }^{2}$ Zur Struktur des Textes s. u.a. Urban 2004, 57-68; Milazzo 2007, 173-179. Zum Charakter der Rede s. von Arnim 1898, 472-476. Zum Aufbau BeKKer-Nielsen 2008, 136-140; Ma 2000, $113 f$.
} 
liegt das Land aus dem gleichen Grunde zu zwei Dritteln brach. Viele Stadtbewohner, so wird weiter ausgesagt, sind arbeitslos, während andererseits Arbeitskräfte fehlen, um das ungenutzte Land zu bearbeiten.

Diese Angaben sind in der modernen Forschung verschiedentlich aufgegriffen und interpretiert worden. Form und Grad der Rezeption des Euboikos Logos Dion von Prusas sind dabei stärker als dies vielleicht bei anderen antiken Schriften zu beobachten ist, stark zeitgebunden. ${ }^{3}$ Auch fallen die Bewertungen der genannten Passagen sehr unterschiedlich aus.

\section{Der Euboikos in der sozialgeschichtlichen Debatte}

Die erste vertiefte Auseinandersetzung mit Dion und den in seinen Reden zu findenden Angaben zur Wirtschafts- und Sozialgeschichte datiert bereits an den Beginn des 20. Jahrhunderts. Die unterschiedlichen Positionen in der deutschen Forschung um die Jahrhundertwende sind dabei auch vor dem Hintergrund der sogenannten „Bücher-Meyer-Kontroverse“ zu sehen. Dabei ging es um die Grundsatzfrage der Bewertung der antiken Wirtschaft. Während die „Primitivisten“, orientiert an Karl Bücher, den Unterschied zwischen der antiken Wirtschaftsweise und der modernen, frühindustriellen Gesellschaft betonten, sahen Eduard Meyer und andere „Modernisten“ Parallelen bzw. Analogien zwischen der antiken und der frühneuzeitlichen wie zeitgenössischen Ökonomie. ${ }^{4}$ Verbunden war diese Debatte mit einer intensivierten Auseinandersetzung mit antiken Texten unter wirtschaftgeschichtlicher Perspektive. Schon bei Robert von Pöhlmann finden die Reden Dions - allerdings nicht konkret der Euboikos Logos - als wirtschaftshistorische Quellen Berücksichtigung. So zieht er die or. 15 als Beleg für die teilweise harten Arbeitsverhältnisse heran, Angaben aus or. 31 wiederum im Rahmen seiner Ausführungen zu Zinsen, Verschuldung und Landverpachtung im Griechenland der hohen Kaiserzeit. ${ }^{5}$ Eine erste ausführlichere Würdigung des Euboikos Logos erfolgte durch Eduard Meyer, und zwar in einer Beilage zu seiner Geschichte des Altertums. Allein dieses gesonderte Eingehen auf die Rede zeigt die exzeptionelle Bedeutung, die er ihr zuerkennt. Meyer betrachtet den Bericht Dions als „charakteristisch für die Zustände der Zeit" ${ }^{6}$ Die Verödung eines großen Teils

\footnotetext{
${ }^{3}$ Für einen Überblick über die Forschungsgeschichte s. SwAIN 2000a.

${ }^{4}$ S. hierzu SCHNEIDER 1990, 417-445

${ }^{5}$ Von Pöhlmann 1925. S. dort, 219, in der Fußnote den Verweis auf or. 15 für das Eingehen die individuelle Freiheit einschränkender Dienstverhältnisse; s. 326f. zum Problem der Zinsen den Verweis auf or. 31,69; 329 in der Argumentation gegen Schuldentilgung; s. bezüglich der Frage der Landaufteilung den Verweis auf or. 31,70; s. 377f. bezüglich der Diskussion über das wahre Königtum den Verweis auf or. 1.

${ }^{6}$ Weiter spricht Von Pöhlmann 1925, 164 davon, dass der Text einen „lebendigen Einblick in die Ursachen, auf denen der Verfall des Altertums beruht“", bieten könne.
} 
des Ackerlandes wird von ihm als typisch und dementsprechend der Bericht Dions als realistisch eingeschätzt. Gleiches gilt für den geschilderten Rückgang der Bevölkerung, der sowohl in der Stadt dadurch auszumachen sei, dass zahlreiche Häuser unbewohnt blieben, als auch daran, dass auf dem Land weite Gebiete menschenleer seien. Die Beschreibung des Lebens der Jäger sieht Meyer als Beleg für die in dieser Zeit praktizierte Form der Landwirtschaft, nämlich eine von Großgrundbesitzern betriebene Weidewirtschaft im Gegensatz zu dem auf kleinen, gepachteten Parzellen betriebenen Ackerbau. Die Verhältnisse bzw. der von Dion beschriebene Niedergang werden von Meyer als typisch angesehen, denn „überall in Griechenland sah es schon zu Beginn der Kaiserzeit ebenso aus“. ${ }^{7}$ Er geht so weit, diese Verhältnisse für die Folgezeit auch auf Rom und Italien zu übertragen. ${ }^{8}$ Neben einer Analyse der Angaben zur wirtschaftlichen Situation geht Meyer im zweiten Teil seiner Betrachtungen auf eine weitere Ebene der Darstellung ein. Er nimmt an, dass Dion diese Rede auch zur „moralisierenden Betrachtung" verfasst habe. Zielsetzung sei es, das ärmliche Leben auf dem Land zu loben und mit dem Streben nach Geld und den negativen Auswirkungen des Gewerbes zu kontrastieren. Aufgrund dieser Erzählabsicht könne „nicht jede Angabe auf die Goldwaage gelegt und als statistisch exakt betrachtet werden“. Generell urteilt Meyer, dass im Euboikos Logos die „tatsächlichen Verhältnisse“ geschildert würden und dieser somit „unschätzbares Material“ für eine Untersuchung der Gründe biete, die schließlich zum Untergang des Römischen Reiches führten.

Weniger Berücksichtigung findet der Euboikos Logos dann bei Michael Rostovtzeff in seinem grundlegenden Werk „Gesellschaft und Wirtschaft im römischen Kaiserreich". Während er auf andere Reden Dions durchaus zurückgreift $^{9}$ und auch dessen Vita als beispielhaft angesprochen wird, ${ }^{10}$ erwähnt er die Euböische Rede nur zweimal. ${ }^{11}$ Ihren Quellenwert für die Wirtschaftgeschichte bewertet er dabei durchaus kritisch. So konstatiert er, dass „die berühmte Beschreibung von Euboea ... natürlich Fiktion" sei. Andererseits sieht er bei der Schilderung der Zustände, insbesondere hinsichtlich der in der Rede erwähnten Entvölkerung weiter Landstriche, die tatsächlichen Verhältnisse wiedergegeben. Für diese Beobachtung zieht Rostovtzeff allerdings zum einen auch weitere Quellen heran, zum anderen betont er, im Gegensatz zu Meyer, dass das Land keineswegs vollständig verödet gewesen sei, eine derartige Einstufung sei übertrieben. ${ }^{12}$ So habe es auch weiterhin in den griechischen Städten durchaus Wohl-

\footnotetext{
${ }^{7}$ Meyer 1924, 166f.

${ }^{8}$ Meyer 1924, 167f.

${ }^{9}$ Rostovtzeff 1929, Bd. 1, 93. 97ff. 102f. 117. 120f. 270. 282-286, Bd.2, 2. 277. 282.

${ }^{10}$ Rostovtzeff 1929, Bd. 1, 97. 102, 270. 282-286

${ }^{11}$ Rostovtzeff 1929, Bd. 1, 205.

12 Rostovtzeff, 1929, Bd. 1, $204 \mathrm{f}$.
} 
stand gegeben, auch wenn dieser vielleicht nicht mehr mit früheren Glanzzeiten vergleichbar gewesen sei. Das einzige weitere Mal, dass Rostovtzeff den Euboikos Logos erwähnt, ist im Kontext der kaiserlichen Reformmaßnahmen zur Förderung des Kleinbauerntums. Er sieht ihn als „beredteste Fürsprache" für dieses Programm an, auf das unten noch genauer einzugehen sein wird. ${ }^{13}$

\section{Utopische Motive und Realitätsbezug}

Zahlreiche Ansätze von Meyer wie Rostovtzeff wurden in den folgenden Jahrzehnten weiter verfolgt - wenn auch mit unterschiedlicher Intensität. In der Diskussion des Euboikos spielten dabei verschiedene Fragestellungen eine Rolle. An erster Stelle stand die bereits von Meyer und Rostovtzeff graduell unterschiedlich beantwortete Frage, in welchem Maße Dion reale Verhältnisse beschreibt und tatsächlich eigene Erfahrungen in der Rede verarbeitet hat. Diesbezüglich sind auch in der Folgezeit unterschiedliche Positionen vertreten worden. Von einer Reihe von Forschern wurde der artifizielle und rein literarische Charakter der Schrift betont. So erklärt es Dorothea Reuter für äußerst unwahrscheinlich, dass Dion tatsächlich den von ihm beschriebenen idealen Ort persönlich aufgesucht habe. ${ }^{14}$ Auch François Jouan geht detailliert auf die seiner Meinung nach im Euboikos vorhandenen romanhaften Züge ein. ${ }^{15}$ Die direkt und indirekt von Dion vorgebrachten Reformvorschläge sieht er als unstrukturiert an und nimmt sie entsprechend nicht ernst. Generell kann er keinen echten Realitätsbezug in der Rede erkennen. ${ }^{16}$ Vielmehr sieht er in ihr ",un oeuvre de pure fiction, composée à des fins precises par l'orateur de Pruse“. Dieser habe sich gängiger literarischer Motive bedient, im Anschluss an die aus den griechischen Romanen bekannten Themen und Konstellationen. ${ }^{17}$ Er geht

\footnotetext{
${ }^{13}$ Rostovtzeff 1929, Bd. 283.

${ }^{14}$ Reuter 1932. - Zur Beschreibung des idealen Lebens in der Natur. Zum Charakter der Schrift s. auch Urban 2004, 33-35. BeKKer NieLSen 2008, 136, betont ebenfalls, dass der Euboikos Logos nicht dem gängigen Muster einer politischen Rede entspricht. Er sieht, 140, im Euboikos " a tone and the same time the political testament of Dion and a resigned retrospective view of his own life“. S. auch ebd. 172, zur Folgerung Dions, dass Familie wichtiger sei als sozialer Status. Vgl. außerdem ebd. 178. Desideri 2000, 101 sieht in der Darstellung im Euboikos eine "highly ideologized and at least partially fantastic reconstruction of his previous life".

${ }^{15}$ S. JouAn 1977. Anderson 2000, 146f., zu den Ähnlichkeiten, aber auch den Unterschieden zu einer romanhaften Erzählung. S. auch HoLzBerg 1993, 243-254.

${ }^{16}$ Vgl. Jouna 1977, 40 zu den Angaben der antiken Historiker im Vergleich mit den Ausführungen Dions.

${ }^{17}$ Jouna 1977, 41 formuliert entsprechend: „,... le récit de l'Euboicos comme un oeuvre de pure fiction, composée à des fins precises par l'orateur de Pruse. Pour cette création, Dion s'est servi de motifs littéraires appartenant en quelque sorte au domaine public, et dont beaucoup se retrouvent dans les romans grecs que nous lisons encore." So geht Jouan
} 
nicht so weit, dem Euboikos Logos tatsächlich Romancharakter zuzuschreiben, doch nutzt seiner Meinung nach Dion dieselben narrativen Techniken. ${ }^{18}$ Jouan sieht die Schilderung Dions zudem nicht als gänzlich realitätsfremd an. Vielmehr betont er ebenfalls die bewusste Verankerung der im Euboikos geschilderten Ereignisse in der Wirklichkeit. ${ }^{19}$ So werde die geographische Lage beschrieben und durch präzise Detailangaben ein realistischer Eindruck erzeugt. Gleichzeitig hebt er aber die moralphilosophische Grundlinie der Erzählung hervor, den betonten Gegensatz zwischen dem idyllischen Leben auf dem Lande und der korrumpierten Lebensweise in der Stadt. Die Schilderung Dions sieht er somit einerseits geprägt durch literarische Vorbilder (u.a. die homerische Odyssee), andererseits aber auch durch mögliche eigene Erfahrungen - wenn auch unter weniger dramatischen Bedingungen als den in der Rede geschilderten. ${ }^{20}$ Auch andere Forscher haben einen mehr oder weniger stark ausgeprägten literarischen Charakter des Werkes angenommen. So spricht Ben Edwin Perry hinsichtlich des Euboikos Logos von einem großartigen Roman. ${ }^{21}$ Gilbert Highet dagegen vermutet als Vorbild für den Euboikos ein heute verlorenes Werk der

auf das Motiv des Schiffbruchs, auf die utopischen Züge der Schilderung, die Themen der phantastischen Reise und der Einsamkeit in einer feindlichen Umwelt sowie auf die Elemente der Liebesgeschichte ein. Dabei verweist er auf Parallelen zu anderen Romanen, wie z.B. zu Daphnis und Chloe. S. hierzu auch H. Hommel, „Das hellenische Ideal vom einfachen Leben“, StudGen 11 (1958) 742-751. Für eine Einschätzung des Euboikos Logos als romanhaft s. auch PERry 1967, 70f. Zur Bedeutung der Landschaft im Rahmen des Euboikos und deren romanhafter Beschreibung s. C. DAUDE, „Paysage et expérience romanesque dans le discours VII („Eubéique” ou le „Chasseur”) de Dion Chrysostome”, in: B. Pouderon, Lieux, décors et paysages de l'ancien roman des origines à Byzance : actes du 2e colloque de Tours, 24-26 octobre 2002 (Lyon 2005).

${ }^{18}$ BEKKER-Nielsen 2008, 138-40, sieht ebenfalls typische fiktionale Elemente im Euboikos - wie das utopische Umfeld, die jungen Liebenden, die Stilisierung der Charaktere, die Einteilung in Episode, die dramatische Entwicklung der Ereignisse im Theater. Er widerspricht dementsprechend einer Deutung als Beschreibung realer Gegebenheiten, auch wenn Dion seiner Meinung nach durchaus auf eigene Erfahrungen zurückgegriffen hat. Im zweiten Sprecher vermutet er sogar das alter ego des Autors, im ersten Redner eine Verkörperung seiner typischen Gegner.

${ }^{19}$ JouAn 1993, 194. In ähnlicher Weise spricht Milazzo 2007, 212 von „un tipo di comunicazione realistica, ma anche soggetiva".

${ }^{20}$ Zur Erzähltechnik und der Frage des Realismus s. Anderson 2000, 147-149 auch zur Frage, in welchem Maße das Bild Euboias zuverlässig ist. Zur Selbststilisierung Dions als "Wanderer" in seinen Reden - und auch am Eingang des Euboikos s. Moles 1978, 97. Vgl. zur Frage der Autopsie auch DANEK 2009, 417-423. S. BRunT 1993, 210-212 zu den autobiographischen Elementen und der Annahme eines Vortrags in Rom. Moles 1995, 177f. geht ebenfalls aufgrund von bestimmten Bezügen von einem Vortrag in Rom aus. Vgl. Moles 2003, 190. Jones 1978, 56 betont die Kritik an außerordentlichem Luxus und vermutet daher, dass die Rede für eine römische Zuhörerschaft bestimmt war. BEKKER-NIELSEN 2008, 136 geht davon aus, dass sie von Dion am Ende seines politischen Lebens verfasst wurde und jedenfalls nicht an eine munizipale Öffentlichkeit gerichtet war.

${ }^{21}$ S. Perry 1967, 70f. 
Neuen Komödie. ${ }^{22}$ Antonino Milazzo wiederum betont die Anklänge an Homer und die idealisierten Gastmahlbeschreibungen sowie das Lob des einfachen Lebens in der Epik. ${ }^{23}$ Vielfach ist in der Forschung auf die novellistischen Elemente der Erzählung hingewiesen worden. ${ }^{24}$ Auch wurde häufig das starke Element der Idealisierung betont. ${ }^{25}$ Die konträre Position, also eine Akzeptanz der Faktizität der Rede, ist ebenfalls verschiedentlich vertreten worden. So sieht Ben Berry in dem Bericht über die ökonomischen Verhältnisse eine Auseinandersetzung mit den realen Gegebenheiten der Zeit. ${ }^{26}$ Die Armut auf dem Lande und die Schwierigkeiten der ärmeren Bevölkerungsschichten in den Städten, ihre Unterdrückung durch die wohlhabenden Bürger, sind für ihn die zentralen Themen des Euboikos Logos. Seiner Meinung nach kennt Dion die Armut aus eigener Erfahrung und entwirft aus diesem Grund Lösungsvorschläge. Auch wenn Berry durchaus Motive der Idylle und auch Elemente der Satire in der Schilderung Dions erkennt, konstatiert er einen „realism which we do not usually associate with orations of the Second Sophistic". In der Beschreibung der Zustände auf Euboia sieht Berry entsprechend eine zutreffende Schilderung von "several symptoms of economic decay in Greece in the second century, both in the country and in the city".

Abschließend sei noch auf diejenigen Forscher verwiesen, die die Euböische Rede zwar als Kommentar zu realen Zeitphänomenen ansehen, aber insgesamt eher als abstrakte Erörterung, die nicht ortsgebunden ist. ${ }^{27}$ So erkennt Jean-Marie Bertrand in keiner Weise Bezüge zu realen Verhält-

\footnotetext{
${ }^{22}$ Highet 1973, 35-40. MA 2000, 110 sieht in der Rede eine Kombination von „,artful protestations of autopsy", phantastischen Elementen, solchen aus der Neuen Komödie, der Hirtendichtung und dem Roman. S. auch 118f. zu den realistischen Elementen.

${ }^{23}$ Milazzo 2007, 163-226. Zum Motiv des Banketts und den literarischen Vorbildern s. Bost-Pouderon 2008, 113-120. Vgl. auch A. Billault, „Paysages de Dion Chrysostome”, in: C. Mauduit / P. Luccioni (eds.), Paysages et milieu naturels dans la litérature antique (Lyon 1998) 123-41.

${ }^{24}$ Moles 1995, 178 sieht idyllische und novellistische Elemente sowie Anklänge an die Neue Komödie, an die Geschichte des Odysseus, an den Mythos vom Goldenen Zeitalter sowie an Platon. Gleichzeitig betont er aber auch die Elemente, die Realismus implizieren sollen - so Dions Verweis auf sein persönliches Erlebnis sowie realistische Bezüge in der Schilderung selbst (u.a. hinsichtlich der Geschichte und der Lebensverhältnisse der Jäger). BEKKER-Nielsen 2008, 138 sieht in der Darstellung „many of the hallmarks of fictional narrative“, darunter die Anklänge an eine Utopie, das junge Liebespaar, die stereotypen Charaktere, die Einteilung der Rede in „Episoden“ sowie die dramatische Auflösung im Theater. S. auch Anderson 2000, $147 \mathrm{zu}$ den typischen Elementen einer Novelle. BRENK 2000, 271, spricht von „a curious mixture of contemporary reality and fictional/mythical themes". Auch er erkennt Elemente der Novelle in der Erzählung. Vgl. Alcock 1993, 30; Canevari 1962, 16-18.

${ }^{25}$ Zur Darstellung der idealen Gemeinschaft bei Dion s. Jones 1978, 56-64. Zur Idealisierung der Lebensweise des Jägers BRENK 2000, 272-274.

${ }^{26}$ BERry 1983, 70-80.

${ }^{27}$ Moles 1995, 178 spricht insgesamt von „knowing irony and fictionality“, gleichzeitig aber auch von einer Verankerung im realen Leben.
} 
nissen auf Euboia. Es handelt sich seiner Auffassung nach beim Euboikos Logos um den reinen Entwurf einer Utopie, die von Dion im Kontext seines politischen Programms entworfen werde. ${ }^{28}$ Rüdiger Vischer sieht im Lob des naturverbundenen Lebens das zentrale Motiv der Rede ${ }^{29}$ und als wichtige Themen u.a. die Gastfreundschaft, die Selbstbeschränkung sowie das Verhältnis zwischen Familie und Gesellschaft bzw. Staat sowie die aus Bedürfnislosigkeit resultierende innere Freiheit. ${ }^{30}$ Auch von anderen Forschern ist die Rede primär als Lob der Autarkie verstanden worden. ${ }^{31}$ Adolf Ritter ordnet den Euboikos in den Kontext der übrigen Reden Dions ein und setzt dessen Themen in Beziehung zu den dort propagierten Idealen. So würden von Dion generell die Armut und Tugendhaftigkeit gelobt sowie die innere Freiheit - unabhängig vom sozialen Stand - als Ziel des menschlichen Lebens gesehen. In den Zusammenhang dieser generellen Grundauffassung stellt Ritter auch den Euboikos Logos bzw. das dort zu findende Lob des einfachen Lebens auf dem Lande, das noch nicht durch die städtische Lebensweise korrumpiert ist. Es handelt sich also auch seiner Meinung nach eher um ein bewusst von Dion entworfenes, moralisierendes Gegenbild zu realen Zuständen als um eine tatsächliche Zustandsbeschreibung des Lebens der Landbevölkerung. ${ }^{32}$ Der zugespitzte Gegensatz zwischen Stadt und Land ist vielfach als dominierendes Thema der

\footnotetext{
${ }^{28}$ Bost-Pouderon, 2008.

${ }^{29}$ VIsCHER 1965, 157-179. Er sieht bei Dion eine Aufforderung zum Leben in der Natur zurückzukehren. Ausführlich geht er, 151-162, auf die Kontrastierung zwischen der bedürfnislosen Lebensweise in der Natur und dem degenerierten Leben in der Stadt ein. Dabei verweist er auch auf die philosophisch-literarischen Vorbilder.

${ }^{30}$ VIscher 1965, 162-70. Als fundamentale Werte sieht Vischer bei Dion den Gleichheitsgedanken und gleichzeitig ein Pflichtbewusstsein gegenüber der Gemeinschaft. Entsprechend steht für ihn Dion in stoischer Tradition. Auf die Bedeutung wirtschaftlicher Fragen geht Vischer nur kurz ein (167-168). Im Zuge seiner Erörterung betont er besonders das im Euboikos zu findende Lob einer autarken Lebensweise und die Ablehnung der Geldwirtschaft. Außerdem thematisiert er kurz die Wertung der Arbeit durch Dion. Er habe dieser einen ethischen Wert beigemessen und entsprechend zum einen gefordert, dass jeder einer Beschäftigung nachgehe, zum anderen der Art des Berufes eine große Bedeutung zugeschrieben. Zum Euboikos, dem Lob des einfachen Lebens und der Arbeit s. von ArNim 1898, 492-504. S. auch Moles 1995, 178, zum zentralen Thema, dem einfachen und autarken Leben.

${ }^{31}$ S. BRENK 2000, 262-265 zum Konzept der autarkeia bei Dion und dem dahinterstehenden kynischen und stoischen Gedankengut (und Abweichungen davon). $\mathrm{Zu}$ den diesbezüglichen Äußerungen im Euboikos s. 270-278. Wie er feststellt, beinhaltet die autarkeia bei Dion durchaus die Einbindung in familäre Abhängigkeiten.

32 Ritter 1988, 140 sieht als wichtigste Themen der "Moralpredigt“ die lobende Wertung von Armut und Tugend. Letztere umfasse nach Dion das vollkommene Glück und bringe die innere Freiheit, d.h. die Unabhängigkeit von den äußeren Lebensumständen. Außerdem sei das Lob des einfachen Lebens zentral, wie u.a. in der Schilderung des Lebens der Jäger deutlich werde. Als wichtigste Themen der Rede sieht JonEs ebenfalls die Vereinbarkeit von Tugend mit Armut bzw. Arbeit sowie ein Lob des Landlebens. S. auch Jones 1978, 56.
} 
Rede gesehen worden, so auch von Tonnes Bekker Nielsen. Dieser konstatiert gleichzeitig eine von Dion befürchtete „Verländlichung“ der Polis. ${ }^{33}$ Auch Paolo Desideri thematisiert ausführlich die Idealisierung des Landlebens im Euboikos. ${ }^{34}$ Er propagiert einen „,ideological way of reading the entire text". Die Stadt werde einerseits als Ort des Zusammenlebens zu vieler Menschen und des Konflikts, andererseits als Raum der Geldwirtschaft präsentiert, in dem es für die Armen nur wenige Möglichkeiten gebe. ${ }^{35}$ Auch John Ma betont die ideologische Konzeption der Polis und das von Dion betonte mangelnde Verständnis zwischen Stadt und Land sowie den Gegensatz zwischen den beiden Welten. ${ }^{36}$ Wie er herausstellt, wird - entgegen der Vorstellungen des Aristoteles - das Leben außerhalb der Polis idealisiert. ${ }^{37}$ Weitere Forscher haben zumindest in eine ähnliche Richtung argumentiert. So bestehen für Paul Mazon die Grundzüge des Werkes in der Ausmalung der bukolischen Szenerie, einer stoischen Eröterung und einem moralischen Appell. ${ }^{38}$ Eugen Braun wiederum betont den Einfluss kynischer und stoischer Gedanken sowie den Einfluss der Vorstellungen von einem Goldenen Zeitalter. Der Euboikos Logos ist seiner Auffassung nach durchaus moralphilosophisch orientiert. Wie er hervorhebt, sind die Motive des Goldzeitaltermythos jedoch eng mit der realistisch geprägten Schilderung verbunden. Die Beschwörung einer idealen Zeit diene v.a. dazu, die Rede stilistisch reizvoll zu gestalten; im Hintergrund stünden dementsprechend „,sozialkritische Intentionen “ und die Absicht Dions, die Möglichkeit eines anderen Lebensentwurfs aufzuzeigen. ${ }^{39}$ Auch Peter Brunt sieht das primäre Ziel Dions bzw. des Euboikos

\footnotetext{
${ }^{33}$ BeKKer-Nielsen 2008, 45-46 zum Gegensatz von Stadt und Land im Euboikos - und gleichzeitig der dort ausgedrückten Befürchtung, dass die Stadt ihren Charakter verliert und zu einer ländlichen Siedlung wird.

${ }^{34}$ Desideri 2000, 99. BeKKeR-Nielsen 2008, 178 zur im Euboikos beschriebenen Idylle bzw. dem Kontrast zwischen Stadt und Land.

${ }^{35}$ Desideri 2000, 95 sieht in den Äußerungen Dions zu Stadt und Land seine Art, den Niedergang der Polis in seiner Zeit zu reflektieren. Diese sei seiner Auffassung nach nicht mehr der ideale Ort menschlichen Zusammenlebens sondern vielmehr das Land. Vgl. ebd. 102, zum Land als Metapher für Freiheit, zur Stadt als Metapher für Sklaverei. Vgl. bereits M. SzarmaCh, „De oratione Dionis VII quid iudicandum”, Meander XXXII (1977) 189-195. Zum Lob des Landlebens s. auch BRunt 1993, insb. 215-216.

${ }^{36}$ Ma 2000, 114-117. Brenk 2000, 271 sieht bei Dion allerdings auch eine gegenseitige Abhängigkeit von Stadt und Land.

${ }^{37}$ Zur Propagierung des Landlebens als Ideal einer freien und natürlichen Lebensweise S. Desideri 2000, 100f. S. auch - allerdings in Bezug auf andere Reden O. ANDreI, „Il tema della concordia in Dione di Prusa (or. XXXVIII, XXXIX, XL, XLI). Ceti dominanti ed ideologia nel II sec. d. C.”, SRISF 1 (1981) 89-120; A. Bravo Garcia „Notas sobre el tema de la concordia en Dio de Prusa“, Habis 4 (1973) 82-92, A. R. R. Sheppard „Homonoia in the Greek Cities of the Roman Empire", AncSoc 15-17 (1984) 229-52.

${ }^{38}$ Mazon 1943, 47-80.

${ }^{39}$ E. Braun sieht Dion durchaus als Realisten (E. BRAUn, „Der Jäger und die Goldene Zeit. Anmerkungen zu D. Chr. or. 7“, in: M. Ваumbach / H. Köhler / A.M. Ritter (eds.),
} 
Logos darin, zeitgenössische, v.a. stoische Vorstellungen über Armut und Arbeit zu vermitteln. ${ }^{40}$

\section{Der Euboikos als Quelle für die ökonomischen Verhältnisse}

Bei allen bisher genannten den Euboikos Logos betreffenden Wertungen mit Ausnahme der etwas ausführlicheren Darlegungen von Meyer - handelt es sich nur um kürzere Erwähnungen der Rede in anderen Kontexten bzw. um Analysen, die weniger die wirtschaftsgeschichtliche Relevanz des Textes betreffen. Auch beschränken sich die Betrachtungen meist auf den ersten Teil der Rede, die Geschichte des Jägers. Eingehender setzte sich John Day in seinem 1951 erschienen Aufsatz „The Value of Dio Chrysostom's Euboean Discourse for the Economic Historian" mit der wirtschaftlichen und sozialen Lage auf Euboia auseinander. ${ }^{41}$ Dabei geht allerdings auch er weniger auf die Angaben im Euboikos Logos ein als vielmehr auf die archäologischen Befunde und die übrigen literarischen wie epigraphischen Zeugnisse. Day diskutiert entsprechend in seinen Darlegungen weniger die konkreten Einzelaussagen bei Dion. Vielmehr geht es ihm darum, die seiner Meinung nach in der Forschung verbreitete zu hohe Wertschätzung des Euboikos Logos als wirtschaftsgeschichtliche Quelle zu korrigieren. ${ }^{42}$ Seiner Ansicht nach ist die Argumentation einer Reihe von Forschern problematisch, wenn sie zum einen auf die teilweise auch andernorts im Griechenland dieser Zeit zu beobachtenden Verarmungsten-

Mousopolos Stephanos. FS für Herwig Görgemanns (Heidelberg 1998)). So sei das idyllische Leben der Jäger wie auch deren vorbildliche moralische Grundhaltung nicht als utopisches Ideal konzipiert. Dies belegt seiner Ansicht nach die zweite Hälfte des Euboikos Logos. Als Anregung für Dion sieht Braun die Beschreibung der Polis bzw. ihrer Geschichte bei Platon. So basiere das Glück der Jäger nicht auf Reichtum, sondern vielmehr auf der inneren Zufriedenheit. Dagegen werde das Streben nach Besitz bei Dion als Grund für innere Konflikte gesehen. Prinzipiell sieht Braun hinter Dions Äußerungen eine "stoisch-kynische Individualethik", auf der auch seine Kritik an den gesellschaftlichen Verhältnissen basiere. Zum kynischem Einfluss bei Dion s. auch Urban 2004, 45-49. Zu den verschiedenen Ansätzen einer philosophischen wie utopischen Ausdeutung der Rede s. auch Milazzo 2007, 165-168. S. zudem Bost-Pouderon 2008, 105-122 zu den utopischen Elementen bzw. Motiven des Goldenen Zeitalters sowie philosophischen Bezügen im Euboikos (im Vergleich auch mit der 35. Rede).

${ }^{40}$ BRUNT 1993 sieht eher stoische Einflüsse als kynisches Gedankengut. So weist er darauf hin, dass die im Euboikos beschriebene Familie nicht betteln müsse, sondern sogar noch etwas abgeben könne. Zu den stoischen Quellen bzw. Vorbildern s. ebd. 224-233. Zum Einfluss der Stoa s. bereits von Arnim 1898, 476-491. Moles 1995, 179 sieht bei Dion kynische, aber auch sokratische und platonische Elemente der Selbststilisierung.

${ }^{41}$ Day 1951, 209-235. Zu Day s. auch JouAn 1977, 40.

${ }^{42}$ So verweist er, 212, darauf, dass in der philologischen wie althistorischen Forschung (z.B. bei Meyer) der fiktionale und moralisierende Charakter der Rede zwar durchaus erkannt, ihr aber dennoch auch ein realer Quellenwert zugeschrieben werde. 
denzen verweisen, zum anderen den Euboikos Logos als Beleg dafür heranziehen, dass es sich hierbei um ein allgemeines Zeitphänomen handele. ${ }^{43}$ Den Schwerpunkt seiner Untersuchung legt Day dann darauf, die Aussagen des Euboikos Logos zu widerlegen. Er zeichnet auf der Basis v.a. literarischer und epigraphischer Quellen die wirtschaftsgeschichtliche Entwicklung Euboias nach und kommt zu dem Schluss, dass die Wirtschaftskraft dort zwar abgenommen habe, doch die Städte insgesamt noch wohlhabend gewesen seien. Auf Basis der Angaben Dions bzw. eines in der Rede auftretenden Rhetors kommt er zu dem Schluss, dass es auf Euboia auch in der Zeit Dios noch wohlhabende Personen und auch größere Güter gegeben habe. Auch gibt es seiner Ansicht nach keine Hinweise darauf, dass größere Teile des Landes nicht bearbeitet worden seien. Day sieht es daher letztlich als Dions Absicht an, in der Rede eine Utopie zu entwerfen. ${ }^{44}$ Das abschließende Urteil, das Day über den Wert des Dion als wirtschaftshistorische Quelle fällt, ist dementsprechend vernichtend: Es habe zwar die von Dion geschilderten Verhältnisse in Teilen des Reiches gegeben, „but the economic historian should not utilize the Euboean Discourse as evidence for conditions in Euboea or for any other specific place. ${ }^{\prime 45}$ Diese Einschätzung hat in der Folgezeit die Rezeption der Euböischen Rede stark geprägt. Sie ist in den folgenden Jahrzehnten kaum mehr dezidiert und ausführlich als für die Wirtschaftsgeschichte relevante Quelle diskutiert worden. ${ }^{46}$ Als eine zuverlässige Quelle nicht nur für die Verhältnisse auf Euboia sondern für ein reichsweit zu beobachtendes Phänomen des Bevölkerungsrückgangs ist die Rede nur noch selten, z.B. von Sirago, bewertet worden. ${ }^{47} \mathrm{C}$. P. Jones bezog in dieser Frage immerhin noch eine eher ausgleichende Position. Zum einen kann der Euboikos Logos seiner Meinung nach einen Einblick in die Verhältnisse auf dem Land und in der Stadt bieten. ${ }^{48}$ Andererseits konstatiert Jones, dass „many of the ingredients of this idyll have a literary flavor: some resemble the drama, especially the New Comedy, others recall conventional descriptions of rustic or primitive vir-

\footnotetext{
${ }^{43}$ DAy 1951, 212f. Day betont in diesem Zusammenhang zu Recht, dass sich die Verhältnisse in den Provinzen des Reiches generell nicht vergleichen ließen bzw. sehr unterschiedlich sein konnten.

${ }^{44}$ DAY 1951, 212.

${ }^{45}$ DAY 1951, 235.

${ }^{46}$ KeIl 1969, 564, zu einer kritischen Einschätzung der Angaben Dions.

${ }^{47}$ Harris 1991, 38-69.

${ }^{48}$ Jones 1978, 61. Zudem sei es übertrieben anzunehmen, dass Dion nie Euboia besucht habe - Jones verweist zudem darauf, dass das von Dion entworfene Bild eines wirtschaftlichen Niedergangs in den Schilderungen des Plutarch eine Bestätigung findet. An anderer Stelle betont Jones, 64, dass Dion zwar auf eigene Erfahrung zurückgreife, „but tined with utopian ideals". Bezüglich der persönlichen Elemente der Darstellung betont Jones die Verbindung mit den stoischen Grundüberzeugungen Dions und seinen teilweise unerfreulichen politischen Erfahrungen in Prusa.
} 
tue." 49 Bemerkenswert ist auch, dass der Euboikos Logos bei Wirtschaftshistorikern wie z.B. Moses Finley und Richard Duncan-Jones keine große Rolle spielt. So kommt Finley in seinem Werk „Die antike Wirtschaft“ nur einmal und dann nur in einer Fußnote auf Dion von Prusa zu sprechen. Es ist dann aber eben nicht die Euböische Rede, sondern die 79. Rede, die von Finley im Rahmen einer Diskussion des Handels mit Luxusgütern herangezogen wird. ${ }^{50}$ Von Richard Duncan-Jones wird ebenfalls meist nur knapp auf die Reden Dions verwiesen, die generell als Quelle für die Verhältnisse der Kaiserzeit nur wenig herangezogen und genutzt werden. Die wenigen zu benennenden Ausnahmen betreffen Angaben zu Bithynien ${ }^{51}$ oder zu sozialen Unruhen. ${ }^{52}$ Auch die Person Dions wird mehrmals thematisiert, d.h. seine privaten Vermögensverhältnisse sowie seine soziale Stellung werden beispielhaft für die gesellschaftlichen Verhältnisse seiner Zeit angesprochen. ${ }^{53}$ Auch hier findet aber keine eingehende Analyse der Reden statt. So kommt Duncan-Jones in seinem Werk „Structure and Scale in the Roman Economy" nur in einer Fußnote auf Dion zu sprechen und auch hier nur auf dessen Karriere. ${ }^{54}$ Nur selten thematisiert DuncanJones direkt den Euboikos Logos. So wird diese Rede von ihm - wenn auch erneut nur in einer Anmerkung - im Kontext einer Erörterung der Bürgerrechtsfrage mit Blick auf die kaiserzeitlichen Poleis erwähnt. Er verweist hier auf die Angabe Dions, dass auch ein armer Bauer, der auf dem Gebiet einer Stadt lebt, Inhaber von deren Bürgerrecht sei, da er ja auch berechtigt sei, an der dort durchgeführten sportulatio zu partizipieren. Duncan-Jones bewertet diese Angabe allerdings als nicht zuverlässig und bemerkt, dass die Verteilung sich wohl auf diejenigen beschränkt habe, die innerhalb der Stadtmauer lebten. ${ }^{55}$ Auch Geoffrey de Ste. Croix hat sich mit dieser Frage bzw. der entsprechenden Passage bei Dion auseinandergesetzt, kommt allerdings ebenfalls zu dem Schluss, dass die auf dem Lande lebende Bevölkerung wohl selten von Geldverteilungen profitierte. ${ }^{56}$ Als letztes Beispiel

\footnotetext{
${ }^{49}$ Zum Vergleich mit der Olbischen Rede s. Jones 1978, 61-63, zum Verweis auf möglicherweise ähnliche Vorstellungen in seiner Rede über die Essener s. 63f.

${ }^{50}$ Finley 1993, 155 - zu Luxusgütern erfolgt ein Verweis auf or. 79, die allerdings v.a. auf die Verhältnisse in Rom zielt.

${ }^{51}$ Duncan-Jones 1974, 84, 88, 262 Anm. 1 (zu Bithynien).

52 Duncan-Jones 1978, 38, Anm.3, 346 (zu Versorgungskrisen und diesbezüglichen Gegenmaßnahmen).

${ }^{53}$ Duncan-Jones 1978, 21, Anm. 4 (zu Dions persönlichen Verhältnissen); 37, Anm.2 (zu Dions privaten Verhältnissen).

${ }^{54}$ Duncan-Jones 1990, 164, Anm. 37

${ }^{55}$ Duncan-Jones 1990, 259, Anm. 1; vgl. Jones 1978, 60.

${ }^{56}$ Ste. Croix 1981, 18 diskutiert ebenfalls die Frage des Anrechts auf die Zuteilung. Er betont, dass im Osten die Bauern häufig nicht Bürger der Polis waren und daher selten von Verteilungen profitiert hätten. In diesem Zusammenhang führt er ebenfalls die Aussage bei Dion an, dass die Teilhabe an den Zuteilungen Anzeichen für den Besitz des Bürgerrechtes ist. Er verweist in diesem Zusammenhang auf ein bithynische Inschrift (IGGR II,69), die
} 
kann Thomas Pekáry genannt werden, der sich in seiner Abhandlung zur antiken Wirtschaftsgeschichte lediglich auf Angaben in den Reden Dions bezieht, die Hungerrevolten oder Preissteigerungen betreffen. ${ }^{57}$ In weitaus stärkerem Maße als der Euboikos Logos - und hierauf sei nur kurz verwiesen - sind generell die Städtereden Dions als Quellen für die Wirtschaftsgeschichte der hohen römischen Kaiserzeit herangezogen worden. Dies gilt bereits für die Arbeiten von Michael Rostovtzeff, aber auch für die Analysen von A.H.M. Jones. ${ }^{58}$ Als weitere Autoren, die sich u.a. auf die Reden Dions stützen, sind David Magie und Ramsey MacMullen zu nennen. ${ }^{59}$ In besonderem Maße werden die Angaben in den Reden Dions für die Wirtschaftsgeschichte Bithyniens ausgewertet, ${ }^{60}$ aber auch weitere Reden Dions werden für die jeweiligen lokalen Gegebenheiten herangezogen. ${ }^{61}$ Der Grund für die mangelnde Berücksichtigung des Euboikos Logos liegt, wie bereits oben angesprochen, darin, dass die Zuverlässigkeit der Angaben Dions bezüglich der wirtschaftlichen Lage Euboias stark in Zweifel gezogen worden sind. Ein allgemeiner Niedergang der griechischen Poleis im 2. Jahrhundert ist in der neueren Forschung zunehmend in Frage gestellt worden. ${ }^{62}$ Ma sieht die Darstellungen des Niedergangs im Euboikos ebenfalls eher als ",stereotypes documenting perceptions rather than realities", wobei er insbesondere auf die archäologischen Befunde in Karystos verweist. ${ }^{63}$ Weiterhin betont er, dass sich die Angaben weder im Erzählbericht Dions noch in der Darstellung des Jägers finden sondern vielmehr in der Rede des Rhetors in der Volksversammlung. Dieser habe möglicherweise

eine entsprechende Praxis belegt - allerdings mit dem Hinweis, dass es sich um das einzige Zeugnis für eine Verteilung auch an die Landbevölkerung handele.

${ }^{57}$ PÉKARY 1979, 90 zu bei Dion erwähnten Hungerrevolten; s. S. 99 zu bei Dion erwähnten Preisanstiegen für Lebensmittel; S. 101 zum Verweis auf or. 46,10 für verschieden hohe Preise.

${ }^{58}$ S. Jones 1940; vgl. ders. 1937.

${ }^{59}$ Magie 1950, 570. 577. 581. 588-590. 599f. $602 \mathrm{zu}$ den Verhältnissen in Bithynien; MACMulLEN 1966, 163-191, zu städtischen Unruhen.

${ }^{60}$ So von E. GRen, Kleinasien und der Ostbalkan in der wirtschaftlichen Entwicklung der römischen Kaiserzeit (Uppsala / Leipzig 1941); s. auch BEKKER-NIELSEN 2008.

${ }^{61}$ So bei DAY 1973, 178, 180 (allerdings kritisch den Angaben Dions gegenüber).

${ }^{62}$ Zur Lage der griechischen Städte in der römischen Kaiserzeit s. die differenzierten Ausführungen von C. Leppeley, Rom und das Reich in der Hohen Kaiserzeit (München 2001) 218-339. S. Аьсоск 1993, 24-32, zu den Quellen für die wirtschaftliche Situation Griechenlands in der Kaiserzeit - und deren Problematik. Eher von einem Niedergang in der Kaiserzeit ging noch U. KAнRSTEDT, Das wirtschaftliche Gesicht Griechenlands in der Kaiserzeit (Bern 1954) aus. Für einen allgemeinen Überblick über die wirtschaftliche Entwicklung Griechenland s. J. A. O. Larsen „Roman Greece”, in: T. Frank (ed.), An Economic Survey of Ancient Rome, Bd. IV (Paterson 1959) 259-496. Zur Darstellung der wirtschaftlichen Lage Griechenlands bei Dion s. auch N. MÉTHY "Dion Chrysostome et la domination romaine", AC 63 (1994) [173-192] 182f.; vgl. D. PLÁcIDo „El mundo griego en época de Trajano”, in: J. Alvar / J. M. BlánQuez (eds.), Trajano (Madrid 2003) 139-154.

${ }^{63}$ MA 2000, 109. 
einzelne Elemente bewusst übertrieben. Er urteilt daher, dass es bei Dion nicht um eine Darstellung der Polis sondern um eine Diskussion von Bildern der Stadt gehe. Kritisch hat sich auch bereits Susan Alcock mit der These eines wirtschaftlichen Niedergangs Griechenlands in der Kaiserzeit auseinandergesetzt. Sie sieht das Bild, das die antiken Autoren vom kaiserzeitlichen Griechenland zeichnen, durch das „disappointment of élite tourists" bedingt. ${ }^{64}$ Diese hätten die griechischen Poleis mit dem Ideal einer Stadt bzw. insbesondere auch mit den großen Städten außerhalb Griechenlands wie z.B. Rom verglichen. ${ }^{65}$ Nach Meinung Alcocks spiegelt die Rede also nicht so sehr die Realität als vielmehr zeitgenössische Wahrnehmungen und Befürchtungen - auch angesichts der zunehmenden Konzentration von Grundbesitz in den Händen der Elite. ${ }^{66}$ Zudem verweist sie darauf, dass sich gerade auch für den Süden Euboias Zeugnisse einer wirtschaftlichen Blüte finden. ${ }^{67}$ Immerhin sieht sie die Angaben im Euboikos Logos bezüglich der dortigen Wirtschaftsweise als zuverlässig an. ${ }^{68}$ Generell lässt sich jedoch feststellen, dass in der wirtschaftsgeschichtlichen Diskussion stets die Bithynischen Reden eine stärkere Rolle gespielt haben. Eine Verbindung der in diesen zu findenden Schilderungen mit denjenigen in der Euböischen Rede könnte sich für die Zukunft als fruchtbarer Ansatz erweisen. Auch wären in künftige Untersuchungen die Ergebnisse der neueren

\footnotetext{
${ }^{64}$ S. auch die Angaben des „anständigen“ Redners im Euboikos.

65 S. Aьсоск 1993, 29. Sie sieht, 30, in der Rede eher ein Plädoyer das Leben in Einfachheit,
} eine Darlegung über die Vereinbarkeit von Armut und Tugend. Wie sie konstatiert, fehlen jedoch Belege, die den Bericht Dions stützen würden.

${ }^{66}$ Alcock 1993, 30; sie sieht, 85f., gerade im Euboikos Hinweise für eine Akkumulation von Besitz in den Händen weniger. Dies führte ihrer Ansicht nach zu der bei Dion angesprochenen Verödung des Landes bzw. zu dem Rückgang der auf dem Land lebenden Bevölkerung. Die Großgrundbesitzer hätten dazu tendiert, ihren Lebensmittelpunkt in die Polis selbst zu verlegen. Auch die Art der Nutzung des Landes habe sich dementsprechend verändert, da es von diesen eher extensiv als intensiv bewirtschaftet worden sei. Bedingt durch die Größe des Besitzes hätten diese Teile des Landes auch weniger intensiv genutzt - z.B. durch Weidewirtschaft - bzw. sogar, wie im Euboikos beschrieben, völlig vernachlässigt.

${ }^{67}$ Alcock 1993, 101. Sie konstatiert, dass zwar offenbar die Besiedlung auf dem Land zurückgegangen sei, in Karystos aber neue zivile wie religiöse Bauten nachzuweisen seien. So geht sie eher von einer - auch durch den Abbau des Cipollino-Marmor bedingten - Blüte der Stadt aus. Als Parallelen werden von ihr u.a. zudem Melos und Tanagra angeführt. Für die wirtschaftlich gute Lage von Karystos. S. auch PICARD 1979, 212-213.

${ }^{68}$ Alcock 1993, 114-116, konstatiert auf der einen Seite die mögliche Tendenz zu einer verstreuteren Siedlungsweise auf dem Land - regional auch bedingt durch den Verlust der politischen Unabhängigkeit und Mitbestimmung und damit einhergehend eines Bedeutungsverlustes der Polis als politischen Zentrums. In diesem Zusammenhang verweist sie auch auf den Euboikos Logos. Andererseits verweist sie aber auch auf Faktoren, die eine verstärkte Ansiedlung in den Städten begünstigten wie das Interesse der Großgrundbesitzer, ein angenehmeres Leben in der Polis zu führen, aber auch wirtschaftlichen Druck und Suche nach Einkommensmöglichkeiten (mit Hinweis auch auf die Bemerkungen Dions in or. 35,16$)$. 
archäologischen Forschung stärker einzubeziehen als dies bisher geschehen ist. $^{69}$

\section{Die Rede als Quelle für die politischen Verhältnisse}

Der Euboikos Logos wird in der Forschungsdiskussion der letzten Jahrzehnte immerhin partiell im Kontext verschiedener anderer Fragestellungen als Quelle gewürdigt. So ist neben den die Landwirtschaft betreffenden Reformansätzen auch die Beschreibung der Stadt und der dortigen politischsozialen Verhältnisse in der Forschung aufgegriffen worden. ${ }^{70}$ Bereits bei Meyer ist dies der Fall, der betont, dass die geschilderte Polis die für diese Zeit typischen Charakteristika aufweist. Dies galt seiner Meinung nach für die politisch-soziale Struktur wie für die äußere Gestalt der Stadt und ihre wirtschaftliche Lage. Bezüglich letzterer wird von ihm hervorgehoben, dass die Einwohner ihren Unterhalt mit Handel und Handwerk verdienen, daneben aber auch Kleinvieh besitzen, das innerhalb der Stadtmauern weidet. Hinsichtlich der Besitzverhältnisse sieht er es als typisch an, dass das Land Eigentum von Großgrundbesitzern ist, die darauf Ackerbau und Viehzucht betreiben. Auch andere Forscher haben die im Euboikos Logos beschriebenen gesellschaftlichen Hierarchien und politischen Strukturen in den Blick genommen. So ist John Ma zu der Auffassung gekommen, dass im Euboikos die in der Kaiserzeit übliche Verfahrensweise in der Ekklesia geschildert wird. ${ }^{71}$ Als Beleg für einen hohen Grad an Realismus

\footnotetext{
${ }^{69}$ Die archäologische Forschung der letzten Jahrzehnte hat zudem gezeigt, dass für das Griechenland des 2. Jahrhunderts durchaus von einer verstärkten Bautätigkeit auszugehen ist. Vgl. R. Dalongeville / M. Lakakis / A. Rizakis, Paysages d'Achaie. Le bassin du Peiros et la plaine occidentale (Athen 1992); C. FLÄMIG, Grabarchitektur der römischen Kaiserzeit in Griechenland (Leidorf 2007) (zur Grabarchitektur); s. auch die Spezialuntersuchungen von J. Bergemann, Die römische Kolonie von Butrint und die Romanisierung Griechenlands (München 1998); J.M. Fossey, Boetia Antiqua (Amsterdam 1989-1996); A. Schachter, Cults of Boiotia (London 1981-1994).

${ }^{70}$ So auch bei SALMERI 1982, 82-87, wenn dieser auch im Kontext der Erörterung der politischen Verhältnisse nur knapp auf den Euboikos Logos zu sprechen kommt. Nur ein kurzer Verweis findet sich auch bei Desideri 1991b, 3952. Zur Beschreibung der Stadt s. Jones 1978, 58. Zur rhetorischen Strategie, der Haltung gegenüber der Polis allgemein s. M. H. Quet „Rhétorique, culture et politique. Le fonctionnement du discours idéologique chez Dion de Pruse et dans les Moralia de Plutarque", DHA IV (1978) 51-119.

${ }^{71}$ MA 2000, 108-124. Er sieht in der Darstellung Rückgriffe auf die typische athenische Volksversammlung - so die bedrohlich erscheinende Rolle der Masse, das Rederecht jedes Bürgers, die Art der Entscheidungsfindung in der Volksversammlung. Auch in den Reden der einzelnen Rhetoren sieht er eine Widerspiegelung bestimmter Typen und Einstellungen. So bringe der erste Redner die Kritik an reichen Bürgern, die sich nicht engagieren, zum Ausdruck. Der zweite Redner sei gemäßigter, ziele mehr auf die Belange der Polis, orientiere sich dabei aber an den demokratischen Spielregeln und übertreibe daher bei seiner Beschreibung der Zustände auf Euboia. Zum Verlauf der Volksversammlung s. JonEs 1978, 58-61. Auch Moles 1995, 178, sieht die Schilderung der städtischen Zustände als rea-
} 
der Beschreibung führt er die Reden Dions in Prusa an. ${ }^{72}$ Auch dort zeige sich, dass die Honoratiorenschicht mit der Versammlung eher verhandle und diese nicht dominiere. Des weiteren zieht er epigraphische und papyrologische Quellen heran, die seiner Meinung nach belegen, dass die gängigen Verfahrensweisen und auch die Argumentationsstrategien den von Dion geschilderten entsprachen. ${ }^{73}$ Beispielhaft können noch die Untersuchungen von Arjan Zuiderhoek genannt werden, der ebenfalls die Beschreibungen in der Euböischen Rede im Rahmen seiner Analyse heranzieht. ${ }^{74}$ So diskutiert er in seiner Untersuchung zur Lage der griechischen Polis in der römischen Kaiserzeit den im Euboikos geschilderten Ablauf der Volksversammlung. Auch er sieht - wenn auch mit gewissen Vorbehalten - die Beschreibung Dions als eine Wiedergabe der realen Verhältnisse an. Generell betrachtet Zuiderhoek die Reden Dions - wie auch die Schriften des Plutarch - als Zeugnisse für die auch in der Kaiserzeit noch gegebene politische Bedeutung der Volksversammlung in den griechischen Poleis und ihre weiterhin zentrale Rolle. ${ }^{75}$ Er sieht auch in der bei Dion gegebenen Schilderung der Zusammensetzung der Volksversammlung einen Reflex realer Verhältnisse. So stimme es mit den Gegebenheiten überein, dass die Mehrzahl der Anwesenden Handwerker und Händler war. Die Tatsache, dass im Euboikos die Bauern und Jäger trotz ihres Bürgerrechts nur selten die Stadt besuchen und an den öffentlichen Versammlungen teilnehmen, sieht er als Beleg dafür, dass in diesen mehrheitlich Angehörige nicht-agrarischer Berufsgruppen saßen. ${ }^{76}$ Darüber hinaus zieht Zuiderhoek Reden Dions als Beleg für innere Unruhen in den Poleis der Kaiserzeit heran. ${ }^{77}$ Auch im Kontext der Analysen der politischen Strukturen im griechischen Osten wird, so lässt sich jedoch feststellen, die Euböische

listisch an, so betont er die korrekten Formulierungen in dem Ehrendekret. Vgl. auch Anm. 80 zur Übersetzung.

${ }^{72}$ MA 2000, 119-122 verweist zudem auf Inschriften, die das Fortbestehen demokratischer Institutionen und solcher Praktiken, wie sie im Euboikos beschrieben werden, in dieser Zeit belegen.

${ }^{73}$ BeKKer-Nielsen 2008, 138 wendet sich zwar gegen eine Wertung der Rede als Beschreibung tatsächlicher Ereignisse bzw. Orte und betont diesbezüglich die Unterschiede zur Borysthenischen Rede. Entsprechend betrachtet er die von Dion beschriebene Stadt als Fiktion. Allerdings habe Dion bei diesem Entwurf auf reale Erfahrungen zurückgegriffen. Als weitere Inspirationsquelle sieht Bekker-Nielsen die Beschreibung der Phäakenstadt bei Homer.

${ }^{74}$ ZUIDERHOEK 2008, 417-445.

75 Zuiderhoek 2008, 433 sieht "evidence for the continuing importance, vitality, and decision-making powers of the public assemblies".

${ }^{76}$ Zuiderhoeк 2008, 439. Er verweist in diesem Zusammenhang auf die von Dion in Prusa gehaltenen Reden. Wie er feststellt, nahmen in der Kaiserzeit v.a. Handwerker und Händler, also die Angehörigen der collegia, an der Volksversammlung teil. Dementsprechend wäre die Beschreibung Dions zutreffend.

77 Zuiderhoeк 2008, 442 zu den auch für Kleinasien von Dion beschriebenen städtischen Unruhen. Desideri 2000, 106 betont allerdings, dass von Dion das Recht und die Pflicht 
Rede - wenn überhaupt - dann meist nur kurz als mögliche Quelle angesprochen. Konkreter ist die Rede immerhin von Bekker-Nielsen gedeutet worden. Er sieht im zweiten Redner das alter ego Dions. ${ }^{78}$ In den extremen und aggressiven Äußerungen des ersten Redners sieht er eine Widerspiegelung von Dions Erfahrungen in der munizipalen Politik bzw. Anklänge an die negativen Charakterisierungen, die er in einigen Reden von seinen Gegnern gibt. Dabei richte sich die Kritik Dions gegen diejenigen Angehörigen der Elite, die den Normen und Erwartungen nicht entsprechen; der erste Sprecher sei somit eine Verkörperung der - geizigen - politischen Gegner Dions. Auch Jones sieht entsprechend in der Beschreibung, die Dion von der Volksversammlung in der Polis gibt, einen Beleg für die sich verschärfenden sozialen Gegensätze. ${ }^{79}$

\section{Die Rede als Quelle für die sozialen Verhältnisse der Kaiserzeit}

Kurze Erwähnung findet der Euboikos Logos zudem in Handbüchern zur Geschichte der römischen Kaiserzeit. Auch hier wird die Rede allerdings meist nur am Rande herangezogen bzw. Verweise auf diese beschränken sich auf die Fußnoten. Passagen aus dem Euboikos Logos werden in diesen Fällen meist angeführt, um die Verarmung auf dem Lande bzw. die Verödung der Städte zu belegen. ${ }^{80}$ So nennt Karl Christ in seiner Geschichte der römischen Kaiserzeit Dion nur selten - und dann meist mit Bezug auf die Gestalt des Dion selbst, seine Karriere und seine Grundhaltungen. Der Euboikos Logos findet in diesem Kontext nur kurz Erwähnung. ${ }^{81}$ François Jacques und John Scheid beziehen sich ebenfalls nur einmal auf die Eu-

des Bürgers propagiert werden, sich - im Rahmen der im Römischen Reich gegebenen Möglichkeiten - in der Polis zu engagieren.

${ }^{78} \mathrm{Zu}$ den einzelnen Rednern s. BEKKER-Nielsen 2008, 138-140. S. Jones 1978, 60f. zu den Details der Auftritte der einzelnen Redner.

${ }^{79}$ Jones 1978, 58. Dabei verweist er auf die konkreten bei Dion zu findenden Angaben bezüglich der verschiedenen gesellschaftlichen Gruppen - der kleinen Schicht wohlhabender Großgrundbesitzer, der reichen Schiffseigentümer sowie der großen Masse der ärmeren Bevölkerung, die sich in der Stadt sammle, um dort angenehmer und sicherer zu leben. Mratscheк-Halfmann 1993, 244, führt Dion ausdrücklich als eine der Quellen an, die eine zunehmende Spaltung der Gesellschaft in arme und reiche Bürger in der Kaiserzeit belegen.

${ }^{80}$ Wesentlich häufiger wird allerdings auch hier auf die Städtereden Dions Bezug genommen, die hinsichtlich der infrastrukturellen Probleme sowohl umfassendere wie auch präzisere Angaben liefern. Vgl. Desideri 1991a, 3887-3888. Zu der generellen Einschätzung Dions durch Desideri s. SwaIN 2000a, 35-40.

${ }^{81}$ Christ 1992, 282 zur Ausweisung durch Domitian; 290 zum idealen Königtum; 375 zu den Leinweber von Tarsus; s. auch 344f. 
böische Rede. ${ }^{82}$ Auch bei ihnen sind dann wieder die von Dion angesprochene Entvölkerung, die vorgeschlagenen Lösungsansätze und ein möglicher Zusammenhang mit tatsächlichen kaiserlichen Reformen, von Bedeutung. ${ }^{83}$

Eine gewisse Rolle spielt der Euboikos Logos in Untersuchungen zur Armut - auf dem Lande wie auch in der Stadt. So bewertet Ste. Croix den Euboikos Logos - neben Plutarch - als ",the only other passage ... in Greek literature which shows any concern about provision of a livelihood for the urban poor". Auch er geht in der Folge allerdings nur sehr kurz auf die Ausführungen im Euboikos bezüglich der angemessenen Beschäftigungen der in der Stadt lebenden Armen sowie deren Ansiedlung auf dem Lande ein. ${ }^{84}$ Die Angaben im Euboikos Logos sind daher häufig weniger als im Detail genaue Beschreibungen gesehen worden, denn als Anknüpfungspunkte für generelle Überlegungen hinsichtlich der sozialen Situation verarmter Bevölkerungsschichten. Michael Trapp sieht in der ausführlichen Beschreibung der euböischen Landschaft eine rhetorische Strategie, um die beabsichtigte Wirkung der Rede und deren Ziel - die Diskussion des moralischen Status der Armen und insbesondere der Frage einer angemessenen Beschäftigung der städtischen Armen - zu unterstreichen. ${ }^{85}$ In jüngerer Zeit sahen Hans-Joachim Drexhage, Heinrich Konen und Kai Ruffing in den Angaben zur Situation der ärmeren Bevölkerung sogar einen

\footnotetext{
${ }^{82}$ JACQUes / Scheid 1998, 416. Daneben werden or. 47 (196), or. 43 (212) und or. 31 (240) herangezogen.

${ }^{83}$ Jacques / Scheid 1998, 196 (or. 47), 212 (or. 43), 240 (or. 31). S. ebd. 416, zu den Privilegierungen. Sie verweisen auf möglicherweise bereits seit der Zeit Vespasians erfolgte Vergünstigungen im Falle der Urbarmachung brachgefallenen Landes und sehen diese Praxis als Grundlage für erfolgreiche Wirtschaftsreformen in Nordafrika. Allerdings sehen sie hinter der kaiserlichen Gesetzgebung des 2. Jahrhunderts n.Chr. primär das Bestreben, den Gewinn aus den Domänen zu maximieren. - mit Verweis u.a. auf ein Gesetz aus Gazoros/Makedonien aus dem Jahre 158 n.Chr. (publiziert in BCH 86, 1962, 57-63). S. Jones 1978, 59f. Wie er feststellt, war die Verpachtung von Land in der römischen Kaiserzeit durchaus üblich; dagegen sei es ungewöhnlich gewesen, Ländereien zu verschenken oder abgabenfrei zu vergeben. Auch er verweist allerdings auf die Praxis, Steuerfreiheit unter der Bedingung zu gewähren, dass das Land wieder urbar gemacht wird (mit Verweis auf Beispiele aus Makedonien und Boiotien, die Gesetzgebung Nervas, Trajans und Hadrians).

${ }^{84}$ Ste. Croix 1981, 200. Für ihn ist der Euboikos eine der wenigen Stellen in der antiken griechischen Literatur, in der die Lage der städtischen Armen thematisiert wird. Wie er feststellt, befasst sich Dion aber hauptsächlich mit den für die Armen ungeeigneten Beschäftigungen (angemessen ist nur die Tätigkeit als Handwerker) und dann mit einer möglichen Ansiedlung auf dem Land. BRUNT 1993, 211 vermutet, dass Dion bei seinem Vorschlägen aber auch an die Praxis der Getreideversorgung in Rom dachte. Vgl. zur Einschätzung beider Forscher HARRIs 1991, 3878.

${ }^{85} \mathrm{M}$. Trapp, "Sense of place in the Orations of Dio Chrysostomos”, in: D. InNes / H. Hine / Chr. Pelling (eds.), Ethics and Rhetoric. Classical Essays for Donald Russell on his SeventyFifth Birthday (Oxford 1995) [163-175] 164f. Auch Mratschek-Halfmann 1993, geht in ihrer Untersuchung zur Darstellung der Oberschicht in der kaiserzeitlichen Literatur mehrfach auch auf Dion von Prusa ein, so, 20, auf dessen Einstellung zur Armut; vgl. auch 244.
} 
"locus classicus“ für die Diskussion der schwierigen Lebenssituation der Armen in der Stadt. Gleichzeitig verweisen sie aber auch auf die in gewisser Weise relativierenden Aussagen Dions, dass prinzipiell in den Städten jeder Arbeit finden könne - auch wenn dies für Arbeiter ohne Ausbildung natürlich schwierig sei. ${ }^{86}$ Ähnlich argumentiert Frederick Brenk bezüglich der Einstellung Dions zur Haltung gegenüber den Armen. ${ }^{87}$ Wie er betont, wird von Dion die Armut nicht als ideale Lebensweise angesehen bzw. sozialer Aufstieg ausgeschlossen, wie auch die Jägerfamilie durchaus in bescheidenen aber ausreichenden Verhältnissen lebe. ${ }^{88}$ Auch von anderen Autoren wird die Haltung Dions zu körperlicher Arbeit und den Beschäftigungsmöglichkeiten für die ärmeren Bürger in den Mittelpunkt der Betrachtung gerückt. ${ }^{89}$ Hinsichtlich des von Dion propagierten Reformprogramms fehlt bislang allerdings eine Einbeziehung z.B. auch der Bithynischen Reden, in denen teilweise ähnliche Gedanken erscheinen. Dies ist umso bedeutsamer als die im Euboikos Logos vorgebrachten Überlegungen die Motivation für Dions Bemühungen um die städtische Infrastruktur liefern.

Immerhin wird er auch in der Forschungsdiskussion zu den Eliten und politischen Institutionen in den östlichen Provinzen des Reiches partiell als Quelle herangezogen. Dabei ist es dann allerdings primär die Gestalt Dions selbst - als Repräsentant der griechischen Oberschicht, die themati-

\footnotetext{
${ }^{86}$ Drexhage / Konen / Ruffing kommen ebenfalls nur kurz auf Dion bzw. den Euboikos zu sprechen: H.-J. Drexhage / H. Konen / K. Ruffing, Die Wirtschaft des Römischen Reiches (1.-3. Jahrhundert). Eine Einführung (Berlin 2002) 279. Sie betonen die Bedeutung der Lohnarbeit in der römischen Kaiserzeit bzw. wenden sich gegen deren Unterschätzung und führen - unter anderem - auch Angaben im Euboikos als möglichen Beleg an. Konkret verweisen sie in diesem Zusammenhang auf die Erwähnung von Arbeitern, die im Dienst eines Großgrundbesitzers die Herden hüteten (s. insbesondere zu 7,105f.). Des Weiteren gehen sie kurz auf dessen Einschätzung ein, dass jeder Arbeitswillige - wenn auch evtl. mit Hilfe - in der Stadt Beschäftigung finden könne, andererseits aber die nicht ausgebildeten Arbeiter sich mit Problemen konfrontiert sahen, da die Wirtschaft in der Stadt monetarisiert war und sie Arbeitsangebote wie Infrastruktur benötigt hätten.

${ }^{87}$ BRENK 2000, 264-267, 270-278. Auch zur Sympathie für die Armen und die Stellungnahme gegen die Prostitution, die seiner Meinung nach über die Kritik der Stoa und der Kyniker hinausgeht.

${ }^{88}$ Alсоск 1993, 107f. zur Frage der zunehmenden Bedeutung der Geldwirtschaft bzw. der Möglichkeit einer Anstellung in der Stadt. Sie verweist darauf, dass auch die Familie des Jägers sich zunächst um letzteres, wenn auch erfolglos, bemüht hätte.

${ }^{89}$ BRunt 1993, 211-218 zu den Vorschlägen Dions und seiner Auffassung von manueller Arbeit. Zu den als angemessen angesehenen Beschäftigungen s. ebd., 219-221. Moles 1995, 179 sieht die Vorschläge Dions für die Armen als „practicable enough“ und spricht von „balances between ideal and reality, between seriousness and entertainment and between moral absolutism and accomodation of audience prejudice".Wie DesIDERI 2000, 100, zudem bemerkt, bietet Dion nicht, wie von ihm angekündigt, eine Liste angemessener Beschäftigungen sondern vielmehr eine Reihung nicht geeigneter Arbeiten. Vgl. Anm. 121-130 zur Übersetzung.
} 
siert wird. ${ }^{90}$ Die persönliche Lebensgeschichte Dions wird teilweise ebenfalls als Indiz für die Zustände im Reich erwähnt. ${ }^{91}$ So vertritt MratschekHalfmann sogar die Auffassung, dass Dion die typischen Ansichten eines Angehörigen der Elite äußere - bis hin zu Gleichgültigkeit - und entsprechend die Lage der verarmten Bevölkerung nicht als ausweglos darstelle. ${ }^{92}$ Gerade hier bieten sich der Forschung aber durchaus noch weitere Möglichkeiten, die Beschreibungen im Euboikos Logos als Quelle zu nutzen. So gewährt insbesondere die Schilderung einen Einblick in die Struktur der Elite. Dabei zeigt sich gerade auch die Vielschichtigkeit der Oberschicht. Von einer homogenen, die Polis kontrollierenden Schicht der Euergeten kann offenbar nicht gesprochen werden.

\section{Der Euboikos als Quelle für die antike Sklaverei}

In Fortsetzung der Anfang des 20. Jahrhunderts geführten Diskussion spielt der Euboikos Logos weiterhin eine gewisse Rolle in der Forschungsdebatte zur Bedeutung von Lohnarbeit und Sklaverei in der Antike. Dabei sind durchaus verschiedene Positionen vertreten und die entsprechenden Passagen unterschiedlich interpretiert worden. Brunt bezieht diese in seine Diskussion der philosophischen Grundhaltung Dions ein und sieht auch hier den Einfluss zumindest stoischer Ideen. ${ }^{93}$ Ein eher negatives Bild der Rolle der Lohnarbeit im römischen Reich entwarf Ste. Croix, der die Angaben im Euboikos eher als Beleg für die schlechte Entlohnung der Arbeiter und deren geringe Rolle im Rahmen öffentlicher Bauprojekte heranzog. ${ }^{94}$ Von Drexhage et.al. wurde dagegen die Bedeutung der freien Lohnarbeiter gerade auch mit Blick auf die Angaben im Euboikos Logos unterstrichen. Dabei wandte man sich v.a. gegen die Auffassung der antiken Gesellschaftsordnung als einer Sklavenhaltergesellschaft. Wie generell bezüglich der Rezeption der Euböischen Rede zu beobachten, ist die Interpretation bestimmter Passagen jeweils von der generellen Auffassung und Haltung gegenüber der wirtschaftlichen Entwicklung im 2. Jahrhundert abhängig. Weiterhin lässt sich feststellen, dass auch für die Diskussion der Rolle von Sklaverei und Lohnarbeit in der römischen Kaiserzeit stärker andere Re-

\footnotetext{
${ }^{90}$ S. Mratscheк-Halfmann 1993, 2 zu or. 76,22f. zu Herkunft und Vermögen Dions, 29 zu den sozialen Beziehungen, 35 Aufstieg, 37 und 39f., 220 zu Reichtum und Stiftungen.

${ }^{91}$ Duncan-Jones 1990, Anm. 37; Day 1973, 249; P. Garnsey / R. SAller, The Roman Empire. Economy, Society and Culture (London 1987) 11, 37.

${ }^{92}$ Mratschek-Halfmann 1993, 20.

${ }^{93}$ BRUnt 1993, 221-224. Dion zeigt aber seiner Meinung eine stärker human geprägte Einstellung, insbesondere hinsichtlich der Sklaverei.

${ }^{94}$ Ste. Croix 1981, 188, verweist auf die Angaben in 7,11-12 als Beleg für die schwierige Situation der Lohnarbeiter im römischen Reich. Er geht, 194, u.a. auf Basis der Schilderung in 7,104-52 sogar davon aus, dass freie Lohnarbeit bei öffentlichen Arbeiten keine größere Rolle spielte.
} 
den Dions - so diejenigen zur Sklaverei und einzelne Städtereden - herangezogen werden. ${ }^{95}$ Dabei werden besonders häufig seine Angaben zu den Leinenwebern in Tarsos bzw. ihrem Aufstand (or. 34) als Beispiel für soziale Probleme und Unruhen in der Kaiserzeit diskutiert. ${ }^{96}$

\section{Der Euboikos als Spiegel kaiserzeitlicher Politik}

Eine gewisse Rolle hat in der Forschung, wie bereits angesprochen, die Frage gespielt, ob Dion mit seiner Rede und den in diese integrierten Reformvorschlägen direkt Bezug auf die Agrarpolitik Kaiser Trajans nimmt. ${ }^{97}$ So ist von Paul Mazon die These vertreten worden, dass Dion beabsichtigte, mit dem Euboikos Logos regelrecht Propaganda für das Reformprogramm des Kaisers zu machen. ${ }^{98}$ Als realer Hintergrund der bei Dion auftauchenden Forderungen nach einem mehrjährigen Abgabenerlass als Anreiz für Neusiedler ist die Gesetzgebung dieser Zeit gesehen worden. Wie epigraphische und andere literarische Zeugnisse belegen, war man staatlicherseits im 2. Jahrhundert n.Chr. bereit, die Okkupation brachliegenden Landes zu tolerieren und Zugeständnisse bezüglich der Steuern zu machen. Insbesondere im Zusammenhang von Diskussionen der lex Manciana

\footnotetext{
${ }^{95}$ Vgl. P. CRETIA, „Dion de Pruse et l'esclavage”, StudClas III (1961) 369-75, zu den stoischen und kynischen Elementen der Sichtweise Dions, allerdings in or. 14 und 15. S. FiNLEY 1981, 163-166 zur Thematisierung der Sklaverei - allerdings ebenfalls in anderen Reden; 190, zu Arbeitern, allerdings ebenfalls in einer anderen Rede; ebenso E.M. STAERMAN, „Der Klassenkampf der Sklaven zur Zeit des Römischen Kaiserreiches“, in: H. SchNeider (Hrsg.), Sozial- und Wirtschaftsgeschichte der römischen Kaiserzeit (Darmstadt 1981) [307-335] 330, 332 zu Sklaven; MacMullen 1974, 257, konstatiert in seiner Untersuchung zum Verhältnis von freiem Bauerntum und Lohnarbeit denn auch, dass Dion bei seinem Bericht über Euböa nur „,a little“ über die dortigen Verhältnisse berichte.

${ }^{96}$ Jones 1974, 102 zum Königtum; 51, 359 zu den Leinenwebern in Tarsus; vgl. FinLey 1981, 189.

${ }^{97}$ S. z.B. SALMERI 1982, 82-87. Er verweist auf den in der Volksversammlung vorgebrachten Reformvorschlag, um die Produktivität zu erhöhen und die Armen zu versorgen. Zur Einschätzung durch SALmeri s. Swain 2000a, 43f. Vgl. die Angaben in Anm. 83.

${ }^{98}$ Mazon 1943, 47-80; vgl. JouAn 1977, 40. Jones 1978, 59f., vermutet dagegen, dass sich Dion der aktuellen Gesetzgebung durchaus bewusst war, seine Stellungnahme jedoch in erster Linie als ein Schüler des Musonius und Angehöriger der griechischen Oberschicht formulierte, dem an dem Wohlstand der Stadt gelegen war. S. außerdem Moles 1995, 178, zum Verweis auf die kaiserliche Gesetzgebung. S. auch Moles 1995, 180, zur Bezugnahme auf die Gesetzgebung Trajans. Er sieht diesbezüglich allerdings keine einseitige Stellungnahme für die römische Herrschaft sondern verweist auch auf die Kritik an Korruption und Luxus. Zu den Angaben des zweiten Redners s. BeKKer-Nielsen 138. Wie er betont, verteidigt dieser den Jäger, widmet sich in seiner Rede aber vor allem den innerstädtischen Problemen. S. auch Lepelley 2001, 320f. zu den bei Dion erwähnten Vorschlägen bzw. den kaiserlichen Programmen. Zum Zusammenhang mit der lex Manciana, der städtischen Armut und kaiserlichen Programmen s. Sirago 1958 174-176, 293-5. Zur Situation in Nordafrika s. auch P. GARNSEY, „Rome's African Empire under the Principate”, in: P. GARnSEY / C.R. Whittaker (eds.), Imperialism in the Ancient World (Cambridge 1978) 223-254.
} 
und der Maßnahmen Hadrians zur Förderung der Agrarwirtschaft wird von einigen Forschern auch auf die entsprechenden Passagen im Euboikos Logos Bezug genommen. ${ }^{99}$ So sieht Francesco de Martino in den kaiserlichen Verordnungen keine grundsätzliche Änderung in der römischen Wirtschaftspolitik, jedoch - und hier verweist er auf die Ausführungen Dions - eine Reaktion auf reale Probleme. ${ }^{100}$ So geht auch er davon aus, dass die arme Landbevölkerung dem Druck der reicheren Bürger und der Magistrate ausgesetzt war und vielfach ihre Äcker aufgab. Eben diesem Problem habe die kaiserliche Gesetzgebung abhelfen sollen - De Martino verweist hier ebenfalls auf die lex Manciana, die lex Hadriana und die Gesetzgebung des Pertinax. ${ }^{101}$ Als Beleg für die Glaubwürdigkeit der Nachrichten bei Dion sieht er die parallelen Angaben in anderen Quellen. Ziel der kaiserlichen Politik sei es gewesen, das brachliegende Land wieder der Bewirtschaftung zuzuführen. ${ }^{102}$ Gleichzeitig konstatiert De Martino allerdings, dass es durchaus prosperierende Städte im griechischen Raum gegeben habe. ${ }^{103}$ Ähnlich argumentiert Bruce Harris, der als Parallele für die von Dion entworfenen Reformvorschläge auf die Passagen in den Pliniusbriefen (so IX,37,2-4) sowie auf die lex Manciana verweist. ${ }^{104}$ Er vermutet, dass Dion wie Plinius von einem entsprechenden kaiserlichen Programm

\footnotetext{
${ }^{99}$ R. Scholl / Chr. Schubert, „,Lex Hadriana de agris rudibus und lex Manciana”, in: Archiv für Papyrusforschung 50/1 (2004) 79-84. Zum realen Hintergrund der Vorschläge Dions bzw. der diesbezüglichen Gesetzgebung s. auch Jaques / Scheid 1998, 416.

${ }^{100}$ De Martino 1985, 283. So erklärt er: „Die Beschreibung Euböas bei Dio von Prusa enthält möglicherweise einige Übertreibungen, aber man kann schwerlich annehmen, er habe sich alles aus den Fingern gesogen."

${ }^{101}$ De Martino 1985, 283 u.a. mit Verweis auf entsprechende Angaben auch bei Herodian.

${ }^{102}$ De Martino 1985, 283; wie er feststellt, blieben diese Maßnahmen jedoch darauf beschränkt, aufgegebenes Land wieder einzubinden. Durchgreifende Maßnahmen gegen die Krise der Landwirtschaft bzw. ein dezidiertes politisches Reformkonzept sieht er nicht.

103 S. De Martino 1985, 513. Er betont die lokal durchaus unterschiedliche wirtschaftliche Entwicklung im griechischen Raum. So konstatiert er zwar einen vielerorts zu beobachtenden Niedergang sowohl des Bürgertums wie der städtischen Wirtschaft. Auch seien viele Städte realiter nicht mehr existent gewesen. In bestimmten Gegenden - wie Arkadien, Boiotien, Phokis und Thessalien sei jedoch kein wirtschaftlicher Abstieg im Vergleich zu früheren Zeiten zu beobachten.

${ }^{104}$ Harris 1991, 3853-81. Zum Zusammenhang mit der lex Manciana s. SAlmeri 1982, 85-87; zu den Bestimmungen der lex s. FLACH 1978, 441-492. Zu einem ähnlichen, in das späte 2. Jahrhundert n.Chr. datierenden Gesetz aus Makedonien s. CL. VATIN, „Une inscription inédite de Macédoine", BCH 86 (1962) 57-63. S. auch RostovtzefF 1910, 15, der hinsichtlich gewisser Regelungen in Alexandria als Parallele auf den Euboikos verweist. Auch an anderer Stelle, 388, geht er kurz auf das Okkupationsrecht ein. Er hebt hervor, dass dieses normalerweise den Polisbügern zugestanden worden sei. Auf Euboia sei die Lage im 1. Jahrhundert n.Chr. allerdings so kritisch gewesen, dass man auch Fremden dieses Recht zuerkannt habe, allerdings unter erschwerten Auflagen.
} 
Kenntnis hatten. ${ }^{105}$ Was die realen Gegebenheiten bzw. die Motive für diese staatliche Förderung betrifft, äußert sich Harris zurückhaltender. Er beurteilt die Schilderung der Verödung und Verarmung Euboias als übertrieben und verweist auf gegenteilige Berichte bei Strabon und Pausanias sowie auf den epigraphischen Befund. Bedingt ist die Überzeichnung seiner Meinung nach durch die Intention Dions bzw. den Aufbau der Rede, in deren zweitem Teil die Armut zum zentralen Thema wird. ${ }^{106}$ Auch Richard Duncan-Jones geht in seinem Werk „Money and Government in the Roman Empire" kurz auf das kaiserliche Programm ein, eine mehrjährige Steuerbefreiung zu gewähren, um unbebautes Land wieder in die landwirtschaftliche Nutzung zu überführen. Der Euboikos Logos wird von ihm dabei neben anderen literarischen Zeugnissen aufgeführt, allerdings nicht weiter diskutiert. ${ }^{107}$

Abschließend kann somit festgestellt werden, dass das Potential, das der Euboikos Logos für die wirtschaftshistorische Forschung bietet, bisher noch nicht gänzlich ausgeschöpft worden ist. Zum einen sind offenbar die Städtereden Dions als potentiell wertvollere Quellen betrachtet worden, zum anderen ist der Euboikos Logos forschungsgeschichtlich häufiger als rein literarisches Werk gesehen und diskutiert worden. Möglicherweise standen Einzelangaben in der Rede zeitweise auch im Widerspruch zu dominierenden Forschungsansätzen: Die starke Betonung der Rolle der Lohnarbeit und das vergleichsweise knappe bzw. indirekte Eingehen auf die Sklaverei passten nicht in das Bild, das Forscher wie z.B. noch Finley von der hohen Kaiserzeit entworfen hatten. Abhängig ist die Rezep-

\footnotetext{
${ }^{105}$ Harris 1991, 3869 betont die Parallelen, die das von Dion vorgeschlagene Konzept (also die abgabenfreie Verpachtung für zehn Jahre und die anschließende Zahlung eines Teils des Ertrages) zur Gesetzgebung Trajans.

${ }^{106}$ Harris 1991, 3870f., zur Diskussion, auf welche Zeit der in der Rede erwähnte Tod des reichen Großgrundbesitzers und die Konfiskation seines Besitzes zu datieren sei. Vgl. Highet 1973, 35-40. HARRis 1991, 3871 verweist zudem auf die Angaben bei anderen kaiserzeitlichen Autoren - so Plutarch - und in weiteren Reden Dions, den Eindruck bestätigen. Dagegen werde die wirtschaftliche Situation bei Strabon und Pausanias positiver beschrieben und dieses Bild sieht HARRIs auch in den Inschriften bestätigt. Auch er kommt daher zu dem Schluss, dass Dion den Niedergang auf Euboia übertreibt, und zwar auch, um die Grundlage für seine späteren Ausführungen bezüglich der Armut zu schaffen. Auch sieht er, 3877, die Haltung Dions in sozialen Fragen zudem durch seine moralischen bzw. stoischen Grundüberzeugungen bestimmt. Vgl. in diesem Sinne bzw. zur Sympathie für die Armen und der Forderung nach einer angemessenen wie würdigen Beschäftigung auch SALMERI 1982, 84f. Zum Realitätsgehalt des Berichts über den Schiffbruch s. N. GEORGANTZOGLOU, der vergleichbare Berichte bei Herodot und Livius heranzieht (N. GEORGANTzoglou, „The Koila of Euboia”, Parousia III [1985] 243-279).

${ }^{107}$ Duncan-Jones, S.54, Zu den Privilegierungen im Zusammenhang mit der Wiederurbarmachung verweist er u.a. auf die Gesetzgebung des Hadrian und des Pertinax, aber auch auf den Euboikos Logos. Seiner Meinung nach seien die Regelungen zwar einerseits darauf ausgerichtet gewesen, die Einnahmen aus den Abgaben so hoch zu halten wie möglich, andererseits aber auch einen gewissen Spielraum zu gewährleisten, falls sich anfänglich bei der Kultivierung Schwierigkeiten einstellen sollten.
} 
tion der Euböischen Rede immer auch von der jeweiligen Einschätzung der wirtschaftlichen Lage in der Kaiserzeit - wird ein allgemeiner Rückgang des Wohlstandes angenommen, dient der Euboikos Logos als Beleg hierfür, wird ein möglicher Niedergang negiert, erscheint er dagegen als eher abstrakte Reflexion über Armut und Reichtum. Gerade hier bieten sich allerdings auch für die Zukunft noch Möglichkeiten für weiterführende Untersuchungen. In diese wäre insbesondere eine detaillierte Analyse des epigraphischen Materials einzubeziehen. Generell lässt sich zudem feststellen, dass gerade der zweite Teil der Rede noch zu wenig diskutiert wurde: Der Euboikos Logos ist vielleicht nicht so sehr Lob des Landlebens als vielmehr eine reflektierte Auseinandersetzung mit den Problemen der Polis in dieser Zeit. 



\title{
Die Topographie der Karystia in der Euböischen Rede des Dion von Prusa - Autopsie oder Fiktion?
}

\author{
Hans Rupprecht Goette
}

Topographische Angaben im Text Dions lassen sich in zwei Kategorien scheiden: Erstens wird eine Berglandschaft mit kleinen Dörfern und Einzelgehöften fern von städtischen Siedlungen geschildert; unterhalb dieser gebirgigen, abgelegenen Gegend liegt - zweitens - eine Stadt, die der Autor mit einigen Details zu ihrem Aussehen und ihren Einrichtungen charakterisiert. Im folgenden wird die topographische Darstellung Dions in diese beiden Teile gegliedert mit dem tatsächlichen, durch landeskundliche Forschung ${ }^{1}$ beleuchteten Befund in der Karystia ${ }^{2}$ verglichen. Interessant ist dies auch für die in der älteren Forschung immer wieder diskutierte Frage, ob Dion so, wie er ausdrücklich in $\S 1$ und $\S 81$ versichert, aus eigener Anschauung ein konkretes euböisches Landes- und Stadtbild beschrieb, das als Hintergrund für sein Generalthema über die richtige Lebensform diente ${ }^{3}$ (s. Anm. 4 und 98 zur Übersetzung).

\footnotetext{
${ }^{1}$ Gerade in den letzten Jahrzehnten konnten durch die archäologischen Forschungen des Southern Euboea Exploration Project (SEEP) sowie einige Ausgrabungen griechischer Archäologen die Kenntnisse über die antike Karystia maßgeblich erweitert werden.

${ }^{2}$ Dieser Name für das gesamte Polis-Gebiet von Karystos begegnet uns bereits bei Herodot (IX 105) und Theophrast (HP VIII 4,4). Über die Grenze zum Demengebiet von Eretria wird in der Forschung, freilich aus dem Blickwinkel Eretrias, gestritten (s. etwa die Diskussion der älteren Meinungen bei GeнRкe 1988), zuletzt wurde das Thema dann mittels neuer ausgedehnter Surveys und der Interpretation von Horos-Felsinschriften wieder auf-

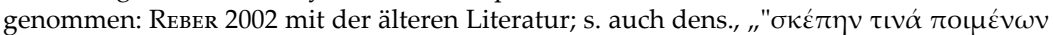

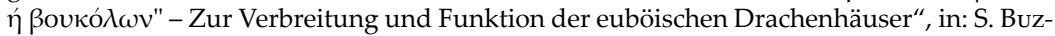
zi u.a. (Hrsgg.), Zona Archaeologica. Festschrift H. P. Isler. Antiquitas 3, 42 (Bonn 2001) 339-351. Eine 2010 abgeschlossene Dissertation zum südlichen Demengebiet Eretrias von S. FACHARD (Schweizer Archäologische Schule in Griechenland) ist noch unpubliziert.

${ }^{3} \mathrm{Im}$ folgenden werden die einschlägigen Artikel in den bekannten Lexika $(R E, D N P$; PECS, LAUFFER u. a.) nicht eigens zitiert. Um die Anmerkungen nicht zu überlasten, konzentrieren sich die Literatur-Angaben einerseits auf die wichtigsten älteren Werke seit dem 19. Jh. und andererseits auf neuere Beiträge, insbesondere solche archäologischen oder landeskundlichen Charakters. Allgemein zur Geschichte von Karystos und zu Quellensammlungen sei auf folgende Werke verwiesen: Schaubert 1847; RHangabé 1852; Baumeister 1864; Bursian 1872; Lolling 1877; Geyer 1903; Ziebarth 1939; Philippson 1951; Wallace 1972; Vranopoulos 1987; W. Рн. Chapman, Karystos: City-State and Country Town (Baltimore 1993).
} 


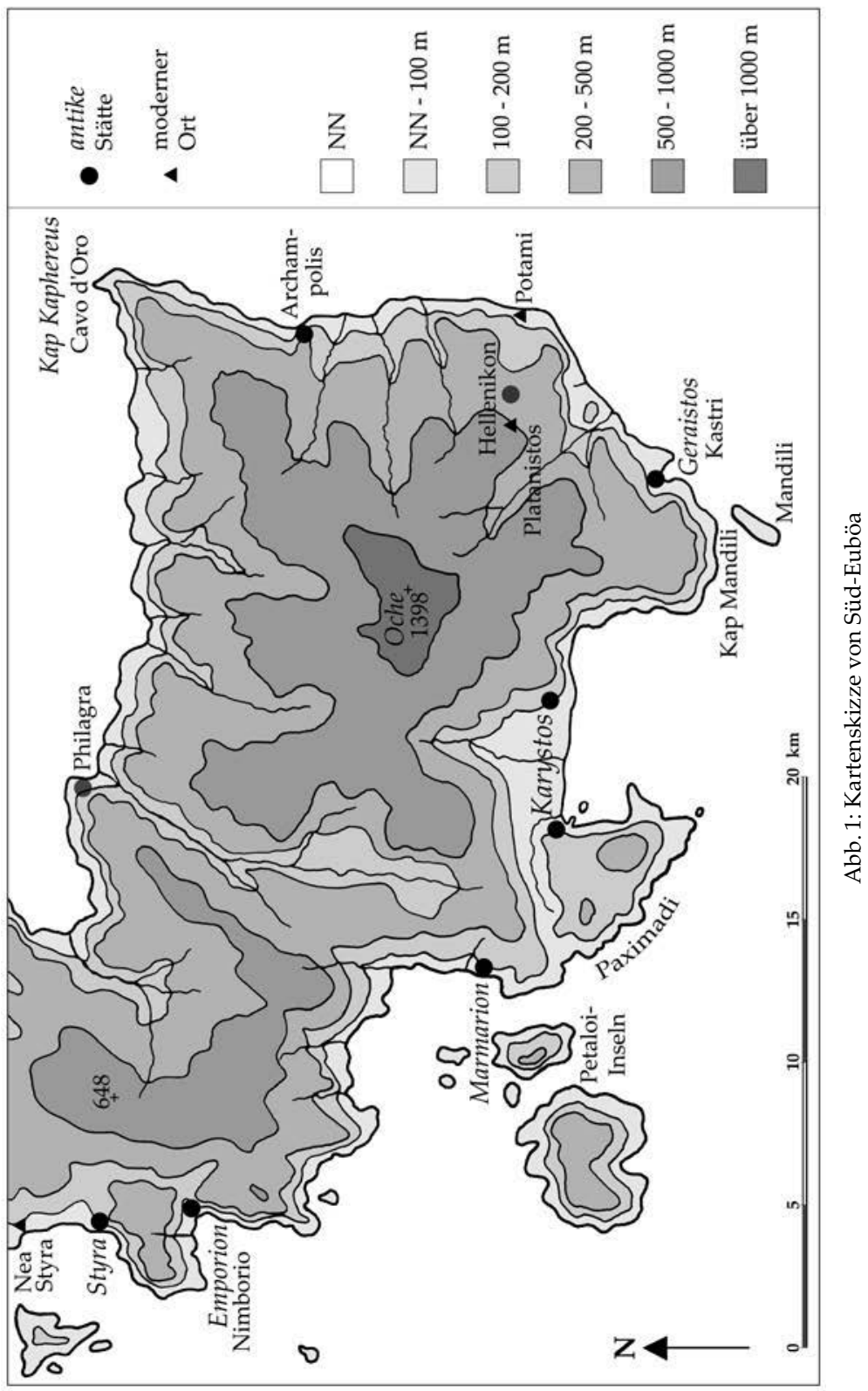




\section{Die Landschaft der Jäger-Episode}

Die Berglandschaft ist anhand Dions Angaben genau lokalisierbar: Sie befindet sich in unmittelbarer Nachbarschaft des berüchtigten Kap Kaphereus an der Südostseite von Euböa (Abb. 1), das ausdrücklich (§ 31) genannt und dessen Gefährlichkeit für die Seefahrt zudem durch den Hinweis auf die Nauplios-Episode (§ 32; s. Anm. 43 zur Übersetzung) sehr bildhaft vor Augen gerufen wird. Dieses in der Antike auch als „Xylophagos", bei den Venezianern dann als "Cavo d'Oro“ bekannte Kap (Abb. 2) war - und ist bis heute ${ }^{4}$ - wegen der dort herrschenden starken Winde und

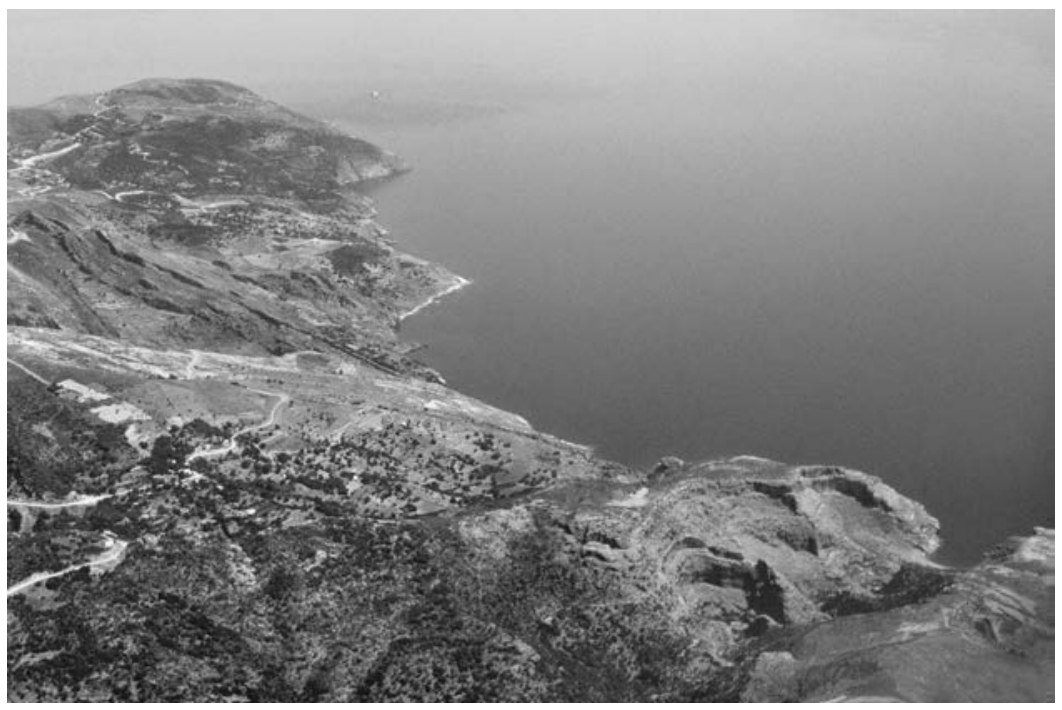

Abb. 2: Ansicht von Euböas Südost-Küste, im Hintergrund Kap Kaphereus

gefährlichen Strömungen berüchtigt; die schroffe, hohe Felsenküste (Abb. 2) bot - anders als die Westseite Euböas ${ }^{5}$ im geschützten südlichen und nördlichen Golf - kaum Landungsmöglichkeiten ${ }^{6}$ und somit Schutz für Schiffe oder kleine Boote wie das, mit dem Dion von Chios aus übersetzte. Dies gilt für einen recht langen Abschnitt der in weiter Kurve einwärts

\footnotetext{
${ }^{4}$ Baumeister 1864, 31 mit Anm. 92f.; Geyer 1903, 6-9; Richards 1930; Philippson 1951, 565f.; Wallace 1972, 37-41; Mason / Wallace 1972. Die Gegend war bis kürzlich von arvanitischer Bevölkerung bewohnt, man sprach dort überwiegend albanisch: PhiLIPpson

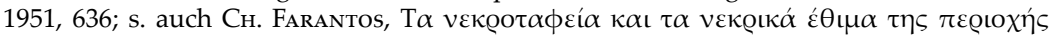

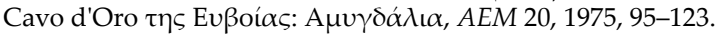

${ }^{5}$ Philippson 1951, 551-560; die Häfen im euböischen Kanal diskutiert ausführlich GEHRKE 1992.

${ }^{6}$ Gehrke 1992, 100 mit Anm. 11f. und dem Hinweis auf Thuc. IV 109, 3.
} 
geschwungenen Insel-Ostküste, den in antiken Quellen und auch bei Dion $\left(\S 7^{7}\right)$ sogenannten „Höhlungen von Euböa“: Hier befinden sich fast keine Buchten mit einem zum Anlanden geeigneten Strand; einige wenige - wie etwa die von Philagra unterhalb einer antiken und mittelalterlich umgebauten Festung gelegen ${ }^{8}$ - sind von steilen Felskaps gerahmt und zeigen nur eine schmale Öffnung, in die hohe Wellen auf einen steinigen Strand ( $§$ 2) rollen. Und selbst, wenn man Kap Kaphereus in südwestlicher Richtung, also durch den äußerst stürmischen Kanal zwischen Euböa und Andros passiert hatte, setzte sich die unwirtliche Felsküste noch weiter fort (Abb. 2): Typisch sind sehr kleine, sich zum Meer öffnende Schluchten wie die von Archampolis ${ }^{9}$ (Abb. 3 a-b). Mit einem Sandstrand (ohne antike Siedlungsspuren) öffnet sich allein das Tal von Potami ${ }^{10}$ (Abb. 4). Erst die relativ tiefe Bucht von Geraistos bot sicheren Anker- und Landeplatz (Abb. 5); so ist es auch keineswegs erstaunlich, dass hier ein berühmtes Heiligtum des Poseidon ${ }^{11}$ lag, das dem Seefahrer vor oder nach gefährlicher Passage die Gelegenheit bot, sich schutzflehend oder dankbar an den Gott zu wenden.

In $\S 10$ wird angegeben, dass die ärmliche Hütte des Jägers, der dem gestrandeten und von seinen Begleitern verlassenen Dion hilfreich Unterkunft bietet, 40 Stadien von der Steilküste beim Kap Kaphereus entfernt in den Bergen, also an den östlichen Hängen des Oche-Gebirges liegt; das kleine Grundstück ist auf zwei Seiten durch steile Abhänge begrenzt, liegt also in einem Tal und hält somit - wie normalerweise alle kleinen Gehöfte im antiken Griechenland - die geringe Feldfläche von Bebauung frei. Die von Dion beschriebene Lage der Hütte ist zudem dadurch gekennzeichnet,

\footnotetext{
${ }^{7}$ Hier Lehmann Anm. 7 zur Übersetzung; zur Diskussion über die Lokalisierung durch Strabo u. a. Baumeister 69 Anm. 91; Geyer 1903, 7-9; Richards 1930; Pritchett 1969; WalLACE 1972, 82-105; Mason / Wallace 1972; Gehrke 1992.

${ }^{8}$ Baumeister 1864, 33; Philippson 1951, 626 mit Anm. 4; 743; Sackett u.a. 1966, 80; WaLlace 1972, 122-125; Koder 1973, 122f.; Triantaphyllopoulos 1974, 225-227; SKouras 1975, 348f.; Reber 2001, 455f. Abb. 11f.; zuletzt: Chiridoglou 2008/9, 39f. Abb. 3-5.

${ }^{9}$ Zur exzeptionellen topographischen Situation der Antikenstätte: BAumeister 1864, 31-33; Wallace 1972, 31 Anm. 30; Keller 1985, 263-267; Keller 1983; Reber 2001, 451-453 Abb. 1-4; s. auch mit (verfehlter) Deutung und Datierung: Panagopoulou 1995; s. zudem S. 188 mit Anm. 55. Zuletzt zu Archampolis und zwei Türmen des 4. Jhs. v. Chr. in der Nähe von Kap Kaphereus: Chiridoglou 2008/9, 41f. Anm. 30f. mit Abb. 6.

${ }^{10}$ Dieses Tal, das vom Oche-Gebirge herabkommt, entwässert die Gegend von Platanistos; es ist von der Küste bei Geraistos durch drei, nahezu parallel verlaufende Höhenrücken getrennt. An seiner Nordseite liegt mehrere Kilometer oberhalb der Potami-Mündung das eindrucksvolle, mit archaischer Architektur aus parischem Marmor bekrönte Terrassenheiligtum „Hellenikon“, dazu s. vor allem G. Papavasıleiou, Av $\alpha \sigma \kappa \alpha \phi \alpha i$ ċv Eủßoí $\alpha$, Prakt (1908) 101-113 und zuletzt Goette 2007/2000.

11 Allgemein: Baumeister 1864, 34f.; Geyer 1903, 6-7. 111-113; Lehmann-Hartleben 1923, 255; Philippson 1951, 629; Keller 1985, 201. 210. 212-214; Keller / Wallace 1990; Gehrke 1992, 104f. mit Anm. 41; zu den archäologischen Funden: Choremis 1974; JACoвSEN / Smith 1968; Chiridoglou 2009, 1085-1105; s. auch u. S. 183 mit Anm. 41f.
} 


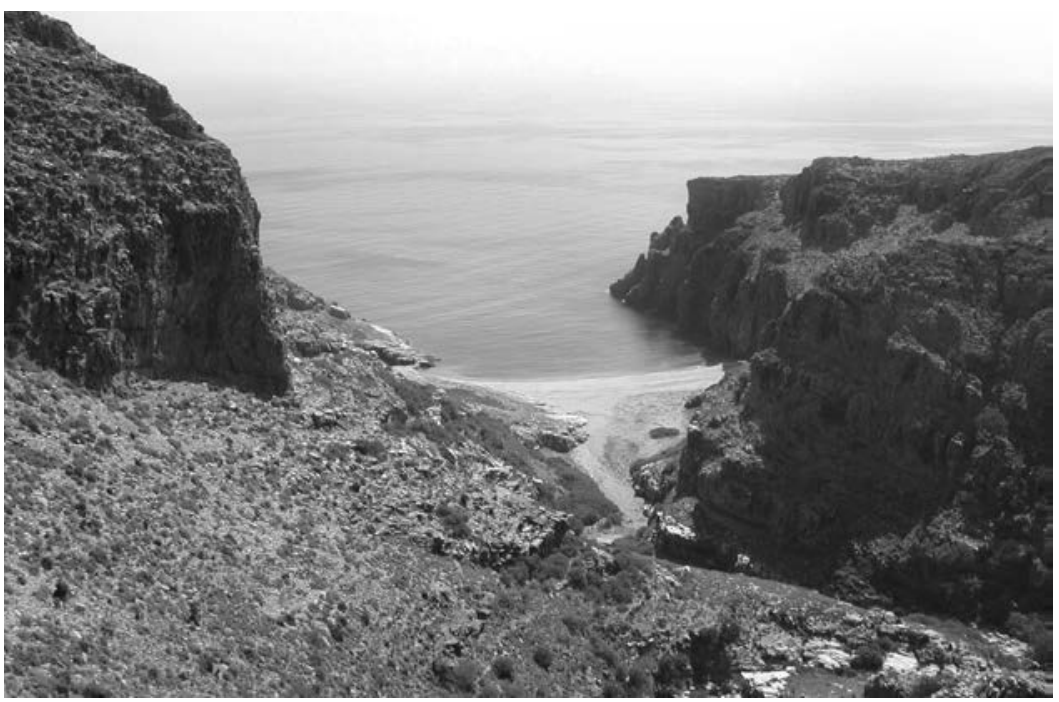

(a) Archampolis: Überblick der Schlucht von Süden

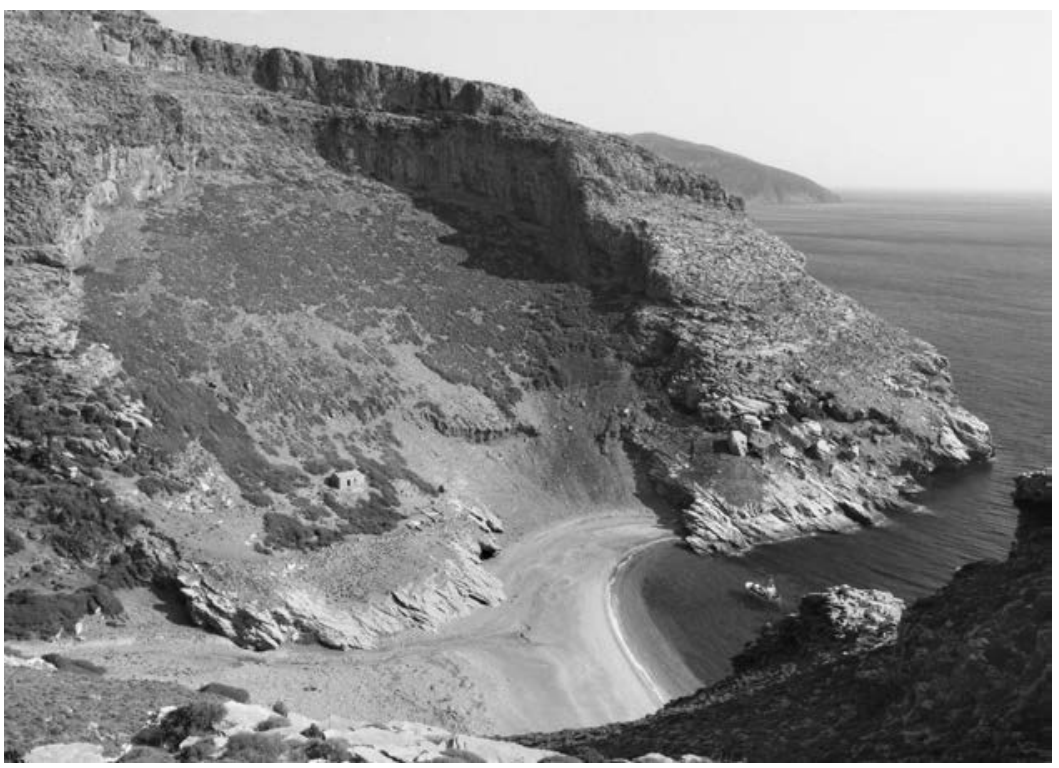

(b) Archampolis: die Bucht mit den Erzwerkstätten von Westen

Abb. $3 \mathrm{a}-\mathrm{b}$ : Archampolis 
dass die Schlucht so tief ist, dass deren Seitenwände den Grund, in dem ein Bach mit klarem, einer Quelle reichlich entspringendem Wasser fließt, im Schatten halten. Derartige topographische Angaben lassen sich gut mit Situationen an den Hängen des Oche-Massivs vereinbaren, das sich direkt neben dem Meer bis zu 1398 m hoch auftürmt und Süd-Euböa geologisch, klimatisch wie auch optisch, etwa von Attika ${ }^{12}$ her, beherrscht. Auch alle anderen Schilderungen der Gegend - das bergige Weideland und die nur zur Subsistenzwirtschaft geeigneten geringen Ackerflächen, die weit stehenden Eichen, der Schnee, der dazu zwingt, das Vieh im Winter in die Ebenen zu treiben, sowie das Jagdwild (Rehe, Hirsche, Hasen und Bären) - lassen sich mit Zustandsbeschreibungen aus der Neuzeit (d. h. vor dem Beginn des Straßenbaus und der anschließenden Zersiedelung sowie der großflächigen Brandzerstörungen seit den frühen 1980er Jahren) parallelisieren. ${ }^{13}$ Nur eine konkrete Angabe Dions, nämlich diejenige über die Purpurfischerei beim Kap Kaphereus, kann nicht bestätigt werden. Zwar ist dieses Handwerk für das antike Euböa archäologisch belegt, ${ }^{14}$ aber statt für die Karystia ließ es sich in der Gegend von Chalkis und Eretria, wo das Meer viel flacher ist, nachweisen. Somit mutet es wie ein Zirkelschluß an, wenn die - mit negativer Bewertung dieses Berufsstandes belastete - Erwähnung der Purpurfischer am Kap Kaphereus südost-euböischen Küste durch Dion als einziger Beweis für diesen Industriezweig in Südost-Euböa immer wieder angeführt und als Quelle ernst genommen wird.

\footnotetext{
${ }^{12}$ S. Eur. Iph. Taur. 1451; dazu Gehrke 1992, 111 Anm. 80. Zum Oche-Massiv: Philippson 1951, 565-567. 627-631.

${ }^{13}$ Vgl. etwa Teller (1880), zitiert bei Philippson 1951, 628: „Alle Reisenden ... erschöpfen sich in Schilderungen des überaus wilden und eigenartigen Charakters, den diese tiefen unzugänglichen Wände dem landschaftlichen Bild verleihen. “ Zudem Bursian (1859): „Die Abhänge sind teils mit Laubholz (Eichen und Platanen) und in der Nähe der einzelnen an ihnen liegenden Dörfchen mit Baumgärten, teils mit Viehweiden bedeckt. Getreide wird in diesen Engtälern, die schwer zugänglich und daher im Altertume wie in der Neuzeit von der Welt abgeschieden, von Fremden äußerst selten betreten wurden, fast gar nicht gebaut ...". Platanen findet man vor allem im Tal von Platanistos, weiteren LaubbaumBestand noch an der nach wie vor weniger besuchten Ostküste; schließlich finden sich südlich unterhalb des Oche-Gipfels heute noch Reste des von allen Besuchern bewunderten Kastanien-Waldes. - Zum Baumbestand s. auch R. Meiggs, Trees and Timber in the Ancient Mediterranean World (Oxford 1982) bes. 204-209.

${ }^{14}$ Die anhand von Muschelansammlungen bei Werkstätten nachweisbare MurexFischerei bei Chalkis findet Bestätigung durch Textstellen bei Aristoteles oder Athenaios: DAY 1951, 215 mit weiteren Nachweisen. Zuletzt wurden bei Grabungen in Eretria Murexmuscheln bei Werkstätten der Purpurfärberei entdeckt: s. SснміD 1999 und die GrabungsVorberichte in AntK 42, 1999, 120 sowie AntK 43, 2000, 123, zudem Ducrey u.a. 2004, 128f. - Die in der Antike im Mittelmeer lebenden und für die Purpurfärberei verwendeten Murex-Arten sind Haustellum brandaris und Hexaplex trunculus, die beide auf Felsen in seichtem Wasser nahe der Küste leben, also in ganz anderen Meeresbedingungen als denen, die an der Steilküste von Kap Kaphereus und seiner Umgebung mit den tiefen Wassern herrschen.
} 


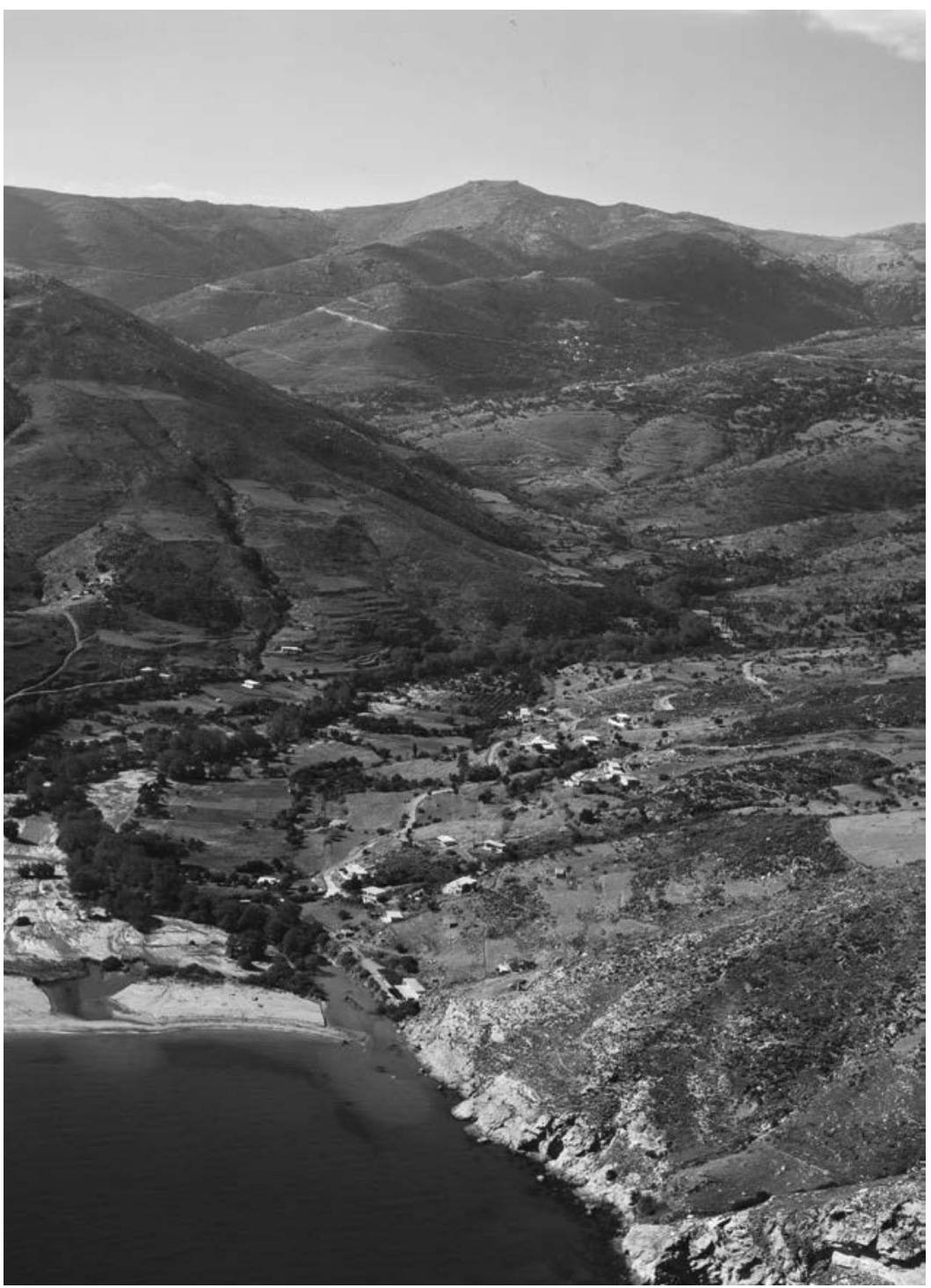

Abb. 4: Die Mündung des Potami mit dem Tal hinauf nach Hellenikon und Platanistos 


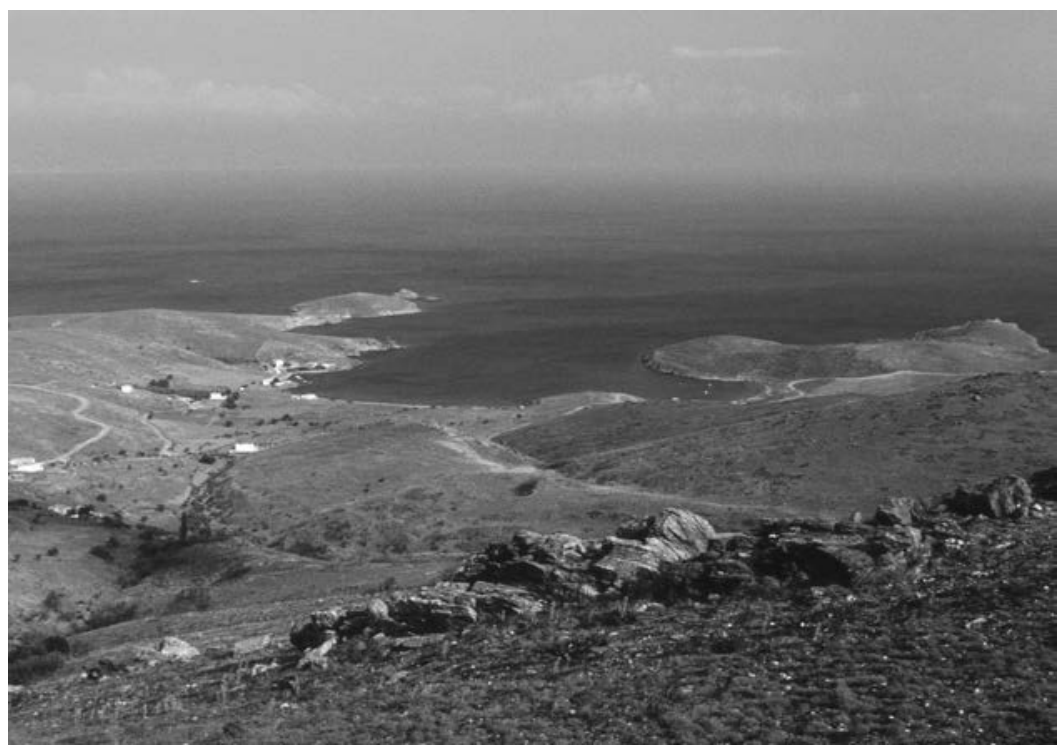

Abb. 5: Die Küste von Süd-Euböa mit der Bucht von Geraistos (Kastri)

\section{Die Stadt der Jäger-Episode}

Dion gibt in seiner Schilderung folgende Details über die namentlich nicht bezeichnete Stadt unterhalb des Oche-Massivs an: Sie ist von hohen Mauern mit Türmen umschlossen und besitzt viele (teilweise leer stehende) Häuser. Man sieht dort ein Theater und ein Gymnasium mit Statuen des Herakles und von Heroen und Göttern; letzteres wird als Acker genutzt, während die Agora, an der ein Buleuterium und ein Prytaneum liegen, als Viehweide dient; überhaupt gibt es größere Freiflächen für Ackerland und Weiden innerhalb der Mauern. Weitere Charakteristika sind die gute Bodenqualität in der Ebene vor der Stadt, in der Chora, sowie die Tatsache, dass man Schiffe vor Anker liegen sieht.

Allein der Zusammenhang zwischen dem Bergland an den Hängen des Oche-Massivs, einem Ankerplatz und somit der Nachbarschaft zum Meer wie auch zu einer fruchtbaren Ebene läßt zunächst kaum einen anderen Schluss zu, als dass dem Leser mit dieser Stadt Karystos beschrieben wird, zumal eine alternative Siedlung mit den genannten Charakteristika in jener Gegend aus der Antike sonst nicht bekannt ist. Und tatsächlich befand sich diese süd-euböische Polis am Rand einer fruchtbaren Ackerebene (heute Kampos genannt), die sich mit einer breiten, offenen Bucht nach Süden zum Meer hin öffnet und sich als langgestrecktes Tal auch nach Westen 


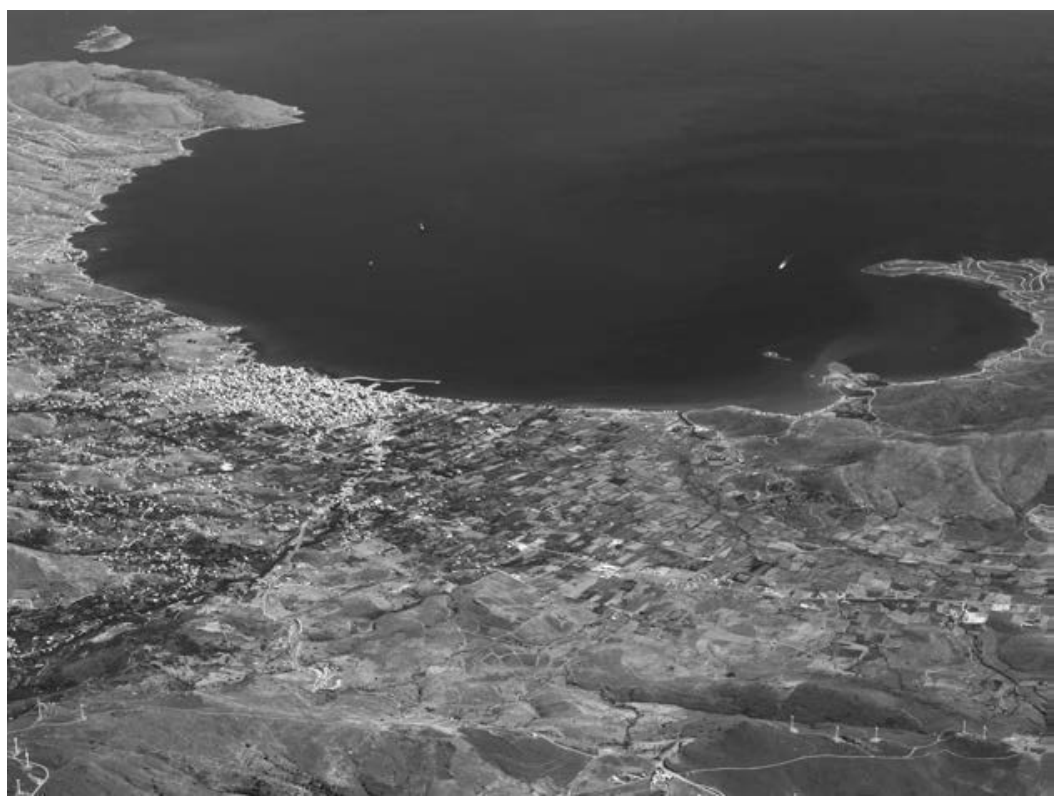

Abb. 6 a: Die Bucht von Karystos - Überblick von Norden (von links nach rechts: MandiliInsel und Kap Bouras - moderne Stadt Karystos - Ebene Kampos - Plakari, daneben kleines Kap und winzige Vor-Insel, rechts davon der Beginn der Paximadi-Hügel - Kap Mnema)

fortsetzt (Abb. 6a/b-8). Die Bay von Karystos diente (und dient bei starkem Sturm vor der Weiterfahrt in die Ägäis selbst großen Schiffen noch heute) zudem auch als Ankerplatz. Ob es allerdings hier an der Küste einen regelrechten Hafen - gar einen direkt „,in den Stadtbereich einbezogenen Hafenplatz" (s. Anm. 30 zur Übersetzung) - gegeben hat, ist mehr als fraglich: Von einer Verlade-Mole haben die frühen Reisenden ${ }^{15} \mathrm{im}$ 19. Jahrhundert nichts berichtet, dagegen waren und sind immer noch die Weite der Bucht und die Anfälligkeit gegen Fallwinde vom Oche herab sowie gegen die sommerlichen Etesien (Meltemia) ${ }^{16}$ für einen Hafen sehr ungeeignet; jeder Besucher wird fast an jedem Tag des Jahres genau das Gegenteil von dem erleben, was Dion (§ 23) mit dem Bild eines ruhigen, Teich-artigen Be-

\footnotetext{
${ }^{15}$ Als Schaubert 1847, also zwei Jahre nach der Neu-Gründung von Karystos (unter dem Namen Othonopolis: s. Koumanoudis 1988), mit dem Kutter in die Bucht unter dem Oche einlief, gab es neben dem Bourtzi-Fort bereits ein „Molo“: SсHAUвERT 1847, doch hat er dieses nicht als antike Installation beschrieben. BuRsIAN 1872, 432 interpretierte wenig überzeugend eine Mauer „am Strande“ als Teil einer Mole.

${ }^{16}$ Philippson 1951, 629 (,Die Bai ist schweren umlaufenden Böen vom Lande her, Fallwinden von der Ócha herunter, ausgesetzt und daher nicht ganz sicher."); KeLLER 1985, 46 mit weiterer Literatur.
} 


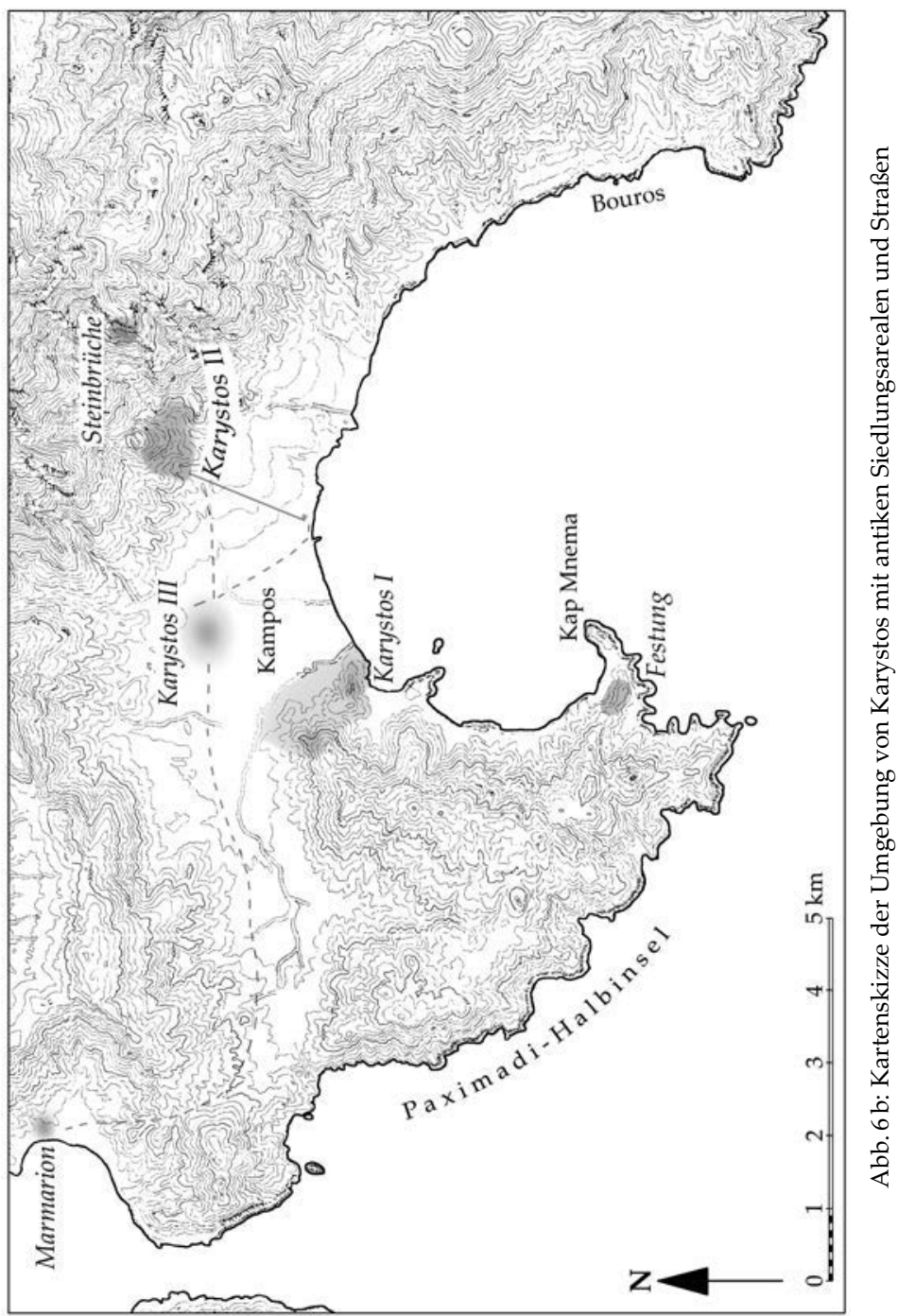

ckens vor Augen stellt. In der Neuzeit wurden die künstlichen Molen (s. Abb. 9) zum Schutz der Fischerboote aufgrund der unangenehmen Winde zwar immer mehr ausgebaut, dennoch aber ist der Fährbetrieb zwischen Raphina (Attika) und Karystos inzwischen eingestellt und nach Marmari(on) verlegt worden. Archäologische Forschungen jüngerer Zeit ${ }^{17}$ haben

\footnotetext{
${ }^{17}$ Wallace 1972, 70-73; 78-81 mit Anm. 1; Goette 1994, 265f. mit Anm. 13f.
} 
zudem gezeigt, dass im Bereich des modernen Hafens offenbar in der Antike, nämlich in der römischen Kaiserzeit, ${ }^{18}$ im Rahmen des kaiserlichen Marmorhandels vom sog. karystischen Stein (Cipollino) Säulen verladen wurden; doch wird jene Tätigkeit angesichts der topographischen und klimatischen Gegebenheiten keinen großen Umfang gehabt haben. Dies belegt eindrucksvoll der Vergleich mit anderen Hafenplätzen in der näheren Umgebung: Denn einerseits wissen wir vom Ausbau eines kaiserzeitlichen Hafens für den Marmortransport in der westlich von Karystos gelegenen Bucht von Marmarion, ${ }^{19}$ die vor den Fallwinden des Oche besser geschützt und zudem durch die vorgelagerten Petaloi-Inseln auch vor der Wirkung der gefährlichen Stürme bewahrt war; andererseits ist eine antike Straßenverbindung auf der nördlichen Hangseite des Kampos-Tales (Abb. 6b: gestrichelt) bekannt, die den Transport des abgebauten Cipollino von den Steinbrüchen am Oche-Hang nach Westen bis nach Marmarion ermöglichte und dabei einen römisch-kaiserzeitlichen Vorort von Karystos (Abb. 6b: 'Karystos III') passierte. ${ }^{20}$ Schließlich ist auch der Vergleich mit einer weiteren Verladestelle für Cipollino aufschlußreich: Beim modernen Örtchen Nimborio, in dessen Toponym noch der antike Begriff Emporion enthalten ist (Abb. 1), sind nicht nur antike Steinbrüche und von Türmen bewachte Transportstraßen bekannt, sondern in der geschützten Bucht existieren zudem eindrucksvolle, aus großen Marmorblöcken bestehende Reste einer kaiserzeitlichen Mole ${ }^{21}$ eine Einrichtung, die eben in der Bucht von Karystos nicht nachgewiesen werden konnte. Bereits aufgrund dieses Faktums

\footnotetext{
${ }^{18}$ Freilich läßt sich nicht ausschließen, dass auch noch viel später, etwa durch die Venezianer, antike Bauteile abtransportiert wurden und beim Verladen ins Meer fielen, s. dazu Goette 1994, 291 mit Anm. 53. - Zur wichtigen Steinbruchtätigkeit bei Karystos s. u. S. 188 mit Anm. 57.

${ }^{19}$ Baumeister 1864, 27; Bursian 1872, 431; Geyer 1903, 106; Philippson 626; Wallace 1972, 70-73; KELLER 1985, 223-225. Von dem literarisch überlieferten Apollon-Tempel sind bislang keine sicher zuweisbaren Reste entdeckt worden, anders, jedoch ohne Beleg $\mathrm{H}$. KALCYK, in DNP 7 (1999) 927 s. v. „Marmarion“.

${ }^{20}$ KeLLER 1985, 222-225; die an der Kreuzung mehrerer antiker Straßen liegende kaiserzeitliche Siedlung 'Karystos III' befindet sich im Gebiet des heutigen Alamanaïka, unmittelbar westlich eines Flussbettes (Megalorhevma), das von den Oche-Hängen im Gebiet der hellenistisch-römischen Stadt herkommt. Schon E. SCHAUBERT hatte 1847 in diesem Gebiet 'Karystos III' zahlreiche antike Spuren beobachtet. In der Nähe von Alamanaïka hat man große Tonvorkommen sowie Töpferbetriebe für die antike Keramik- und Terrakottenproduktion, zudem zahlreiche Gehöfte und auch ein archaisches Heiligtum entdeckt, s. Keller 1985, passim; Chiridoglou 2006 b.

${ }^{21}$ Dazu Schaubert 1847; Papageorgakis 1964; Lambraki 1980; Tsoflias 1982; Zappas 1982; ausführlich zuletzt VANHOve 1996, 22-38, bes. 22f. mit Abb. 43f.; die Steinbrüche liegen oberhalb von Nimborio am Hang des Pyrgari; oft behandelt ist der Turm (besser: das Turmgehöft) östlich oberhalb der Bucht: zuletzt mit der älteren Literatur REBER 2002, 50 Taf. 12, 4; Chiridoglou 2008/9, 46f. Abb. 10. - Eine Hafenmole sahen Baumeister (1868, 24f.) und Bursian $(1872,431)$ zudem auch in Styra, jedoch ist davon heute nichts mehr erhalten.
} 
ist die Rekonstruktion eines regelrechten, d. h. ausgebauten Hafens ${ }^{22}$ an der Bay von Karystos nicht wahrscheinlich; die hier angesprochene Skepsis wird aber durch weitere Indizien noch maßgeblich gestützt. Die sied-

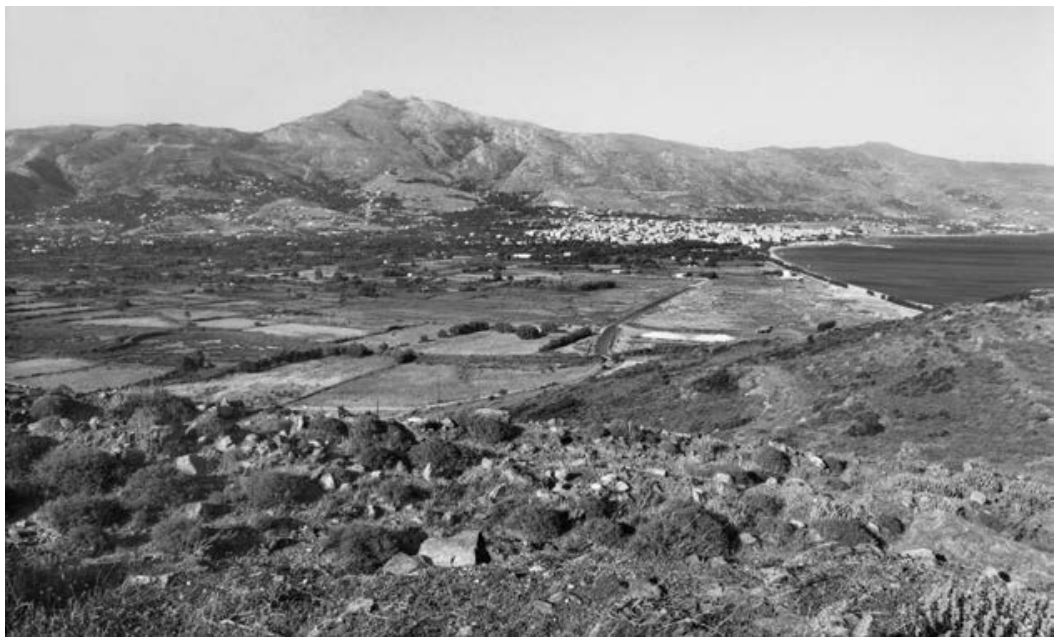

(a) Blick von Plakarí über Kampos nach Karystos mit dem Oche im Hintergrund

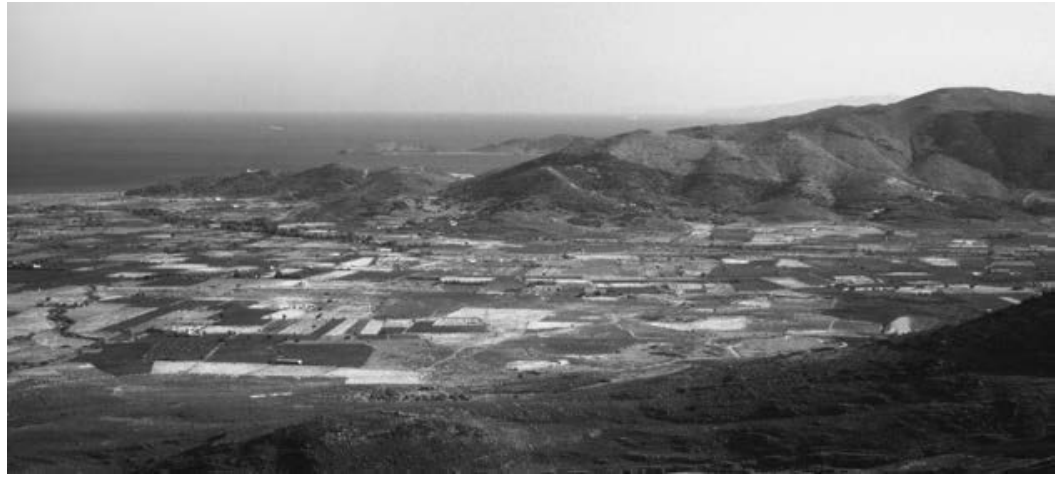

(b) Blick von Norden über Kampos auf Plakarí und die Paximadi-Ostküste mit Kap Mnema

Abb. $7 \mathrm{a}-\mathrm{b}$

lungsarchäologische Forschung der letzten Jahrzehnte ${ }^{23}$ hat für die gesamte Umgebung des modernen Karystos nämlich folgende Entwicklung er-

\footnotetext{
${ }^{22}$ Keller 1985, 225: „The fact that Karystos had no formal port facilities at the shore of the bay, three kilometers south of the Roman city, accounts for the lack of evidence of a port quarter".

${ }^{23}$ Zum folgenden s. insbesondere Keller 1985. Zuvor schon WALlace 1972. Zusätzlich zu diesen grundlegenden Arbeiten s. die Vorberichte der Forschungen des SEEP-Teams:
} 


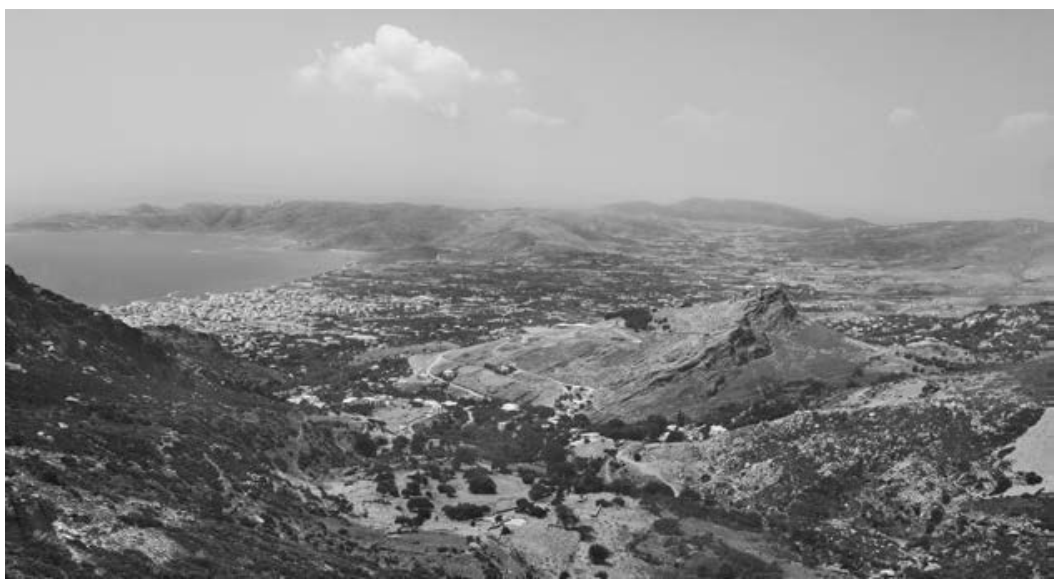

Abb. 8: Blick von den Steinbrüchen oberhalb von Palaiokastro ('Karystos II') über Castel Rosso in die Ebene von Kampos in Richtung auf Marmari (oben rechts hinter den Hügeln und vor den Petaloi-Inseln) und auf die Paximadi-Halbinsel (links)

mittelt (Abb. 6b): Die erste Polis Karystos hat am Nordostende der die Bay von Karystos westlich begrenzenden Paximadi-Halbinsel gelegen (Abb. 7-8) und wurde überragt von einem geometrisch-archaischen Heiligtum ${ }^{24}$ auf der Anhöhe namens Plakarí. Die Wohnsiedlung, die sich wohl bis in die Ebene zum Rhigia-Fluss hin erstreckt hat, ist heute durch Schwemmboden zugedeckt; ob sie je eine Stadtmauer besessen hat, wie die ältere Forschung aufgrund einer Herodot-Nachricht ${ }^{25}$ immer - aber wohl nicht ausreichend begründet ${ }^{26}$ - erschlossen hat, ist derzeit archäologisch nicht nachweisbar;

Keller 1987. 1989. Keller / Wallace 1986. 1987. 1988. 1990. 2006; Kosso 1989. 1996; S. A. H. KEnNELL, "The fieldwork of the Canadian Archaeological Institute at Athens 2003“, Mouseion 48 (2004) 331-344 und ders. „The fieldwork of the Canadian Archaeological Institute at Athens 2004", Mouseion 49 (2005) 287-301.

${ }^{24}$ Zuletzt zum Heiligtum von Plakarí: CHIRIdoglou 2004.

${ }^{25}$ Herodot VI 99: Die Perser belagerten die Stadt auf dem Weg von Delos nach Eretria, nachdem die Karystier sich zunächst nicht ergeben und den Persern gegen Athen und Eretria anschließen wollten. Nahezu alle Interpreten von Herodots Historien, Historiker der Perserkriege und Stadtmauer-Forscher, haben diese Nachricht auf die Existenz einer Befestigung von Karystos bezogen, s. zur letzteren Gruppe stellvertretend etwa F. E. WINTER, Greek Fortifications (Toronto 1971) 61-64. 108 Anm. 18. 298.

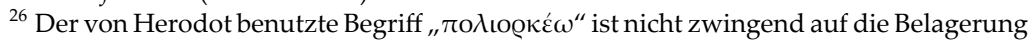
einer ummauerten Siedlung zu beziehen - die Karystier mögen etwa die Landung der persischen Flotte am Strand eine Zeitlang verhindert haben, während die Perser die Bucht von Karystos und die übrige Küste mit ihrer Flotte geschlossen und somit die Siedlung von der Außenwelt abgeschnitten, also belagert haben. - Es ist in diesem Zusammenhang auch zu beachten, dass längst nicht alle großen und bedeutenden archaischen Poleis eine Stadtmauer besaßen. Dies gilt zwar für Eretria (C. KRAuse, Das Westtor, Eretria 4 [1972]; S. FACHARD, „L'enceinte urbaine d'Erétrie“, AntK 47, 2004, 91-109; Ducrey u.a. 2004, 178-185), 
wenn dies der Fall gewesen sein sollte, so kann es sich wohl nur um einen Schutzwall aus Lehmziegeln auf einem Steinsockel gehandelt haben, der dann aber nicht zu Dions Zeiten Anlass für die geschilderte eindrucksvolle Stadtmauer mit Türmen gewesen sein kann - eine solche Mauer, die viel Pflege erfordert, wird in der Kaiserzeit schon lange Jahrhunderte nicht mehr existiert haben.

Die sandige Bucht östlich unterhalb des genannten Kultplatzes auf der Anhöhe Plakarí war ein geeigneter Landungsplatz für Schiffe, die man dort auf den Strand ziehen konnte; aber auch dieser Naturhafen kann nicht Dions Bild von vor Anker liegenden Schiffen auf einer Teich-ähnlichen ruhigen Wasserfläche hervorrufen.

In frühklassischer Zeit wurde die gesamte Paximadi-Halbinsel südlich von 'Karystos I' mit kleinen Gehöften besiedelt; dass diese (zumindest teilweise) von athenischen Kleruchen angelegt und genutzt wurden, belegen Grabungsfunde ebenso wie die Existenz einer an strategisch günstiger Position gelegenen kleinen Festung beim Kap Mnema an der Südostseite von Paximadi. ${ }^{27}$

Gegenüber, auf der östlichen Seite der Bucht auf der Halbinsel von Bouros, befanden sich an einer Straße zum Hafenort Geraistos in klassischer bis hellenistischer Zeit weitere Bauernhöfe; zudem hat man eine Töpferwerkstatt für einfaches Kochgeschirr und einen Wachturm entdeckt. ${ }^{28}$ Wie die lockere Besiedlung der hügeligen Paximadi-Halbinsel ist also auch hier am Hang des Höhenzuges von Kap Mandili (auch Kap Geraistos) eine echte, zumal befestigte Stadt klassischer, hellenistischer oder römischer Zeit nicht vorhanden.

aber z. B. nicht für Chalkis (pointiert S. C. BAKHuizen, Studies in the Topography of Chalcis in Euboea. Chalcidian Studies I [Leiden 1985] 91; „There is no evidence for an Archaic or fifth century city wall of Chalcis", eine Aussage, die sich bis heute auch nach vielen Ausgrabungen bestätigt hat). Freilich besaß Chalkis eine befestigte Akropolis auf einem östlich gelegenen Bergrücken. Dasselbe scheint auch für Styra zu gelten: Die Siedlung lag nahe dem Meer in der Ebene, war auf mehrere kleine Hügel verteilt, hatte aber östlich oberhalb auf dem Kliosi-Berg (beim mittelalterlichen Kastro Larmena) eine zumindest im 4. Jh. stark bewehrte Akropolis (SACKETT u.a. 1966, 78-80 Nr. 88; mit anderer Interpretation: GeHRKE 1988, 25 mit Anm. 57 und Reber 2002, 43-45 mit Anm. 32).

${ }^{27}$ Wallace 1972, 74-77; Keller 1985, 206f.; Keller 1982. 1983. 1987. 1988. In spätrömischer und byzantinischer Zeit wurden auf Paximadi zudem auch landwirtschaftliche Betriebe geführt (Kosso 1989), die wie diejenigen Farmen jener Epoche in der Kampos-Ebene deutlich größere Flächen bearbeiteten. Zu den antiken Siedlungsresten in der KamposEbene s. demnächst auch Z. TANosić / M. Chiridoglou in den Akten der Tagung „Styria Gaia“, 3.-5. 7. 2009 in Styra (Hrsg. Demos Styron, I. Liritzis).

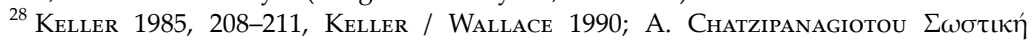

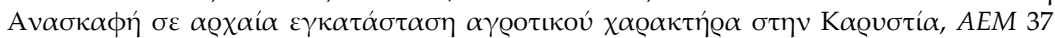
(2007) 7-18; demnächst auch J. Wickens in den Akten der Tagung „Euboea and Athens: a Colloquium in Memory of Malcolm B. Wallace“, Athen 26.-27. 6. 2009 (Hrsg. Canadian Institute in Greece, A. TomLinson). 


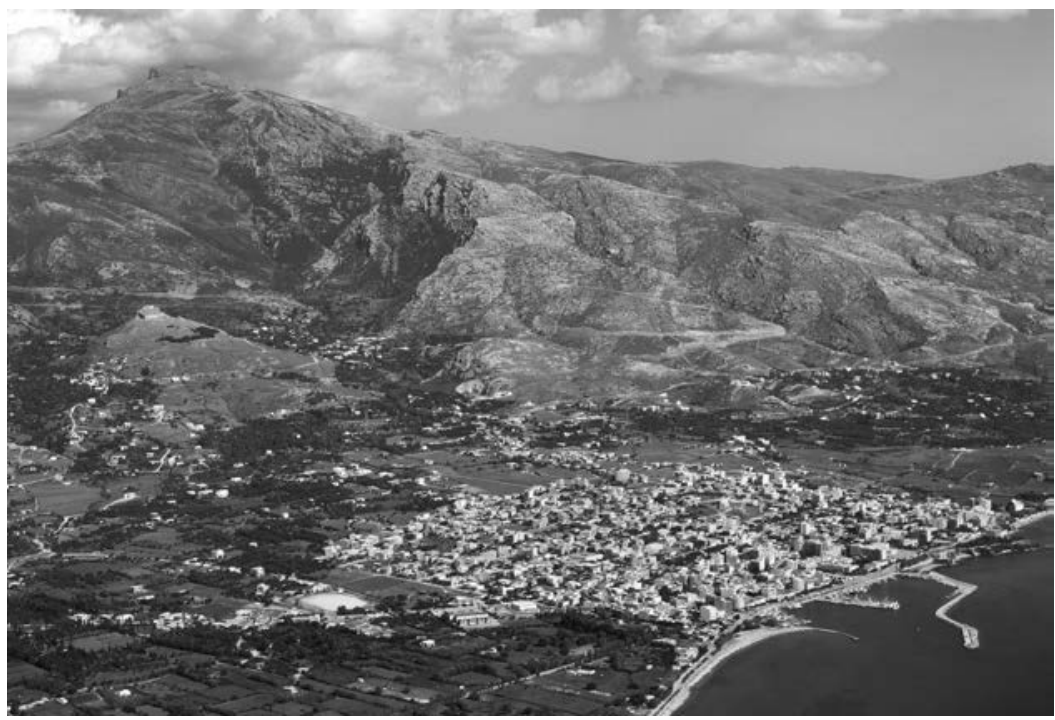

Abb. 9: Überblick von Nordwesten auf Karystos und das Gebiet von Palaiochora mit dem Castel Rosso; darüber der Oche-Gipfel

Dasselbe gilt schließlich auch für das gesamte Gelände der modernen Stadt Karystos, die 1845 als Othonopolis ${ }^{29}$ an der Küste gegründet wurde, aber nur sehr langsam wuchs - viele Insulae des von klassizistischen Architekten im sog. hippodamischen System entworfenen Stadtplans werden erst in den letzten Jahren bebaut, viele von ihnen blieben über mehr als 100 Jahre leer. ${ }^{30}$ Immer dann, wenn in diesem modernen Stadtgebiet (Abb. 9) ausgegraben wurde, stieß man nie auf Siedlungsspuren, sondern allenfalls auf Nekropolen oder einzelne Gräber, ${ }^{31}$ in einem Fall sogar auf

\footnotetext{
${ }^{29}$ Koumanoudis 1988. - Anwachsen der Einwohnerzahl der Stadt: 1889: 1278; - 1928: 1866;-1940: 2901;-1951: 3118;-1971: 3550;-1991: 4663; dazu s. Philippson 1951, 631 und

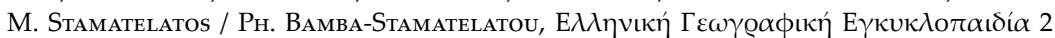
(Athen o. J., ca. 1995) 58 s. v. Karystos 2 (mit 2 Abb.).

${ }^{30}$ Richtig und weit vorausschauend deshalb schon Schaubert 1847: „Die neue, hier regelmäßig angelegte Stadt, $\mathrm{O} \theta \omega \nu$ ó то $\lambda\llcorner\varsigma$ genannt, besteht erst aus 25 bis 30 Häusern und verspricht wenig für die Zukunft, indem die Einwohner die jetzige, eine Stunde oberhalb gelegene, in viele Viertel zerstreute Stadt, schwerlich ihre Häuser und fruchtbaren Gärten und namentlich das reichlich fließende Wasser verlassen werden, um sich an der schlechten Reede, wo kein Handel ist, anzubauen“; s. auch die alten Pläne und Photographien in Koumanoudis 1988; vgl. auch Luftbilder aus den 40er Jahren des 20. Jhs. mit solchen in Google Earth oder hier Abb. 9.

${ }^{31}$ Keller 1985, 291f.; A. Chatzidimitriou, „New Excavation Data from Ancient Karys-

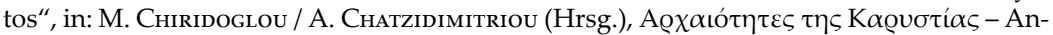
tiquities of Karystia (Karystos 2006) 52-91; CHIRIdoglou 2006. - Abweichend von der allgemein bezeugten Chronologie der Nekropolen auf der Nordostseite der Bucht förderte
} 
das marmorne Mausoleum eines bedeutenden, offenbar im kaiserlichen Cipollino-Abbau und -handel engagierten römischen Beamten. ${ }^{32}$ Dabei hat sich anhand der Grabbeigaben gezeigt, dass die Bestattungen erst seit dem mittleren oder späteren 4 . Jh. v. Chr. hier stattgefunden haben, was darauf schließen läßt, dass erst seit jener Zeit auf der Nordostseite der Bay von Karystos in größerem Umfang gesiedelt wurde. Und tatsächlich haben schon die frühen Besucher der Gegend festgestellt, dass nicht an der Küste sondern etwa drei Kilometer nördlich des Strandes, an den Hängen des Oche antike Siedlungsspuren zuhauf existieren.

Weil sich also einerseits im modernen Stadtgebiet von Karystos keine größeren Stadtreste aus den Jahrhunderten vor der spätklassischen Epoche nachweisen lassen, andererseits die archäologischen Befunde in der Gegend von Plakarí von geometrischer Zeit bis in das 5. Jh. v. Chr. reichen, muss geschlossen werden, dass man das karystische Polis-Zentrum um 350 v. Chr. oder etwas später von der Westseite der Bucht auf deren Ostseite verlegt hat. Dort hat es dann bis in die Neuzeit bestanden, und zwar im Gebiet der heutigen Gemeinden Drynomiá und Grampiá, die unterhalb des venezianischen Castel Rosso in einer wasserreichen Gegend am Hang liegen, bis heute auch unter dem Namen Palaiochora ${ }^{33}$ bekannt (Abb. 9). Dieses Toponym ist offensichtlich am hellenistisch-kaiserzeitlichen sowie auch mittelalterlichen Siedlungsareal fixiert, weil man immer gesehen hat, dass hier gutes Baumaterial ${ }^{34}$ und zahlreiche Funde die lange Wohntradition belegen. Jenseits eines Flusslaufes (das Megalorhevma), den eine Brücke überspannte, begann im Süden der Stadt eine schnurgerade Straße (Abb. 6b), an der zu Beginn eindrucksvolle Grabterrassen, sonst allerdings meist einfachere Nekropolen lagen; am Ende der Straße erhob sich dann der oben erwähnte repräsentative Grabbau in der Form eines peristylen Tempels. ${ }^{35}$ Die meisten antiken Inschriften auf Stelen oder Basen, viele Skulpturen und Bauglieder sowie dichte Scherben- und Dachziegelstreuungen sind in Palaiochora, nördlich des von der Brücke überspannten Flusslaufes bezeugt; eine recht große Menge von antiken Materialien ist

nur eine der neuen Ausgrabungen ältere Befunde, nämlich solche von Gräbern des frühen 5. Jhs. v. Chr., zutage; doch liegt diese Nekropole westlich außerhalb der modernen Stadt, entfernt also von der Gräberstraße, am Rand der Kampos-Ebene: CHIRIDoglou 2006a, 122-140 (Nekropole auf dem Papachatzis-Grundstück).

${ }^{32}$ Goette 1994.

33 So schon Baumeister 1864, 27; Lolling 1877, 420f.; unsicher und mit Bezug auf Dion: Geyer 1903, 102-108; Wallace 1972, 8-11. Zu den Inschriftfunden s. Ziebarth 1939; Choremis 1971; Wallace 1972, 287-336.

${ }^{34}$ Es besteht aus dem lokalen Sandstein, der von den Brüchen auf Kap Mnema (bei der klassischen Festung nahe dem Paximadi-Kap) stammt, sowie aus (oft pentelischem) Marmor. $\mathrm{Zu}$ archäologischen Grabungen im Gebiet s. zuletzt: CHIRIDOGLOU 2008/9, 43f. mit Abb. 8-9.

${ }^{35}$ Zuletzt Goette 1994, 283f. mit Abb. 18; Chiridoglou 2006a, 100 mit Karte. 
auch heute noch beim Gang durch die Zitronenhaine des Gebietes zu entdecken. Die kontinuierliche Lebensdauer dieser Siedlung von frühhellenistischer Zeit bis in die spätantike ${ }^{36}$ und byzantinische ${ }^{37}$ Epoche und darüber hinaus - betrachten wir etwa das venezianische Castel Rosso, ${ }^{38}$ das Palaiochora weithin sichtbar überragt (Abb. 9) - wird durch all diese Denkmäler eindrucksvoll belegt. Und so wird unmittelbar klar, dass hier - also fern der Küste und eines etwaigen Hafens, der dann aber ohne eigentliche Hafensiedlung ${ }^{39}$ und somit nicht in die Stadt Karystos einbezogen war die Polis gelegen hat, die Dion vor Augen gestanden hätte, hätte er mit seiner Beschreibung der Stadt denn tatsächlich Karystos gemeint.

Kehren wir noch einmal zum Problem des Hafens zurück. Haben wir einerseits bereits gesehen, dass in der Bucht von Karystos keine bedeutende Hafenanlage existiert haben kann, so erstaunt andererseits, dass auf eine solche scheinbar durch zwei Inschriften, ${ }^{40}$ die das Kollegium von $\mathrm{Li}$ menophylakes als karystische Amtspersonen bezeugen, verwiesen wird. Da diese sog. Polizisten nur für Karystos belegt sind, ist nicht genau zu klären, welche Aufgaben sie im einzelnen hatten; die Bedeutung des Amtes für die Stadt geht aber aus der langen Zeitspanne hervor, die es nach den Inschriften existiert hat, als auch durch die Mitgliederzahl des Kollegiums (sechs in einem hochhellenistischen Schaltjahr, drei in der späteren Inschrift). Demnach müssen die Limenophylakes an einem wichtigen Hafen gearbeitet haben, und das kann im Polis-Gebiet von Karystos zu jener Zeit nur Geraistos ${ }^{41}$ gewesen sein (Abb. 1. 5. 10). Denn dieser Platz war einerseits wegen seiner besonderen Position im Netz der Seerouten sowie andererseits wegen seiner weit über Euböa hinausreichenden Bedeutung des dortigen Poseidon-Heiligtums mit Asylierecht eine ,international' wichtige Stätte, eng verbunden mit Kalauria und Tainaron (Abb. 10), aber auch mit anderen Orten der Ägäis. ${ }^{42}$ Dass der Rat von Karystos diesen Hafen-

\footnotetext{
${ }^{36}$ Die Tatsache, dass man in Karystos eine Fassung des diokletianischen Preisediktes aufstellte, ist ein sprechender Beleg für die Bedeutung der Stadt noch im beginnenden 4 . Jh. n. Chr., s. S. Lauffer, Diokletians Preisedikt (Berlin 1970/1) 26f. mit Taf. $13 f$.

${ }^{37} \mathrm{Vgl}$. z. B. größere Baureste jener Zeit: Kosso 1996.

${ }^{38}$ KODER 1973, 118-125.

${ }^{39}$ Keller 1985, 225 (s. o. Anm. 22). - Zu der Annahme, dass bei Karystos selbst kein regelrechter Hafen angelegt war, passt auch die Liste bei Ps.-Skylax, Periplus 58, wo Eretria, Chalkis und Histiaia jeweils ausdrücklich mit einem Hafen, Karystos aber nur allein, ohne einen solchen genannt wird, dazu s. GEYER 1903, 102.

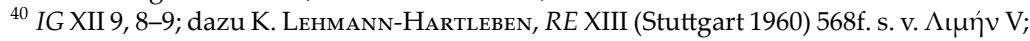
Day 1951, 230; WALlace 1972, 313f.

${ }^{41}$ Ältere Literatur zu Geraistos: s. o. Anm. 11. In der tiefen, geschützten Bucht wurden auch Reste einer Mole beobachtet.

${ }^{42}$ Schumacher 1993, bes. 67f. 77-80 mit Darlegung der (auch inschriftlichen, s. JAсовson / Sмітн 1968 zur Stele von Kimolos) Quellen. In Geraistos wurden Hafenzölle erhoben (s. Demosth. or. 4,34 für das Jahr 352; Keller 1985, 203; Schumacher 1993, 77), und dafür wurden auch andernorts Beamte eingesetzt (s. Lehmann-Hartleben a. O.). Poseidon-
} 


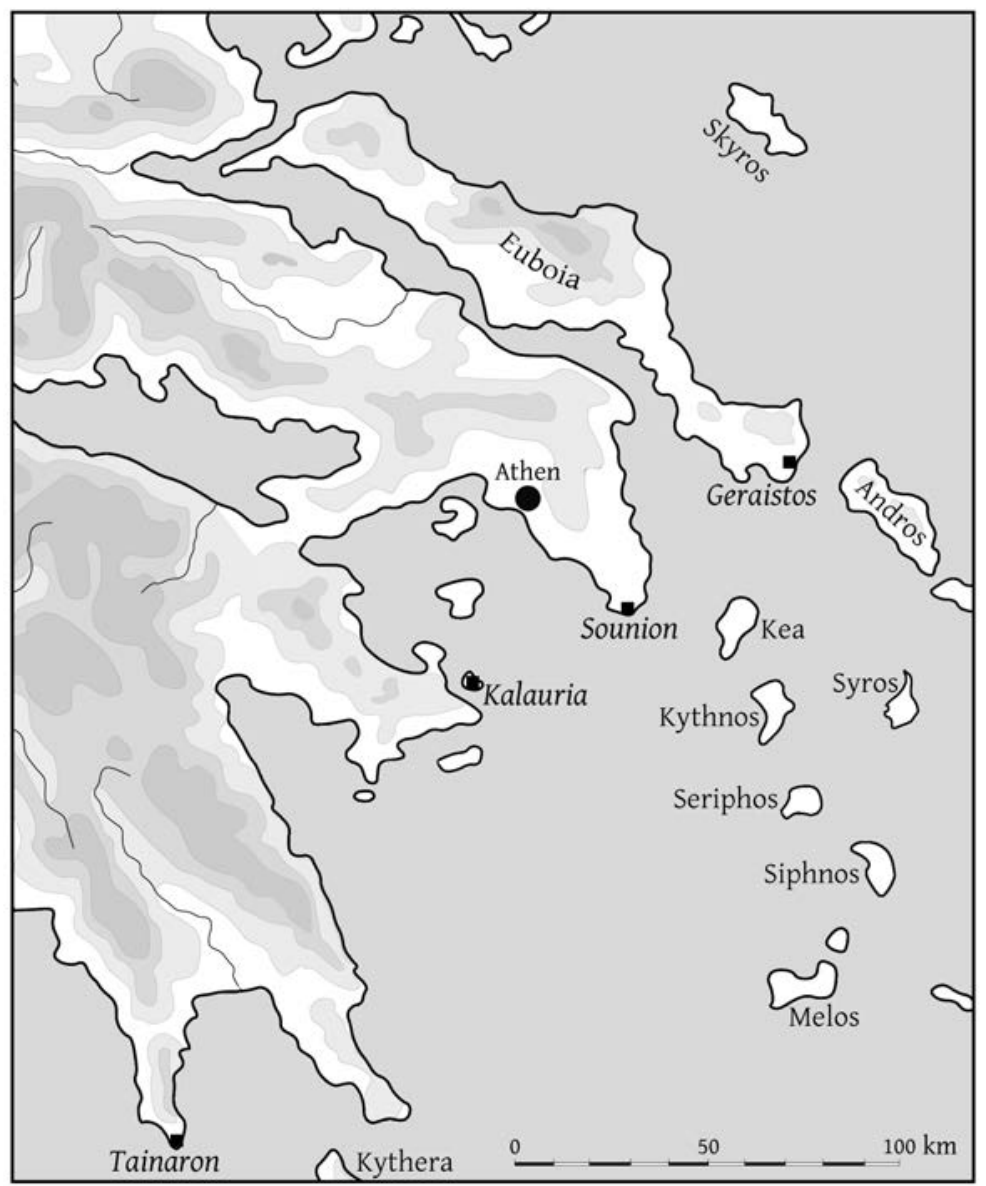

Abb. 10: Kartenskizze Süd-Griechenlands mit den wichtigsten Poseidon-Heiligtümern

platz kontrollierte, geht aus Münzprägungen mit dem Kopf des Poseidon ebenso hervor wie aus der Tatsache, dass dort, also in der Stadt Karystos selbst, über die Aufstellung einer kimolischen Stele in Geraistos zur Ehrung eines karystischen Bürgers entschieden wurde. Zudem hat die Polis Karystos dort Zölle erhoben (wie etwa auch Athen in Sounion), ein Ein-

Heiligtümer an für den Seeverkehr wichtigen Hafenplätzen waren offenbar beliebte Plätze für die Eintreibung von Zöllen, s. dazu etwa auch die Parallele in Sounion (Abb. 10): IG I3 8;

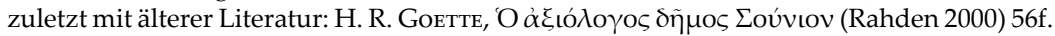
Abb. 120. 
kommen des Staates, das durch das genannte Beamtenkollegium beaufsichtigt worden sein mag. So kann man die Limenophylakes als einen weiteren Beleg für die Bedeutung jenes Hafens interpretieren und eben mit Geraistos, der Bucht beim heutigen Kastri, ${ }^{43}$ und nicht mit dem Hauptort selbst verbinden.

Aufgrund der topographischen Situation an der Bucht von Karystos und der geschilderten Siedlungsgeschichte der Polis sind Zweifel an Dions Autopsie von Karystos schon an diesem Punkte angebracht. Somit ist es umso interessanter zu prüfen, welche der vom Autor beschriebenen übrigen Charakteristika der Stadt sich mit dem, was wir von der antiken Siedlung im Bereich von Palaiochora kennen, vereinbaren lassen.

Die Stadtmauer schildert Dion als mächtiges, mit Türmen besetztes Bauwerk. Von einem solchen sind im Gebiet der hellenistisch-römischen Stadt keine Reste gefunden worden. Denn die Mauerstücke, die bisweilen in der älteren Forschung ${ }^{44}$ auf die (vermeintliche, da eben nur ${ }^{45}$ bei Dion erwähnte) Siedlungsbefestigung bezogen wurden, gehören zu einem Analemma, das aus groben, teilweise naturbelassenen großen Steinen aufgeschichtet wurde; es ist bei noch heute bis etwa fünf Metern Höhe leicht geböscht und besitzt nur eine Tiefe von etwas mehr als einem Meter; die Stützfunktion zugunsten einer darüber gelegenen, durch Anschüttung maßgeblich erweiterten Platzanlage wird auch daraus kenntlich, dass die Mauer nur eine Schauseite besitzt, die Rückseite, die im aufgehöhten Erdreich steckt, dagegen ohne Ausarbeitung auskommt und - ganz entsprechend der groben Blockzurichtung - unregelmäßig und nicht auf Sicht gebildet ist.

Handelt es sich bei dieser Ruine also nicht um eine Stadt- oder Akropolismauer, so ist zu konstatieren, dass Dions anschauliche Bemerkung über die karystische Befestigung vor Ort nicht bestätigt werden kann; denn auch in den spät- und nachantiken Gebäuden im Gelände von Palaiochora findet man keine Spolien - erst recht keine in der zu erwartenden Zahl -, die man auf ein solches Bauwerk beziehen könnte.

Somit richtet sich der Blick auf die Mauern des Castel Rosso (Abb. 8-9. 11), der venezianischen Burg auf einem steilen Felsen, die auf den ersten Blick wie eine antike Akropolis wirkt. Und eine solche $a r x^{46}$ hat Livius für

\footnotetext{
${ }^{43}$ Der Name rührt von einem hier einst vorhandenen Kastell her, von dem noch geringe Reste erhalten sind: CHIRIDoglou 2008/9 und 2009; zum mittelalterlichen Kastri: Koder 1973, 122.

${ }^{44}$ Rhangabé 1852, 33; Bursian 1872, 432; Philippson 1951, 630; Choremis 1971, 263 Taf. $233 \mathrm{~d}$; zuletzt wieder Chiridoglou 2008/9, 42 mit Anm. 33 Abb. 7. - Wie hier vorgeschlagen interpretieren die Mauerreste auch Lolling 1877, 421 und KelLer 1985, 132 Nr. 86.

${ }^{45} \mathrm{Zu}$ der im Zusammenhang einer Herodot-Stelle vermuteten spätarchaischen Stadtbefestigung s. o. S. 179 mit Anm. 25f.

${ }^{46}$ Liv. XXXII 17. Zur Burg Castel Rosso: Koder 1973, 118f. - Zu den zuvor erwähnten Stützmauer-Resten s. KeLLer 1985, 218.
} 
Karystos überliefert. Doch auch hier gilt derselbe negative Befund wie für Palaiochora: Im gesamten Gelände des „Kokkinokastro“47 gibt es keine antiken Scherben oder Dachziegel, und in den hoch aufragenden Mauern der Burg ist nur eine Handvoll antiker (z. T. marmorner) Blöcke verbaut - Castel Rosso nimmt demnach nicht die Stelle einer antiken Akropolis ein, ${ }^{48}$ diese bleibt nach wie vor zu suchen.

Von den übrigen Bauten und Einrichtungen, die Dion für die vorgestellte Stadt nennt, wird das Theater am genauesten beschrieben: Es handelt sich um einen halbrunden Bau, eine Form, die seit dem letzten Drittel des 4. Jhs. v. Chr. die vorherrschende war, wobei das Theatron (auch: Koilon) mit den Zuschauersitzen in griechischen Theatern mehr als ein Halbrund bildete, während römische Theater die Cavea auf genau den halben Kreis beschränkten. Von einem solchen Bau ist wiederum im antiken Karystos keine Spur erhalten, obwohl die geschwungenen Steine, aus denen die Sitzreihen in der Regel - nämlich dann, wenn man sie nicht (wie etwa in Syrakus) aus dem natürlichen Fels meißelte - gefertigt wurden, als Spolien einerseits nur schlecht verwendbar waren, andererseits heute leicht identifizierbar wären. ${ }^{49}$ Immerhin aber gibt es einige Quellen, ${ }^{50}$ die einen Dionysos-Kult in Karystos belegen; und geringe Reste einer ionischen Marmorarchitektur nahe der antiken Brücke über das Megalorhevma im Süden der antiken Stadt wurden hypothetisch auf den Dionysos-Tempel bezogen, weil man die bereits genannte Inschrift IG XII 9, 20 nahebei entdeckt hatte. Doch sind all diese Indizien $\mathrm{m}$. E. nicht ausreichend, Dions Erwähnung des Theaters als einer auf Autopsie beruhenden Nachricht zu vertrauen.

\footnotetext{
${ }^{47}$ So Sкouras 1975, 357f. Nr. 45 Abb. 48.

${ }^{48}$ Die Befunde sind bereits beschrieben von den frühen Reisenden und auch von CHOREMIS 1971, 263 und KELLER 1985, 218f. In früheren Jahren wurden dagegen größere, schwer transportierbare antike Funde aus dem Bereich von Palaiochora zum oder in das Kastell geschafft, s. etwa Choremis 1971, 263 Taf. 233 g (eine Statuenbasis, die nach abermaligem Transport heute vor dem Museum von Karystos steht).

${ }^{49}$ In Palaiochora liegt in einer Kapellenruine (Keller 1985, 145 Nr. 104 Abb. 80) ein marmorner Block mit faszettiertem Bogen und zwei Rosetten, der zwar an solche Bauglieder von der Skene des athenischen Dionysostheaters (E. Fiechter, Das Dionysos-Theater von Athen III [1936] Abb. 14 Taf. 12) erinnert, deshalb aber nicht zwingend auf eine Theaterbühne auch in Karystos zu beziehen ist, da derartige Bögen auch sonst in antiker Architektur bezeugt sind, s. etwa das Tor zu einer langen Säulenstraße auf der Nordseite der Athener Akropolis (Travlos 1971, 38f. Abb. 46f. [das sog. Agoranomion]) oder die Spolien (vielleicht aus dem Eleusinion) in der Kleinen Metropolis-Kirche von Athen: K. Michel / A. STRUCK, „Die mittelbyzantinischen Kirchen Athens“, AM 31 (1906) 281-324 Abb. 8 und 16 Beil. 1f.; P. STEIner, „Antike Skulpturen aus der Panagia Gorgoepikoos“, AM 31 (1906) 325-341.

${ }^{50}$ IG XII 9, 20. - Wallace 1972, 312 Nr. 3. - Weihrelief (wahrscheinlich aus Karystos) in Chalkis, Arch. Mus. 337: G. DAux, „Le relief éleusinien du Musée de Chalcis“, BCH 88 (1964) 443-451; G. Mrlonas, To vт' á@ı AEphem (1965) 1-6. Zum Dionysos-Kult in Karystos: Wallace 1972, 109f.; Chiridoglou $1996 / 7$.
} 
Dies gilt dann auch für die übrigen Angaben. Denn die Erwähnung eines Gymnasiums mit sehr allgemeiner Nennung von typischer StatuenAusstattung $^{51}$ oder die Nennung einer Agora ${ }^{52}$ mit daran liegendem Prytaneum und Buleuterium ${ }^{53}$ passen auf fast jede antike Polis. Und auch die Mitteilung, dass es innerhalb (wie natürlich zudem außerhalb) der Stadt offene, unbebaute Areale gab, die als Viehweiden und Äcker genutzt wurden, wird zwar im Hinblick auf den angestrebten Gesamttenor der Schrift negativ bewertet, muss aber in der antiken Welt keine Seltenheit, sondern geradezu normal gewesen sein. ${ }^{54}$

Es ist also festzuhalten, dass einige der topographischen Schilderungen Dions so allgemein sind, dass sie sich leicht auch auf andere Städte beziehen lassen, jedenfalls nicht für das antike Karystos spezifisch sind, obwohl man aufgrund der Nähe der Stadt zum erwähnten Kap Kaphereus zunächst an jene Polis denken mag. Dies gilt auch für die Angaben, die Dion von der Berglandschaft bei jener Landspitze macht: Sie sind in aller Regel nicht falsch, sie setzen aber die Autopsie des Autors (und damit den geschilderten Schiffbruch, der wie ein Topos anmutet) keineswegs voraus.

Andere Aussagen sind mit jener süd-euböischen Stadt und ihrer Umgebung gar nicht zu verbinden, sie können als regelrecht falsch gelten: Dies betrifft den Hafen ebenso wie die Stadtmauer oder das Theater. Und die Purpurfischerei, die bei Dion als dem einfachen Leben entgegenstehende Erwerbsquelle mit negativer Wertung - sie verdirbt den Charakter der diesen Beruf ausübenden Menschen - erwähnt wird, lässt sich in der Karystia nicht nachweisen.

Umgekehrt verwundert es, dass ausgerechnet solche Industriezweige, die sowohl in der antiken Literatur als auch im archäologischen Befund vielfach bezeugt sind, sich in Dions Bericht nicht finden. Dies gilt einerseits

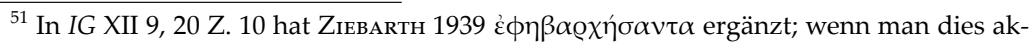
zeptiert, mag damit die Einrichtung eines hellenistischen Gymnasiums in Karystos epigraphisch gestützt sein, s. DAY 1951, 231. - Bildwerke, die Herakles als Schutzherrn solcher Einrichtungen sowie ganz unspezifisch „Heroen und Götter“ darstellen, gehören zur ,Normal'-Ausstattung von Gymnasia, s. R. von Den Hoff, „Ornamenta gymnasiode? Delos und Pergamon als Beispielfälle der Skulpturenausstattung hellenistischer Gymnasien", in: D. КАн / P. Scholz, Das hellenistische Gymnasion. International Conference Proceedings, September 27-30, 2001, Johann Wolfgang Goethe-Universität, Frankfurt am Main. Wissenskultur und gesellschaftlicher Wandel 8 (Berlin 2004) 373-405.

${ }^{52}$ IG XII 9, 20 überliefert ausdrücklich das Amt des Agoranomos in Karystos.

${ }^{53} \mathrm{Zu}$ den Beamten - darunter Archonten, Strategen, Agoranomoi - s. das epigraphische Material aus Karystos bei Ziebarth 1939. Von der Boulé erfahren wir z. B. durch das Ehrendekret aus Kimolos (Jacobson / Sмiтн 1968; Sснumacher 1993; s. o. Anm. 42), s. auch hier Anm. 32 zur Übersetzung.

${ }^{54}$ E. Kirsten konnte deshalb auch in PhiLıppson 1951, 694 für die mittelgriechischen Städte schreiben: „Die ausgedehnten Mauerringe waren selten mit Häusern gefüllt, ein Teil also stets als Fluchtburg gedacht".
} 


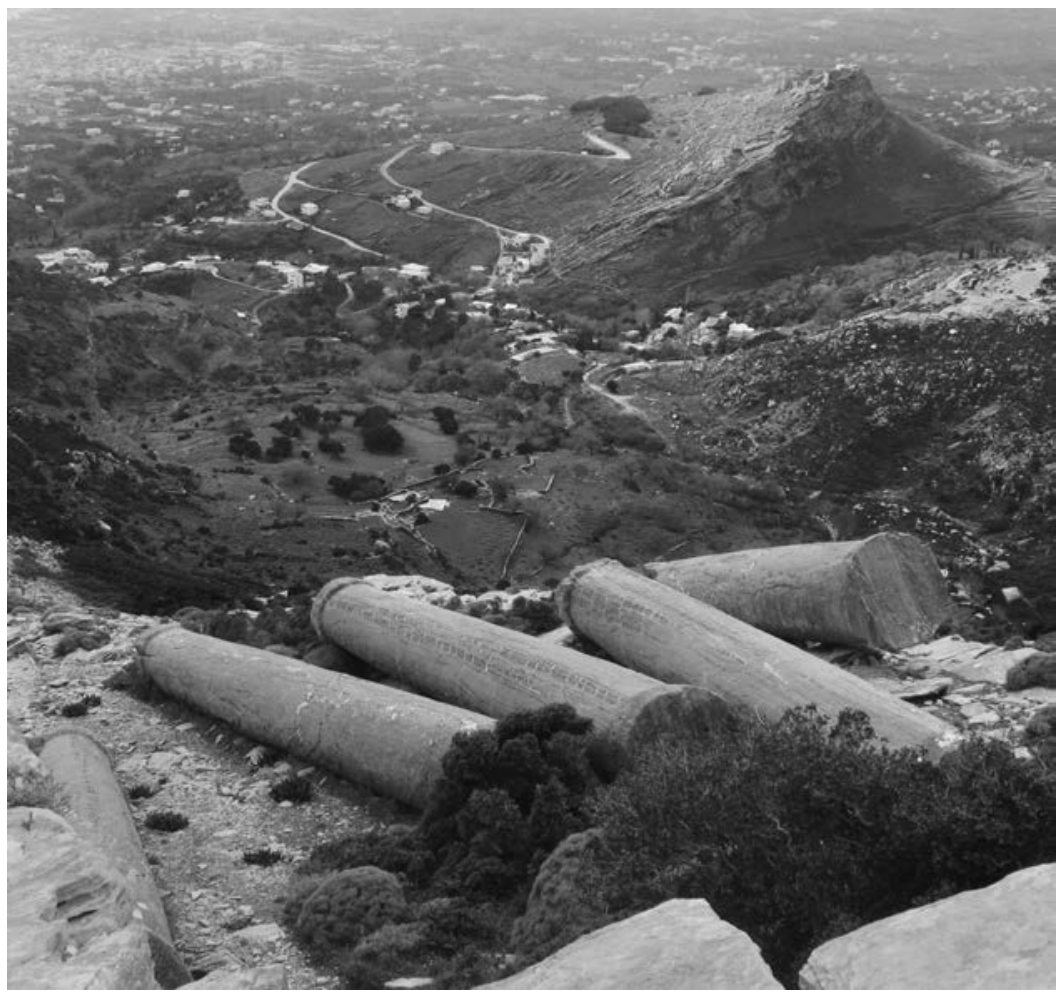

Abb. 11: Die Steinbrüche 'Kylindroi' oberhalb von Palaiochora und Castel Rosso

für den Metallabbau und die Verarbeitung der geförderten Erze, ${ }^{55}$ sodann für die Gewinnung des Asbest ${ }^{56}$ und schließlich für die des Marmors, das Brechen des grün-weißen Cipollino ${ }^{57}$ (Abb. 11). Insbesondere letztere Industrie, die zu Zeiten von Dion in der Karystia fast ihre höchste Blüte erreicht hatte, hätte auch dem ,pädagogischen' Impetus der Schrift - man

\footnotetext{
${ }^{55}$ Erz- und Verhüttung: Philippson 1951, 630. 632; Day 1951, 231 und Keller 1985, 228 (,slag heaps“); 263-266 zum Befund in Archampolis; s. auch Panagopoulou 1995 mit hier Abb. 3 b.

${ }^{56}$ Asbest: Baumeister 1864, 28 mit Anm. 87 mit den Quellen; Geyer 1903, 106 mit Anm. 1.

${ }^{57} \mathrm{Zu}$ den Cipollino-Steinbrüchen: Baumeister 1864, 28 mit Anm. 87; Lolling 1877, 420; Geyer 1903, 106 mit Anm. 1; Philippson 1951, 630; Papageorgakis 1964; V. Hankey, „A Marble Quarry at Karystos“, Bulletin du Musée de Beyrouth 18 (1965) 53-59; LAмвRAкі 1980; Tsoflias 1982; Zappas 1982; Keller 1985, 228; Goette 1994; P. Pensabene, „Le colonne sbozzate di cipollino nei distretti di Myloi e di Aetos (Karystos)“", in: Pensabene 1995, 311-315; M. BRUno, „Su un fusto colossale di cipollino sopra le cave di Kylindroi nel distretto di Myloi“, in: Pensabene 1995, 327-330; Vanhove 1996; Sutherland 2002; s. zudem o. S. 177 mit Anm. 18.
} 
beachte die negative Wertung dieses Luxus in $\S 117$ - gedient, galt doch die Verwendung von buntem Steinmaterial seit republikanischer Zeit als Ausdruck von übertriebenem Luxus; zudem war der Buntmarmor-Abbau und -Handel in der Kaiserzeit das Monopol des Herrschers in Rom, der somit die einfache Bevölkerung , ausbeutete'. Wäre der Autor wirklich nach Karystos gekommen, so hätte er zumindest den aufwendigen, sicher auch überaus geschäftigen Betrieb des Cipollino-Transportes vom Berg hinab (Abb. 11) zu den Verladestellen an der Küste (insbesondere in Marmarion) beobachtet - und es steht zu erwarten, dass er ihn tendenziös kritisiert und als Gegenbild zum ,einfachen, glücklichen Leben der armen Jäger' in ihren Berghütten ausführlich gegeißelt hätte.

Keine dieser für Karystos in den schriftlichen und den archäologischen Quellen so überaus typischen Charakteristika kennt Dion. Zusammen mit den anderen Indizien, die sich aus den topographischen Beobachtungen in der Karystia im Vergleich mit Dions Schrift ergeben, deutet dies für den Archäologen darauf hin, dass es sich im Euboikos Logos nicht um einen Augenzeugenbericht handelt, sondern um ein von topischen und allgemeinen Angaben bestimmtes Bild, das der Tendenz der Schrift geschuldet ist. 



\title{
Was begründet Menschenwürde? Eine antike Antwort auf eine moderne Frage*
}

\author{
Barbara Zehnpfennig
}

\section{Die Problemlage}

„Habt ihr die Blöße bedeckt, gibt sich die Würde von selbst." Mit diesem Schiller-Zitat untermauerte 1956 der Grundgesetzkommentator Günter Dürig seine zuvor entwickelte Position, ein bestimmtes Minimum an Subsistenzmitteln sei für den Menschen unerlässlich, um ein Leben in Würde führen zu können. Damit nahm sein Artikel über den „Grundrechtssatz von der Menschenwürde ${ }^{\prime 1}$ eine überraschende Wendung. Zuvor hatte Dürig nämlich für ein Verständnis der Menschenwürde plädiert, das diese als Ausdruck einer "Seinsgegebenheit" des Menschen deutete: „Jeder Mensch ist Mensch kraft seines Geistes, der ihn abhebt von der unpersönlichen Natur und ihn aus eigener Entscheidung dazu befähigt, seiner selbst bewusst zu werden, sich selbst zu bestimmen und sich und die Umwelt zu gestalten. ${ }^{2}$ Wenn die Würde des Menschen demnach in einer inneren Disposition liegt, wie kann sie ihm da von außen genommen werden?

Dieses Dilemma ist bezeichnend für die Unsicherheit im Umgang mit dem zentralen und zugleich schillerndsten Begriff liberaler Rechtsstaatlichkeit: Obwohl die Menschenwürde vom Bundesverfassungsgericht als „Wurzel aller Grundrechte ${ }^{\text {"3 }}$ bezeichnet wurde und damit auch als Grundlage der auf ihnen ruhenden politischen Ordnung betrachtet werden kann, sind Reichweite, Begründung und Gehalt der Menschenwürde alles andere als unumstritten. Dass sie nicht zuletzt in der antiken und christlichen Tradition fußt, wird noch allgemein konzediert. ${ }^{4} \mathrm{Ob}$ sie jedoch im Grundgesetz als subjektives oder objektives Recht aufzufassen ist, ob die Achtung vor der Menschenwürde den Staat zur Bereitstellung des Existenzmini-

\footnotetext{
${ }^{*}$ Herrn Kollegen Werner Heun bin ich für seine kritische und intensive Auseinandersetzung mit meinen Thesen zu großem Dank verpflichtet. Das Ergebnis unseres Dialogs fällt allerdings ausschließlich in meine Verantwortung.

${ }^{1}$ Dürig 2008, 186.

${ }^{2}$ DÜrIG 2008, 180.

${ }^{3}$ BVerfGE 93, 266 [293], zitiert nach: DreIER 2004, Rn. 162.

${ }^{4} \mathrm{Zu}$ der komplexen geistesgeschichtlichen Vorgeschichte des Würdebegriffs vgl. HeuN 2009, 59-73.
} 
mums verpflichtet oder nicht, ob die Menschenwürde vorpositiv, möglicherweise sogar naturrechtlich verankert ist oder sich erst der rechtlichen Positivierung verdankt - all dies wird kontrovers behandelt und zeigt eines: Ein oder sogar der Kerngehalt unseres demokratischen Systems, die Würde des einzelnen Menschen, zu deren Schutz sich alle staatliche Ordnung bekennen muss, ist letztlich ungeklärt. Wir sind uns unserer eigenen Grundlagen nicht gewiss.

Das wird an einem so gewichtigen Begriff wie der Menschenwürde besonders deutlich: Hier berühren sich Moralität und Legalität, die Kant so strikt getrennt wissen wollte. ${ }^{5}$ Der Menschenwürde-Paragraph des GG hat einen „ethisch-philosophischen Gehalt", 6 ist aber zugleich Verfassungsnorm. Wenn der Staat der Achtungs- und Schutzpflicht gegenüber der Menschenwürde nachkommen will, die ihm die Verfassungsgeber zugeschrieben haben, muss er auf rechtliche Regelungen zurückgreifen, die ein bestimmtes Verständnis von Menschenwürde implizit immer schon voraussetzen - eben weil Menschenwürde als solche kein juristischer Begriff ist. Doch was ist hier sinnvoller Weise vorauszusetzen? Schon der Streit um die Rechtsnatur von Artikel 1 bezeugt, dass die gegenwärtige Debatte mehr Fragen aufwirft, als Antworten parat zu haben - Anlass genug, einen Blick zurück in die Geschichte zu tun und die Tradition, die anerkanntermaßen unser modernes Selbstverständnis geprägt hat, einer näheren Betrachtung zu unterziehen.

Dion von Prusas Euböische Rede erscheint als der geeignete Bezugspunkt, um zu prüfen, ob sich in der Antike noch jene Klarheit in Bezug auf das Verständnis menschlicher Würde findet, die in der Moderne offenbar verlorengegangen ist. Kann der stoische Würdebegriff, der in der Euböischen Rede zum Tragen kommt, auch heute wieder orientierend wirken? Lassen sich im Rückgang auf die vorchristliche Philosophie Kriterien für die sinnvolle Ausfüllung eines Begriffs von Menschenwürde gewinnen, die auch in einem sich als säkular verstehenden Staat noch Akzeptanz finden könnte? Diesen Fragen soll im folgenden nachgegangen werden. Zuvor aber seien noch einmal zentrale Linien der aktuellen juristischen Kontroverse über die Menschenwürde nachgezeichnet, um das Dionsche Konzept auf die in dieser Kontroverse aufscheinenden Probleme hin untersuchen zu können.

\footnotetext{
5 „Diese Gesetze der Freiheit heißen, zum Unterschiede von Naturgesetzen, moralisch. So fern sie nur auf bloße äußere Handlungen und deren Gesetzmäßigkeit gehen, heißen sie juridisch; fordern sie aber auch, dass sie (die Gesetze) selbst die Bestimmungsgründe der Handlungen sein sollen, so sind sie ethisch, und alsdann sagt man: die Übereinstimmung mit den ersteren ist die Legalität, die mit den zweiten die Moralität der Handlung." (Immanuel Kant, Die Metaphysik der Sitten, Einleitung, Werkausgabe Band VIII, hrsg. von W. Weischedel [Frankfurt am Main 1977] 318.)

${ }^{6}$ Dreier 2004, Rn.1.
} 


\section{Menschenwürde in der aktuellen Diskussion}

Für die juristische Debatte der letzten Jahre war die Neukommentierung des Artikel 1 des Grundgesetzes durch Matthias Herdegen ${ }^{7}$ eine Herausforderung: Sein entschiedenster Kritiker, Ernst-Wolfgang Böckenförde, sah in dem neuen Kommentar das , "ideelle und normative Grundgerüst" , auf dem die deutsche Verfassung bisher ruhte, ernsthaft in Frage gestellt. Nun nämlich sei die Menschenwürdegarantie entgegen bisheriger Deutungstradition nicht mehr als „bewusste Übernahme eines vor-positiven geistig-ethischen Gehalts in das positive Recht ${ }^{\mu 9}$ behandelt. Dadurch werde sie dem Zeitgeist ausgeliefert und somit verhandelbar. Worin bestand Herdegens Neuansatz, und was war diesem vorausgegangen?

Beginnen wir mit dem Letzteren. 1954 hatte der Jurist Carl Hans Nipperdey in seinem Artikel „Die Würde des Menschen“10 den Standpunkt vertreten, die menschliche Würde sei im Wesen des Menschen, seinem „Eigenwert" und seiner "Eigenständigkeit" ${ }^{\prime 11}$ verankert, mithin naturrechtlich begründet. Würde komme dem Menschen als je einzelnem zu, sei angeboren, unverlierbar und auch durch den Sündenfall nicht beeinträchtigt. Damit war ganz klar indiziert, dass das positive Recht jenem Sachverhalt nur Rechnung tragen, ihn aber nicht schaffen konnte. Würde, so die Konsequenz dieses Ansatzes, ist etwas dem Menschen Immanentes, das ihm nicht genommen, aber auch nicht - etwa staatlicherseits - von außen zugesprochen werden kann. Insofern sah Nipperdey im Artikel 1 die „letzte Wurzel und Quelle aller später formulierten Grundrechte und damit selbst das materielle Hauptgrundrecht. “12

In der Auffassung, dass die Menschenwürde selbst ein Grundrecht sei, wollte ihm Günter Dürig in seinem Grundgesetzkommentar, der bis zu der Neukommentierung durch Herdegen maßgeblich blieb, nicht folgen. Zwar ging auch Dürig davon aus, dass die Menschenwürde etwas vorpositiv Gegebenes und damit staatlichem Zugriff Entzogenes sei. Doch erblickte er anders als Nipperdey in der Garantie der Menschenwürde durch die Verfassung eben kein subjektives Grundrecht, sondern ein objektives Prinzip, das den Grundrechten vorausgeht und in ihnen konkretisiert wird. Danach ist der Anspruch auf Achtung der Menschenwürde also Ausdruck eines objektiven sittlichen Wertes, der in subjektive Rechte übersetzt werden muss. Dürig nannte den Art. 1 I GG nach Wintrich daher das ",oberste Konstitutionsprinzip allen objektiven Rechts ${ }^{13}{ }^{13}$ wodurch

\footnotetext{
${ }^{7}$ Herdegen 2003.

${ }^{8}$ BÖCKENFÖRDE 2004, 1216.

${ }^{9}$ BÖCKENFÖRDE 2004, 1218.

${ }^{10}$ Nipperdey 2008, 189-238.

11 Nipperdey 2008, 189.

12 Nipperdey 2008, 200.

${ }^{13}$ Dürig 2008, 175, 178.
} 
die Menschenwürdegarantie zu Basis und Maßstab allen folgenden Rechts wurde. Menschenwürde ist demnach etwas Menschlich-Allgemeines. Ihre Achtung bezeichnet nicht ein Recht des einzelnen, das immer dann zur Geltung gebracht werden müsste, wenn die anderen verbrieften Grundrechte wie Meinungs-, Versammlungsfreiheit etc. den jeweils relevanten Bereich nicht abdeckten. Vielmehr ist die Menschenwürdegarantie in Dürigs Verständnis die "höchstrangige Norm des objektiven Rechts.“ 14

Welcher Stand war mit dieser Einschätzung erreicht? Nipperdey wie Dürig sahen in der Menschenwürde etwas vorpositiv Gegebenes; Nipperdey sprach ausdrücklich von einer naturrechtlichen Begründung, Dürig redete vorsichtiger von einer "Seinsgegebenheit", eben der oben zitierten Auffassung vom Wesen des Menschen, auf die sich die Verfassungsgeber geeinigt hätten, weil Weitergehendes im weltanschaulich neutralen Staat nicht vermittelbar gewesen sei. ${ }^{15}$ Der christliche Hintergrund wird hier also nicht mehr explizit erwähnt. Für Nipperdey stellte der Menschenwürdeparagraph selbst schon ein Grundrecht dar, für Dürig hingegen ein Prinzip, das erst in Menschenrechte aufgelöst werden muss. Worin Menschenwürde liegt, darin sind sich die beiden Autoren wieder ziemlich einig: die „Freiheit sittlicher Entscheidung“ bei Nipperdey ${ }^{16}$ korrespondiert der Betonung der Geistnatur des Menschen, die ihn zur Selbstbestimmung befähige, bei Dürig. ${ }^{17}$ Beide Autoren sehen darin etwas, was den Menschen aus der übrigen Natur heraushebt.

Beide vertreten aber auch die Auffassung, dass unzureichende finanzielle Mittel die Menschenwürde beeinträchtigen. Heißt es bei Nipperdey noch recht allgemein, Menschenwürde könne nicht „völlig unabhängig von den materiellen Gütern des Lebens bestehen", 18 so begründet Dürig seine analoge Einschätzung schon konkreter. Da der Mensch als „Leib-SeeleGeist-Einheit" zu verstehen sei, habe er "als solcher" ohne entsprechende Subsistenzmittel „nicht das, was seine Würde ausmacht, nämlich die Fähigkeit, sich in freier Entscheidung über die unpersönliche Umwelt zu erheben. Er lebt nicht, er vegetiert. " ${ }^{19}$ Wer nun aber angesichts der Bedingungslosigkeit, mit der dem Menschen zuvor Menschenwürde zugesprochen wurde, Zweifel an dieser Begründung bekommt, dem wird beschieden, der konkrete Mensch könne durchaus einen solchen Grad an sittlicher Vollkommenheit erreichen, dass er von den ökonomischen Bedingungen

\footnotetext{
${ }^{14}$ Dürig 2008, 178.

15 Dürig 2008, 180.

16 Nipperdey 2008, 190.

17 Dürig 2008, 180.

${ }^{18}$ Nipperdey 2008, $193 \mathrm{f}$.

${ }^{19}$ Dürig 2008, 185f.
} 
unabhängig ist. Dem Menschen als solchem sei dies jedoch nicht gegeben. ${ }^{20}$

Dass der Mensch an sich offenbar weniger vermag als der konkrete Mensch, mag verwundern. Aber hier zeigt sich nur das generelle Problem: Sobald das, was als intrinsische Eigenschaft des Menschen verstanden werden kann, in eine Rechtsnorm verwandelt wird, zählen nur noch die extrinsischen Bezüge: Das Innere des Menschen kann und soll das Recht nicht regeln. Es kann immer nur das Verhältnis zwischen Staat und Bürgern bzw. der Bürger untereinander normieren. Wenn die Verfassung die staatliche Gewalt dazu verpflichtet, die Menschenwürde zu achten und zu schützen, hat das jedoch Auswirkungen auf das Verständnis dessen, was es zu achten und zu schützen gilt. Denn ist mit einem solchen Gebot nicht unterstellt, dass mit der Verletzung der Achtung zugleich die Würde verletzt ist? ${ }^{21}$

Insofern bleibt eine Ambivalenz. Menschenwürde wird in den dargestellten Positionen zum einen nach der „Mitgifttheorie“ als etwas Angeborenes, Unverlierbares und Unveräußerliches behandelt; ${ }^{22}$ ob man sie nun christlich in der Gottesebenbildlichkeit oder weltanschaulich neutraler in der Natur des Menschen verankert, ist demgegenüber zunächst einmal zweitrangig. ${ }^{23}$ Solche Verankerung signalisiert aber andererseits Unverfügbarkeit und Unabhängigkeit - eine Unabhängigkeit, die nicht gegeben ist, wenn Menschenwürde sich nur unter bestimmten ökonomischen Bedingungen entfalten kann. Gerade wenn die Würde wesentlich in der Freiheit der Entscheidung besteht, wie Nipperdey und Dürig betonen, stellte sie sich selbst in Frage, sofern sie sich diese Freiheit durch die äußeren Bedingungen erst gewähren ließe. Da hilft auch die Unterscheidung von potentieller und aktueller Menschenwürde nicht weiter. Wird meine Entscheidungsfreiheit erst dann virulent, wenn man sie mir gibt, existiert sie de facto nicht.

So erscheint es geradezu als logische Konsequenz, die Spannung zwischen sittlichem Gehalt und rechtlicher Normierung positiv-rechtlich aufzulösen, wie es u.a. Matthias Herdegen bei seiner Neukommentierung von Artikel 1 tat. Nunmehr gibt es nämlich keine vorpositive Begründung der Menschenwürde mehr. Als nur noch positiv-rechtlicher Begriff kann es für

\footnotetext{
${ }^{20}$ Ebd.

${ }^{21}$ Im Erfurter Kommentar zum Arbeitsrecht, (hrsg. von R. MüLLER-GLÖGE / U. PREIS / I. Sснміdт, 10. Aufl. 2010) schreibt zwar T. Dieterich zu Art. 1: „Die Menschenwürde kann nicht genommen werden; verletzbar ist aber der aus ihr folgende Achtungsanspruch" (Rn. 7). Doch wie beides voneinander zu trennen ist, wird nicht klar, zumal der Schutz dem „Kernbereich der Individualität, Identität und Integrität“ (ebd.) gelten soll.

${ }^{22} \mathrm{Zu}$ den verschiedenen Theorien der Bestimmung der Menschenwürde vgl. Dreier 2004, Rn. 54-57, und Heun 2009, 68 f.

${ }^{23}$ Die Begründung spielt erst im folgenden eine Rolle, bei der Betrachtung der Neukommentierung von Art. 1 GG.
} 
die Menschenwürde keinen verbindlichen Maßstab jenseits des Rechts geben: „Für die staatsrechtliche Betrachtung sind [...] allein die (unantastbare) Verankerung im Verfassungstext und die Exegese der Menschenwürde als Begriff des positiven Rechts maßgebend. " ${ }^{24}$ Wollte man die Menschenwürde überpositivem Recht zuordnen, träte „eine metajuristische Offenbarungslehre an die Stelle einer juristischen Methodik ${ }^{\prime 25}$ Damit hat sich das Verständnis der Menschenwürde gegenüber den Anfängen des Grundgesetzes, die noch stark von der totalitären Erfahrung geprägt waren, massiv verändert; ihr Inhalt bestimmt sich alleine aus der Auslegung, welche wiederum von der aktuellen geistigen Lage abhängt. Böckenförde fasst bündig zusammen, was in Herdegens Ansatz zum Leitfaden der Auslegung wird: „die Aufnahme und Mitteilung der Deutungsvielfalt, ein Abstellen auf das, was sich dabei als Konsens zeigt, und die zurückhaltendskeptische Suche nach Evidenzurteilen.“ All dies öffne „das Tor zur Abwägung [...] und zu flexibler Handhabung “26 - ein Urteil, das sicherlich realistisch ist. Dafür spricht auch Herdegens eigene Einschätzung: „Trotz des kategorialen Würdeanspruchs aller Menschen sind Art und Maß des Würdeschutzes für Differenzierungen durchaus offen, die den konkreten Umständen Rechnung tragen. “27

Weil schon die Würde - trotz ihres geistesgeschichtlichen Hintergrunds, den auch Herdegen anerkennt - etwas Gesetztes, nicht etwas Gegebenes ist $^{28}$ wird auch die Weise, wie sie zu achten ist, Auslegungssache. Damit gerät in der Tat alles in Fluss. Die Pluralität der Deutungen ist nicht mehr Anlass zur Wahrheitssuche, sondern Ausdruck der Unbestimmtheit des Gegenstandes. Ein Wesen des Menschen gibt es nicht, vielmehr ist als seine Würde zu achten, was dafür gehalten wird, bzw. was die Mehrheit dafür hält. Auch was als Mensch zu bezeichnen ist, ist damit der Deutung offen - ein Punkt, der in Böckenfördes Kritik eine zentrale Rolle spielt. Denn nun wird durchaus diskutierbar, ob bereits dem Nasciturus das Mensch-Sein zuzusprechen ist, ${ }^{29}$ und wenn der Zeitgeist dies verneint, kann der Mensch mit dem Noch-nicht-Menschen so verfahren, wie er es für angemessen hält. Deshalb befürchtet Böckenförde, dass mit dem neuen Kommentar - der freilich seine Vorgänger in der juristischen

\footnotetext{
${ }^{24}$ Herdegen 2003, Rn. 17.

${ }^{25}$ Herdegen 2008, 58.

${ }^{26}$ BÖCKENFÖRDE 2004, 1218.

${ }^{27}$ Herdegen 2003, Rn. 50.

${ }^{28}$ Wenn Herdegen sagt: „Nicht die Menschenwürde, aber ihre Gewährleistung im und durch den Staat des Grundgesetzes ist eine Schöpfung des positiven Rechts“ (Herdegen 2003, Rn. 20), scheint er zunächst etwas Außerrechtliches anzuerkennen. Da dieses jedoch nicht Gegenstand des Rechts ist, das Recht aber implizit auf das Verständnis der Menschenwürde zurückwirkt, findet m.E. doch die Relativierung der Menschenwürde statt, die Böckenförde moniert.

${ }^{29}$ Vgl. dazu Heun 2002.
} 
Literatur hatte ${ }^{30}$ - ein Dammbruch provoziert wird. Die Relativierung des Würdeschutzes führt „,notwendig auch zur Relativierung der Unabdingbarkeit und Unantastbarkeit der Menschenwürde selbst". ${ }^{31}$ Doch wie reagiert Böckenförde auf diesen „Angriff auf Artikel 1“? Wie begründet er, dass man sich nicht von der Vorstellung eines vor-positiven Fundamentes der Menschenwürde verabschieden darf? Er plädiert keineswegs für eine Rückkehr zum Naturrecht, sondern er rekurriert auf den Willen der Verfassungsväter und -mütter. Diese hätten eine normative Fundierung der Menschenwürde jenseits des positiven Rechts gewollt. Und worin besteht wiederum dieses Fundament? Es ist ein Begriff von Menschenwürde, der sich aus der Tradition des Christentums und der Aufklärung, besonders der Philosophie Kants herleitet. ${ }^{32}$ Ist damit der befürchteten Relativierung der Menschenwürde tatsächlich ein Riegel vorgeschoben?

Das erscheint in zweierlei Hinsicht fraglich. Erstens ist der Rekurs auf den Willen der Verfassungsschöpfer eine rein Rechts-immanente Betrachtungsweise. Damit ist nichts über den von den Verfassungsschöpfern gemeinten Sachverhalt ausgesagt. Wäre der Wille des Parlamentarischen Rates ein gänzlich anderer gewesen, müsste man ihn dann ebenso achten? Aus juristischer Perspektive mag das fraglos sein, nicht aber aus philosophischer. Denn im konkreten Fall war es gerade der antitotalitäre Konsens, der zu der besonderen Betonung der Menschenwürde im GG führte. Man könnte sich aber z. B. auch eine rassistische Ausfüllung des Menschenwürdebegriffs denken. Würde dieser vorpositive Gehalt ebenfalls auf Böckenfördes Zustimmung stoßen? Hier besteht der Verdacht, dass der Rückgriff auf die subjektive Auslegung, also den Willen der Verfassungsväter, nicht aus formalen, sondern aus inhaltlichen Gründen erfolgt.

Zweitens bedeutet der Rückbezug auf eine bestimmte geistig-philosophische Tradition letztlich nicht weniger eine Auslieferung an den - nun historisch verstandenen - Diskurs als Herdegens Abstellen auf den jeweils aktuellen Konsens. Die Tradition ist nur ein in die Geschichte ausgedehnter Diskurs - es sei denn, man verstünde diese Tradition als Ausdruck des Erfassens eines Sachgehalts, der jenseits der Tradition angesiedelt ist.

Nun scheint mit der Erwähnung Kants und seines Gebots, den Menschen „,als Zweck an sich selbst“ zu behandeln, ${ }^{33}$ ein Inhalt der Menschenwürdegarantie benannt zu sein, der überzeitliche und überdiskursive Geltung beanspruchen kann. Doch was macht den Menschen zum Selbstzweck, warum soll man ihn nach der „Objektformel“ nicht in der Weise eines Dings, eines Objekts behandeln, sondern als etwas, das seinen Wert

\footnotetext{
${ }^{30}$ Böckenförde nennt die Positionen von Peter Lerche, Hasso Hofmann, Horst Dreier und Brigitte Zypries (BöcKENFÖRDE 2004, 1219-1222).

${ }^{31}$ BÖCKENFÖRDE 2004, 1219.

32 BÖCKENFÖRDE 2004, 1223.

33 BÖCKENFÖRDE 2004, 1225.
} 
in sich trägt? Das „Recht auf Rechte“ zu haben, wie Böckenförde die Kantische Formel wendet, ${ }^{34}$ will begründet sein.

In der gegenwärtigen Diskussion haben allerdings naturrechtliche Begründungen ganz offensichtlich keine Chance mehr, es sei denn, man wollte sich dem Vorwurf aussetzen, essentialistisch oder ontologisch zu denken bzw. Menschenwürde wie eine „platonische Idee“ zu behandeln. ${ }^{35}$ Doch wer sich solchen Denkverboten beugt, ist selber schuld. Die Behauptung eines nicht-hintergehbaren Fortschritts in den Grundfragen des Menschen wie z. B. der seines Selbstverständnisses ist gewagt. Insofern sei nun ungeachtet aller fragwürdigen Vorbehalte unbefangen ein Blick in die Antike geworfen, nicht zum Urheber jener ominösen „Ideen“ selbst, sondern zu einem Autor, der sich in platonischer Tradition sieht, aber auch kynisches und stoisches Gedankengut assimiliert hat - Dion von Prusa.

\section{Dions Verständnis von Menschenwürde}

Der Schritt zu Dion ist äußerlich der Schritt in eine andere Welt. Abgesehen von einer zweitausendjährigen Geschichte, die zwischen seiner Euböischen Rede und der eben geschilderten Diskussion um die Menschenwürde liegt, ist auch die literarische Form denkbar unterschiedlich: Anstelle der nüchternen Juristensprache findet sich eine blumige Erzählung, die den gemeinten Sachverhalt bildlich darstellt und rhetorisch überhöht. Jene Einkleidung ist der Sache aber nicht wesentlich; aufgrund dessen kann von ihr auch wieder abstrahiert werden.

Die - schon andernorts dargelegte ${ }^{36}$ - Struktur der Euböischen Rede ist, noch einmal zusammengefasst, die folgende: Nach einem Prooimion schildert Dion seine wahrscheinlich fiktive ${ }^{37}$ Begegnung mit einem Jäger, einem einfachen Mann, dessen frugales und bedürfnisloses Leben als schlechterdings vorbildlich vorgeführt wird, als Beispiel für eine Existenz, die ihre Würde in sich trägt. Diese Existenz offenbart sich zunächst in einer Erzählung des Jägers, dann in dem direkten Miterleben seines Alltags seitens des Autors. Im letzten Teil der Euböischen Rede reflektiert der Autor dann noch einmal seine Erfahrungen, wobei der schon in der Erzählung des Jägers wichtige Kontrast zwischen dem Leben auf dem Land und dem Leben in der Stadt eine wesentliche Rolle spielt. Hier wird Natürlichkeit gegen Dekadenz, Mitmenschlichkeit gegen Selbstsucht ausgespielt und da-

\footnotetext{
${ }^{34} \mathrm{Ebd}$.

${ }^{35}$ So der gegen BöcKenförde gerichtete Einwand Hubert MARKLS (H. MARKL, Wer bestimmt, wann das Leben beginnt? Zur Frage der Deutungshoheit über den Lebensbegriff [BerlinBrandenburgische Akademie der Wissenschaften 2003] 11) - eine Einschätzung, die Böckenförde weit von sich weist.

${ }^{36}$ Vgl. den Beitrag von D. GaLl in diesem Band, S. 123-136.

${ }^{37}$ Auf den fiktiven Charakter des Erlebten weist z. B. Reuter 1932 hin.
} 
mit auch die Frage thematisiert, inwieweit ein erfülltes, in Würde zugebrachtes Leben an ökonomische Bedingungen geknüpft ist.

Schon an diesem Punkt liegt es nahe, den Bogen zur modernen Diskussion zu schlagen. Aber bereits zuvor, wenn Lebenseinstellung und Lebenspraxis des schlichten Mannes dargestellt werden, bietet es sich an, den hier zugrundegelegten Würdebegriff mit der modernen Begriffsbestimmung bzw. -verwirrung in Beziehung zu setzen. Dass Dion die Lebensweisen des Land- und des Stadtmenschen, des Armen und des Reichen etc. idealtypisch zugespitzt zeichnet, deutet darauf hin, dass er an ihnen Grundsatzfragen festmachen will. Auch insofern scheint ein zeitübergreifender Vergleich legitim.

Was kennzeichnet das Leben des Jägers, und worin liegt seine Würde begründet? Kurz gefasst, ist es das Verhältnis zum Mitmenschen und zur Arbeit, das die besondere Existenzweise des Jägers ausmacht. Letztlich drückt sich darin aber auch ein bestimmtes Selbstverhältnis aus, und in diesem ist dann wohl die eigentliche Würde zu suchen. Das soll nun konkretisiert werden.

Der Jäger trifft auf einen Schiffbrüchigen (Dion) und bietet ihm sofort eine Unterkunft und eine Mahlzeit an (§5), obwohl er selbst nur sehr wenig besitzt und den Gestrandeten nicht kennt. Man könnte das mit der typisch griechischen Philoxenie erklären, nach welcher der Begriff „Xenos“ nicht nur den Fremden, sondern auch den Gastfreund bezeichnet. Wenn Dion jedoch an späterer Stelle ( $§ 55)$ einen anderen Schiffbrüchigen davon berichten lässt, dass von seinen Schicksalsgenossen nur diejenigen bei den Purpurfischern, denen sie begegnet waren, Aufnahme fanden, die über Geld verfügten, zeigt sich, dass solch bedingungslose Bereitschaft zu teilen nicht selbstverständlich war. Das Besondere an der Haltung des Jägers ist der Verzicht auf Reziprozität. Bei den Reichen - die von Dion durchgängig als dekadent dargestellt werden - wird Gastfreundschaft nur unter ihresgleichen gewährt, in der Erwartung einer adäquaten Gegengabe (§ 88). Und selbst bei Hochzeiten, wenn also innigste Zuwendung zu erwarten wäre, regiert bei ihnen das Kalkül: Es werden Nachforschungen über das Vermögen angestellt, Brautgeschenke und Mitgiftbeträge ausgehandelt und (Ehe-)Verträge geschlossen (§ 80). Das Ganze erscheint als Geschäft. Hier hat die Berechnung also die Mitmenschlichkeit erstickt.

Dions Kritik an der Reziprozitätserwartung kann in ihrer Bedeutung gar nicht überschätzt werden. Bei Platon, den Dion verehrt, ist die Reduktion auf Reziprozität immer Ausdruck eines - oft unerkannten - Egoismus. Wenn der kaufmännisch denkende Metöke Kephalos in der Politeia Gerechtigkeit als „Wiedergeben, was man empfangen hat " versteht, ${ }^{38}$ lässt er Gerechtigkeit zu einem Interessenkalkül verkommen. Wenn der Sophist

\footnotetext{
${ }^{38}$ Plat., Rep. 331a-c. Zur Interpretation vgl. ZehnPfennig 2008.
} 
Protagoras im gleichnamigen Dialog per Mythos erklärt, dass Aidos und Dike, Scham und Recht, und das bedeutet: wechselseitige Anerkennung, bloß deshalb unter die Menschen kam, weil sonst ihr Überleben gefährdet gewesen wäre, ${ }^{39}$ sieht er Politik nur als Strategie der Nutzenoptimierung. Natürlich ist mit dem Prinzip der Reziprozität der Vertragsgedanke gemeint. Und dass die politische Gemeinschaft auf dem Vertragsprinzip gründet, ist nicht nur sophistische Position, sondern eines der Grundparadigmen der neuzeitlichen Staatstheorie, der Theorie vom Gesellschaftsvertrag. Mit der Kritik an der Reziprozität als tragendem Prinzip ist somit im Kern auch das neuzeitliche Staatsdenken getroffen.

Doch damit nicht genug. Der Vertragsgedanke bezeichnet selbstredend auch das Prinzip des Rechts: Verpflichtung auf Gegenseitigkeit. Ist dieses ganz auf sich gestellt, liegt ihm also nichts weiter zugrunde als das Interesse, das Eigene geschützt zu sehen und als Preis dafür auch das NichtEigene als solches zu achten, so reduziert sich auch das Recht auf ein egoistisches Nutzenkalkül. Damit ist man wieder bei der Frage nach einer vorpositiven Begründung des positiven Rechts, die uns schon zu Beginn beschäftigte und am Ende noch einmal aufgegriffen werden soll.

Wie charakterisiert Dion des weiteren das Leben des Jägers? Arbeitsam, aber von geringen Bedürfnissen fristet der Jäger ein Dasein, das Dion als glückliches erscheint (§ 65), und dies trotz der Armut des Mannes. Denn diese Armut ist für den Jäger nicht von Bedeutung, weil sein Leben ganz offensichtlich von Werten und Prinzipien getragen ist. Neben einer Gastfreundschaft, die dem Fremden mehr zu geben bereit ist, als man sich selbst zuerkennt (§ 57), gehört zu den lebensleitenden Prinzipien auch, dass man aus dem Unglück anderer keinen Nutzen ziehen darf (§ 52). Man muss seine Bürgerpflichten getreulich erfüllen (\$§ 42. 49f.) und helfen, wenn ein anderer in Not geraten ist (\$§ 54-58). Ausführlich schildert Dion ebenfalls das harmonische Familienleben des Jägers, das von gegenseitiger Achtung getragen ist und trotz traditioneller Rollenverteilung und -differenz zwischen den Geschlechtern die Gemeinsamkeit in den Mittelpunkt stellt. Das elterliche Verhalten ist von Fürsorge, das der Kinder von Respekt gekennzeichnet; auf jeden Fall erscheint das Zusammenleben als wesentlicher Kraftquell und als Wert, der mit Reichtum nicht aufzuwiegen ist. Daher besteht gar kein Interesse daran, den eigenen sozialen Status zu verbessern. Die Tochter heiratet den Mann, den sie liebt und der ebenso arm ist wie ihre eigene Familie ( $\$ 70)$. Die neue Verbindung wird also nicht zum gesellschaftlichen Aufstieg genutzt; sie entspringt unverfälschter Neigung.

Und eben dies scheint der Schlüssel zu der gesamten Lebensweise zu sein. Sie ist bestimmt durch die Liebe zum Nächsten, durch die Liebe zur

\footnotetext{
${ }^{39}$ Plat., Prot. 320c-322d. Dazu Zehnpfennig 2005, 69f.
} 
Arbeit. Das verschafft Autarkie. Daher resümiert Dion auch: „So musste ich diese Leute glücklich preisen und zu der Überzeugung kommen, dass sie am ehesten ein glückliches Leben führten“ (§ 65) - anders als die Reichen, die ihm schon immer unglücklich erschienen seien, noch viel mehr jedoch, „als ich die Armut und die Freiheit dort, in der Hütte, erlebte" (§ 66). Selbst in puncto Genuss seien diese nahezu besitzlosen Menschen den Reichen überlegen gewesen, wahrscheinlich weil das NichtSelbstverständliche viel intensiver und dankbarer wahrgenommen wird als das im Überfluss Vorhandene.

In Dions Bewertung des einfachen Lebens findet sich ein Begriffspaar, das in der Moderne so kaum vorkommt, nämlich Armut und Freiheit. Bei der eingangs dargestellten juristischen Bewertung der Menschenwürde wurde Armut als Hinderungsgrund für die Entfaltung der menschlichen Freiheit und somit als Beeinträchtigung der Menschenwürde behandelt. Bei Dion scheint sich eher der Reichtum freiheitsmindernd auszuwirken, betrachtet man, wie er das Leben der Reichen beschreibt: Sie hängen so sehr an ihrem Besitz, dass sie ihn nicht mit anderen teilen wollen, obwohl ihnen der Verzicht viel leichter fallen müsste als denjenigen, die nur wenig haben (\$§ 82-91); eher lassen sie ihr Eigentum brach liegen, so dass es für die Gemeinschaft keinen Nutzen bringt, als dass sie es Armen zur Bearbeitung oder als Wohnstatt zur Verfügung stellten (§§ 34. 50); in ihrer Arroganz umgeben sie sich nur mit gleich reichen, aber wertlosen Menschen und verachten den wertvollen Menschen, sofern er nicht ihrer Schicht zugehört (§§ 83-90); den Schaden aus dieser oberflächlichen Kategorisierung ihrer Mitmenschen müssen sie dann hinnehmen, und sei es, wie im Fall des Menelaos, in Gestalt des Verlustes des Besitzes, des Verlustes der Ehefrau und des Ertragens eines zehn Jahre langen Krieges - des Trojanischen Krieges (\$§ 94-96).

Diese Menschen - das will Dion offenkundig klar machen - sind in der Tat völlig unfrei, weil sie ihr Glück an ihren Reichtum binden und damit das Entscheidende im Leben versäumen. Das, was nicht mit Geld zu erwerben ist, wie ein liebevolles Verhältnis zum Mitmenschen, ein wertegeleitetes Dasein, Sinnerfüllung durch eine produktive Tätigkeit, bleibt den Reichen als Erfahrung verschlossen. All dies zu realisieren, liegt aber in der Hand des je einzelnen, insofern ist es Teil seiner Freiheit. Was vom Geld abhängt, ist hingegen immer extern determiniert: So ist es stets ungewiss, ob der Besitz wirklich sicher ist, und fraglich, ob man durch dessen Verwendung tatsächlich das Glück erreicht, das man sich davon erhofft. Wenn Dion das Leben der Reichen als von Gier, Missgunst und Geiz gekennzeichnet darstellt (\$§ 81-91), ${ }^{40}$ weckt er erhebliche Zweifel, ob dies Ausdruck eines glücklichen Lebens sein kann. Seine Kritik an den Dich-

\footnotetext{
${ }^{40}$ U. a. mittels einer recht eigenwilligen Interpretation der Odyssee, vgl. dazu auch Anm. 103 des Übersetzers.
} 
tern (§§ 97-102) - die er mit Platon teilt - beruht auf deren Insinuation, Reichtum sei etwas höchst Erstrebenswertes und die Voraussetzung dafür, anderen Wohltaten erweisen zu können. ${ }^{41}$ Damit bestätigen die Dichter das Vorurteil der Menge (§§ 98f.), die sie liebt, weil sie sich in ihrer Dichtung wiedererkennt. Gegen solche Dichtung tritt Dion mit seiner Rede ganz explizit an. Der Jäger ist ein Beispiel dafür, wie wertvoll gerade die immaterielle Zuwendung ist und wie viel beglückender es ist, selbstlos das Wenige zu teilen als mit Kalkül große Geschenke zu machen.

Wenn Freiheit eine wesentliche Voraussetzung für ein in Würde verbrachtes Leben ist, dann hängt diese Freiheit jedenfalls nicht von äußerem Wohlstand $a b$, das betont Dion immer wieder (\$§ 81. 103). Natürlich erscheinen das Leben des Jägers und das Leben der Reichen idealisiert, typologisch zugespitzt. Doch andererseits ist die Wertzuweisung - hier der edle Arme, dort der selbstsüchtige Reiche - nicht so eindeutig, wie es zunächst wirken mag. Wenn vom städtischen Proletariat die Rede ist, kommt auch das Thema Kriminalität zur Sprache ( $\$ 40)$; die Wankelmütigkeit und Manipulierbarkeit der Menge in der Ekklesia (\$§ 24. 33. 39) legt den Schluss nahe, dass Schlichtheit und Anstand nicht unbedingt korrelieren. Eher schon ließe sich ein Zusammenhang zwischen ländlicher Einfachheit und menschlicher Güte sowie städtischer Dekadenz und menschlicher Verworfenheit ausmachen. Aber auch hier gibt es Ausnahmen: die Purpurfischer sind ebenso geldgierig wie die Städter (§55); der Redner aus der Stadt, der den Jäger bei seiner Ladung vor die Ekklesia verteidigt ( $\S \S$ 33-40. 60f.), nimmt das Risiko auf sich, sich den Zorn der Menge zuzuziehen, um den Jäger zu seinem Recht kommen zu lassen. Sicherlich legt Dion nahe, dass die städtische Existenz den Menschen eher korrumpiert als das Leben im Einklang mit der Natur - hier spricht ganz unverkennbar der Stoiker. Er unterstellt aber keinen Automatismus. Was er mit den genannten Beispielen wohl andeuten will, ist, dass die äußeren Umstände zwar einen Einfluss auf die Art haben, wie man sein Leben lebt; letztlich bestimmend können sie jedoch nicht sein. Denn die Freiheit, auf der die Würde gründet, ist eine innere.

Wie aber verhält es sich mit der Arbeit, wenn schon Armut und Reichtum, ländliche und städtische Existenz sekundäre Faktoren des gelingenden Lebens sind? Ist das Lob der Arbeit, das Dion in seiner Rede so vernehmlich singt, ein Hinweis darauf, dass die Würde des Menschen auf seinem Sein als homo laborans beruht?

Zweifellos erkennt Dion der Arbeit bei der Frage nach einem menschenwürdigen Leben eine sehr wichtige Stellung zu. Der Jäger hat sich dem Ungemach, das seiner Familie zustieß, als man ihr widerrechtlich ihre Rinder nahm (§ 12), nicht ergeben, sondern sich wie schon sein Vater eine selb-

\footnotetext{
${ }^{41}$ Ein Gedanke, der sich allerdings auch bei Aristoteles findet (Politik 1263b5-8) und damit die von Sokrates in Platons Politeia I widerlegte Kephalos-Position wiederholt.
} 
ständige Existenz aufgebaut. Er jagt das Wild, das wohl Allgemeinbesitz ist, und er bebaut Land, das der Gemeinde gehört, aber brach liegt. Der Jäger erwartet also keine Fremdalimentierung, sondern ist von sich aus tätig geworden, und gerade diese selbst erarbeitete Autarkie macht offenbar einen großen Teil seiner Lebenszufriedenheit aus (vgl. § 20, hier bezogen auf die Elterngeneration). Allerdings bestreitet er seine Existenz auf der Grundlage von Gütern, die nicht die seinen sind. Als er sich deswegen vor der Ekklesia verantworten soll, stellt ihn sein Ankläger auch als eine Art Parasit dar, der von Gemeindeeigentum lebt, aber weder Steuern noch Pacht entrichtet (§§ 27-29).

Interessant ist nun die Strategie des Redners, der als Verteidiger des Jägers auftritt: Er verweist 1. auf die Sozialpflichtigkeit des Eigentums ( $\S \S$ 33f.), 2. auf die positiven Folgen seiner Nutzung ( $\S \S 35 f .40)$ und 3. auf die Rechte, die sich aus dieser Nutzung ableiten ließen ( $\S \S 37.40)$. Damit kehrt er die Wertung seines Vorredners um. Nicht der ist ein Dieb, der Ungenutztes bearbeitet, sondern der beraubt die Gemeinschaft eines Gutes, der sein Privateigentum für sakrosankt erklärt und vor anderen abschirmt, obwohl er selbst damit gar nichts anfängt. Nun zur Argumentation im einzelnen:

1. Für den Verteidigungsredner verdient derjenige Tadel, der Gemeindeland und Privateigentum verkommen lässt, nicht aber derjenige, der es einer sinnvollen Nutzung zuführt, auch wenn es ihm nicht gehört. Eigentum verpflichtet - so der Tenor seiner Rede -, und man kann nicht anderen einen Verstoß gegen die Gemeinschaftspflichten vorwerfen, wenn man selbst Eigentum als Freibrief zu asozialem Verhalten versteht. Offenbar war es damals, zu Dions Zeiten, tatsächlich ein Problem, dass große Landflächen verwilderten. Dion macht dafür „Nachlässigkeit“ und „Mangel an Menschen" verantwortlich (§ 34) und erwähnt auch leerstehende Häuser in der Stadt (§ 50). ${ }^{42}$ Wenn also nicht einmal Knappheit, sondern sogar ein Überangebot an brachliegenden Ländereien besteht, ist es umso verwerflicher, letztere Arbeitswilligen vorzuenthalten.

2. Arbeit schafft nämlich Wert - eine frühe Vorwegnahme der Arbeitswertlehre von John Locke, Adam Smith, David Ricardo und Karl Marx. Und auch wenn Dion nicht explizit sämtlichen Wert auf die Arbeit zurückführt, macht er doch implizit klar, dass Unbearbeitetes wertlos ist (§ 34). Das Eigentum erfährt durch Bearbeitung also eine Aufwertung. Insofern hat auch der Besitzer von der Nutzung seines Besitzes durch andere einen Vorteil, den der Redner nicht nur im Pekuniären, sondern auch im Sozialen ansiedelt: Wüstes Land sieht unschön aus und erregt Mitleid mit sei-

\footnotetext{
${ }^{42}$ Zum demographischen Wandel seit dem zweiten vorchristlichen Jahrhundert vgl. Anm. 45 des Übersetzers sowie den darin enthaltenen Literaturhinweis.
} 
nem Besitzer, da es von einer unglücklichen Lebenslage zu zeugen scheint. Selbst wenn der Verteidiger des Jägers dieses Argument nur aus rhetorischen Gründen verwendet - es verdeutlicht auf jeden Fall, dass man mit dem Verlust der sozialen Anerkennung argumentieren und somit durch Appell an den Eigennutz zu gemeinschaftsfreundlichem Verhalten motivieren kann. So fordert der Redner seine Mitbürger auch dringlich auf, ihr Land anderen Bürgern und gänzlich Mittellosen zur Verfügung zu stellen, um beide Bevölkerungsgruppen von „den zwei größten Übeln“ zu befreien: „Untätigkeit und Armut“ (§ 36). Mit der „Armut“ kann hier nur die Variante gemeint sein, die aufgrund fehlender eigener Erwerbstätigkeit zu völliger Abhängigkeit führt oder zur Kriminalität verleitet. Die Armut des Jägers, die eher Bedürfnislosigkeit ist, kann nicht als Übel verstanden sein, da sie ein freies Leben nicht verhindert.

3. Da Arbeit als wertschaffend eine anzuerkennende Leistung darstellt, sollen diejenigen, die bisher ungenutztes Land einer Nutzung zuführen, belohnt werden - und zwar nicht nur mit den erwirtschafteten Erträgen, sondern auch mit Vergünstigungen wie langer Pachtfreiheit etc. Der Redner schlägt unterschiedliche Konditionen für Bürger und für Nichtbürger vor (§ 37) und erwägt sogar, bei besonders hohem Arbeitseinsatz das Bürgerrecht verleihen zu lassen. Zudem soll bei Kaufinteresse das Land zu einem geringeren Preis als dem üblichen übereignet werden $(\S 40)$. Hier nimmt die überaus positive Einschätzung der Arbeit also eine Wendung, die sie später auch in der Arbeitswertlehre von John Locke nimmt: Arbeit begründet Eigentum. Bürgerrecht, geminderte Pacht, geminderter Preis all dies sind durch Arbeit erworbene Anrechte, also Rechte, die nicht per Geburt bzw. Vererbung bestehen, sondern durch Leistung errungen werden.

Damit ist nicht nur der sozialen Einbindung ansonsten außerhalb der Gemeinschaft Stehender das Wort geredet. Vielmehr liegt in diesem Ansatz auch das Prinzip der sozialen Durchlässigkeit. Gesellschaftlicher Aufstieg kann mittels eigener Leistung erreicht werden. Letzteres ist die logische Konsequenz des stoischen Glaubens an die grundlegende Gleichheit der Menschen, die Dion darauf zurückführt, dass „das ganze Menschengeschlecht [...] von seinem Schöpfergott mit denselben charakteristischen Merkmalen ausgestattet worden ist" (§ 138). Welches diese Merkmale sind und was aus der Gleichheit folgt, ist weiter unten noch einmal zu thematisieren. ${ }^{43}$ Was hier festzuhalten ist, ist die augenscheinliche Nähe zur christlichen Botschaft als Erklärung dafür, weshalb sich Stoizismus und Christentum so leicht amalgamieren konnten.

${ }^{43}$ Siehe S. 208-211 
Kann man nun Dions Lob der Arbeit als eine Gleichsetzung von tätigem und würdevollem Leben verstehen? Auf den ersten Blick mag es so erscheinen. Bei näherem Zusehen lässt sich diese Deutung aber nicht halten.

Was zunächst für sie spricht, ist die Art und Weise, wie Dion das arbeitslose Dasein des städtischen Proletariats kennzeichnet. Genötigt, „,beschäftigungslos herumzusitzen", besteht bei diesen Menschen die Neigung oder Gefahr, „sich üblen Dingen zuzuwenden“ (§ 109) - zweifellos eine Anspielung auf kriminelle Betätigungen, die durch Arbeitslosigkeit provoziert werden. Auch seine Zeit in der Volksversammlung oder vor Gericht zu verbringen, anstatt zu arbeiten, findet vor Dions Augen keine Gnade (§ 108). Wenn man an die zuvor geschilderte Emotionalisierbarkeit und Manipulierbarkeit der Menge in der Ekklesia denkt, versteht man auch, wieso. Hinzu kommt etwas, das in der Euböischen Rede zwar nicht explizit zur Sprache gebracht wird, aber sicher mit gemeint ist: Die beschäftigungs-, doch keineswegs bedürfnislose Menge ist immer ein dankbarer Adressat für Umverteilungsrhetorik, was gewiefte Demagogen für ihre Zwecke zu benutzen verstehen. Auf diese Weise an Einkommen zu gelangen, durch Beraubung der Reichen, kann nicht in Dions Sinn sein. Denn das wäre eine Folge von Neid, eine Charaktereigenschaft, die in Dions Tugendkatalog selbstredend nicht vorkommt.

Ein in Würde zugebrachtes Leben ist das eben geschilderte Leben ohne Arbeit also auf keinen Fall. Doch andererseits ermöglicht nicht jede Arbeit eine würdevolle Existenz; es gibt auch Tätigkeiten, die als solche würdelos sind. Was Dion dazu zählt, zeugt wiederum von seiner kynischen Prägung. Viele Berufe dienen nicht der Herstellung jener „wirklich notwendigen und nützlichen Güter" (§ 113), die er alleine als solche gelten lässt. Deshalb schließt er alle Berufe aus, die sich mit der Erzeugung überflüssiger Luxuswaren (§ 117), oberflächlicher Erbauung (§ 119) oder der Beförderung unnötiger gerichtlicher Streitigkeiten befassen (§§ 123f.). Der Hersteller von Kosmetik fällt ebenso unter die genannten Kategorien wie der Stukkateur, der Komödiant ebenso wie der „Rechtsverdreher". Die „maßvolle Lebensweise“ (§118), die Dion als menschenwürdige vorschwebt, ist demnach eher kynisch-karg anzusetzen. Auf jeden Fall ist alles, was über die Grundbedürfnisse hinausgeht oder Bedürfnisse sogar noch künstlich anheizt, zu vermeiden und daher auch nicht als Betätigungsfeld für die Armen zu öffnen. Dazu gehört vor allem die Prostitution (§§ 133-140), welcher der Kyniker eine erstaunlich intensive Betrachtung zuteil werden lässt.

Die angeführten Berufe tragen demnach nicht $\mathrm{zu}$ einem würdevollen Leben bei. Kann aber eine Tätigkeit wie die Prostitution ihrerseits entwürdigend wirken, also Würde nehmen? Da Dion offenbar vor allem die Zwangsprostitution versklavter Menschen vor Augen hat, gilt sein 
ganzer Tadel den Bordellbetreibern, die andere zu schändlichem Tun nötigen. Die Schamlosen sind also die Zuhälter und nicht diejenigen, die sich gegen ihr Schamgefühl prostituieren müssen (§§ 133-135. 138).

Entwürdigung findet somit zunächst einmal auf Seiten der Täter statt; ihr Verhalten ist würdelos, wenn sie andere Menschen aus Geldgier missbrauchen. Die Prostitution selbst, unfreiwillig ausgeübt, kann im Grunde nur dann „Würde und Freiheit" „im Bereich der Seele“ mindern (§ 110), wenn die Seele sich dem Verlust menschlicher Werte, der sich in der Prostitution zeigt, ergibt - wenn sie das Schändliche nicht mehr als solches empfindet. Denkt man Dions Position konsequent zu Ende, kann eine verachtenswerte Arbeit dem Menschen eigentlich nur dann Würde nehmen, wenn er sie bejaht. Wenn er zu ihr gezwungen wird, mag er in den Augen der anderen entehrt sein (§ 138), nicht aber vor sich selbst. Und was von dem Urteil der Leute zu halten ist, sagt Dion mit aller Deutlichkeit: Sie überziehen bestimmte Tätigkeiten mit „Hohn und Spott“, obwohl diese wie z. B. die Arbeit der Amme oder die des Weinlesers durchaus ehrbar sind - nur weil sie im Ruch der Armut stehen (§§114f.). Zugleich zollen sie zweifelhaften Berufen wie dem des Komödianten oder des Aulos-Spielers größte Hochachtung. Die Frage der Würde ist für Dion also keine Frage der sozialen Anerkennung. Auch wenn der Jäger vor der Ekklesia verlacht wird, weil er so unbedarft ist in Bezug auf städtische Gepflogenheiten, gelingt es doch nicht, ihm die Würde zu nehmen (§§ 43-63).

Fassen wir die Ergebnisse zusammen: Menschenwürde ist für Dion unabhängig von Armut oder Reichtum. Denn auch als armer Mensch kann man frei sein, sofern man Armut als Chance sieht, sein Leben durch Arbeit selbständig zu gestalten ( $\$ 125)$. Nicht jede Arbeit trägt jedoch zur Menschenwürde bei, da es auch würdelose Tätigkeiten gibt. Arbeit scheint also die notwendige, aber nicht hinreichende Bedingung für eine freie und somit auch würdevolle Existenz zu sein. Daraus ergeben sich zwei Konsequenzen.

Erstens muss die politische Gemeinschaft, sofern sie sich tatsächlich als eine solche versteht, dafür sorgen, dass ihr zugehörende und bedürftige Menschen aus der Untätigkeit herauskommen und eine Arbeitsmöglichkeit finden, die ehrbar ist - weder gesundheitsschädlich noch seelisch beeinträchtigend noch gesellschaftlich nutzlos (\$§ 109f.). Es geht also nicht darum, sie von der Armut zu befreien - diese ist nicht entehrend -, sondern von der Untätigkeit. Erst die eigene Tätigkeit ermöglicht auch ein selbstbestimmtes Leben, nicht die Alimentierung durch die Gemeinschaft, die den Empfänger der „Wohltaten“ in Unmündigkeit belässt.

Zweitens: Wenn das tätige Dasein nicht schon selbst das Dasein in Würde ist, sondern nur dazu beiträgt, sofern die Art der Tätigkeit entsprechend gewählt ist, dann muss die Würde in etwas liegen, das mit Armut und Reichtum, mit ehrbarer und entehrender Arbeit richtig umgehen lässt. 
Geht man davon aus, dass für Dion Menschenwürde und Lebensglück korrelieren, so ist es aufschlussreich festzustellen, was für Dion im Wettstreit um das Lebensglück den Siegespreis davonträgt: eben weder Armut noch Reichtum, und auch nicht, wie man ergänzend hinzufügen kann, sozial anerkannte oder sozial verachtete Arbeit, sondern „Tugendhaftigkeit und Selbstvollendung" (§ 118).

An dieser Stelle ist auf die zuvor bereits erwähnte Ausstattung der Menschen durch den Schöpfergott zurückzukommen. Das „ganze Menschengeschlecht [verfügt] gemeinsam über Ehre und gleichen Rang", weil es von Gott „mit denselben charakteristischen Merkmalen ausgestattet worden ist, um gerechtermaßen Ehre zu empfangen: nämlich mit Vernunft und dem Wissen um Gut und Böse“ (§ 138). Es ist die Fähigkeit, vernünftig zu urteilen, Gut und Böse zu unterschieden, die den Menschen, und zwar allen Menschen, ob Grieche oder Barbar, ob Freier oder Sklave, gemein ist. Allein dies ist auch Grundlage für äußere Anerkennung, für Ehrung. Dabei ist jene grundsätzliche, eben exclusiv dem Menschen eignende Ausstattung nur die Basis, denn „Tugendhaftigkeit und Selbstvollendung“ sind nicht mitgegeben, sondern, wie die Praxis fehlender Tugendhaftigkeit zeigt, dem einzelnen aufgegeben. Die Vernunftanlage verschafft die Möglichkeit der freien Wahl. Sie im Sinne des moralisch Richtigen zu treffen, liegt aber in der Entscheidung jedes Menschen, und nur darin sind die Menschen gleich.

In der Gestalt des Jägers hat Dion vorgeführt, wie in seinen Augen die richtige Wahl aussieht. Der Jäger hat seine innere Freiheit - der Verzicht auf Reziprozitätserwartung und die von sich aus gebende Liebe ${ }^{44}$-auch in äußere Freiheit umgemünzt. Er hat nicht darauf gewartet, was andere ihm an Wohltaten erweisen könnten, sondern er hat sich eine eigene Existenz aufgebaut. Dass er in dieser glücklich ist, liegt an seiner Bedürfnislosigkeit, welche aber nicht auf Verzicht beruht, sondern auf der Höherschätzung immaterieller gegenüber materiellen Werten. Das ist offenbar selbst einem schlichten Menschen möglich, wie Dion zeigen will, der damit die Gleichheit der Menschen in einem viel substantielleren Sinn begreift als alle, die Gleichheit sozial verstehen.

In Dions Konzeption der Menschenwürde bilden Vernunftanlage, innere Freiheit und aus ihr heraus erfolgende, also selbstbestimmte Verpflichtung gegenüber der Gemeinschaft eine Einheit, die letztlich auch ein bestimmtes Selbstverhältnis ermöglicht: das Bewusstsein, nicht Objekt seiner Lebensumstände sein zu müssen, sondern Gestalter seines Lebens sein zu können. Verantwortung für sich selbst und Mitverantwortung für die Wesen, die einem gleichen, treffen hier zusammen und ermöglichen das, was

\footnotetext{
${ }^{44}$ Auf die Liebe als die Gabe, die auch Arme geben können, verweist Dion explizit in $\S \S 92$ und 93. Und in $\S 133$ geißelt er an der Prostitution, dass sie Menschen „zu lieblosem Geschlechtsverkehr ohne Zuneigung und Zärtlichkeit" zusammenbringe.
} 
ein in Würde zugebrachtes Leben zu Recht als Folge zeitigt: Selbstachtung. Der Jäger wusste um das Richtige seines Tuns und ließ sich darin weder durch den Spott der Leute (\$§ 29f.) noch durch ihre Belobigung (\$§ 62f.) beirren.

\section{Antike Naivität - moderne Aufgeklärtheit?}

In der gegenwärtigen Diskussion würde man das Dionsche Menschenund Weltbild wohl mehrheitlich als historisch interessant, aber sachlich nicht mehr von Belang einschätzen. Der Glaube an ein Wesen des Menschen, gar noch als Folge göttlichen Eingriffs, wird als nicht mehr mehrheitsfähig betrachtet. Spätestens seit der Aufklärung könne man so nicht mehr denken. Pluralismus und Relativismus prägen heute die gesellschaftliche, größtenteils auch die wissenschaftliche Debatte. Was letztlich Geltung beanspruchen darf, wird per Konsens festgestellt, wobei oft genug fraglich bleibt, wie jener Konsens eigentlich ermittelt wurde. Nicht selten scheint der Verdacht berechtigt, dass nicht weiter autorisierte Meinungsführer sich als die Stimme der Mehrheit ausgeben.

Doch das ist nicht das einzige Problem. Menschenwürde und Menschenrechte sind ein, wenn nicht der Schlüsselbegriff demokratischer Politik, gerade auch bei der Auseinandersetzung mit nicht-demokratischen Systemen. Wie lässt sich ein solcher Begriffsgebrauch überhaupt rechtfertigen, wenn es gar kein Wesen des Menschen gibt, sondern die jeweils aktuelle Mehrheitsmeinung darüber befinden kann, was unter dem Rubrum „Mensch“ zu verstehen ist? Sofern explizit von menschlicher Würde, von menschlichen Rechten die Rede ist, wird damit doch offenbar ein Vorrang gegenüber der Würde und den Rechten anderer Lebewesen behauptet. Was wäre, wenn der aktuelle Konsens bspw. die Differenz zwischen Mensch und Tier als nur graduelle beurteilte? Wäre die Rede von der Menschenwürde dann nicht sofort obsolet?

Bei Dion bestimmt sich Menschenwürde intrinsisch; ihr materieller Gehalt folgt aus dem, was dem Menschen gegenüber seinen nicht-menschlichen Mitgeschöpfen spezifisch ist; die aus dem göttlichen Einheitsgrund abgeleitete Vernunft sowie das Wissen um Gut und Böse stiften die Gemeinschaft unter den Menschen, das Gemeinsame gehört also zur menschlichen Natur; daraus ergibt sich eine Verpflichtung gegenüber dem Nächsten. Dieses Konzept ist in sich stimmig, wenn auch in seinen Prämissen noch nicht hinreichend begründet. Auf jeden Fall verortet es die Menschenwürde in der menschlichen Freiheit, das Gute zu wählen und damit der Selbstverantwortung wie der Verantwortung dem anderen gegenüber gerecht zu werden.

Ein solches Konzept, dem mühelos eine christliche Wendung gegeben werden könnte, das aber nicht nur christlich verstanden werden muss, 
ließe sich als vorpositive Grundlage positiven Rechts verwenden, wenn Letztere nicht, wie eingangs dargestellt, als nicht mehr konsensfähig in Frage gestellt wäre. Eine derartige Selbstbeschränkung des Rechts mindert aber nicht nur dessen Verbindlichkeit, da es so keinen Maßstab außer sich hat. Es führt im liberalen Rechtsstaat auch zu einer inhaltlichen Entleerung. Denn die Sicherung der Freiheitsrechte des einzelnen geschieht letztlich durch die Sicherung der analogen Rechte des anderen; die Form wird zum Inhalt, und diese Form ist Reziprozität. Das gilt dann auch für die Menschenwürde, die von ihrer möglichen Verletzung her verstanden wird. ${ }^{45}$

Legt man bei der Menschenwürde die schon erwähnte, auf Kant zurückgehende Objektformel zugrunde, ${ }^{46}$ wird die inhaltliche Entleerung noch deutlicher. Der Mensch ist [auch] als Selbstzweck zu behandeln, weil der kategorische Imperativ als Ausdruck der Vernunftnatur des Menschen das gebietet. Dieser Imperativ ist aber, von allem Empirischen gereinigt, reine Gesetzesform: Handle so, dass die Maxime deines Willens Prinzip einer allgemeinen Gesetzgebung sein könnte. Fußt die Menschenwürde als rechtsbegründendes Prinzip also auf der Vernunft, welche dadurch bestimmt ist, dass sie sich selbst das Gesetz gibt, welches Reziprozität gebietet - dann befindet man sich letztlich im infiniten Regress. ${ }^{47}$

Das scheint die gegenwärtige Lage zu sein. Die aus Antike und Christentum überlieferten Konzepte der Selbstdeutung des Menschen erscheinen als normativ $\mathrm{zu}$ aufgeladen, als inhaltlich $\mathrm{zu}$ voraussetzungsreich. Weil man über das Wesen des Menschen nicht mehr reden möchte, betrachtet man - bei vorausgesetzter Würde - die möglichen Verstöße gegen sie, die Kollision der Rechte, die sich im menschlichen Miteinander ergeben könnte. Das bedeutet: Der Blick verlagert sich auf die Sozialität. Nicht mehr die Würde selbst ist das Thema, sondern deren Anerkennung durch die anderen.

Nun könnte man auch dies als unausweichliche Folge der Verrechtlichung der Menschenwürde betrachten: Das Recht regelt eben nur die Außenbeziehungen der Menschen. Doch wenn die Verbindung zu den außerrechtlichen Grundlagen des Rechts willentlich gekappt wird, kann das gesamtgesellschaftliche Folgen haben. Es ergibt sich eine schleichende Verschiebung, so als läge die Würde in der Anerkennung und nicht in dem,

\footnotetext{
${ }^{45}$ S. HeRDEGen 2003, Rn. 36: „Das heute dominierende Verständnis von Art. 1 Abs. 1 GG füllt den Begriff der Menschenwürde von der Verletzung her [Hervorhebung im Original] mit Inhalt" sowie Heun 2009, 69: „Deshalb [sc. wegen der Vergeblichkeit inhaltlicher Bestimmungsversuche] ist es sinnvoller, die Menschenwürde als juristische Garantie - dem Zweck der Abwehr konkreter Gefährdungen entsprechend - in erster Linie vom Verletzungsvorgang her zu begreifen."

${ }^{46}$ Vgl. S. $197 f$.

${ }^{47}$ Auch Herdegen verweist darauf, dass die Objektformel ein "tautologisches Element" berge (HERDEGEN 2003, Rn. 36.).
} 
was anerkannt wird. Damit ist einer Anspruchshaltung Vorschub geleistet, welche die Herstellung eines menschenwürdigen Daseins primär als Auftrag an die anderen versteht. Insofern wirkt die Rechtsauslegung direkt auf die gesellschaftliche Meinungsbildung zurück. Auffallend ist, dass bei aller sonstigen juristischen Präzision Menschenwürde und Garantie der Menschenwürde in juristischen Texten oft nicht unterschieden werden. ${ }^{48}$ Das läuft auf eine Tilgung der Binnenperspektive heraus: Würde ist nichts Intrinsisches, sondern erst Ergebnis reziproker Akzeptanz.

Erinnern wir uns in diesem Zusammenhang noch einmal an Dions Konzeption. Es machte einen Teil der Würde des Jägers aus, keine Reziprozitätserwartung zu hegen. Die Verpflichtung gegenüber dem anderen entsprang seinem eigenen Wertekanon, nicht der Hoffnung auf eine entsprechende Gegenleistung. Solche Selbstverpflichtung erscheint bei Dion aber nicht als persönliche Marotte, sondern als angemessene Ausfüllung der Entscheidungsfreiheit, die dem Menschen von Natur aus eignet, weil er Vernunftwesen und somit fähig ist, Gut und Böse zu unterscheiden. Er kann auch die falsche Wahl treffen, das ist Teil seiner Freiheit. Seine Freiheit ist somit ebenso sehr Aufgabe wie Gabe. In vernünftiger Weise ausgefüllt, als Selbstverantwortung und Selbstverpflichtung, führt diese Freiheit auch zu gesellschaftlicher Harmonie: Eigentum ist sozial verpflichtend, und Armut hindert nicht am Teilen des Wenigen und an immaterieller Zuwendung. Bei einem Primat der Pflichten ist die Gemeinschaft immer schon mitgedacht. Bei einem Primat der Rechte wird sie zum Problem.

Dass auch die gegenwärtige Philosophie dieses Problem mitunter allzu leicht zu lösen versucht, sei abschließend kurz an einem typischen Beispiel gezeigt. In einem Artikel zum Thema "Soziale Menschenrechte ${ }^{\prime 49}$ ist es für den Autor Stefan Gosepath schlicht evident, dass Menschenrechte dem Menschen „qua Menschsein"50 eignen - und zwar nicht aus anthropologischen Gründen, sondern weil sich die Menschen diese Rechte selbst verliehen hätten. Dass dann im Grunde auch das Menschsein selbst verliehen sein müsste, ist das eine; das andere ist aber die weitergehende Folgerung: Aus der gleichen Achtung oder reziproken Anerkennung, die sich in den Menschenrechten ausdrückt, ergibt sich auch ein „prima facie Gleichverteilungsprinzip für alle politisch zur Verteilung anstehenden Güter", 51 es sei denn, es gibt begründete Ausnahmen. Da die Begründung für diese Ausnahmen aber ebenfalls von allen anerkannt werden können muss, wird die Ausnahme von der Reziprozität ihrerseits wieder reziprok begründet usw.

\footnotetext{
${ }^{48}$ Diese Vermischung findet sich z.B. bei DürIG und bei BöCKENFÖRDE.

${ }^{49}$ Gosepath 2001.

${ }^{50}$ Gosepath 2001, 19.

${ }^{51}$ Gosepath 2001, 34.
} 
Hier zeigen sich die Fallstricke einer modernen Selbstdeutung des Menschen, die sich den überkommenen Deutungen überlegen glaubt. Eine Begründung der Menschenwürde in der Natur des Menschen wird als essentialistisch und überholt verworfen. ${ }^{52}$ So bleibt nur die Übereinkunft, sich Würde zuzusprechen, die wechselseitige Anerkennung. Damit ist das Gleichheitsprinzip als nicht-hintergehbares installiert, ${ }^{53}$ und zwar auf Kosten der Freiheit. Denn wenn es primär das Gleich-Sein ist, das die Menschen auszeichnet, muss diese Gleichheit dort sozial herbeigeführt werden, wo sie faktisch noch nicht besteht - als Verpflichtung der anderen bzw. anonymisiert: der Gesellschaft. So verlagert sich die Würde des Menschen nach außen: in die anderen Menschen, die mir Würde zusprechen, in die äußeren Lebensumstände, die mir ein menschenwürdiges Leben ermöglichen. Kann man dies eigentlich noch als eigene Würde in Anspruch nehmen?

Für Dion war die Gleichheit Ergebnis der menschlichen Freiheit, sich zwischen Gut und Böse zu entscheiden - nur darin sind die Menschen gleich. In dieser Freiheit liegt auch, sich selbstbestimmt zu den äußeren Lebensumständen zu verhalten; nicht ihnen verdankt man Würde, sondern der eigenen Einstellung ihnen gegenüber. Das begründet berechtigte Selbstachtung. Die Alternativen wollen erwogen sein, und hierzu ist der Blick in die Antike geradezu unverzichtbar: ob man ein Leben vorzieht, das sich seiner Maßstäbe unabhängig von äußerer Akzeptanz versichert und darin seine Würde findet, oder ob man, auch gesellschaftlich-rechtlich, auf eine Würde baut, die als „unantastbar" gilt und dennoch im Grunde gänzlich von außen gegeben und auch wieder genommen werden kann.

\footnotetext{
${ }^{52}$ Gosepath 2001, 33.

${ }^{53}$ Bei Gosepath in Gestalt eines Denkverbots: „Diese fundamentale Vorstellung von der gleichen Achtung von Personen oder der gleichen Würde aller Menschen wird von allen Hauptströmungen der modernen westlichen politisch-moralischen Kultur als Minimalstandard akzeptiert. Jede politische Theorie, die Anspruch auf Plausibilität erhebt, muss mit dieser Gleichheitsvorstellung beginnen und kann nicht hinter sie zurück." (Gosepath 2001, 23).
} 



\title{
Armut, Arbeit, Sklaverei und Prostitution in der römischen Kaiserzeit im (Spannungs-)Verhältnis zur dionischen Menschenwürde
}

\author{
Elisabeth Herrmann-Otto
}

\section{Vorüberlegungen}

Mehrere in der Überschrift angedeutete Themenkreise, mit denen sich Dion in seiner 7. Rede, dem Euboikos, beschäftigt, sind auch für uns heute immer noch relevante Anliegen: ich meine zunächst die Armutsproblematik verbunden mit dem Thema Arbeit und Arbeitslosigkeit. Zum anderen steht heute die Menschenwürde zur Disposition, für uns auf das Engste mit der Forderung nach den Menschenrechten verbunden. Mit Sklaverei scheinen wir nur vordergründig nichts mehr zu tun zu haben, obwohl aktuell die Anzahl versklavter Menschen auf nun mehr als siebenundzwanzig Millionen angewachsen ist. ${ }^{1}$ Prostitution rückt in Form der Zwangsprostitution in unseren Gesichtskreis, ein auch der Antike bekannter Teilbereich des ältesten Gewerbes der Welt. ${ }^{2}$ Die Aktualität der dionischen Rede scheint auf der Hand zu liegen, was sich am Ende des Beitrages bestätigen oder verneinen lassen wird. Zunächst sollen aber die oben aufgeführten sozialen Phänomene für die Zeit des Dion selbst umrissen werden, um auf diesem Hintergrund die Frage beantworten zu können, ob der stoischkynische Philosoph mit seinen diesbezüglichen Vorstellungen, Bewertungen und Vorschlägen zur praktischen Umsetzung, die ihm als Kommunalpolitiker an Herzen liegen mussten, einem Trend der Zeit entspricht oder ob er eher als ein singulärer Vordenker einzustufen ist.

In der Forschung ist der Euboikos im Kontext der dionischen Reden sehr kontrovers, bisweilen sogar abwertend behandelt worden. ${ }^{3}$ Vor allem wurde der ökonomische Nutzen der Ausführungen in Frage gestellt und die gesamte Rede in den Bereich der Bukolik und der Utopie, zuweilen auch

\footnotetext{
${ }^{1}$ Bales 2001, 16-18.

${ }^{2}$ Bales 2001, 52-108; E. B. Skinner, Menschenhandel. Sklaverei im 21. Jahrhundert (Bergisch Gladbach 2008) 347-374.

${ }^{3}$ BEKKER-NIELSEN 2008, 136: ,.. [the second] a philosophical discussion of traditional moral and political problems: the nature of the good life, urban unemployment, virtuous and unworthy occupations, etc. These general precepts, however, are of limited interest for a study of Dion's view of local politics...."
} 
einer aufgeklärten und liberalen Utopie verschoben. ${ }^{4}$ Gegen solche Vorbehalte ist dagegen eingewendet worden, dass der erste Teil der Rede, der wie eine ländliche Idylle erscheint, seinen eigentlichen Sinn erst aus dem zweiten Teil bezieht, der stadtreformerischen Tendenzen um ein sozialpolitisches Arbeitsbeschaffungsprogramm für das Großstadtproletariat ergänze, wodurch der Euboikos als stoisch-kynischer Traktat mit Realitätsbezug vor allem für Städter gelesen werde müsse. ${ }^{5}$

Disparater kann man ein und dieselbe Schrift wohl kaum bewerten. Bevor man diese widersprüchlichen Thesen richtig beurteilen kann, soll zunächst dargelegt werden, worum es Dion in seiner Rede überhaupt geht, wie sie ideologisch und faktisch in der römischen Kaiserzeit und in der Tradition der politisch philosophischen Literatur zu verorten ist. Nach Darstellung der einzelnen sozialen Felder soll abschließend die Frage beantwortet werden nach der Originalität der Gedankengänge Dions und ihrer politischen Praktikabilität.

\section{Ein Armutsdiskurs bei Dion von Prusa?}

Nachdem Dion seine Erzählung von dem bedürfnislos lebenden Jäger, seiner Familie und seiner vielfältigen Gastfreundschaft abgeschlossen hat, erinnert er an den eigentlichen Sinn seiner Erzählung: „ein Beispiel für die Lebensführung und die Verhaltensweisen unter den Armen vor Augen zu führen.“ (§ 81) $)^{6}$ Das eigentliche Ziel seiner Ausführungen, das er in der für uns heute wahrscheinlich verlorenen Einleitung bereits dargelegt hatte, konkretisiert er nochmals nach einer geschickten Überleitung in §104: hat er in den einundachtzig vorhergehenden Kapiteln gezeigt, wie Arme auf dem Land ein menschenwürdiges und freies Leben sogar viel besser führen können als Reiche, so will er das nun auch für die Armen in der Stadt untersuchen. Sein Anliegen ist, ob es auch für die städtischen Armen möglich sei, ein besseres Leben als die Reichen zu führen, sodass man Armut überhaupt nicht fürchten müsse.

Dion steht mit dieser seiner Argumentationskette in einer langen Tradition, wie man in der Antike auf Armut schaut. Es handelt sich um den typischen Blick eines Mannes der Oberschicht, der zwar - im Unterschied $\mathrm{zu}$ anderen Autoren - selbst in freiwilliger Armut gelebt hat und mit unteren Bevölkerungsschichten während seines Exils auch verkehrt hat, der

\footnotetext{
${ }^{4}$ Russell 1992, 12-13 mit Verweis auf von ArNim. Vgl. auch den Forschungsüberblick bei SWAIN 2000a, 32-35.

${ }^{5}$ Elliger 1967, XXXIV-XXXV.

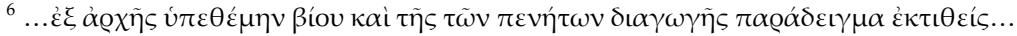


aber in seiner Armutsdefinition ganz eindeutig in den von der Oberschicht geprägten Vorstellungen verankert ist. ${ }^{7}$

Die Armen auf dem Land in Böotien und sicher auch sonst im Hinterland der Städte, d.h. auch in Bithynien, seiner Heimatprovinz, sind nur relativ Arme, denn sie alle leben über dem Existenzminimum und haben ihr bescheidenes Auskommen, von dem sie dem noch bedürftigeren Schiffbrüchigen etwas abgeben können (\$§ 65f.). Damit aber dieses karge Leben oberhalb der Grenze des Existenzminimums gehalten werden kann, bedarf es des vollen Arbeitseinsatzes aller Familienmitglieder. Dieser familiäre auf Subsistenzwirtschaft beruhende Kosmos funktioniert nur, weil alle arbeiten. Dadurch aber sind die bäuerlichen Jäger unabhängig, selbst von der „reich im Dorf“ verheirateten Tochter, der sie das geliehene Saatgut in Form von reifem Getreide zurückerstatten ( $\$ 68)$. In diesem Landleben spielt die Geldwirtschaft keine Rolle. Arm sind diese Leute nur im Vergleich zu den Dörflern und Städtern, d.h. sie sind relativ arm, denn sie leben von ihrer Hände Arbeit. Nur wenn sie nicht arbeiten könnten, würden sie unter das Existenzminimum absinken und zugleich unfrei werden, weil sie von der Gebefreudigkeit anderer abhängig würden. Dann erst wären sie bettelarm. ${ }^{8}$

Wir befänden uns allerdings nicht im römischen Reich bzw. in den weiterhin bestehenden griechisch-hellenistischen Traditionen, wenn bei aller Ländlichkeit und Bäuerlichkeit nicht ein Bezug zur nächstliegenden Stadt, zu deren Territorium die Landgebiete gehören, bestünde. ${ }^{9}$ Allerdings sind der Jäger und seine Familie von Abgaben an die Stadt frei, eine Wunschvorstellung des Dion, die er auch für seine Vaterstadt Prusa vom Kaiser Trajan gerne erwirkt hätte. ${ }^{10}$ Die Jägersfamilie hat dieses Privileg durch euergetisches Handeln erreichen können - durchaus ein utopischer Zug in der Erzählung ( $\S \S 60-62$ ). Durch die Geschichte in der Geschichte soll auch in diesem ersten, fast schon idyllisch ländlichen Teil der Rede die Stadt nicht vergessen werden, um die es eigentlich geht. Dafür bleibt auch

\footnotetext{
${ }^{7}$ Vgl. Sen. Cons. Helv. 12,1:,,Damit Du nicht denkst, zu verniedlichen die Misslichkeiten der Armut - die niemand als beschwerlich empfindet als der, der sie dafür hält - bediente ich mich lediglich der Lehren der Philosophen; zunächst sieh, wie viel größer der Teil der Armen ist, die du um nichts niedergedrückter und bekümmerter finden wirst als Reiche." (Ne me putes ad elevanda incommoda paupertatis, quam nemo gravem sentit nisi qui putat, uti tantum praeceptis sapientium, primum aspice quanto maior pars sit pauperum quos nihilo notabis tristiores sollicitioresque divitibus). PRell 1997, 217-221, zu Dions Lebensphase als kynischstoischer Wanderprediger s. ebd. 76-78, BRENK 2000, 270-275.

${ }^{8}$ Zur Unterscheidung von absoluter und relativer Armut s. Prell 1997, 12-15. Vgl. auch die Sozialpyramide der Gesellschaft in der römischen Kaiserzeit, in der nicht nur die soziale Schichtung sondern, durch die Angabe der Existenzminimumsgrenze, die Dichotomie der Gesellschaft in absolut Arme und relativ Arme, in Reiche und relativ Reiche deutlich wird: SEILER 2011, 71 Abb.1.

${ }^{9}$ Sartre 2001, 371-376.

${ }^{10}$ BeKKer-Nielsen 2008, 125.
} 
der Wanderprediger Dion viel zu sehr ein Stadtmensch. ${ }^{11}$ Sein Anliegen scheint es im zweiten Teil des Euboikos zu sein, wie die städtischen Armen ein menschenwürdiges Leben führen können. Seine klare Antwort lautet: „Es könnte freilich sein, dass etwa für solche Armen Arbeitsmöglichkeiten in Städten nur spärlich vorhanden sind." (§ 105) ${ }^{12}$ Nur wenn diese Menschen von ihrer Hände Arbeit leben können, dann fallen sie nicht unter die Existenzminimumsgrenze, nur dann werden sie nicht zu absolut Armen, zu Bettlern, die von den sporadischen öffentlichen Speisungen, von der seltenen Gebefreudigkeit der Passanten, ${ }^{13}$ viel eher aber von Diebstählen und anderen kriminellen Machenschaften und unehrenhaften Tätigkeiten abhängig werden, um überleben zu können. ${ }^{14}$ Damit ein solcher Zustand die Armen nicht bedroht, bedürfen sie „der Unterstützung von außen“ ( 105) ${ }^{15}$ wie Dion von vorne herein deutlich macht. Denn in der Stadt ist es sehr viel schwieriger als auf dem Land die absolute Armut zu verhindern. In der Stadt braucht man für alles Geld: Essen, Kleidung, Wohnung (§§ 105f.). Für alle grundlegenden Bedürfnisse, die auf dem Land sehr viel einfacher befriedigt werden können, rutscht der Arme, der nur seine Körperkraft hat, schnell in die Schuldenfalle und schließlich in die Kriminalität ab. ${ }^{16}$ Alle diese Zusammenhänge hat Dion im Kopf. Hierin unterscheidet er sich nicht von den Angehörigen seiner eigenen sozialen Schicht, die Armut mit Kriminalität verbinden und sie deswegen als selbstverschuldet aus ihren Gedanken verbannen. Zugleich aber befürchten sie, selbst in die relative Armut zu fallen, vor allem in die Altersarmut. ${ }^{17}$ Das Vorurteil der

\footnotetext{
${ }^{11}$ Nach seiner Rückkehr aus dem Exil lebte Dion wieder in Prusa das Leben eines Städters der Oberschicht. S. BRENK 2000, 272. Bithynien gehört zu den stark urbanisierten Provinzen Kleinasiens. Die Asia Proconsularis hat zu dieser Zeit 500 Städte. S. SARtre 2001, 354. $357 / 8$.

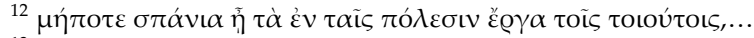

${ }^{13}$ Bei den öffentlichen Speisungen städtischer oder privater Euergeten sind die wirklich armen Bürger nur in den seltensten Fällen mit eingeschlossen. Vgl. z.B. CIL 9, 2962, Iuvanum, Samnium: cuius dedicatione diem / ludorum et cenam / decurionibus et fili(i)s / item quinq(uennalibus) Aug(ustalibus) et / fili(i)s et / plebi epulum dedit. Hier wie in anderen Inschriften erhält das Volk ein geringerwertiges Mal und ein kleineres Geldgeschenk als die städtischen Oberschichten, z.B. auch CIL 10, 5917 Anagnia, Latium. Zu diesem Phänomen forscht innerhalb des SFB 600 „Fremdheit und Armut“ das Teilprojekt B9: „Fürsorgemaßnahmen und Euergetismus als kulturelles und gesellschaftliches Phänomen im hellenistischen und römischen Kleinasien sowie im spätrepublikanischen und kaiserzeitlichen Italien“ zum privaten Euergetismus in Kleinasien und in Italien an der Universität Trier.

${ }^{14}$ Prell 1997, 245-248.

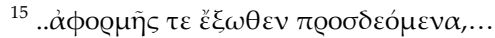

${ }^{16}$ Luc. Pseudolog. 30: „Es ist zu verzeihen, wenn ein Mensch, ehe er sich zum Verhungern entschließt, eine ihm anvertraute Summe abschwört oder wenn er in einem so dringenden Notfalle unverschämt bettelt oder Kleider in öffentlichen Bädern wegstiehlt oder sich zum Zolleintreiben brauchen lässt"(Übers. v. CHR. M. WIELAND, Lukian, Werke in drei Bänden (Berlin 1974).

${ }^{17}$ Herrmann-Otto 2011a.
} 
reichen Städter gegen die Armut, dass sie schrecklich und zu meiden sei, will Dion in seiner Rede genauso bekämpfen, wie er absolute Armut beheben will (§§ 103f.).

\section{Armut und Arbeit in der griechisch-römischen Antike}

Die römische Gesellschaft zur Zeit des Dion ist so strukturiert, dass es eine Fülle von sozialen Netzwerken gibt, wie etwa das Klientelsystem, die Familie, ein vielfältiges Vereinswesen etc., die Notsituationen wie Armut, Alter, Krankheit etc. auffangen. Außerdem ist die soziale Mobilität eine riesengroße in dieser Gesellschaft. Der Aufstieg vom armen Tagelöhner über den Selbstverkauf in die Sklaverei zur Führungsebene des römischen Reiches ist genauso möglich, wie der Absturz aus dem Senatorenstand über Verarmung und kaiserliche Missgunst in die politische und soziale Bedeutungslosigkeit. ${ }^{18}$ In der Praxis bestehen vielfältige Strategien gegen Verarmung in den unterschiedlichen „privaten“ Netzwerken.

Dagegen gab es weder in der römischen Republik noch in der Kaiserzeit staatliche öffentliche soziale Netzwerke wie Alters-, Renten- und Arbeitslosenversicherungen. Der römische Staat war kein Sozialstaat. Dagegen existierten die bereits erwähnten halb öffentlichen halb privaten Netzwerke der Familie, des Patronats und der Vereine. Die römische familia bestand aus zwei, maximal drei Generationen und umfasste außerdem die Sklaven und Freigelassenen. Fürsorge und Hilfe für Verarmte, für Alte und Kranke erfolgte im Rahmen der Familie, d.h. es gab einen sogenannten Generationenvertrag zwischen Eltern und Kindern und eine Verpflichtung der Sklaven und Freigelassenen, für ihre verarmten Herren bzw. patroni zu sorgen. Am meisten gefürchtet war die Altersarmut, wenn die Kinder vor den Eltern verstarben und diese krank und unfähig zur Arbeit in die absolute Armut verfielen. Nicht selten waren die Eltern an diesem kinderlosen Zustand selbst schuld, wenn sie in früheren Jahren in vermeintlich kluger Voraussicht der Erhaltung ihres kleinen Vermögens alle Kinder ausgesetzt hatten außer einem Sohn, der als Erbe gedacht war. Mit seinem vorzeitigen Tod waren sie zu Unterstützungsbedürftigen, zu inopes geworden. ${ }^{19}$

Blanke Armut leitete auch solche Eltern, die zuerst ihre Kinder und später sich selbst in die Sklaverei verkauften. An sich waren alle diese Rechtsgeschäfte nicht gültig, weil weder der Vater den freien Status seines Sohnes

\footnotetext{
${ }^{18}$ Zur „Upward-Mobility“ der Unterschichten s. HerrmanN-Otтo 2001, 171-184; zur Downward-Mobility der Oberschichten s. Herrmann-Otto u.a. 2009, 43-44.

${ }^{19}$ Herrmann-Otтo 2011a, 268-269. Vgl. vor allem den kinderlosen alten Bettler als ,'Gipfel $^{\prime \prime}$ des Elends bei Ps.-Quintil. Decl. 5,9:,,Schau' mich an, einen Zusammengebrochenen und elend durch jede Art von Unheil, und, worin mich niemand schlagen kann, ein Bettler ohne Kinder" (aspicis collapsum et ex omni calamitatium genere miserum et, ultra quod accidentium mensura non exit, in orbitate mendicum).
} 
durch Verkauf ändern konnte, noch konnte man sich selbst rechtskräftig in die Sklaverei verkaufen. Die Diskrepanz zwischen faktisch bestehender Sklaverei und ihrer Rechtmäßigkeit im Einzelfalle war groß. Ein rechtsgültiger Vertrag zugunsten der Sklaverei war nur in äußerster Notlage möglich, wenn der Selbstverkäufer sich am Verkaufspreis gewinnbringend beteiligen ließ, z.B. um seine Schulden zu bezahlen oder seine Familie vor dem Hungertod zu retten. Dann verlor er seine freie Geburt unwiederbringlich. ${ }^{20}$ Da auch diese Fälle des Selbstverkaufs in großer Anzahl überliefert sind, kann man im Bereich der Unterschicht auf eine hohe Armutsquote schließen. Diese relativ Armen, die am Existenzminimum lebten, entgingen dem Absturz in die absolute Armut durch diesen Selbstverkauf in die Sklaverei, wo sie sich bei einem reichen und wohlwollenden Herrn zuerst hocharbeiten und später freikaufen konnten, und nun als freigelassene römische Bürger sozial höher aufstiegen, als ihnen das als verschuldete freie römische Tagelöhner je möglich gewesen wäre. Sie waren vom Netz der familia ihres neuen Herrn aufgefangen worden, nachdem ihr eigenes familiäres Netz nicht mehr Bestand haben konnte. ${ }^{21}$

Armut auf höherem Niveau, relative Armut, konnte auch die Familien der oberen Schichten, des Senatoren- und Ritterstandes befallen. Verarmte ein Senator, sodass sein Vermögen unter die Mindestzensusgrenze von einer Million Sesterzen fiel, dann drohte ihm der Ausschluss aus dem Senatorenstand. Das bedeutete den sozialen und politischen Tod seiner ganzen Familie. Hier griff sowohl bei selbstverschuldeter wie bei unverschuldeter Verarmung zunächst die Standessolidarität ein. Freundschaftsverhältnisse aber auch Klientelbeziehungen halfen, dass der relativ Arme durch Gewährung von Krediten weiterhin standesgemäß leben und politisch tätig sein konnte. ${ }^{22}$ In der Kaiserzeit war der Kaiser selbst der größte Gönner. Milde (clementia) und Freigebigkeit (liberalitas) waren kaiserliche Tugenden. Dennoch wurden vom Kaiser nur noch die unverschuldet in Armut geratenen Senatoren und Ritter unterstützt. Dieses kaiserliche Vorgehen schwächte die alte Standessolidarität und die Klientelsysteme, sodass die relativ Verarmten der Oberschichten zunächst nur aus der eigenen Familie unterstützt wurden, und wenn das nicht mehr möglich war, wurden sie

\footnotetext{
${ }^{20}$ Zum betrügerischen Selbstverkauf s. WIELING 1999, 25f.; A. SöLLnER, Irrtümlich als Sklaven gehaltene freie Menschen und Sklaven in unsicheren Eigentumsverhältnissen. Corpus der Römischen Rechtsquellen zur Antiken Sklaverei IX (Stuttgart 2000) 27f.; Herrmann-Otтo 2001, 178-181.

${ }^{21}$ Der Selbstverkauf ist eine der bislang unterschätzten Quellen der Sklaverei. Er ermöglicht dem Verarmten als Sklave und später Freigelassener eher den sozialen Aufstieg als wenn er freier Bürger geblieben wäre. S. hierzu: Herrmann-Otто 2009, 196-198 mit weiterführenden Literaturangaben.

${ }^{22}$ Chr. Rollinger, ",Kredit und Vertrauen in der römischen Oberschicht" , in: C.W. HerGENRÖDER (Hrsg.), Krisen und Schulden. Historische Analysen und gegenwärtige Herausforderungen (Wiesbaden 2011) 31-56; HerrmanN-Otto u.a. 2009, 41-43
} 
aus ihrem Stand ausgeschlossen. Wie es diesen sozial Abgestürzten und politisch Ausgestoßenen weiterhin ergangen ist, wissen wir nicht. Unsere Quellen schweigen darüber. Manche sind diesem Sturz aus ihren Netzwerken durch Selbstmord zuvorgekommen. ${ }^{23}$

In der römischen Welt gibt es eine Vielzahl von Vereinen: religiöse, berufliche aber auch gesellschaftliche Vereine und die Begräbnis- und Unterstützungsvereine, letztere vor allem für die kleinen Leute. Mitglieder können Freie und mit Erlaubnis der Herren auch Sklaven sein, Bürger und Fremde, Frauen und Männer. In speziellen Vereinen gab es Ausschüsse, die sich über das Geschlecht, den Beruf, den Kult oder das Bürgerrecht definierten. Allen Vereinen war jedoch gemeinsam, dass sie ein religiöses Element aufwiesen und ein Mitgliedsbeitrag gezahlt werden musste. Bei ihnen ging es nie um die Unterstützung absolut Armer. Relativ Arme konnten auf Unterstützung beim Begräbnis, beim Freikauf aus der Sklaverei und auf Hilfe aus finanziellen Notlagen meist durch freundschaftliche Gewährung von Krediten rechnen. ${ }^{24}$

Ein Mensch, der aus allen oben geschilderten Netzwerken herausgefallen war, weil er weder eine Familie hatte, noch zu einer familia gehörte, noch in einem Klientelverhältnis zu einem reichen Patron und Förderer stand, noch Mitglied eines Vereines war, der war ein absolut Armer, der entweder als Bettler von Almosen lebte und / oder sich auf kriminelle Weise sein kärgliches Überleben sicherte. ${ }^{25}$

Auch Dion weiß, dass absolute Armut nur durch die Existenz sozialer Netze zu verhindern ist: seine bäuerlichen Jäger leben in einem Familienverband, in dem sie sich gegenseitig helfen (§§ 64-80). Sind die städtischen Armen, die nur ihre Arbeitskraft haben, weder in einem Klientelsystem noch in einem Verein sozial eingebunden und gibt es außerdem keine Arbeit für sie in der Stadt, dann sind sie der absoluten Armut ausgeliefert. Auch der Besitz von Kindern hilft ihnen da wenig, wenn diese ebenfalls keine Arbeit finden. Sie alle sinken ab in die Kriminalität. Diese Szenerie ist der Hintergrund für Dions Bemerkung: „Werden wir also am Ende in unserer Argumentation sogar genötigt sein, die ,lieben und guten Armen' aus ihren Städten auszuweisen, damit wir wirklich, wie Homer es ausdrückt, zu ,gut bewohnten Städten' gelangen, in denen sich nur noch wohlhabende Leute aufhalten und in deren Mauerring wir, so scheint es,

\footnotetext{
${ }^{23}$ N. Bissen, „Die verschwiegene Armut: Mentalitätswandel der Schuldner in der römischen Kaiserzeit?“, in: C.W. Hergenröder (Hrsg.), Gesellschaftliche Teilhabe trotz Schulden? (im Druck); Herrmann-Otтo u.a. 2009, 43-45. Im Rahmen des Exzellenzclusters „Gesellschaftliche Abhängigkeiten und soziale Netzwerke“ des Landes Rheinland-Pfalz entstehen z.Z. weitere Forschungsarbeiten zum Thema an den Universitäten Mainz und Trier.

${ }^{24}$ JACQUes / ScheId 1998, 363-366; zu den griechisch-hellenistischen Vereinen s. E. Herrmann-Otтo / Сн. SсhÄFеr, „Armut Arme und Armenfürsorge in der paganen Antike“ in: UerLings 2011, [73-81] 77-78.

${ }^{25}$ Prell 1997, 68-74.
} 
keinen freien Lohnarbeiter mehr dulden wollen?“ (§ 107). ${ }^{26}$ Das würde in aller Konsequenz bedeuten, dass in den Städten Senatoren, Ritter, Munizipalaristokratie und besitzendes Bürgertum ihre vielfältigen Geschäfte teils selbst, teils mit ihrer Klientel aus Freien, Freigelassenen und Sklaven abwickelten.$^{27}$ Für den freien, unabhängigen Lohnarbeiter wäre dann kein Platz mehr in der Stadt. Die Frage, die sich in diesem Zusammenhang stellt, ist die nach der staatlichen bzw. städtischen Regulation des freien Arbeitsmarktes, auf dem Sklavenarbeit und abgesprochene Arbeitsvermittlung eine übergroße Konkurrenz darzustellen schienen.

Die Ansiedlung armer Bevölkerungsschichten auf dem Land als Kleinbauern und Pächter hat seit je her zur Entlastung der Städte beigetragen. Das war nicht nur so im klassischen Attika, wie Dion in der Rede vorführt (§ 107). ${ }^{28}$ Auch die Römer haben diese Politik verfolgt, sei es zur Zeit der gracchischen Reformen oder nun zur Zeit des Dion durch Landansiedlung der Kaiser Trajan und Hadrian. ${ }^{29}$ Der Redner meint allerdings, dass eine solche Zwangsumsiedlung nicht nötig sei, sondern: „dass es ihnen gleichwohl auch in der Stadt nicht an Nahrung und Unterhalt mangeln wird." $(\S 108)^{30}$

Nebulös spricht Dion von Unterstützungen von außen (§ 105). Gibt es offizielle Unterstützungsprogramme für den innerstädtischen Arbeitsmarkt? Hat der Redner historische Vorbilder vor Augen wie bei der Zwangsumsiedlung der Armen auf das Land? An dieser Stelle bedarf es einer grundsätzlichen Bemerkung zur Verwaltungsstruktur des Römischen Reiches und der Einstellung der Römer zu einer ",öffentlichen Sozialhilfe“. Trotz der kaiserlichen Zentrale in Rom, trotz der auf Provinzen basierenden Reichsverwaltung, blieben die Städte in der gesamten Kaiserzeit die kleinsten Verwaltungseinheiten mit einer relativen Autonomie, vor allem

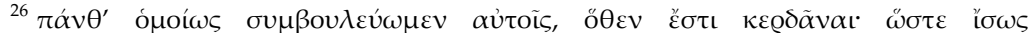

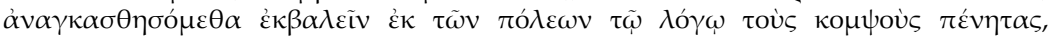

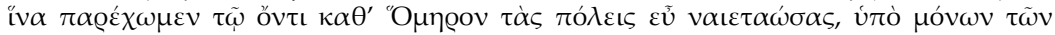

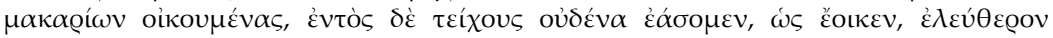

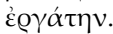

${ }^{27}$ Zur gesellschaftlichen Struktur in den kleinasiatischen Provinzen s. SARTRE 2001, 364-368; MAREK 2010, 566-585.

${ }^{28}$ Ansiedlung und Umsiedlung von Armen, von politisch vertriebenen Heimatlosen zur Entlastung der überbevölkerten griechischen Städte waren zu allen Zeiten ein Thema der griechischen Geschichte. Vgl. das große Siedlungsprogramm der heimatlos umherirrenden politisch vertriebenen Griechen in einem zu erobernden Kleinasien, das Isokrates in seinem Philippos (§§ 120-123) Philipp II. von Makedonien vor seinem Perserfeldzug unterbreitet. Hierzu G. Wirth, Philipp II. Geschichte Makedoniens 1 (Stuttgart 1985) 95-101; G. A. Lehmann, Demosthenes von Athen. Ein Leben für die Freiheit (München 2004) 135-137. S. Anm. 128 zur Übersetzung.

${ }^{29}$ Zur Wiederansiedlung der verarmten Kleinbauern, die in die Städte geflohen waren, im Zuge der gracchischen Reformen s. Сн. SснUвеRт, Land und Raum in der römischen Republik (Darmstadt 1996). Zur Landansiedlungspolitik der Kaiser s. Jones 1978, 59-61.

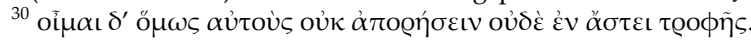


was den innerstädtischen Bereich betraf, zu dem auch der Arbeitsmarkt, wenn wir überhaupt so modern von einem solchen sprechen dürfen, gehörte. Innerstädtische Armut in den Provinzen war kaum ein Problem des Kaisers, eventuell des Statthalters, sollte es viele Städte seiner Provinz betreffen. An sich aber war es ein Problem der Städte selbst. ${ }^{31}$

Hier gab es zwei Möglichkeiten dagegen vorzugehen. Entweder richtete man regelmäßige Armenspeisungen ein, die aus dem städtischen Haushalt oder von Privatleuten finanziert wurden oder die Stadt initiierte ein Arbeitsbeschaffungsprogramm, das teils von der Stadt teils von reichen Mitbürgern (= Euergeten, modern ausgedrückt Sponsoren) finanziert wurde. Welchen dieser Wege schlugen die kaiserzeitlichen Städte ein? Soweit das epigraphische Quellematerial, das allein Aufschluss über die öffentlichen und privaten Wohltätigkeiten (Euergetismus) in den kaiserzeitlichen Städten in Ost und West geben kann, bisher gesichtet ist, scheinen die bettelarmen Obdachlosen und Fremden bei allgemeinen Speisungen und solchen anlässlich feierlicher Ereignisse nicht berücksichtigt worden zu sein. ${ }^{32}$ Das hängt zusammen mit einem ganz anderen Armutsverständnis der Antike im Vergleich zu den späteren christlichen Gesellschaften. Nicht misericordia und caritas sind die leitenden Prinzipien, sondern die eigene dignitas und auctoritas, die auf liberalitas und beneficium beruht. Anders ausgedrückt: oberstes Handlungsprinzip ist Gabe und Gegengabe, do $u t$ des. Ich gebe, damit ich noch mehr zurückerhalte, ich gebe, um mein eigenes Ansehen zu vergrößern. ${ }^{33}$ Der Bettler auf der Brücke kann nichts zurückgeben, und ist er darüber hinaus noch ein Fremder, eine Frau oder ein Kind, die ohne Wahlrecht sind, dann ist er für das Prestige jedes möglichen Gebers völlig uninteressant und irrelevant. Alle diese Personen sind Ausgestoßene aus der Gesellschaft, sie sind die Verlierer, die Kriminellen, die man aus der Stadt ausweisen müsste, wie Dion auf Homer hinweisend formuliert. Seneca, Stoiker und Politiker wie Dion, allerdings im lateinischen Westen in der hohen Reichspolitik und einige Jahrzehnte früher tätig, schreibt zu den Bettelarmen: „Auf die Sublicius-Brücke versetze mich

\footnotetext{
${ }^{31}$ JaCQues / Scheid 1998, 273-293; Ausbüttel 1998, 135-151. 191-197.

${ }^{32}$ Die bisherigen Forschungsergebnisse des Teilprojektes B9 des SFB 600 Fremdheit und Armut laufen in dieser Richtung. S.o. Anm.13. Erste Veröffentlichungen sind für 2012 geplant. Zu Oberitalien s. ähnlich: B. Goffin, Euergetismus in Oberitalien (Bonn 2002); zu Kleinasien: QuAß 1993, 255-269. Nur in Notsituationen wie Hungersnöten etc. partizipierten auch die absolut Armen an außergewöhnlichen Speisungen. Im Normalfall der frumentationes wurden bei den Empfängern fester Wohnsitz und Bürgerrecht vorausgesetzt. S. hierzu J. Heinrichs, "Armut“, DNP 2 (1997) 19. Auch die privaten und kaiserlichen Alimentarstiftungen unterstützen nicht die Kinder der Bettelarmen vgl. AusBütтеL 1998, [152-158] 154-155.

${ }^{33}$ Zum Euergetismus:s. Сн. SсhäFer / Сн. Quetring, „,Euergetismus“, in: UerLings 2011, 45-46; W. Eск, ,,Der Euergetismus im Funktionszusammenhang der kaiserzeitlichen Städte ", in: Сн. Michel / O. Masson (Éds.), Actes du Xe Congrès International d'Epigraphie Grecque et Latine (Paris 1997) 305-331.
} 
und verbanne mich unter die Armen: dennoch nicht werde ich mich deswegen verachten, weil ich in der Schar jener sitze, die Hand nach einem Almosen ausstrecken. Was nämlich ist es von Belang, ob dem eine Brotkruste fehlt, dem es nicht fehlt, sterben zu können?“34 Cicero, von den gleichen Grundsätzen ausgehend, schreibt:,,Bisweilen jedoch muss man schenken, und ist diese Art Wohltätigkeit nicht gänzlich zu verschmähen, und oft muss man bedürftigen Menschen, die es verdienen, von seinem Vermögen zuweisen, aber mit Umsicht und Maß“ ${ }^{35}$ Es ist der abgrundtiefe Vorbehalt nicht nur der lateinischen Stoiker sondern der führenden Schichten insgesamt, dass die Bettelarmen Kriminelle und Unwürdige sind, deren sittliche Verworfenheit man nicht durch Almosen unterstützen sollte. Der arme Bettler hat ja, wie Seneca meint, die Freiheit Hungers zu sterben.

Dion, so scheint es mir - aber die Forschungen sind zu diesem Problemkreis noch nicht abgeschlossen - steht in einer anderen Tradition als Cicero und Seneca und gelangt wahrscheinlich deswegen zu ganz anderen, originären Erkenntnissen. Aber auch Dion denkt nicht an Almosengeben. Er erkennt jedoch einen Zusammenhang zwischen Arbeit und Armut in einer anderen bisher noch nicht gedachten Reziprozität, dass nämlich durch Arbeit Armut zu beheben bzw. zu verhindern sei und nicht Arbeit als Zeichen von Armut zu gelten hat. Kann Dion sich bei der Darlegung dieser Gedanken und eines darauf basierenden Arbeitsprogramms auf Vorbilder stützen?

Dion selbst erwähnt mehrfach die positive Bewertung der Arbeit durch Hesiod. Dieser fordert seinen Bruder, der in das Exportgeschäft einsteigen will, dazu auf, lieber fleißig seinen Ackerboden zu bewirtschaften, als sich Geld zu leihen, um in den Handel einsteigen zu können. Hesiod wirft seinem Bruder Arbeitsscheu und Müßiggang vor, die ihn in Verschuldung und Armut bringen werden. ${ }^{36}$ Müßiggang wird in Athen den Gesetzen Drakons zufolge mit dem Tod bestraft. Eine solche Lebensweise scheint für die Entwicklung der jungen Polis Athen bedrohlich zu sein. ${ }^{37}$

\footnotetext{
${ }^{34}$ Sen. De vit. beat. 25,1: In Sublicium pontem me transfer et inter egentes abige: non ideo tamen me despiciam, quod in illorum numero consedero qui manum ad stirpem porrigunt. Quid enim ad rem an frustum panis desit, cui non deest mori posse?

${ }^{35}$ Cic. De off. II 54: Non numquam tamen est largiendum nec hoc benignitatis genus omnino repudiandum est et saepe idoneis hominibus indigentibus de re familiari impertiendum, sed diligenter atque moderate.

${ }^{36}$ Hes. Op. 298-314, bes. 308-314: „Arbeit allein macht die Menschen reich an Herden und Gütern, / Und wer da arbeitet, ist viel lieber den ewigen Göttern. / Arbeit bringt keinerlei Schand, doch Scheu vor der Arbeit bringt Schande. / Bist du nur fleißig, wird schnell dich der Arbeitsscheue beneiden, / weil du bald reich; dem Reichtum jedoch folgt Aufstieg

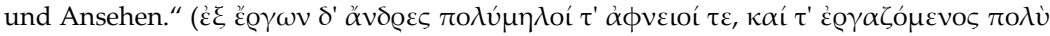

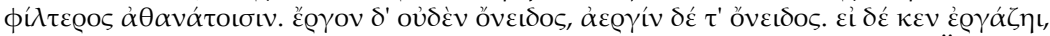

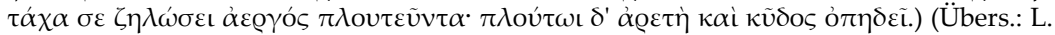
u. K. Hallof, Hesiod Werke in einem Band [Berlin 1994] 58).

${ }^{37}$ Plut. Sol. 17.
} 
Es stellt sich allerdings die Frage, ob bereits vor Dion ein klarer Zusammenhang zwischen Arbeit und Armutsbekämpfung oder Verhinderung der Armut gesehen wurde, mit anderen Worten, ob ein Zusammenhang zwischen Arbeitslosigkeit und Armut schon erkannt werden konnte. Die Zuspitzung unserer Fragestellung ist insofern schwierig, weil sich die griechisch-römischen Gesellschaften nicht wie unsere modernen westlichen Gesellschaften über die Arbeit definieren. Landbesitz ist für die frühen agrarischen Gesellschaften grundlegend, auch wenn die Landbesitzer, adlige und nichtadlige, in den Städten wohnhaft sind und dort ihren politischen Geschäften nachgehen. Wer kein Land hat, wer nicht in Immobilien, Handelsschiffen, Gewerbebetrieben, Bergwerken, Sklaven etc. investiert hat, wer also zum Leben und Überleben von seiner Hände Arbeit leben muss, der gilt als arm. So ergibt sich für den antiken Menschen eher eine Gleichung zwischen Arbeit und Armut und weniger, dass man durch Arbeit Armut vermeiden kann. ${ }^{38}$

Die großen griechischen Staatstheoretiker, die sich Dion methodisch zum Vorbild nimmt ( $\S \S 130 f.),{ }^{39}$ haben sich im Zusammenhang mit der besten Verfassung auch mit der Spaltung der Bevölkerung in Arme und Reiche auseinandergesetzt und diesen ökonomischen und sozialen Gegensatz als verderblich für den Bestand jeglicher Verfassung bewertet. Ihre Vorschläge zur Vermeidung oder Behebung dieses Gegensatzes sind vielfältiger Natur, befassen sich aber nie mit der Arbeit. Entweder werden starre Vermögensgrenzen festgelegt, deren Einhaltung unter staatlicher Kontrolle stehen und Vermögensumverteilungen nach sich ziehen können, oder es wird ein kommunistischer Gemeinschaftsbesitz postuliert. ${ }^{40}$

Zur Verhinderung von Armut wird Geburtenkontrolle empfohlen und gleiche Verteilung von Land an alle Bürger in Aussicht gestellt, die nur bei einer gleichbleibenden Bevölkerungsdichte gelingen kann. Bei Verarmung durch Verschuldung wird Schuldentilgung, Rückkauf aus der Schuldsklaverei und mindestens Rückgabe des konfiszierten Bodens wenn nicht eine Neuaufteilung des Landes gefordert, wie dies Solon teilweise durch-

\footnotetext{
${ }^{38}$ Zur Terminologie der Armut s. Prell 1997, 44-55; vgl. auch KNoch 2010, 306-308, der nach detaillierten Quellenuntersuchungen zu dem Ergebnis kommt, dass der $\pi \varepsilon ́ v \eta \varsigma$ und $\alpha \pi$ ógo $\varsigma=$ pauper der relativ Arme ist, d.h. der von seiner Hände Arbeit lebt. Während der $\pi \tau \omega \chi o ́ \varsigma=$ mendicus, egens den absolut Armen, den Bettler bezeichnet, der sich unter dem Existenzminimum bewegt. Dieses Ergebnis lässt sich auch auf Dions Gebrauch im Euboikos übertragen, obwohl er den Terminus $\pi \varepsilon ́ v \eta \varsigma$ für den relativ Armen bevorzugt ( $\S \S$ 88. 92. 103. 107) und $\dot{\alpha} \pi$ óoo $\varsigma$ nur ganz selten gebraucht (§ 82). Vollkommen abwertend verwendet er den Begriff $\pi \tau \omega \chi$ ó für Bettler (§ 32 ). Ansonsten benutzt er für absolut Arme Umschreibungen (vgl. § 105).

${ }^{39}$ TRAPP 2000, 219-221.

${ }^{40}$ Zu Platon s. Кмосн 2010, 308-313. Zur Interdependenz zwischen der sozialen Struktur der Gesellschaft und der Beständigkeit der Verfassung s. A. WinTERLING, , ,',Arme' und , Reiche'. Die Struktur der griechischen Polisgesellschaften in Aristoteles' "Politik'“, Saeculum 44 (1993) 179-205.
} 
geführt hat. Angestrebt wird eine prosperierende Mittelschicht. ${ }^{41}$ Weder durch Umverteilung noch durch demographische Maßnahmen und Schuldentilgung allein kann die Vermögensungleichheit nachhaltig aufgehoben werden. Aristoteles, der sich empirisch mit den real existierenden Verfassungen beschäftigt, und die materielle Armut der absolut Armen erkennt, schlägt zu ihrer Behebung die Einrichtung eines Fonds vor, in den die städtischen Überschüsse einfließen sollen. Aus ihnen sollen die absolut Armen Starthilfen zum Erwerb eines Landgutes oder eines kleinen Ladens erhalten. Auch bei diesem staatlichen Programm geht es um Vermögensbildung, aus der dann in einem zweiten Schritt Arbeit erwächst. In den übersichtlichen griechischen Stadtstaaten, sogenannten face-to-faceGesellschaften, schien der einzelne absolut Verarmte eine größere Gefährdung für die Gesamtheit darzustellen als in einem großen Flächenstaat wie dem römischen Reich. ${ }^{42}$ Dies mag auch einer der Gründe gewesen sein, dass sich die römischen Staatstheoretiker so gut wie nie mit den absolut Armen beschäftigen. Wenn das einmal geschieht, handelt es sich um versteckte Einzelfallunterstützung, nie um ein umfassender angelegtes Programm. Bei relativer Armut und Verarmung erfolgt stets der Verweis auf die vielen sozialen Netzwerke in der römischen Gesellschaft, die einen solchen Menschen auffangen. Der Staat ist da ganz und gar nicht zuständig. ${ }^{43}$

Theoretisch scheint der Zusammenhang zwischen Arbeitsmangel und Armut in der Antike nicht so deutlich erkannt worden zu sein, während in der praktischen Politik städtische Baumaßnahmen immer dazu gedient haben, neben Sklaven auch freie Arbeiter und Bürger zu beschäftigen, was eine Reduktion des städtischen Proletariats zur Folge hatte. Aber das war wohl eher ein Nebeneffekt, als dass man ein städtisches Arbeitsbeschaffungsprogramm in einer kompetitiven Status-Gesellschaft, wie es die städtische eine war, absichtlich aufgelegt hätte. ${ }^{44}$ Flankierende Maßnahmen

\footnotetext{
${ }^{41} \mathrm{Zu}$ Solon s. K.-W. Welwei, Athen. Von den Anfängen bis zum Beginn des Hellenismus (Darmstadt 2011) 161-163.

${ }^{42} \mathrm{Zu}$ diesem Programm des Aristoteles s. KNOCH 2010, 317.

${ }^{43}$ Zur verstohlenen Einzelfallhilfe s. Sen. De benef. II 9,1-2:,, Es schreiben daher alle Lehrer der Philosophie vor, manche Wohltaten müssten ... unter vier Augen (vollzogen werden): ...was andererseits nicht im Leben voranbringt und geachteter macht, sondern zu Hilfe kommt der Schwäche, der Bedürftigkeit und der Entehrung, muss in der Stille geleistet werden, damit es allein denen bekannt ist, denen es hilft." (Praecipiunt itaque omnes auctores sapientiae quaedam beneficia ... secreto: rursus, quae non producunt nec honesteriorem faciunt, sed succurrunt infirmitati, egestati, ignominiae, tacite danda sunt, ut nota sint solis, quibus prosunt). S. auch KNOCH 2010, 318-323.

${ }^{44}$ Aus diesem Grunde ist es immer schwierig von einem staatlichen Arbeitsbeschaffungsprogramm zu sprechen, etwa beim Wiederaufbau der Akropolis, das von Perikles in der Volksversammlung beantragt worden war. S. hierzu Plut. Per. 12-14; W. Will, Perikles (Hamburg 1995) 66-68; Сн. Schubert, Perikles (Darmstadt 1994) 92-94. Dasselbe gilt für das große Bauprogramm, das Dion in seiner Heimatstadt Prusa eingeleitet hatte (or. 47,12-13), mit dem er letztendlich scheiterte. Zur Problematik s. Elliger 1967, XV-XVI; Jones 1978,
} 
zur Absicherung von Arbeit hat man vielfältig sowohl in Griechenland wie in Rom ergriffen: z.B. sollten die neuangesiedelten Kleinbauern auf ager publicus als finanzielle Starthilfe für Saatgut, Geräte etc. Geld aus dem pergamenischen Schatz erhalten. So jedenfalls beantragte es Tiberius Gracchus. Freigelassene Sklaven, nun römische Bürger, konnten neben ihrer beruflichen Ausbildung auf Teile ihres peculium zur Absicherung ihrer geschäftlichen Unternehmungen zurückgreifen. Und schon im Alten Testament sind die Herren angewiesen, ihren im Yobeljahr freigelassenen Schuldsklaven ein Startkapital mitzugeben. Einzelnen und Gruppen wurde der berufliche Neustart durch individuelle oder staatliche Unterstützungsmaßnahmen durchaus erleichtert, einem Absinken in die Armut vorgebaut. ${ }^{45}$

\section{Sklaverei, Prostitution und Menschenwürde}

Bei seinem Armutsdiskurs und der Entwicklung eines Arbeitsbeschaffungsprogramms zur Bekämpfung von Armut beschäftigt sich Dion mit dem freien Menschen der unteren Schichten. Dass er in diesem Zusammenhang nicht über die Sklaverei sprechen muss, hängt damit zusammen, dass Sklaven auf Grund ihres unfreien Status nicht konsequenterweise arm sind. Sie befinden sich dagegen im Netzwerk der familia ihres Herrn, die ihr Schicksal bestimmt. Handelt es sich um ein reiches und angesehenes Haus, dann kann auch der Sklave zu Reichtum gelangen und nach seiner Freilassung ein gutes Leben zusammen mit seinen freigeborenen Kindern führen, denen alle Aufstiegschancen in der römischen Gesellschaft offen stehen. Ihm selbst als Freigelassenem mit römischem Bürgerrecht ist es noch verwehrt, politische Ämter zu bekleiden. Er kann sich aber als reicher Bürger in den Städten als Augustale im Kaiserkult und als Wohltäter seiner Stadt für die Bürgerschaft betätigen. Freigelassene mit einem solchen Hintergrund sind die großen Karrieristen in der römischen Gesellschaft im Osten und im Westen des Reiches. ${ }^{46}$ Das ist aber nur die eine Seite der Sklaverei. Ihre andere Seite hängt mit Gewalt und Armut zusammen und wird auch von Dion im Rahmen von Prostitution und Aussetzung thematisiert. Dion befasst sich zunächst nur mit der Zwangsprostitution

99; BEKKER-NielsEn 2008, 133-136. Zur allein auf eigene Prestigesteigerung ausgerichteten städtischen Oberschicht s. E. STEPHAN, Honoratioren, Griechen, Polisbürger. Kollektive Identitäten innerhalb der Oberschicht des kaiserzeitlichen Kleinasien, Hypomnemata 143 (Göttingen 2002) 78-85; QuAß 1993, 56-80.

${ }^{45} \mathrm{Zu}$ Tiberius Gracchus s. J. Molthagen, „Die Durchführung der gracchischen Agrarreform“, Historia 22 (1973) 423-458; zum peculium s. W. BucKLAND, The Roman Law of Slavery (Cambridge ND 1970) 159-206, КNOCH 2005, 183; zur Unterstützung des hebräischen Schuldsklaven im 6. Jahr s. Deuteronomium 15, 12-15.

${ }^{46}$ Herrmann-Otto 2009, 160-177. 200-202. 
unfreier Frauen und Kinder, die „durch Kriegsgefangenschaft oder auf andere Weise zu Kaufsklaven geworden sind“ (§ 133). ${ }^{47}$

Er geht davon aus, dass alle diese Menschen, ob sie nun aus dem Barbaricum oder aus den östlichen Provinzen des römischen Reiches stammten, ehemals freie Menschen waren. Wenn das der Fall wäre, handelte es sich um Frauen und Kinder, die als Opfer von Kriegen, Menschenraub, Aussetzung oder illegalem Verkauf in die Sklaverei u.a. auch auf Grund von Verschuldung ihrer Familien auf den Sklavenmarkt gelangt wären. ${ }^{48}$ An späterer Stelle erwähnt er die Kinder, die, illegal geboren, aus amourösen Abenteuern stammen (§ 148). In diesem Zusammenhang kommt er auf die Praxis der Aussetzung zu sprechen, die entweder in den Infantizid oder die Sklaverei führte, wenn der Finder das Kind als Sklavenkind aufzog. ${ }^{49}$ Dion geißelt dieses Vorgehen, das er als Folge unsittlichen Verhaltens bewertet. Dabei vergisst er aber zunächst, dass seine hochverehrten griechischen Staatstheoretiker die Aussetzung als Mittel der Geburtenkontrolle zur demographischen Regulation empfohlen haben. Aussetzung war eine weit verbreitete Praxis in der gesamten griechisch-römischen Antike. Sie wurde nicht nur im Falle illegitimer Kinder angewandt. Auch Väter konnten die Aussetzung ihrer legal in der Ehe gezeugten Kinder anordnen. ${ }^{50}$ Die Gründe waren vielschichtiger Natur: bei befürchteter Armut zur Vermeidung einer zu großen Parzellierung des Erbes unter einer zu großen Kinderschar, oder bei wirklicher Armut, weil man ein weiteres Kind nicht mehr ernähren konnte. Da der Verkauf der eigenen Kinder verboten war, blieb, wenn man kein Risiko eingehen wollte, die Aussetzung. ${ }^{51}$ So liegt auch hier wieder der Bezug zur Armut vor. Aber auch unfreie Kinder wurden ausgesetzt, entweder heimlich durch die Sklavenmutter oder auf Befehl des Sklavenherrn. ${ }^{52}$

War bereits unter den Ausgesetzten oft unklar, ob es sich um ursprünglich freie oder um Sklavenkinder handelte, die alle meistens als Sklaven

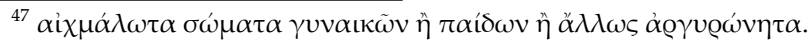

${ }^{48}$ Zur Herkunft der Zwangsprostituierten s. Stumpr 1998, 25-37; Binsfeld 2008, $92-97$.

${ }^{49}$ M. Corbier, "Child Exposure and Abandonment", in: S. Dixon (ed.), Cildhood, Class and Kin in the Roman World (London 2001) 52-73; K. Bradley / K. Ruffing, „Aussetzung / Kindesaussetzung", Handwörterbuch zur Antiken Sklaverei I-III (2010); Binsfeld 2008, 90-92.

${ }^{50}$ Zur Problematik s. Herrmann-Otтo 2011b, 181-183; zur Aussetzung als von den Staatstheoretikern empfohlenes Mittel der Geburtenkontrolle gegen Überbevölkerung und Verarmung s. Polyb. XXXVI 17.

${ }^{51}$ Zur Rechtslage s. Wieling 1999, 16. 27/28.

${ }^{52}$ Dion erwähnt in or. 15,8 heimliche Aussetzungen von Sklavenkindern durch ihre Mütter wegen zu großer körperlicher Belastung durch Arbeit und Kindesaufzucht. Allerdings galt die Sklavin dann als Diebin an ihrer Leibesfrucht, die dem Herrn zustand. Andererseits sind durchaus vom Herrn angeordnete Aussetzungen von Sklavenkindern belegt. Zur Problematik s. E. Herrmann-Otto, Ex Ancilla natus. Untersuchungen zu den "hausgeborenen" Sklaven und Sklavinnen im Westen des römischen Kaiserreiches, Forschungen zur Antiken Sklaverei 24 (Stuttgart 1994) 245 Anm.36. 258-261.
} 
aufgezogen wurden, so war die Statusfrage auf dem Sklavenmarkt kaum noch aufhellbar. Nicht nur ehemals freie Mädchen und Frauen gerieten in die Prostitution, sondern auch solche, die immer Sklavinnen waren. ${ }^{53}$ Wenn Dion hier auch nicht ganz exakt in seiner Formulierung ist, so spricht er sich doch insgesamt gegen die Prostitution aus, ob sie nun von geborenen Sklaven oder von versklavten Freien oder auch von Freien ausgeübt wird, weil er folgenden Grundsatz vertritt: „,...man darf den Missbrauch von entehrten und versklavten Menschen nicht nachsichtig und leichtfertig hinnehmen, und zwar nicht allein aus dem Grund, weil das ganze Menschengeschlecht gemeinsam über Ehre und gleichen Rang verfügt, da es ja von seinem Schöpfergott mit denselben charakterlichen Merkmalen ausgestattet worden ist, um gerechter maßen Ehre zu empfangen: nämlich Vernunft und das Wissen um Gut und Böse." (§ 138). ${ }^{54}$

Dieser stoische Satz von der Gleichheit und Freiheit aller Menschen nach dem Naturrecht bzw. nach einem göttlichen Recht oder im Rahmen der Schöpfungsordnung findet sich im römischen Recht, bei anderen früheren und zeitgenössischen vor allem stoischen Philosophen sowie später im christlichen Gedankengut. Da es sich um eine zentrale Aussage zu Sklaverei und etwaigen Menschenrechten handelt, muss auf diese Problematik differenzierter eingegangen werden. Will Dion von Prusa mit dieser Schlüsselaussage etwa zur Abschaffung der Sklaverei auffordern?

Der stoische Philosoph und Rhetor hat noch drei weitere Reden geschrieben, in denen er sich grundlegend mit dem Verhältnis von Sklaverei und Freiheit beschäftigt (or. 14. 15. 80).$^{55}$ Ein Teil der Forschung hat in diesen Schriften das erste Auftauchen eines abolitionistischen Gedankengutes sehen wollen. Nun geht es aber Dion gar nicht um die Abschaffung von Sklaverei sondern um ihre Relativierung. Er macht in seinen Reden deutlich, dass die wahre Freiheit die innere Freiheit sei und die wahre Sklaverei die innere Abhängigkeit von Begierden, sodass der Mensch nicht Herr ist über sich selbst. Die innere Freiheit ist unabhängig von der äußeren Versklavung und die innere Sklaverei ist ebenfalls unabhängig von der tatsächlichen sozialen Freiheit des Menschen. Durch einen solchen Gedankengang jedoch findet eine Marginalisierung der realen Sklaverei statt, die

\footnotetext{
${ }^{53}$ Sтимpт 1998, 24-28. Zur freiwilligen Prostitution freier, vor allem verarmter Frauen und Witwen s. ebd. 37-42.

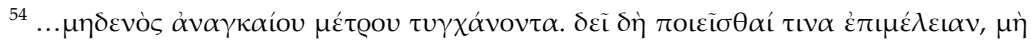

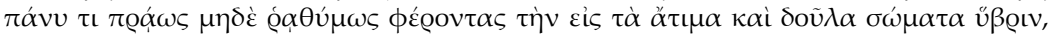

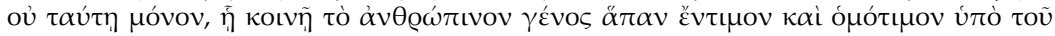

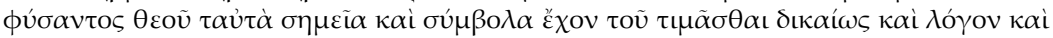

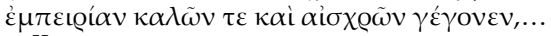

${ }_{55}$ Or. 14 und 15: Knechtschaft und Sklaverei, or. 80: Von der Freiheit. Hierzu die unveröffentlichte Dissertation von I. Loffredo, Die Reden des Dion von Prusa über Sklaverei und Freiheit (Reden 14 und 15) (Trier 2010), die eine Kommentierung der Texte und eine Gesamtinterpretation enthält.
} 
aufzuheben folglich nicht nötig ist, da ja die wahre Freiheit des Menschen die innere Freiheit ist. ${ }^{56}$

Wirft man einen Blick auf das römische Recht, von dem einige Forscher behaupten, dass es von stoischen Gedanken durchzogen sei, so lässt sich hier folgender Tatbestand aufzeigen: die Rechtsgelehrten unterscheiden zwischen dem Naturrecht (ius naturale), dem Völkergemeinrecht (ius gentium) und dem römischen, dem zivilen Recht, dem ius civile. Nach dem ius naturale sind alle Menschen gleich und frei. „Die Sklaverei ist dagegen eine Einrichtung des Völkergemeinrechts, nach dem jemand entgegen dem Naturzustand dem Eigentum eines anderen unterworfen wird ". ${ }^{7}$ Es gibt zwei Arten der Sklaverei: die eine, die allen Völkern gemein sind, das ist die Sklaverei aus Kriegsgefangenschaft und aus der Geburt von einer Sklavin. Alle anderen Entstehungsgründe der Sklaverei sind im je eigenen Recht eines Volkes verankert, d.h. im ius civile, wie etwa die Strafsklaverei, der betrügerische Selbstverkauf etc. ${ }^{58}$ Wie aber die Sklaverei eine Einrichtung des Völkergemeinrechtes ist, so ist auch die Beendigung der Sklaverei durch die Freilassung eine Einrichtung des Völkergemeinrechts. Das bedeutet, dass für den römischen Juristen die Sklaverei keine ewige, unveränderliche Institution ist. Sie ist vielmehr ein transitorischer Zustand, in den jeder Mensch geraten kann, aus dem jeder aber auch wieder herauskommen kann. Aus diesem Grunde bedarf es auch unter rechtlichem Aspekt nicht der Aufhebung der Sklaverei, da sie ein vorübergehender $\mathrm{Zu}$ stand ist, der jederzeit durch eine vollgültige Freilassung beendet werden kann. Sowohl den römischen Juristen wie den stoischen Philosophen liegt die Forderung nach der Abschaffung der Sklaverei deswegen völlig fern. ${ }^{59}$

Dagegen aber gibt es bei beiden Gruppen die Einforderung der Menschenwürde. Grausame Folterungen, unzureichende Ernährung, Verwahrlosung der Kleidung, körperliche Ausbeutung etc. das alles widerspricht dem Verhaltenskodex, auf welchen die römischen Juristen und mit ihnen die Kaiser die römischen Sklavenbesitzer verpflichten. Wer diese Regeln nicht einhält, hat mit empfindlichen Strafen und dem Ausschluss aus der entsprechenden Gesellschaftsschicht zu rechnen. ${ }^{60}$

Ganz ähnlich verhält es sich mit der dionischen Menschenwürde. Sie wird nicht nur von den Sklavenbesitzern gegenüber den Zwangsprostitu-

\footnotetext{
${ }^{56}$ Zur Problematik s. G. WöHRLE, „Der, freie‘ Sklave. Antike Sklaverei und das Konzept der ,inneren' Freiheit", in: Herrmann-Oтто 2005, 35-55. Zu protoabolitionistischen Tendenzen bei manchen antiken Autoren s. Flaig 2009, [72-82] 75.

${ }^{57}$ Dig. I 5,4,1 (Florentinus): servitus est constitutio iuris gentium, qua quis dominio alieno contra naturam subicitur.

${ }^{58} \mathrm{~S}$. hierzu die tabellarische Darstellung der Entstehungsarten der Sklaverei nach römischem Recht in: Herrmann-Otto 2009, 262 Abb.1.

${ }^{59}$ Zur Problematik s. E. Herrmann-Otтo, „Die Bedeutung der antiken Sklaverei für die Menschenrechte“ , in: Herrmann-Otto 2005, 56-81.

${ }^{60}$ Zur Problematik KNoch 2005, 41-89.
} 
ierten eingefordert. Sondern auch in anderen beruflichen Tätigkeiten, die selbst von Freien ausgeübt werden, sieht der Philosoph die menschliche Würde verletzt. Die Bordellbesitzer und die Prostituierten, alles infame Berufstätigkeiten, wenn sie von freien Menschen betrieben werden, stellen nur eine aber besonders in der Kritik stehende Berufsgruppe dar. ${ }^{61}$ Nun weiß Dion aber, dass er mit dieser seiner Ansicht nicht nur gegen die Meinung der Mehrheit seiner Zeitgenossen steht, sondern auch gegen eine von alters her öffentlich durch Gesetze geschützte Institution. Das demokratische Athen leistete sich ein städtisches Bordell mit eigenen Sklavinnen für jedermann zu erschwinglichen Preisen. Auch Sklaven machten von diesen Billigangeboten Gebrauch. Überall im römischen Reich gab es Bordellbetriebe mit freien und unfreien Frauen oder auch selbständig agierende Prostituierte aller Preisklassen, die staatlich zugelassen an den römischen Staat eine Steuer zahlten. ${ }^{62}$ Das älteste Gewerbe war ein großes Sammelbecken für Verarmte: als Zuhälter und Kupplerinnen für Männer und ältere Frauen, als Prostituierte für junge Frauen und Kinder beiderlei Geschlechts, die nicht anders ihr Geld verdienen konnten. Armut und Prostitution, Sklaverei und Prostitution sind die gängigen Verbindungsmuster. Niemand hatte dabei ein schlechtes Gewissen, auch wenn jeder wusste, dass in den verkommenen Spelunken in Hafennähe, an den Stadttoren und in der Nähe der Märkte Kriminalität und Gewalt blühten und gediehen. ${ }^{63}$ Selbst ein Moralist wie Plutarch hatte da keine Bedenken, da die Praxis der öffentlichen Bordelle, ähnlich wie die Praxis des sexuellen $\mathrm{Zu}$ griffs des Herrn auf seine eigene Sklavenschaft als Prävention und Schutz der Ehe diente. Das aber bezweifelt Dion ganz grundlegend. ${ }^{64}$

Der Philosoph nutzt sein Thema der Arbeitsbeschaffung für die städtischen Armen dazu, einen moralischen Rundumschlag gegen die Sittenlosigkeit seiner Zeit zu starten, die nicht allein auf Rom und Italien beschränkt, sondern überall im Reich anzutreffen ist. Seine Moralvorstellungen, die vom stoischen Denken geprägt sind, sind u.a. auch auf dem Hin-

\footnotetext{
${ }^{61}$ McGinn 1998, 21-69.

${ }^{62} \mathrm{Zu}$ Athen: E.E. Cohen, „Free and Unfree Sexual Work: An Economic Analysis of Athenian Postitution”, in: Faraone / McClure 2006, 95-124. Zur Kundschaft und dem Phänomen der Massenprostitution in der Antike infolge des direkten Zugriffs des Herrn auf seine Haussklaven und -sklavinnen: Sтимрт 1998, 174-192; zur Prostituiertensteuer s. ebd. 342-352; McGinn 1998, 248-288.

${ }^{63}$ Stumpr 1998, 61-78; 151-174; SEILER 2011, 77-79.

${ }^{64}$ Plut. Coni. praec. 140B: „Wenn sich ein Privatmann in einem Anfall von Geilheit und Ausgelassenheit an einer Dirne oder Sklavin vergeht, so soll die Frau nicht böse darüber werden ...sie soll sich damit trösten, dass er aus Respekt gegen sie seine Trunkenheit und Geilheit an einer anderen ausließ.“ (Übers. SNell, 97). Zur Thematisierung der ehelichen Liebe bei Plutarch als Zeitphänomen s. Görgemanns 2011.
} 
tergrund der gesellschaftlichen Strukturen seiner bithynischen Heimat zu betrachten. ${ }^{65}$

Es sind eine Vielzahl von Grabstelen und Grabinschriften aus Pontus und Bithynien bekannt, die das Eheleben und die Familienstruktur der provinzialen Oberschicht widerspiegeln. Drei Aspekte möchte ich dabei besonders hervorheben. Bei den ikonographischen Darstellungen von Totenmahlszenen wird die meist auf einem Stuhl sitzende Frau von ihrem auf einer Kline liegenden Mann mit einem Kranz ausgezeichnet. In einer agonal geprägten Gesellschaft, wie es die hellenistisch-römische ist, bedeutet dies, dass die Keuschheit der Frau von ihrem Mann ausgezeichnet wird. ${ }^{66}$ $\mathrm{Zu}$ diesem hohen Ideal der Ehefrau kommt das der mater familias hinzu: immer wieder wird hervorgehoben, oft von den Frauen selbst, dass sie Mütter von vielen Kindern sind, einmal sogar von sieben lebend geborenen, von denen sie vier aufgezogen hat. Die anderen drei hat sie als alumni weggegeben. ${ }^{67}$ Es gibt also nicht nur in der Doppelprovinz Pontus-Bithynien die Sitte, Kinder, die man nicht mehr ernähren konnte, auszusetzen, man konnte sie auch an andere, eventuell kinderlose Menschen als Zöglinge

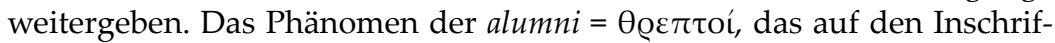
ten immer wieder zu finden ist, wird durch Plinius in seinem Briefwechsel bestätigt. ${ }^{68}$ Allerdings scheint es sich bei ihm wirklich um Ausgesetzte zu handeln, die als Sklaven aufgezogen wurden und um deren Ingenuität nun ein Statusprozess geführt werden muss. Das Problem der Zöglinge stellt sich jedoch in den kaiserzeitlichen Rechtsquellen als so komplex dar, dass selbst der Kaiser Trajan auf diese Schwierigkeiten in seinem Antwort-

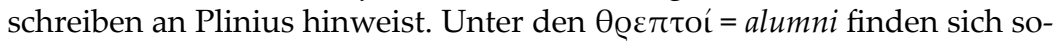
wohl von den Eltern ausgesetzte wie von ihnen fortgegebene Kinder, die frei oder unfrei aufgezogen wurden. Relative und absolute Armut können dabei eine Rolle gespielt haben, ${ }^{69}$ nicht alleine Sittenlosigkeit, wie Dion uns glauben machen will. Ob das auf den Inschriften überlieferte Ehe- und Familienideal der Wirklichkeit immer entsprochen hat, wissen wir nicht. Aber unabhängig von aller philosophischen Theorie hat es in der Bevölkerung diese moralischen Vorstellungen gegeben, die man bestrebt war, repräsentativ darzustellen, auch wenn sie in der Praxis nicht immer umsetzbar waren.

\footnotetext{
${ }^{65}$ R. Hawley, „Marriage, Gender and the Family in Dio”, in: Swain 2000, [125-137], 126-134.

${ }^{66}$ Marek 2003, 147-154 mit Abb. 228. 229. 234. 235.

${ }^{67}$ MareK 2003, 137-140 mit Abb. 218-220.

${ }^{68}$ Plin. ep. X 65. 66; s. hierzu Marek 2010, 576-578.

${ }^{69}$ Unter Berücksichtigung der juristischen und epigraphischen Quellen s. HerrmanNОтто 2011b, 187-195.
} 


\section{Dions einzigartige sozio-ökonomische Erkenntnisse}

Obwohl Dion den Zusammenhang zwischen Arbeitslosigkeit und absoluter Armut bei all denjenigen erkannt hat, die kein Vermögen haben und nur von ihrer Hände Arbeit leben müssen, empfiehlt er den absolut Armen jedoch nicht alle Berufe, die in den Städten auszuüben sind. Seine Bewertungskriterien sind dabei nicht materieller Art, dass es sich etwa um unterbezahlte Tätigkeiten handeln könnte. Vielmehr sondert er Berufe aus, in denen man zwar viel Geld verdienen kann und in denen man sogar, weil es sich um öffentliche Tätigkeiten handelt, durch die Stadt abgesichert ist. Seine Bewertungskriterien sind sowohl ethischer wie physischer Natur, sowohl im Blick auf den einzelnen Berufstätigen wie auch im Blick auf den Nutzen für die Gemeinschaft: „Die Beschäftigungen und Handwerksbereiche sind insgesamt in der Stadt ebenso zahlreich wie vielgestaltig.... Sie alle im Einzelnen aufzuzählen ist angesichts der großen Zahl gar nicht leicht und auch nicht sinnvoll und angemessen." (\$§ 109f.). ${ }^{70}$ Dion gibt einen positiven Kriterienkatalog, nach welchem man eventuell selbst die Berufe bewerten könnte. (§§ 112f.) Wichtig ist für ihn, dass

1. die Würde des Menschen gewahrt bleibt,

2. die Seele keinen Schaden nimmt,

3. der Körper gesund bleibt (Bewegung, keine Verweichlichung),

4. das Einkommen zum Leben ausreichend ist (oberhalb der Grenze des Existenzminimums),

5. die Bewertung der zu verrichtenden Arbeiten durch den Arbeiter positiv ist.

Wenn diese Kriterien erfüllt sind, dann ist das Ziel, das sich Dion in seiner Rede gesteckt hat, erreicht: die absolute Armut ist beseitigt, und die Arbeitenden haben ihr Auskommen in einer Weise, dass sie zufrieden sind und anderen Hilfe und Gastfreundschaft gewähren können wie der böotische bäuerliche Jäger aus dem ersten Teil der Rede (§ 113). Armut, im Sinne von relativer Armut, und absolute Armut, die durch entsprechende Berufstätigkeit behoben werden kann, sind nicht mehr zu fürchten und keine Übel, wie die Reichen seiner eigenen Gesellschaftsschicht immer behaupten. Vorurteile wären abgebaut, die gegenseitige Akzeptanz und der gesellschaftliche Ausgleich und Frieden in der Stadt hergestellt.

Wenn Dion mit seiner Erkenntnis des Zusammenhangs von Arbeit und Armutsbekämpfung und deren theoretischer Umsetzung auch originell zu sein scheint, so bleibt er in der ethischen Bewertung der Berufe doch der

\footnotetext{
${ }^{70}$ Epigraphisch sind für das Athen des 5./4. Jhs. in Stadt und Land 160 Berufe belegt, s. Herrmann-Otтo 2009, 78-79, zur Fülle städtischer Berufe im kaiserzeitlichen Rom s. ebd. $160-168$.
} 
Tradition verbunden. Die hohe Ästimation der Landwirtschaft und die geringe Schätzung des Handwerks gehen auf die staatstheoretischen Schriften der Griechen zurück. ${ }^{71}$ Aber auch die Römer singen ein Preis- und Tugendlied auf die bäuerlichen Tätigkeiten und den Landbesitz. Handel und Geldgeschäfte dagegen haben sie nur auf der Ebene der Großunternehmer positiv bewertet. Der Kleinhändler und der Geldwechsler sind dagegen verachtet und entstammen nicht selten dem Sklavenmilieu. Wer darauf angewiesen ist, bei einem argentarius oder faenerator einen Kredit aufzunehmen, der ist im gesellschaftlichen Ansehen tief gesunken. ${ }^{72}$ Berufe, die dem städtischen Luxus dienen, wie der Kosmetik der Frauen und der prunkvollen Ausschmückung der Häuser, wurden von den Moralisten, Kynikern und Stoikern kritisiert. Als Schüler des Musonius Rufus und bedürfnisloser Wanderprediger war Dion von der Schädigung der Seele durch den Luxus überzeugt. Hersteller und Konsumenten wollte er davor bewahren. Die archäologischen Zeugnisse aus Bithynien allerdings, Grabmäler und Bauten, zeigen, dass Dion mit solchen Ansichten eher auf verlorenem Posten stand..$^{73}$

Es ist eine große Leistung des Dion von Prusa den Zusammenhang zwischen Arbeitslosigkeit und absoluter Armut erkannt und deren Bekämpfung durch Arbeit als Lösungsmöglichkeit dargelegt zu haben. Die praktische Durchführung dieser richtigen Beobachtung und Erkenntnis bleibt jedoch deswegen hinter den antiken Möglichkeiten zurück, weil der Redner moralische und eugenische Bewertungskriterien so absolut formuliert, dass es fast unklar ist, welche Berufe die absolut Armen denn überhaupt noch ausüben können, ohne moralisch und körperlich Schaden zu nehmen. Dennoch ist Dion nicht allein als Moralist zu fassen sondern auch als politisch aktiver Mensch der Oberschicht. Er scheint zu erkennen, dass auch eine Verantwortung der Stadt, ihrer Beamten und der Gesetzgeber besteht, vor allem der ärmeren Bevölkerung ausreichende und würdige Arbeitsmöglichkeiten zur Verfügung zu stellen, um sie nicht in Kriminalität, Sklaverei, Müßiggang und absolute Armut zu treiben.

Betrachtet man andere Stoiker im römischen Reich, die zur gleichen gesellschaftlichen Schicht wie Dion gehörten und ebenfalls, wenn auch im

\footnotetext{
${ }^{71}$ KNOCH 2010, 311. 315.

${ }^{72}$ Zur Bewertung der agrarischen Besitzverhältnisse und der Finanzgeschäfte der römischen Oberschicht, die ganz rigide am Standeskodex dieser Gesellschaftsschicht orientiert ist, und daher zu einer Abwertung aller außerhalb der Oberschicht betriebenen Transaktionen führt s. Chr. RolLinger, Solvendi sunt nummi. Die Schuldenkultur der späten römischen Republik im Spiegel der Schriften Ciceros (Berlin 2009) 63-100. 128-146.

${ }^{73}$ Vgl. die mit Parfümfläschchen, Schmuckkassetten, Spiegeln, Ölfläschchen, aber auch Spindeln reich verzierten Grabsteine bithynischer Frauen in: MAREK 2003, Abb. 221. 222. 225. Vgl. ebd. auch Abb. 130. 136. 190. 194. 202. 203 reichverzierte Mauern, Toreingänge, Sarkophage und Grabstelen, die Reichtum und Luxus der Menschen und Städte in den Provinzen Pontus und Bithynien zeigen.
} 
Westen des Reiches, politisch tätig waren, dann ist ein Unterschied erkennbar. Dion beschäftigt sich wirklich mit den absolut Armen und will ihre Probleme lösen sowohl zu ihrem eigenen Nutzen wie auch zum Nutzen der Stadt. Darüber hinaus will er seinen Standesgenossen zeigen, dass man Armut nicht zu fürchten braucht, weil sie durch Arbeit und Genügsamkeit behebbar ist. Weder bei Cicero noch bei Seneca, um die prominentesten lateinischen Vertreter zu nennen, spielt Arbeit eine Rolle. Außerdem beschäftigen sie sich nur mit der relativen Armut, in die ihre Standesgenossen fallen können, und wie man ihnen dann durch Gaben (beneficia) helfen kann. Der aus euergetischem Handeln gewonnene Prestigegewinn spielt bei ihnen eine unübersehbare Rolle. Deswegen kann die absolute Armut, der absolut Arme überhaupt nicht in den Blick dieser beiden Staatsmänner und Philosophen kommen.

Durch die Blickrichtung auf die gesamte Stadt, ihr Territorium und alle dort Wohnenden erweist sich Dion von Prusa zwar als geistig in der Tradition der großen griechischen Staatstheoretiker stehend. In der Radikalität seiner Forderungen aber, die in nuce wirtschaftsethische Prinzipien enthalten, hat der kommunalpolitisch engagierte Philosoph und Rhetor als singulärer Vordenker in seiner Zeit zu gelten.

Besitzt die Rede des Dion Chrysostomos für uns noch Relevanz? Wenn wir auch heute in anderen gesellschaftlichen, ökonomischen und politischen Zusammenhängen leben, so bleibt doch eines bestehen: welche beruflichen Tätigkeiten ein Mensch auch immer ausübt, sie dürfen seine Würde nicht verletzen. Wie wir diese für uns heute definieren, das zeigen andere Beiträge dieses Bandes. 



\title{
Einflüsse der Stoa auf die Entwicklung von Menschenwürde und Menschenrechten bis zum Ende des 18. Jahrhunderts
}

\author{
Werner Heun
}

\section{Vorbemerkung}

Der Stoa wird allgemein ein großer Einfluss auf die Entwicklung von Menschenwürde und Menschenrechten eingeräumt, wenngleich auch immer wieder die Unterschiede zwischen modernen Menschenrechten und stoischen Vorstellungen, die in der philosophischen Pflichtenlehre der Stoa wurzeln, betont werden. ${ }^{1}$ Die These, die stoischen Lehren bildeten die Grundlage der späteren Menschenrechte, bedarf freilich in mehrfacher Hinsicht der begrifflichen und historischen Differenzierung und behutsamen Nuancierung, bevor den Einflüssen im folgenden systematisch und diachron nachgegangen wird.

Häufig werden die Konzeption der Menschenwürde und die Idee der Menschenrechte entwicklungsgeschichtlich weitgehend gleichgesetzt. ${ }^{2}$ Diese Identifikation der beiden unterschiedlichen Ideen wird durch die heute herrschende, wenngleich nicht unproblematische Interpretation des Grundgesetzes nahegelegt, wonach die Menschenwürdegarantie des Art. 1 Abs. 1 GG geradezu die Basis und den unantastbaren Kern der Menschenrechte darstellt. ${ }^{3}$ Historisch ist diese Sichtweise freilich zumindest irreführend, wenn nicht sogar unzutreffend. Den Menschenrechtserklärungen des 18. Jahrhunderts ist die Menschenwürde unbekannt und fremd. Erst nach dem 2. Weltkrieg im Gefolge der Menschenrechtserklärung der Vereinten Nationen aus dem Jahr $1948^{4}$ wird die Menschenwürde vom

\footnotetext{
${ }^{1}$ Vgl. z.B. Hofmann 1995(1988) 5; ders., „Menschenrechte und Demokratie“, Juristenzeitung (2001) [1-8] 3; CANCIK 1983, 194-204; knapp H. DreiER, in: DreiER 2004, Vorb. Rn. 2; für die Menschenwürde etwa H. MeYer, Geschichte der abendländischen Weltanschauung Bd. I (Würzburg u.a. 1947) 335.

${ }^{2}$ Vgl. z.B. H. Dreier, in: Dreier 2004, Art. 1 I, Rn. 7.

${ }^{3}$ Das Bundesverfassungsgericht spricht von einem ,obersten Wert" BVerfGE 5, 85 (204) und von der Menschenwürde "als dem Mittelpunkt des Wertsystems der Verfassung“ BVerfGE 35, 202 (225); s.a. Dreier 2004, Art. 1 I, Rn. 40 auch mit weiteren Nachweisen.

${ }^{4}$ Zuvor schon in der Präambel der UN-Charta von 1945; zur Entstehungsgeschichte der Rechteerklärung s. W. VöGELE, Menschenwürde zwischen Recht und Theologie (Gütersloh 2000) 200-235.
} 
philosophischen Konzept zur juristischen Garantie transformiert, besonders prominent und wirkungsmächtig im Grundgesetz. ${ }^{5}$ Bis dahin entwickeln sich die Idee der Menschenwürde und die wesentlichen Elemente der Menschenrechtskonzeption jedoch weitgehend unabhängig und unverbunden nebeneinander. Verbindungen bestehen immerhin bei der Herausbildung der Gleichheitsvorstellungen, die ideengeschichtlichen Einflüsse divergieren ansonsten aber erheblich. Sie konvergieren allenfalls auf höchstem Abstraktionsniveau in der gemeinsamen Grundvorstellung eines personenbezogenen Individualismus. Zwischen beiden Konzepten ist folglich scharf zu unterscheiden, auch die wirkungsgeschichtlichen Stränge verlaufen weitgehend separat.

Es ist aber nicht nur zwischen der Menschenwürde einerseits und den Elementen der Menschenrechtsidee andererseits $\mathrm{zu}$ trennen; noch anspruchsvoller ist die Aufgabe, die Einflüsse der Stoa auf die Entwicklung der beiden, erst am Ende des 18. Jahrhunderts ausgereiften Konzepte präzise zu eruieren. Trotz aller Kenntnisse der antiken Philosophen und Schriftsteller und des Enthusiasmus der amerikanischen Founding Fathers ${ }^{6}$ wie der französischen Revolutionäre für die Antike sind die direkten Anleihen bei der Stoa nur minimal. Die indirekten Einflüsse über die zwei Jahrtausende seit etwa 300 v. Chr. sind dagegen vielfältig gebrochen. Der Vorgang der Vermittlung und Verwandlung beginnt bereits in der Antike, da die Lehren der Stoa den späteren Zeiten, besonders dem Mittelalter und der Renaissance, außer durch den Stoiker Seneca ${ }^{7}$ vornehmlich durch Cicero vermittelt werden, ${ }^{8}$ der selbst der Schule der Stoa nicht unmittelbar zugerechnet werden kann. ${ }^{9}$ Vor allem verbinden sich stoische Gedanken seit der Patristik in einem ständigen Austauschprozess mit christlichen Vorstellungen, so dass es oft nahezu unmöglich ist, generell antike und speziell stoische sowie christliche Anteile voneinander zu scheiden. ${ }^{10}$ Das gilt freilich in beiden Richtungen. Was vielfach als genuin christliche Konzeption angesehen wird, beruht oftmals auf der Rezeption antiker Philosophie und Literatur, die bis in die Neuzeit in mehreren Wellen erfolgt. Die Patristik ist als Teil der Spätantike antiken philosophischen Quellen ver-

\footnotetext{
${ }^{5}$ Vgl. Heun 2009.

${ }^{6}$ Vgl. dazu W. Heun, „Die Antike in den amerikanischen politischen Debatten in der zweiten Hälfte des 18. Jahrhunderts“", in: HZ Beiheft 55 (2011) 65-83.

${ }^{7}$ Vgl. dazu L. D. Reynolds, The Medieval Tradition of Seneca's Letters (Oxford 1965); Reynolds 1983, 356-381; K.-D. Nothdurft, Studien zum Einfluß Senecas auf die Philosophie und Theologie des zwölften Jahrhunderts (Leiden/Köln 1963) 47-201.

${ }^{8}$ Reynolds 1983, 54-142; vgl. auch zur Rezeption antiker Literatur im Mittelalter, ders. / N. G. Wilson, Scribes and Scholars: A Guide to the Transmission of Greek and Latin Literature, 2nd ed. (Oxford 1974) 70-107.

${ }^{9}$ Vgl. J. G. F. Powell, Introduction, in: ders. (ed.), Cicero The Philosopher (Oxford 1995) [1-35] 23-26; Colish 1990, vol. I, 61-158; Spanneut 1973, 112-119.

${ }^{10}$ Vgl. dazu insbes. M. Spanneut, Le Stoïcisme des Pères de l'Église (Paris 1957) 54-77 und Spanneut 1973, 130-209.
} 
haftet, wesentliche Gedanken werden sentenzenhaft durch Laktanz ${ }^{11}$ und Isidor von Sevilla ${ }^{12}$ vermittelt und weitergetragen, maßgebend sind für die Folgezeit aber die karolingische Renaissance vornehmlich für die Textüberlieferung, ${ }^{13}$ dann die sog. Renaissance des 12. Jahrhunderts, ${ }^{14}$ die von einem grundlegenden Individualisierungsschub begleitet wurde ${ }^{15}$ sowie der mit einem weiteren Individualisierungsschub verbundene ${ }^{16}$ Humanismus der Renaissance ${ }^{17}$ ausgehend vom Italien des 14 . Jahrhunderts bis ins 16. Jahrhundert. ${ }^{18}$ Außerdem vermischen sich häufig die Traditionslinien des (Neo-)Platonismus und der Stoa, ${ }^{19}$ was die Archäologie stoischer Einflüsse weiter erschwert. Angesichts dieser Probleme verwundert es wenig, dass präzise Analysen über die konkreten Einflüsse weithin fehlen.

\footnotetext{
${ }^{11}$ Lact. Inst., vorliegend bes. III 8-15 (dignitas) (ed. E. Hеск / A. WLosok, Fasc. 2 [Berlin 2007] 218-254) und V 14,16f. (aequalitas) (ed. Fasc. 3 [Berlin 2009] 487-491. 493-503); s. auch unten Anm. 55.

${ }^{12}$ I. von Sevilla, Etym. (ed. W.M. Lindsay, Etymologiarum sive Originum Libri XX, 2 vols. [Oxford 1911, repr. 1957]) V De legibus.

${ }^{13}$ J. E. SAndys, History of Classical Scholarship, vol. I, 2. ed. (Cambridge 1906) 471-501; W. Ullmann, The Carolingian Renaissance and the Idea of Kingship (London 1969) 3-42; H. Schutz, The Carolingians in Central Europe, their History, Arts and Architecture (Leiden u.a. 2004) 135-216.

${ }^{14}$ Klassisch C. H. Haskins, The Renaissance of the Twelfth Century (Cambridge, Mass. 1927) (repr.); und die Essaysammlung R. L. Benson / G. Constable (eds.), Renaissance and Renewal in the Twelfth Century (Cambridge, Mass. 1982); sowie R. W. Southern, Scholastic Humanism and the Unification of Europe, vol. I Foundations (Oxford 1995).

${ }^{15}$ Vgl. C. Morris, The Discovery of the Individual 1050-1200 (London 1972); vgl. auch vorsichtiger C. Walker Bynum, "Did the Twelfth Century Discover the Individual?“, Journal of Ecclesiastical History 31 (1980), 1-17; zu den christlichen Grundlagen vgl. K.-H. OHLIG, "Christentum - Individuum - Kirche“, in: R. van Dülmen (Hrsg.), Entdeckung des Ich (Köln u.a. 2001) 11-40; ferner C. J. Nederman, "Individual Autonomy“, in: Cambridge History of Medieval Philosophy, vol. II (Cambridge 2010) 551-564.

${ }^{16}$ Klassisch J. Burckhard, Die Kultur der Renaissance in Italien (1860) (Bern 1943) 145-183; jüngerer Überblick R. vAN DüLMEN, Die Entdeckung des Individuums 1500-1800 (Frankfurt a. M. 1997).

${ }^{17}$ Vgl. zum Humanismus hier nur die umfassende Sammlung A. RABIL, Jr. (ed.), Renaissance Humanism. Foundations, Forms, and Legacy, 3 vols. (Philadelphia 1988); sowie R. WeIss, The Dawn of Humanism in Italy (London 1947) (repr. 1970).

${ }^{18} \mathrm{Zu}$ den grundlegenden Unterschieden dieser Renaissancen vgl. E. PANofsky, Die Renaissancen der europäischen Kunst (Frankfurt a. M. 1979) 57-117.

${ }^{19}$ Vgl. insbes. NeschKe-HentschKe 1995-2003, bes. vol. I, 183-202; vgl. zur Zeit der Renaissance vor allem N. A. Rовв, Neoplatonism of the Italian Renaissance (London 1935), zum Mittelalter R. KLibansky, The Continuity of the Platonic Tradition during the Middle Ages (1939) (Ndr. New York 1982).
} 


\section{Der Ausgangspunkt: Stoische Lehren}

Bereits bei Zenon, dem Begründer der Stoa, finden sich um 300 v. Chr. zentrale Elemente der politischen Lehre dieser Philosophenschule. ${ }^{20}$ Hierzu zählt zuallererst ein ausgeprägter Egalitarismus, der die natürliche Gleichheit aller Menschen, ${ }^{21}$ im übrigen auch eine Gleichstellung von Mann und Frau, ${ }^{22}$ propagiert und die Sklaverei als widernatürlich ablehnt. ${ }^{23}$ Die Gleichheit ist zu einem Weltbürgertum ausgeweitet. ${ }^{24}$ Ihre Grundlage findet der Kosmopolitismus in der Gleichsetzung von Natur und Vernunft. Dem Gesetz der Natur folgen bedeutet der Vernunft folgen. ${ }^{25}$ Das Naturgesetz ist göttlich, aber es gibt keinen transzendenten Schöpfer, vielmehr ist die Vernunft innerweltlich gedacht. ${ }^{26}$ Daraus resultiert die stoische Pflichtenlehre, wonach der Einzelne in Übereinstimmung mit dem Logos, mit der Natur, leben soll. ${ }^{27}$ Die ideale Gleichheit wird als Wirklichkeit in einen ursprünglichen Naturzustand verlegt, ${ }^{28}$ der aber seiner kritischen Maßstabsfunktion nie ganz entkleidet wird. Sklaverei wird daher als Realität hingenommen und zugleich als contra naturam kritisiert. Gleichwohl bleiben diese Lehren dem Bereich der Ethik reserviert ${ }^{29}$ und stellen kein objektives oder gar subjektives Recht dar. Die Vorstellung subjektiver Menschenrechte bleibt der Antike fremd. ${ }^{30}$ Daran ändert auch die Rezeption durch die römische Jurisprudenz nichts, die vielmehr vor allem überlieferungs- und wirkungsgeschichtlich hohe Bedeutung entfaltet.

Obwohl die römischen Juristen die stoischen Lehren übernehmen und feststellen, dass nach dem Recht der Natur alle Menschen frei geboren werden, ${ }^{31}$ alle gleichwertig (aequales) sind ${ }^{32}$ und die Sklaverei gegen die Natur

\footnotetext{
${ }^{20}$ Zur stoischen Ethik vgl. vor allem E. Zeller, Die Philosophie der Griechen in ihrer geschichtlichen Entwicklung, 3. Teil, 1. Abt., 5. Aufl. (Leipzig 1920) (Ndr. 1990) 210-318; O. RIETH, Grundbegriffe der stoischen Ethik, Problemata 9 (Berlin 1933); Forschner 1995.

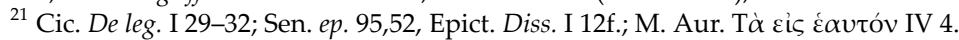

${ }^{22}$ Diog. Laert. VII 175; vgl. auch VI 12.

${ }^{23}$ Diog. Laert. VII 121f.; vgl. auch VI 16; Sen. ep. 47.

${ }^{24}$ Cic. De re pub. III 22f.; Cic. De fin. III 67; Sen. ep. 95,52 sowie 28,4; Epict. Diss. I, 9. II,

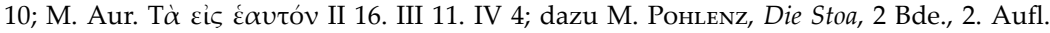
(Göttingen 1959) I 135-139; A. A. T. Ehrhardt, Politische Metaphysik von Solon bis Augustin, Bd. I (Tübingen 1959) 161-163. 180-188; W. W. TARN, Alexander the Great and the Unity of Mankind (London 1933) 14-28; die Bedeutung Alexanders negierend dagegen H.C. BALDRY, The Unity of Mankind in Greek Thought (Cambridge 1965) 113-134.

${ }^{25}$ Diog. Laert. VII 87f.; Arnim, SVF I frg. 179; Sen. ep. 90,4f.

${ }^{26}$ Vgl. Cic. De fin. III 64.

${ }^{27}$ Vgl. Forschner 1995, 183-211.

${ }^{28}$ Vgl. Sen. ep. 90,36-46.

${ }^{29}$ Vgl. Forschner 1995, 104-113.

${ }^{30}$ Zum Unterschied antiker und neuzeitlicher Freiheitsvorstellungen s. Heun 2006, Rn. 3-10.

${ }^{31}$ Dig. 1,1,3; zum Stoizismus im römischen Recht vgl. insbes. CoLisH 1990, vol. I, 341-389.

${ }^{32}$ Dig. 50,17,32.
} 
ist, ${ }^{33}$ bleibt dies rechtlich folgenlos und führt nicht zur Forderung nach $\mathrm{Ab}$ schaffung der Sklaverei. Außer durch Ciceros und Senecas Schriften werden aber zentrale stoische Vorstellungen vor allem durch die im Corpus Juris niedergelegten Sentenzen weitergetragen, sie bilden einen ständig präsenten Zitatenschatz, der losgelöst von seinen philosophischen Grundlagen weitreichende traditionsbildende Macht entfaltet.

\section{Menschenwürde}

In der juristischen Debatte wird die Menschenwürde häufig als Säkularisat christlicher Vorstellungen angesehen. Danach bildet allein der Gedanke der Gottesebenbildlichkeit nach Genesis 1, 46 den Kern und die Grundlage des Art. 1 Abs. 1 GG. ${ }^{34}$ Damit ist ein ganz bestimmtes ontologisches Verständnis der Menschenwürde verbunden, das harte verfassungsrechtliche Konsequenzen nach sich zieht. ${ }^{35}$ Der christliche Exklusivitätsanspruch ist freilich nicht haltbar, vielmehr verbinden sich hier christliche mit römischstoischen Einflüssen in beinahe unentwirrbarer Weise.

Zunächst ist die imago Dei-Vorstellung völlig losgelöst von der Idee der Würde des Menschen. Schon der Begriff der Würde ist weder im Hebräischen $^{36}$ noch im Griechischen, ${ }^{37}$ den beiden Sprachen des Alten und des Neuen Testaments, bekannt. Das Wort dignitas, von dem sich dignity und dignité ableiten, ist römisch ${ }^{38}$ und bedeutet ursprünglich einen eng mit dem Gedanken der Ehre verknüpften sozialen Rang und Status. Dieser Würdebegriff ist gerade nicht egalitär, sondern Auszeichnung der nobilitas und folgt der „Logik der proportionalen Gerechtigkeit, die jedem nach Rang und Verdienst das Seine zuteilen soll. “39 Als Ausdruck der Ehre war diese Art der Würde bis zum Ende des 18. Jahrhunderts einzig und allein

\footnotetext{
${ }^{33}$ Dig. $1,5,4$.

${ }^{34}$ Vgl. nur exemplarisch die Verfassungsrichter E. BENDA, „Menschenwürde und Persönlichkeitsrecht", in: Handbuch des Verfassungsrechts, 2. Aufl. (Berlin 1994) § 6 Rn. 2; P. Kirснноғ, „Die Wertgebundenheit des Rechts, ihr Fundament und die Rationalität der Rechtsfortbildung“, in: E. Herms (Hrsg.), Menschenbild und Menschenwürde (Gütersloh 2001) [156-172] 162; E.-W. BöсKENFöRdE, „Bleibt die Menschenwürde unantastbar?“, Blätter für deutsche und internationale Politik 49 (2004), [1216-1227] 1222f.; dezidiert dagegen z.B. Dreier 2004, Art. 1 I, Rn. 6-8.

${ }^{35}$ So wird daraus nicht zuletzt ein Verbot der Embryonenforschung oder der PID abgeleitet, vgl. hier nur exemplarisch C. StarcK, in: v. Mangoldt / KLein / Starck, GGKommentar, Bd. 1, 6. Aufl. (München 2010) Art. 1 Rn. 98-107, Gegenposition Heun 2002, 517-524.

${ }^{36} \mathrm{Vgl}$. H. H. CoHn, ", On the Meaning of Human Dignity“, Israel Yearbook on Human Rights 13 (1983), [226-251] 247.

${ }^{37}$ Vgl. Pöschl 1992, 637f.

38 Pöschl 1992, 638-644; Pöschl 1989, 7-32.

${ }^{39}$ H. Оттмann, „Die Würde des Menschen. Fragen zu einem fraglos anerkannten Begriff“, in: Festschrift Schöpf (Würzburg 1998) [167-181] 169.
} 
dem Adel vorbehalten. Diese Form sozialer Würde wurde erst in den beiden Revolutionen des 18. Jahrhunderts auf alle Bürger erstreckt und egalisiert. ${ }^{40}$

Von diesem sozialen Rangverständnis unterscheidet sich erstmals ein universalistisches und egalitäres Verständnis von Würde in der mittleren Stoa, das vor allem von Cicero rezipiert und wirkungsmächtig formuliert worden ist ${ }^{41}$ und bis in die Neuzeit nachhaltige Wirkung entfaltet hat. Dignitas wird allen Menschen gleichermaßen zugesprochen und bezeichnet ihren auf der Vernunft beruhenden besonderen Rang im Kosmos. Diese Würde wird allerdings als Verpflichtung zur Erfüllung der Bestimmung des Menschen und nicht als irgendwie gearteter Anspruch verstanden. Die Selbsterkenntnis bedeutet insbesondere Wahrnehmung des Göttlichen im Menschen, und begründet in Fortführung platonischer Gedanken auch die Verpflichtung, nach Gottähnlichkeit zu streben. ${ }^{42}$ Schon hier wird die Affinität von stoischem Würdegedanken und imago Dei-Vorstellung deutlich. Es kommt hinzu, dass auch die Idee des Menschen als imago Dei nicht nur im Alten ${ }^{43}$ und im Neuen Testament ${ }^{44}$ auftaucht, sondern generell in der Antike verbreitet ist. ${ }^{45}$ Die Humanisten der Renaissance greifen daher auf diese antiken Autoren wie auf die Bibel gleichermaßen zurück.

Die spätantike Patristik verknüpft schließlich die biblische imago DeiVorstellung und die platonisch-stoische Bestimmung der Menschenwürde. ${ }^{46}$ Maßgebender Ausgangspunkt ist die kritische Genesis-Exegese des jüdisch-hellenistischen Philosophen Philo Judaeus, ${ }^{47}$ der platonisch-stoische und biblische Gedanken verschmilzt und über Clemens von Alexandria und Origines auf die christliche Theologie einwirkte. ${ }^{48}$ Für Philo ist

${ }^{40}$ T. PAIne, „,The Rights of Man“, in: ders., The Complete Writings, 2 Bde (New York 1945) I [243-458] 277; vgl. auch Heun 2009, 63f.

${ }^{41}$ Cic. De off. I 105-107 (106); dazu Cancik 2002, 19-39; Pöschl 1989, 32-42.

${ }^{42}$ Vgl. grundlegend Merкi 1952, 1-64; knappe Zusammenfassung in Merкi 1959, Sp. 459-479.

${ }^{43}$ Gen 1,26, vgl. auch Hamman 1987. 9-19; R. McL. Wilson, „The Early History of the Exegesis of Genesis 1:26", Studia Patristica 1 (1957), 420-437.

${ }^{44}$ Hier ist allerdings in erster Linie Christus Bild Gottes, s. 2 Cor. 4,4, Col. 1, 15; Hamman 1987, 19-33.

${ }^{45}$ Vgl. z.B. auch Ov. Met. I 82; Plat. Prot. 320d, wonach Prometheus den Menschen nach dem Bild der Götter erschafft; ferner Cic. De leg. I 59; Sen. ep. 48, 11 und 59, 14; s. МеrкI 1959, Sp. 459-462; Merki 1952, 65-91; Pöschl 1989, 42f.

${ }^{46}$ Zur Entwicklung bis Augustinus vgl. Hamman 1987, 34-237; s. ferner R. BRUCH, „Die Würde des Menschen in der patristischen und scholastischen Tradition“, in: Festschrift $P$. Asveld (Graz 1981) [139-154] 139-145.

${ }^{47}$ Phil. Al. Opif. 69,72, Philo zitiert nach L. Cohn / P. Wendland (edd.), Philonis Alexandrini Opera Quae Supersunt, 7 Bde. (Berolini 1896-1930) (Ndr. 1962/63).

${ }^{48}$ Zur Entwicklung bis zur Renaissance vgl. v.a. C. TrinkHAus, "The Renaissance Idea of Dignity of Man“, in: Dictionary of the History of Ideas, Vol. IV (New York 1973) 136-147; KondyLis 1992, 645-677; H. BAKER, The Dignity of Man. Studies in the Persistence of an Idea (1947) (Ndr. als: The Image of Man, [Cambridge 1961] danach zitiert). 
der Geist das Abbild Gottes im Menschen. Außerordentlich folgenreich ist seine Formulierung, dass der Mensch als Mikrokosmos zu verstehen ist, der im Grenzbereich zwischen Sterblichkeit und Unsterblichkeit angesiedelt ist. ${ }^{49}$ Die Formel vom Menschen als Mikrokosmos wird von Isidor von Sevilla aufgenommen ${ }^{50}$ und ist damit das ganze Mittelalter präsent. Pico della Mirandola ${ }^{51}$ knüpft deshalb an eine lange Tradition ${ }^{52}$ an, wenn er die Würde des Menschen mit dessen Eigenschaft als Mikrokosmos begründet.

Neben Clemens von Alexandria, Origines und Basilius von Nyssa transportiert vor allem die Schrift seines Bruders Gregor von Nyssa De hominis opificio die Vorstellung, dass die Gottähnlichkeit die Würde des Menschen ausmacht. ${ }^{53}$ Dabei bringt der Begriff der homoiosis den dynamischen Prozess der platonischen Assimilation an Gott zum Ausdruck. ${ }^{54}$ Die Erschaffung des Menschen als imago Dei indiziert die ursprüngliche Vollkommenheit, die nach dem Sündenfall erst allmählich wiedergewonnen werden kann. Ebenfalls einflussreich durch lateinische Übersetzungen prägt Nemesius von Emesa mit seinem Traktat De natura hominis die späteren Würdekonzeptionen. ${ }^{55}$ Der Mensch verbindet Sterblichkeit mit Unsterblichkeit, Vernunft mit Unvernunft und spiegelt als Mikrokosmos die ganze Schöpfung. Seine Würde beruht auf seiner Gottesebenbildlichkeit. Bei Nemesius findet sich eine emphatische Beschreibung des Menschen, der die Welt beherrscht und zugleich auf die transzendente Gotteserkenntnis ausgerichtet ist, die teilweise das Menschenverständnis der Renaissance vorwegnimmt. Ein griechisches Manuskript dieser Schrift gehörte auch zur Bibliothek Manettis. ${ }^{56}$

Diese frühchristliche, platonisch-stoisch geprägte Tradition der Betonung der Menschenwürde wird aber durch den beherrschenden Einfluss Augustinus' für lange Zeit gebrochen. Bei Augustinus kommt der Begriff lediglich ein einziges Mal an wenig zentraler Stelle vor. ${ }^{57}$ Seine Erbsündelehre und Ablehnung der Willensfreiheit entziehen der Würdekonzeption entscheidende Elemente, obwohl die imago Dei-Lehre bei ihm eine zentra-

\footnotetext{
${ }^{49}$ Phil. Al. Post. 12; Plant. 7; vgl. auch Opif. 23, 51.

${ }^{50}$ I. von Sevilla, De natura rerum, c. IX De mundo, 2 (PL 83, Sp. 978).

${ }^{51}$ P. della Mirandola, Heptaplus, in: E. Garin (ed.), Giovanni Pico della Mirandola, De hominis dignitate, Heptaplus, De ente et uno e Scritti vari (Florenz 1942) [168-383] 266-286, wonach der Mensch eine eigene Welt bildet; in der oratio kommt der Ausdruck selbst nicht vor; vgl. dazu DE Lubac 1974, 160-183.

${ }^{52}$ R. Allers, "'Microcosmos from Anaximandros to Paracelsus“, Traditio 2 (1944) 319-407.

${ }^{53}$ Greg. Nyss. De opif. hom., PG 44 (1863), Sp. 123-256, c. 3f.; dazu J.T. MucKLE, „The doctrine of St. Gregory of Nyssa on man as the image of God“, Medieval Studies 7 (1945) 55-84.

${ }^{54}$ Dazu Merki 1952, 92-164.

${ }^{55}$ Nemes. Em. De nat. hom., Ausgabe Halle 1802 (repr. 1967), c. 1 (griech. S. 63-66, lat. S. 13f.), (= PG 40, 503-818 (532f.); wichtig auch Lactanz, s. dazu M. PERrin, L'Homme antique et chretien: L'Anthropologie de Lactance 250-325 (Paris 1981) 419-428.

${ }^{56} \mathrm{Zu}$ Manetti s. Anm. 70.

${ }^{57}$ Aug. QEv. II 33,3; Pöschl 1992, 645.
} 
le, aber andere Rolle spielt. Unter dem Einfluss neoplatonischer Gedanken ist nach seiner psychologischen Trinitätslehre der menschliche Geist ein Abbild der Trinität. Augustinus unterscheidet scharf zwischen imago, similitudo und aequalitas und betont die Erschaffung des Menschen nach Gottes Bilde, während die platonisch-stoische, prozesshafte similitudo zurücktritt. ${ }^{58}$

Die Dominanz Augustinischer Lehren, die christlich-platonischen Hierarchievorstellungen im Gefolge von (Pseudo-) Dionysius Areopagita ${ }^{59}$ sowie die Schriften über die miseria und excellentia hominis, ${ }^{60}$ die bis zur Schwelle der Neuzeit reichen, ${ }^{61}$ lassen kaum Raum für stoische Einflüsse auf den Menschenwürdegedanken. ${ }^{62}$ Überhaupt verliert die Idee der Menschenwürde bis zu dem erneuten Wiederaufleben humanistischer Einflüsse im 12. Jahrhundert ${ }^{63}$ nahezu jede Relevanz. ${ }^{64}$ Trotz der Präsenz Ciceros im Werk von Thomas von Aquin bleibt die Menschenwürdekonzeption des Aquinaten, die er wie zuvor Bernhard von Clairvaux ${ }^{65}$ eng mit der

\footnotetext{
${ }^{58}$ Vgl. G. B. LAdNER, The Idea of Reform. Its Impact on Christian Thought and Action in the Age of the Fathers, rev. ed. (Cambridge 1967) 185-203; J. E. Sullivan, The Image of God: The Doctrine of St. Augustinus and its Influence (Dubuque, Iowa 1963) 38-164. Beim späten Augustinus spielt die Differenz aber kaum noch eine Rolle.

${ }^{59}$ Aug. De civ. dei XI 22. XIX 15; zu Dionysius' Vorstellung B. R. Suchla, Dionysius Areopagita, Leben - Werk - Wirkung (Freiburg u.a. 2008) 97-103; allgemein auch FLÜCKIGER 1954, 360-387; P. E. Sigmund, „Hierarchy, Equality, and Consent in Medieval Christian Thought“, in: J. R. Pennock / J. W. Chapman (eds.), Equality. Nomos IX (New York 1967) 134-153.

${ }^{60}$ Als Höhepunkt dieser Schriften gilt Innozenz III., De miseria humanae conditionis (Lugano 1955).

${ }^{61}$ Vgl. dazu K. Seelmann, Miseria et excellentia hominis (Mskr. 2010) i.E.; vgl. aber auch zur Veränderung in der Renaissance A. BucK, „Die Rangstellung des Menschen in der Renaissance, dignitas et miseria hominis“, Archiv für Kulturgeschichte 42 (1960) 61-75.

${ }^{62}$ Das schließt stoische Einflüsse auf andere Bereiche keineswegs aus, vgl. z.B. für Augustinus: Colish 1990, vol. II, 142-238.

${ }^{63}$ W. Ullmann, Medieval Foundations of Renaissance Humanism (London 1977) 89-117; in: SOUTHERN 1970 [„,Medieval Humanism“ 29-60] 49f.; zur wiederauflebenden Würdediskussion insbes. L. HöDL, „Zur Entwicklung der frühscholastischen Lehre von der Gottesebenbildlichkeit des Menschen“, in: L'homme et son destin d'après les penseurs du Moyen Age. Actes du premier Congrès international de philosophie médiévale, Louvain-Bruxelles, 28 août- 4 sept. 1958 (Paris 1960) 347-359; R. JAVELET, Image et resemblance au douzième siècle de S Anselm à Alan de Lille (Straßburg 1967), Southern 1970 („Scholastic Humanism“) 22-32.

${ }^{64}$ Zwar finden sich in der karolingischen Renaissance bei Paulus Diakonus und Scotus Eriugena Anknüpfungen an die menschliche Würde aufgrund der Gottesebenbildlichkeit, die aber einerseits vor allem zum Dienst Gottes verpflichtet und andererseits lediglich im Geiste wurzelt, s. KondyLis 1992, 645f.; daneben begründet auch die Ambrosius zugeschriebene, aber wohl dem 9. Jahrhundert zuzuordnende Schrift De dignitate conditionis humanae (PL 17, 1105-1108) die Würde auf die Gottesebenbildlichkeit; schließlich findet sich die Formel der "Deus qui humanae substantiae dignitatem mirabiliter condidisti“ seit der Spätantike im wohl auf Leo I. d. Gr. zurückgehenden Opfergebet der Messe, s. PöschL 1992, 645; und näher САNCIK 1987, 83-87.

${ }^{65}$ KondyLis 1992, 647f.; die Willensfreiheit wird allerdings bereits von Eriugena propagiert; zur Bedeutung der Willensfreiheit s. auch L. Sozzı, „La Diginitas Hominis dans la
} 
Willensfreiheit verknüpft, ${ }^{66}$ von unmittelbaren (platonisch) stoischen Einflüssen unberührt, ja kehrt sich davon geradezu ab. Übereinstimmung besteht - aber aus eigenständig christlichen Überzeugungen heraus - lediglich darin, dass die Würde Verpflichtung, konkret "verpflichtende Gabe Gottes ", 67 ist, die durch Sündhaftigkeit aufgegeben und verloren wird. ${ }^{68}$

In der italienischen Renaissance erhält die menschliche Würde eine weitere Bedeutung, die teils eine Fortführung von, teils eine Antithese zu mittelalterlich-christlichen Vorstellungen ist. Petrarca ist der Protagonist dieser Bedeutungsveränderung. ${ }^{69}$ Er zieht einerseits die imago Dei-Idee heran, fügt aber andererseits einen neuen Aspekt hinzu, indem er die kreativen Fähigkeiten des Menschen und seine Fähigkeit zu vernünftigem und selbstverantwortlichem Handeln hervorhebt. Die Betonung der schöpferischen Autonomie ist auch gegen die miseria-Schrift Innozenz' III., gegen die asketische Ablehnung der Sinnlichkeit und der vita activa gerichtet. Im Kern folgen auch Manetti ${ }^{70}$ und Pico della Mirandola, der den Menschen als Mikrokosmos und aufgrund seiner Vernunft und Gestaltungskraft als plastes und fictor seiner selbst begreift, ${ }^{71}$ dem Konzept Petrarcas. Auch bei ihnen spielt die Gottesebenbildlichkeit eine maßgebende Rolle. Obwohl gerade Cicero bei Petrarca generell zu den mit Vorliebe zitierten Autoren gehört und Manetti auf De officiis an einer Stelle Bezug nimmt, lassen sich trotz aller Nähe und indirekten Anknüpfungen unmittelbare Einflüsse stoisch-ciceronischer Gedanken auf die Würdekonzepte kaum festma-

Littérature Française de la Renaissance“, in: A.H.T. Levi (ed.), Humanism in France (Manchester u.a. 1970) [176-198] 180-182.

${ }^{66}$ Zur Würdekonzeption Thomas von Aquins knapp KondyLis 1992, 649-651; C. ENDERs, Die Menschenwürde in der Verfassungsordnung (Tübingen 1997) 180-184.

${ }^{67}$ Kondylis 1992, 648.

${ }^{68}$ Thomas von Aquin, Summa Theologiae II-II, 64. 2 ad 3.

${ }^{69}$ Petrarca, De remediis utriusque fortunae 2, 93; dazu C. TRINKHAUs, In our Image and Likeness, 2 vols. (London 1970) I, 179-199; biographisch K. STIERLE, Francesco Petrarca: Ein Intellektueller im Europa des 14. Jahrhunderts (München u.a. 2003).

${ }^{70}$ G. Manetti, Über die Würde und Erhabenheit des Menschen (Hrsg. A. Buck) (Hamburg 1990); dazu CANCIK 2002, 28f.; O. GlaAP, Untersuchungen zu Gianozzo Manetti, De Dignitate et Excellentia Hominis. Ein Renaissance-Humanist und sein Menschenbild (Stuttgart u.a. 1994); M. Schmeisser, „Wie ein sterblicher Gott...“. Giannozzo Manettis Konzeption der Würde des Menschen und ihre Rezeption im Zeitalter der Renaissance (Paderborn 2006); A. Thumfahrt, „Giannozzo Manetti“, in: Gröschner u.a. 2008, 73-92.

${ }^{71}$ G. P. della Mirandola, Oratio de hominis dignitate (1487) (ed. A. BucK) (Hamburg 1990) 6-7; dazu de Lubac 1974, 57-89; Cancik 1987, 78-81; O. W. Lembcke, „Die Würde des Menschen frei zu sein“, in: Gröschner u.a. 2008, 159-186; grundlegend zu Pico E. CAsSIRER, "Giovanni Pico della Mirandola“, Journal of the History of Ideas 3, Philadelphia (1942), 123-144. 319-346, auch in: P. O. Kristeller / P. P. Wiener (eds.), Renaissance Essays (Rochester 1968) 11-60; sowie zur Würde ders., Individuum und Kosmos in der Philosophie der Renaissance (Darmstadt 1927) (Ndr. 1977) 88-92; P. O. Kristeller, Eight Philosophers of the Italian Renaissance (Palo Alto 1964 repr.) 47-71. 
chen, bei Pico sind ohnehin platonische $e^{72}$ und hermetische $e^{73}$ Traditionen besonders wirksam.

Am stärksten ist der Einfluss stoischer Gedanken, vermittelt durch Cicero, zwei Jahrhunderte später spürbar bei der Menschenwürdekonzeption Samuel von Pufendorfs, der an zentraler Stelle bei der Begründung der Menschenwürde stoisches Gedankengut reproduziert. ${ }^{74}$ Selbst Kant nimmt vereinzelt bei der Darlegung der Menschenwürde als moralischem Prinzip die Stoiker in Anspruch, ${ }^{75}$ damit einmal mehr die Verankerung seiner Würdekonzeption in der Tugend- und nicht in der Rechtslehre dokumentierend. ${ }^{76}$ Die Menschenwürde findet daher in den Menschenrechtserklärungen und Grundrechtskatalogen auch nicht einmal ansatzweise Aufnahme. ${ }^{77}$ Erst im 19. Jahrhundert gehen die Idee der Menschenwürde und der Anspruch auf eine ökonomisch-soziale Existenzsicherung eine Verbindung ein, die erstmals von Ferdinand Lassalle mit der staatlichen Verpflichtung zur Sicherung eines „wahrhaft menschenwürdigen Daseins" wirkmächtig formuliert wurde. ${ }^{78}$ Die äußeren Anklänge an die Verknüpfung von Armut und Würde bei Dion von Prusa ${ }^{79}$ dürfen aber ebenfalls nicht über die kategoriale Differenz zur sozialen Frage im 19. Jahrhundert

\footnotetext{
${ }^{72}$ Vgl. E. Garin, Der italienische Humanismus (Bern 1947) 92-134.

${ }^{73} \mathrm{Zu}$ ihrer Bedeutung grundlegend F. A. YATES, Giordano Bruno and the Hermetic Tradition (Chicago/London 1964) 1-189, zur oratio Picos ebd. 102-112, speziell zur Würde S. 110f.

${ }^{74}$ S. von Pufendorf, De iure naturae et gentium (1672) 2,1,5; s. Welzel 1958, 47; CANCIK 2002, 30-33; Kobusch 1993, 67-82.

${ }^{75}$ I. Kant, Die Religion innerhalb der Grenzen der bloßen Vernunft, 2. Aufl. Königsberg 1794, 2. Stück (ed. Weischedel) 1968, IV, S. 709; dazu CANCıK 2002, 34-36.

${ }^{76}$ Vgl. dazu R. RuzickA, "Moral, Naturrecht und positives Recht bei Kant", in: H. HolzHEY / G. KoHLER (Hrsg.), Verrechtlichung und Verantwortung (Bern u.a.1987) 141-157; HeuN $2009,66$.

${ }^{77}$ Der von H. Welzel (Ein Kapitel aus der amerikanischen Erklärung der Menschenrechte. John Wise und Samuel Pufendorf, in: Festgabe R. Smend [Göttingen 1952] 387-411) behauptete Einfluss Pufendorfs auf die Grundrechte der Amerikanischen Revolution, der vielfach repetiert worden ist (z.B. САNCIK 2002, 33; КовUSCH 1993, 101-106), ist so nicht haltbar. J. Wise, A Vindication of the Government of New England Churches (Boston 1717, 2. ed. 1772) hatte keinen nennenswerten Einfluss auf die moderne Grundrechtskonzeption, in den amerikanischen Standardwerken wird er nicht einmal erwähnt, einzig C. Rossiter, Seedtime of the Republic (New York 1953) 205-226 behandelt Wise ausführlich, um freilich dann selbst festzustellen (S. 360f.), dass man vergeblich nach ", a single significant quotation from Wise " fahnden könne und die 2. Aufl. seiner Vindication schlicht nicht zur Kenntnis genommen worden sei. Pufendorf wurde in erster Linie als Völkerrechtslehrer wahrgenommen und hat auch über Blackstone, selbst wenn dieser ihn gelegentlich zitiert, keinen nennenswerten Einfluss auf die Verfassungen oder die Grundrechte ausgeübt; vgl. im übrigen auch D. S. Lutz, „The Relative Influence of European Writers on Eighteenth Century American Political Thought", American Political Science Review 78 (1984) 189-197.

${ }^{78}$ F. Lassalle, „Das Arbeiterprogramm“ (1861/62), in: ders., Reden und Schriften (München 1970) 22-60 (40).

${ }^{79}$ Dio, or. 7,91-116.
} 
und der dadurch ausgelösten Sozialverpflichtung des Staates hinwegtäuschen.

\section{Menschenrechte}

Die Menschen- und Grundrechte in den amerikanischen und französischen Rechteerklärungen sind als Ganzes ein fundamental neues Konzept, das freilich verschiedene Elemente und Traditionslinien aufgreift und verbindet. Deshalb läßt sich das rechtliche Konzept der Menschenrechte nicht auf stoische oder sonstige philosophische wie juristische Vorbilder zurückführen, wohl aber sind einzelne Elemente auch durch stoische Ideen beeinflusst. Vier Elemente sind für die kategorial neue Rechtekonzeption konstitutiv. Die Grundrechte werden erstens in Verfassungen verankert, die einen Vorrang vor anderen Rechtsquellen beanspruchen. Grundrechte sind zweitens vor allem auch - jedenfalls in der amerikanischen Version ${ }^{80}$ - subjektive (Abwehr-) Rechte und begründen drittens einen individuellen Freiheitsraum gegenüber dem Staat. Sie beruhen viertens auf dem Gedanken der Gleichheit. Stoische Einflüsse sind dabei unterschiedlich wirksam.

1. Obwohl die Verfassung am Ende des 18. Jahrhunderts ebenfalls eine fundamentale Neuerung darstellt, ${ }^{81}$ ist sie im Ansatz ohne die Tradition des Naturrechts ${ }^{82}$ nicht zu verstehen. Der Gedanke eines Naturrechts, also eines für alle Menschen als Vernunftwesen allgemein verbindlichen Normensystems mit Vorrang auch gegenüber positiven Gesetzen, geht schon auf die Sophisten zurück, ${ }^{83}$ erfährt aber durch die Stoa eine entscheidende Modifizierung und Erweiterung, so dass sie seit Pufendorf als Begründer des Naturrechts gilt. ${ }^{84}$ Sie löst das Naturrecht vor allem aus der platonischaristotelischen Bindung an die Polis und erweitert es auf die Menschheit, ${ }^{85}$ deren umfassende Gemeinschaft das Telos der natürlichen Entwicklung ist. ${ }^{86}$ Das Naturrecht wird zum universalverbindlichen Normensys-

\footnotetext{
${ }^{80}$ Zur Differenz zwischen amerikanischen und französischen Rechteerklärungen vgl. HoFMANN 1995(1988) 15-21.

${ }^{81}$ Zur Ideengeschichte vgl. v.a. H. Hofmann, "Zur Idee des Staatsgrundgesetzes“, in: ders., Recht - Politik - Verfassung (Frankfurt a. M. 1986) 261-295; zum Konzept des Konstitutionalismus W. Heun, „Die Struktur des deutschen Konstitutionalismus des 19. Jahrhunderts im verfassungsgeschichtlichen Vergleich“, Der Staat 45 (2006) [365-382] 366-369.

${ }^{82} \mathrm{Vgl}$. dazu vor allem die historischen Überblicke FLüCKIGER 1954, 86-475 (bis zu Thomas von Aquin); Ilting 1978; M. B. Crowe, The Changing Profile of the Natural Law (Den Haag 1977).

${ }^{83}$ ILting 1978, 245-250.

${ }^{84}$ Vgl. J. SAUTER, "Die philosophischen Grundlagen des antiken Naturrechts", Zeitschrift für öffentliches Recht 10 (1930/31) [28-81] 71f.

${ }^{85}$ Dazu schon oben Anm. 24; zum stoischen Naturrecht ILTING 1978, 255-258; FuÜCKIGER 1954, 186-213; G. Watson, „The Natural Law and Stoicism“, in: A.A. Long (ed.), Problems in Stoicism (London 1971) 216-238; speziell zu Cicero C. R. Kesler, Cicero and the Natural
} 
tem, das einen Vorrang gegenüber den positiven Gesetzen beanspruchen kann. ${ }^{87}$ Die als imperative Norm gedachte lex aeterna ${ }^{88}$ ist für alle Menschen als Vernunftwesen aufgrund ihrer Vernünftigkeit erkennbar. Diese stoische Lehre findet dann auch Eingang in das römische Recht und wird dadurch weiter tradiert. ${ }^{89}$ Obwohl die christlichen Auffassungen der Erschaffung der Welt ex nihilo, der göttlichen Offenbarung und der Schöpfergewalt den stoischen Grundvorstellungen der ewigen Ordnung der Natur und der menschlichen Vernunfterkenntnis diametral entgegengesetzt waren, wird schon im Neuen Testament ${ }^{90}$ und dann durch die Patristik, auch durch Augustinus, die stoische Naturrechtsidee im Kern übernommen. ${ }^{91}$ Die lex aeterna wird nur mit der göttlichen Vernunft gleichgesetzt. Diese stoisch-christliche Naturrechtsidee wird von Thomas von Aquin erstmals systematisch entfaltet und ausdifferenziert. ${ }^{92}$ Bei Duns Scotus und noch schärfer bei Wilhelm von Ockham wird die Begründung des Naturrechts voluntaristisch auf den göttlichen Willensakt umgestellt. ${ }^{93}$ Nachdem noch

Law (Cambridge 1985); N. Wood, Cicero's Social and Political Thought (Berkeley 1988) 70-77; K. M. Girardet, Die Ordnung der Welt (Wiesbaden 1983) 23-84.

${ }^{86}$ Vgl. Arnim, SVF 3, frg. 172 und 19.

${ }^{87}$ Cic. De leg. II 11-15., bes. 13; begrifflich wird diese Differenzierung allerdings erst durch den Timaeus-Kommentar des Chalcidius begründet, s. S. KutTneR, „Sur les origines du terme droit positif", RHDFE 4 ser. 15 (1936) 728-740, auch in: ders., The History of Ideas and Doctrines of Canon Law in the Middle Ages (London 1980); Neschke-Hentschke 1995-2003, vol. II, 83-88, bes. 84 .

${ }^{88}$ Zur lex aeterna in der Stoa s. ILting 1978, 257.

${ }^{89}$ Dig. 1,1,1 und 1,1,9; vgl. näher R. Voggensperger, Der Begriff des ius naturale im Römischen Recht (Basel 1952) 63-129; ein Gegensatz zwischen Naturrecht und positivem Recht ist im römischen Recht aber praktisch nicht vorstellbar, vgl. M. JusT, „Das Verhältnis zwischen Naturrecht und positivem Recht in der griechischen und römischen Rechtsanschauung", in: Gedächtnisschrift G. Küchenhoff (Berlin 1987) [119-140] (139f.); vgl. auch A. WATson, Law Making in the Later Roman Republic (Oxford 1974) 186-193; zur umstrittenen Frage der Bedeutung für die Praxis vgl. hier nur W. WALDstein, „Entscheidungsgrundlagen der römischen Juristen“, in: ANRW 2, 15 [3-100] 78-89 mit weiteren Nachweisen.

${ }^{90}$ Röm 2,14f.

${ }^{91}$ Zur Abhängigkeit Augustinus' von Cicero s. A. Schubert, Augustins lex-aeterna-Lehre nach Inhalt und Quellen (Münster 1924); generell zur Patristik Itting 1978, 259-263.

${ }^{92}$ Dazu Ilting 1978, 263-266; W. Kluxen, Philosophische Ethik bei Thomas von Aquin, 3. Aufl. (Hamburg 1998) 230-241; D. J. O'Connor, Aquinas and Natural Law (London 1967) generell zu den scholastischen Naturrechtslehren M. GrabmanN, „,Das Naturrecht der Scholastik von Gratian bis Thomas von Aquin", in: ders., Mittelalterliches Geistesleben, Bd. I (München 1926) 65-103; R. Weigand, Die Naturrechtslehre der Legisten und Dekretalisten von Irnerius bis Accursius und von Gratian bis Johannes Teutonicus (München 1967); R. SpEcht, „Materialien zum Naturrechts-Begriff der Scholastik“" Archiv für Begriffsgeschichte 21 (1977) 86-113; H. J. Johnson (ed.), The Medieval Tradition of Natural Law (Michigan 1987); zuletzt G. R. Evans, "Law and Nature“, Cambridge History of Medieval Philosophy vol. II (Cambridge 2010) 565-576.

${ }^{93}$ ILTING 1978, 266-273 
Grotius $^{94}$ wieder stärker an die stoische Gemeinschaftslehre der oikeiosis ${ }^{95}$ angeknüpft hatte, erfolgt der grundlegende Umbruch durch Thomas Hobbes, der die Naturrechtslehre auf eine völlig neue Grundlage stellt und sich damit auch maßgebend von den Vorstellungen der Stoa entfernt. ${ }^{96}$ In seiner frühen Schrift De cive war Hobbes noch von einer stoisch-ciceronischen Konzeption ausgegangen, im Leviathan wird dieser Ansatz jedoch völlig aufgegeben und Hobbes gelangt zu einer radikalen Neukonzeption, die es ablehnt, das Naturrecht auf die objektiven Urteile der Vernunft zu gründen, sondern vielmehr allein den Willen und die Vernunft des einzelnen Menschen als maßgebend ansieht. Anerkannt werden natürliche Rechte, insbesondere das Recht auf Selbsterhaltung, aber kein übergeordnetes Normensystem. ${ }^{97}$ Das Recht ebenso wie die Gerechtigkeit basierten daher allein auf den auf individueller Übereinstimmung beruhenden vertraglichen Absprachen. Lediglich die Gleichberechtigung aller bleibt implizite Grundlage dieser Konstruktion. Hobbes steht damit in der Tradition der epikureischen, ${ }^{98}$ nicht der stoisch-christlichen Ethik. Das herkömmliche Naturrecht wird zur lediglich im forum internum bindenden Moral abgewertet, der mangels Sanktionen die notwendige äußere Verbindlichkeit fehlt. Das bürgerliche Gesetz gewinnt dadurch letztlich uneingeschränkten Vorrang und unangefochtene Geltung.

Für die Entwicklung der Menschenrechte und des Vorrangs der Verfassung ist es indes wichtiger, dass John Locke vor allem in seinen Two Treatises Elemente der klassischen stoisch-christlichen Naturrechtslehre mit solchen der epikureisch-hobbesianischen Konzeption zu einer nicht immer ganz konsistenten Mischung amalgamiert, ${ }^{99}$ die ihrerseits nachhaltigen Einfluss auf die Amerikanische Revolution ausübt. ${ }^{100}$ Zukunftsweisend sind in diesem System allerdings eher die über die Stoa hinausreichenden Elemente: Der Ausgangspunkt des Strebens der Bürger nach Schutz ihres

\footnotetext{
${ }^{94} \mathrm{H}$. Grotius, De jure belli ac pacis (1625), Prol. 6,8,57; zur Widersprüchlichkeit des Konzepts ILting 1978, 279.

${ }^{95}$ Zur oikeiosis-Lehre: Forschner 1995, 142-159.

${ }^{96}$ Vgl. bereits ILting 1978, 280-286; und jetzt grundlegend B. Ludwig, Die Wiederentdeckung des Epikureischen Naturrechts (Frankfurt a. M. 1998) 271-291. 401-429; ders., "Cicero oder Epikur? Über einen Paradigmenwechsel in Hobbes' politischer Philosophie“, in: G. Boros (Hrsg.), Der Einfluss des Hellenismus auf die Philosophie der Frühen Neuzeit (Wiesbaden 2005) 159-179.

${ }^{97}$ Prägnant L. Strauss, The Political Philosophy of Hobbes. Its Basis and its Genesis, 2. ed. (Chicago u.a. 1952) XIf.: "Traditional natural law is primarily and mainly an objective "rule and measure", a binding order prior to and independent of the human will, while modern natural law is, or tends to be, primarily and mainly a series of "rights", of subjective claims, originating in the human will." Vgl. auch Strauss 1956, 124-262.

${ }_{98}$ Vgl. dazu nur N. W. De WITT, Epicurus and his Philosophy (Minneapolis 1954) (Ndr. Westport 1973) 216-248; P. Mitsis, Epicurus' Ethical Theory (Ithaca u.a.1988) 19-58.

${ }^{99}$ Dazu eingehend Euchner 1969, 7-14. 57-118; knapp ILTing 1978, 287.

${ }^{100}$ Vgl. J. DunN, „The Politics of Locke in England and America“, in: J. W. Yolton (ed.), John Locke, Problems and Perspectives (Cambridge 1969) 45-80.
} 
Lebens, ihres Eigentums und ihrer Wohlfahrt wird einerseits zur Grundlage eines individuellen natürlichen Rechts auf Eigentum ${ }^{101}$ und andererseits zum Staatszweck ${ }^{102}$ erhoben. Immerhin hält Locke an dem traditionellen Vorrang des Naturrechts vor den positiven Gesetzen fest und löst den Gegensatz nicht vollständig auf, auch wenn die Erhaltung des Staates als ebenfalls traditioneller naturrechtlicher Grundsatz prinzipiell starke Einschränkungen der individuellen Rechte, jedoch nicht den völligen Entzug des natürlichen Rechts auf Eigentum, erlaubt.

Wenn sich die Protagonisten der Neuordnung in der Amerikanischen und Französischen Revolution auf das Naturrecht berufen, dann wird damit zwar auch an die überlieferten Formeln, wie sie aus der stoischchristlichen Tradition und den klassischen Stellen des Justinianischen Corpus juris bekannt sind, aber nur noch sehr begrenzt an die jeweiligen Konzepte angeknüpft. Vielmehr sind es die hobbesianisch-epikureischen Elemente der Theorie Lockes, die hier wirksam werden. Für die Entwicklung der Verfassung als vorgeordnete rechtliche Ordnung ist das Naturrecht kaum Vorbild. ${ }^{103}$ Daran ändert auch die kurze Anrufung der laws of nature in der Declaration of Independence ${ }^{104}$ nichts. Der Vorrang der Verfassung beruht vielmehr auf dem mit den Naturrechtslehren lediglich verbundenen Sozialvertragsgedanken und dem Vorrang des Common Law, kaum auf der Idee des Naturrechts selbst. Die Ausrichtung des Staatszwecks auf Freiheit, Eigentum und den pursuit of happiness ist den hobbesianischepikureischen Elementen der Theorie Lockes und kaum stoischen Lehren zu verdanken. ${ }^{105}$ Nichts anderes gilt für die französische Menschenrechtserklärung, selbst wenn in den Entwürfen vereinzelt stoische Formulierungen auftauchen, ${ }^{106}$ die indes bezeichnender Weise in der endgültigen Version der Déclaration keine Aufnahme gefunden haben.

2. Sowohl im Hinblick auf die den Menschenrechten zugrundeliegende Freiheitskonzeption als auch im Hinblick auf die Ausbildung des Konzepts der subjektiven Rechte sind die Wirkungen stoischer Lehren allen-

\footnotetext{
${ }^{101}$ Vgl. EuCHNER 1969, 80-95.

102 Vgl. Euchner 1969, 198-209.

${ }^{103}$ Vgl. G. Wood, The Creation of the American Republic 1776-1787 (New York 1969) 9f. 259-305.

${ }^{104}$ Hier zitiert nach Peterson 1984, 19.

105 Trotz seiner schlüssigen Konzeption spielt Pufendorfs Theorie in dieser Hinsicht keine Rolle. Zu Pufendorfs Naturrechtstheorie Ilting 1978, 286-292; Welzel 1958, 31-58; zu seinem geringen Einfluss oben Anm.77.

${ }^{106}$ CANCIK 1983, 206, der hier freilich die Mischung epikureisch-lockescher Elemente mit dem durchaus unterschiedlichen stoischen Selbsterhaltungstrieb im Einklang mit der Natur verschleift; wie CANCiK auch Hofmann 1995(1988) 3; Strauss 1956, 188. 190; vgl. insoweit Diog. Laert. VII 84; Cic. De fin. III 5,1 mit Hobbes, Leviathan, c. 14; vgl. auch die Übersetzung von oikeiosis bei M. SchofIELD, "Two stoic approaches to justice“ ${ }^{\prime \prime}$ in: A. LAKs / M. Schofield (ed.), Justice and Generosity (Cambridge u.a. 1995) [191-212] 196.
} 
falls gering. Vielmehr sind in beiden Fällen die Grundlagen geradezu eine Abkehr von den Auffassungen der Stoa.

Die Vorstellung von subjektiven Rechten, die dazu noch gegen den Staat gerichtet sein könnten, ist der Stoa fremd. Es ist geradezu die Pointe der stoischen Lehren, dass sie keine Rechtslehre oder politische Philosophie darstellen, sondern vielmehr eine ethische Pflichtenlehre begründen. ${ }^{107}$ Sie zielt darauf, ein philosophisches Leben, im Sinne eines weisen und gelingenden Lebens, zu führen. Die Übereinstimmung mit der Vernunft und Natur des Menschen sowie mit den natürlichen Gesetzen der Welt anzustreben ist die Bestimmung des Menschen, die seine Tugend ausmacht. Die zentralen Leitgedanken der Autarkie, Ataraxie und Apathie zielen nicht auf äußere Durchsetzung, sondern markieren eine innere Haltung, deren prinzipiell auch der Sklave in seinem Status der Abhängigkeit fähig ist.

Die Entwicklung des juristischen Konzepts subjektiver Rechte erfolgt deshalb auch völlig unabhängig von stoischen Lehren. Man kann die Herausbildung subjektiver Rechte eng mit dem Humanismus der Renaissance des 12. Jahrhunderts und der Entstehung der Kanonistik in Verbindung bringen, ${ }^{108}$ jedoch nicht mit der Stoa. Auch die Ausbildung der Differenzierung zwischen ius und lex im frühen 15. Jahrhundert und die weitere Formierung der subjektiven Rechte im rationalen Naturrecht seit Grotius $^{109}$ läßt sich nicht auf stoische Wurzeln zurückführen.

3. Ähnliches lässt sich für die Freiheitskonzeption feststellen. Im Unterschied zu der klassischen griechischen Vorstellung und insbesondere auch zu Aristoteles, wo die Polis der Bezugspunkt ist und die exklusive politische Gemeinschaft darstellt, die auch die Natur des Menschen definiert, ist in der Stoa nicht mehr die Polis, sondern die Menschheit der Endpunkt des Prozesses der Gemeinschaftsbildung. Der Mensch ist deshalb ein von Natur zur Gemeinschaft bestimmtes Lebewesen. ${ }^{110}$ Die Ausdehnung des Gemeinschaftsbezugs ist aber erkauft durch eine Entpolitisierung und damit zugleich Moralisierung des Gemeinschaftsbezugs. Politische Partizipation ist anders als bei Aristoteles kein Wesensmerkmal der natürlichen Ordnung. Die Ausbildung eines Begriffs der inneren Freiheit in der späten Stoa

\footnotetext{
${ }^{107}$ Sen. ep. 66,39; s. bereits oben Anm. 27.

108 Tierney 1997, 43-77; A. BRetT, Liberty, Right and Nature: The Language of Individual Rights in Later Scholastic Thought (Cambridge u.a. 1997); K. W. NöRR, „Zur Frage des subjektiven Rechts in der mittelalterlichen Rechtswissenschaft“, in: D. Medicus (Hrsg.), Festschrift für Hermann Lange (Stuttgart u.a. 1992) 193-204, C. J. ReID, „The Canonistic Contribution to the Western Rights Tradition: An Historical Inquiry“, Boston College Law Review 33 (1991) 37-92.

${ }^{109}$ R. Tuck, Natural Rights Theories (Cambridge u.a. 1979) 24-31. 58-81; TIERney 1997, 207-235. 316-342.

${ }^{110}$ Arnim, SVF 3, frg. 172, 19; Sen. De ira II 31; s.o. Anm. 86.
} 
ist ein Zeichen der parallelen Aushöhlung der politischen Freiheit. ${ }^{111}$ Die Menschenrechtskonzeptionen des 18. Jahrhunderts setzen daher eine Freiheitskonzeption um, die sich von antiken Vorstellungen grundlegend abhebt ${ }^{112}$ und von Thomas Hobbes in enger Verbindung mit seiner epikureischen Naturrechtslehre begründet wird. Im Leviathan wird erstmals die radikale Idee negativer Freiheit formuliert, ${ }^{113}$ die letztlich auch den grundrechtlichen Abwehrrechten zugrunde liegt. Die nahezu vollständige Aufgabe der prinzipiell auf den Naturzustand begrenzten negativen Freiheit im Staat durch die Unterwerfung unter den Monarchen im Herrschaftsvertrag beraubt diese Konzeption nicht ihres revolutionären Charakters. Anders als in der antiken und der nachfolgenden republikanischen Tradition wird das Recht bei Hobbes durch seinen Zwangscharakter als Gegensatz zur Freiheit definiert. ${ }^{114}$ Im Konzept der Grundrechte hat dies bis heute zur Folge, dass staatliche Gesetze jedenfalls prinzipiell und zunächst als Eingriff in die individuellen Grundrechte aufgefasst werden können. ${ }^{115}$

John Locke hält an diesem Begriff der negativen Freiheit fest, ${ }^{116}$ richtet den Zweck des Staates aber verstärkt auf die Freiheitssicherung aus. Der Freiheitsbegriff gewinnt bei Locke normativen Charakter, ${ }^{117}$ während er bei Hobbes mit Willkür gleichgesetzt wird. Ebensowenig wie mit dem negativen Freiheitsbegriff ist die Stoa mit der republikanischen Tradition verbunden, deren Freiheitsbegriff an die antiken Polisvorstellungen anknüpfend gemeinschaftsbezogen und politisch orientiert ist und die Freiheit nur in einem republikanischen Gemeinwesen mit Selbstregierung

\footnotetext{
${ }^{111}$ Der Neostoizismus des 16. und Anfang des 17. Jahrhunderts etwa bei Justus Lipsius folgt dann auch zunächst dieser Haltung, vgl. dazu grundlegend W. DiltheY, „Die Autonomie des Denkens, der konstruktive Rationalismus und der pantheistische Monismus nach ihrem Zusammenhang im 17. Jahrhundert" , in: ders., Gesammelte Schriften Bd. II (Leipzig u.a. 1914) 246-296; sowie G. Abel, Stoizismus und Frühe Neuzeit (Berlin 1978); SPANneut 1973, 213-316; zu Lipsius vgl. insbes. J. L. SAunders, Justus Lipsius. The Philosophy of Renaissance Stoicism (New York 1955) 67-116; G. Oestreich, Antiker Geist und moderner Staat bei Justus Lipsius (1547-1606) (Göttingen 1989) 69-87. 106-151; außerdem vermischt sich der Neostoizismus gerade anfangs mit Elementen des Taciteismus, vgl. dazu hier nur K. C. Schellhase, Tacitus in Renaissance Political Thought (Chicago 1976) 127-149.

112 Zu den Differenzen s. Heun 2006, Rn. 3ff.; vgl. auch J. P. ReID, The Concept of Liberty in the Age of the American Revolution (Chicago u.a. 1988) insbes. S. 29 f. 56.

${ }^{113}$ Hobbes, Leviathan II c. 21; I c. 14; unter negativer Freiheit wird verstanden, dass sich ein Mensch ungehindert durch andere betätigen kann.

${ }^{114}$ Hobbes, Leviathan II c. 26; vgl. dazu H. Hofmann, Einführung in die Rechts- und Staatsphilosophie, 4. Aufl. (Darmstadt 2008) 127. 135-139; anders dann aber noch Locke, Treatises II, 57.

${ }^{115}$ Vgl. hier nur B. Pieroth / B. Schlink, Grundrechte Staatsrecht II, 26. Aufl. (Heidelberg u.a. 2010) 56-63.

${ }^{116}$ J. Locke, An Essay Concerning Human Understanding (1689) II 21,15; Treatises II 57; HeuN 2006, Rn. 9 mit weiteren Nachweisen.

${ }^{117}$ Vgl. H. Bielefeldt, Neuzeitliches Freiheitsrecht und politische Gerechtigkeit (Würzburg 1990) $53 \mathrm{f}$.
} 
gewährleistet sieht. ${ }^{118}$ Aus diesen Quellen speisen sich die in Rousseau kulminierenden Vorstellungen einer (demokratischen) Partizipation und der demokratischen, egalitären Funktion des Gesetzes, die allerdings der Begründung der Menschenrechte tendenziell zuwiderlaufen, weil der Einzelne ganz in der volonté générale aufgeht. ${ }^{119}$

4. Mit dem Grundsatz der Gleichheit wird indes der Aspekt der Menschenrechte angesprochen, der am ungebrochensten den Einfluss der Stoa widerspiegelt und zugleich die engste Verbindung mit dem Menschenwürdediskurs aufweist. Im locus classicus De legibus von Cicero wird die Vorstellung der natürlichen Gleichheit aller Menschen als vernunftbegabten und tugendhaften Wesen ausformuliert. ${ }^{120}$ Die Stoa löst den Menschen aus den konkreten politischen und sozialen Zusammenhängen und betrachtet ihn als Teil einer kosmopolitischen Gemeinschaft aller Vernünftigen, wie dies insbesondere bei Seneca zum Ausdruck kommt. ${ }^{121}$

Im Unterschied zu den Menschenrechtskonzeptionen bleibt diese Gleichheit aber auf den Bereich der Ethik beschränkt und ist nicht politisch oder sozial gemeint. Zwar sind auch die Sklaven vernunftbegabte Menschen, die Institution der Sklaverei selbst wird freilich nicht angegriffen, die Gleichheit in den freien Naturzustand verwiesen. ${ }^{122}$ Immerhin wird die Sklaverei als contra naturam angesehen ${ }^{123}$ und Seneca hat auch zu mitmenschlicher Behandlung der Sklaven aufgerufen. ${ }^{124}$ Zwischen diesem rein ethischen Verständnis und einer politisch-rechtlichen Umsetzung besteht indes noch ein kategorial-qualitativer Unterschied.

Wirkungsgeschichtlich wird diese Beschränkung der stoischen Gleichheitsidee auf die Ethik freilich partiell überdeckt und überspielt durch die Aufnahme der zentralen Kernaussagen durch die römische Jurisprudenz im Corpus Juris Civilis, wo sie ganz aus ihrem ursprünglichen philosophischen Kontext gelöst sind, ${ }^{125}$ aber auch wenig praktische Wirkung entfalten konnten.

Als solche konnten die römischen Rechtsregeln fast unverändert in die Präambel der Declaration of Independence ${ }^{126}$ und in Art. 1 der Déclaration

\footnotetext{
${ }^{118}$ Heun 2006, Rn. 6 mit weiteren Nachweisen.

${ }^{119}$ Vgl. Heun 2006, Rn. 7 mit weiteren Nachweisen.

${ }^{120}$ Cic. De leg. I 29-35.

${ }^{121}$ Sen. ep. 15,95 .

${ }^{122}$ Sen. ep. 90.

${ }^{123}$ Dig. 1,1,4; sowie $1,5,4$.

${ }^{124}$ Sen. ep. 7; s.a. Gaius, Inst. 1, 53; vgl. M. T. Griffin, Seneca: A Philosopher in Politics, 2. ed. (Oxford u.a. 1992) 256-285.

${ }^{125}$ Dig. 50,17,32 sowie Anm. 123.

${ }^{126} \mathrm{Zu}$ ihrer Bedeutung zuletzt mit weiteren Nachweisen W. Heun, „,Der 4. Juli 1776 - Die Vergegenwärtigung der Revolution in der Erinnerungskultur der USA“, in: R. GRösCHNER / W. Reinhard (Hrsg.), Tage der Revolution - Feste der Nation (Tübingen 2010) 73-92.
} 
von $1789^{127}$ übernommen werden. Sie finden sich aber auch in mittelalterlichen Gesetzbüchern ${ }^{128}$ und wurden so auch überliefert und rezipiert. Allerdings zeigt sich daran ebenso, dass die Lehre sich durchaus mit sozialer und rechtlicher Ungleichheit vereinbaren und in ein hierarchisches System einbetten ließ. Erst im 18. Jahrhundert konnte die ursprünglich stoische Gleichheitsidee politisch-soziale Sprengkraft entfalten. ${ }^{129}$ Diese lange Verzögerung politisch-sozialer Wirkungskraft ist neben den allgemeinen politisch-sozialen Strukturen auch auf die Verbindung des stoischen Gleichheitsideals mit der christlichen Vorstellung der Gleichheit aller Menschen vor Gott ${ }^{130}$ zurückzuführen. Auch diese christliche Gleichheit blieb in einem Raum außerhalb der politischen und sozialen Wirklichkeit verbannt, indem die Gleichheit vor Gott heilsgeschichtlicher Ausgangs- und Endpunkt zugleich war. ${ }^{131}$ Zudem drängten in der Theologie das Erbsündedogma und die Übernahme neoplatonischer Ordo- und Hierarchievorstellungen die frühchristliche Gleichheit, soweit sie auch im Gemeindeleben galt, zugunsten einer Betonung von Ungleichheit und Hierarchie zurück. ${ }^{132}$ Es bedurfte erst der Reformation mit ihrer innerkirchlich antihierarchischen Stoßrichtung ${ }^{133}$ und dann der Erneuerung des rationalen Naturrechts im 17. Jahrhundert, um die Gleichheit zum allgemeinen normativen Postulat umzuformen, ${ }^{134}$ ohne damit im status civilis Ungleichheiten $^{135}$ bis hin zur Sklaverei auszuschließen. ${ }^{136}$ Insoweit gehen diese Ansätze noch nicht wesentlich über die stoische Gleichheitskonzeption hinaus. Erst in der Aufklärung im 18. Jahrhundert wird die Forderung nach

\footnotetext{
${ }^{127}$ Vgl. dazu S.-J. SAmwer, Die französische Erklärung der Menschen- und Bürgerrechte von 1789/91 (Hamburg 1970) 174-191.

${ }^{128}$ Vgl. z.B. P. de Beaumanoir, Les coutumes de Beauvaisis, 1283 (ed. Salmon), 2 Bde. (Paris 1899) (Ndr. 1970), II, 235 (§ 1453); s. auch N. Conn, Das neue irdische Paradies (Reinbek 1988) $212 f$.

${ }^{129}$ Zum wichtigen Einfluss der Literatur der Empfindsamkeit im 18. Jahrhundert L. Hunt, Inventing Human Rights. A History (New York u.a. 2007) 35-69.

${ }^{130}$ Vgl. Mt 20, 8ff.; Lk 7, 1ff.; Röm 2,11; Gal 3,28, Flückiger 1954, 284-323. 327-347.

${ }^{131}$ Vgl. besonders deutlich, E. Troeltsch, Die Soziallehren der christlichen Kirchen und Gruppen, Gesammelte Schriften Bd. I, 3. Aufl. (Tübingen 1923) 60-83.

132 S.o. Anm.59.

${ }^{133}$ Vgl. O. DANN, Gleichheit und Gleichberechtigung (Berlin 1980) 72.

${ }^{134}$ Hobbes, Leviathan I, c. 13-15; Locke, Treatises II 4-9 sowie II 123. 131; zu Locke jetzt WALDRON 2002.

135 So insbes. Pufendorf, De jure III 2,9 sowie II 2,1f.; zur Gleichheit bei Pufendorf H. DeNZER, Moralphilosophie und Naturrecht bei Samuel Pufendorf (München 1972) 87-89. 148f.

${ }^{136}$ Locke, Treatises II 24,85; zur Position Lockes kontrovers: kritisch J. Welchman, „Locke on Slavery and Inalienable Rights“, Canadian Journal of Philosophy 25 (1995) 67-81; verteidigend W. Uzgalis, " "The Same Tyrannical Principle”. Locke's Legacy on Slavery", in: T. C. Lотт (ed.), Subjugation and Bondage. Critical Essays on Slavery and Social Philosophy (Lanham u.a. 1998) 49-77; WALDRON 2002, 197-206.
} 
staatsbürgerlicher rechtlicher Gleichheit erhoben ${ }^{137}$ und in den Revolutionen durchgesetzt. ${ }^{138}$

Die etwas doppelbödige Haltung der Stoa zur Sklaverei spiegelt sich freilich noch in den Revolutionen des 18. Jahrhunderts. Die natürliche Gleichheit in der Unabhängigkeitserklärung hatte Jefferson noch mit der Forderung nach Abschaffung des Sklavenhandels - nicht der Sklaverei verknüpft, der Congress hatte diese Passage indes gestrichen. ${ }^{139}$ Die Haltung der Gründungsväter war ambivalent. ${ }^{140}$ Die Grundrechtserklärungen und -kataloge nahmen das Gleichheitspostulat immer weniger auf, weil die Brisanz des Gleichheitsrechts für die Sklavenfrage erkannt wurde. ${ }^{141}$ In der Bundesverfassung wurde die equal protection clause erst 1868 nach dem Bürgerkrieg verankert. ${ }^{142}$ Diese allmähliche Delegitimierung der Sklaverei wurde nicht durch den Rückgriff auf stoische Naturrechtsvorstellungen und durch das menschenrechtliche Gleichheitspostulat erreicht. Zwar lag eine Erstreckung auf die Sklaven wegen des prinzipiell universalen Anspruchs der naturrechtlichen Gleichheit durchaus nahe und hat die Institution sicher auch unterhöhlt. ${ }^{143}$ Die Kritik an der Sklaverei und die Forderung nach Abschaffung erst des Sklavenhandels, dann der Sklaverei selbst verdankt sich aber der puritanischen Kritik am Erbsündedogma als Rechtfertigung der Sklaverei ${ }^{144}$ und wurde gerade „nicht in der Sprache der Menschen- und Bürgerrechte“ formuliert. ${ }^{145}$ Selbst die viel stärker egalitär ausgerichtete französische Menschenrechtserklärung mündete nicht in eine Abolitionsbewegung. Die Sklavenbefreiung 1794 er-

\footnotetext{
${ }^{137}$ C. de Montesquieu, L'Esprit des Lois (1748), VIII, c. 3; V, c. 4; J. J. Rousseau, Contrat social (1762) I, c. 6; erst Rousseau verurteilt dezidiert die Sklaverei (ebd. I, 3f.); während Montesquieu in seinen (zu Lebzeiten unveröffentlichten) Pensées (Nr. 1935, in: Oeuvres complètes, Pléiade ed. vol. I [Paris 1973] 973-1574, 1467) den stoischen Satz, dass die Sklaverei dem Naturrecht widerspricht, allein betont, rechtfertigt er bei aller naturrechtlichen Kritik im L'Esprit des Lois XV, c. 7, (vol. II, S. 496) die Sklaverei mit klimatischen Gründen.

${ }^{138}$ Art. 1, 6 Erklärung von 1789, prägnanter dann die Erklärung von 1793, Art. 3, dazu vgl. M. Gauchet, Die Erklärung der Menschenrechte (Reinbek bei Hamburg 1991) 211.

${ }_{139}$ S. Peterson 1984, 22.

${ }^{140}$ Die Ambivalenz zeigt idealtypisch Jefferson, vgl. P. FinKelman, Slavery and the Founders: Race and Liberty in the Age of Jefferson (Armonk 1996) 162-196; D. B. Davis, The Problem of Slavery in the Age of Revolution 1770-1823 (Ithaca u.a. 1975) 169-184.

${ }^{141}$ Der Gleichheitssatz wird vor allem in die Virginia Bill of Rights von 1776 aufgenommen, spielt dann aber kaum noch eine Rolle, vgl. W. P. Adams, Republikanische Verfassung und bürgerliche Freiheit (Darmstadt 1973) 163-190.

${ }^{142}$ Amendment 14; vgl. zur Entstehungsgeschichte J. B. James, The Framing of the Fourteenth Amendment (Urbana 1965).

${ }^{143}$ Vgl. E. Foner, The Story of American Freedom (New York u.a. 1998) 29-37.

${ }^{144}$ Vgl. a. E. Flaig, "Sklaverei“", in: Hist. Wörterbuch d. Phil. Bd. 9 (Darmstadt 1995) [Sp. 976-985] 980f.; D. B. Davis, Slavery and Human Progress (New York 1984) 129-153.

${ }^{145}$ Osterhammel 2000, 55; eine Ausnahme ist aber J. Otis, The Rights of the British Colonies Asserted and Proved (Boston 1764), in: B. Bailyn (ed.), Pamphlets of the American Revolution 1750-1776, vol. I (Cambridge, Mass.1965) [418-482] 438-441.
} 
folgte erst nach dem erfolgreichen Sklavenaufstand auf Saint-Domingue, hatte eine antibritische Stoßrichtung ${ }^{146}$ und wurde 1804 von Napoleon wieder zurückgenommen. ${ }^{147}$ Die Abschaffung der Sklaverei gehört erst zur Geschichte des 19. Jahrhunderts. ${ }^{148}$ Diese Entwicklung spiegelt insofern die Einbettung der letztlich in der Stoa wurzelnden Gleichheitsidee in die sozialen und politischen Zusammenhänge ebenso wieder wie die inhärente universalistische Wirkungs- und Sprengkraft.

\section{Resümee und Ausblick}

Der Einfluss der Stoa auf die Ideen der Menschenwürde und der Menschenrechte bis zum Ende des 18. Jahrhunderts ist vielgestaltig und sehr unterschiedlich. Außer bei der Gleichheitsidee verlaufen die Traditionslinien der Menschenwürdekonzeption und der Menschenrechte nicht gemeinsam, sondern völlig getrennt, erst nach dem 2 . Weltkrieg werden beide zusammengeführt - mit durchaus ambivalenten Folgen. Die Einflüsse der stoischen Lehren sind zum einen vielfältig gebrochen, zum anderen erfolgen sie in mehreren Wellen der Antikerezeption. Während bei der Menschenwürde die nachhaltige Rezeption schon in der Patristik erfolgt, an die selbst in der italienischen Renaissance angeknüpft wird, werden die stoischen Naturrechtsideen in mehreren Ansätzen und Anläufen immer wieder erneut aufgegriffen und der Zeit angepaßt. Der Vorrang der Verfassung speist sich indes vornehmlich aus anderen Traditionsquellen. Der Gleichheitsgedanke wird dagegen nach langer Überlagerung durch christliche Vorstellungen erst wieder im rationalen Naturrecht des 17. Jahrhunderts reaktiviert, nachdem er allerdings formelhaft auch während dieser langen Latenzperiode tradiert wurde. Demgegenüber sind die anderen notwendigen Elemente und Voraussetzungen der Menschenrechtsidee, nämlich das Konzept der Rechte und der Begriff negativer Freiheit, der stoischen Ethik fremd und insofern fundamentale Neuerungen der nachantiken Ideengeschichte.

\footnotetext{
${ }^{146}$ Vgl. hierzu H. Sieberg, „Französische Revolution und Sklavenfrage in Westindien“, GWU 42 (1991) 405-416.

${ }^{147}$ Vgl. zum Ganzen C. WANQUET, La France et la première abolition de l'esclavage 1794-1802: Le cas des colonies orientales Île de France (Maurice) et La Réunion (Paris 1998).

${ }^{148}$ Dazu und zu den Gründen H. Thомаs, The Atlantic Slave Trade. The History of the Atlantic Slave Trade, 1440-1870 (London u.a. 1997) 449-557; H. S. KLeIN, The Atlantic Slave Trade (Cambridge u.a. 1999) 183-206; knapp Flaig 2009, 199-214; Osterhammel 2000, 52-66.
} 
D. Anhang 



\section{Literaturverzeichnis}

\section{Abkürzungen}

$A A A$

AC

ADelt

AEM

AEphem

AJA

$A M$

AntK

$A W$

$B C H$

$B S A$

$\mathrm{CAH}$

CIL

CRAI

DHA

$D N P$

$H W R h$

IG

IGGR

IK

JHS

JNG

ÖJh

PAA

PECS

$P G$

PIR

$P L$

Prakt

RA

$R A C$

$R E$

RHDFE

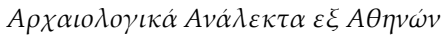

L'Antiquité Classique

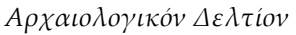

Archäologisch-epigraphische Mitteilungen aus Österreich

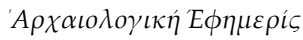

American Journal of Archaeology

Mitteilungen des Deutschen Archöologischen Instituts, Athenische Abteilung

Antike Kunst

Antike Welt. Zeitschrift für Archäologie und Kulturgeschichte

Bulletin de correspondance hellénique

The Annual of the British School at Athens

The Cambridge Ancient History

Corpus inscriptionum Latinarum

Comptes rendus / Académie des inscriptions et belles-lettres

Dialogues d'histoire ancienne

Der Neue Pauly

Historisches Wörterbuch der Rhetorik

Inscriptiones Graecae

Inscriptiones Graecae ad res Romanas pertinentes

Inschriften Kleinasiens

Journal of Hellenic Studies

Jahrbuch für Numismatik und Geldgeschichte

Jahreshefte des Österreichischen Archöologischen Institutes in Wien

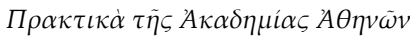

The Princeton Encyclopedia of Classical Sites

Patrologiae cursus completus, series Graeca

Prosopographia Imperii Romani

Patrologiae cursus completus, series Latina

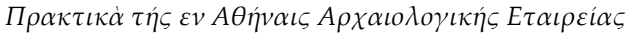

Revue archéologique

Reallexikon für Antike und Christentum

Paulys Realencyclopädie der classischen Altertumswissenschaft

Revue historique du droit français et étranger 
SRISF

Studi e Ricerche dell' Istituto di Storia, Fac. di Lettere e Filosofia, Univ. di Firenze

StudGen Studium Generale

SVF

Stoicorum veterum fragmenta

Syll.

Sylloge inscriptionum Graecarum

\section{Ausgaben, Kommentare und Übersetzungen}

a. Dion, Euboikos

RusSell 1992

URBÁN 2004

ELLiger 1967

KLAUCK 2000

NesSELRATH 2003

Nesselrath 2009
D. A. Russell (ed.), Dio Chrysostom: Orations 7, 12, 36 (Cambridge 1992)

Dión de Prusa. Euboico o El Cazador (Or. VII), ed., intr. trad. y com. de Á. Urbán (Cordoba 2004)

\section{b. Dion, Weitere Werke}

W. Elliger, Dion Chrysostomos sämtliche Reden (Zürich 1967)

H.-J. Klauck (Hrsg.), Dion von Prusa. Olympische Rede, SAPERE II (Darmstadt 2000)

H.-G. Neselrath (Hrsg.), Dion von Prusa. Menschliche Gemeinschaft und göttliche Ordnung. Die Borysthenes-Rede, SAPERE IV (Darmstadt 2003)

H.-G. Neselrath (Hrsg.), Dion von Prusa. Der Philosoph und sein Bild, SAPERE XIII (Tübingen 2009)

\section{Sekundärliteratur (und Editionen anderer Autoren)}

Alcok 1993

Anderson 1976

Anderson 1989

Anderson 2000

v. Arnim 1891

v. Arnim 1898

Ausbüttel 1998

BÄBLER 2003

BALES 2001
S. E. Alсоск, Graecia Capta. The Landscapes of Roman Greece (Cambridge 1993)

G. Anderson, Studies in Lucian's comic Fiction (Leiden 1976)

G. Anderson, "Sophists and their Outlook in the Early Empire“, ANRW II,33,1 (1989) 79-208

G. Anderson, "Some Uses of Storytelling in Dio“, in: D. InNEs / H. Hine / Chr. Pelling (eds.), Dio Chrysostom. Politics, Letters, and Philosophy (Oxford 2000) 143-160

H. v. Arnim, „Die Entstehung und Anordnung der Schriftensammlung Dios von Prusa", Hermes 26 (1891) 366-407

H. v. Arnim, Leben und Werke des Dio von Prusa, mit einer Einleitung: Sophistik, Rhetorik, Philosophie in ihrem Kampf um die Jugendbildung (Berlin 1898)

F. M. Ausbüttel,Die Verwaltung des römischen Kaiserreiches (Darmstadt 1998)

B. BÄBLER, „Der Schauplatz des Borysthenitikos: das antike Olbia“, in: Nesselrath 2003, 95-112

K. BALEs, Die neue Sklaverei (München 2001) 
BAumeister 2002

Berry 1983

Bertrand 1992

Binsfeld 2008

BÖCKENFÖRDE 2004

Bost-Pouderon 2008

BRENK 2000

BRUdERMÜLLER /

Seelmann 2008

BRUNT 1993

BURSIAN 1872

CANCICK 1983

CANCICK 1987

CANCICK 2002

Canevari 1962

Chapman 1993

Chiridoglou 1996/7

Chiridoglou 2004

Chiridoglou 2006a

Chiridoglou 2006b
A. BAumeister, Topographische Skizze der Insel Euboia (Lübeck 1864)

E. Berry, "Dio Chrysostom the moral philosopher", GER XXX (1983) 70-80

J.-M. Bertrand, „Le chasseur dans la ville“, in: M.-F. Baslez / P. Hoffmann / M. Trédé (Éds.), Le monde du roman grec (Paris 1992) 85-92

A. Binsfeld, "Menschenhandel und Frauenhandel“, in: H. HeINEN (Hrsg.), Menschenraub, Menschenhandel und Sklaverei in antiker und moderner Perspektive. Forschungen zur Antiken Sklaverei 37 (Stuttgart 2008) 86-98

E.-W. BöCKENFÖRDE, „Bleibt die Menschenwürde unantastbar?“, Blätter für deutsche und internationale Politik 10 (2004) 1216-1227

C. Bost-Pouderon, "Ethnographie et utopie“, Kentron 24 (2008) 105-122

F. E. BRENK, „Dio on the Simple and Self-Sufficient Life “, in: SwaIN 2000, 261-278

G. Brudermüller / K. Seelmann (Hrsgg.), Menschenwürde. Begründung, Konturen, Geschichte (Würzburg 2008)

P. A. Brunt, Studies in Greek History and Thought (Oxford 1993)

C. Bursian, Geographie von Griechenland II (Leipzig 1872)

H. CANCICK, "Gleichheit und Freiheit. Die antiken Grundlagen der Menschenrechte“, in: G. KeHrer (Hrsg.), „Vor Gott sind alle gleich“. Soziale Gerechtigkeit, soziale Ungleichheit und die Religion (Düsseldorf 1983) 190-211

H. CANcick, "Die Würde des Menschen ist unantastbar", in: H. Funke (Hrsg.), Utopie und Tradition (Würzburg 1987) 73-107

H. CANCICK, „Dignity of Man and Persona in Stoic Anthropology. Some Remarks on Cicero, De officiis I, 105-107“, in: D. Kretzmer / E. KLEIN (Hrsgg.), The Concept of Human Dignity in Human Rights Discourse (Den Haag 2002) 19-40

A. Canevari, "Aspetti dell'Euboico di Dione di Prusa“, Diadosis, Voci di presenza classica, Rass. delle Assoc. di Culture class. del Tortonese (Tortona 1962) 16-18

W. Ph. Chapman, Karystos: City-State and Country Town (Baltimore 1993)

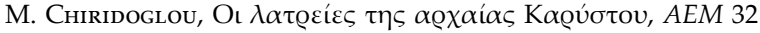
(1996-1997) 175-191

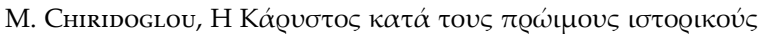

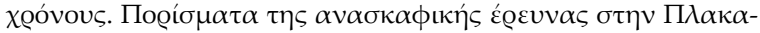
อท́, AEM 35 (2003-2004) 69-80

M. Chiridoglou, „Karystos in the Archaic to Late Classical Period (6th to 4th century B.C.). Data from the salvage excavations", in:

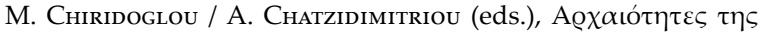

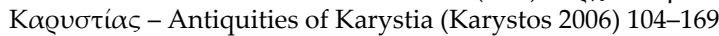

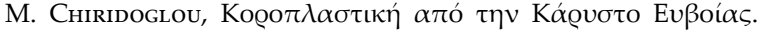

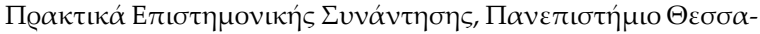
$\lambda$ í $\alpha \varsigma$, Volos 27. 2.-2. 3. 2003 (Volos 2006) 1057-1076 
Chiridoglou 2008/9

Chiridoglou 2009

Сhoremis 1971

Choremis 1972

Сhoremis 1973

Choremis 1973

Colish 1993

Christ 1992

DANeK 2009

DAY 1951

DAY 1973

Del Corno 1980

De Lubac 1974

De Martino 1985

Desideri 1978

Desideri 1991a

Desideri 1991b

Dieterich 2010

Dreier 2004

DuCREY U.a. 2004

DunCAn-Jones 1974

Duncan-Jones 1990

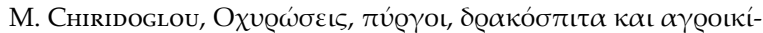

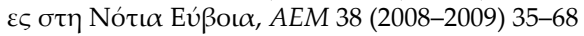

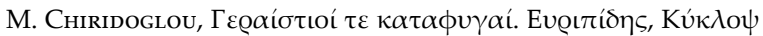

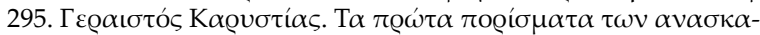

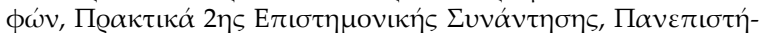

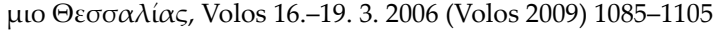

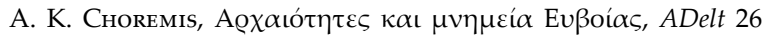
(1971) В 262-263

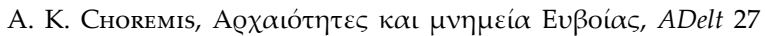
(1972) B 351

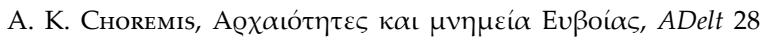
(1973) В 312

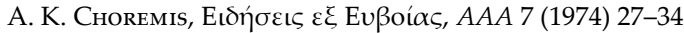

M. L. Colish,The Stoic Tradition from Antiquity to the Early Middle Ages, 2 vols., 2. ed. (Leiden 1990)

K. Christ, Geschichte der römischen Kaiserzeit. Von Augustus bis Konstantin (München 1992)

G. DANEK, „Autopsie und Fiktionalität: Der Euboikos des Dion Chrysostomos", in: E. Karamalengou / E. Makrigianni (eds.), Antiphilesis. Studies in Classical, Byzantine and Modern Greek Literature and Culture. In Honour of John-Theophanes A. Papademetriou (Stuttgart 2009), 417-423

J. DAY, „The Value of Dio Chrysostom's Euboean Discourse for the Economic Historian", in: P. R. Coleman-Norton (ed.), Studies in Roman Economic and Social History in Honor of Allan Chester Johnson (Princeton 1951) 209-235

J. Day, An Economic History of Athens under Roman Domination (New York 1973)

D. Del Corno, „Studi recent su Dione di Prusa“, Athenaeum 58 (1980) 191-193

H. De Lubac, Pic de la Mirandole. Études et discussions (Paris 1974)

F. De Martino, Wirtschaftsgeschichte des alten Rom (München 1985)

P. Desideri, Dione di Prusa (Mesina / Firenze 1978)

P. Desideri, „Dione di Prusa fra ellenismo e romanità“, ANRW II,33,5 (1991) 3882-3902

P. Desideri, „Tipologia e varietà di funzione comunicativa degli scritti dionei", ANRW II,33,5 (1991) 3903-3959

Erfurter Kommentar zum Arbeitsrecht, begr. Von Th. Dieterich, hrsg. von R. Müller-Glöge / U. Preis/ I. Sсhмidt, 10. Aufl. (München 2010)

H. Dreier (Hrsg.), GG-Kommentar, Bd. I. 2. Aufl. (Tübingen 2004)

P. Ducrey u.a. (Hrsgg.), Eretria, a Guide to the Ancient City (Fribourg 2004)

R. Duncan-Jones, The Economy of the Roman Empire (Cambridge 1974)

R. Duncan-Jones, Structure and Scale in the Roman Economy (Cambridge 1990) 
DunCAN-Jones 1995

DüRIG 2008

EUCHNER 1969

FARANTOS 1975

FARAone / McClure 2006

FINLEY 1981

FINLEY 1993

FLACH 1978

FLAIG 2009

FLÜCKIGER 1954

ForNARo 2006

ForNARO 2009

FORSCHNER 1995

FORSCHNER 2003

GANGLOFF 2006

GeHrke 1988

GEHRKe 1992

Geyer 1903

GörgEMANNs 2011

Goette 1994

Goette 2007(2000)
R. Duncan-Jones, Money and government in the Roman Empire (Cambridge 1995)

G. DüRIG, „Der Grundrechtssatz von der Menschenwürde“, in: Brudermüller/ Seelmann 2008, 173-187 (ursprünglich erschienen in Archiv des öffentlichen Rechts 81 [1956])

W. Euchner, Naturrecht und Politik bei John Locke (Frankfurt a. M. 1969) (repr. 1979)

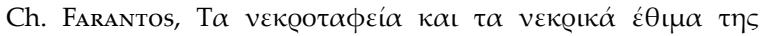

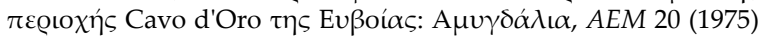
95-123

Ch. A. Faraone / L. K. McClure (eds.), Prostitutes and Courtesans in the Ancient World (Wisconsin 2006)

M. Finley, Economy and Society in Ancient Greece (London 1981)

M. FINLEY, Die antike Wirtschaft (München 1993)

D. FLACH, „Inschriftenuntersuchungen zum römischen Kolonat in Nordafrika", Chiron 8 (1978) 441-492

E. FLAIG, Weltgeschichte der Sklaverei (München 2009)

F. FlücKIger, Geschichte des Naturrechts. Bd I. Altertum und Frühmittelalter (Zürich 1954)

S. Fornaro, „Immagini di donne in Dione Crisostomo”, in: Chr. Ulf / R. Rollinger (Hrsgg.), Frauen und Geschlechter (Wien / Köln / Weimar 2006) 325-337

S. Fornaro, ,Inhalt und Themen der Reden“, übers. v. H.-G. NesSElRATH, in: Nesselrath 2009, 3-20

M. Forschner, Die stoische Ethik, 2. Aufl. (Darmstadt 1995)

M. Forschner, „Philosophie und Politik: Dions philosophische Botschaft im Borysthenitikos" , in: Nesselrath 2003, 128-156

A. Gangloff, Dion Chrysostome et les mythes. Hellénisme, communication et philosophie politique (Grenoble 2006)

H.-J. Gehrke, „Eretria und sein Territorium, Boreas“, Münstersche Beiträge zur Archäologie 11 (1988) 15-42 Abb.

H.-J. Genrke, "Zur Rekonstruktion antiker Seerouten. Das Beispiel des Golfs von Euboia“, Klio 74 (1992) 98-117

F. Geyer, Topographie und Geschichte der Insel Euboia (Berlin 1903)

H. Görgemanns (Hrsg.), Plutarch, Dialog über die Liebe, SAPERE X (2., korrigierte und erweiterte Auflage Tübingen 2011)

H. R. Goztte, „Der sogenannte römische Tempel von Karystos. Ein Mausoleum der Kaiserzeit" , AM 109 (1994) 259-300

H. R. Goette, „H. G. Lolling in Elliniko bei Platanistos (Karystia)“, in: K. FitTschen (Hrsg.), Historische Landeskunde und Epigraphik in Griechenland. Akten des Symposiums veranstaltet aus Anlaß des 100. Todestages von H. G. Lolling (1848-1894) in Athen vom 28. bis 30. 9. 1994 (Münster 2007) 283-291 (vgl. Pari-

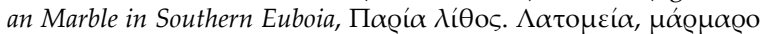

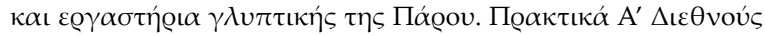

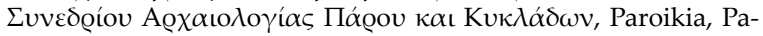
ros 2.-5- 10. 1997 [Paros 2000] 399-403) 
Gosepath 2001

GRÖSChNER U.a. 2008

Hamman 1987

HARRIS 1991

Hawley 2000

Herdegen 2003

Herdegen 2008

Hermann-Otto 2001

Hermann-Otto 2005

Hermann-Otto 2009

Hermann-Otto u.a. 2009

Hermann-Otto 2011a

Hermann-Otto 2011b

Heun 2002

Heun 2006

Heun 2009

Highet 1973
St. Gosepath, "Soziale Menschenrechte“, in: Th. Frank /A. JeniSCHen/ N. Rosemann (Hrsgg.), Soziale Menschenrechte - die vergessenen Rechte? Zur Unteilbarkeit der Menschenrechte (Berlin 2001) 15-42

Th. Gröschner / S. Kirste / O. W. LembKe (Hrsgg.), Des Menschen Würde (Tübingen 2008)

A.-G. Hammann, L'Homme, Image de Dieu (Paris 1987)

B. F. Harris, "Dio of Prusa: A Survey of Recent Work“, ANRW II,33,5 (Berlin 1991) 3854-3881

R. Hawley, "Marriage, Gender, and the Family in Dio“, in: SwaIN 2000, 125-139

M. Herdegen, in: Maunz / Dürig, Kommentar, Art. 1, I, Stand 2003

M. Herdegen, „Deutungen der Menschenwürde im Staatsrecht", in: Brudermüller / Seelmann 2008, 56-66

E. Herrmann-Otto, „Soziale Mobilität in der römischen Gesellschaft: Persönliche Freiheit im Spiegel von Statusprozessen", in: H. Bellen / H. Heinen (Hrsgg.), Fünfzig Jahre Forschungen zur antiken Sklaverei an der Mainzer Akademie 1950-2000. Forschungen zur Antiken Sklaverei 35 (Stuttgart 2001) 171-184

E. Herrmann-Otto (Hrsg.), Unfreie Arbeits- und Lebensverhältnisse von der Antike bis in die Gegenwart. Eine Einführung. Sklaverei Knechtschaft - Zwangsarbeit 1 (Hildesheim 2005)

E. Herrmann-Otтo, Sklaverei und Freilassung in der griechischrömischen Welt (Hildesheim 2009)

E. Herrmann-Otto / N. Bissen / Chr. Rollinger, "Schuldner/Gläubigerbeziehungen im römischen Senatorenstand", Zeitschrift für Verbraucher- und Privatinsolvenzrecht 8 (2009) 37-45

E. Herrmann-Otto, "Altersarmut in der Antike“, in: Uerlings 2011, 265-272

E. Herrmann-Otto, „Kindsein im römischen Reich“, in: H. HeiNEN (Hrsg.), Kindersklaven - Sklavenkinder. Schicksale zwischen Zuneigung und Ausbeutung in der Antike und im interkulturellen Vergleich. Forschungen zur Antiken Sklaverei 39 (Stuttgart 1911) 171-202

W. Heun, "Embryonenforschung und Verfassung - Lebensrecht und Menschenwürde des Embryos", JuristenZeitung 11 (2002) 517-524

W. Heun, "Freiheit und Gleichheit“, in: D. Merten / H.-J. Papier (Hrsgg.), Handbuch der Grundrechte, Bd. II (Heidelberg 2006) § 34 (437-472)

W. Heun, ,'Die Menschenwürde - Vom philosophischen Konzept zur juristischen Garantie", Annales Universitatis Scientiarum Budapestinensis de Rolando Eötvös Nominatae, Sectio Juridica, tomus 50 (2009) 59-73

G. Highet, „The Huntsman and the Castaway”, GRBS 14 (1973) 35-40 
Hofmann 1995(1988) H. Hoffmann, "Zur Herkunft der Menschenrechtserklärungen“ (1988), in: ders., Verfassungsrechtliche Perspektiven (Tübingen 1995) 3-22

Holzberg 1993 N. Holzberg, ,Romanhafte Erzählprosa in der griechischen Literatur", in: Anregung 39 (1993) 243-254

ILTING 1978

K.-H. Ilting, „Naturrecht“, in: O. Brunner / W. Conze / R. KoselLECK (Hrsgg.) Geschichtliche Grundbegriffe, Bd. IV (Stuttgart 1978) 245-313 (= ders., Naturrecht und Sittlichkeit [Stuttgart 1983] 35-114)

Jacobsen / Smith 1968 T. W.Jacobsen / P. M. Sмiтh, „Two Kimolian Dikast Decrees from Geraistos in Euboia", Hesperia 37 (1968) 184-199

Jacques / Scheid 1998 F. Jaceues / J. Scheid (Hrsgg.), Rom und das Reich in der Hohen Kaiserzeit 44 v.Chr.-260 n.Chr., Bd. 1: Die Struktur des Reiches (Stuttgart / Leipzig 1998)

JoNEs 1937

A. H. M. Jones, Cities of the Eastern Roman Provinces (Oxford 1937)

JONES 1940

A. H. M. Jones, The Greek City (Oxford 1940)

JoNES 1974

A. H. M. Jones, The Roman Economy. Studies in Ancient Economic and Administrative History (Oxford 1974)

JONES 1978

C. P. Jones, The Roman World of Dio Chrysostom (Cambridge [Mass.] 1978)

JoUAN 1977

F. JuAn, „Les themes romanesques dans 1'Euboicos de Dion Chrysostome", REG XC (1977) 38-46

JoUAN 1993

KAH / SchOLZ 2004

F. JuAn, ,, Les récits de voyage de Dion Chrysostome: réalité et fiction", in: M.-F. Baslez / Ph. Hoffmann, L. Pernot (Éds.), L'invention de l'autobiographie d' Hesiode à Saint Augustin. Actes du deuxième colloque de l'Équipe de recherche sur l'hellénisme post-classique (Paris 1993) 189-198

D. KAH / P. Scholz (Hrsgg.), Das hellenistische Gymnasion (Berlin 2004)

KeIL 1969

J. KeIL, "The Greek Provinces“, CAH XI (Cambridge 1969) 555-605

Keller 1982

D. Keller, „Final Neolithic Pottery from Plakari, Karystos“, in: P. SpItAels (Hrsg.), Studies in South Attica 1 (Gent 1982) 47-67

KELLER 1983

D. Keller, "Archampolis: An Early Iron Age Settlement and Sanctuary", AJA 88 (1983) 249

KeLLer 1985

D. Keller, Archaeological Survey in Southern Euboea, Greece: A Reconstruction of Human Activity from Neolithic Times through the Byzantine Period. Diss. phil. Indiana University (1985)

KeLLer 1987

D. Keller, „Southern Euboea Exploration Project“ , AJA 91 (1987) 321

KeLLer 1989

D. Keller, „Classical Greek Agricultural Sites: The Karystian Evidence", AJA 93 (1989) 275

Keller / Wallace 1986 D. Keller / M. B. Wallace, "The Canadian Karystia Project“, ClassViews 30 (1986) 155-159

Keller / Wallace 1987 D. Keller / M. B. Wallace, ,,The Canadian Karystia Project 1986“, ClassViews 31 (1987) 225-227

Keller / Wallace 1988 D. Keller / M. B. Wallace, „The Canadian Karystia Project: Two Classical Farmsteads“", ClassViews 32, 1988, 151-157 
Keller / Wallace 1990 D. Keller / M. B. Wallace, „Pre-modern Land Routes in Southern Euboia", ClassViews 34 (1990) 195-199

КNOCH 2005

St. KNoch, Sklavenfürsorge im römischen Reich. Sklaverei - Knechtschaft - Zwangsarbeit 2 (Hildesheim 2005)

KNOCH 2010

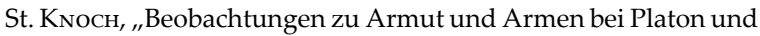
Aristoteles, Cicero und Seneca“, Klio 92 (2010) 305-330

Kовusch 1993

T. Kовusch, Die Entdeckung der Person (Freiburg i. Br. u.a.1993)

Koder 1973

J. Koder, Negroponte (Wien 1973)

KONDYLIS 1992

P. Kondylis, "Würde II-VIII", in: O. Brunner / W. Conze / R. Koselleck (Hrsgg.), Geschichtliche Grundbegriffe, Bd. VII (Stuttgart 1992)

Kosso 1989

C. Kosso, "Roman and Byzantine Sites on the Paximadhi Peninsula“, AJA 93 (1989) 261

Kosso 1996

C. Kosso, "A Late Roman Complex at Palaiochora near Karystos in Southern Euboia, Greece“, ClassViews 40 (1996) 201-230

Koumanoudis 1988

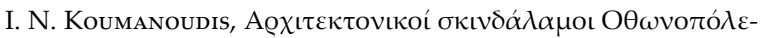

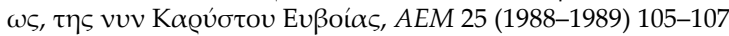

KytZler 2002

LAMBRAKI 1980

B. Kytzler, „Utopie“, DNP 12/1 (2002) [Sp. 1070f.]

A. LAmbraki, „Le cipolin de la Karystie. Contribution à l'étude des marbres de la Grèce exploités aux époques romaine et paléochrétienne", RA 1980, 31-62

LEHMANN-HARTLEBEN

K. Lehmann-Hartleben, Die antiken Hafenanlagen des Mittelmee1923 res, Klio Beih. 14 (Leipzig 1923)

LOLLING 1877

H. G. Lolling, Reisenotizen aus Griechenland 1876 und 1877, bearb. B. Heinrich, hrsg. H. Kalcyk (Berlin 1989)

MA 2000

J. MA, „Public Speech and Community in the Euboicus”, in: SwaIN 2000, 108-124

MacMullen 1966 R. MacMullen, Enemies of the Roman Order (Cambridge Mass. 1966)

MacMullen 1974 R. MacMullen, „Peasants, during the Principate”, ANRW II,33,1 (1974) 253-261

Magie 1950

D. Magie, Roman Rule in Asia Minor (Princeton 1950)

MAREK 2003

Chr. Marek, Pontus et Bithynia. Die römischen Provinzen im Norden Kleinasiens (Mainz 2003)

MAREK 2010

Chr. Marek, Geschichte Kleinasiens in der Antike (München 2010)

MARKL 2003

H. MARKL, Wer bestimmt, wann das Leben beginnt? Zur Frage der Deutungshoheit über den Lebensbegriff, Berlin-Brandenburgische Akademie der Wissenschaften 2003

Mason / Wallace 1972 H. J. Mason / M. B. Wallace, "Appius Claudius Pulcher and the Hollows of Euboia", Hesperia 41 (1972) 128-140

Mazon 1943

P. Mazon, ,Dion de Pruse et la politique agraire de Trajan”, Lettres d'Humanité 2, (Paris 1943) 47-80

McGinN 1998

Th. A. J. McGinn, Prostitution, Sexuality, and the Law in Ancient Rome (Oxford 1998) 
MERKI 1952

Merki 1959

Meyer 1924

Milazzo 2007

Moles 1978

Moles 1995

Moles 2003

MratscheK-HaLfmanN 1993

NeschKe-HentschKe 1995-2003

NiPPERDEY 1954

Osterhammel 2000

Panagopoulou 1995

Papageorgakis 1964

Papavasileiou 1903

PAPAVASIleiou 1905

PekÁry 1979

Pensabene 1995

PERRY 1967

Peterson 1984

Philippson 1951

PiCARd 1979

von PöHLManN 1925

Pöschl 1992
H. Merki, OMOI $\Omega \Sigma I \Sigma \Theta E \Omega$. Von der platonischen Angleichung an Gott zur Gottähnlichkeit bei Gregor von Nyssa, Paradosis VII) (Fribourg 1952)

„Ebenbildlichkeit“, in: RAC, Bd. IV (1959) Sp. 459-479

E. Meyer, Kleine Schriften, Bd. 1 (Halle 1924²)

A. M. Milazzo, Dimensione retorica e realità politica. Dione di Prusa nelle orazioni III, V, VII, VIII (Hildesheim / Zürich / New York 2007)

J. Moles, ,The Career and Conversion of Dio Chrysostomos", JHS 98 (1978) 79-100

J. Moles, „Dio Chrysostomos, Greece, and Rome”, in: D. InNes / H. Hine / Chr. Pelling (eds.), Ethics and Rhetoric. Classical Essays for Donald Russell on his Seventy-Fifth Birthday (Oxford 1995) 177-192

J. Moles, „Dio und Trajan“, in: K. Piepenbrink (Hrsg.), Philosophie und Lebenswelt in der Antike (Darmstadt 2003) 186-207

S. Mratscheк-Halfmann, Divites et Praepotentes. Reichtum und soziale Stellung in der Literatur der Prinzipatszeit (Stuttgart 1993)

A. Neschke-Hentschкe, Platonisme politique et théorie du droit naturel, vol. I (Leuven/Paris 1995), vol. II (Leuven/Paris 2003)

C. H. Nipperdey, „,Die Würde des Menschen“, in: Brudermüller / SeElmann 2008, 189-238 (ursprünglich erschienen in: Die Grundrechte. Handbuch der Theorie und Praxis der Grundrechte, hrsg. v. F. L. Neumann u.a., Bd. 2 [Berlin 1954] 1-10

J. Osterhammel, Sklaverei und die Zivilisation des Westens (München 2000)

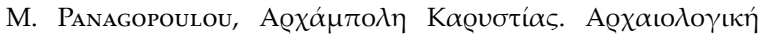

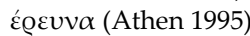

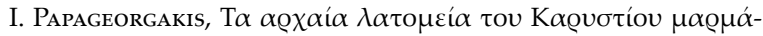
@OU, PAA 39 (1964) 262-284

G. Papavasileiou, Áv $\alpha \sigma \kappa \alpha \phi \alpha i ̀$ ċv Eủßoí $\alpha$, Prakt 1903, 36-39

G. Papavasileiou, Eủßot $\alpha \kappa \alpha ́$, AEphem 1905, 1-36

Th. PekÁRY, Die Wirtschaft der griechisch-römischen Welt (Wiesbaden 1979)

P. Pensabene (ed.), Marmi antichi II, StMisc 31 (Rom 1993-1995)

B. E. Perry, The Ancient Romances. A Literary-historical Account of their Origins (Berkeley / Los Angeles 1967)

T. Jefferson, Writings, ed. M. D. Peterson (New York 1984)

A. Philippson, Die griechischen Landschaften I 2 (Frankfurt 1951)

O. Picard, Chalcis et la Confédération Eubéenne, Étude de numismatique et d'histoire (Paris 1979)

R. von Pöhlmann, Geschichte der sozialen Frage und des Sozialismus in der antiken Welt (München 1925)

V. Pöschl, "Würde“, in: O. Brunner / W. Conze / R. KoselLECK (Hrsgg.), Geschichtliche Grundbegriffe, Bd. VII (Stuttgart 1992) 637-645 
Pöschl 1989

Prell 1997

PritchetT 1969

QuAß 1993

ReARdon 1983

Reber 2001

Reber 2002

Reuter 1932

ReYNOLDS 1983

RhANGABÉ 1852

RichaRds 1930

RITTER 1988

Rostovtzeff 1910

RostovtzefF 1929

SACKETT u.a 1966

SALMERI 1982

SARTRE 2001

SCHAUbert 1847

SCHMID 1999

SCHNEIDER 1990
V. Pöschl, Der Begriff der Würde im antiken Rom und später (Heidelberg 1989)

M. Prell, Armut im antiken Rom. Von den Gracchen bis Kaiser Diokletian (Stuttgart 1997)

W. K. Pritchett, Studies in Ancient Greek Topography II 3. The Hollows of Euboia (Los Angeles 1969)

F. QuAß, Die Honoratiorenschicht in den Städten des griechischen Ostens. Untersuchungen zur politischen und sozialen Entwicklung in hellenistischer und römischer Zeit (Stuttgart 1993)

B. P. Reardon, „Travaux récents sur Dion de Pruse”, REG 96 (1983) 286-292

K. Reber, „Unbekanntes Euböa“, AW 32 (2001) 449-460

K. Reber, „Die Südgrenze des Territoriums von Eretria (Euböa)“, AntK 45 (2002) 40-53

D. Reuter, Untersuchungen zum Euboikos des Dion von Prusa (Diss. Leipzig, Weida i. Thüringen 1932)

L. D. Reynolds, Texts and Transmission (Oxford 1983)

A. R. Rhangabé, „Mémoire sur la partier méridionale de l'île d'Eubée", CRAI 3 (1852) 197-239

G. Richards, „Hollows of Euboea“, ClRev 44 (1930) $61 \mathrm{f}$.

A. M. Ritter, "Zwischen „Gottesherrschaft" und „einfachem Leben". Dio Chrysostomus, Johannes Chrysostomus und das Problem einer Humanisierung der Gesellschaft“, JAC 31 (1988) 127-143

M. Rostovtzeff, Studien zur Geschichte des römischen Kolonates (Leipzig / Berlin 1910)

M. Rostovtzeff, Gesellschaft und Wirtschaft im römischen Kaiserreich, Bd. 1 und 2 (Leipzig 1929)

L. H. Sackett / V. Hankey / R. J. Howell / T. Jacobsen / M. Popham, „Prehistoric Euboea. Contributions towards a Survey", BSA 61 (1966) 33-112

G. SAlmeri, ", La politica e il potere saggio su Dione di Prusa“, Quaderni del Siculorum Gymnasium IX (Catania 1982)

M. SARtre, „Die anatolischen Provinzen“, in: Cl. Lepelley (Hrsg.), Rom und das Reich in der hohen Kaiserzeit. 44v. Chr. -260 n. Chr. Bd. II: Die Regionen des Reiches (München 2001) 341-398

E. Schaubert, Archäologische Abhandlungen [1844-1848], Konvolut handschriftlicher Aufzeichnungen, Berlin, Antikensammlung, Staatliche Museen zu Berlin, Preussischer Kulturbesitz: Reise nach den Nördlichen Sporaden 1847; demnächst vorgelegt und kommentiert von H. R. Goette / F. PAjor

S. G. Schmid, „Decline or Prosperity at Roman Eretria? Industry, Purple Dye Works, Public Buildings, and Gravestones", JRA 12 (1999) 273-293

H. Schneider, ",Die Bücher - Meyer Kontroverse ", in: W.M. CALDer III. / A. Demandt / E. Meyer (Hrsgg.), Leben und Leistung eines Universalhistorikers (Leiden 1990) 417-445 
Scholl / Schubert 2004 R. Scholl / Chr. Schubert, „Lex Hadriana de agris rudibus und lex Manciana", in: Archiv für Papyrusforschung 50/1 (2004) 79-84

Schumacher 1993 R. W. M. Schumacher, „Three related sanctuaries of Poseidon. Geraistos, Kalaureia, and Tainaron", in: N. Marinatos / R. HäGG (Hrsgg.), Greek Sanctuaries. New Approaches (London / New York 1993) $62-87$

SChWENDTNER $1994 \quad$ R. Schwendtner, Utopie. Überlegungen zu einem zeitlosen Begriff (Hamburg 1994)

SEILER 2011

St. SeiLer (Hrsg.), Armut in der Antike. Perspektiven in Kunst und Gesellschaft (Trier 2011)

SirAgo 1958

SKouras 1975

SOUTHERN 1970

V. A. Sirago, L'Italia agraria sotto Traiano (Leuven 1958)

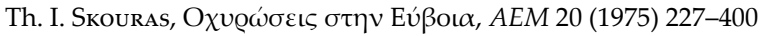

R. W. Southern, Medieval Humanism and other Essays (New York 1970)

SpanNeut 1973

M. Spanneut, Permanence du Stö̈cisme, de Zenon à Malraux (Gembloux 1973)

Ste. Croix 1981 G. E. M. de Ste. Croix, The Class Struggle in the Ancient World (London 1981)

STEPHAN 2002

E. Stephan, Honoratioren, Griechen, Polisbürger. Kollektive Identitäten innerhalb der Oberschicht des kaiserzeitlichen Kleinasien. Hypomnemata 143 (Göttingen 2002)

Strauss 1956

L. Strauss, Naturrecht und Geschichte (Stuttgart 1956)

StUMpr 1998

B. E. Stumpr, Prostitution in der römischen Antike (Berlin 1998)

SUTHERLAND 2002

J. SutherLand / A. Sutherland, „Roman Marble Quarrying near Karystos, Southern Euboea", Journal of Cultural Heritage 2 (2002) 251-259

SwAIN 2000

S. Swain (ed.), Dio Chrysostom. Politics, Letters, and Philosophy (Oxford 2000)

SwAIN 2000a

S. SwaIN, „Reception and Interpretation“, in: SwaIN 2000, 13-50

TIERNEY 1997

B. TierneY, The Idea of Natural Rights (Atlanta 1997)

TRAPr 2000

M. Trapp, „Plato in Dio“, in: Swain 2000, 213-239

Travlos 1971

J. Travlos, Bildlexikon zur Topographie des antiken Athen (Tübingen 1971)

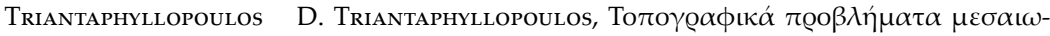
1974 vıкń Evßoí

TsOFLias 1982

P. Tsoflias, „Les carrières antiques de marbre de l'Eubée du Sud“, Bulletin des Musées royaux d'art et d'histoire Bruxelles 53 (1982) 71-79

UERLINGS 2011

H. UerLings (Hrsg.), Armut - Perspektiven in Kunst und Gesellschaft (Darmstadt 2011)

VANhove 1996 D. VANHove, Roman Marble Quarries in Southern Euboea and the Associated Road Systems. Monumenta Graeca et Romana 8 (Leiden 1996)

VISCHER 1965

R. VIsCHER, Das einfache Leben. Wort- und motivgeschichtliche Untersuchungen zu einem Wertbegriff der antiken Literatur (Göttingen 1965) 
Vujčı́́ 2009

WALDRON 2002

WALLACE 1972

WALLACE 1989

Wallace / Keller 2006

WeLzel 1958

WIELING 1999

WINIARCZYK 2011

ZAPPAS 1982

ZEHNPFENNIG 2005

ZeHNPFENNIG 2008

Ziebarth 1939

ZUIDERHOEK 2008
N. Vujčıć, „Popular Assemblies in the Emperial Period and the Discourses of Dion of Pruse“, Epigraphica Anatolica 42 (2009) 157-169

J. WALDRon, WALDRon (Cambridge u.a. 2002)

M. B. Wallace, The History of Karystos from the Sixth to the Fourth Centuries B. C. Diss. phil. University of Toronto (1972)

M. B. Wallace, „,Athenian Settlements in Euboia in the Fifth Century B.C.“, AJA 93 (1989) 275

M. Wallace / D. Keller / J. Wickens / R. Lamberton, „The Southern Euboean Exploration Project (SEEP): 25 Years of Archaeological Research", in: M. Chiridoglou / A. Chatzidimitriou (eds.),

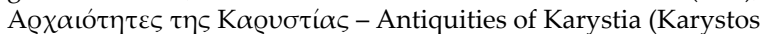
2006) $18-49$

H. Welzel, Die Naturrechtslehre Samuel Pufendorfs, 2. Aufl. (Berlin 1958)

H. Wieling, Die Begründung des Sklavenstatus nach ius gentium und ius civile. Corpus der Römischen Rechtsquellen zur Antiken Sklaverei I (Stuttgart 1999)

M. WiniarczyK,Die hellenistischen Utopien. Beiträge zur Altertumskunde 293 (Berlin / Boston 2011)

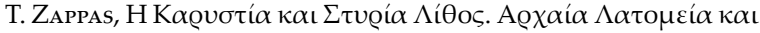

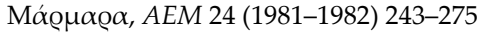

B. Zehnpfennig, Platon zur Einführung (Hamburg ${ }^{3} 2005$ )

B. Zehnpfennig, „Die Bedeutung des ersten Buches der Politeia für das platonische Staatskonzept", in: P. Nitschкe (Hrsg.), Politeia. Staatliche Verfasstheit bei Platon (Baden-Baden 2008) 35-38

E. Ziebarth, IG XII 9 (Berlin 1915) 1-10 Nr. 1-51; 143-173 „,testimonia et notae“; 174 f. „libri et itinera“; Suppl. (Berlin 1939)

A. Zuiderhoek, „On the political sociology of the Imperial Greek City", GRBS 48 (2008) 417-445

\section{Abbildungsnachweis}

Alle Abbildungen (Kartenskizzen und Photographien) von H. R. GoetTE. 


\section{Stellenregister (in Auswahl)}

\begin{tabular}{|c|c|c|}
\hline Aelianus & 121f.: $113^{148}$ & El. \\
\hline VH III 1: $89^{20}$ & $122: 10^{20}, 115^{158}$ & 424-431: $104^{99}$ \\
\hline Aeneas Tacticus & or. $32: 12$ & 428f.: $107^{110}$ \\
\hline Poliorc. III 5f.: $92^{33}$ & $22 f .: 93^{36}$ & $\operatorname{Tr} .84: 87^{6}$ \\
\hline Apuleius & $89: 93^{35}$ & \\
\hline Metam. & or. $34: 12$ & Herodotus \\
\hline II 18: $98^{55}$ & $21-23: 96^{49}$ & IV 71-73: $14^{31}$ \\
\hline IV $23,4: 98^{55}$ & 27f.: $7^{12}$ & VI 99: $179^{25}$ \\
\hline Aristophanes & 29f.: $6^{8}$ & VIII 13f.: $87^{6}$ \\
\hline Thesm. 387: $111^{137}$ & or. 35 & IX 105: $167^{2}$ \\
\hline Aristoteles & 15: $114^{151}$ & Hesiodus \\
\hline Ath. Pol. 10,1f.: $99^{63}$ & 18-24: $87^{4}$ & $O p$ \\
\hline Polit. 1263b5-8: & or. $38,8: 119^{178}$ & 298-314: $222^{36}$ \\
\hline $202^{41}$ & or. $40: 14$ & 298-316: $111^{133}$ \\
\hline & $8: 98^{54}$ & 311: $111^{138}$ \\
\hline Cicero & 10: $109^{124}$ & Homerus \\
\hline De off. II 54: $222^{35}$ & 30f.: $19^{47}$ & Il. \\
\hline & or. 41 & VI 175: $118^{174}$ \\
\hline Demosthenes & $1.6: 15^{35}$ & XVI 179f.: $118^{174}$ \\
\hline or. 18 & $6: 10^{19}$ & $\mathrm{Od}$ \\
\hline $127: 110^{129}$ & or. $42,4 \mathrm{f} .: 21^{52}$ & VIII 224-228: \\
\hline 258: $111^{137}$ & or. $44,12: 16^{38}$ & $106^{105}$ \\
\hline $261: 110^{129}$ & or. 45 & XI 235-257: \\
\hline Dio & 1: $21^{51}$ & $118^{171}$ \\
\hline or. $1: 13$ & 1f.: $14^{32}$ & XIV 55-81: \\
\hline 51: 14 & 2f.: $16^{38}$ & $105^{101}$ \\
\hline $52: 101^{73}$ & 4f.: $15^{37}$ & XV 16: $106^{105}$ \\
\hline or. $2: 14$ & $8: 93^{35}$ & XVII \\
\hline or. $3: 13$ & 12: $109^{124}$ & $10-15: 106^{106}$ \\
\hline 98f.: $119^{178}$ & 12-16: $19^{47}$ & $455-7: 129^{24}$ \\
\hline 124f.: $113^{150}$ & 13: $96^{49}$ & 455-457: \\
\hline or. $6,60-62: 88^{13}$ & or. $46: 6,9^{18}$ & $105^{102}$ \\
\hline or. $12: 14$ & $2: 8^{13}$ & 549f.: $105^{103}$ \\
\hline $20: 88^{13}$ & 9: $7^{11}$ & XIX \\
\hline $61: 101^{73}$ & or. 47 & 158: $106^{105}$ \\
\hline 85: $110^{128}$ & 14f.: $15^{36}$ & 306-328: \\
\hline or. 13: 13 & $15: 17^{42}$ & $105^{103}$ \\
\hline 10f.: $88^{12}$ & or. 50 & XXI \\
\hline $31-37: 117^{166}$ & $1-5: 7^{12}$ & 11-40: $106^{105}$ \\
\hline or. $15,8: 226^{52}$ & 5. $10: 10^{19}$ & 150f.: $111^{139}$ \\
\hline or. $18: 11^{21}$ & or. $52: 6$ & 311-319: \\
\hline or. 19 & or. 79 & $105^{104}$ \\
\hline $1-3: 14^{32}$ & $1-5: 117^{166}$ & 330-342: \\
\hline 1f.: $13^{30}$ & $2: 91^{30}$ & $105^{104}$ \\
\hline 5: $112^{143}$ & & Horatius \\
\hline or. $31: 11$ & Iripides & Sat. I 5,88: $109^{125}$ \\
\hline
\end{tabular}




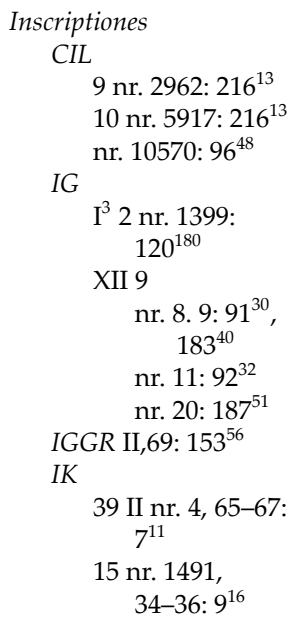

Lactantius

Inst.

III 8-15: $237^{11}$

V 14,16f.: $237^{11}$

Livius

XXXI 47: $87^{6}$

XXXII 17: $185^{46}$

Lucianus

De salt. 41. 43: $112^{143}$

Pseudolog. 30: $216^{16}$

Musonius Rufus

Diss.

12: $117^{165}$

12-13b: $115^{158}$

13a: $115^{161}$

14: $115^{161}$

Philostratus

V. Apol.

I 7: $14^{33}$

V 37: $21^{51}$

VII $7: 14^{31}$

V. Soph.

I 7: $86^{1}$

VII 1: 21
Plato

Apol.

17a: $128^{19}$

36d: $128^{20}$

Gorg.

494e: $119^{178}$

515e: $110^{129}$

Leg.

$774 \mathrm{c}: 110^{132}$

844d-e: $104^{93}$

Prot. 339a-347d: 133

Rep.

331a-c: $199^{38}$

380a-c: $112^{143}$

372b: $102^{81}$

580b: $112^{142}$

Symp.

202d: $111^{135}$

482b-d: $120^{180}$

Theaet. 149a-150d: $111^{137}$

Plinius

ep.

III 4,3f.: $119^{180}$ $\mathrm{X}$

17a,3: $8^{14}$

17a. b: $16^{41}$

23: $16^{41}$

23,2: $8^{14}$

24: $16^{41}$

54: $19^{47}$

55: $19^{47}$

58-60: $15^{37}$

81: $15^{37}, 17^{43}$, $17^{44}$

$81,7 \mathrm{f} .: 10^{19}$

Plutarchus

Amat.

1,749B-C: $112^{146}$

10,755A-B:

$112^{146}$

11,755B: $93^{35}$

23,768E: $119^{178}$

Coni. praec. 140B:

$229^{64}$
De aud. poet.

4,21B: $108^{119}$

12,33C: $108^{119}$

Praec. ger. reip.

798A-825F: $93^{35}$

800C: $93^{36}$

801E: $93^{36}$

817A-B: $94^{37}$

819F: $93^{36}$

Polybius

XII 26b,5: $105^{103}$

XXXVI 17,5-10: $95^{45}$

Ps.-Quintilianus

Decl. 5,9: $217^{19}$

Seneca

Cons. Helv. 12,1: $215^{7}$

De vit. beat. 25,1: $222^{34}$

Sophokles

Aleadai fr. 88 RADT: $107^{119}$

Strabo

X 1,2 p. $445,6 f .: 87^{6}$

XII 6,1 p. 568,8: $109^{125}$

Suetonius

Dom. 12,1f.: $15^{34}$

Synesius

Dion

$$
\begin{aligned}
& \text { 1,9: } 10^{20} \\
& \text { 2: } 86^{1} \\
& \text { 2,38c: } 21 \\
& \text { 3: } 86^{4}, 89^{20}
\end{aligned}
$$

Theophrastus HP VIII 4,4: $167^{2}$

Valerius Maximus

I 8,10: $87^{6}$

Xenophon

Mem. II 7: $133^{148}$ 


\section{Namensregister}

Agora $97^{52} .143 .174 .187$

Alexandria $112^{143} \cdot 163^{104}$

Altersarmut 216. 217

alumni $118^{176} .230$

Ambrosius $242^{64}$

Antiochien (am Orontes) $116^{162}$

¿̇ $\pi \alpha \omega \gamma \eta \dot{n}$-Verfahren $94^{41} \cdot 98^{55}$

Apameia 15. 19. $113^{148}$

Aphrodite Pandemos $116^{165}$

Apollonios von Tyana 13

Apologie, platonische 127. 132. 136. 137

Arbeit 141. 149 ${ }^{30}$. 201-203. 205. 206. 213. 222. 223

Arbeitsbeschaffungsprogramm siehe

Beschäftigungsprogramm

Arbeitslosigkeit 205. 213. 223. 231. 232

Arbeitswille $108^{121}$

Archampolis 170. 171

Argos $112^{145}$

Aristoteles 150. 224. 249

Armenspeisungen 221

Armut 22. $86^{2} .108^{121} .108^{122} .109^{124}$ $113^{148} \cdot 113^{150} \cdot 130.132 .133 .148 .149$. $149^{32}$. 159. 164. 165. 200. 201. 210.

214. 217. 219. 222. 223. 231. 232

Artemis $103^{91}$

Atlantis 138. 140

Aufklärung 197. 208. 252

Augustinus 241. 246

Aulos $112^{145}$

Aussetzung 225. 226

Autarkie 149. 149 $9^{31}$. 201. 203

Authentizität 5. $87^{8} .104^{98} .124 .138$

Bärenjagd $89^{23}$

Bedürfnislosigkeit 149. 198. 204. 207

beneficia 233

Bernhard von Clairvaux 242

Beschäftigungsprogramm 18. $110^{130}$. $110^{132} \cdot 112^{144} \cdot 123.221 .222$. 224. 225 . 229

Bettler 216. 219. 221. 222. $223^{38}$

Bevölkerungsrückgang siehe Entvölkerung

Bibliotheksbau 17. 18

Binnenerzählung 124. 125. 127
Bordelle $115^{159} \cdot 116^{165} .229$

Böckenförde, Ernst-Wolfgang 193

Bukolik $137^{44} .213$

Buleuterium 174. 187

Bundesverfassungsgericht 191

Bücher-Meyer-Kontroverse 144

Bürgerrecht $96^{49}$. 153. 204. 219

Castel Rosso 183. 185. $185^{46} .186$

Chalkis $87^{7} \cdot 180^{26}$

Chios $112^{145}$

Christentum 197. 204

Cicero 222. 233. 236. 239. 240. 243. 251

Cipollino-Marmor $91^{30} .111^{141} .177 .182$. 188. 189

Claudius $6^{9} \cdot 10 \cdot 12 \cdot 96^{48}$

curator $8 \cdot 9^{16} \cdot 19^{46}$

Danae-Mythos $117^{169} \cdot 119^{179}$

Demeter $103^{91}$

Demosthenes 132

Diatribe 136

dignitas 239. 240

Dion

- als Bauherr $8^{15} \cdot 17.18 \cdot 109^{124} \cdot 110^{130}$

- als Stadtpolitiker 5. 6. 9. 15. 16. 18. $109^{124} \cdot 110^{130}$

- als Wanderphilosoph 13. 14. 19. $88^{13}$. $147^{20} .215^{7}$

- als Wohltäter $6^{9} \cdot 9^{18} \cdot 17$

- Verbannung 12-14. 20. 87 $.88^{12} .214$

Domitian 13. 15. 20. $89^{17}$

Dürig, Günter 191. 193-195

Ehe $115^{161} .134 .229 .230$

Ehebruch $115^{158} .117^{166}$

Ehre 239

Eiche $101^{73}$

Eigentum 203. 204. 210. 248

Eileithyien $115^{161}$

Ekklesia $91^{30} \cdot 92^{32} \cdot 92^{34} \cdot 93^{37} \cdot 126.156$

Elite 3. 158. 160. 161

Entvölkerung $96^{50} .145 .152 .155^{66} .159$

Ephebie $97^{52}$

Ephesos $93^{36} \cdot 116^{162}$

Epik 148 
Epiktet 10. 22

Eranos $106^{107}$

Eretria $87^{7} \cdot 167^{2} \cdot 179^{26}$

Eriugena, Johannes Scotus $242^{64}$

Erzähler 125. 128. 129. 133-135. 140

- extradiegetischer 134. 135

- intradiegetischer 134

- metadiegetischer 134

Euergetismus $6^{1} .221$

Eumaios $106^{106} .129$

Eurytos $106^{105}$

Existenzminimumsgrenze $215^{8} .216$

familia 217. 219. 225

Flavius Archippos 15

Flavius Sabinus, T. $14.14^{31}$

footpage[60] 98

Founding Fathers 236

Freigelassene 225

Freiheit 149. 149 ${ }^{32}$. 195. 201. 202. 207. 208. 210. 211. 222. 227

- negative 250. 254

Gastfreundschaft $88^{11}$. 126. 127. 130. 133 . 149. 199

Gastmahl 120. $120^{181}$. 128. 133. 137

Gattung 136. 141

Geburtenkontrolle 223. 226

Geburtenrückgang $95^{45}$

Geraistos $170.170^{10}$. 180. 183. 184

Gerste $99^{65}$

Gerstenschrot $104^{94}$

Gesellschaftsvertrag 200

Gladiatorenspiele $113^{148}$

Gleichheit $116^{164}$. 204. 211. 227. 238. 245. 251-254

Goldzeitaltermythos $148^{24} .150$

Gottesebenbildlichkeit 239. 241. 243

Gracchus, Tiberius 225

Grundgesetz 196

Grundrecht 193. 245

Gymnasium 97 $7^{52}$. 143. 174. 187

Hadrian $89^{23} .163 .164^{107} .220$

Hafen 183

Hase $90^{26} \cdot 102^{84}$

Heiratsvermittlerin $104^{97}$

Helena $107^{111}$

Herdegen, Matthias 193. 195

Hermione $107^{113}$

Hesiod 132

Hirse $99^{65}$

Hirten $88^{16}$
Hirtenhunde $89^{22} \cdot 90^{24}$

Hirtenleben 137

Hobbes, Thomas 247. 250

Hochzeit $103^{88} .128$

Homer 129. 132

homoiosis 241

Homosexualität $117^{167} \cdot 119^{178} \cdot 120^{180}$

Honoratiorenschicht 20. 157

Höhlen von Euböa $87^{6} .91^{30} .94^{39} .170$

Humanismus 237. 249

Idealisierung 141. 148. 150. 202

Idylle 143. 148. 214

Idyll/Eidyllion (Gattung) 137

imago Dei-Vorstellung 239. 240. 243

Insel (als Utopie-Ort) 139. 140

Integration 3

Isidor von Sevilla 237. 241

ius civile 228

ius gentium 228

ius naturale siehe Naturrecht

Jagd $37^{183} \cdot 89^{21} \cdot 100^{70}$

Jagdhunde $90^{24}$

Kampos 174. 177

Kant, Immanuel 192. 197. 209

Kap Kaphereus $87^{6} .87^{7} .91^{30} \cdot 95^{42} \cdot 95^{43}$. 169. $170.172^{14} \cdot 187$

Kap Mandili 180

Kap Mnema 180. $182^{34}$

Karystia 167

Karystos 5. $91^{30} .92^{32} .174 .175 .175^{15}$ 177. $179^{25} \cdot 179^{26} \cdot 181-187$

Kleinbauerntum 146

Klientelsystem 217-219

Komödie, neue $148^{24}$

Kosmopolitismus 238. 251

Kriminalität $98^{55} \cdot 110^{131}$. 134. 202. 204. 216. 219.229

Kulturkritik 127

Kuss $101^{77}$

Kynismus 4

Laktanz 237

Landbesitz 223

Landflucht $110^{128}$

Landleben 137. $149^{32}$

Landverpachtung 144. $159^{83}$

Lassalle, Ferdinand 244

Legalität 192

lex aeterna 246

lex Hadriana 163 
lex Manciana $162.162^{98} \cdot 163.163^{104}$

lex Pompeia 7. $106^{107}$

lex Scantinia $120^{180}$

libertinage 20. 22. $115^{158} \cdot 117^{166}$

Limenophylakes $91^{30} .183 .185$

Liturgie $92^{34} \cdot 94^{39} \cdot 94^{40} \cdot 100^{68}$

Locke, John $116^{164}$. 203. 204. 247. 248. 250

Lohnarbeit/Lohnarbeiter $160^{86} .161$. $161^{94} .164 .220$

Luxus 189

Luxuskritik $147^{20} .162^{98} .232$

Manetti, Giannozzo 243

Marmarion 177. 189

Marx, Karl 203

Medimnos $99^{65}$

Megalorhevma $177^{20} .182 .186$

Menelaos 20. $107^{111} .107^{112} \cdot 107^{114} .130$. 134. 201

Menschenrechte 194. 208. 213. 227. 235. 238. 247. 251

Menschenrechtserklärung 235. 244

Menschenwürde 20. $116^{164} .130 .133$. 134. 141. 191-197. 201. 206-208. 210. 213. 228. 235. 244

- Relativierung $196^{28} .197$

Menschenwürdegarantie 194. 197. 210. 235

Mimos-Possen $112^{143}$

Mitmenschlichkeit $105^{100} \cdot 106^{106}$

Moralität 192

Morus, Thomas $138^{53} \cdot 139^{148}$

Murex-Fischerei siehe Purpurfischerei

Musonius Rufus 10. 22. $115^{158} .232$

Müßiggang $110^{131} .222$

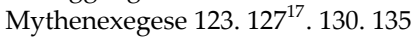

Mythos 137. 138

Naturrecht 197. 228. 245-248

Nauplios $91^{30} .95^{43}$

Nausikaa $118^{172}$

Neoptolemos $107^{113}$

Neostoizismus $250^{111}$

Nero $88^{17}$

Nerva 15

Netzwerke, soziale 217. 224

Niedergang 145. 154. 155. $163^{103} \cdot 164^{106}$. 165

Nimborio 177. $177^{21}$

Niobe $71^{183}$

Nipperdey, Carl Hans 193-195

nobilitas 239

Novelle 137. 148. $148^{24}$
Oche-Gebirge $88^{14} \cdot 91^{30} \cdot 170.170^{10} \cdot 174$

Odyssee 125. 127. 129. 132. 136. 147

Odysseus $20.105^{101} \cdot 106^{105} \cdot 106^{108} \cdot 125$. $125^{10} .129 .134 .148^{24}$

Oichalia $106^{105}$

oikeiosis 247

Opfertiere $103^{91}$

Othonopolis siehe Karystos

Palaiochora 182. 183. 185. 186. $186^{48}$. $186^{49}$

Pantomimen-Tanz $112^{143}$

Paris $107^{112} .130$

Partheniai $118^{175}$

Patristik 236. 240. 246

Paulus Diaconus $242^{64}$

Peisistratos $109^{128}$

Penelope $105^{103} \cdot 105^{104} \cdot 106^{105} \cdot 127^{17} \cdot 130$

Pertinax $96^{48} \cdot 163.164^{107}$

Petaloi-Insel 177

Petrarca, Francesco 243

Pflichtenlehre, stoische 235. 238. 249

Phäaken $106^{105} .106^{108} \cdot 129.130 .139$

Philanthropie $106^{107}$. 129. 132. 133

Philon von Alexandria 240

Philoxenie 133. 199

Pico della Mirandola 241. 243. 244

Piraterie/Piraten $100^{70} .126 .129$

Plakarí 179. 180. 182

Platanistos $170^{10} .172^{13}$

Plethron $94^{40}$

Pluralismus 208

Plutarch 3. 11. 229

Polyphemos $120^{181}$

Potami 170

Proletariat 202. 205

Prostitution 20. 22. $114^{152} \cdot 115^{158} \cdot 116^{164}$. $116^{165} \cdot 117^{166} \cdot 131.134 .205 .206 .213$. 225. 227. 229

Protagoras 200

Prusa 7. 15. 19. $19^{47} \cdot 93^{37} \cdot 94^{37} \cdot 109^{124}$. $113^{148} \cdot 215$

Prytaneum $101^{78}$. 127. 128. 140. 174. 187

Pufendorf, Samuel von 244. 245

Purpurfischer $111^{140}$. 140. 202

Purpurfischerei $87^{7} .172 .172^{14} .187$

Räuberbanden $98^{55} \cdot 100^{70}$

Rederecht $93^{37}$

Reformprogramm 22. 131. 135. 146. 160. 162

Reh $90^{26}$

Reichtum 130. 165 
Reisebericht 123. 128. 130.134-136. 138. 139. 141

Relativismus 208

Renaissance 237. 243

Reziprozität 199. 200. 209

Rhea $115^{161}$

Ricardo, David 203

Rom-Kritik $117^{166} .131 .141$

Roman $86^{4} .128 .129 .146 .147 .147^{17}$

Rousseau, Jean-Jacques 251. $253^{137}$

Salvius Otho Cocceianus, L. 14. $14^{31}$

Satire 148

Schiffbruch 124. 125. 127. 127 ${ }^{18}$. 128. 129. $147^{17}$

Schuldentilgung 223

Selbstbestimmung 194

Selbstverkauf 218. $218^{21}$

Seneca 221. 222. 233. 236. 239. 251

Sittenverfall 123. 229

Sklavenhandel $116^{164}$

$$
\text { - Abschaffung d. } 253
$$

Sklaverei $116^{164} .161 .162$. 164. 213. 217. 218. 223. 227-229. 251. 253

- Abschaffung d. 227. 228. 254

Smith, Adam 203

Smyrna $112^{145} \cdot 116^{162}$

Sokrates 127. 128. 132. 133. 140

Solon 223

Sozialpyramide $215^{8}$

Spende $98^{59} \cdot 100^{68} \cdot 100^{69} \cdot 106^{107}$

Staatsmodell $139^{56}$

Stadt-Kritik 126

Stadtarmut siehe Armut

Standessolidarität 218

Stoa 4. 20. $112^{142} \cdot 116^{164}$. 204. 235. 236. 240. 249. 251. 253

Styra $180^{26}$

Symposion siehe Gastmahl
Tachygraphie 21

Tarsos $93^{37} \cdot 94^{37} \cdot 96^{49} \cdot 116^{162}$

Telemachos $106^{106} .129$

Testament, Neues 246

Theater 174. 186

Theokrit 137

Thomas von Aquin 242. 246

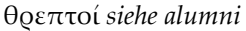

Thyestes $71^{183}$

Titus 11. 21

Trajan 13. 17. $112^{143} \cdot 119^{178} \cdot 162.215$. 220. 230

Trinität 242

Tugend 149. $149^{32}$

Tyro $118^{171}$

Unabhängigkeitserklärung, amerikanische $116^{164} .248 .251$

Utopie 5. 86 $.137-141.139^{55} .143 .149$. 152. 213

Verarmung 152. 158. 164. 217. 218. 223. 224

Verfassung 192-197. 245. 248

Vergil 137

Verödung 144. $155^{66} .158 .164$

Vespasian 12

Viehwirtschaft $89^{18}$

Vollmondphase $103^{88} \cdot 103^{89}$

Wasserversorgung $109^{125}$

Wein $120^{181}$

Weizen $99^{65}$

Weizenmehl $104^{94}$

Wilhelm von Ockham 246

Willensfreiheit 241. 243

Wohlfahrtspolitik 8

Zenon 238

Zweite Sophistik 3. 138 


\section{Die Autoren dieses Bandes}

Dr. Dorit Engster ist Lehrkraft für besondere Aufgaben an der Georg-August-Universität Göttingen. Ihre Interessens- und Forschungsschwerpunkte sind die Religionsgeschichte, die Geschichte der antiken Wissenschaft, griechische und römische Normenkonzepte sowie Formen der Repräsentation und Herrschaftslegitimation.

Schriftenauswahl: Konkurrenz oder Nebeneinander? Untersuchungen zu den Mysterienkulten und zur Religionskonkurrenz in der hohen römischen Kaiserzeit (München 2002); „,Synkretistische Phänomene bei Gottheiten in antiken Mysterienkulten“, in: Die Welt der Götterbilder, hrsg. v. B. Groneberg und H. Spieckermann (Berlin / New York 2007) 206-236; „,Der Kaiser als Wundertäter - Kaiserheil als neue Form der Legitimation“" in: Tradition und Erneuerung. Mediale Strategien in der Zeit der Flavier, hrsg. v. N. Kramer und Chr. Reitz (Berlin / New York 2010) 289-307; „Alexandria als Stadt der Forschung und Technik“, Biblische Notizen 147 (2010) 49-66.

Prof. Dr. Dorothee Gall ist Inhaberin des Lehrstuhls für Klassische Philologie (Latinistik) an der Rheinischen Friedrich-Wilhelms-Universität Bonn. Ihre Forschungsschwerpunkte liegen im Bereich der Literatur der augusteischen Zeit und der lateinischen Literatur der Renaissance. Derzeit arbeitet sie u.a. an einem Forschungsbericht zur horazischen Lyrik.

Schriftenauswahl: Die Bilder der horazischen Lyrik (Königstein/Ts. 1981); "Ipsius umbra Creusae" - Creusa und Helena (Mainz 1993); Zur Technik von Nachahmung und Zitat bei den Römern. Vergil, die Ciris und Cornelius Gallus (München 2000); Die Literatur in der Zeit des Augustus (Darmstadt 2006); Rekonstruktion und Neuerschaffung: Boccaccios Werkmetaphorik in der Genealogia deorum gentilium (Berlin 2011).

Prof. Dr. Hans Rupprecht Goette ist Klassischer Archäologe am Deutschen Archäologischen Institut. Schwerpunkte seiner Forschungen sind die Historische Landeskunde Griechenlands, das griechische Theater sowie antike Plastik und Ikonographie.

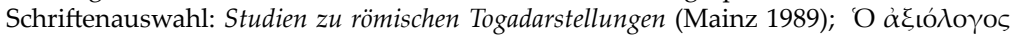

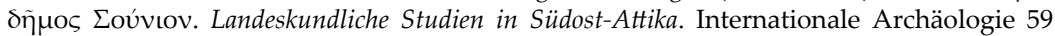
(Rahden 2000); Athens, Attica and the Megarid. An Archaeological Guide (London / New York 2001); (zusammen mit G. Schörner) Die Pan-Grotte von Vari (Mainz 2004); (zusammen mit J. Hammerstaedt) Athen. Ein literarischer Stadtführer (München 2004).

Prof. Dr. Elisabeth Herrmann-Otto ist Professorin für Alte Geschichte an der Universität Trier. Ihre Forschungsschwerpunkte sind die antike Sozial- und Wirtschaftsgeschichte (besonders Sklaverei- und Armutsforschung), die Kulturgeschichte (mit Schwerpunkt Alters-, Gender- und Zeremonialforschung) sowie das frühe Christentum. Von 2003 bis 2009 war sie Sprecherin des DFG-Graduiertenkollegs 846 „Sklaverei - Knechtschaft und Frondienst - Zwangsarbeit. Unfreie Arbeits- und Lebensformen von der Antike bis zum 20. Jahrhundert". Sie ist Mitherausgeberin des Handwörterbuchs zur Antiken Sklaverei (HAS) der Akademie der Wissenschaften und der Literatur, Mainz.

Schriftenauswahl: „Ecclesia in Re publica“. Die Entwicklung der Kirche von pseudostaatlicher zu staatlich inkorporierter Existenz. Europäisches Forum 2 (Frankfurt 1980); „Ex ancilla natus". Untersuchungen zu den "hausgeborenen" Sklaven und Sklavinnen im Westen des römischen Kaiserreiches. FAS 24 (Stuttgart 1994); Konstantin der Große. Gestalten der Antike (Darmstadt 2007, 2. durchgesehene Auflage, Darmstadt 2009); Sklaverei und Freilassung in der griechisch-römischen Welt. Olms Studienbücher Antike (Hildesheim 2009). 
Prof. Dr. Dr. h.c. Werner Heun ist Direktor des Instituts für Allgemeine Staatslehre und Politische Wissenschaften der Juristischen Fakultät der Georg-August-Universität Göttingen. Seine Forschungsschwerpunkte liegen in deutschem und amerikanischem Verfassungsrecht, der deutschen und amerikanischen Verfassungsgeschichte, Finanzrecht, Medizinrecht, Kirchenrecht und Staatstheorie.

Schriftenauswahl: Das Mehrheitsprinzip in der Demokratie. Grundlagen, Struktur, Begrenzungen (Berlin 1983); Staatshaushalt und Staatsleitung. Das Haushaltsrecht im parlamentarischen Regierungssystem des Grundgesetzes (Baden-Baden 1989); Das Budgetrecht im Regierungssystem der USA (Baden-Baden 1989); Funktionell-rechtliche Schranken der Verfassungsgerichtsbarkeit (Baden-Baden 1992); The Constitution of Germany (Oxford 2011); (zusammen mit M. Honecker, M. Morlok, J. Wieland) Evangelisches Staatslexikon (Stuttgart 2006); (Hrsg.) Deutsche Verfassungsdokumente 1806-1849, Teil I-VI (München 2006-2008).

Prof. Dr. Gustav Adolf Lehmann war von 1975 bis 1993 als Lehrstuhlinhaber im Fach Alte Geschichte an der Universität zu Köln, danach bis zu seiner Emeritierung 2010 an der GeorgAugust-Universität Göttingen tätig. Seine Forschungsschwerpunkte liegen vornehmlich in den Epochen des griechischen Altertums und in der antiken Historiographie, ferner im Bereich der späten Römischen Republik und der frühen Kaiserzeit. Er arbeitet z. Zt. u. a. an einer Untersuchung zur Hellas-Politik Alexanders des Großen.

Schriftenauswahl: Politische Reformvorschläge in der Krise der späten römischen Republik: Cicero De legibus III und Sallusts Sendschreiben an Caesar (Meisenheim a. Gl. 1980); Oligarchische Herrschaft im klassischen Athen: $\mathrm{Zu}$ den Krisen und Katastrophen der attischen Demokratie im 5. und 4. Jh. v.Chr. (Opladen 1997); Ansätze zu einer Theorie des griechischen Bundesstaates bei Aristoteles und Polybios (Göttingen 2001); Demosthenes von Athen: Ein Leben für die Freiheit. Biographie (München 2004).

Prof. Dr. Barbara Zehnpfennig ist Professorin für Politische Theorie und Ideengeschichte an der Universität Passau. Ihre Forschungsschwerpunkte sind antike, speziell platonische Philosophie, amerikanisches Verfassungsdenken und Totalitarismus. Sie hat u.a. zwei platonische Dialoge (Symposion, Phaidon) übersetzt, eine weitere Übersetzung ist in Planung.

Schriftenauswahl: Reflexion und Metareflexion. Ein Strukturvergleich von Platons "Charmides" und Fichtes "Bestimmungen des Menschen" (Freiburg 1987); (Hrsg.) Politisches Denken. Jahrbuch 2008: Die Herrschaft des Gesetzes und die Herrschaft des Menschen - Platons Nomoi (Berlin 2008); Platon zur Einführung (4. Aufl. Hamburg 2011); (Hrsg.) Die Politik des Aristoteles (Baden-Baden 2011). 


\section{SAPERE \\ Scripta Antiquitatis Posterioris ad Ethicam REligionemque pertinentia \\ Schriften der späteren Antike zu ethischen und religiösen Fragen}

Lieferbare Bände nach Bandnummern:

XIX Armut-Arbeit-Menschenwürde

Die Euböische Rede des Dion von Prusa

Eingeleitet, übersetzt und mit interpretierenden Essays versehen von Gustav A. Lehmann, Dorit Engster, Dorothee Gall, Hans Rupprecht Goette, Elisabeth Herrmann-Otto, Werner Heun und Barbara Zehnpfennig

2012. X, 276 Seiten. ISBN 978-3-16-151825-6 fadengeheftete Broschur.

XVIII Libanios: Für Religionsfreiheit, Recht und Toleranz

Libanios' Rede für den Erhalt der heidnischen Tempel

Eingeleitet, übersetzt und mit interpretierenden Essays versehen von Heinz-Günther Nesselrath, Okko Behrends, Klaus S. Freyberger, Johannes Hahn, Martin Wallraff und Hans-Ulrich Wiemer

2011. XI, 276 Seiten. ISBN 978-3-16-151002-1 Broschur; ISBN 978-3-16-151003-8 Leinen.

XVII Synesios von Kyrene: Polis - Freundschaft - Jenseitsstrafen Briefe an und über Johannes

Eingeleitet, übersetzt und mit interpretierenden Essys versehen von Katharina Luchner, Bruno Bleckmann, Reinhard Feldmeier, Herwig Goergemanns, Adolf Martin Ritter, Ilinca Tanaseanu-Doebler

2010. XI, 243 Seiten. ISBN 978-3-16-150654-3 Broschur; ISBN 978-3-16-150655-0 Leinen.

XVI Plutarch: On the daimonion of Socrates Human liberation, divine guidance and philosophy Edited by Heinz-Günther Nesselrath. Introduction, Text, Translation and Interpretative Essays by Donald Russell, George Cawkwell, Werner Deuse, John Dillon, Heinz-Günther Nesselrath a.o.

2010. X, 225 Seiten. ISBN 978-3-16-150137-1 Broschur; ISBN 978-3-16-150138-8 Leinen. 


\section{Joseph und Aseneth}

Herausgegeben von Eckart Reinmuth. Eingeleitet, ediert, übersetzt und mit interpretierenden Essays versehen von Eckart Reinmuth, Stefan Alkier, Brigitte Boothe, Uta B. Fink, Christine Gerber, KarlWilhelm Niebuhr u.a.

2009. XI, 280 Seiten. ISBN 978-3-16-150161-6 Broschur; ISBN 978-3-16-150162-3 Leinen.

\section{Cornutus: Die Griechischen Götter}

Ein Überblick über Namen, Bilder und Deutungen

Herausgegeben von Heinz-Günther Nesselrath, eingeleitet, übersetzt und mit interpretierenden Essays versehen von Fabio Berdozzo, George Boys-Stones, Hans-Josef Klauck, Ilaria Ramelli und Alexei V. Zadorojnyi

2009. X, 259 Seiten. ISBN 978-3-16-150071-8 Broschur; ISBN 978-3-16-150072-5 Leinen.

XIII Dion von Prusa: Der Philosoph und sein Bild Herausgegeben von Heinz-Günther Nesselrath, eingeleitet, ediert, übersetzt und mit interpretierenden Essays versehen von Eugenio Amato, Sotera Fornaro, Barbara E. Borg, Renate Burri, Johannes Hahn u.a.

2009. XI, 317 Seiten. ISBN 978-3-16- 149440-6 Broschur; ISBN 978-3-16-149441-3 Leinen.

XII Rufus of Ephesus: On Melancholy

Edited by Peter E. Pormann. Introduction, Text, Translation and Interpretative Essays by Philip J. van der Eijk, Vivian Nutton, Peter E. Pormann, Thomas Rütten, Peter-Klaus Schuster, Simon Swain a.o. 2008. XV, 332 Seiten. ISBN 978-3-16-149759-9 Broschur; ISBN 978-3-16-149760-5 Leinen.

\section{Der apokryphe Briefwechsel zwischen Seneca und Paulus} Zusammen mit dem Brief des Mordechai an Alexander und dem Brief des Annaeus Seneca über Hochmut und Götterbilder Eingeleitet, übersetzt und mit interpretierenden Essays versehen von Alfons Fürst, Therese Fuhrer, Folker Siegert und Peter Walter 2006. X, 215 Seiten. ISBN 978-3-16-149130-6 Broschur; ISBN 978-3-16-149131-3 Leinen. 